ANL-80-40

\title{
FAST BREEDER REACTOR STUDIES
}

\author{
C. E. Till, Y. I. Chang, J. H. Kittel, \\ H. K. Fauske, M. J. Lineberry, M. G. Stevenson, \\ P. I. Amundson, and K. D. Dance
}

MASTER

BASE TECHNOLOGY

ARGONNE NATIONAL LABORATORY, ARGONNE, ILLINOIS Prepared for the U. S. DEPARTMENT OF ENERGY under Contract W-31-109-Eng-38 
The facilities of Argonne National Laboratory are owned by the United States Government. Under the terms of a contract (W-31-109-Eng-38) among the U. S. Department of Energy, Argonne Universities Association and The University of Chicago, the University employs the staff and operates the Laboratory in accordance with policies and programs formulated, approved and reviewed by the Association.

\section{MEMBERS OF ARGONNE UNIVERSITIES ASSOCIATION}

The University of Arizona

Carnegie-Mellon University

Case Western Reserve University

The University of Chicago

University of Cincinnati

Illinois Institute of Technology

University of Illinois

Indiana University

The University of Iowa

Iowa State University
The University of Kansas

Kansas State University

Loyola University of Chicago

Marquette University

The University of Michigan

Michigan State University

University of Minnesota

University of Missouri

Northwestern University

University of Notre Dame
The Ohio State University

Ohio University

The Pennsylvania State University

Purdue University

Saint Louis University

Southern Illinois University

The University of Texas at Austin

Washington University

Wayne State University

The University of Wisconsin-Madison

\section{NOTICE}

This report was prepared as an account of work sponsored by an agency of the United States Government. Neither the United States Government or any agency thereof, nor any of their employees, make any warranty, express or implied, or assume any legal liability or responsibility for the accuracy, completeness, or usefulness of any information, apparatus, product, or process disclosed, or represent that its use would not infringe privately owned rights. Reference herein to any specific commercial product, process, or service by trade name, mark, manufacturer, or otherwise, does not necessarily constitute or imply its endorsement, recommendation, or favoring by the United States Government or any agency thereof. The views and opinions of authors expressed herein do not necessarily state or reflect those of the United States Government or any agency thereof.

Printed in the United States of America

Available from

National Technical Information Service

U. S. Department of Commerce

5285 Port Royal Road

Springfield, VA 22161

NTIS price codes

Printed copy: A19

Microfiche copy: A01 


\section{DISCLAIMER}

This report was prepared as an account of work sponsored by an agency of the United States Government. Neither the United States Government nor any agency Thereof, nor any of their employees, makes any warranty, express or implied, or assumes any legal liability or responsibility for the accuracy, completeness, or usefulness of any information, apparatus, product, or process disclosed, or represents that its use would not infringe privately owned rights. Reference herein to any specific commercial product, process, or service by trade name, trademark, manufacturer, or otherwise does not necessarily constitute or imply its endorsement, recommendation, or favoring by the United States Government or any agency thereof. The views and opinions of authors expressed herein do not necessarily state or reflect those of the United States Government or any agency thereof. 


\section{DISCLAIMER}

Portions of this document may be illegible in electronic image products. Images are produced from the best available original document. 


\section{ANL- 80-40}

ARGONNE NATIONAL LABORATORY

9700 South Cass Avenue

Argonne, Illinois 60439

\section{FAST BREEDER REACTOR STUDIES}

PART 1

ALTERNATIVE FUEL-CYCLE AND DEPLOYMENT STRATEGIES:

THEIR INFLUENCE ON LONG-TERM ENERGY SUPPLY AND RESOURCE USAGE

C. E. Till, Y. I. Chang, and R. R. Rudolph

PART 2

DESIGN AND PERFORMANCE CHARACTERISTICS OF ALTERNATIVE FUELS AND FUEL CYCLES

Y. I. Chang and C. E. Till

PART 3

STATUS OF LMFBR FUELS AND MATERIALS DEVELOPMENT

J. H. Kittel, L. A. Neimark, L. G. Waltere, $R$. E. Einziger and D. E. Mahagin

PART 4

SAFETY IMPLICATIONS OF ALTERNATIVE FUEL TYPES

H. K. Fauske

PART 5

FUEL CYCLE OPTIONS

M. J. Lineberry, H. F. McFartane, P. I. Amundson

R. W. Goin and D. S. Webster

PART 6

INTERNATIONALIZATION AND COLLOCATION

M. G. Stevenson, P. B. Abrambon and L. G. LeSage

PART 7

SAFEGUARDS

P. I. Amundson and G. K. Rusch

PART 8

DEPLOYMENT CONSIDERATIONS

K. D. Dance, Y. I. Chang and T. A. Daly

ANNEX

DECOMMISSIONING OF A LARGE CENTRAL-STATION LMFBR

POWER PLANT: A COMPARISON WITH THE PWR

A. Amorosi, J. R. Honekamp and H. O. Monson 
FAST BREEDER REACTOR STUDIES

\section{ABSTRACT}

This report is a compilation of Fast Breeder Reactor (FBR) resource documents prepared to provide the technical basis for the U.S. contribution to the Intemational Nuclear Fuel Cycle Evaluation. The eight separate parts deal with the altemative fast breeder reactor fuel cycles in terms of energy demand, resource base, technical potential and current status, safety, proliferation resistance, deployment, and nuclear safeguards. Part One addresses the relationship between energy demand, uranium/thorium resources, and the breeder deployment option; Part Two presents a consistent comparison between the breeding performance of the various alternatives; Part Three describes the status of development of the three candidate LMFBR fuel types -- oxide, carbide, and metal; Part Four compares the safety implications of the fuel types to the (U, Pu)oxide reactor; Part Five reviews fuel-cycle technology with emphasis on proliferation resistance in intemational, secured-area, and integral-cycle deployment; Part Six examines proliferation, technical, legal, and national-incentive issues in the intemationalization and collocation of major FBR facilities; Part Seven describes fissile-materials safeguards technology and proliferation risks associated with diversion; Part Eight discusses factors in national breeder development and deployment decisions. An Annex compares the cost of decommissioning light-water and fast breeder reactors. 
- 
FOREWORD

The purpose of this report is to summarize the studies that were carried out to provide the technical basis for the U.S. contributions to the International Nuclear Fuel Cycle Evaluation (INFCE) Working Group 5 on Fast Breeders. These studies were carried out under the auspices of the Division of Reactor Research and Technology of the Department of Energy by several organizatons under the technical direction of a central group at Argonne National Laboratory. The studies cover most facets of the Fast Breeder Reactor field and in so doing provide a review of many of the considerations relevant to the breeder reactor program at the present time.

The reports document the technical and analytical basis for the U.S. contributions and are the responsibility of their authors only. However, the official U.S. contributions to INFCE, written specifically to the INFCE requirements for format and content, were in large part based on these reports.

The International Nuclear Fuel Cycle Evaluation was prompted by proliferation concerns. The Final Communique of the Organizing Conference of INFCE, October 21,1977 , states:

"The participants in the Organizing Conference of the International Nuclear Fuel Cycle Evaluation are conscious of the urgent need to meet the world's energy requirements and that nuclear energy for peaceful purposes should be made widely available to that end. They are also convinced that effective measures can and should be taken at the national level and through international agreements to minimize the danger of the proliferation of nuclear weapons without jeopardizing energy supplies or the development of nuclear energy for peaceful purposes."

The scope of these studies was set by their INFCE context; they deal primarily with the fast breeder reactor fuel cycle. Only to the extent they influence the choice of fuel cycle are other areas of fast reactor design brought in.

The President, in proposing the International Nuclear Fuel Cycle Evaluation on April 7, 1977, said

"Among other things, we will explore the establishment of an international nuclear fuel cycle program aimed at developing alternative fuel cycles and a variety of international and U.S. measures to assure access to nuclear fuel supplies and spent fuel storage for nations sharing nuclear nonproliferation objectives."

These studies therefore concentrate upon developing information on a full range of alternatives to the current international reference breeder cycle. To make a thorough review and examination of alternatives and options possible there is much more emphasis on alternative breeder reactors and cycles in these reports than is normally found in breeder program discussions and descriptions. Although the fast breeder is normally thought of as a mixed $\mathrm{Pu} / \mathrm{U}$ oxide fueled 
system, a variety of fueling alternatives is possible. The aim in these studies is to accurately characterize the potential and the status of the alternatives.

INFCE is an international study. International considerations and requirements are therefore emphasized in these studies, with attention given to U.S. domestic requirements within this contest.

Its potential for energy production provides the driving force for international breeder development. The strength and urgency of the need for the breeder on both an international and national basis is a topic of vital interest, and one with many facets. The signficance of the energy potential of the breeder varies with national situation and some of these considerations are examined in this report. The characteristics of the type of breeder reactor introduced affect both its energy potential and proliferation risk. The characteristics of the breeder reactor alternative types were therefore developed on a consistent normalized basis so these characteristics can be compared.

The reality of alternative fuel cycle options depends on the status of fuel development. The reference mixed-oxide fuel system is much the most advanced, and best documented, and an attempt is made to characterize and compare the status of fuel development for the alternative fuel types in considerable detail. The various options for fabrication and reprocessing are discussed and the administrative arrangements and safeguards options are presented.

Lastly, to provide specific examples of how the various characteristics might fit together in possible fast reactor deployment scenarios, contrasting types of deployment are defined and the characteristics of each are identified and discussed.

The general intent of this work was to provide a positive contribution to international discussions and to discussions of appropriate directions for reactor programs in the U.S. and elsewhere.

Charles E. Till, Director Applied Physics Division Argonne National Laboratory 


\section{PART 1}

ALTERNATIVE FUEL-CYCLE AND DEPLOYMENT STRATEGIES:

THEIR INFLUENCE ON LONG-TERM ENERGY

SUPPLY AND RESOURCE USAGE

Abstract ............................. 1

I. Introduction. . . . . . . . . . . . . . . . 1

II. Methodology and Assumptions . . . . . . . . . . . 4

A. Scope, Timing, Demand and Resource Assumptions. . . . . . 4

B. Reactor Characteristics and Fuel Cycle Assumptions. . . . . 7

C. Systems Analysis Methodology. . . . . . . . . . . 7

III. Reference International Deployment of Breeders on Pu/U Cycle. • 10

A. The Effect on Uranium Consumption of the

Basic Reactor Type. . . . . . . . . . . . . . 10

B. The Influence on Uranium Consumption of the FBR Introduction Date . . . . . . . . . . . . 13

C. Influence on Uranium Consumption of Advanced Breeders . . . . 14

IV. Secured Area Breeder Deployment with Symbiotic

Cycles Using Thorium. . . . . . . . . . . . . . . .

A. The Effect on Uranium Consumption of Thorium

Content in the Breeder for a Fixed Energy

Demand Schedule ......................

B. The Effect on Uranium Consumption of Client Denatured Reactor Type for a Fixed Energy Demand Schedule . . . . . . . . . . . . . .

C. The Influence of Breeder Thorium Content on System Growth Potential. . . . . . . . . . . . 22

D. Energy Supply Flexibility Derivable from a Symbiotic Deployment Base . . . . . . . . . . . 24

E. Summary . . . . . . . . . . . . . . . 25

V. Implications of Reactor Deployment Scenario on Amounts of Plutonium Generated and Amounts in Storage . . . . . 25

VI. Summary . . . . . . . . . . . . . . . . 27

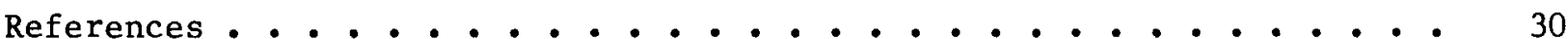


PART 2

DESIGN AND PERFORMANCE CHARACTERISTICS OF ALTERNATIVE FUELS AND FUEL CYCLES

Abstract. . . . . . . . . . . . . . . . . . .

I. Introduction . . . . . . . . . . . . . . . . .

II. Design Ground Rules, Constraints and Methodologies . . . . . . 32

A. Design Ground Rules and Constraints. . . . . . . . . . 32

B. Neutronic Data and Methods . . . . . . . . . . . 33

III. Core Design and Performance Characteristics. . . . . . . . 38

A. Reference Core Design Characteristics. . . . . . . . . 38

B. Performance Characteristics. . . . . . . . . . . 43

1. Comparison of Breeding Performance Between Oxide, Carbide and Metal Fuels. . . . . . . . . . .

2. Comparison of Breeding Performance Between

Fue1 Cycle Options . . . . . . . . . . . . 50

3. Breeding Performance of Heterogeneous Cores. . . . . . 53

4. Breeding Performance of GCFR Fuel Cycles . . . . . . . 54

5. Safety-Related Physics Parameters. . . . . . . . 55

IV. Sensitivities and Ranges of Breeding Performance . . . . • . 55

A. Oxide Fuel . . . . . . . . . . . . . . 55

B. Carbide Fue1 ................. . . 57

C. Metal Fuel ................... 58

D. Alternative Fuel Cycles. . . . . . . . . . 59

1. Reference Pu/U Cycle . . . . . . . . . . . . 60

2. Pu/U Core with Thorium Radial Blanket Only . . . . . . 60

3. Pu/U Core with Thorium Axial and Radial Blanket. . . . . 62

4. Pu/Th Core with Thorium Blanket. . . . . . . . . 62

5. $233_{\mathrm{U}} / \mathrm{Th}$ Core with Thorium Blanket........... 62

6. Heterogeneous Core with Thorium Blanket. . . . . . 63

V. Summary. . . . . . . . . . . . . 63

Acknowledgments . . . . . . . . . . . . . 67

References. . . . . . . . . . . . . . 68

Appendix: Detailed Mass Flow Data. . . . . . . . . . . 70 
PART 3

STATUS OF LMFBR FUELS AND MATERIALS DEVELOPMENT

Abstract. . . . . . . . . . . . . . . . . . . 109

I. Introduction . . . . . . . . . . . . . . 109

II. Oxide Fuels. . . . . . . . . . . . . . . . 110

A. Status of Development................. 111

1. Candidate Oxide Fuel Types . . . . . . . . . . 111

2. Feasible Element Designs . . . . . . . . . . . 111

3. Irradiation Performance. . . . . . . . . . . 112

4. Modeling of Fuel Element Behavior. ......... 115

B. Key Issues . . . . . . . . . . . . . 115

1. Thermal Performance. . . . . . ..... 115

2. Mechanical Performance . . . . . . . . . . 117

3. Chemical Behavior. ................. 118

4. Run-Beyond-Cladding-Breach . . . . . . . . . 118

5. Blanket Rod Performance. . . . . . . . . . . 119

C. Activities Required to Resolve Key Issues. . . . . . . 120

1. Thermal Performance. . . . . . . . . . 120

2. Mechanical Performance . . . . . . . . . . 120

3. Chemical Behavior. . . . . . . . . . . . 121

4. Run-Beyond-Cladding-Breach . . . . . . . . . 121

5. Blanket Rod Performance. . . . . . . . . . 121

D. Summary of Oxide Fuel Status . . . . . . . . . . 121

III. Carbide Fuels. . . . . . . . . . . . . . . . 121

A. Status of Development. . . . . . . . . . . 121

1. Candidate Carbide Fuel Types . . . . . . . . . 122

2. Fuel Properties. . . . . . . . . . . . . 122

3. Feasible Element Designs . . . . . . . . . . 122

4. Irradiation Performance. . . . . . . . . . . 124

5. Modeling of Fuel Element Behavior. . . . . . . . 130

B. Key Issues . . . . . . . . . . . . . . 130

1. Cladding Carburization and Embrittlement . . . . . . 131

2. Fue1/Cladding Mechanica1 Interaction . . . . . . . 131 
3. Loss of Sodium Bond . . . . . . . . . . 131

4. Blanket Development . . . . . . . . . . . 132

5. Fuel Element Performance Predictions. . . . . . . 132

C. Activities Required to Resolve Key Issues . . . . . . . 132

1. Cladding Carburization and Embrittlement. . . . . . 132

2. Fue1-Cladding Mechanical Interaction. . . . . . . . 132

3. Loss of Sodium Bond . . . . . . . . . . . . . 133

4. Blanket Development ................ 133

5. Fuel Element Performance Predictions. . . . . . . 133

D. Summary of Carbide Fuel Status. . . . . . . . . 133

IV. Metal Fuels . . . . . . . . . . . . . . . . . 134

A. Status of Development . . . . . . . . . . 134

1. Candidate Metal Fuel Types. . . . . . . . . 134

2. Fuel Properties . . . . . . . . . . . . . 134

3. Feasible Element Designs. . . . . . ...... 135

4. Irradiation Performance . . . . . . . . . . . 136

5. Modeling of Fuel Element Behavior.......... 140

B. Key Issues. . . . . . . . . . . . . 140

1. Thermal Performance........... 140

2. Mechanical Performance. . . . . . . . . . . 141

3. U-Pu-Zr Alloy Restructuring . . . . ....... 141

4. Blanket Development ................. 141

5. Fuel Element Performance Prediction . . . . . . . 141

C. Activities Required to Resolve Key Issues . . . . . . . 142

1. Thermal Performance . . . . . . . ..... 142

2. Mechanical Performance. . . . . . . . . . . 142

3. U-Pu-Zr Alloy Restructuring . . . . . . . . . . 142

4. Blanket Development . . . . . . . . . . . . 142

5. Fuel Element Peformance Predictions . . . . . . . 143

D. Summary of Metal Fuel Status. . . . . . . . . . 143

V. Cladding/Duct Alloys. . . . . . . . . . . . . . 143

A. Status of Development . . . . . . . . . . . . 143

B. Key Technical Issues. . . . . . . . . . . . . . 144

C. Activities Required to Resolve Key Issues . . . . . . . 145 
VI. Neutron Absorbers . . . . . . . . . . . . . . 145

A. Status of Development . . . . . . . . . . 145

1. Boron Carbide . . . . . . . . . . . 145

2. Other Neutron Absorbers . . . . . . . . . . 146

B. Activities Required to Resolve Key Issues . . . . . . . 146

C. Summary of Absorber Materials Status. . . . . . . . 146

VII. Summary and Conclusions . . . . . . . . . . . . . . 146

References . . . . . . . . . . . . . . . . 148

PART 4

SAFETY IMPLICATIONS OF ALTERNATIVE FUEL TYPES

Abstract . . . . . . . . . . . . . . . . . . 151

I. Introduction and Summary. . . . . . . . . . . . . 151

II. Key Energetics Issues and Desirable Fuel Characteristics. • • • 155

III. Accident Energetics - Oxide Fueled LMFBRs . . . . . . . . . 161

A. Initiators of Core-Disruptive Accidents . . . . . . . 161

B. Potential for Core Disruption ............ 161

1. Fuel-failure Propagation. ............. 161

2. Loss of Plant Protection Systems. . . . . . . . 162

a. Unprotected TOP . . . . . . . . . . 162

b. Unprotected LOF . . . . . . . . . . . . 164

C. Potential for Energetics. . . . . . . . . . . 164

1. Core Disruption at High Power Leve1s. . . . . . . . 164

2. Core Disruption at Low Power Levels . . . . . . . 165

D. Reactor Disassembly and Structural Design Considerations. - . 166

E. Resolution of Key Issues. . . . . . . . . . . . 168

F. Summary ...................... 172

IV. Accident Energetics - Carbide Fueled LMFBRs . . . • . • • • . 172

A. Introduction. . . . . . . . . . . . . . . 172

B. The Potential for Core Disruption . . . . . . . . . 173 
TABLE OF CONTENTS (contd)

$\underline{\text { Page }}$

1. Fue1-Failure Propagation . . . . . . . . 173

2. Loss of Plant-Protection Systems. . . . . . . . 173

a. Unprotected TOP . . . . . . . . . 173

b. Unprotected LOF . . . . . . . . . . . . 173

c. Potential for Energetics. . . . . . . . . . . . 174

1. Core Disruption at High Power Leve1 . . . . . . . 174

2. Core Disruption at Low Power Leve1. . . . . . . 176

D. Resolution of Key Issues. . . . . . . . . . . . 176

E. Summary . . . . . . . . . . . . . . . . 176

V. Accident Energetics - Metal Fueled LMFBRs . . . . . . . . 176

A. Introduction. . . . . . . . . . . . . . 176

B. The Potential for Core Disruption . . . . . . . . . 179

1. Fuel-Failure Propagation. . . . . . . . . . 179

2. Loss of Plant-Protection Systems. . . . . . . . 180

a. Unprotected TOP . . . . . . . . . . 180

b. Unprotected LOF . . . . . . . . . . . 180

C. Potential for Energetics. . . . . . . . . . . 180

1. Core Disruption at High Power Levels. . . . . . . . 180

2. Core Disruption at Low Power Levels . . . . . . . 180

D. Resolution of Key Issues. . . . . . . . . . . . . 181

E. Summary . . . . . . . . . . . . . . . . 181

VI. Post-Accident Heat Removal - Oxide, Carbide,

and Metal Fueled LMFBRs . . . . . . . . . . . . . . 181

A. In-Vessel Retention . . . . . . . . . . . . . 181

B. Ex-Vessel Retention . . . . . . . . . . . . . . 183

C. Inherent Retention in Concrete.............. 183

VII. GCFR Considerations . . . . . . . . . . . . . . • 184

A. Introduction. . . . . . . . . . . . . . . . 184

B. Accident Energetics . . . . . . . . . . . . . 184

C. Post-Accident Heat Removal. . . . . . . . . . ... 185

D. Resolution of Key Issues. . . . . . . . . . . . 185

E. Summary . . . . . . . . . . . . . . 185

VIII. Conclusions . . . . . . . . . . . . . . . . 186 
Acknowledgments. . . . . . . . . . . . . . . . . . . .

References . . . . . . . . . . . . . . . . . . .

FUEL CYCLE OPTIONS

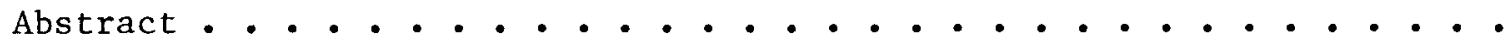

I. Introduction. . . . . . . . . . . . . . . . .

A. Deployment Scenarios. . . . . . . . . . . . .

1. Reference International System. . . . . . . . . 193

2. Secured Area System . . . . ......... 193

3. Integral Cycle System . . . . . . . . . . 193

B. Content of this Chapter . . . . . . . . . . 193

II. Generic Review of the Fuel Cycle. . . . . . . . . . . . 194

A. Generic FBR Fuel Cycle Description. . . . . . . . . . 194

B. Fuel Reprocessing .................. 195

1. Aqueous Processes . . . . . . . . . . 195

2. Non-Aqueous Processes ............. 196

C. Fuel Fabrication. . . . . . . . . . . . . 196

1. Oxide Fuel Fabrication. . . . . . . . . . 197

2. Metal Fuel Fabrication. ............ 197

D. Waste Management and Disposal . . . . . . . . 197

E. Transportation. . . . . . . . . . . . . . 198

F. Fuel Cycle Proliferation Defenses and Vulnerable Points • . 198

1. Elements of Proliferation Defenses. . . . . . . . 198

2. Sensitive Elements of the Fuel Cycle. . . . . . . . 199

a. Process Materials . . . . . . . . . 199

b. Process Techniques. .............. 199

c. Process Equipment .............. 200

d. Facilities. ............... 200

3. Overview of Safeguards. . . . . . . . . . 201

a. International Safeguards. . . . . . . . 202

b. National Safeguards . . . . . . . . . 203 
III. Fuel Cycle in the Reference International System. . . . . . . 206

A. Reference FBR Fuel Cycle. . . . . . . . . . 207

1. Reprocessing of FBR Mixed-Oxide Fuels by Aqueous

Solvent Extraction. . . . . . . . . . . . 207

2. Reprocessing Differences for Metal and Carbide Fue1 . . 211

3. Diversion Potential in Reprocessing . . . . . . . . 211

4. Safeguards for Reprocessing . . . . . . . . . 212

5. Fabrication of Mixed Oxide Fuel for FBRs. . . . . . 214

6. Fabrication of Metal Fuel for FBRs. . . . . . . . 217

7. Fabrication of Carbide Fuels for FBRs . . . . . . . 219

8. Diversion Potential in Fabrication. . . . . . . . 219

9. Safeguards for Fabrication. . . . . . . . . . 220

10. Waste . . . . . . . . . . . . . . . . 222

11. Transportation. . . . . . . . . . . . . 223

a. Domestic Transportation Safeguards. . . . . . 224

b. Internationa1 Transportation Safeguards . . . . . 225

B. Modifications to the Reference Processes: Feasibility,

Implications and Impact on Diversion Resistance . . . . .

1. Alternate Methods of Fuel Reprocessing. . . . . . 226

a. Coprocessing. . . . . . . . . . . 227

b. Coprocessing with Low Decontamination . . . . . 229

c. Halide Volatility Processes . . . . . . . . 230

d. Dry Processes . . . . . . . . . . . 231

2. Fue1 Spiking. . . . . . . . . . . . 231

3. Plant Design Features to Inhibit Flexibility or Alteration (Civex Approach). . . . . . . . 233

4. Collocation of Fabrication and Reprocessing Plants. . . 236

5. Engineering the Use-Denial of Materials and Facilities. . . . . . . . . . . . 237

6. Fuel Fabrication. . . . . . . . . . 238

a. Alternate Fuel Fabrication Processes. . . . . . 238

b. Impact of High Gamma Fuels. . . . . . . . . 239

c. Impact of Mixed U/Pu Feed Material. . . . . . . 240

7. Pre-Irradiation . . . . . . . . . . . 240

8. ${ }^{238} \mathrm{Pu}$ Denaturing of Plutonium Fuels . . . . . . . 242

IV. Fuel Cycle in the Secured-Area System . . . . . . . . . . . . 243

A. Overview of Reactor and Fuel Cycle Characteristics. . . . 243 
1. Type of Reactors Deployed . . . . . . . . . . 243

2. Demands on the Fuel Cycle Facilities. . . . . . . 245

3. Characteristic Deployments. . . . . . . . 247

B. Reprocessing in the Secured-Area System . . . . . . . . 248

1. A Thorex-process Description. . . . . . . . . . 249

2. 3-Way Separation Process. . . . . . . . . 250

3. Unique Features in Reprocessing of

Thorium-Based Fuels . . . . . . . . . 250

C. Fabrication of Thorium-Based Fuels. . . . . . . . 251

1. Oxide Fuel Pellets. . . . . . . . . . . 251

2. Impact of Carbide and Metal Fuel. . . . . . . . 253

3. Particle Methods. . . . . . . . . . . 254

D. Waste . . . . . . . . . . . . . . 254

E. Transportation. . . . . . . . . . . . . 254

F. Safeguards................... . . . 255

G. Feasibility of Alternatives in Reprocessing or

Fabrication to Enhance Proliferation Resistance . . . . . 256

H. Summary of the Secured-Area Fuel Cycle. . . . . . . . 257

V. Fuel Cycle in the Integral System . . . . . . . . . . 258

A. Integral Cycle Operation of EBR-II. . . . . . . . 258

B. A Pyrochemical Process. . . . . . . . . . . . 259

C. Reprocessing with Pyrochemical Techniques . . . . . . . 260

D. Fuel Fabricated in the Integral Cycle . . . . . . . . 262

E. Safeguards in the Integral Cycle. . . . . . . . . . 262

F. Transportation in the Integral Cycle. . . . . . . . . 263

G. Overt Diversion Potential in the Integral Cycle . . . . . 263

VI. Status of FBR Fuel Cycle Technology . . . . . . . . . . . 264

A. Reprocessing. . . . . . . . . . . . 264

1. Aqueous Solvent Extraction. . . . . . . . . 264

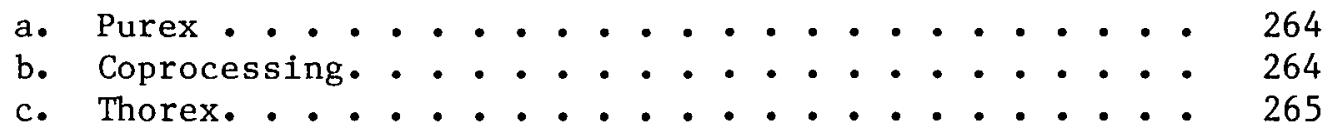

2. Fluoride Volatility Processes . . . . . . . . 265

3. Pyrochemical Processes. . . . . . . . . . . 265

B. Fabrication .................... . . 265

C. Transportation. . . . . . . . . . . . . 267 
D. Waste Handling. . . . . . . . . . 267

E. Safeguards...................... 267

VII. Summary, Key Technical Issues and Conclusions . . . . . . . . 268

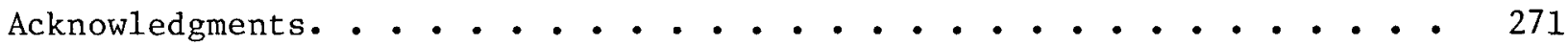

References . . . . . . . . . . . . . . . . . 272

PART 6

INTERNATIONALIZATION AND COLLOCATION

OF FBR FUEL CYCLE FACILITIES

Abstract . . . . . . . . . . . . . . . . . . 280

I. Introduction. . . . . . . . . . . . . . . 280

II. Incentives and Evolutionary Trends Toward

Collocation and Internationalization. . . . . . . . . 281

A. Evolution . . . . . . . . . . . . . . 281

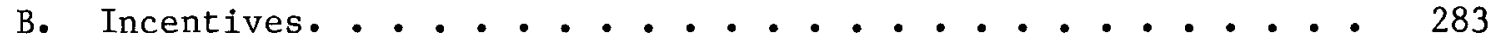

III. International Cooperation in the Breeder Fuel Cycle • • • • • 285

IV. Non-Proliferation Features. . . . . . . . . . . 285

A. Collocation Considerations. . . . . • . . . . 286

B. Internationalization Considerations . . . . . . . . 286

C. Deployment Strategy . . . . . . . . . . . . . 287

V. Technical Issues. . . . . . . . . . . . . . . 288

A. Technical Considerations in Selecting a
Specific Collocation Configuration. . . . . . . 288

1. FBR Spent Fuel Characteristics. . . . . . . . 288

a Large Throughput of Plutonium . . . . . . . 289

b. High Fissile Content. . . . . . . . . . . 289

c. Decay Heat and Activity . . . . . . . . . 289

2. FCC Configurations. . . . . . . . . . 290

a. Reference Centers . . . . . . . . 290

b. Transition Centers................ 290

c. Integral Center... . . . . . . . . . 290 
B. Technical Considerations Related to Siting of

Collocated Facilities . . . . . . . . . . . .

1. Collocation of Fuel Fabrication, Reprocessing, Nitrate Conversion, and Waste Solidification. . . . . . . .

a. Chemical Effluents. . . . . . . . . . 293

b. Water Requirements. . . . . . . . . . 293

c. Radiological Effluents. . .......... 293

2. Collocation of Power Generation and

Fuel Cycle Facilities . . . . . . . . . . 294

a. Thermal and Chemical Effluents. . . . . . . . 294

b. Radiological Effluents. . . . . . ..... 295

c. Deployment Configuration Effects. . . . . . . . 296

d. Transmission Cost Penalties and

Power Reliability Considerations. . . . . . . 298

VI. Legal, Administrative, and Acceptability Considerations

of International FBR FCCs . . • . • • . • • • • • • . 299

A. Legal/Administrative Considerations . . • . . • . • 299

1. Lega1 Status and Structure. . . . . . . . . . 299

2. Governmental Role ................. 299

3. International Administrative Structure. . . . . . . 299

4. Commercial/Service Arrangements . . . . . . . . 300

5. Industrial Arrangments. . . . . . . . . . . 300

6. Technology. . ............... 300

7. Financial Matters .. . . . . . . . . . 300

8. Special Privileges and Guarantees . . . . . . . . . 301

9. Staffing. . . . . . . . . . . . . . . 301

10. Physical Protection and Emergency Responsibilities. •. 301

B. Acceptability Considerations in Implementing FBR FCCs . . • 301

VII. Summary and Findings. . . . . . . . . . . . . 302

References . . . . . . . . . . . . . . . 304

PART 7

SAFEGUARDS

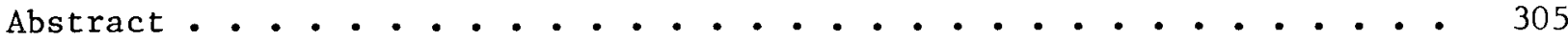

I. Introduction. . . . . . . . . . . . . . 305 
II. Background Material . . . . . . . . . . . . 307

A. Legal Background on IAEA Safeguards Implementation. • • • 307

B. Historical Background of Domestic Safeguards. . . . . . 309

III. Potential Diversion Concerns. . . . . . . . . . . 310

A. Subnational Leve1 . . . . . . . . . . . 310

B. National Level. . . . . . . . . . . . . . 310

IV. Safeguards. . . . . . . . . . . . . . . 311

A. Introduction. . . . . . . . . . . . 311

B. The Generic Safeguards System . . . . . . . . . 311

1. Physical Protection System. . . . . . . . . . 311

2. Materials Control and Accountability System . . . . . 313

3. System Structure. . . . . . . . . . . 313

4. Non-Destructive Assay Techniques. . . . . . . 315

a. Alpha Monitors................ 317

b. Gamma Absorption Techniques, Absorptometry. . . . 317

c. Absorption-Edge Densitometry. . . . . . . 317

d. Gamma-ray Analysis. . . . . . . . . . 317

e. Neutron and Neutron Coincidence Counting. . . . . 318

f. Quantitative X-Ray Flourescence Analysis of SNM in Solution. . . . . . . . . . 318

g. Active Neutron Techniques . . . . . . . . 318

5. Statistical Decision Analysis . . . . . . . 318

C. Safeguarding the Reference FBR Cycle. . . . . . . . 320

1. Power Plant Safeguards. . . . . . . . . 320

2. Transportation Safeguards ............ . 323

3. Reprocessing Plant Safeguards . . . . . . . . 324

4. Fuel Fabrication Plant Safeguards . . . . . . . 326

5. Fuel Storage Safeguards . . . . . . . . . 327

6. Fuel Cycle Waste Safeguards . . . . . . . . . 327

D. Safeguarding Alternative Fuel Systems . . . . . . . . 328

1. Denatured Uranium/Thorium . . . . . . . . . 328

2. High Radiation Level Fuel (HRLF). . . . . . . . . 329

3. Co-processing . . . . . . . . . . . . . 330

4. Civex (Low Decontamination and Co-processing Fuel Cycle) . . . . . . . . . 331

V. Summary . . . . . . . . . . . . . . . • . 332 
Acknowledgments. . . . . . . . . . . . . . . . . 332

References . . . . . . . . . . . . . . . 333

PART 8

DEPLOYMENT CONSIDERATIONS

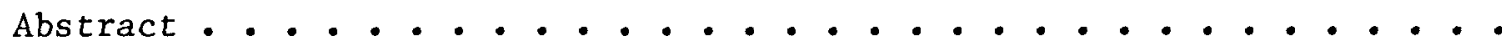

I. Introduction. . . . . . . . . . . . . . 337

II. Historical Perspective and Current Nuclear Status . • . • • • . 340

A. Reactor Technology. . . . . . . . . . . . 340

B. Fuel Cycle Technology .................. 341

1. Enrichment. . ................ 341

2. Fabrication . . . . . . . . . . 342

3. Reprocessing. . . . . . . . . . . . . 342

C. Uranium Supply. . . . . . . . . . . . . . 345

D. Fast Breeder Reactor. . . . . . . . . . . . 345

III. Breeder Development Considerations in Non-Breeder Nations . • • 346

A. Factors Influencing Breeder Development

Decisions in Non-Breeder Nations. . . . . . . . . 348

1. Potential for Deployment. . . . . . . . . 348

2. Anticipated Mode of Deployment. . . . . . . . . 348

3. Independent Development/Collaborative Development . . • 348

B. Considerations in Setting General Nuclear

Development Priorities in Consumer Nations. . . . . . . 349

C. Areas for Nuclear Development . . . . . . . . . 350

1. Low Cost, Genera1 Conventional Nuclear Support. . . . 350

2. Conventional Nuclear Component Manufacture. . . . . . 350

3. Breeder Reactor NSSS RD\&D . . . . . . . . . . . 350

4. Sodium Technology RD\&D. . . . . . . . . . . 350

5. Reprocessing. . . . . . . . . . . . 351

IV. Breeder Deployment Considerations . . . . . . . . . . 351

A. Strategies.................... . 351

1. Buy Reactor/Buy Fuel Cycle Services . . . . . . . . 351

2. Build Reactor/Buy Fuel Cycle Services . . . . . . . 352 
3. Buy Reactor/Build Fuel Cycle Facilities . . . . . . 352

4. Build Reactor/Buy Fuel Cycle Facilities . . . . . . 352

5. Build Reactor/Build Fuel Cycle Facilities .... . . 352

6. Develop Reactor/Develop Fuel Cycle Facilities . . . . 352

B. Factors to be Considered in Breeder Deployment Decisions. • 353

1. Resource Adequacy . . . . . . . . . . . . 353

2. Assurance of Supply . . . . . . . . . . . . 353

3. Economics . . . . . . . . . . . . . . 354

4. Health, Safety and Environment. . . . . . . . . 354

5. Non-Proliferation . . . . . . . . . . . . 354

6. FBR Performance Assurance . . . . . . . . . 355

7. Technological/Industrial Base . . . . . . . . 355

8. Planning Horizon. . . . . . . . . . . . 356

9. Prestige/Status . . . . . . . . . . . . 356

V. Overall Deployment Considerations and Conclusions . • • • • • 356

ANNEX

DECOMMISSIONING OF A LARGE CENTRAL-STATION LMFBR POWER PLANT: A COMPARISON WITH THE PWR

I. Abstract. . . . . . . . . . . . . . . 359

II. Introduction. . . . . . . . . . . . . . . . 359

III. Description of LMFBR Compared to PWR Reactor. . • • • • • • 360

A. Basic Features of LMFBR Compared to PWR . . . . . . . 360

B. Brief Description of LMFBR. . . . . . . . . . . . 360

C. Comparison of LMFBR with PWR. . . . . . . . . . . 366

IV. Primary System Radioactivity. . . . . . . . . . . . • 373

A. Activation of Components and Structures . . . . . . . 373

B. Comparison of LMFBR with PWR Activation . . . . . . . . 374

1. Introduction. . . . . . . . . . . . . 374

2. Comparison of LMFBR and PWR Fluxes. . . . . . . . . 378

3. Comparison of Activation and Dose Rate. . . . . . 382

C. Deposition of Fission Products and

Activated Corrosion Products. . . . . . . . . . . 
V. Sodium Radioactivity, Decontamination, and Disposal . . . . • 389

A. Sodium Radioactivity. . . . . . . . . . . 389

B. General Cleaning Methods. . . . . . . . . . 389

C. Sodium Disposal . . . . . . . . . . . . . . 392

VI. Steps in Dismantling and Shipping Intermediate

System Components and Piping. . . . . . . . . . . . . 394

VII. Steps in Dismantling Reactor Vessel and its Components. • . . . 395

VIII. Timing and Costs. . . . . . . . . . . . . . 399

A. Timing. . . . . . . . . . . . . . . . 399

1. Time Consideration in the Reactor Dismantling . . . . 400

2. Disposal of Reactor Components. . ........ . 400

3. Total Personnel Exposure.............. 400

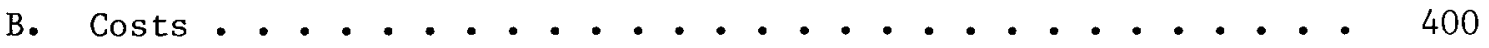

IX. State of Technology . . . . . . . . . . . . . 403

X. Summary and Conclusions . . . . . . . . . . . . . . 404

References . . . . . . . . . . . . . . . 4 408 
xxii 
PART 1

\title{
ALTERNATIVE FUEL-CYCLE AND DEPLOYMENT STRATEGIES: THEIR INFLUENCE ON LONG-TERM ENERGY SUPPLY AND RESOURCE USAGE
}

C. E. Till, Y. I. Chang, and R. R. Rudolph (Argonne National Laboratory)

\begin{abstract}
This report examines the implications of alternative fast breeder fuel cycles and deployment strategies on long-term energy supply and uranium resource utilization. An international-aggregate treatment for nuclear energy demand and resource base assumptions was adopted where specif $1 C$ assumptions were necessary for system analyses, but the primary emphasis was placed on understanding the general relationships between energy demand, uranium resource and breeder deployment option. The fast breeder deployment options studied include the reference $P u / U$ cycle as well as alternative cycles with varying degrees of thorium utilization.
\end{abstract}

\section{INTRODUCTION}

The studies reported here were performed as part of the U.S. efforts in support of the International Nuclear Fuel Cycle Evaluation (INFCE) Working Group 5 on Fast Breeder Reactors. These studies were carried out to provide technical and analytical background for that portion of the U.S. contribution to Subgroups 5A (The Role of the Fast Breeder in the Future Energy Economy) and 5D (Alternative Breeder Cycles) dealing with the broad resource and energy supply implications of breeders. The U.S. contributions are drawn from these studies, but this report as it stands is not an official U.S. contribution.

The work of the International Nuclear Fuel Cycle Evaluation deals primarily with measures that may be taken "to minimize the danger of the proliferation of nuclear weapons without jeopardizing energy supplies or the development of nuclear energy for peaceful purposes." The quotation is from the Final Communique of the Organizing Conference of INFCE, October 21, 1977, and in context, it is stated that the participants are convinced that effective measures can and should be taken at the national level and through international agreements to accomplish this. A main purpose of the U.S. contribution is to aid in a full presentation and discussion of alternative technologies and institutional arrangements, and in the identification of those deserving further exploration and consideration. 
The subject matter of this report is limited to those issues that are amenable to systems analyses -- primarily the interactions between energy supply capability, resource usage, and reactor characteristics. The energy generation implications resulting from a variety of possible fast breeder deployment options are presented.

Specifically, this study has as its objectives to investigate:

1. The long-term power production and uranium utilization incentives for FBR deployment;

2. The sensitivities of achievable long-term power production and uranium utilization to breeder type and introduction date;

3. The impacts on long-term power production and uranium utilization of increasing thorium utilization in fast breeder fuel cycles; and

4. The implications of various reactor deployment scenarios as to the amounts of plutonium generated and the amounts in storage.

In any systems analysis, the results are determined by the input assumptions such as energy requirements and rates of growth, nuclear market share, uranium resources, nuclear technology status, and economics, all of which are intrinsically difficult to forecast for long periods into the future. Nevertheless, because the fast breeder is a long-term supply option, its important role will be played only well into the next century. This implies that conclusions will be sensitive to long-term projections of uncertain parameters.

The approach taken in this study was to adopt an international-aggregate treatment for demand and resource base assumptions, where specific assumptions were necessary to the analyses, but to focus primarily on the relationships between energy demand, uranium resource and breeder deployment option. Understanding of the general relationships is likely to be more useful to energy policy planning than specific projections and scenarios, in any case.

The methodology and assumptions used in the study are described in Section II. An international-aggregate treatment was used for the energy demand and uranium resources, and the OECD Nuclear Energy Agency data were used as a base case.

Three alternative FBR deployment options have been considered throughout the preparation of the U.S. contribution to the INFCE Working Group 5 study of breeders. These deployment options have been called:

1. Reference Internationa1 Deployment,

2. Secured Area Deployment, and

3. Integral Cycle Deployment.

Each option comprises a distinctly different approach to the tradeoffs between means to achieve:

1. Uranium ore extensions by use of breeders, 
2. Minimal incremental nuclear weapons proliferation risk, and

3. Material energy independence and/or autonomy of action for all nations.

While the details of each of the three deployment options may vary, their fundamental characteristics are:

The Reference International Deployment -- places no constraint on breeder fuel cycle type or breeder reactor location. The reprocessing/refabrication links of the cycle might be located without constraint or they might be confined to Fuel Cycle Centers under international control. (This option includes the historically perceived deployment pattern for breeders.)

The Secured Area Deployment -- constrains the breeder reactors to be collocated with the reprocessing/refabrication links of the cycle and constrains the location of the secured area to a small number of specified locations. No fresh fuel containing plutonium is allowed outside the secured area. This constraint could (but need not necessarily) lead to the use of thorium and symbiotic cycles.

The Integral Cycle Deployment -- constrains the breeder reactors to be collocated with the reprocessing/fabrication links of the fuel cycle. However, in this case, the location of the integral cycle center is unconstrained as is the fuel cycle type.

Each of these characteristic deployment configurations possesses both advantages and disadvantages as to its ability to simultaneously provide for uranium ore extension, minimal proliferation risk, and material energy independence and/or autonomy. The tradeoffs are discussed in other reports of this series, $1-3$ where the differences of the three alternatives lead to major impacts.

For the issues addressed in this report, it is not necessary or useful to consider each deployment scenario specifically. Rather, it is sufficient to consider only two classes of cases:

1. Breeder deployment not constrained as to fuel cycle type, and

2. Breeder deployment constrained to employ thorium to varying degrees.

These two classes of cases provide results which include all possibilities for the three deployment scenarios.

The case of unconstrained breeder deployment is analyzed in Section III. In this deployment scenario, we assume the $\mathrm{Pu} / \mathrm{U}$ cycle is the reference cycle for fast breeders, and the role of fast breeders is examined compared to scenarios without fast breeder introduction. The influence of breeder introduction date is also examined, with some emphasis placed on the possible role of advanced breeder design types to gain flexibility to meet unexpected demand under various constraints including delays in introduction. Two types of studies are done in this section. In the first, an energy demand curve is specified and the uranium ore requirements are minimized by the optimal 
sequence of deployment of the reactor types available. In the second, a fixed upper limit on the uranium resource is specified and the energy output is maximized by the optimal sequence of deployment of the reactor types available.

The cases of breeders cons rained to use varying degrees of fertile thorium is studied in Section IV. Conversion of thorium to ${ }^{23} 3 \mathrm{U}$ in breeders (perhaps confined to location as in the Secured Area Deployment) is envisioned to support dispersed converter reactors operating on a denatured thorium cycle. An important parameter for this symbiotic cycle is the ratio of (Dispersed)/ (Secured Area) power. This ratio and the long-term nuclear energy supply potential are determined as a function of degree to which thorium replaces ${ }^{238} \mathrm{U}$ as the fertile material of the breeders. Studies are also made of the potential for recovery of long-term nuclear energy supply upon return from the symbiotic cycles to unconstrained breeder deployment.

Concern has arisen with plutonium recycle and the fast breeder because plutonium is a weapons usable material and its quantity increases in time through breeding in the fast reactors. In Section $V$ the implications of an expanding plutonium economy associated with fast breeders are examined quantitatively, compared to the scenarios without fast breeder introduction.

Finally, a summary of the main points is presented in Section VI.

\section{METHODOLOGY AND ASSUMPTIONS}

A. Scope, Timing, Demand and Resource Assumptions

The base cases for main studies in this report use the OECD-NEA estimates of demand and resource availability. ${ }^{4}$ Table I, reproduced from Ref. 4, summarizes the uranium resource position. The resource estimates include "reasonably assured" and "estimated additional" resources at a forward cost cut-off of $\$ 50 / 1 \mathrm{~b} \mathrm{U} \mathrm{U}_{8}$. The "forward" cost implies incremental mining cost and does not include the exploration and property acquisition costs, nor return on investment. In summary, the world (excluding nations with centrally planned economies) uranium resource base is estimated to be about 4.3 million tonnes of uranium $\left(=5.6\right.$ million short tons of $\left.\mathrm{U}_{3} \mathrm{O}_{8}\right)$ of which 1.7 million tonnes of uranium $\left(=2.2\right.$ million short tons of $\left.\mathrm{U}_{3} \mathrm{O}_{8}\right)$ are contributed by the U.S.

In the system studies the resource estimates of Table I were used primarily as reference data points. Analyses were carried out for a range of resource bases where sensitivities to choice of resource base is important. In other cases, where this was sufficient, the resource usage was simply displayed against the background of these reference data points.

The nuclear energy demand estimates of Ref. 4 extend to 2025. The characteristics of the breeder, however, coupled with the lead times required for the large, new technology that the breeder represents, basically define its time frame. Estimates to the year 2025 are insufficient. In the studies of this report, three fairly distinct time phases can be identified.

During the first phase, through the year 2000, the fast breeder is clearly in mainly developmental and demonstration state, and nuclear energy will be supplied almost entirely by already commercialized converter reactor types. The breeder is allotted no significant fraction of the demand. During a 
TABLE I. World Uranium Resource Position (Thousand Tonnes U)a

\begin{tabular}{|c|c|c|c|c|c|}
\hline & \multicolumn{2}{|c|}{ Reasonably Assured Resources } & \multicolumn{2}{|c|}{ Estimated Additional Resources } & \multirow[b]{2}{*}{ Total } \\
\hline & $\begin{array}{c}<\$ 80 / \mathrm{kg} \mathrm{U}^{\mathrm{b}} \\
\left(<\$ 30 / 1 \mathrm{~b} \mathrm{U}_{3} \mathrm{O}_{8}\right)\end{array}$ & $\begin{array}{c}\$ 80-130 / \mathrm{kg} \mathrm{U} \\
\left(\$ 30-50 / 1 \mathrm{~b} \mathrm{U} \mathrm{U}_{3} \mathrm{O}_{8}\right)\end{array}$ & $\begin{array}{c}<\$ 80 / g k ~ U \\
\left(<\$ 30 / 1 \mathrm{~b} \mathrm{U}_{3} \mathrm{O}_{8}\right)\end{array}$ & $\begin{array}{c}\$ 80-130 / \mathrm{kg} \mathrm{U} \\
\left(\$ 30-50 / 1 \mathrm{~b} \mathrm{U}_{3} \mathrm{O}_{8}\right)\end{array}$ & \\
\hline Australia & 289 & 7 & 44 & 5 & 345 \\
\hline Canada & 167 & 15 & 392 & 264 & 838 \\
\hline South Africa & 306 & 42 & 34 & 38 & 420 \\
\hline United States & 523 & 120 & 838 & 215 & 1696 \\
\hline Other African countries & 218 & 6 & 118 & 10 & 352 \\
\hline Western Europe & 57 & 325 & 41 & 37 & 460 \\
\hline Countries not included above & 87 & 29 & 44 & 16 & 176 \\
\hline Total (rounded) $10^{3}$ tonnes U & 1650 & 540 & 1510 & 590 & 4290 \\
\hline $10^{3} \mathrm{ST} \mathrm{U}_{3} \mathrm{O}_{8}$ & 2150 & 700 & 1960 & 770 & 5580 \\
\hline
\end{tabular}

aReproduced from OECD-NEA Report, February 1978.

befined as "reserves" 
transition phase, approximately 2000-2025, fast breeders could be introduced on a commercial scale, but if allowance is made for gradual market penetration, the impact on the total nuclear sector would remain partial and only a start would be made on the long-term effects. Only during the final phase, that of a mature breeder economy, in the decades after 2025, would the full impact of the fast breeder be shown. The time horizons used for system studies in this report were therefore carried out at least through 2075 to adequately account for these effects.

The OCD-NEA report gives two sets of projections. The first, termed "present trend," is the basis for the base case wherever the terminology is used in this report. The second, much higher projection, termed the "accelerated" case in the reference was based on the assumption of a return to the post oil embargo sense of urgency for nuclear energy expansion. In the work of this report the realism of the latter projection is implicitly discounted, selecting instead an arbitrary doubling of the present-trend growth rate after the year 2000 as sufficient for the examination of sensitivities to large demand. For the extension beyond 2025, simple linear extrapolation was used. The foregoing is summarized by Fig. 1 .

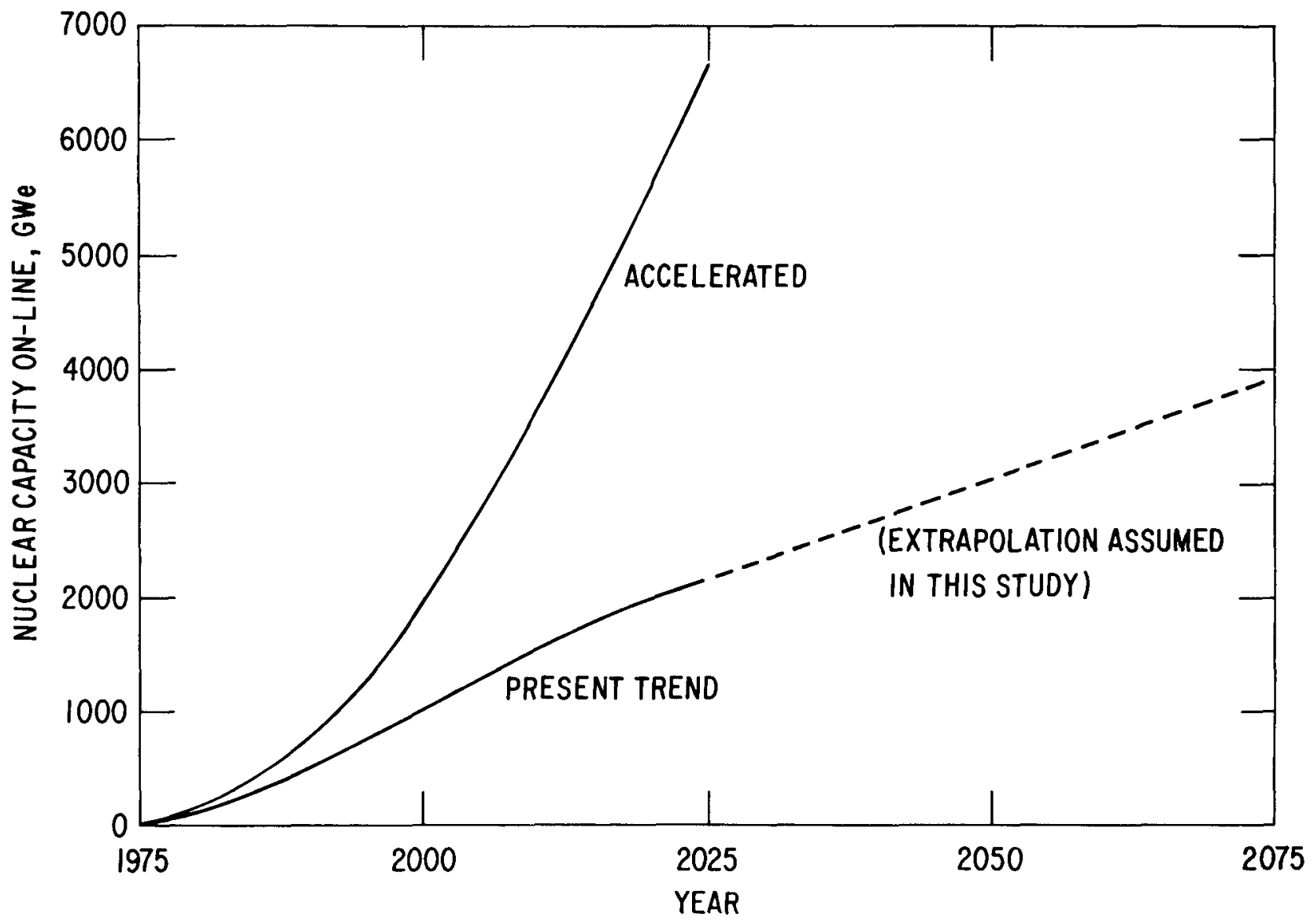

Fig. 1. International-aggregate Nuclear Energy Demand Projections (Data Source: OECD Nuclear Energy Agency, Ref. 4). 
B. Reactor Characteristics and Fuel Cycle Assumptions

The characteristics of converter reactors used in this study are presented in Table II. The data were derived from Ref. 5.

Various alternative fast breeder design types were considered in this report, including various fuel types, oxide, carbide, metal and current oxide under the following fuel cycle options:

- Pu/U core, U blankets,

- Pu/U core, U axial blanket, Th radial blanket,

- Pu/U core, Th axial and radial blankets,

- Pu/U core, Th internal, axial and radial blankets,

- Pu/Th core, Th axial and radial blankets,

- ${ }^{233} \mathrm{U} / \mathrm{Th}$ core, Th axial and radial blankets,

- ${ }^{23} \mathrm{3} \mathrm{U} / \mathrm{U}$ core (denatured), Th axial and radial blankets.

The performance characteristics of these alternative fuel cycle options are summarized in Table III. The data were taken from the design analysis performed for the INFCE studies. ${ }^{6}$ The performance characteristics were analyzed for conceptually feasible alternative fast breeder options assuming an equivalent state of the development. Obviously, there are greater uncertainties associated with the technical feasibility of the alternatives considered in this report than for the present reference FBR designs. The purpose of this work is to identify the potential payoffs associated with alternative concepts in the deployment scenarios constrained by nonproliferation considerations. Representive "current" oxide performance characteristics were also included in this study to compare with other advanced design concepts. The detailed design assumptions and additional performance characteristics information are described in Ref. 6.

For the external fuel cycle, a $1 \%$ loss factor and 1 -year lead time were assumed for fabrication, and a $1 \%$ loss factor and 1-year lag time for reprocessing. These external cycle assumptions were applied to all reactor types. The tails assay was assumed to be $0.2 \%$.

\section{Systems Analysis Methodology}

The ALPS ${ }^{7}$ linear programming reactor systems analysis code was used to perform the calculations which form the basis of this study. For the systems analysis performed in this report, economic competition between reactor types was suppressed. The reactor mixes for various fast breeder deployment scenarios were determined by uranium resource optimization constrained by fissile material availability and with specified constraints on the advanced converter or breeder introduction date and initial introduction rate.

Two different approaches were employed for the resource utilization optimization. In the first approach, the cumulative uranium consumption was minimized for a given energy demand. This is a conventional approach to such system studies. The output of the analysis is the cumulative uranium consumption as a function of time (or the total resource requirements) which can then be compared to the estimated resource availability, the production capacity, or any other limiting factor of interest. 
TABLE II. Converter Reactor Fuel Utilization Characteristics

\begin{tabular}{|c|c|c|c|c|c|c|}
\hline & \multicolumn{4}{|c|}{ LWR } & \multicolumn{2}{|c|}{ CANDU Denatured Th } \\
\hline & $\begin{array}{l}\text { Once- } \\
\text { Through }\end{array}$ & $\begin{array}{l}\text { Uranium } \\
\text { Recycle }\end{array}$ & $\begin{array}{l}\mathrm{Pu} \\
\text { Burner }\end{array}$ & $\begin{array}{l}{ }_{23{ }^{3}}{ }^{T h} \\
\text { Makeup }\end{array}$ & $\begin{array}{c}23^{5} \mathrm{U} \\
\text { Makeup }\end{array}$ & $\begin{array}{c}233^{U} \mathrm{U} \\
\text { Makeup }\end{array}$ \\
\hline $\begin{array}{l}\text { Discharge Burnup, } \\
\mathrm{MWD} / \mathrm{kg}\end{array}$ & 33 & 33 & 33 & 35 & 16 & 16 \\
\hline \multicolumn{7}{|l|}{$\begin{array}{l}\text { Initial Core Loading } \\
\text { Per GWe }\end{array}$} \\
\hline $\mathrm{kg}^{233} \mathrm{U}$ & 0 & 0 & 0 & 1582 & 0 & 1648 \\
\hline $\mathrm{kg} 235 \mathrm{U}$ & 1800 & 1800 & 153 & 24 & 2121 & 24 \\
\hline kg Fissile $\mathrm{Pu}$ & 0 & 0 & 2147 & 0 & 0 & 0 \\
\hline kg Total Heavy Metal & 79700 & 79700 & 79700 & 79700 & 113000 & 113000 \\
\hline \multicolumn{7}{|l|}{$\begin{array}{l}\text { Equilibrium Loading } \\
\text { Per GWe-yr }\end{array}$} \\
\hline $\mathrm{kg}{ }^{233} \mathrm{U}$ & 0 & 0 & 0 & 722 & 685 & 831 \\
\hline $\mathrm{kg}^{235} \mathrm{U}$ & 804 & 804 & 50 & 62 & 258 & 52 \\
\hline $\mathrm{kg}$ Fissile $\mathrm{Pu}$ & 0 & 0 & 1003 & 0 & 0 & 0 \\
\hline kg Heavy Metal & 25100 & 25100 & 25100 & 23500 & 56100 & 56100 \\
\hline $\operatorname{ST~} \mathrm{U}_{3} \mathrm{O}_{8}^{\mathrm{b}}$ & 192 & 192 & 0 & 0 & - & 0 \\
\hline MT SWU & 119 & 119 & 0 & 0 & - & 0 \\
\hline \multicolumn{7}{|l|}{$\begin{array}{l}\text { Equilibrium Discharge } \\
\text { Per GWe-yr }\end{array}$} \\
\hline $\mathrm{kg}{ }^{233} \mathrm{U}$ & - & 0 & 0 & 435 & 685 & 729 \\
\hline $\mathrm{kg}^{235} \mathrm{U}$ & - & 216 & 27 & 62 & 108 & 52 \\
\hline kg Fissile $\mathrm{Pu}$ & - & 163 & 646 & 57 & 30 & 32 \\
\hline kg Heavy Metal & - & 24300 & 24300 & 22700 & 55200 & 55200 \\
\hline $\mathrm{ST} \mathrm{U}_{3} \mathrm{O}_{8}^{\mathrm{b}}$ & - & 43 & 0 & 0 & - & 0 \\
\hline MT SWU ${ }^{b}$ & - & 6 & 0 & 0 & - & 0 \\
\hline \multicolumn{7}{|l|}{ Lifetime Requirements ${ }^{c}$} \\
\hline $\mathrm{kg}^{233} \mathrm{U}$ & - & 0 & 0 & 8970 & 0 & 3540 \\
\hline kg Fissile $\mathrm{Pu}$ & - & -4830 & 11200 & -1690 & -900 & -944 \\
\hline $\mathrm{ST} \mathrm{U}_{3} \mathrm{O}_{8}^{\mathrm{b}}$ & 5810 & 4540 & 0 & 0 & 1450 & 0 \\
\hline MT swU $^{b}$ & 3610 & 3450 & 0 & 0 & 1400 & 0 \\
\hline
\end{tabular}

assumed $75 \%$ capacity factor

bAssumed $0.2 \%$ tails assay

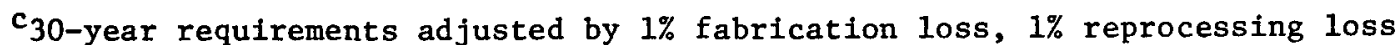
and end-of-life credit. 
TABLE III. Summary of Breeding Performance and Mass Flow Data for FBR Fuel Cycles (kg/GWe)

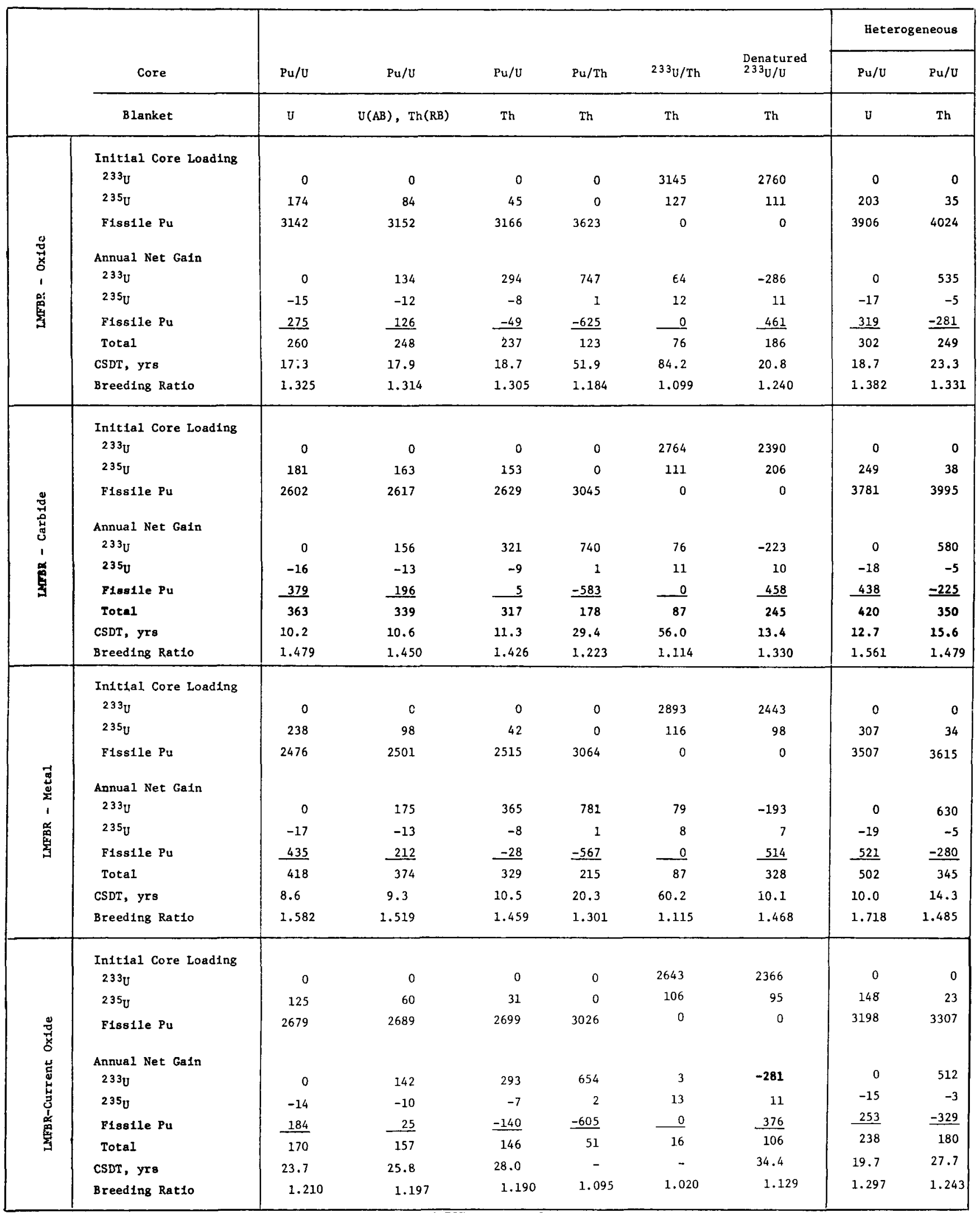

Footnote: 1. Mass flow data are normalized to 1000 MWe and $75 \%$ capacity factor.

2. Breeding ratio and compound system doubling time are calculated with equal weighting for all fissile isotopes. The ${ }^{23} \mathrm{U}$ balance includes credit for ${ }^{23}{ }^{3} \mathrm{~Pa}$

3. Compound system doubling time is calculated with 1 year external cycle time and 27 losses. 
In the second approach, the energy production for each scenario was maximized for a fixed resource base. It was not intended in this approach to imply that the resource will actually cut of $f$ at a fixed number. However, the approach provides a useful consistent framework for comparing the energy supply capabilities of various alternative deployment options.

The uncertainties are large in both the energy demand projection and in the resource estimate. The two approaches described above complement each other in understanding the problem. The first approach is useful for near-term planning where the energy demand may be fairly predictable. The second approach eliminates the need for a quantitative projection of long-term energy demand and provides useful insight into the difference in long-term potential that exists between various deployment scenarios.

III. REFERENCE INTERNATIONAL DEPLOYMENT OF BREEDERS ON Pu/U CYCLE

A variety of technical modifications and institutional arrangements to minimize proliferation risk are envisioned for the fuel cycle and reactor facilities using the $\mathrm{Pu} / \mathrm{U}$ breeder cycle. These are treated in companion reports in this series. In the system studies of this section such measures would have negligible impact, if any, on the reactor performance characteristics and the resource utilization implications that follow from them.

The effects examined in this section are the influence on the demand/ resource relationships of:

1. Reactor Type: Light Water Reactor, Advanced Converter Reactor and Fast Breeder Reactor,

2. Fast Breeder Reactor Timing, and

3. Fast Breeder Reactors with Improved Breeding Properties.

A. The Effect on Uranium Consumption of the Basic Reactor Type

To set the breeder in context, the initial comparison of interest is simply that of basic reactor type. The cumulative uranium consumptions as a function of time for four simplified scenarios were calculated for the base case (the present-trend energy demand curve shown in Fig. 1, which we will refer as the "base" energy demand case):

1. LWR once-through cycle only,

2. LWR utilizing uranium and plutonium recycle,

3. LWR once-through cycle + advanced converter reactor

(denatured thorium cycle),

4. LWR uranium recycle + LMFBR.

The Advanced Converter Reactor case was represented by CANDU reactor operating on a denatured thorium cycle with $235 \mathrm{U}$ makeup. For the LMFBR case, a range of performance characteristics was taken based on the four fuel design 
types presented in Table III. The introduction date for both ACRs and LMFBRs was assumed to be 2000 , with an introduction rate of 150 GWe total during the first five year period and 300 GWe total during the next five year period. These clearly are very high introduction rates. At the very least they imply that well before the year 2000 there must have been several reactor deployment of the commercial type assumed to be introduced in quantity in the year 2000. This may be consistent with developments in at least some non-U.S. reactor programs.

Figure 2 places the cumulative uranium consumption for the four scenarios against the background of the "reasonably assured" plus "estimated additional" resource levels. The continuous resource usage of converters, greater or lesser, depending on type, exhausts the resources soon after the year 2010 for any of the converter scenarios. Further, if 30-year forward requirements were accounted for, the point of commitment of all resources would be reached by the year 2000 .

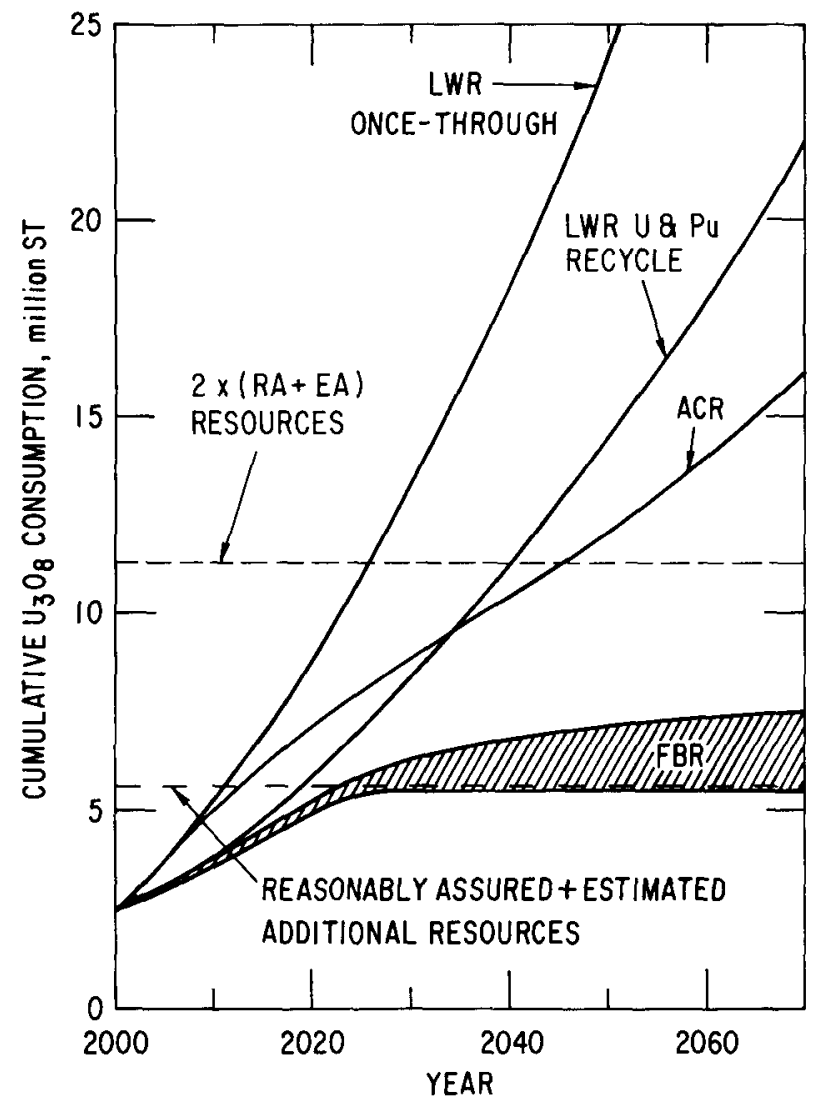

Fig. 2.

Cumulative Uranium Consumption as a Function of Time for Various Deployment Options.

Advanced Converter Reactor introduction does not help, when introduced in significant numbers only on this time scale. The date, probably realistic, of the year 2000 for such ACR introduction causes the LWRs constructed to that date to have already consumed the reference resources. Even allowing for further resources, however, so the LWR does not have this effect, it is worth noting that the ACR cumulative uranium consumption follows the LWR once-through curve for a time, then starts to drop below it. It is only after consumption of resources about double the reference value that the ACR shows any improvement over the LWR on recycle. This is due to the fact that advanced converter 
reactors (in this case, denatured thorium cycle in CANDU reactors with selfgenerated uranium recycle and ${ }^{235} \mathrm{U}$ makeup) require more uranium than LWRs during their startup period. At equilibrium, the uranium requirements are reduced significantly, but such savings can be realized only if the energy demand does not continue to grow.

For all breeder cases (the top of the shaded portion shows the current oxide case, the bottom shows carbide or metal) the uranium consumption for this base demand begins to slow significantly around 2025. With the advanced breeder cycles no additonal uranium is consumed after 2030, and by fortunate coincidence only, the consumption levelled off just under the reference values of the resources. For the lower gain breeders, the uranium consumption continues but eventually levels off when the breeder fissile doubling capability catches up with the energy growth.

Looked at another way, as energy potential from a fixed resource base, the four reactor scenarios are compared again in Fig. 3 for the reference resource base of 5.6 million $\mathrm{ST}_{3} \mathrm{O}_{8}$ and in Fig. 4 for a doubled base of 11.2 million $\mathrm{ST}_{3} \mathrm{U}_{8}$. The integrated area under each curve in Figs. 3 and 4 represents the maximum energy obtainable for the consumption of each fixed resource base.

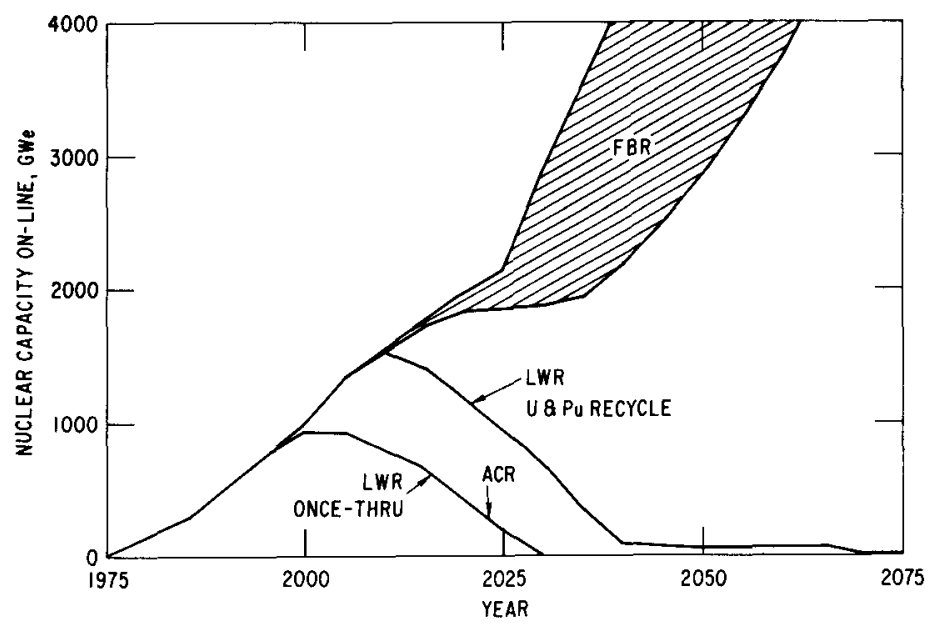

Fig. 3.

Energy Supply and Growth Potential of Various Deployment Options for a Fixed Resource Base of 5.6 Million ST $\mathrm{U}_{3} \mathrm{O}_{8}$.

Fig. 4 .

Energy Supply and Growth Potential of Various Deployment Options for a Fixed Resource Base of 11.2 Million ST $\mathrm{U}_{3} \mathrm{O}_{8}$.

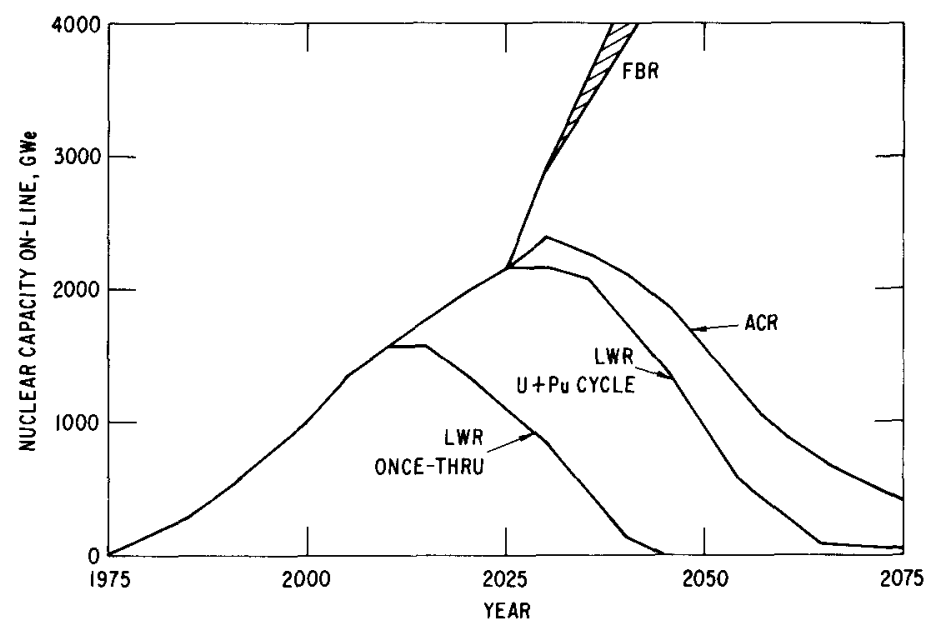


These figures illustrate in another way, this time by fixing the resource base, effects similar to those shown in Fig. 2, which were derived by fixing the demand.

1. For the smaller resource base the incentive for the advanced converter reactor recycle is non-existent, because the resource base is consumed mostly in the LWR once-through cycle before the advanced converter reactor can be deployed.

2. For the large resource base, LWR recycle is about as resourceeffective as the ACR.

3. The fast breeder reactor energy supply potential is very high in either case. In the smaller resource base case, the advanced breeders have significantly more supply capability; in the large resource situation, any breeder is satisfactory.

B. The Influence on Uranium Consumption of the FBR Introduction Date

The introduction date taken for the FBR is a very important variable in studies of this kind. It is well to reiterate here that the term Introduction Date as used in this report is specifically not the date for the first such reactor, nor is it the date for significant power production from the first several commercial versions of the reactor. It is the date at which sufficient numbers of the reactor type are coming on line that they are becoming an appreciable fraction of the capacity additions in that year, and it therefore implies that those prior stages of initial breeder introduction have been successful. The upper limit of the amounts allowed for any non-LWR type in these studies in the years following introduction was stated in Section II as 150 GWe total in the first five years, 300 GWe total in the next five years, and no constraint thereafter other than the fissile availability constraint.

Figure 5 displays the total uranium resource requirements as a function of breeder introduction date, for the base demand scenario, against the background of the resource estimates. The figure is a summary of a set of calculations in which the FBR of the indicated kind was introduced, subject to the introduction constraint stated above, first in the year 2000, then in 2010, and finally in 2020. By 2020, with this demand, the curves became asymptotic. The figure indicates that this base projected demand could be met under the assumptions stated within the estimated resource levels if the Breeder Introduction Date was the year 2000 or earlier, if the breeders were high-gain systems. For year 2000 introduction, low-gain breeders require an additional 2 million $\mathrm{ST} \mathrm{U}_{3} \mathrm{O}_{8}$. This latter difference is not large on the scale of differences between converter and breeder types, but is substantial on the scale of reasonably assured resources. For this base demand, as the introduction date is extended past the year 2000, progressively more uranium will have to be found, and if it is, the amounts of plutonium generated by converters become sufficient to allow any of the breeder types considered to meet the demand. Each five year delay is equivalent to about 1.5 million ST $\mathrm{U}_{3} \mathrm{O}_{8}$ additional requirements for this demand. 


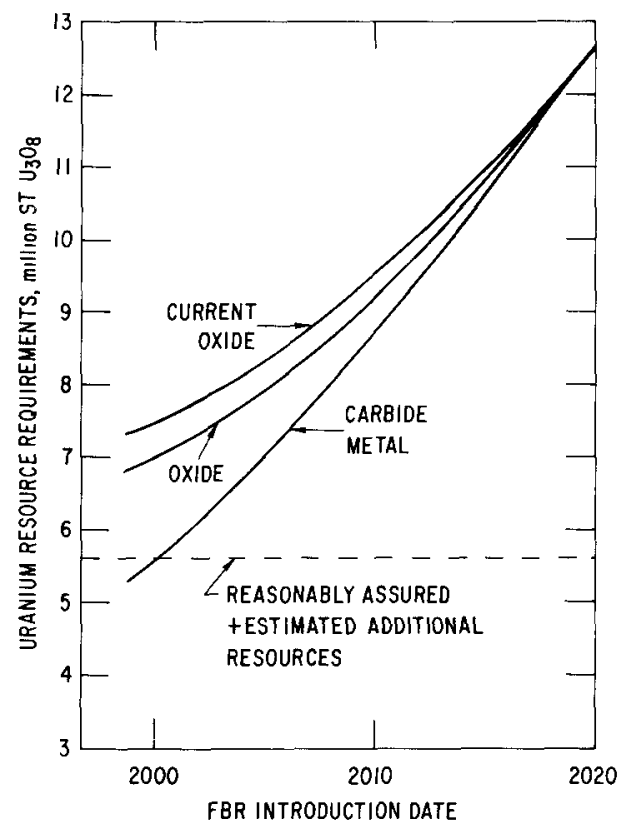

Fig. 5 .

Unanium Resource Requirements as

a Function of FBR Introduction

Date for Various Fuel Types.

(Base Energy Demand).

\section{Influence on Uranium Consumption of Advanced Breeders}

Fast breeder fuel cycles using advanced fuels whether advanced oxide, carbide or metal, are in a far less developed state than the reference LMFBR oxide fuel. It was recognized from the earliest days, however, the incentives in breeding performance exist for development of one or more of these fuel forms. The status of such fuels development and the reactor designs using these fuels that were developed for these studies are given in companion reports, Refs. 6 and 8 . In this section some of the effects of successful development of such fuels are examined in the present context of aggregate international demand and resource estimates.

The base international demand used in Fig. 5 and throughout this report amounts to an average total international yearly growth rate of about $40 \mathrm{GWe} / \mathrm{yr}$ between the year 2000 and the year 2050, more at the beginning of the time period and less at the end. As noted in the previous discussion of Fig. 5, large-scale introduction of breeders with current-oxide breeding characteristics even as early as the year 2000 would require appreciably more uranium than the present reference estimates, but if such amounts are found and used in converters, the resulting plutonium stocks enable the lower-gain breeder to meet the demand perfectly adequately: $40 \mathrm{GWe} / \mathrm{yr}$ is a relatively 1 ow-growth rate in percentage terms.

For higher growth rates the breeder performance characteristics begin to dominate and the effect of advanced fuels becomes very substantial. For the high growth case used in this report (doubled growth rate after the year 2000), very large differences in uranium requirements are shown between the breeder fuel types. The data are shown in Fig. 6. The uranium usages are large, well beyond the reference amounts. The differences between breeder types are of the order of these reference amounts. Probably the major point to be derived from these data is that more uranium will have to be found if these demand schedules turn out to be necessary, but introduction of improved breeders in place of present breeders materially helps. 


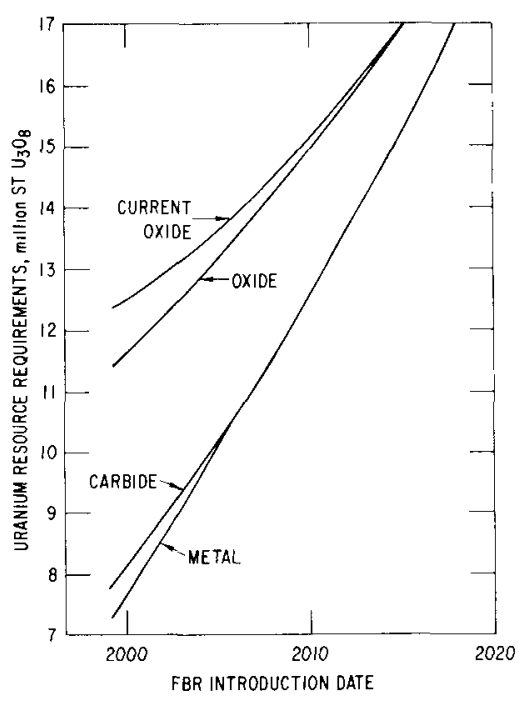

Fig. 6 .

Uranium Resource Requirements as a Function of

FBR Introduction Date for

Various Fuel Types.

(Large Energy Demand;

Doubled Growth Rate After

2000).

It is in these types of considerations that the substantive incentives for advanced breeder development lie. They have the property of providing a strong hedge against unanticipated high demand. Figure 7 exemplifies this property. The figure shows the uranium resource requirements resulting from a range of nuclear capacity growth rates from the year 2000 onward. The resource requirements for advanced fuel cycles are relatively insensitive to large increases in the assumed growth rates. For the year 2000 introduction they hold the uranium requirements in the range of the estimates over a fairly wide range of demands.

The incentives for improved breeding lessen as the available uranium resources expand. Large uranium resources enable converters to meet demands and the plutonium generated removes plutonium-supply obstacles to additions in breeder capacity. At the other extreme, the incentives for improved breeding are very great if the uranium supplies are constricted and the breeder is required to make large contributions to energy supplies in the first half of the next century.

Breeder capabilities can be throttled by plutonium supply problems arising either in plutonium flow logistics or in the amount of LWR plutonium available to supply breeders until their natural doubling characteristics catch up with the installation rates required of them.

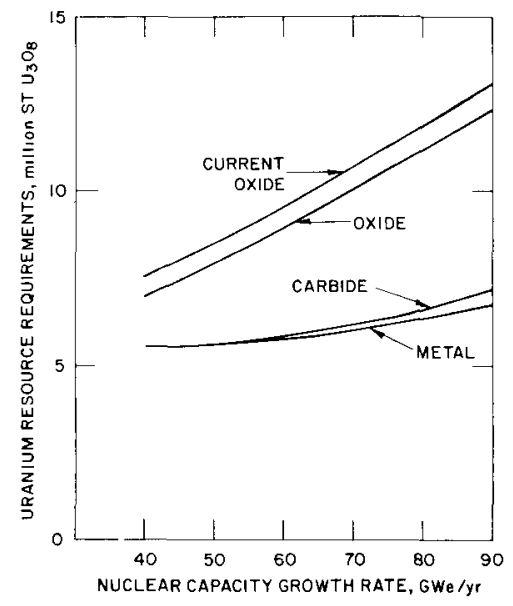

Fig. 7 .

Uranium Resource Requirements as a Function of Nuclear Energy Demand Growth Rate for Various FBR Fuel Types. 
Plutonium flow bottlenecks will show up as increases in external cycle times. One or two years external cycle time are normal assumptions. Figure 8 shows the effect of increases in external cycle times for the base demand case, breeder introduction in the year 2000. The present breeder requires additional $\mathrm{U}_{3} \mathrm{O}_{8}$ mining if the external cycle time is increased from one to two years, and the requirements increase substantially for each additional year. For the high-gain breeders the $\mathrm{U}_{3} 0_{8}$ requirement is the same up to three years, and starts to increase substantially only at four years. Plutonium flow logistics may present problems if the future deployments involve restricted transport and heavy safeguards. Insensitivity to external cycle time may then become a feasibility issue.

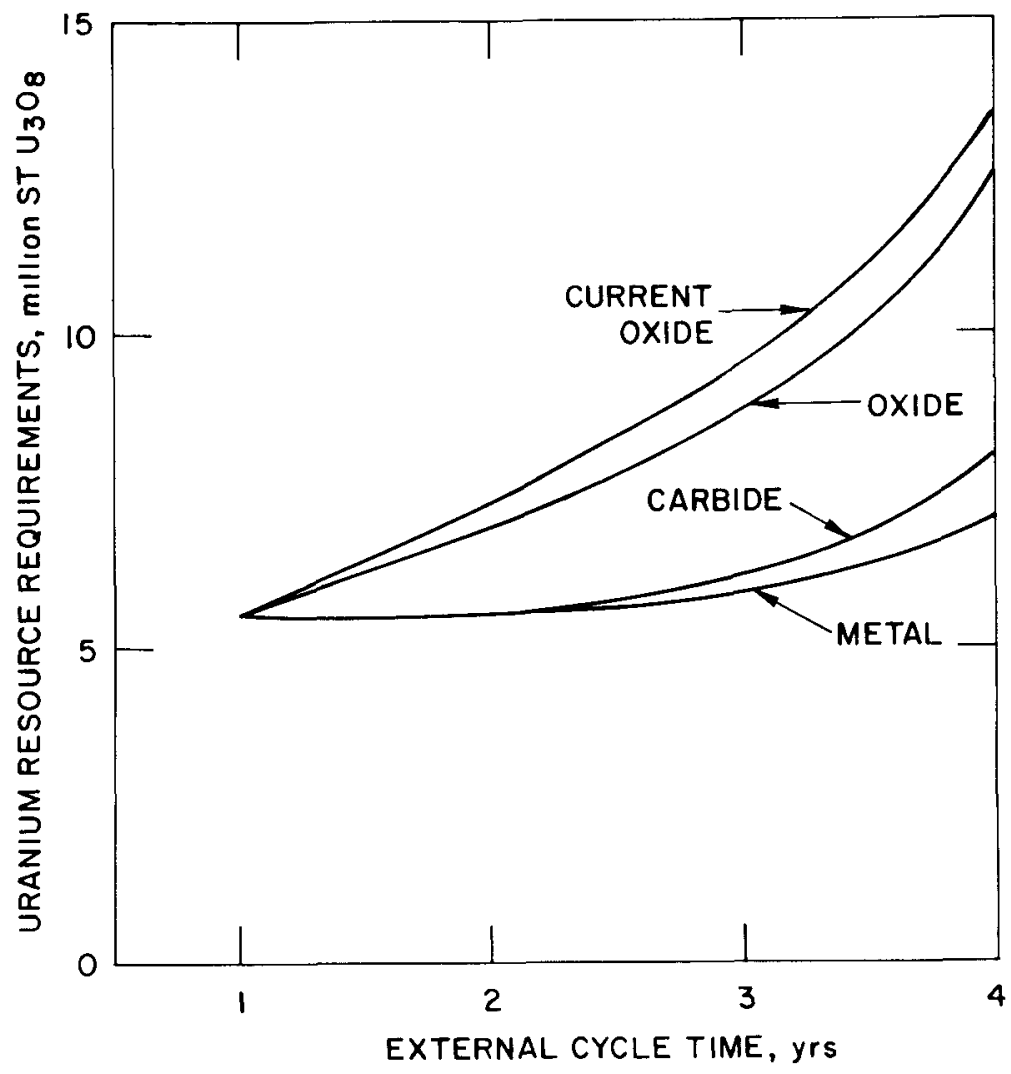

Fig. 8 .

Unanium Resource Requirements as a Function of External Cycle Time Assumed.

Another area of interest in plutonium supply effects on the breeder, in addition to the overall amount available from converter usage of the uranium resource base, is the sensitivity of the breeder to the plutonium stock accumulated at the time of breeder introduction. A reduced sensitivity to the magnitude of accumulated plutonium stocks could be important in either of two diametrically opposed situations. First, in a situation where plutonium containing spent fuel has been placed in nonretrievable storage, or, at the opposite extreme, when plutonium has been used in recycle in converter reactors. Figure 9 examines the effect of availability of accumulated plutonium stock, for the base demand case. For any given level of ore requirement, if the LWR stockpile is not available, breeder introduction would be necessary about ten years before it would be if the stockpile is available, if the present breeder is to meet demand. The corresponding time difference for a high gain breeder is about four years. 


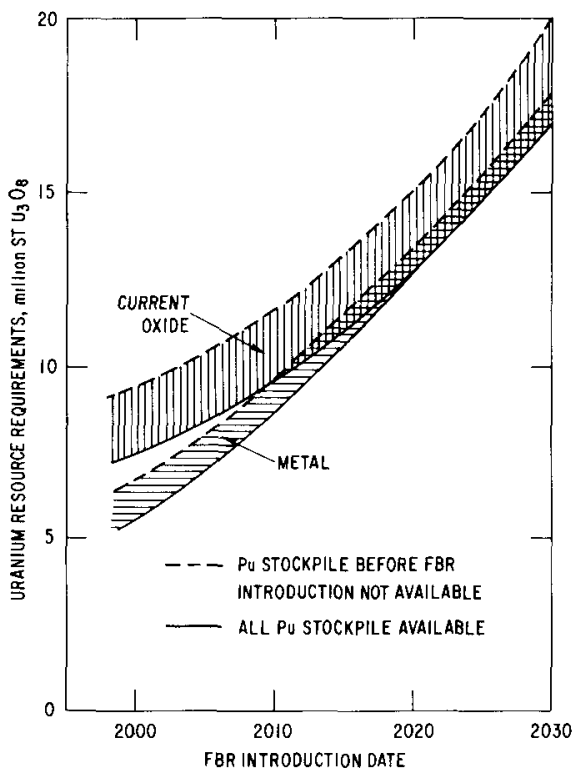

Fig. 9.

Effect of Pu Stockpile

Availability for the FBR

Startup on the Uranium

Requirements.

IV. SECURED AREA BREEDER DEPLOYMENT WITH SYMBIOTIC CYCLES USING THORIUM

One form of the Secured Area Deployment scenario assumes that the deployment of plutonium-fueled fast breeders is limited within the geographically confined and safeguarded areas of Fuel Cycle Centers. The nature and arrangements for such Secured Area Deployment are examined in other reports in this series. ${ }^{1,2}$ For these studies the feasibility and non-proliferation advantages for the Secured Area Deployment are assumed to be established, and the implications of alternative fast breeder cycles applicable for such a deployment scenario are examined.

The Secured Area Deployment scenario in itself does not exclude the use of the pure $\mathrm{Pu} / \mathrm{U}$ breeder cycle. However that option was addressed in the previous section and here the implications of using breeders in secured areas to produce $233 \mathrm{U}$ from thorium to supply denatured converter reactors deployed outside the secured area are the subject. A symbiotic system of confined fast breeders and dispersed converter reactors is implied.

Clearly, thorium represents a viable energy resource in any event, particularly for countries with major thorium deposits, providing the appropriate fissile material flows can be established. Symbiosis with the breeder $\mathrm{Pu} / \mathrm{U}$ cycle may be of interest simply for this reason. The feasibility of maintaining a converter system by supplying its incremental ${ }^{23} 3_{U}$ requirements, quite apart from proliferation questions related to Secured Areas, is still the question. The fuel flow considerations are similar to those for secured Area discussions in any case, in that ratios of breeders to converters and amount of ore required, remain the principal feasibility questions.

The impact on breeding of the replacement of fertile ${ }^{238} \mathrm{U}$ by fertile ${ }^{232} \mathrm{Th}$ in fast breeder reactors was examined in detail in a companion report of this series. 6 There it was shown that the replacement of ${ }^{238} \mathrm{U}$ by thorium always leads to a decrement in breeding ratio. This occurs primarily because of the smaller fast fission effect of thorium relative to ${ }^{238} \mathrm{U}$. 
The decrement in breeding ratio is not large if the thorium is confined to the blankets of the breeder, but is substantial if thorium is used in the reactor core. In either case, the result of replacing ${ }^{238} \mathrm{U}$ by thorium is a replacement of bred plutonium by bred $233 \mathrm{U}$. Increasing replacements of fertile ${ }^{238} \mathrm{U}$ by fertile ${ }^{232} \mathrm{Th}$ in breeders leads to two effects:

1. Increasing amounts of $233 \mathrm{U}$ are available for fueling larger numbers of dispersed converter or breeder reactors operating on a denatured $233 \mathrm{U}$ fuel cycle, but

2. Less plutonium is available to continue to expand the number of "Secured Area" breeder reactors which are the very "factories" in which the $233 \mathrm{U}$ is generated.

It is clear then that a tradeoff exists between the rate at which the symbiotic system can grow (effect 2) and the ratio of dispersed converter reactors to confined ${ }^{23} \mathrm{U}$ generating breeders (effect 1 ).

It is the purpose of this section to discuss the nature of this tradeoff as a function of degree of thorium utilization in the breeder and breeder type.

A. The Effect on Uranium Consumption of Thorium Content in the Breeder for a Fixed Energy Demand Schedule

For the base energy demand case, breeder induction in the year 2000 , breedes characteristics in Table III and the denatured thorium cycle LWR characteristics listed in Table II, the effects of breeder thorlum concent are quantified in Fig. 10. The cumulative uranium consumption is shown as a function of time for the various degrees of thorium utilization in a breeder that in turn provided the fueling requirements for denatured thorium cycle LWRs. Because a fixed demand must be met, and the capacities of both reactor types are constrained by fissile supply -plutonium in the breeder case and $233 \mathrm{U}$ for the LWR -- additiona1 $235 \mathrm{U}$ fueled LWRs are required with most symbiotic combinations. Where these are required, $\mathrm{U}_{3} 0_{8}$ consumption rises. Cases are shown extending from thorium usage in the breeder radial blanket only, through axial blankets, internal blankets in a hecerogeneous design, and finally, in totally displacing $238 \mathrm{U}$ as the fertile material. For each geometric variation, the range corresponding to fuel type -- oxide, carbide and metal -- is indicated by shaded areas.

There are overlaps between fuel types, but, in general, the uranium requirements are dictated

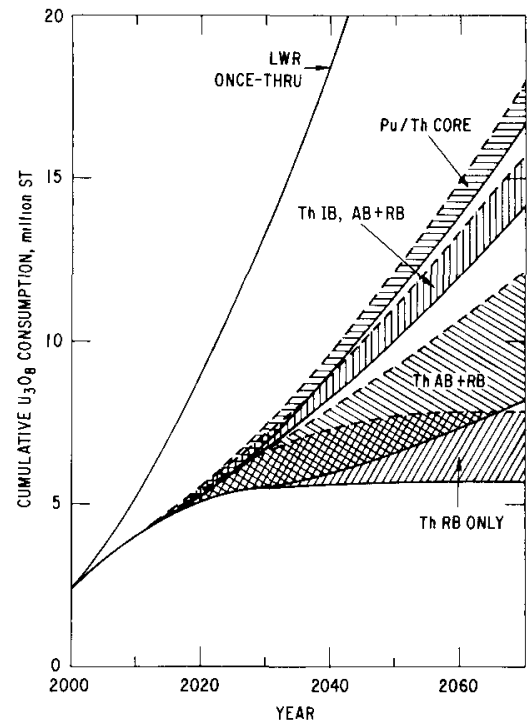

Fig. 10 .

Cumulative Uranium Consumption as a Function of Time for Various EBR Alternative Cycles (Symbiosis with Denatured LWR). most strongly by the degree of the thorium utilization in the breeder. The uranium requirements increase progressively in the amounts shown in the figure as more thorium is incorporated into the fast breeders, from the thorium radial blanket only to the full thorium core. 
The ratio of breeders to dispersed converters is the other important factor. It is likely to be particularly important in the scenarios that confine breeders to Secured Areas. Normal economic and engineering pressures will tend toward maximizing the number of converters in such a symbiotic system because of the freedom in deployment that in this scenario only the converters enjoy. A basic tradeoff results. Specifying an increase in the ratio of dispersed converters to secured breeders translates directly into an increase in $\mathrm{U}_{3} 0_{8}$ requirements, if the demand is to continue to be met.

The maximum converter/breeder ratio allowed by each of the variants in Fig. 10 is shown in Fig. 11, again plotted as a function of time. The converter/breeder ratio is termed the outside/inside ratio to correspond to the Secured Area usage. The outside converters include both denatured thorium cycle LWRs and those standard uranium cycle LWRs, fueled from additional mining of $\mathrm{U}_{3} 0_{8}$, necessary to meet the base demand. The shaded areas again show the effect of breeder fuel type.

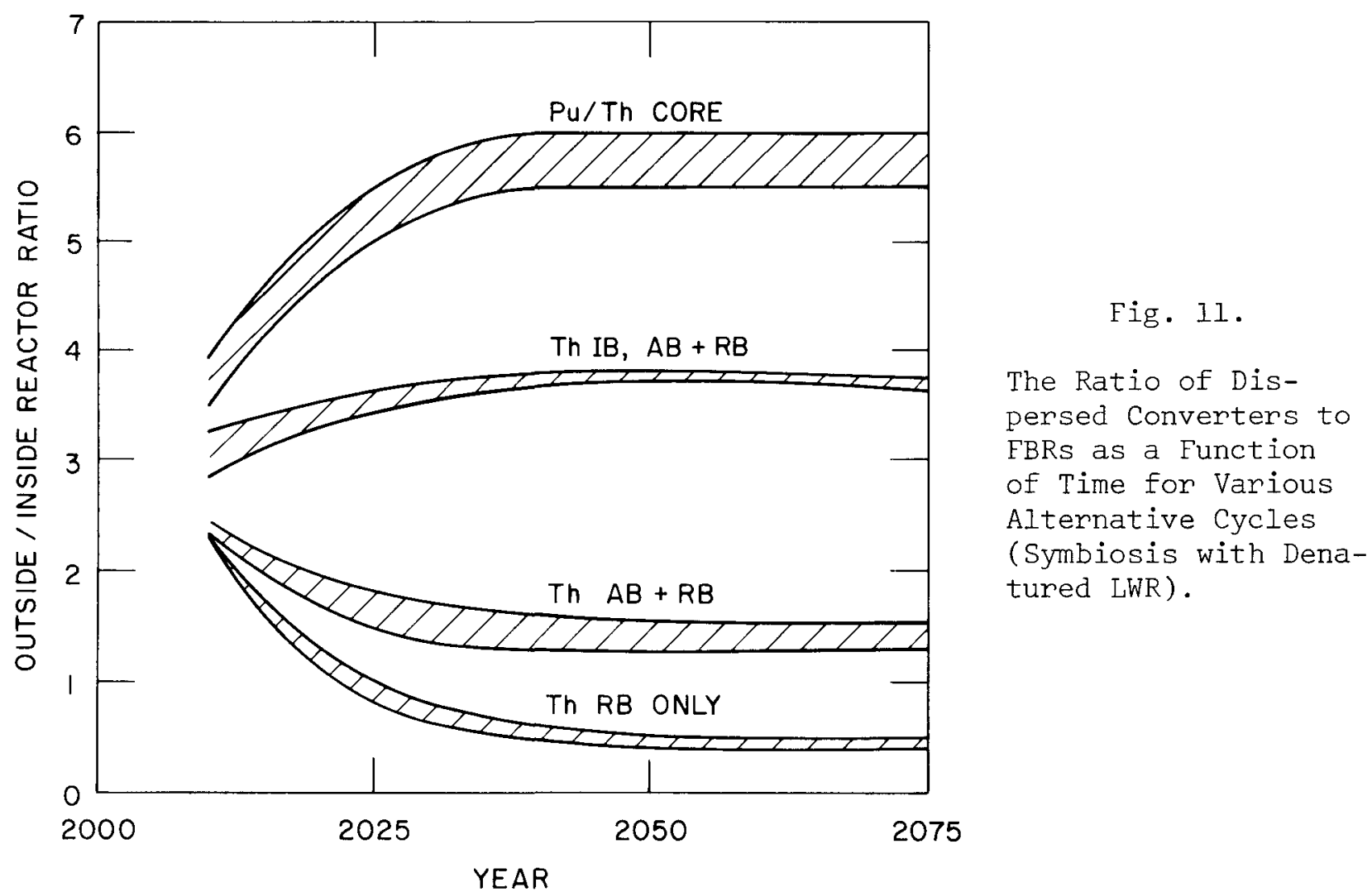

The tradeoff between reactor ratio and uranium consumption is shown explicitly in Fig. 12. Here the asymptotic reactor ratios from Fig. 11 are plotted as a function of their corresponding $\mathrm{U}_{3} \mathrm{O}_{8}$ consumption for the various fuel types. The shaded areas give ranges of combinations of reactor ratios and uranium consumption possible with design variations, including fuel type, for each of the breeder reactor thorium configurations. The advanced fuel types show significant uranium consumption improvements for the thorium external blanket cases, with the improvement lessening as thorium is introduced in the core. 


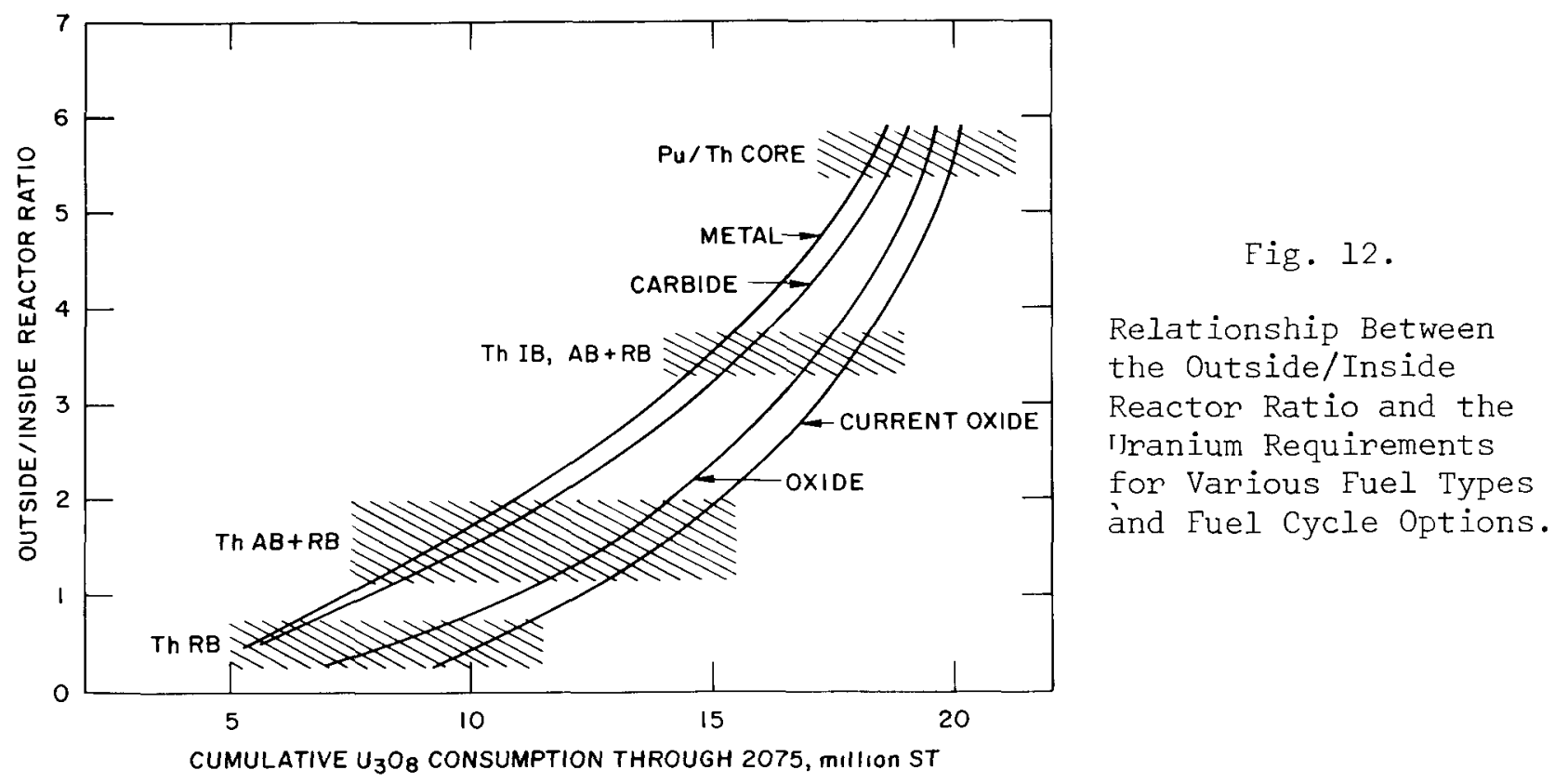

For any given reactor configuration and fuel type, the tradeoff between reactor ratio and uranium consumption is direct. There is no quantifiable optimum. The balance depends on the relative weight given to the two factors. In the Secured Area context, it depends on the relative importance assigned to confining breeders to such areas. Qualitatively only, the reactor ratios should be maximized without inducing unacceptable penalties in uranium resource requirements. For the reference demand case, Fig. 12 quantifies the possibilities.

\section{B. The Effect on Uranium Consumption of Client Denatured Reactor Type for a Fixed Energy Demand Schedule}

In addition to the breeder fueling configuration, the other major reactor variable is the type of client reactor the breeder feeds. The previous section took the LWR on a denatured thorium cycle as the client (outside) reactor. LWRs seem likely to totally dominate the nuclear capacity at the times of possible symbiotic breeder cycle introduction. Because their existence is likely to be a fact and they require fuel, their case is likely to be of most practical interest. However, this may not necessarily be so, and this section examines the effects of the symbiotic use of non-LWR reactor types as the client reactor being fed by the breeders.

The range of such possibilities is scoped by the addition of the denatured $\left({ }^{233} \mathrm{U} /{ }^{238} \mathrm{U}-\right.$ fueled) Fast Breeder Reactor and the denatured Advanced Converter Reactor to the combinations considered. The characteristics of the denatured FBR are given in Table III, and the denatured advanced converter characteristics are listed in Table II.

Figure 13 gives the uranium consumptions for the base demand case as a function of client reactor type. The shaded range again shows the effect of breeder fuel type. In the cases shown the plutonium/thorium fueled system was selected as the inside breeder to maximize the outside/inside ratio. 


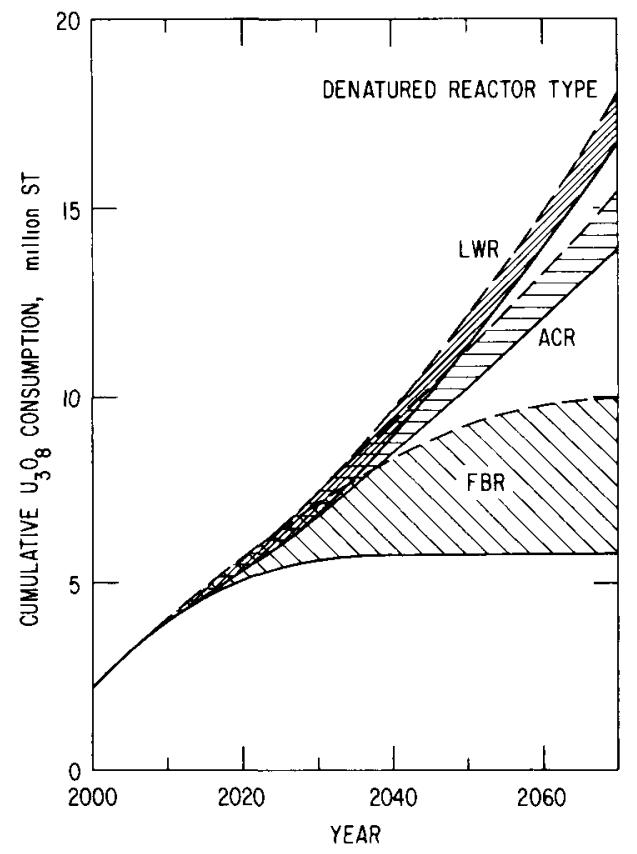

Fig. 13 .

Cumulative Unanium Consumption as a Function of Time for Various Symbiosis of Pu/Th Cycle FBRs and Denatured Reactor Types.

The corresponding outside/inside ratios are shown in Fig. 14. The shaded areas again have the same meaning. Taken together, Figs. 13 and 14 illustrate the major features of changes in client reactor type. First a rather substantial improvement in reactor ratio is possible with the ACR, with an accompanying rather marginal improvement in uranium consumption. As with the LWR, reoptimization would improve one at the expense of the other. Second, use of the denatured FBR as the outside reactor drops the uranium consumption appreciably, particularly for the advanced fuels, but the reactor ratio decreases as well. Again, reoptimization giving a different balance between the two factors is possible. With the denatured FBR, however, if advanced fuels are used a stable reactor ratio between 2 and 3 is possible, with this demand, wherein no further $\mathrm{U}_{3} \mathrm{O}_{8}$ consumption is required.

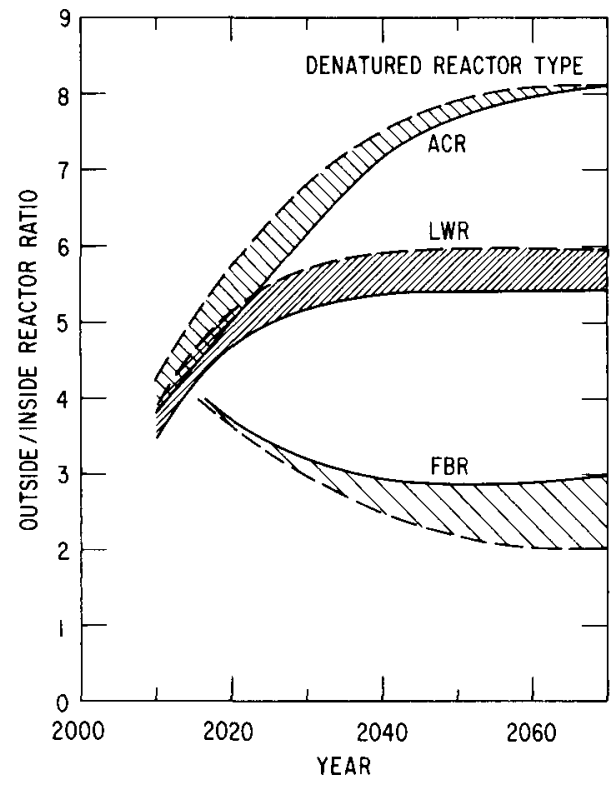

Fig. 14 .

The Outside/Inside Reactor Ratio as a Function of Time for Various Symbiosis of Pu/Th Cycle FBRs and Denatured Reactor Types. 


\section{The Influence of Breeder Thorium Content on System Growth Potential}

In Sections $A$ and $B$ the implications of meeting a fixed demand were presented. In this section the maximum energy production possible from a fixed resource base is examined for each of the breeder fueling options. Specifically, the uranium resource base was fixed at the reference total of 5.6 million ST $\mathrm{U}_{3} \mathrm{O}_{8}$, "reasonably assured" plus "estimated additional," and the shape of the demand curve was allowed to vary to maximize the total electrical energy produced for each of the various fueling options.

In this section the denatured LWR is again taken as the client reactor type. Although 5.6 million $\mathrm{ST}_{3} \mathrm{O}_{8}$ was used because it is the reference data point, the main effects of interest are not sensitive to the particular choice of resource base.

The results for a given resource assumption, in fact, can be accurately extrapolated to other resource base assumptions because the energy supply potential for the symbiotic system is directly related to the resource base. The LWR plutonium discharge is directly proportional to the resource base, which in turn controls the fast breeder capacity for plutonium-fueled thorium cycles; this in turn determines the ${ }^{23} \mathrm{U}$ production and the denatured converter reactor capacity.

First, the energy growth potentials are compared for thorium fueling in the breeder radial blanket only, for the three breeder fuel forms. The results are presented in Fig. 15. Because the thorium utilization is minimal in this fuel configuration, the breeding characteristics are very similar to the reference $\mathrm{Pu} / \mathrm{U}$ cycle and the reactor remains a net producer of plutonium. The overall system, therefore, has growth potential by itself without relying on the continuous supply of plutonium from LWRs. The growth rate depends on the breeding performance, but it is not a strong function of fuel type. Advanced breeders do provide a higher growth potential, but not strikingly so, because the plutonium production in the oxide breeder core and axial

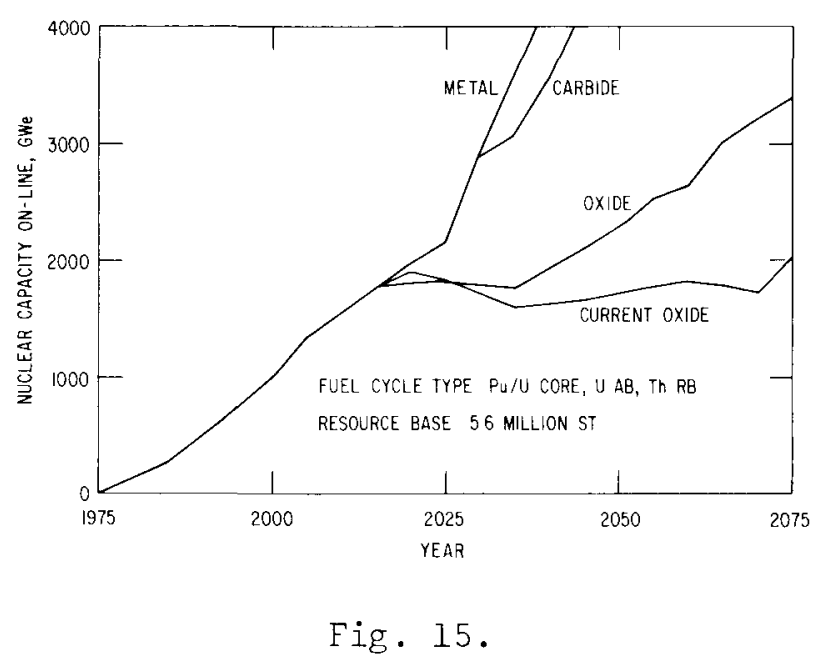

Energy Supply and Growth Potential of Various FBR Fuel Types for a Fixed Resource Base of 5.6 Million ST $\mathrm{U}_{3} \mathrm{O}_{8}$ (Fuel Cycle Type: Pu/U Core, U Axial Blanket, Th Radial Blanket). blanket, when coupled with the small amounts coming back from the denatured LWRs is sufficient to hold the net system plutonium breeding above unity.

Second, the energy growth potentials for thorium fueling in the axial blanket as well were compared. Figure 16 gives the results. The figure shows that if thorium is utilized in the axial blanket as well as the radial blanket, the growth potential is eliminated, however, a near-equilibrium level capacity is reached in the long term. This asymptotic capacity depends sensitively on 


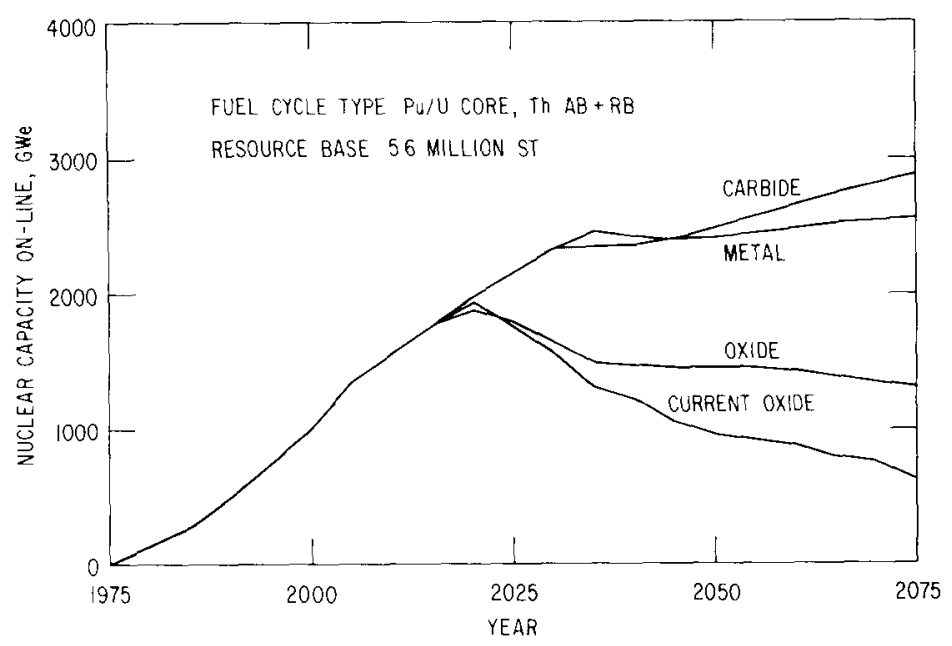

Fig. 16.

Energy Supply and Growth Potential of Various FBR Fuel Types for a Fixed Resource Base of 5.6 Million $\mathrm{ST} \mathrm{U}_{3} \mathrm{O}_{8}$ (Fuel Cycle Type: Pu/U Core, Th Blankets).

the reactor breeding performance characteristics. In this case, the properties of improved breeding offered by the advanced breeders assume importance, advanced breeders achieving about double the steady-state capacity of lowergain breeders.

Thirdly, in Fig. 17 heterogeneous cores with thorium internal blankets, in addition to the radial and axial blankets, are compared for the various breeder fuel forms. In this fueling configuration, the fast breeder is a net plutonium consumer, and thus the capacity cannot be maintained even in the steady-state condition. System breeding is sufficiently below unity that the differences have narrowed between the various breeder fuel forms.

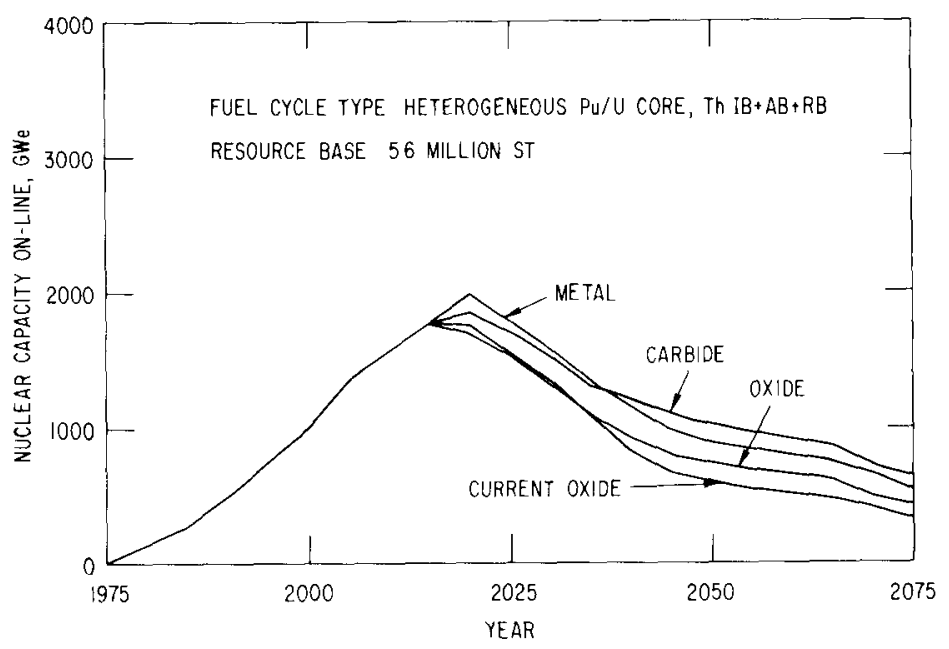

Fig. 17 .

Energy Supply and Growth Potential of Various FBR Fuel Types for a Fixed Resource Base of 5.6 Million $\mathrm{ST}_{3} \mathrm{O}_{8}$ (Fuel Cycle Type: Heterogeneous Pu/U Core, Th Blankets).

Finally, the cases for pure $\mathrm{Pu} / \mathrm{Th}$ cores with thorium blankets are compared in Fig. 18. The figure shows the overall energy supply potential to be sharply reduced. Further, the differences between fuel types are very small. There are two reasons for this. First the reactor performance characteristics themselves are not much different between fuel types for $\mathrm{Pu} / \mathrm{Th}$ fueling (see Ref. 6). Second, the fast breeder portion of the system is very small in this case, the system characteristics are dominated by the converter reactor characteristics, and the overall system plutonium breeding is far below unity. The result is a fairly rapid plutonium consuming die-away system. 


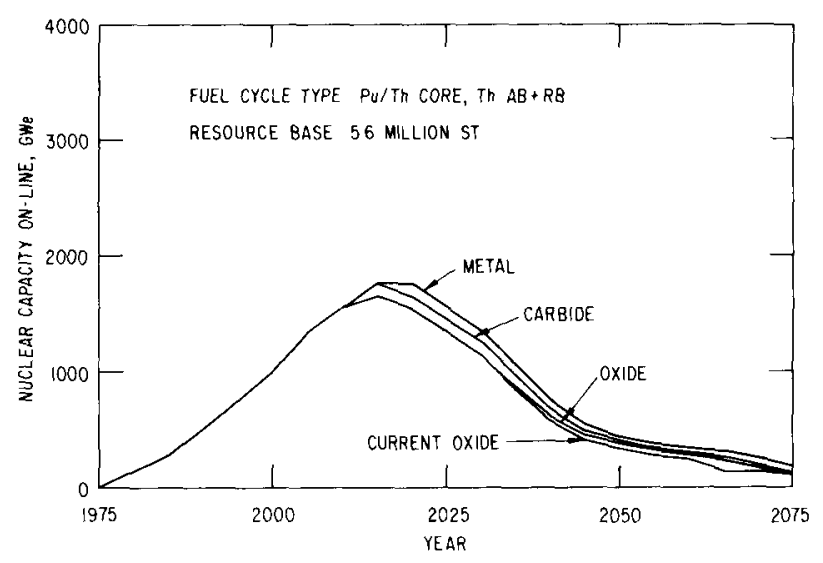

Fig. 18 .

Energy Supply and Growth Potential of Various FBR Fuel Types for a Fixed Resource Base of 5.6 Million ST U3 $\mathrm{O}_{8}$ (Fuel Cycle Type: Pu/Th Core, Th Blankets).

D. Energy Supply Flexibility Derivable from a Symbiotic Deployment Base

In this section the point of view remains that of the maximum energy potential extractable from a fixed-resource base. It is obvious from the analysis presented in the previous section that the major drawback of the symbiotic system is its limited long-term growth potential. However, some element of flexibility is inherent in this scenario. Suppose that this deployment strategy is implemented on the basis of projections that the future energy demand will level off, then events transpire to cause the energy demands to increase unexpectedly. The question that follows is whether or not the growth capability of the fast breeder could be recovered by making a transition from the symbiotic system to the reference $\mathrm{Pu} / \mathrm{U}$ cycle. This aspect, which can be thought of as the degree of hedging allowed against unpredicted future energy demand growth, is examined briefly in this section.

The situation postulated above was simulated in the following way. First oxide breeders with $\mathrm{Pu} / \mathrm{U}$ cores and thorium axial and radial blankets were assumed to be deployed, starting in the year 2000, with these breeders feeding denatured LWRs. A forced transition to the reference Pu/U cycle in the year 2025 was assumed with the further assumption that the fueling requirements for the reactors on-line to that time must be maintained for the remainder of their 30-year plant lifetime. The achievable recovery in energy growth capability is shown in Fig. 19 as a function of breeder fuel type. Recovery is possible in every instance. With oxide breeders growth recovery takes about 30 years. The comparable figure for advanced breeders is about 10 years.

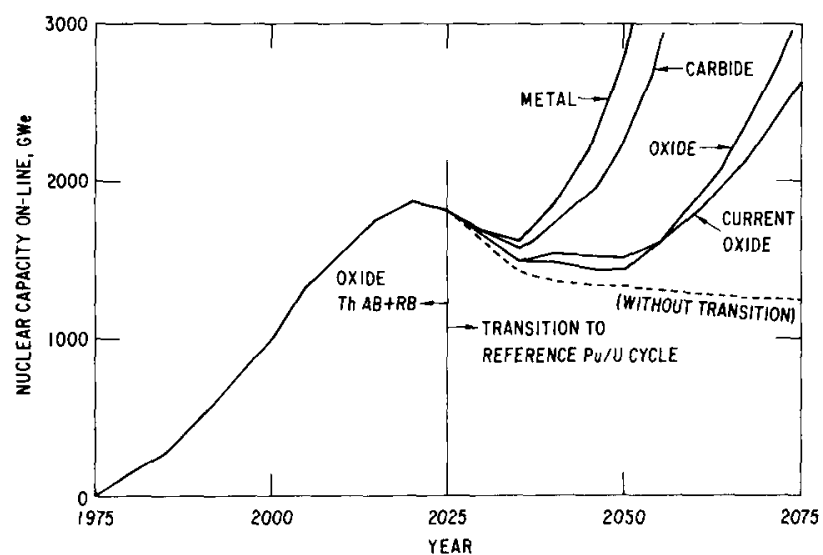

Fig. 19.

Comparison of Growth Recovery Capability by Making Transition from Symbiotic System (Oxide FBR with Th Blankets + Denatured LWR) to Reference Pu/U Cycle. 
E. Summary

1. Among various thorium-based alternative fuel cycles for the fast breeders, thorium utilization in the blanket only appears to offer two feasibility advantages over thorium utilization in both core and blankets. First, core fueling remains the same as the reference $\mathrm{Pu} / \mathrm{U}$ fuels, so incremental R\&D requirements for alternative fuels can be minimized. Second, and more fundamentally, breeding performance is not degraded significantly if the thorium usage is limited to the blanket. The $\mathrm{Pu} / \mathrm{Th}$ fuel cycle option burns plutonium and generates $233 \mathrm{U}$ for converter reactor uses, so the $\mathrm{Pu} / \mathrm{Th}$ cycle is simply a transmuter. The breeding capacity of the fast breeder is suppressed in the latter cycle, the breeding chain cannot be maintained, so overall system breeding is ruled out. This in turn rules out self-sustained system growth.

2. Increases in the ratio of converter/breeder power production are possible only at the expense of increasing uranium consumption if a given demand growth rate must be met.

3. Advanced breeders offer more flexibility in implementing symbiotic systems, whatever the acceptable tradeoff may turn out to be in terms of the reactor ratio and uranium requirements. They achieve a higher outside/inside reactor ratio for the same amount of uranium consumption, or conversely, uranium consumption can be reduced for the same reactor ratio.

4. Symbiotic systems have a degree of flexibility in reacting to developments causing an unexpectedly high demand. The time constant is fairly long, perhaps one decade for advanced breeders, increasing to about three decades for current oxide systems.

V. IMPLICATIONS OF REACTOR DEPLOYMENT SCENARIO ON AMOUNTS OF PLUTONIUM GENERATED AND AMOUNTS IN STORAGE

The magnitude of the "plutonium economy" associated with the principal reactor deployment options is examined in this section. To the degree that the total amounts of plutonium represent an index of proliferation hazard, the degree can be quantified by identification of the amounts of plutonium associated with the reactor scenarios studied in the previous sections. Here are two main factors - the overall size of the nuclear electric component, and the mix of reactor utilized -- and both vary with time. The purpose of this section is to quantify the effect of these factors on the magnitude of the cumulative plutonium production, and the amounts of plutonium in storage, as a function of time.

Four representative reactor scenarios are compared:

1. LWR Once-Through Cycle,

2. LWR, followed by a Denatured Thorium Cycle in CANDU,

3. LWR, followed by the FBR on the Reference Plutonium Cycle,

4. LWR, followed by an FBR and Denatured LWR Symbiotic System. 
The comparisons are made for three generic types of energy growth scenarios: for continuous growth, for non-growing equilibrium capacity, and for a fixed resource base, where, in the latter case, the energy demand growth is determined by the system capability. The advanced reactor types were introduced in the year 2000 with the constraints previously described.

The continuous growth and the fixed resource base cases use the same base-case international data used in the previous sections. The non-growing equilibrium capacity case uses the base-case growth to the year 2025, but level from then on. In both the continuous growth and non-growing equilibrium cases no limit is set on uranium consumption.

The results are summarized in Figs. 20 and 21.

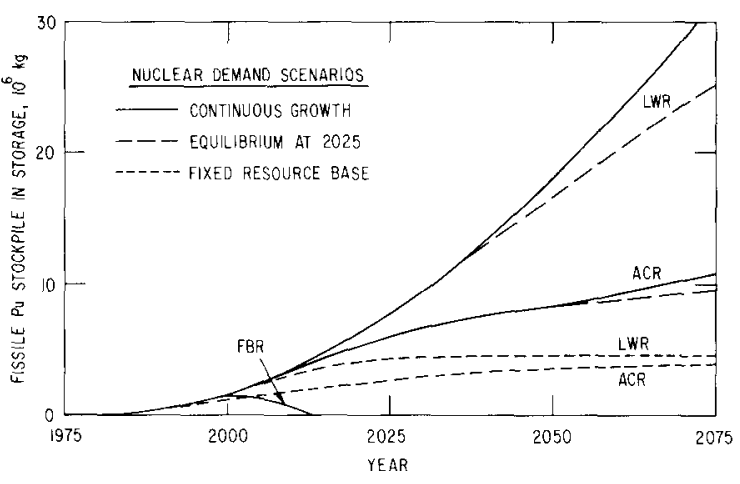

Fig. 20 .

Cumulative Fissile Pu Stockpile in Storage as a Function of Time for Various Scenarios.

Fig. 21.

Ratio of Cumulative Pu Production to Cumulative Energy Production as a Function of Time for Various Scenarios.

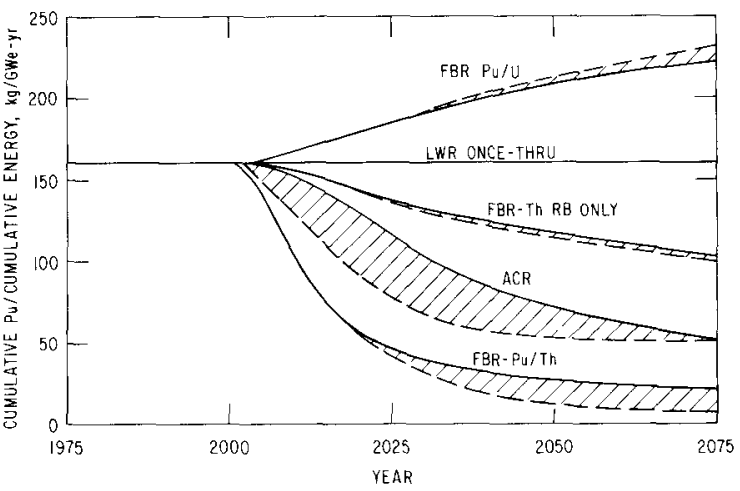

Figure 20 shows the cumulative fissile plutonium stockpiles in storage. The stockpile continuously cumulated in the once-through cycle is shown -largest for the continuous growth case, but still large for the non-growing equilibrium case. The fixed resource case has fixed once-through plutonium production as well, and its amount is shown on the figure. For the case of the LWR followed by denatured thorium cycle CANDUs, labeled ACR in the figure, the amounts are lessened, but again there is little difference between the continuous and leveled growth cases. Neither FBR case stores plutonium, and the LWR-generated backlogs are used up soon after the year 2010.

In the pure plutonium breeder scenarios the cumulative plutonium produced increases as its reactor usage increases, so its energy production rises in proportion as well. The amount of energy produced for a given plutonium 
presence is one index of plutonium benefit-to-risk. With no nuclear power production, no plutonium is produced. Assuming energy production, however, the different reactor deployments lead to different ratios of energy to cumulative plutonium production. The ratio of cumulative plutonium to cumulative energy is shown in Fig. 21 for the four reactor deployment scenarios. The shaded areas cover the range of the three different demand scenarios. The solid line gives the continuous and levelled growth cases and the dashed line the fixed resource case. The figure shows that there is little difference in the ratio of cumulative plutonium to cumulative energy between once-through and breeder cycles. The plutonium production decreases with time for the denatured thorium cycles, as ${ }^{23} \mathrm{U}$ produced in place of plutonium and burned in the converters. Plutonium-burning converters supported by breeders would show similar effects.

VI. SUMMARY

The purpose of this study, performed as part of the U.S. efforts in support of the INFCE Working Group 5, was to investigate the implications on long-term energy supply and resource utilization of alternative fuel cycles and various deployment strategies constrained by non-proliferation considerations. The performance characteristics of alternative fuel cycle options were taken from the design analysis described in a comparison report. 6 In other comparison reports, 1,3 a variety of technical modifications and institutional arrangements to minimize proliferation risk are discussed. For the system studies performed in this report, however, it is sufficient to consider only two classes of cases: breeder deployment not constrained as to fuel cycle type and breeder deployment constrained in fuel cycle type (or equivalently, constrained to secured area deployment).

Two different approaches were employed for energy supply and resource utilization studies. In the first approach, the cumulative uranium consumption was minimized for a given energy demand (OECD-NEA estimates of internationalaggregate demand). In the second approach, the energy production for each scenario was maximized for a fixed resource base. (Here again, internationalaggregate resource estimates compiled by the OECD-NEA were used as a base case.) The two approaches complement each other in providing insight into the difference in long-term potential that exists between various deployment scenarios.

Key results on the various implications of alternative fuel cycles and deployment strategies are summarized in the following.

1. Reference International Deployment of Breeder on Pu/U Cycle: To set the breeder in context, a few representative converter reactor scenarios were compared with breeder scenarios in terms of the cumulative uranium consumption for the base case of international-aggregate energy demand. The continuous resource usage of converter scenarios, including Advanced Converter Reactor case (represented by denatured thorium cycle in CANDU reactors for this study), exhausts the "reasonably assured" plus "estimated additional" resources soon after the year 2010. If 30-year forward requirements were accounted for, the point of commitment of all resources would be reached by the year 2000 .

With a full scale introduction of breeders starting in the year 2000, the uranium consumption for the base demand begins to slow significantly 
around 2025. With the high-gain breeders, no additional uranium is consumed after 2030, and by fortunate coincidence only, the consumption levels off just under the estimated resources. For the lower gain breeders, the uranium consumption continues but eventually levels off when the breeder fissile doubling capability catches up with the energy growth. The low-gain breeders require an additiona 12 million $\mathrm{ST} \mathrm{U}_{3} \mathrm{O}_{8}$ compared to the high-gain breeders. This difference is not large on the scale of differences between converter and breeder types, but is substantial on the scale of reasonably assured resources.

In analyzing the effect of breeder performance characteristics, we note that the incentives for improved breeding lessen as the available uranium resources expand. Large uranium resources enable converters to meet demands and the plutonium generated removes plutonium-supply obstacles to additions in breeder capacity. At the other extreme, the incentives for improved breeding are very great if the uranium supplies are constricted, and the breeder is required to make large contributions to energy supplies in the first half of the next century. High-gain breeders will also accommodate adequately to a range of contingencies such as delays in breeder introduction, larger-thanexpected energy growth rates, plutonium flow logistics, etc.

2. Secured Area Deployment with Symbiotic Cycles Using Thorium: For symbiotic deployment scenarios, consisting of thorium-based breeder fuel cycles and denatured converter reactors supported by $233_{\mathrm{U}}$ from breeders, the uranium resource requirements to meet the base energy demand are dictated most strongly by the degree of thorium utilization in the breeder. The uranium requirements increase progressively as more thorium is incorporated into the breeders, from the radial blanket only to the full thorium core.

Thorium utilization only in the blanket appears to offer two feasibility advantages over thorium utilization in both core and blankets. First, core fueling remains the same as the reference $\mathrm{Pu} / \mathrm{U}$ fuels, so incremental R\&D requirements for alternative fuels can be minimized. Second, and more fundamentally, breeding performance is not degraded significantly if the thorium usage is limited to the blanket. The $\mathrm{Pu} / \mathrm{Th}$ fuel cycle option burns plutonium and generates $233_{\mathrm{U}}$ for converter reactor uses, so the $\mathrm{Pu} / \mathrm{Th}$ cycle is simply a transmuter. The breeding capacity of the fast breeder is suppressed in the latter cycle, the breeding chain cannot be maintained, so overall system breeding is ruled out. This in turn rules out self-sustained system growth.

The ratio of dispersed converters to breeders is another important factor, particularly in the scenarios that confine breeders to secured areas. Normal economic and engineering pressures will tend toward maximizing the number of converters in such a symbiotic system because of the freedom in deployment that the converters enjoy in this scenario only. There exists a basic tradeoff between the reactor ratio and the resource utilization. The ratio of dispersed converters to breeders can be increased by using more thorium in the breeder cycle. However, this results in an increased uranium resource requirements for a given energy demand.

The analysis on the effect of breeder performance characteristics indicates that advanced breeders offer more flexibility in implementing symbiotic systems, whatever the acceptable tradeoff may turn out to be in terms of the reactor ratio and uranium requirements. They achieve a higher 
outside/inside reactor ratio for the same amount of uranium consumption, or conversely, uranium consumption can be reduced for the same reactor ratio.

Symbiotic systems do offer a degree of flexibility in reacting to developments causing an unexpectedly high demand. The time constant is fairly long, perhaps one decade for advaced breeders, increasing to about three decades for low-gain breeders.

3. Implications of Reactor Deployment Scenario on Amounts of Plutonium Generated: In the pure plutonium breeder scenarios the cumulative plutonium produced increases as its reactor usage increases, so its energy production rises in proportion as well. The amount of energy produced for a given plutonium presence is one index of plutonium benefit-to-risk. With no nuclear power production, no plutonium is produced. Assuming energy production, however, the different reactor deployments lead to different ratios of energy to cumulative plutonium production. There is little difference in the ratio of cumulative plutonium to cumulative energy between once-through and breeder cycles. The plutonium production decreases with time for the denatured thorium cycles, as ${ }^{233} \mathrm{U}$ produced in place of plutonium and burned in the converters. Plutonium-burning converters supported by breeders would show similar effects.

\section{ACKNOWLEDGMENTS}

The authors wish to acknowledge the contributions of D. C. Wade in reviewing the analyses and providing useful comments. 
1. M. J. Lineberry et al., Fuel Cycle Options, Part 5 of this report.

2. M. G. Stevenson, P. B. Abramson and L. G. LeSage, Internationalization and Collocation of FBR Fuel cycle Facilities, Part 6 of this report.

3. P. I. Amundson and G. K. Rusch, Safeguards, Part 7 of this report.

4. Nuclear Fuel Cycle Requirements and Supply Considerations, Through the Long-Term, OECD Nuclear Energy Agency (February 1978).

5. Y. I. Chang, C. E. Till et al., Altemative Fuel Cycle Options; Per formance Characteristics and Impact on Nuclear Power Growth Potential, ANL-77-70 (September 1977).

6. Y. I. Chang and C. E. Till, Design and Performance Characteristics of Alternative Fuels and Fuel Cycles, Part 2 of this report.

7. R. W. Hardie, W. E. Black and W. W. Little, ALPS, A Linear Programming System for Forecasting Optimum Power Growth Patterns, HEDL-THE-72-31 (April 1972).

8. J. H. Kittel et al., Status of Fuels and Materials Development, Part 3 of this report. 


\title{
PART 2
}

\section{DESIGN AND PERFORMANCE CHARCTERISTICS OF ALTERNATIVE FUELS AND FUEL CYCLES}

Y. I. Chang and C. E. Till

(Argonne National Laboratory)

Technical Contributors:

\author{
J. C. Beitel \\ R. D. McKnight \\ S. K. Bhattacharyya \\ R. W. Schaefer \\ E. K. Fujita \\ B. J. Toppel \\ H. Henryson II \\ R. B. Turski \\ R. P. Hosteny \\ (Argonne National Laboratory)
}

\begin{abstract}
This report documents performance characteristics of a wide range of fast breeder rector designs and filel cycle options to provide the bases for the study of alternatives that is the primary focus of the International Nuclear Fuel Cycle Evaluation. Since breeding performance is at the center of many of the feasibility questions connected with alternative forms of breeder development, particular attention was given to a consistent comparison between varlous alternatives and quantitative analyses that provide physical understanding of intrinsic differences in their breeding performance.
\end{abstract}

\section{INTRODUCTION}

The objective of this report is to present a full range of possible breeder options, document their performance characteristics, and provide an analysis of the calculated differences in their breeding performance. The incentives or disincentives for the various alternatives -- their impacts on resource utilization, possible non-proliferation advantages, adaptability to improved deployment scenarios, technology status, etc., are treated in other reports in this series, all based on the design and performance characteristics presented here. In particular, the implications of various alternative breeder cycles on possible roles for the fast breeder in the future power economy are treated in a companion report (Ref. 1) as a direct consequence of the technical analyses described in this report. 
The concepts covered in this report are those that were considered to be both feasible technically (in most cases, however, only after very substantial development effort) and of relevance to the INFCE considerations. Primary attention was given to fuel cycle type ( $\mathrm{Pu} / \mathrm{U}, \mathrm{Pu} / \mathrm{Th}, 233 \mathrm{U} / \mathrm{Th}, 233 \mathrm{U} / \mathrm{U}$, etc.) and to fuel type (oxide, carbide, metal). The other two main variants in breeder design -- core design concept (homogeneous, heterogeneous) and reactor concept (LMFBR, GCFR) -- were given lesser emphasis, but for completeness were covered as well.

Very much greater uncertainty must be assigned to the technical feasibility of the alternatives considered in this report than for the present well-established reference FBR designs. Analysis of a given reactor option certainly does not imply that its current technological status is adequate to allow such a reactor to be built. The implied premise in any analyses of this kind is that the required technology can be developed if the decision is made to do so. Its purpose is to identify potential performance payoffs associated with alternative concepts, if the required development was undertaken and was successful. The current technological status, associated key issues, and main $R \& D$ requirements to resolve the issues for the various fuel and fuel cycle types are discussed in other reports in this series. (Refs. 2 and 3 ).

Meaningful comparisons of performance characteristics require commonality between designs in the ground rules, constraints and design procedures. Such commonality of design basis was stressed in these studies. The design basis is described in Section II.

Section III presents the design and performance characteristics of a consistent set of designs for the various alternatives. Analysis of the systematics of the breeding performance is presented to provide generic understanding of the differences between fuel types, fuel cycle types and design concepts. Because they are important to and characteristic of the design type, safety-related physics parameters are also compared in this section.

In Section IV, uncertainties in the ranges of the breeding performance are illustrated by showing the impact of design variations that may be necessary for conservatism or for other reasons.

Finally, key results and observations are summarized in Section $v$. Detailed mass flow data are presented in the Appendix.

II. DESIGN GROUND RULES, CONSTRAINTS AND METHODOLOGIES

A. Design Ground Rules and Constraints

Design analysis is a complex and often judgmental process with interplay and tradeoffs required between materials, mechanical, thermal/hydraulic, and nuclear design considerations. In order to facilitate a consistent comparison between various alternative designs, ground rules were adopted for the general reactor specifications, based on the DOE-sponsored Proliferation-Resistant LMFBR Core Design Study (PRLCDS) program.4 These are presented in Table I. These ground rules were developed by DOE, GE, AI, CE, WARD, ORNL, HEDL, and ANL for comparative analysis of alternative LMFBR concepts. 
The reactor was assumed to be of a 1000 MWe size, currently seen as a typical size in a fully developed commercial deployment scenario. The other parameters are also representative of commercial scale.

TABLE I. Groundrules on General Reactor Specifications for LMFBRs

\begin{tabular}{lc}
\hline Reactor Power, MWe & 1000 \\
Reactor Power, MWth & 2740 \\
Thermal Efficiency, \% & 36.5 \\
Core Height, in. & $40(101.6 \mathrm{~cm})$ \\
Axial Blanket Thickness, in. & $15(38.1 \mathrm{~cm})$ \\
Radial Blanket Thickness, rows & 3 \\
Reactor Outlet Temperature, ${ }^{\circ} \mathrm{F}$ & $930\left(499^{\circ} \mathrm{C}\right)$ \\
Reactor $\Delta \mathrm{T},{ }^{\circ} \mathrm{F}$ & $280\left(156^{\circ} \mathrm{C}\right)$ \\
Cycle Length, years & 1 \\
Capacity Factor, $\%$ & 75 \\
Fuel Residence Time, cycles & 2 \\
Core &
\end{tabular}

For the design parameters affected by specific design choice, the following constraints were applied:

1. The fuel design and operating conditions to be limited so that the total steady-state plus transient cumulative damage function ( $C D F)$ is less than 0.75 , but neither steadystate $\mathrm{CDF}$ nor transient $\mathrm{CDF}$ is greater than 0.5 .

2. The nominal peak linear power to be less than $70 \%$ of the power-to-melt value.

3. The fuel pin pitch/diameter ratio to be greater than 1.15 .

4. The maximum pressure drop through the pin bundle, exclusive of the inlet and exit losses, to be less than 90 psi $(620 \mathrm{kPa})$.

5. The maximum sodium coolant velocity to be 1 ess than $35 \mathrm{ft} / \mathrm{sec}$ $(10.7 \mathrm{~m} / \mathrm{sec})$.

6. The maximum bending stress on the duct wall to be less than 18000 psi (124 MPa).

7. The duct-duct clearance to be set to provide allowance for dilation due to irradiation-induced swelling and creep throughout the life of the duct.

These constraints are summarized in Table II. For all designs the structural material (cladding and duct) was assumed to be $20 \%$ C.W. SS 316 . The swelling, creep and time-to-rupture properties assumed for $20 \%$ C.W. SS 316 are presented in Figs. 1-4. The material properties presented in Figs. 1-4 represent an improvement over the SS316 properties compiled in the Nuclear System Materials Handbook.5

\section{B. Neutronic Data and Methods}

The basic cross section data used for the neutronics analysis were ENDF/B-IV6 with the exception of the cross section data for $232 \mathrm{Th}$. Because thorium-containing cycles are prominent among the alternatives of interest, 
TABLE II. Design Constraints Assumed for LMFBRs

1. Fuel Design CDF

$\begin{array}{ll}\text { Steady-state } & <0.5 \\ \text { Transient } & <0.5 \\ \text { Total } & <0.75\end{array}$

2. Nominal Peak Linear Power

$<70 \%$ of Power-to-Melt

3. Fuel Pin Pitch/Diameter Ratio

$>1.15$

4. Bundle Pressure Drop

$<90$ psi $(620 \mathrm{kPa})$

5. Maximum Coolant Velocity

$<35 \mathrm{ft} / \mathrm{sec}(10.7 \mathrm{~m} / \mathrm{sec})$

6. Duct Wa11 Stress

$<18000$ psi $(124 \mathrm{MPa})$

7. Duct-Duct Interaction due to Irradiation-Induced Swelling and Creep at End-of-Life Conditions

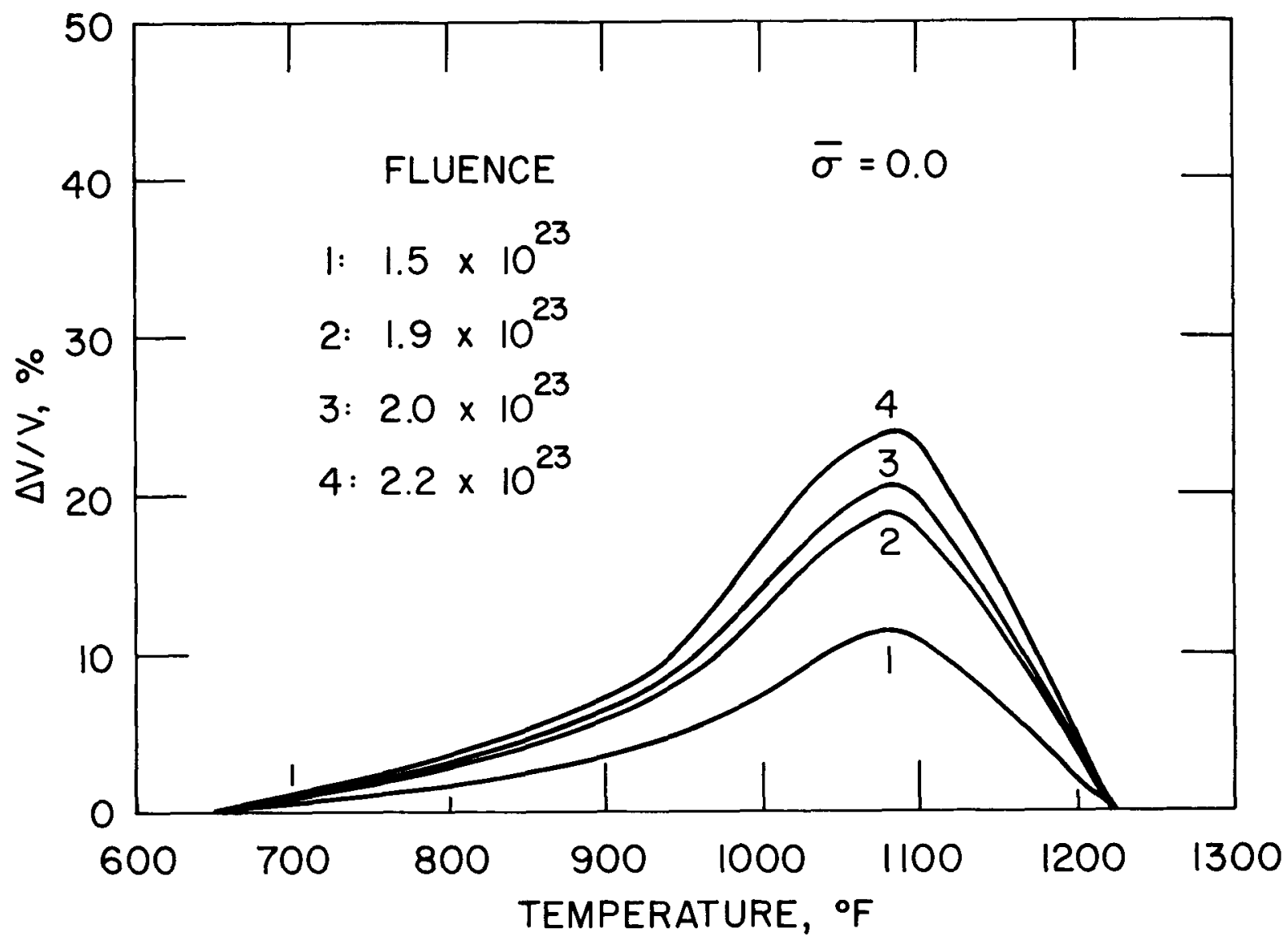

Fig. 1. Irradiation Induced Swelling for $20 \%$ C.W. SS316 $(\bar{\sigma}=0)$. 


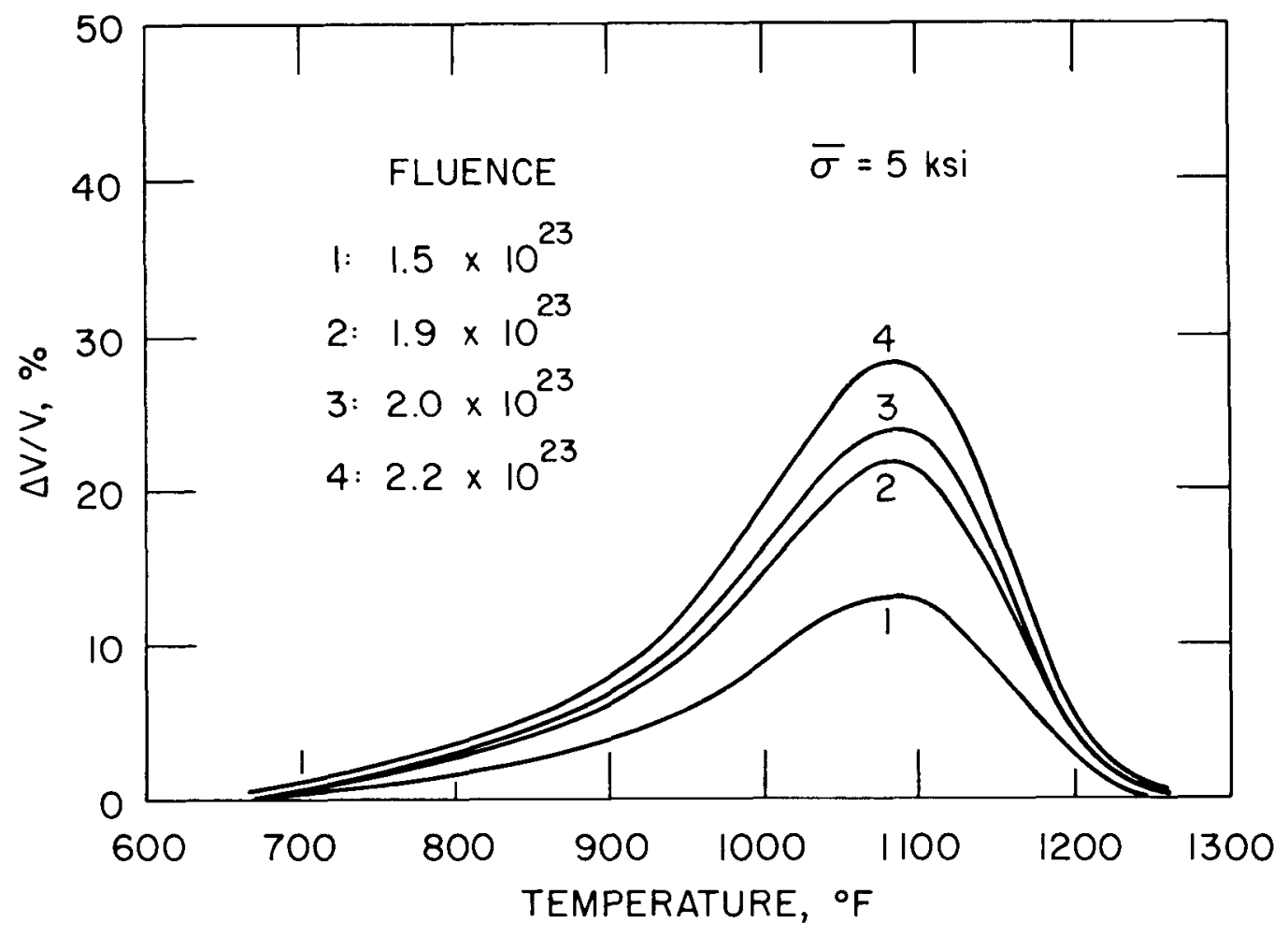

Fig. 2. Irradiation Induced Swelling for $20 \%$ C.W. SS316 ( $\bar{\sigma}=5 \mathrm{ksi})$.

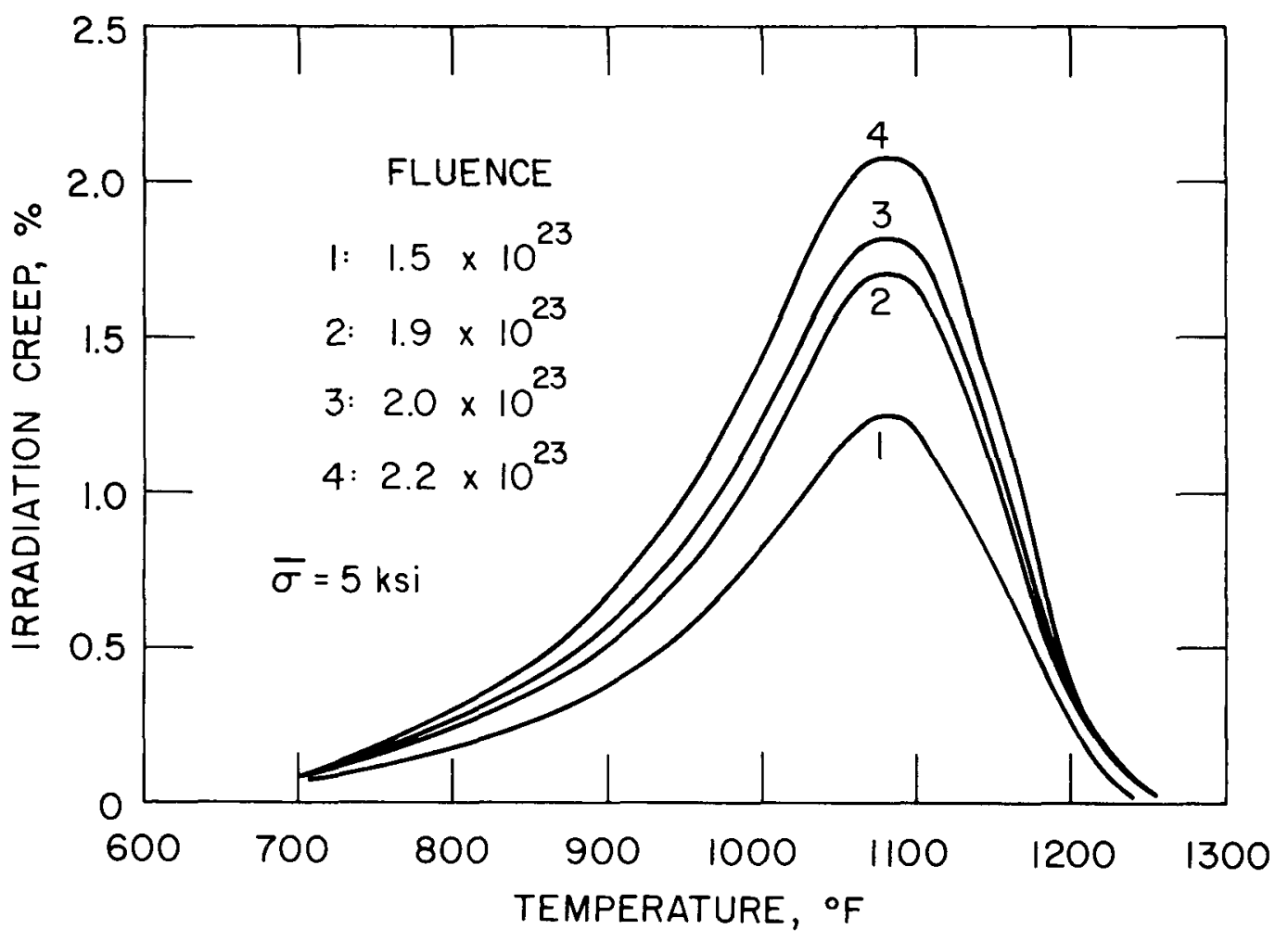

Fig. 3. Irradiation Induced Creep for $20 \% \mathrm{C}$.W. SS316. 
thorium data is particularly important to these analyses. For $232 \mathrm{Th}$, therefore, a new evaluation of Smith and Poenitz was used, because the ENDF/B-IV data for $232 \mathrm{Th}$ (which is essentially the original evaluation of 1966), is

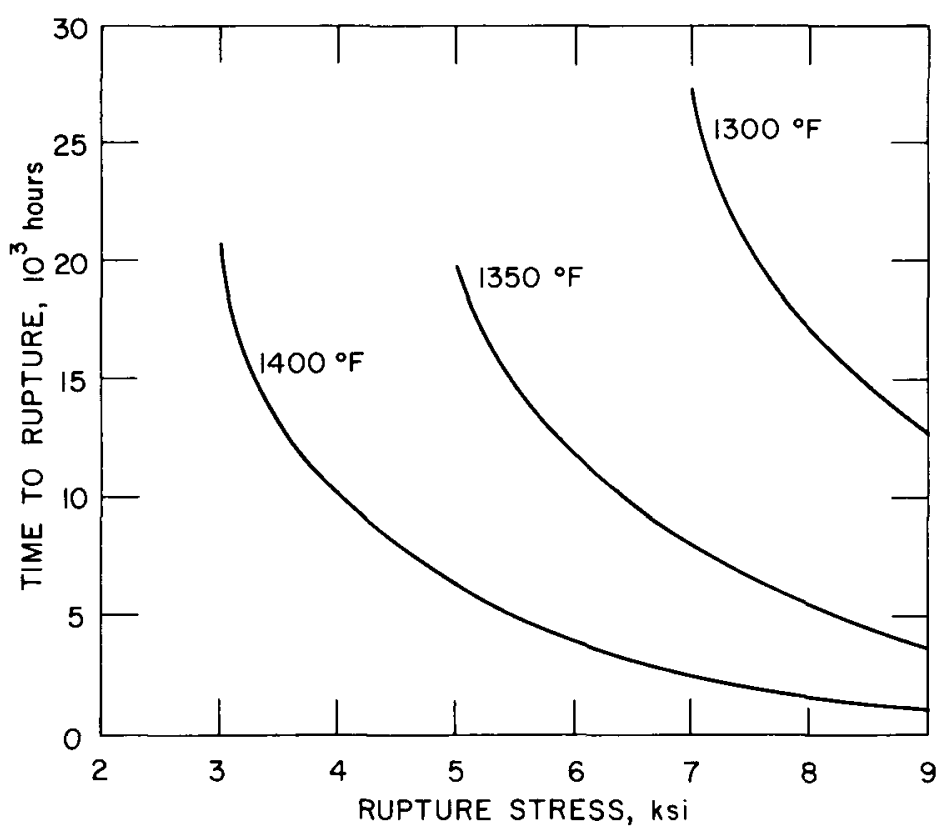

Fig. 4. Time to Rupture as a Function of Stress for $20 \%$ C. W. SS316. known to be in error in the energy range of interest to fast reactor analysis. The Smith-Poenitz evaluation of 232 Th cross sections is based on the experimental data base available to October 1977.

Although large differences between ENDF/B-IV and SmithPoenitz evaluations exist in both fission and capture cross sections, the most striking difference is in the capture cross section in the energy range between $50 \mathrm{keV}$ and $600 \mathrm{keV}$. As shown by the comparison in Fig. 5, the new evaluation gives considerably lower values in this energy range.

Detailed attention was given to commonality of procedure in preparing the cross section data for each of the options. The basic cross section data files were processed with the $\mathrm{MC}^{2}-2 / \mathrm{SDX}^{8}, 9$ code system. First a 171-group $(\Delta \mathbf{u}=0.1$ ) base library was generated using weighting spectra from 2040-group slowing down calculations for $\mathrm{Pu} / \mathrm{U}$ and $\mathrm{U} / \mathrm{Th}$ core compositions. Special $238 \mathrm{U}$ and $232 \mathrm{Th}$ blanket cross sections in the fine-group library were obtained using the core leakage as an external source for the blanket slowing down problems. Using this fine-group base library, broad-group libraries were generated with the SDX code for each combination of fuel type (oxide, carbide, and metal), fuel-cycle type ( $\mathrm{Pu} / \mathrm{U}, \mathrm{Pu} / \mathrm{Th}$, etc.), and core/blanket combination. A separate set of cross sections were generated specifically for the GCFR. Resonance and spatial self-shielding calculations were performed using the resonance integral formulation and the integral transport cell calculation options. Using the appropriate cell-averaged fine-group data, one-dimensional diffusion theory calculations provided a space-energy weighting spectrum for group condensation. Eight-group cross section sets were generated for the depletion calculation and twenty-group sets were generated for the safety coefficient calculations.

The sodium void reactivity and Doppler coefficients were analyzed using two-dimensional $\mathrm{r}-\mathrm{z}$ diffusion theory calculations with the DIF2D code. 10 The breeding performance was analyzed using two-dimensional $\mathrm{r}-\mathrm{z}$ diffusion theory and depletion calculations for an equilibrium cycle condition with the REBUS-2 code.11 For all fuel cycle options utilizing Pu fuel, the isotopic composition for the loading was assumed to be: 


$\begin{array}{lr}{ }^{238} \mathrm{Pu} & 1.0 \% \\ 2{ }^{29} \mathrm{Pu} & 67.3 \% \\ 240 \mathrm{Pu} & 19.2 \% \\ { }^{241} \mathrm{Pu} & 10.1 \% \\ 242 \mathrm{Pu} & 2.4 \%\end{array}$

The diluent uranium was assumed to have a $2{ }^{35} \mathrm{U}$ enrichment of $0.2 \%$. For the $233^{3}$ fueling options, the following isotopic composition was assumed at loading:

$\begin{array}{lr}2{ }^{33} \mathrm{U} & 75.2 \% \\ 23{ }^{3} \mathrm{U} & 21.1 \% \\ 235_{\mathrm{U}} & 3.0 \% \\ 236_{\mathrm{U}} & 0.7 \%\end{array}$

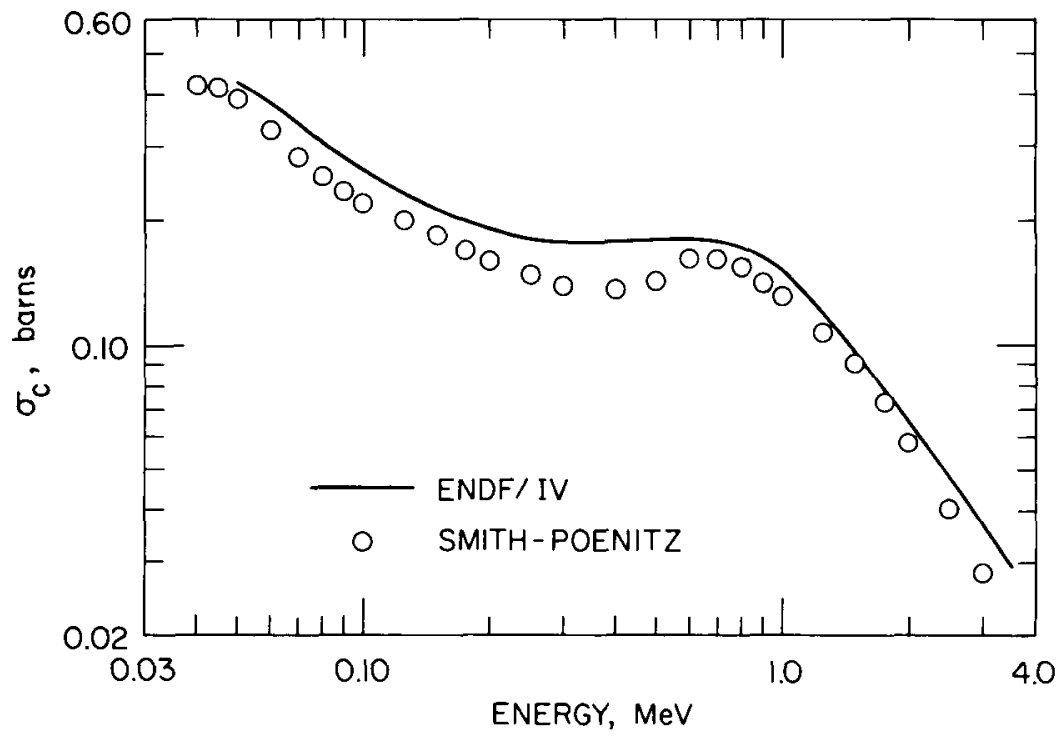

The performance characteristics presented in this report are described in terms of mass flow data (inventory, gain, loading and discharge, etc.), the breeding ratio, and the compound system doubling time. The breeding ratio is defined as:

$B R=\frac{\text { Total atoms of fissile isotopes produced during equilibrium cycle }}{\text { Total atoms of fissile isotopes destroyed during equilibrium cycle }}$.

The decay loss of ${ }^{241} \mathrm{Pu}$ during irradiation is also included in the fissile destruction term. The compound system doubling time is defined as : 12

$$
\operatorname{CSDT}=0.693 \times \frac{\mathrm{M}\left(1+R F \times \frac{\mathrm{T}_{\text {ex }}}{\mathrm{T}_{\text {cycle }}}\right)}{\left(\mathrm{G}-\mathrm{L}_{\mathrm{p}}-\mathrm{L}_{\mathrm{d}}\right) \times(\text { Cycles/Year })}
$$

where

$$
\begin{aligned}
& M= \text { BOEC fissile inventory (including the blanket fissile } \\
& \text { inventory), } \\
& \mathrm{RF}= \text { Refueling fraction, } \\
& \mathrm{T}_{\text {ex }}= \text { External cycle time, } \\
& \mathrm{T}_{\text {cycle }}=\text { Cycle length, }
\end{aligned}
$$




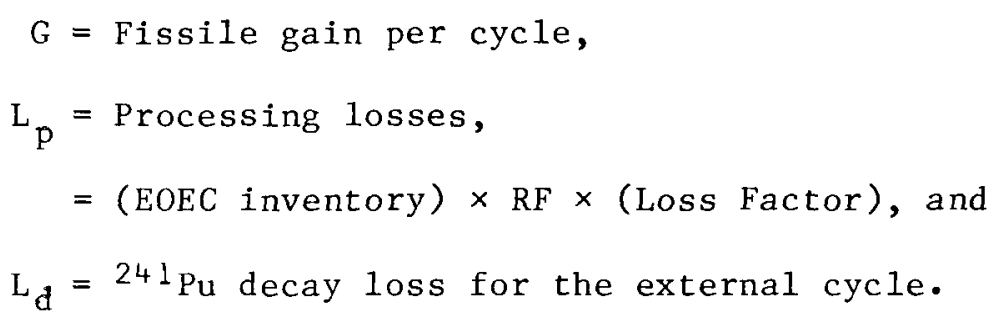

In this study, a 1-year external cycle time and a $2 \%$ processing loss factor were assumed. The "fissile" isotopes in the BR and CSDT definitions include $233 \mathrm{U}$ (with credit for ${ }^{233} \mathrm{~Pa}$ ), ${ }^{235} \mathrm{U}, 239 \mathrm{Pu}$, and ${ }^{241} \mathrm{Pu}$.

Although the doubling time defined in this manner reasonably wel1 represents the doubling capability of a breeder economy for the $\mathrm{Pu} / \mathrm{U}$ cycle, the doubling time as defined above has very little physical meaning for alternative cycles involving symbiosis with converter reactors. Nevertheless, where doubling time is quoted in this report, the above definition is used for all fuel cycle types, but on the understanding that it is only as a relative figure-of-merit. (For the systems studies that give the implications of breeding performance the particular definition used is immaterial as actual mass flows are used throughout.) In fact, the doubling time calculated for any given design is sensitive to the definition itself and to the assumptions applied. Throughout this report the doubling time should be viewed only as a figure-of-merit. Because of differences in definition, doubling time values may not be consistent with others reported in the literature. In comparing such numbers it is necessary to be precise about the defintion used.

\section{CORE DESIGN AND PERFORMANCE CHARACTERISTICS}

\section{A. Reference Core Design Characteristics}

A wide range of fast breeder performance characteristics has been reported for various design studies, including demonstration plants, 13,14 conceptual designs, $15-17$ and a large number of survey studies.18,19 Some of the differences in the breeding performance are due to intrinsic characteristics of the design concepts or fuel types; and others are simply due to different assumptions and the degree of conservatism applied to the design.

Since the objective of this study is to explore various alternatives to the current design types, the maximum achievable consistency between alternatives is important to the required comparisons. The always difficult task of achieving a consistent design comparison is made more difficult by the large number of permutations that are possible for alternative fast breeder designs, and by the wide variation in technology status that exists between the various alternatives.

The possible permutations include: 


\begin{tabular}{lllll} 
Reactor & & Fuel Cycle Type \\
Concept & $\begin{array}{l}\text { Fuel } \\
\text { Type }\end{array}$ & $\begin{array}{c}\text { Core } \\
\text { Concept }\end{array}$ & Core & Blanket \\
\hline LMFBR & Oxide & Homogeneous & $\mathrm{Pu} / \mathrm{U}$ & $\mathrm{U}$ \\
GCFR & Carbide & Heterogeneous & $\mathrm{Pu} / \mathrm{Th}$ & $\mathrm{Th}$ \\
& Metal & & $\mathrm{U} / \mathrm{Th}$ & \\
& & $\mathrm{U} / \mathrm{U}$ & \\
\hline
\end{tabular}

To make this study manageable, clearly impractical or unpromising options were screened out first. Priority was then given to a consistent comparison between fuel types (oxide, carbide and metal), and fuel-cycle types (Pu/U cycle, Pu/Th cycle, etc.), to identify intrinsic differences in their breeding performance.

Consistency is also influenced by the fact that the design and associated performance characteristics depend strongly on the technology of the different fuels. The data base required for the reference mixed oxide design is adequately known, but for most alternative options the data base is meager. The status of fuels development is discussed in detail in a companion report of this series. 2

The intent in this work was to make the designs correspond to fuels at similar levels of development. For options where little data exists this is clearly a judgmental process. An effort was made to reflect equivalent degree of conservatism in the selection of fuels performances. The corresponding reactor designs then represent equivalent conceputally feasible systems, but systems whose actual feasibility would depend on the success of the required development.

The reference fuel designs used in this study were primarily derived from the PRLCDS designs. In Table III the normalized fuel designs used for the INFCE study are summarized and compared with representative PRLCDS designs. The oxide and carbide fuel designs have been extensively analyzed and the designs selected for this study represent typical design ranges. As Ref. 2 discusses, however, the technology of carbides is well behind that of oxides.

Metallic fuel has only recently come under consideration again as an alternative fuel for FBRs, with the interest stimulated largely by INFCE objectives. Far fewer design studies have been conducted for this fuel type. However, the irradiation experience obtained with the EBR-II Mark-II helped considerably in guiding the design of the metal-fueled LMFBRs reported here.

The reference core design characteristics for the oxide, carbide and metal fueled LMFBRs are displayed in Table IV. Also shown in Table IV are characteristics for the GCFR design, which was developed by General Atomics.

The fuel designs described in Tables III and IV are typical designs in the optimum doubling time range for the $\mathrm{Pu} / \mathrm{U}$ cycle. The same mechanical design features (those in Table IV) were assumed for all fuel cycle options to 
TABLE III. Comparison of Fue1 Design Parameters

\begin{tabular}{|c|c|c|c|c|c|c|c|c|c|}
\hline & \multicolumn{3}{|c|}{ INFCE } & \multicolumn{6}{|c|}{ PRLCDS } \\
\hline & Oxide & Carbide & Metal & $\begin{array}{l}\text { G.E. } \\
\text { Oxide }\end{array}$ & $\begin{array}{l}\text { W-ARD } \\
\text { Oxide }\end{array}$ & $\begin{array}{c}\text { C-E } \\
\text { Carbide }\end{array}$ & $\begin{array}{c}\text { AI } \\
\text { Carbide }\end{array}$ & $\begin{array}{l}\text { ANL- } \\
\text { Low DT }\end{array}$ & 1 Low SI \\
\hline \multicolumn{10}{|l|}{ Driver Fuel } \\
\hline Fuel Material & $\mathrm{Pu}^{\mathrm{U}} \mathrm{UO}_{2}$ & $\mathrm{Pu}-\mathrm{UC}$ & $\mathrm{Pu}-\mathrm{U}-10 \mathrm{wt} \% \mathrm{Zr}$ & $\mathrm{Pu}-\mathrm{UO}_{2}$ & $\mathrm{Pu}-\mathrm{UO}_{2}$ & $\mathrm{Pu}-\mathrm{UC}$ & $\mathrm{Pu}-\mathrm{UC}$ & $\mathrm{Pu}-\mathrm{U}-\mathrm{Zr}$ & $\mathrm{Pu}-\mathrm{U}-\mathrm{Zr}$ \\
\hline Fuel/Clad Bond & $\mathrm{He}$ & $\mathrm{Na}$ & $\mathrm{Na}$ & $\mathrm{He}$ & $\mathrm{He}$ & $\mathrm{Na}$ & $\mathrm{Na}$ & $\mathrm{Na}$ & $\mathrm{Na}$ \\
\hline Pin o.d., in. & 0.29 & 0.37 & 0.31 & 0.29 & 0.31 & 0.37 & 0.37 & 0.35 & 0.27 \\
\hline Cladding Thickness, in. & 0.014 & 0.015 & 0.015 & 0.012 & 0.013 & 0.015 & 0.015 & 0.024 & 0.019 \\
\hline Thickness/o.d., Ratio & 0.048 & 0.041 & 0.048 & 0.041 & 0.042 & 0.041 & 0.041 & 0.069 & 0.069 \\
\hline $\mathrm{p} / \mathrm{d}$ Ratio & 1.186 & 1.178 & 1.213 & 1.200 & 1.150 & 1.198 & 1.170 & 1.176 & 1.253 \\
\hline Plenum/Fuel Ratio & 1.2 & 0.7 & 1.2 & 0.8 & 1.1 & 0.5 & 0.7 & 1.00 & 1.00 \\
\hline Smeared Density, \% T.D. & 90 & 80 & 75 & 90 & 91 & 77 & 81 & 75 & 75 \\
\hline Peak Linear Power, kW/ft & 14.0 & 28.0 & 20.0 & 13.5 & 14.2 & 30.0 & 23.9 & 25 & 20 \\
\hline Peak Burnup, MWD $/ \mathrm{kg}$ & 70 & 70 & 75 & 93 & 89 & 103 & $\sim 86$ & 72 & 93 \\
\hline Peak Fast Fluence, $10^{23}$ nvt & $1: 7$ & 2.1 & 2.7 & 2.0 & 2.1 & 2.6 & $\sim 1.9$ & 2.4 & 2.7 \\
\hline \multicolumn{10}{|l|}{ Radial Blanket } \\
\hline Fuel Material & $\mathrm{UO}_{2}$ & UC & $\mathrm{U}$ & $\mathrm{UO}_{2}$ & $\mathrm{vo}_{2}$ & UC & UC & $\mathrm{U}-\mathrm{zr}$ & $\mathrm{U}-\mathrm{Zr}$ \\
\hline Fuel/clad Bond & $\mathrm{He}$ & $\mathrm{Na}$ & $\mathrm{Na}$ & He & $\mathrm{He}$ & $\mathrm{He}$ & $\mathrm{Na}$ & $\mathrm{Na}$ & $\mathrm{Na}$ \\
\hline Pin o.d., in. & 0.470 & 0.472 & 0.461 & 0.471 & 0.491 & 0.577 & 0.558 & 0.581 & 0.481 \\
\hline Cladding Thickness & 0.015 & 0.015 & 0.015 & 0.015 & 0.015 & 0.020 & 0.016 & 0.015 & 0.015 \\
\hline Thickness/o.d., Ratio & 0.032 & 0.032 & 0.033 & 0.032 & 0.031 & 0.035 & 0.029 & 0.026 & 0.031 \\
\hline $\mathrm{p} / \mathrm{d}$ Ratio & 1.070 & 1.070 & 1.070 & 1.080 & 1.07 & 1.071 & 1.070 & 1.10 & 1.10 \\
\hline Smeared Density, \% T.D. & 90 & 90 & 85 & 95 & 93 & 96.4 & 92 & 75 & 75 \\
\hline
\end{tabular}


LMFBR

Oxide Carbide Metal GCFR

\section{General Reactor Data}

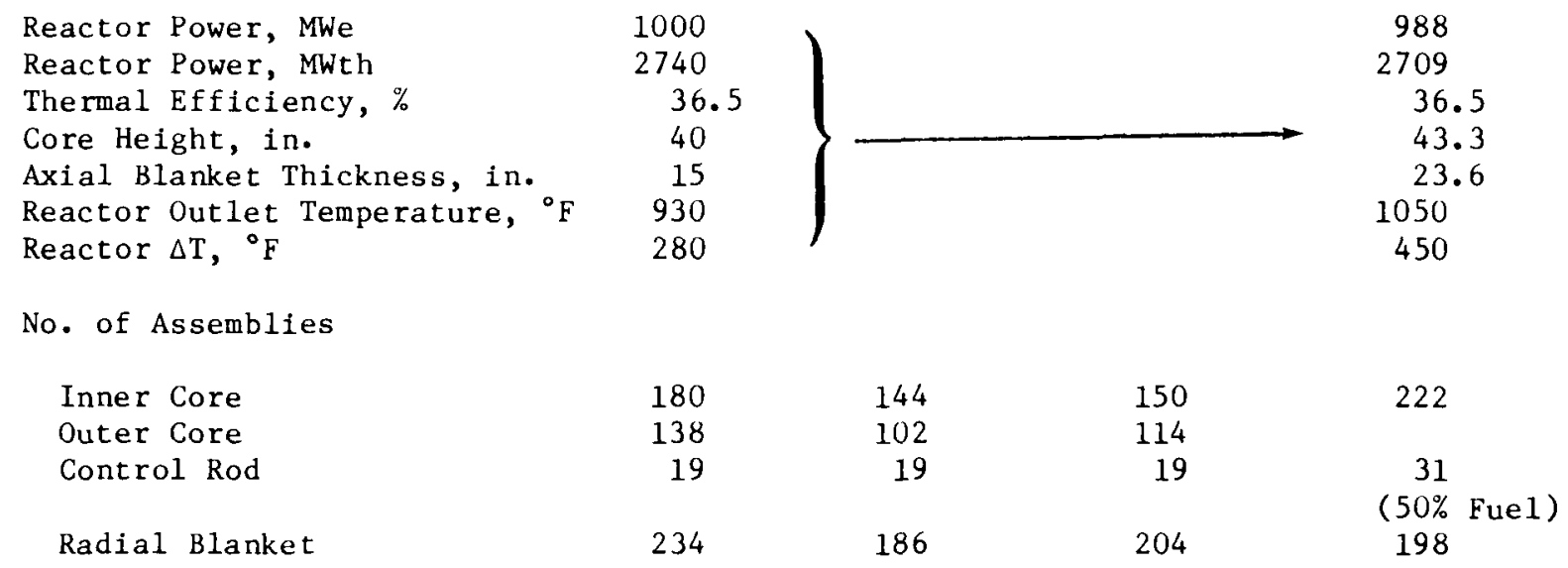

\section{Fuel Design Data}

Fuel Material

Fuel/Clad Bond

Pin o.d., in.

Cladding Thickness, in.

$\mathrm{p} / \mathrm{d}$ Ratio

Wire Spacer Diameter, in.

Plenum Length, in.

Fuel Smeared Density, \% T.D.

Linear Power, $\mathrm{kW} / \mathrm{ft}$

Nominal Peak

Ave rage

Assemb1y Design

\footnotetext{
No. of Pins

As sembly Pitch, in.

Duct Outside Flat-to-Flat, in.

Duct Wall Thickness, in.

Interassembly Gap, in.

Nozzle-to-Nozzle $\Delta$, psi

Peak Coolant Velocity, ft/sec
}

\section{Core Volume Fractions}

Fue1 (Smeared)

0.4238
0.1969
0.3793

271

6.310

6.040

0.141

0.270

90

26.0

$\mathrm{Pu}-\mathrm{UC}$
$\mathrm{Na}$

0.370
0.015
1.178
0.065
28
80

28.0

18.1

169

6.372

6.067

0.141

0.305

90

32.3

Pu-U-10 wt\% Z
Na 0.310
0.015
1.213
0.066
48
75

20.0

12.9

217

6.292

5.927

0.138

0.365

90

28.8
$\mathrm{Pu}-\mathrm{UO}_{2}$

He

0.296

0.016

1.44

Grid Spacer

Vented

90

14.0

9.0

324

8.543

8.004

0.122

0.539

42

238

0.3846

0.5879 (He) 
TABLE IV. (Contd)

LMFBR

Oxide Carbide Metal GCFR

Radial Blanket Assembly

Fuel Material

Fuel/Clad Bond

Duct Outside Flat-to-Flat, in.

Duct Wa11 Thickness, in.

No. of Pins

Pin o.d., in.

Cladding Thickness, in.

p/d Ratio

Fuel Smeared Density, \% T.D.

RB Volume Fractions

Fuel (Smeared)

Structure

Sodium

0.5592

0.1656

0.2752
UC

$\mathrm{Na}$
U

$\mathrm{Na}$

$\begin{array}{cccc}6.040 & 0.067 & 5.927 & 8.004 \\ 0.141 & 0.141 & 0.138 & 0.122 \\ 127 & 127 & 127 & 90 \\ 0.470 & 0.472 & 0.461 & 0.717 \\ 0.015 & 0.015 & 0.015 & 0.014 \\ 1.070 & 1.070 & 1.070 & 1.137 \\ 90 & 90 & 85 & 90\end{array}$

Fuel Management

Fuel Residence Time, fpd
RB Residence Time, fpd

$2 \times 274$

$5 \times 274$

compare the effect of various fueling options in evolutionary steps. Hence, the performance characteristics presented in this report may not in every case represent optimum performance for alternative cycles. The doubling time is normally used as a performance index for the $\mathrm{Pu} / \mathrm{U}$ cycle, however it is not clear whether the same criteria should be applied to mixed cycles

TABLE V. Theoretical Density of Fuel Materials $(\mathrm{gm} / \mathrm{cc})$

\begin{tabular}{llrl}
\hline & Pu & U & \multicolumn{1}{c}{ Th } \\
\hline Oxide & 11.46 & 10.96 & 10.00 \\
Carbide & 13.49 & 13.61 & 10.63 \\
Metal $^{\mathrm{a}}$ & 19.84 & 19.01 & 11.68 \\
\hline a $_{\text {U-Pu-10 }} \mathrm{wt \%}$ & $\mathrm{Zr}$ & $15.7 \mathrm{gm} / \mathrm{cc}$ &
\end{tabular}
as well. This aspect is discussed more in Section IV.D.

With the same fuel pin mechanical design for each, the fuel material and its density change in each fuel cycle option. The fuel densities assumed for various designs are presented in Table $V$. For the metal fuel case, a smear density of $80 \%$ was assumed for $\mathrm{Pu} / \mathrm{Th}$, and a smear density of $90 \%$ for the Th blanket.

In addition to the homogeneous core configurations, selected heterogeneous configurations were also analyzed. 
For these designs, the same driver fuel and blanket assembly characteristics were assumed as for the reference designs. The core layouts for the reference designs and heterogeneous designs are shown in Figs. 6-12.
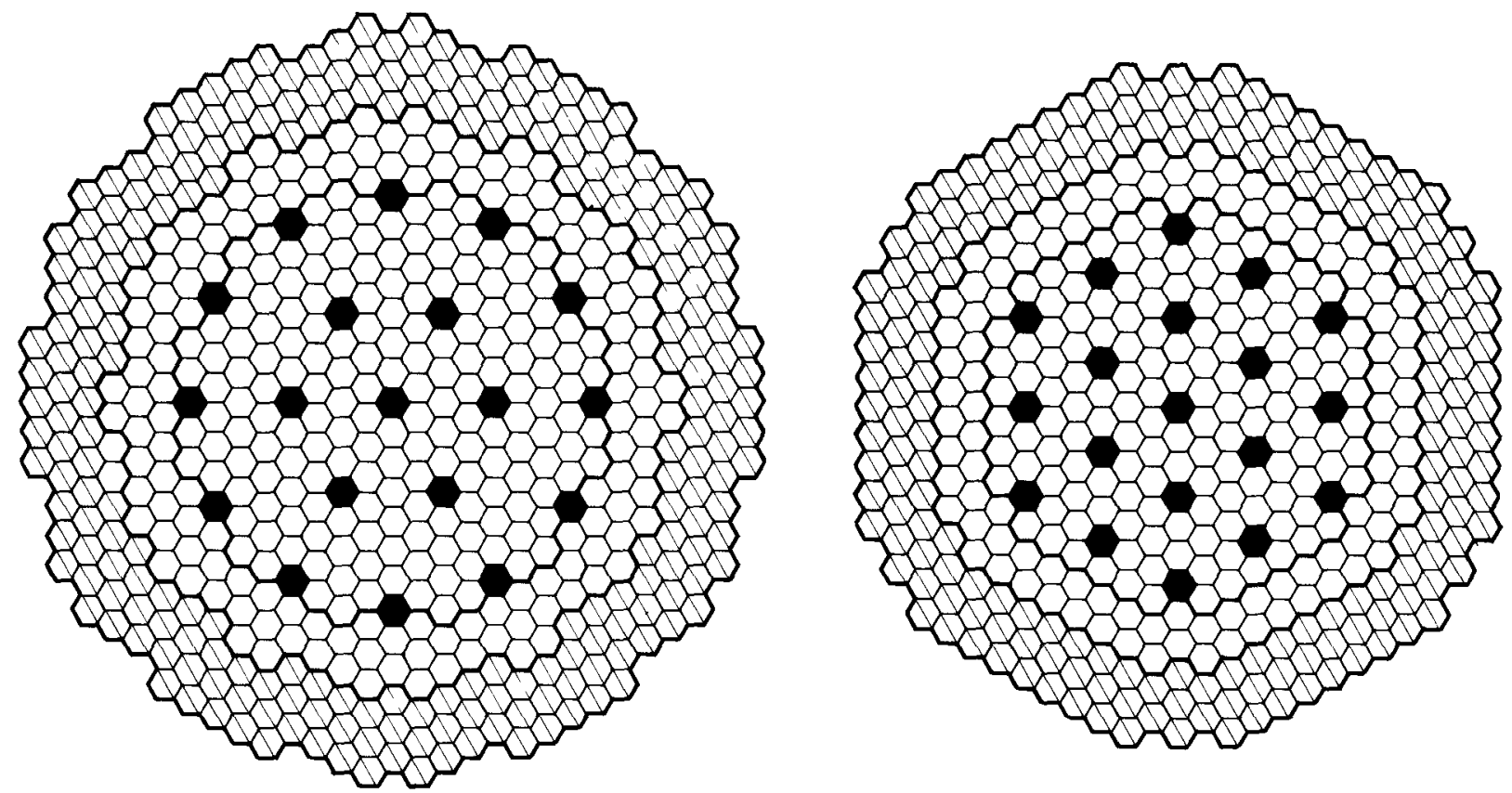

$\square\left\{\begin{array}{l}\text { CORE ZONE I (180) } \\ \text { CORE ZONE 2 (138) }\end{array}\right.$
$\square$ CONTROL (19)

Fig. 6. Core Layout for Oxide Design.
RADIAL BLANKET (234) 


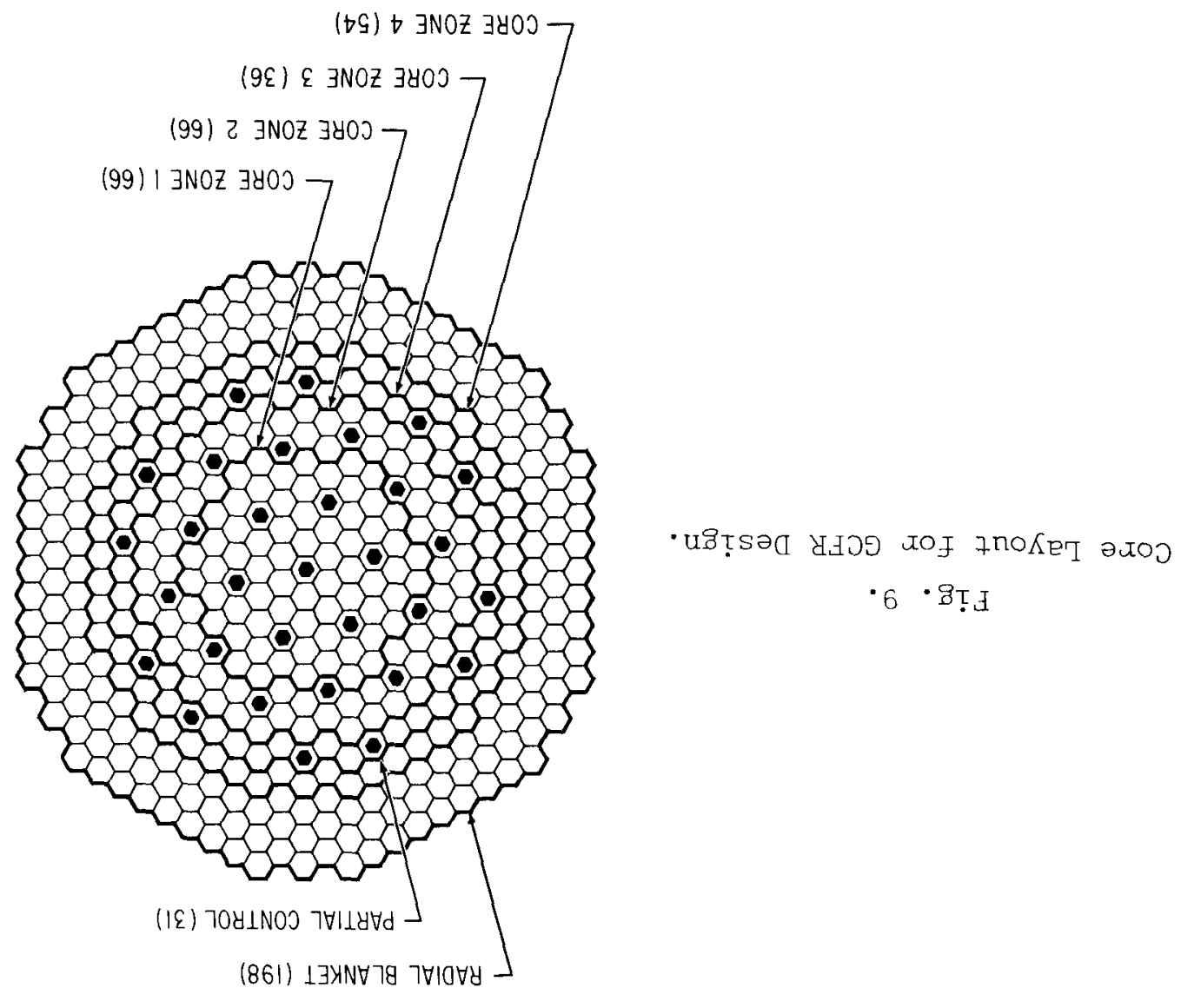

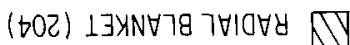

(61) 70Y1NOJ

(bli) $2 \exists \mathrm{NOZ} \exists \mathrm{H} 00$

(OG।) I $\exists$ NOZ $\exists y 03\}$

- usțsəa tełan uof znoאer auos

$\cdot 8 \cdot 8$ ?

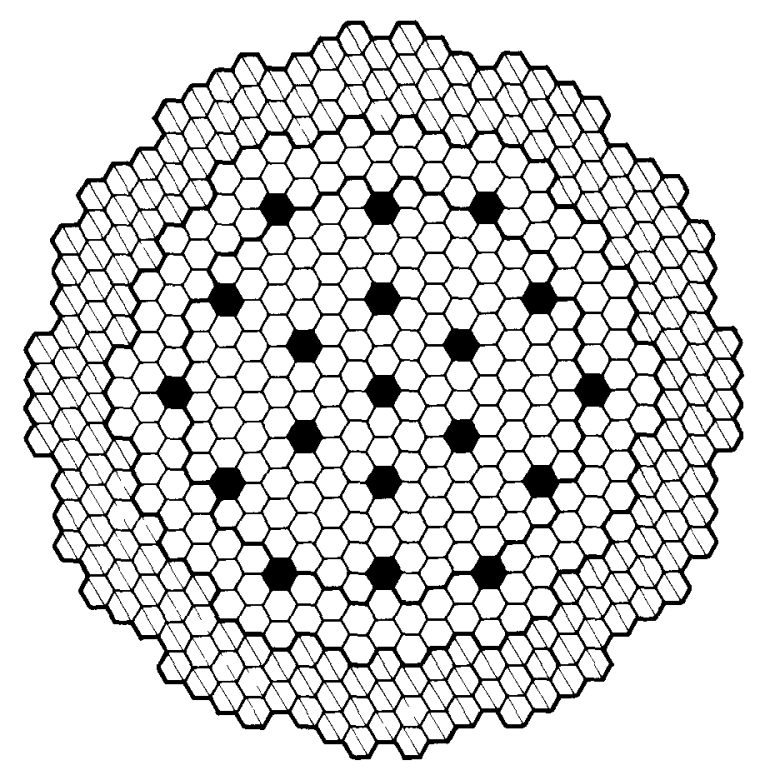




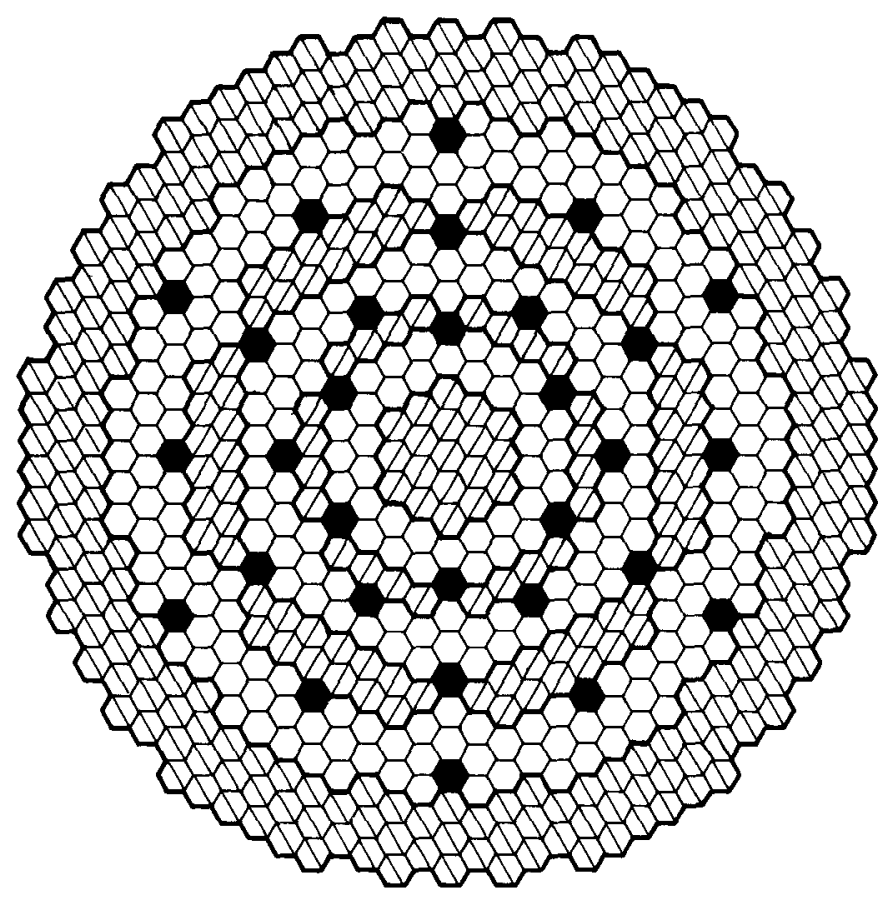

Fig. 10 .

Core Layout for Heterogeneous Oxide Design.

Fig. 11.

Core Layout for Heterogeneous Carbide Design.

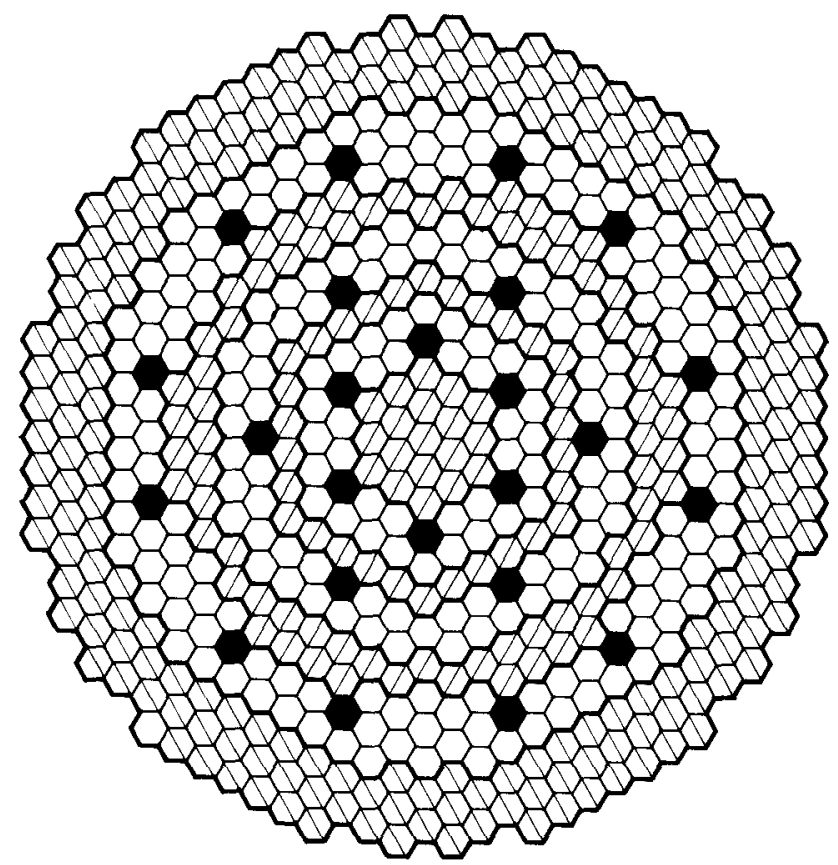




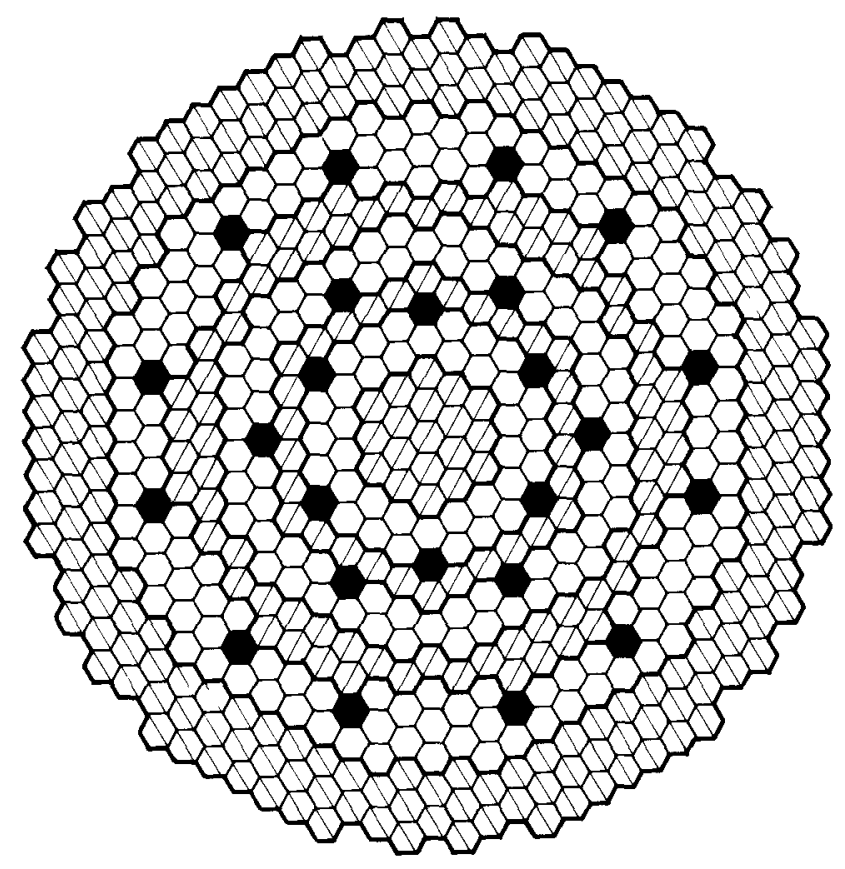

Fig. 12.

Core Layout for Heterogeneous Metal Design.

CORE (234)

Q7] INTERNAL BLANKET (|2|)

CONTROL (24)

$\triangle 7$ RADIAL BLANKET (204)

1. LMFBR-oxide, carbide, metal

a. Homogeneous core

- $\mathrm{Pu} / \mathrm{U}$ core, U blanket

- $\mathrm{Pu} / \mathrm{U}$ core, $\mathrm{U}$ axial blanket and Th radial blanket

- Pu/U core, Th blanket

- Pu/Th core, Th blanket

- $233 \mathrm{U} / \mathrm{Th}$ core, Th blanket

- $233 \mathrm{U} / \mathrm{U}$ core (denatured), Th blanket

b. Heterogeneous core

- Pu/U core, U internal, axial and radial blanket

- $\mathrm{Pu} / \mathrm{U}$ core, Th internal, axial and radial blanket

2. GCFR-oxide homogeneous core

- Pu/U core, U blanket

- Pu/U core, $\mathrm{U}$ axial blanket and $\mathrm{Th}$ radial blanket

- Pu/U core, Th blanket

- Pu/Th core, Th blanket

- ${ }^{23}{ }^{3} \mathrm{U} / \mathrm{Th}$, Th blanket

- $233 \mathrm{U} / \mathrm{U}$ core (denatured), Th blanket. 
TABLE VI, Sumary of Breeding Performance and Mass Flow Data (kg/GWe)

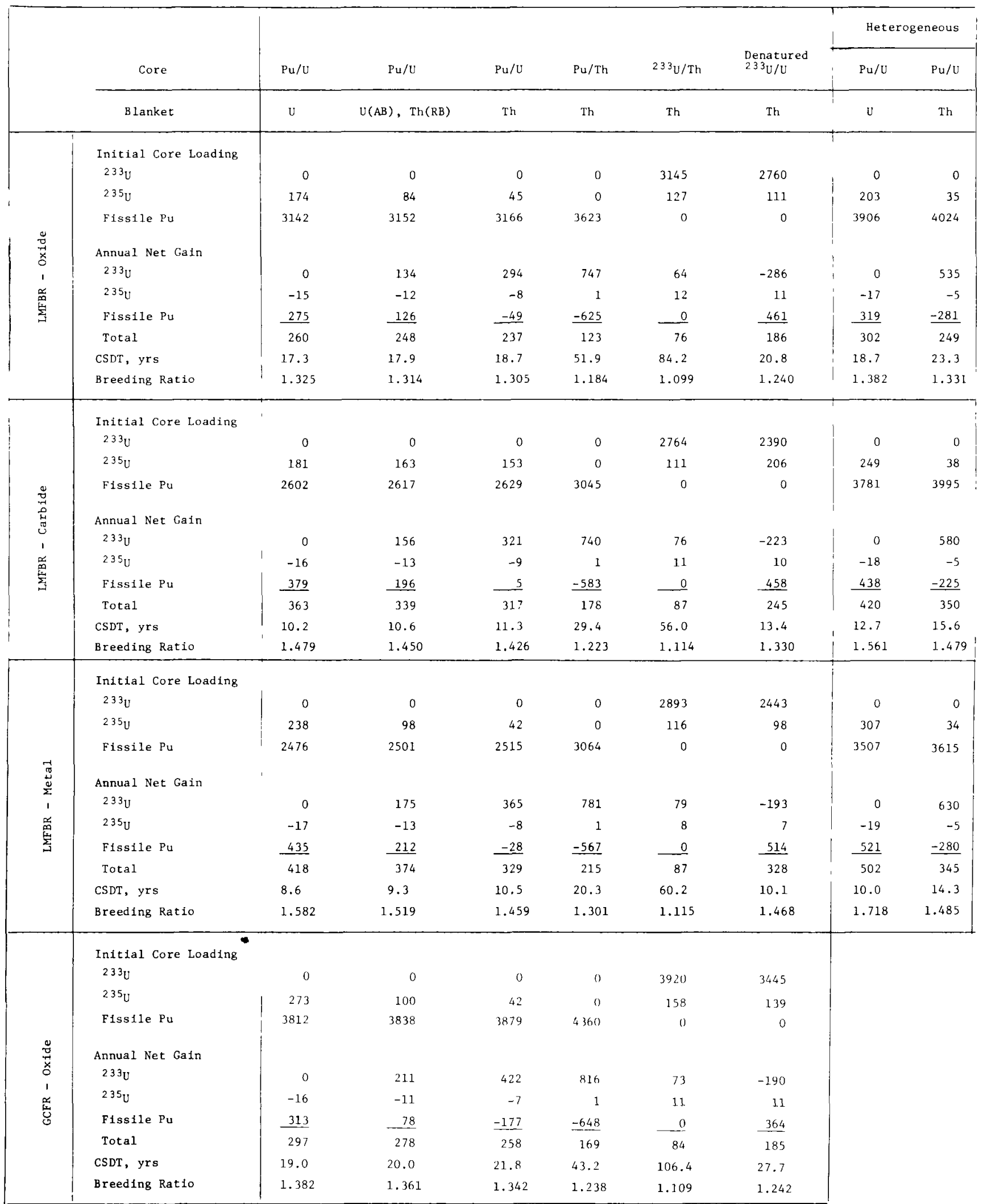

Footnote: 1. Mass flow data are normalized to 1000 MWe and $75 \%$ capacity factor.

2. Breeding ratio and compound system doubling time are calculated with equal weighting

for all fissile isotopes. The $233 \mathrm{U}$ balance includes credit for ${ }^{23} \mathrm{~Pa}$

3. Compound system doubling time is calculated with 1 year external cycle time and

$2 \%$ losses. 
The core specific power, average core discharge burnup and peak fast fluence $(E \geqslant 0.1 \mathrm{MeV})$ data for various fuel types and fuel cycle options are summarized in Table VII. More detailed performance characteristics and mass flow data are compiled in the Appendix.

TABLE VII. Summary of Core Specific Power, Average Burnup and Peak fast Fluence

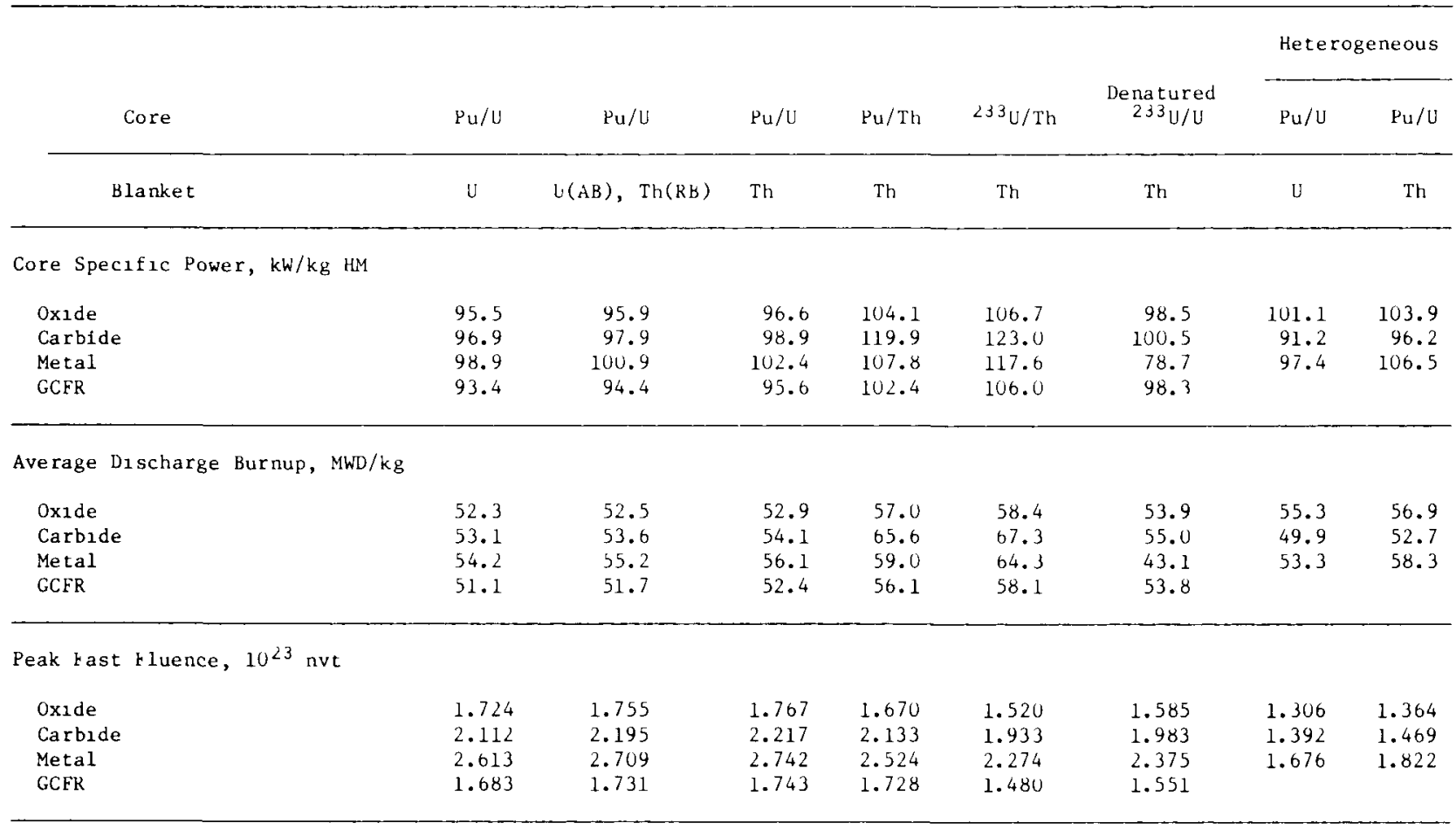

From Table VI we note that the breeding performance is improved for the carbide fuel over the oxide fuel, and for the metal fuel over the carbide fuel, both in the breeding ratio and the doubling time. The GCFR has a higher breeding ratio than the oxide fueled LMFBR but the doubling time is also higher because of the increased fissile inventory requirements. Between fuel cycle types, the breeding performance worsens as thorium is added.

To understand the directions designs might take in response to different energy supply/resource/deployment requirements, a physical understanding of the components of the breeding ratio is useful. As discussed in Section II, the breeding ratios presented in Table VI are integrated breeding ratios over the equilibrium cycle resulting from depletion analyses. To understand the generic trends in the breeding performance for various fuel and fuel cycle types we examine the breeding ratio components based on the neutron balance. The instantaneous breeding ratio can be alternatively expressed as: ${ }^{20}$

$$
B R=\eta-1+\varepsilon-A-L-D \text {, }
$$

where

$n=$ number of neutrons produced by fissions in fissile isotopes per neutron absorption in fissile isotopes, 


$$
\begin{aligned}
& =\frac{\sum_{i}^{i} \int_{i} \Sigma_{f}^{i} \phi d E d V}{\sum_{a}^{i} \phi d E d V} ; i=\text { fissile isotopes, } \\
& \varepsilon=\text { number of excess neutrons produced by fissions in } \\
& \text { fertile isotopes per neutron absorption in fissile } \\
& \text { isotopes, } \\
& =\frac{\sum \int\left(\nu_{j}-1\right) \Sigma_{f} \phi^{j} d E d V}{j} ; \quad \begin{array}{l}
j=\text { fertile isotopes } \\
i=\text { fissile isotopes }
\end{array} \\
& \sum \int \Sigma_{a}^{i} \phi d E d V
\end{aligned}
$$

and the last term, D is independent of the neutron balance, but accounts for the equivalent loss in the breeding ratio due to the radioactive decay of ${ }^{241} \mathrm{Pu}$.

The term ( $n-1)$ represents the excess neutrons available for breeding due to fissile isotope fissions and the term $\varepsilon$ represents the excess neutrons due to fertile isotope fissions. A combination of these two terms defines the maximum breeding ratio theoretically achievable if all excess neutrons could be absorbed in fertile isotopes. In reactors, some neutrons are absorbed in the non-fuel material and some leak out. These neutron losses are accounted for by the terms $\mathrm{A}$ and $\mathrm{L}$.

A static neutron balance based on cycle-averaged reaction rates can be used to identify the individual contributions of each of the component terms in the breeding ratio. Even though the integrated breeding ratio computed explicitly in the depletion calculation cannot be reproduced precisely by the instantaneous neutron balance, the breeding performance trends are reproduced well and the physical explanation of the trends is made obvious by a comparison of the contribution of the components.

1. Comparison of Breeding Performance Between Oxide, Carbide and Metal Fuels: For the reference $\mathrm{Pu} / \mathrm{U}$ cycle, the breeding ratio components based on the neutron balance are compared in Table VIII between oxide, carbide and metal fueled LMFBRs. The total neutron excess is about 14 points higher for carbide and 32 points higher for metal fuel than for oxide fuel. About one-half of the increment is due to the increase in $n$-values of fissile isotopes and the other half to the increase in fertile fission bonus as the spectrum hardens. 
The parasitic neutron losses are also compared in Table VIII. Absorption in the structural material contributes $60-70 \%$ of the total absorption losses, the fission products contribute about $25 \%$, and absorption losses due to the coolant and fuel

TABLE VIII. Comparison of Breeding Ratio Components between Oxide, Carbide and Metal Fueled LMFBRs for Pu/U Cycle

\begin{tabular}{|c|c|c|c|}
\hline & Oxide & Carbide & Metal \\
\hline$\eta$ of Fissile Isotopes & 2.283 & 2.353 & 2.450 \\
\hline Fertile Fission Bonus, $\varepsilon$ & 0.356 & 0.429 & 0.509 \\
\hline Total Excess Neutrons & & & \\
\hline$n-1+\varepsilon$ & 1.639 & 1.782 & 1.959 \\
\hline \multicolumn{4}{|l|}{ Neutron Losses } \\
\hline $\begin{array}{l}\text { Structure } \\
\text { Fission Products } \\
\text { Coolant } \\
0, \mathrm{C} \text {, or } \mathrm{Zr}\end{array}$ & $\begin{array}{l}0.158 \\
0.055 \\
0.010 \\
0.008 \\
\end{array}$ & $\begin{array}{l}0.131 \\
0.058 \\
0.009 \\
0.001 \\
\end{array}$ & $\begin{array}{l}0.127 \\
0.058 \\
0.008 \\
0.025 \\
\end{array}$ \\
\hline Tota1 Absorption Loss & 0.231 & 0.199 & 0.218 \\
\hline Leakage Loss & 0.046 & 0.051 & 0.082 \\
\hline Pu-241 Decay Loss & 0.031 & 0.029 & 0.032 \\
\hline Total Loss & 0.308 & 0.279 & 0.332 \\
\hline Net Neutrons for Breeding & 1.331 & 1.503 & 1.627 \\
\hline $\begin{array}{l}\text { Actual Integrated BR from } \\
\text { Depletion Calculation }\end{array}$ & 1.325 & 1.479 & 1.582 \\
\hline
\end{tabular}

diluent constituents are negligible. The variations in the absorption losses between oxide, carbide and metal are very small, resulting in only $2-3$ point differences in the breeding ratio. The leakage loss is higher for the metal design because of the harder neutron spectrum and the smaller core configuration, compared to either the oxide or carbide design. The impact of ${ }^{241} \mathrm{Pu}$ decay loss to the breeding ratio is about the same for all three designs and amounts to about a 3 point reduction in the breeding ratio.

Overall, the difference in total neutron losses between fuel design types is rather small. It is the basic neutronic properties of the carbide and metal fuels themselves (as reflected in $\eta$ and $\varepsilon$ ) that are directly responsible for their improved breeding performance.

Of course, for a given design type, the breeding ratio can be improved by design modifications. For example, designs that give an increased fuel volume fraction result in a higher breeding ratio because the hardened spectrum increases excess neutrons available and reduces the parasitic absorption losses. However, this relationship is true for any fuel type, and the inherent differences in the breeding potential between fuel types are unchanged. This is illustrated in Fig. 13 where the breeding ratio is plotted as a function of the fuel volume fraction for the three fuel types. The range of different fuel volume fraction designs was accomplished by varying the fuel pin diameter but applying the same ground rules and constraints (Tables I and II) to all designs.

As shown in Fig. 13, the functional relationship between the breeding ratio and fuel volume fraction is similar for all fuel types. However, there is an inherent difference of $10-15$ points in the breeding ratio between the oxide and the carbide curves, and also between the carbide and the metal curves. The circled points in Fig. 13 are the reference designs presented earlier, which correspond to optimum or near-optimum designs for minimum compound system doubling time.

2. Comparison of Breeding Performance Between Fuel Cycle Options: From Table VI we note that the breeding ratio is not affected much when thorium is utilized in the blankets in place of the uranium. For example, the 
breeding ratio is reduced only by 1 point by the use of thorium in the radial blanket of the oxide LMFBR. When thorium is utilized in the axial blanket as well the breeding ratio penalty is about 2 points. The reason for the small

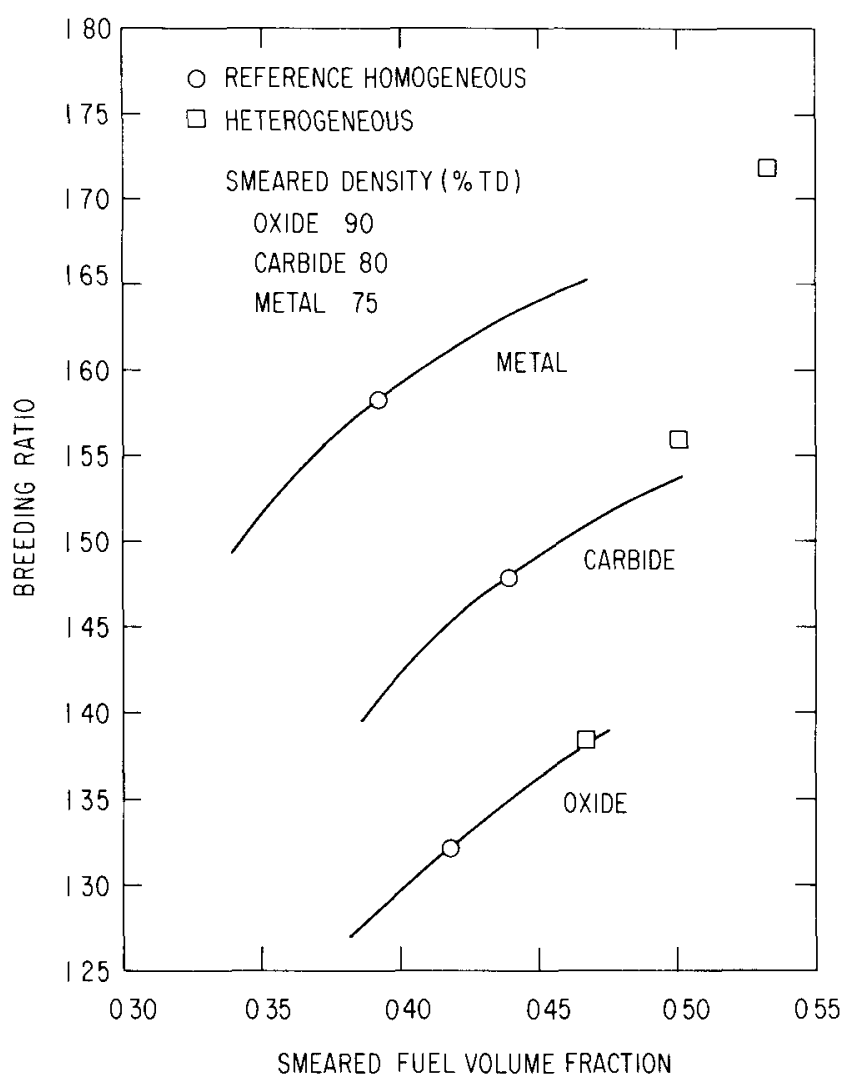

Fig. 13.

Breeding Ratio as a Function of Fuel Volume Fraction of Various Fuel Types. breeding ratio penalty for the thorium blanket is that the breeding ratio is primarily dictated by the n-value of fissile isotopes, which depends only on the core fissile material, and by the fertile fission bonus, which is largely determined by the core fertile material. (For the reference $\mathrm{Pu} / \mathrm{U}$ cycle, only about $15 \%$ of the total fertile fission bonus is contributed by the blanket fertile material.) These breeding characteristics are set by the choice of the core fuel.

For carbide cores the breeding ratio penalty for thorium blankets is somewhat greater than for oxide and the penalty is further increased for metal cores. This is because the thorium densities for carbide and metal fuels, but particularly for metal, are considerably less than the corresponding uranium fuel densities, resulting in a further reduction in the blanket fertile fissions and an enhanced neutron leakage.

The situation for all fuels worsens rapidly when thorium is introduced into the core itself.

Even if plutonium fueling is maintained, if thorium is used as the core fertile material, the breeding ratio penalty is substantial. As shown in Tables IXa-c, the main reason for the reduced breeding ratio of the $\mathrm{Pu} / \mathrm{Th}$ cycle is the reduction of the fertile fission bonus. The heavy penalty in the fertile fission bonus is slightly offset by an increased $n$-value of fissile isotopes, due to a hardened spectrum, and a reduced parasitic absorption loss. However, the effect of the drop in fertile fission dominates and the breeding ratio for the $\mathrm{Pu} / \mathrm{Th}$ cycle is reduced by 14 points for oxide fuel and 28 points for metal.

Also shown in Tables IXa-c are the breeding ratio components for the $233_{\mathrm{U}} / \mathrm{Th}$ cycle. When $233_{\mathrm{U}}$ is substituted for plutonium in addition to the fertile substitution of thorium, the $n$-value is decreased and there is additional decrease in the fertile fissions (due to the absence of the ${ }^{240} \mathrm{Pu}$ and $\left.{ }^{242} \mathrm{Pu}\right)$. The breeding ratios for all fuel types are reduced to the range of 1.1 . 
TABLE IXa. Comparison of Breeding Ratio Components between $\mathrm{Pu} / \mathrm{U}, \mathrm{Pu} / \mathrm{Th}$ and $233_{\mathrm{U}} / \mathrm{Th}$ Cycles (a) Oxide Fueled L.MFBR

\begin{tabular}{|c|c|c|c|}
\hline & $\mathrm{Pu} / \mathrm{U}$ & $\mathrm{Pu} / \mathrm{Th}$ & $2{ }^{33} \mathrm{U} / \mathrm{Th}$ \\
\hline$n$ of Fissile Isotopes & 2.283 & 2.299 & 2.269 \\
\hline Fertile Fission Bonus, $\varepsilon$ & 0.356 & 0.140 & 0.083 \\
\hline \multicolumn{4}{|l|}{ Total Excess Neutrons } \\
\hline$\eta-1+\varepsilon$ & 1.639 & 1.439 & 1.352 \\
\hline \multicolumn{4}{|l|}{ Neutron Losses } \\
\hline $\begin{array}{l}\text { Structure } \\
\text { Fission Products } \\
\text { Coolant } \\
0, \mathrm{C} \text {, or } \mathrm{Zr}\end{array}$ & $\begin{array}{l}0.158 \\
0.055 \\
0.010 \\
0.008 \\
\end{array}$ & $\begin{array}{l}0.139 \\
0.044 \\
0.009 \\
0.007 \\
\end{array}$ & $\begin{array}{l}0.115 \\
0.028 \\
0.008 \\
0.006 \\
\end{array}$ \\
\hline Total Absorption Loss & 0.231 & 0.199 & 0.157 \\
\hline Leakage Loss & 0.046 & 0.043 & 0.041 \\
\hline Pu-241 Decay Loss & 0.031 & 0.029 & 0 \\
\hline Total Loss & 0.308 & 0.271 & 0.198 \\
\hline Net Neutrons for Breeding & 1.331 & 1.168 & 1.154 \\
\hline $\begin{array}{l}\text { Actual Integrated BR from } \\
\text { Depletion Calculation }\end{array}$ & 1.325 & 1.184 & 1.099 \\
\hline
\end{tabular}

TABLE IXb. Comparison of Breeding Ratio Components between $\mathrm{Pu} / \mathrm{U}, \mathrm{Pu} / \mathrm{Th}$ and $2{ }^{3} \mathrm{U} / \mathrm{Th}$ Cycles (b) Carbide Fueled LMFBR

\begin{tabular}{|c|c|c|c|}
\hline & $\mathrm{Pu} / \mathrm{U}$ & $\mathrm{Pu} / \mathrm{Th}$ & ${ }^{23}{ }^{3} \mathrm{U} / \mathrm{Th}$ \\
\hline$n$ of Fissile Isotopes & 2.353 & 2.335 & 2.275 \\
\hline Fertile Fission Bonus, $E$ & 0.429 & 0.152 & 0.093 \\
\hline $\begin{array}{l}\text { Total Excess Neutrons } \\
\qquad \eta-1+\varepsilon\end{array}$ & 1.782 & 1.487 & 1.368 \\
\hline \multicolumn{4}{|l|}{ Neutron Losses } \\
\hline $\begin{array}{l}\text { Structure } \\
\text { Fission Products } \\
\text { Coolant } \\
0, \mathrm{C} \text {, or } \mathrm{Zr}\end{array}$ & $\begin{array}{l}0.131 \\
0.058 \\
0.009 \\
0.001 \\
\end{array}$ & $\begin{array}{l}0.120 \\
0.047 \\
0.008 \\
0.001 \\
\end{array}$ & $\begin{array}{l}0.106 \\
0.029 \\
0.007 \\
0.001 \\
\end{array}$ \\
\hline Total Absorption Loss & 0.199 & 0.176 & 0.143 \\
\hline Leakage Loss & 0.051 & 0.065 & 0.059 \\
\hline Pu-241 Decay Loss & 0.029 & 0.025 & 0 \\
\hline Total Loss & 0.279 & 0.266 & 0.202 \\
\hline Net Neutrons for Breeding & 1.503 & 1.221 & 1.166 \\
\hline $\begin{array}{l}\text { Actual Integrated BR from } \\
\text { Depletion Calculation }\end{array}$ & 1.479 & 1.223 & 1.114 \\
\hline
\end{tabular}


TABLE IXC. Comparison of Breeding Ratio Components between

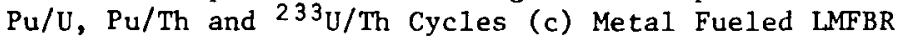

\begin{tabular}{|c|c|c|c|}
\hline & $\mathrm{Pu} / \mathrm{U}$ & $\mathrm{Pu} / \mathrm{Th}$ & $2{ }^{3} 3 \mathrm{U} / \mathrm{Th}$ \\
\hline$\eta$ of Fissile Isotopes & 2.450 & 2.425 & 2.293 \\
\hline Fertile Fission Bonus, $\varepsilon$ & 0.509 & 0.164 & 0.103 \\
\hline $\begin{array}{l}\text { Total Excess Neutrons } \\
\qquad-1+\varepsilon\end{array}$ & 1.959 & 1.589 & 1.396 \\
\hline \multicolumn{4}{|l|}{ Neutron Losses } \\
\hline $\begin{array}{l}\text { Structure } \\
\text { Fission Products } \\
\text { Coolant } \\
0, \mathrm{C} \text {, or } \mathrm{Zr}\end{array}$ & $\begin{array}{l}0.127 \\
0.058 \\
0.008 \\
0.025 \\
\end{array}$ & $\begin{array}{l}0.111 \\
0.037 \\
0.006 \\
0 \\
\end{array}$ & $\begin{array}{l}0.098 \\
0.023 \\
0.006 \\
0 \\
\end{array}$ \\
\hline Total Absorption Loss & 0.218 & 0.154 & 0.127 \\
\hline Leakage Loss & 0.082 & 0.109 & 0.103 \\
\hline Pu-241 Decay Loss & 0.032 & 0.028 & 0 \\
\hline Total Loss & 0.332 & 0.291 & 0.230 \\
\hline Net Neutrons for Breeding & 1.627 & 1.298 & 1.166 \\
\hline $\begin{array}{l}\text { Actual Integrated BR from } \\
\text { Depletion Calculation }\end{array}$ & 1.582 & 1.301 & 1.115 \\
\hline
\end{tabular}

For the $233^{\mathrm{U}} / \mathrm{U}$

cycle (denatured fresh fuel), the breeding performance is much better than for the $\mathrm{Pu} / \mathrm{Th}$ cycle. In fact, the breeding ratio for the $233 \mathrm{U} / \mathrm{U}$ cycle is about ha1f-way between the reference $\mathrm{Pu} / \mathrm{U}$ cycle and the Pu/Th cycle. The reason is due to the fast fission contribution of ${ }^{238} \mathrm{U}$ and the improved n-value due to the buildup of $239 \mathrm{Pu}$. At equilibrium cycle discharge, the buildup of $239 \mathrm{Pu}$ is about $30 \%$ of the total fissile mass.

3. Breeding Performance of Heterogeneous Cores: As shown in Table VI the breeding ratio for the heterogeneous design is higher than that for the homo-

geneous design. This is because the heavy metal volume fraction in the core region is effectively increased by the inclusion of internal blanket assemblies with high heavy metal volume fraction.

The relationship between the breeding ratio and the effective core fuel volume fraction is similar for both homogeneous and heterogeneous designs. This is illustrated in Fig. 13. If we compare a homogeneous and a tightlycoupled heterogeneous design on the basis of effective core fuel volume fraction, the breeding performance is about the same. Slight deviations occur, as shown in Fig. 13, because of different structure/coolant volume ratio and design assumptions. Of course, if the fuel volume fraction is increased beyond an optimum value, the doubling time will increase once again.

In Table $\mathrm{X}$, the breeding ratio components for heterogeneous designs are presented. Comparing them to the reference homogeneous designs presented in Table VIII we note that the breeding ratio improvement results from the combined effect of an increased number of excess neutrons and reduced absorption losses. As mentioned above, the same effect will be true of the homogeneous design if a similar high fuel volume fraction design is used.

For the heterogeneous designs with thorium blankets, the breeding performance is degraded from the uranium blanket cases because of the reduced fertile fission effect. 
4. Breeding Performance of GCFR Fuel Cycles: The breeding ratio components for the GCFR fuel cycles are presented in Table XI. The differences in the neutronic characteristics between the oxide fueled LMFBR and the GCFR,

TABLE X. Breeding Ratio Components for Heterogeneous LMFBRs

\begin{tabular}{|c|c|c|c|c|c|c|}
\hline & \multicolumn{3}{|c|}{$\mathrm{Pu} / \mathrm{U}$ Core, U Blanket } & \multicolumn{3}{|c|}{ Pu/U Core, Th Blanket } \\
\hline & Oxide & Carbide & Meta1 & Oxide & Carbide & Metal \\
\hline$\eta$ of Fissile Isotopes & 2.310 & 2.362 & 2.494 & 2.332 & 2.405 & 2.501 \\
\hline Fertile Fission Bonus, $\varepsilon$ & 0.371 & 0.446 & 0.499 & 0.274 & 0.324 & 0.315 \\
\hline $\begin{array}{l}\text { Total Excess Neutrons } \\
\qquad \begin{array}{l}\eta-1+\varepsilon\end{array}\end{array}$ & 1.681 & 1.808 & 1.993 & 1.606 & 1. 729 & 1.816 \\
\hline \multicolumn{7}{|l|}{ Neutron Losses } \\
\hline $\begin{array}{l}\text { Structure } \\
\text { Fission Products } \\
\text { Coolant } \\
0, \mathrm{C} \text {, or } \mathrm{Zr}\end{array}$ & $\begin{array}{l}0.146 \\
0.041 \\
0.009 \\
0.008 \\
\end{array}$ & $\begin{array}{l}0.119 \\
0.039 \\
0.007 \\
0.001 \\
\end{array}$ & $\begin{array}{l}0.104 \\
0.032 \\
0.006 \\
0.014 \\
\end{array}$ & $\begin{array}{l}0.141 \\
0.038 \\
0.008 \\
0.008 \\
\end{array}$ & $\begin{array}{l}0.117 \\
0.033 \\
0.097 \\
0.001 \\
\end{array}$ & $\begin{array}{l}0.109 \\
0.027 \\
0.006 \\
0.012 \\
\end{array}$ \\
\hline Total Absorption Loss & 0.204 & 0.166 & 0.156 & 0.195 & 0.158 & 0.154 \\
\hline Leakage Loss & 0.049 & 0.046 & 0.078 & 0.047 & 0.060 & 0.104 \\
\hline Pu-241 Decay Loss & 0.042 & 0.047 & 0.051 & 0.040 & 0.046 & 0.044 \\
\hline Total Loss & 0.295 & 0.259 & 0.286 & 0.282 & 0.264 & 0.302 \\
\hline Net Neutrons for Breeding & 1.386 & 1.549 & 1.708 & 1.324 & 1.465 & 1.514 \\
\hline $\begin{array}{l}\text { Actual Integrated BR from } \\
\text { Depletion Calculation }\end{array}$ & 1.382 & 1.561 & 1.718 & 1.331 & 1.479 & 1.485 \\
\hline
\end{tabular}

derived from the change in coolant type, are due to a harder GCFR spectrum caused by the absence of sodium moderation. However, because of the heat transfer characteristics of helium cooling, GCFR designs can not easily achieve fuel volume fractions as high as those of LMFBR designs. Thus for feasible design ranges the neutron energy spectrum of the GCFR is intermediate between the oxide and carbide fueled LMFBR spectra, but much closer to the oxide LMFBR spectrum.

The breeding ratio components presented in Table XI for the GCFR fuel cycles are very similar to those of corresponding oxide fueled LMFBR fuel cycles presented in Table IXa. The neutron excess is slightly higher for the GCFR, and this is partially offset by increased losses. The net effect is that the breeding ratio is somewhat higher for the GCFR than for the oxidefueled LMFBR, but the fissile inventory is higher as well, resulting in a longer doubling time. 
5. Safety-Related Physics Parameters: The sodium void reactivity and the Doppler coefficient are compared in Table XII for various fuel types and fuel cycle options. The effective delayed neutron fractions are tabulated in Table XIII.

TABLE XI. Breeding Ratio Components for GCFR Fuel Cycles

\begin{tabular}{|c|c|c|c|}
\hline & $\mathrm{Pu} / \mathrm{U}$ & $\mathrm{Pu} / \mathrm{Th}$ & $233 \mathrm{U} / \mathrm{Th}$ \\
\hline$n$ of Fissile Isotopes & 2.353 & 2.385 & 2.287 \\
\hline Fertile Fission Bonus, E & 0.368 & 0.144 & 0.093 \\
\hline Total Excess Neutrons & & & \\
\hline$\eta-1+\varepsilon$ & 1.721 & 1.529 & 1.380 \\
\hline \multicolumn{4}{|l|}{ Neutron Losses } \\
\hline Structure & 0.152 & 0.134 & 0.117 \\
\hline Fission Products & 0.038 & 0.029 & 0.018 \\
\hline Coolant & 0.000 & 0.000 & 0.000 \\
\hline $0, \mathrm{C}$, or $\mathrm{Zr}$ & 0.007 & 0.006 & 0.005 \\
\hline Total Absorption Loss & 0.197 & 0.169 & 0.140 \\
\hline Leakage Loss & 0.095 & 0.093 & 0.083 \\
\hline Pu-241 Decay Loss & 0.041 & 0.038 & 0 \\
\hline Total Loss & 0.333 & 0.300 & 0.223 \\
\hline Net Neutrons for Breeding & 1.388 & 1.229 & 1.157 \\
\hline $\begin{array}{c}\text { Actual Integrated BR from } \\
\text { Depletion Calculation }\end{array}$ & 1.382 & 1.238 & 1.109 \\
\hline
\end{tabular}

For the $\mathrm{Pu} / \mathrm{U}$ core, the sodium void reactivity effect and the Doppler coefficient are about the same for the oxide and carbide fuels. However, the metal fuel has a significantly higher void reactivity and a lower Doppler coefficient.

For the heterogeneous cores the sodium void reactivity is reduced to less than half of that for the corresponding homogeneous designs. In the U.S. this characteristic is generally felt to be the main rationale for considering heterogeneous design concepts.

For thorium-based fue 1 cycles, the sodium void reactivity is sharply reduced. For the $\mathrm{Pu} / \mathrm{Th}$ core, the void reactivity is reduced by $30-40 \%$. For $233 \mathrm{U} / \mathrm{Th}$ cores, for all fuel types, the sodium void reactivity becomes slightly negative.

The sodium void reactivities presented in Table XII were calculated for the end-of-equilibrium

cycle condition. Only the flowing sodium in the core and axial blanket regions was voided. If all sodium in the core and axial blanket regions were voided, the reactivity worth would increase by $20-25 \%$. For the heterogeneous core, the sodium in the internal blanket region was not voided. The void reactivity increases by about $50 \%$ if the internal blanket region is voided as we11.

\section{SENSITIVITIES AND RANGES OF BREEDING PERFORMANCE}

In the previous section the breeding performance characteristics for "reference" designs were compared. In this section, we will examine the sensitivities of the performance characteristics to design variations that may be necessary for conservatism or for other reasons.

\section{A. Oxide Fuel}

The oxide fuel design for the CRBR incorporates a small pin size ( 0.23 in. 0. d. and 15-mil cladding thickness), mainly because of the extensive irradiation data base for such pins obtained in support of both FTR and CRBR designs. However, the breeding performance associated with the small pin 
design is rather poor. In Table XIV we compare the performance characteristics of oxide designs ranging from the CRBR-type to advanced designs.

TABLE XII. Summary of Safety-Related Physics Parameters

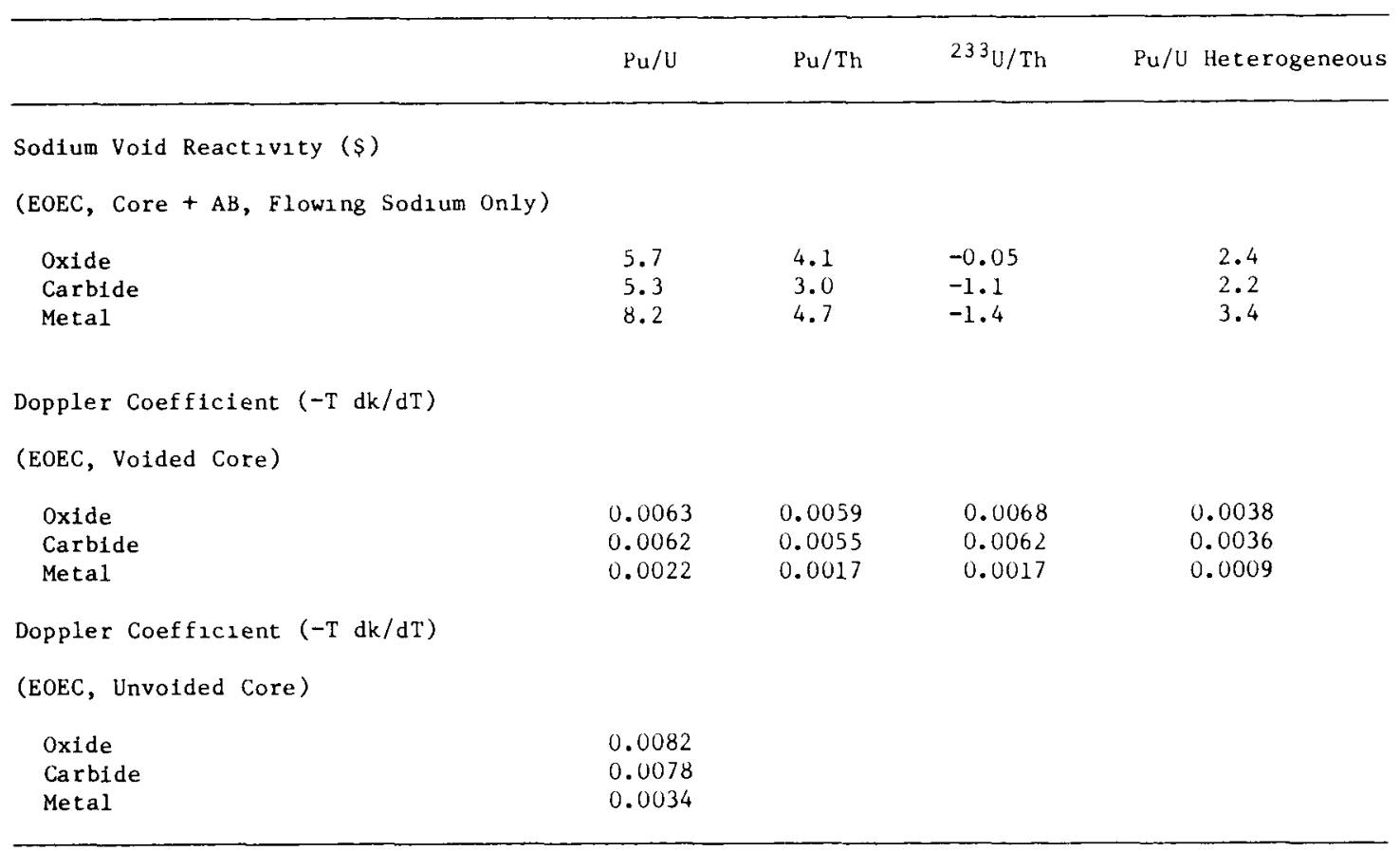

TABLE XIII. Delayed Neutron Fraction

\begin{tabular}{lllll} 
& $\mathrm{Pu} / \mathrm{U}$ & $\mathrm{Pu} / \mathrm{Th}$ & $233_{\mathrm{U} / \mathrm{Th}}$ & $\begin{array}{c}\text { Pu/J } \\
\text { Heterogeneous }\end{array}$ \\
\hline Oxide & 0.00362 & 0.00298 & 0.00337 & 0.00364 \\
Carbide & 0.00375 & 0.00302 & 0.00340 & \\
Metal & 0.00378 & 0.00306 & 0.00341 & 0.00391 \\
\hline
\end{tabular}

TABLE XIV. Ranges of Oxide Fuel Performance

\begin{tabular}{|c|c|c|c|c|c|c|c|}
\hline & & $\mathrm{BR}$ & CSDT, Yrs. & $\begin{array}{l}\text { IC Inventory } \\
\mathrm{kg} / \mathrm{GWe}\end{array}$ & $\begin{array}{l}\text { Net Ga1n } \\
\mathrm{kg} / \text { GWe-yr }\end{array}$ & $\begin{array}{l}\text { Sodium Void } \\
\text { Reactivity, } \$\end{array}$ & $\begin{array}{l}\text { Doppler } \\
-\mathrm{Tdk} / \mathrm{dT}\end{array}$ \\
\hline 1. & $\begin{array}{l}\text { CRBR-type } \\
0.23 \text { in. P2n o.d. }\end{array}$ & 1.12 & 72.8 & 3130 & 103 & 3.7 & 0.0045 \\
\hline 2. & Extrapolate CRBR-type to $1000 \mathrm{MWE}$ & 1.16 & 36.6 & 2910 & 144 & 6.0 & 0.0055 \\
\hline \multicolumn{8}{|c|}{ 3. Moderate Design Improvements } \\
\hline & $\begin{array}{ll}\text { Cladding Thickness } & 15 \rightarrow 12 \mathrm{~m} 1 \mathrm{ls} \\
\text { Linear Power } & 11+12 \mathrm{~kW} / \mathrm{ft} \\
\text { Smeared Density } & 86+90 \% \mathrm{~T} . \mathrm{D} .\end{array}$ & 1.21 & 23.7 & 2680 & 184 & 6.2 & 0.0054 \\
\hline \multicolumn{8}{|c|}{ 4. Further Improvements } \\
\hline & $\begin{array}{ll}\text { Linear Power } & 12 \rightarrow 14 \mathrm{~kW} / \mathrm{ft} \\
\text { Pin } 0 . d . & 0.23 \rightarrow 0.29 \mathrm{in} .\end{array}$ & 1.33 & 17.3 & 3140 & 275 & 5.7 & 0.0063 \\
\hline 5. & Heterogeneous Core Design & 1.38 & 18.7 & 3910 & 319 & 2.4 & 0.0038 \\
\hline
\end{tabular}


A calculation of the CRBR-type design using the same definitions and neutronics analysis methodology applied to the designs discussed in this report yields a breeding ratio of 1.12 , and a very long doubling time $(>70$ years). Such calculations permit a consistent comparison of the CRBR-type design with the reference oxide design data reported above, but may not represent the actual performance characteristics of the CRBR. The treatment is consistent from design-to-design so the numbers in this report should represent good figures-of-merit. If the CRBR-type design is increased to a 1000 MWe size, still using the same fuel design, the breeding ratio is increased by about 4 points. Note also from Table XIV that the sodium void reactivity is increased as the reactor size is increased.

As illustrated in Fig. 13, the breeding performance is improved for higher fuel volume fraction designs. This can be achieved by incorporating larger pin size (in the range of $0.29-0.31$ in. o.d.), thinner cladding, and increased fuel smear density. High linear heat rating also helps to reduce the doubling time. As shown in Table XIV, for moderate improvements in these parameters, a breeding ratio of 1.21 is achieved and with further improvements the breeding ratio is increased to 1.33. These two cases will be used as characteristics of boundary performances for oxide designs in the systems studies presented in the companion report.1 The former represents a "current" oxide design which could be considered feasible without further developmental effort. The latter case is asumed here to represent developmental oxide fuel performance, and fuels corresponding to these conditions are currently being irradiated with promising results. The performance characteristics in this range are representative of the oxide design types.

For comparison purposes, the heterogeneous design using the improved oxide design is also compared in Table XIV. The breeding ratio is increased for the heterogeneous design, but the doubling time is increased too.

The issues associated with oxide fuel breeding performance are not in its technical feasibility. There has been enough irradiation experience accumulated to date to support viable design and a reasonable breeding performance. However, the breeding potential for the oxide fuel is intrinsically inferior to other advanced fuels, and to substantially improve the breeding performance with oxide fuels, it is necessary to push designs to the limit.

\section{B. Carbide Fue1}

The "reference" carbide performance characteristics presented in the previous section were based on a sodium-bonded design. For the sodium-bonded carbide, a 15-mil cladding thickness was assumed because the fuel-clad gap was sized such that the fuel does not contact the cladding until the end of the fuel life.

For the helium-bonded carbide design, (with the same smear density assumed) the fuel swelling is greater than in the sodium-bonded design because of the higher fuel temperature. Furthermore, the fuel-clad gap is minimized to improve the gap conductance. Therefore, fuel-cladding mechanical interaction is inevitable and the fuel swelling must be restrained by the cladding. This would require a thicker cladding. As shown in Table XV if a 20-mil cladding is used for the helium-bonded carbide instead of a 15-mil cladding 
for the sodium-bonded carbide, the breeding ratio is reduced by 5 points and the doubling time is increased from 10 years to 11 years. In addition to the thicker cladding, if the fuel pin pitch-to-diameter ratio is increased from 1.18 to 1.23 because of bundle-duct interaction considerations, the breeding ratio is reduced by an additional 2 points and the doubling time is increased to 12.5 years.

TABLE XV. Ranges of Carbide Fuel Performance

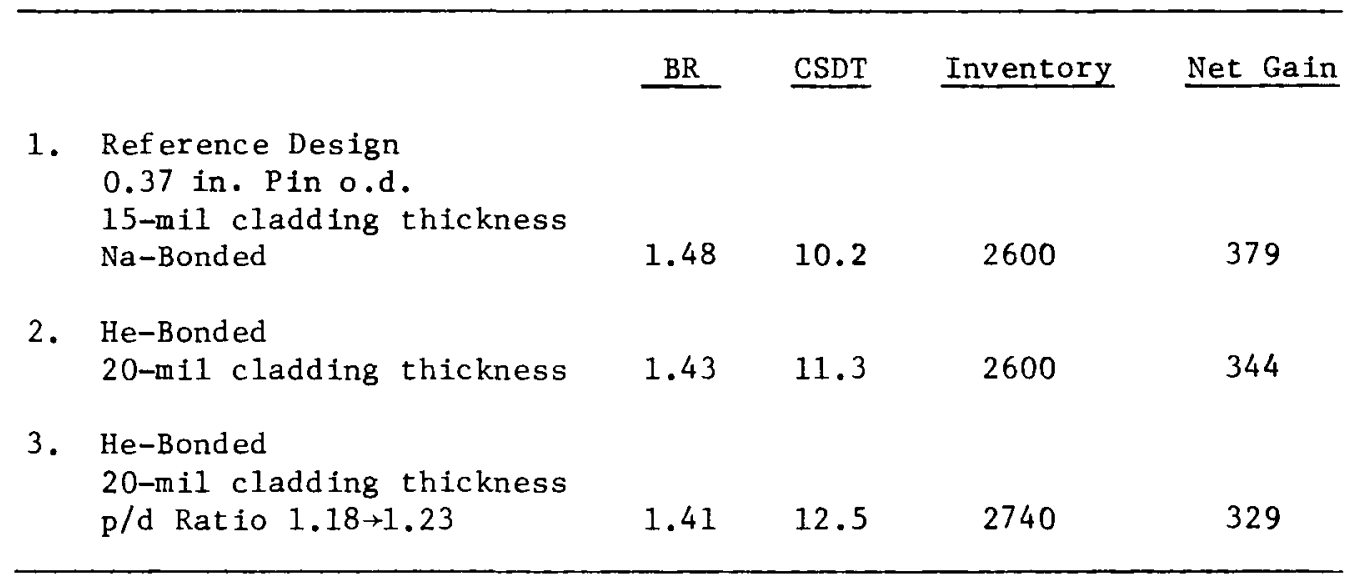

Even though carbide fuel development has been more actively pursued in recent years, the irradiation data base is rather sparse and additional work is required to bring the carbide fuel to a stage of development equivalent to the oxide fuel. Nevertheless, the incentive for development is there, for if carbide fuel can be satisfactorily developed, the expected breeding performance characteristirs should be in the range presented in Table XV.

\section{Metal Fuel}

Although metal fuel was used in the early experimental breeder reactors and is still used in EBR-II, metal fuel development efforts were discontinued in favor of the oxide and carbide fuel development. The main reason for this was that evolving objectives in fast breeder fuel development, in particular high burnup capability and high sodium outlet temperature were not expected to be met by the metal fuel.

In the meantime, however, the metal fuel in the EBR-II driver fuel has demonstrated a high burnup capability, in excess of $10 \%$ burnup, and the LMFBR design goal for the sodium outlet temperature has been reduced from the $1100-1200^{\circ} \mathrm{F}$ range to the $875-930^{\circ} \mathrm{F}$ range. The success experienced by the EBR-II Mark-II driver fuel and associated irradiation tests suggest that metal fuel could potentially be developed as a viable fast breeder fuel satisfying current FBR design objectives. More importantly though, metal fuel inherently has the highest breeding performance potential of all candidate fast breeder fuel types. The implications for the INFCE considerations of the superior breeding potential of metal fuel is that it may provide more flexibility in fast breeder deployment options under various non-proliferation constraints than other fuel types. This aspect is covered in a companion report. 1 
As pointed out in the report on fuels status ${ }^{2}$ however, the irradiation data base is weakest for the metal fuel. There is very little data on plutonium-containing alloys, of the type required for reference design analysis prototypic of commercial application. Thus much greater uncertainties must be assigned to the technical feasibility of such metal fuels than are present for either oxide or carbide fuel.

As shown in Table XVI the impact of the design changes on the breeding ratio is similar to other fuel types. However, the doubling time is not affected much, whereas for low-breeding-gain designs the impact of the design conservatism on the doubling time is very significant.

TABLE XVI. Ranges of Metal Fuel Performance

\begin{tabular}{llccc}
\hline & BR & CSDT & Inventory & Net Gain \\
\hline $\begin{array}{l}\text { 1. Reference Design } \\
\begin{array}{l}0.31 \text { in. Pin } \\
15-\text { mil Cladding }\end{array}\end{array}$ & 1.58 & 8.6 & 2470 & 435 \\
$\begin{array}{l}\text { 2. Increase Cladding Thickness } \\
15 \rightarrow 19 \text { mils }\end{array}$ & 1.53 & 9.3 & 2470 & 405 \\
$\begin{array}{l}\text { Increase Cladding Thickness } \\
15 \rightarrow 19 \text { mils } \\
\text { Reduce Outlet Temperature } \\
930 \rightarrow 875^{\circ} \mathrm{F}\end{array}$ & 1.55 & 8.8 & 2560 & 443 \\
\hline
\end{tabular}

The sodium outlet temperature is an important parameter for the metal fuel design, because of fuel-cladding eutectic considerations and the sensitivity of fuel-clad metallurgical interaction to the cladding temperature. The reference outlet temperature of $930^{\circ} \mathrm{F}$ assumed for this study appears to be acceptable for the metal fuel based on the correlation data developed for the $\mathrm{CDF}$ analysis. It is interesting to note from Table XVI that if the sodium outlet temperature is reduced from 930 to $875^{\circ} \mathrm{F}$ for conservatism, the breeding performance actually improves. Of course, the penalty associated with the low outlet temperature is felt in the reduced thermal efficiency of the plant.

In Fig. 14, the effect of the cladding thickness to pin diameter ratio on the breeding performance is illustrated for a range of fuel volume fractions.

D. Alternative Fuel Cycles

There are still greater uncertainties in the performance characteristics of the thorium-based alternative cycles than for the reference $\mathrm{Pu} / \mathrm{U}$ cycle. First, the irradiation performance data base for the thorium-based fuel types under fast reactor conditions is almost non-existent. ${ }^{2}$ Secondly, the nuclear cross section data for the thorium chain isotopes in a fast spectrum are considerably more uncertain. 
For the performance characteristics presented in Section III, we have assumed the same mechanical design features for the alternative cycles as for the reference $\mathrm{Pu} / \mathrm{U}$ cycle. The reference fuel pin design provides a minimum, or near-minimum, doubling time

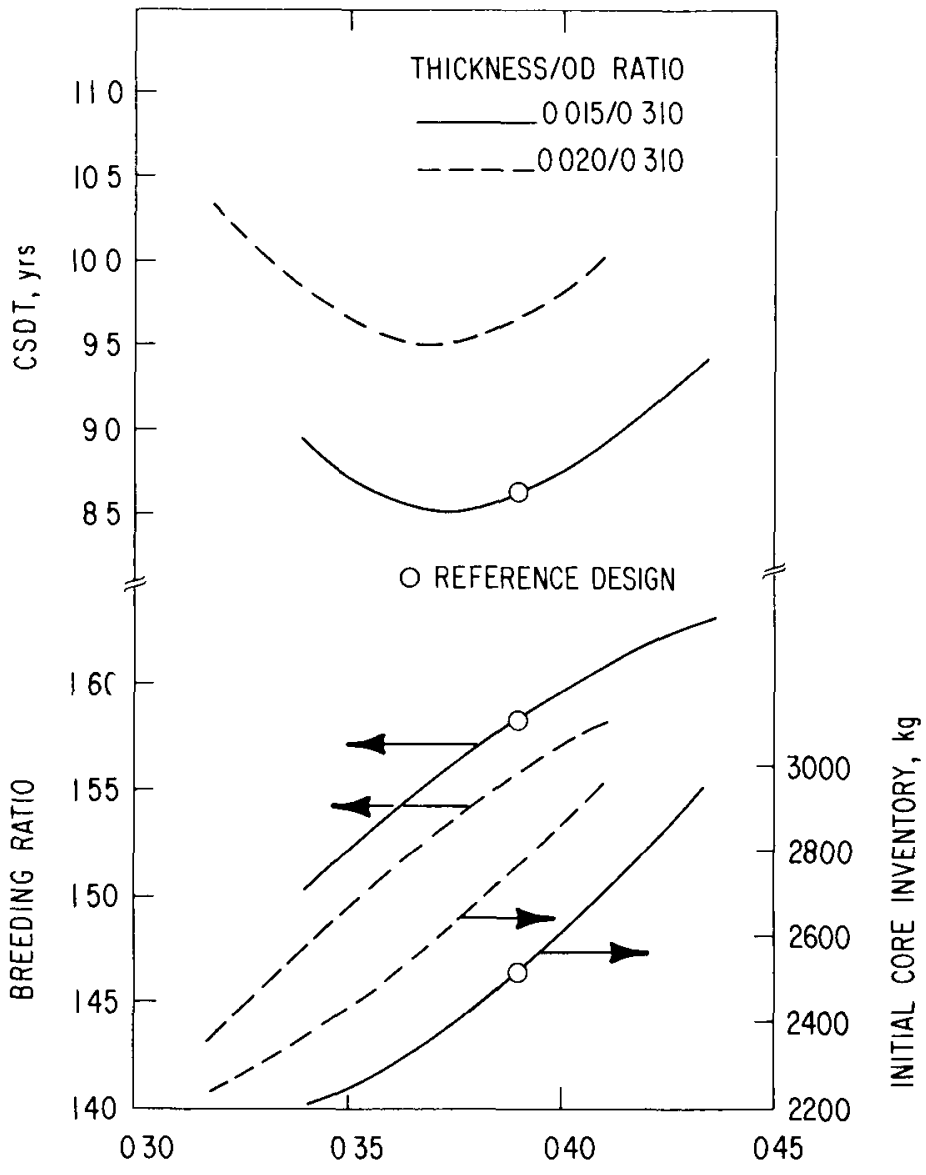

SMEARED FUEL VOLUME FRACTION

Fig. 14 .

Effect of Cladding Thickness/o.d. Ratio on Breeding Performance. for the $\mathrm{Pu} / \mathrm{U}$ cycle. However, the same design does not necessarily result in an optinum doubling time for the alternative cycles. The fuel design for alternative cycles could be reoptimized to improve the performance in particular applications. The doubling time per se is not a unique performance index for various alternative cycles. This aspect will be discussed in the remainder of this section. The tradeoffs between performance indices and considerations involved for each specific fuel cycle option are discussed. (The systems study results presented in Ref. 1 can be consulted for tradeoffs involved with symbiotic systems.)

The breeding performance characteristics for metal fuel presented in Table XVII will be used as an illustration. In Table XVII three alternative fuel pin designs are compared for each fuel cycle option: the reference design used in Section III, a low inventory design, and a high breeding design.

\section{Reference Pu/U Cycle:}

In this cycle option the doubling time is often adopted and is a reasonable performance index for optimization.

2. $\mathrm{Pu} / \mathrm{u}$ Core with Thorium Radial Blanket Only: On the surface, it appears that a high breeding design isdesirable to enhance the ${ }^{23} \mathrm{U}$ production for the symbiotic system application. However, the high breeding is achieved by increasing the core conversion, which enhances the plutonium breeding and reduces the $233 \mathrm{U}$ production. Because the core fueling mode is identical to the $\mathrm{Pu} / \mathrm{U}$ cycle, it is most likely that the optimum core design for the $\mathrm{Pu} / \mathrm{U}$ cycle still remains the optimum design for the thorium blanket case as well. 
TABLE XVII. Specific Inventory vs. Breeding Ratio for Metal Fuel

\begin{tabular}{|c|c|c|c|c|}
\hline & & $\begin{array}{l}\text { Low } \\
\text { Inventory }\end{array}$ & $\begin{array}{l}\text { Reference } \\
\text { Case }\end{array}$ & $\begin{array}{l}\text { High } \\
\text { Breeding }\end{array}$ \\
\hline & Pin o.d. & 0.27 & 0.31 & 0.35 \\
\hline & Fuel Volume Fraction & 0.3403 & 0.3897 & 0.4326 \\
\hline \multirow{5}{*}{ 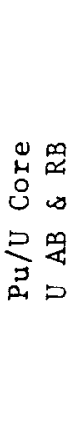 } & $\begin{array}{l}\text { Initial Core Inventory } \\
\text { U-235 } \\
\text { Fis. } \mathrm{Pu}\end{array}$ & $\begin{array}{r}192 \\
2172\end{array}$ & $\begin{array}{r}238 \\
2476\end{array}$ & $\begin{array}{r}290 \\
2891\end{array}$ \\
\hline & $\begin{array}{l}\text { Annual Net Gain } \\
\text { U-233 } \\
\text { U-235 } \\
\text { Fis. Pu }\end{array}$ & $\begin{array}{c}0 \\
-16 \\
378 \\
\end{array}$ & $\begin{array}{r}0 \\
-17 \\
435 \\
\end{array}$ & $\begin{array}{r}0 \\
-18 \\
464 \\
\end{array}$ \\
\hline & Tota 1 & 362 & 418 & 446 \\
\hline & $\operatorname{CSDT}$ & 8.9 & 8.6 & 9.3 \\
\hline & Breeding Ratio & 1.497 & 1.582 & 1.626 \\
\hline \multirow{5}{*}{ 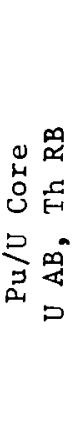 } & $\begin{array}{l}\text { Initial Core Inventory } \\
\text { U-235 } \\
\text { Fis. } \mathrm{Pu}\end{array}$ & $\begin{array}{r}74 \\
2217\end{array}$ & $\begin{array}{r}98 \\
2501\end{array}$ & $\begin{array}{r}126 \\
2914\end{array}$ \\
\hline & $\begin{array}{l}\text { Annual Net Gain } \\
\mathrm{U}-233 \\
\mathrm{U}-235 \\
\text { Fis. } \mathrm{Pu}\end{array}$ & $\begin{array}{r}185 \\
-12 \\
128 \\
\end{array}$ & $\begin{array}{r}175 \\
-13 \\
212 \\
\end{array}$ & $\begin{array}{r}161 \\
-14 \\
263 \\
\end{array}$ \\
\hline & Total & 301 & 374 & 410 \\
\hline & CSDT & 10.3 & 9.3 & 9.8 \\
\hline & Breeding Ratio & 1.413 & 1.519 & 1.573 \\
\hline \multirow{5}{*}{ 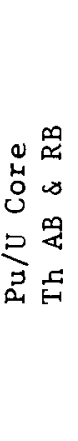 } & $\begin{array}{l}\text { Initial Core Inventory } \\
\text { U-235 } \\
\text { Fis. Pu }\end{array}$ & $\begin{array}{r}31 \\
2241\end{array}$ & $\begin{array}{r}42 \\
2515\end{array}$ & $\begin{array}{r}54 \\
2930\end{array}$ \\
\hline & $\begin{array}{l}\text { Annual Net Gain } \\
\mathrm{U}-233 \\
\mathrm{U}-235 \\
\text { Fis. Pu }\end{array}$ & $\begin{array}{r}361 \\
-7 \\
-104 \\
\end{array}$ & $\begin{array}{r}365 \\
-8 \\
-28 \\
\end{array}$ & $\begin{array}{r}356 \\
-10 \\
20 \\
\end{array}$ \\
\hline & Total & 250 & 329 & 366 \\
\hline & CSDT & 12.5 & 10.5 & 10.8 \\
\hline & Breeding Ratio & 1.346 & 1.459 & 1.516 \\
\hline \multirow{5}{*}{ 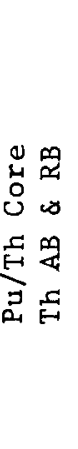 } & $\begin{array}{l}\text { Initial Core Inventory } \\
\text { U-235 } \\
\text { Fis. Pu }\end{array}$ & $\begin{array}{r}0 \\
2675\end{array}$ & $\begin{array}{r}0 \\
3064\end{array}$ & $\begin{array}{r}0 \\
3533\end{array}$ \\
\hline & $\begin{array}{l}\text { Annual Net Gain } \\
\text { U-233 } \\
\text { U-235 } \\
\text { Fis. } \mathrm{Pu}\end{array}$ & $\begin{array}{r}705 \\
1 \\
-554 \\
\end{array}$ & $\begin{array}{r}781 \\
1 \\
-567 \\
\end{array}$ & $\begin{array}{r}843 \\
1 \\
-585 \\
\end{array}$ \\
\hline & Total & 152 & 215 & 259 \\
\hline & CSDT & 26.3 & 20.3 & 19.0 \\
\hline & Breeding Ratio & 1.223 & 1.301 & 1.358 \\
\hline
\end{tabular}


TABLE XVII. (Cont'd)

\begin{tabular}{|c|c|c|c|c|}
\hline & & $\begin{array}{l}\text { Low } \\
\text { Inventory }\end{array}$ & $\begin{array}{l}\text { Reference } \\
\text { Case }\end{array}$ & $\begin{array}{l}\text { High } \\
\text { Breeding }\end{array}$ \\
\hline & Pin o.d. & 0.27 & 0.31 & 0.35 \\
\hline & Fuel Volume Fraction & 0.3403 & 0.3897 & 0.4326 \\
\hline \multirow{8}{*}{ 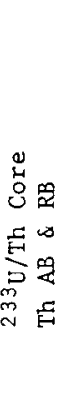 } & Initial Core Inventory & & & \\
\hline & $\begin{array}{l}\mathrm{U}-233 \\
\mathrm{U}-235\end{array}$ & $\begin{array}{r}2542 \\
102\end{array}$ & $\begin{array}{r}2893 \\
116\end{array}$ & $\begin{array}{r}3315 \\
133\end{array}$ \\
\hline & Annual Net Gain & & & \\
\hline & $\mathrm{U}-233$ & 29 & 79 & 113 \\
\hline & $\begin{array}{l}\text { U-235 } \\
\text { Fis. Pu }\end{array}$ & $\begin{array}{l}9 \\
0\end{array}$ & $\begin{array}{l}8 \\
0\end{array}$ & $\begin{array}{l}8 \\
0\end{array}$ \\
\hline & Total & 38 & 87 & 121 \\
\hline & $\operatorname{CSDT}$ & 273.4 & 60.2 & 45.0 \\
\hline & Breeding Ratio & 1.050 & 1.115 & 1.160 \\
\hline \multirow{9}{*}{ 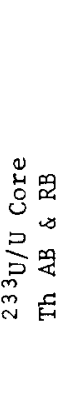 } & \multicolumn{4}{|l|}{ Initial Core Inventory } \\
\hline & $\begin{array}{l}\mathrm{U}-233 \\
\mathrm{U}-235\end{array}$ & $\begin{array}{r}2145 \\
86\end{array}$ & $\begin{array}{r}2443 \\
98\end{array}$ & $\begin{array}{r}2870 \\
116\end{array}$ \\
\hline & \multicolumn{4}{|l|}{ Annual Net Gain } \\
\hline & $\mathrm{U}-233$ & -185 & -193 & -216 \\
\hline & $\mathrm{U}-235$ & 7 & 7 & 7 \\
\hline & Fis. Pu & 439 & 514 & 568 \\
\hline & Total & 261 & 328 & 359 \\
\hline & CSDT & 11.3 & 10.1 & 10.7 \\
\hline & Breeding Ratio & 1.364 & 1.468 & 1.520 \\
\hline
\end{tabular}

3. Pu/U Core with Thorium Axial and Radial Blanket: Considerations for this cycle are qualitatively similar to the previous cycle option. This cycle is on the borderline between a net plutonium producer and a net consumer. Hence, one additional consideration, and probably an important one for optimizing this cycle, would be to maintain the self-sufficiency in plutonium supply by designing FBR to the particular systems application.

4. Pu/Th Core with Thorium Blanket: In this cycle option the plutonium is continuously burned in the fast breeder. Hence, for a fixed amount of external plutonium supplied, there is an incentive to maximize the breeding ratio, independent of the specific inventory requirements. However, since the breeding capability of the fast breeder is suppressed by the properties of thorium and since the breeding chain cannot be maintained, the impact of the improvement for this cycle option on the overall system is marginal (see Ref. 1).

5. $233 \mathrm{U} / \mathrm{Th}$ Core with Thorium Blanket: In this cycle option, the plutonium is not involved at all. The fueling is maintained by the bred $23{ }^{3} \mathrm{U}$. Hence, the cycle is a closed one and the doubling time again is a reasonable performance index for optimization, similar to the $\mathrm{Pu} / \mathrm{U}$ cycle. As shown in Table XVII, the doubling time is reduced for the high breeding design compared to the reference case. The doubling time may be further reduced if the fuel 
volume fraction is increased. The optimum fuel volume fraction for the $2{ }^{3} \mathrm{U} / \mathrm{Th}$ cycle is much higher than that for the Pu/U cycle. A lower doubling time for the ${ }^{23} \mathrm{U} / \mathrm{Th}$ cycle is achievable if the design is reoptimized. On the other hand, the initial fissile inventory requirements would increase too. Initial inventory startup considerations for the ${ }^{233} \mathrm{U} / \mathrm{Th}$ cycle differ somewhat from the $\mathrm{Pu} / \mathrm{U}$ cycle case. With the $\mathrm{Pu} / \mathrm{U}$ cycle, the initial startup of breeder economy is based on the plutonium discharged from LWRs. In the case of the $2{ }^{3} \mathrm{U} / \mathrm{Th}$ cycle, such initial fissile stockpile is not available, and a tradeoff will exist between the doubling time and initial inventory, whether ${ }^{23}{ }^{3} \mathrm{U}$ is supplied based on a symbiotic system or from other sources.

6. Heterogeneous Core with Thorium Blanket: It was pointed out in Section III that the breeding performance of the heterogeneous design with thorium blanket is inferior to that with a uranium blanket for two reasons: a reduced thorium density and a reduced fertile fission effect. The question in this case is whether or not equivalent breeding performance to the uranium reduced thorium density and a reduced fertile fission effect. The question in this case is whether or not equivalent breeding performance to the uranium blanket case could be achieved if additional thorium is allowed in internal blankets. As shown in Table XVIII, even if the thorium internal blanket is increased to match the heavy metal mass of the uranium blanket case, the breeding ratio is not improved significantly. In other words, the breeding performance penalty with the thorium internal blanket is primarily due to the reduced fast fission of thorium as compared to that of ${ }^{238} \mathrm{U}$.

TABLE XVIII. Effect of Blanket Material and Fue1 Density on Breeding Performance of Heterogeneous Metal Designs

\begin{tabular}{|c|c|c|c|}
\hline & $\begin{array}{l}\text { Reference } \\
\text { U Blanket }\end{array}$ & $\begin{array}{r}\text { Reference } \\
\text { Th Blanket } \\
\end{array}$ & $\begin{array}{c}\text { Increase Th IB to } \\
\text { Match U IB HM }\end{array}$ \\
\hline \multicolumn{4}{|c|}{ Initial Core Inventory } \\
\hline$U-235$ & 307 & 34 & 32 \\
\hline Fis. Pu & 3507 & 3672 & 4216 \\
\hline \multicolumn{4}{|l|}{ Annual Net Gain } \\
\hline $\mathrm{U}-233$ & 0 & 657 & 740 \\
\hline $\mathrm{U}-235$ & -19 & -5 & -4 \\
\hline Fis. $\mathrm{Pu}$ & 521 & -290 & -350 \\
\hline Total & 502 & 362 & 386 \\
\hline $\operatorname{CSDT}$ & 10.0 & 13.8 & 14.9 \\
\hline Breeding Ratio & 1.718 & 1.512 & 1.546 \\
\hline
\end{tabular}

\section{SUMMARY}

Comparisons of the performance characteristics of alternatives make commonality in ground rules, constaints and design procedures important, and such commonality of design basis was stressed in this study. Even with this, however, consistency in comparison is inevitably influenced by the widely differing technology status of the various alternative concepts. In particular, the fuel irradiation data base is meager for most alternative options. 
Nevertheless, to identify conceptually feasible design ranges we have attempted to represent each fuel type at an equivalent level of development. Much greater uncertainty must therefore be assigned to the technical feasibility of the alternatives considered in this report than for the present we11established FBR designs. The aim of the study was to identify potential performance payoffs associated with the alternative concepts, if the required development was undertaken and was successful.

In the following, the key results and observations on the performance characteristics of alternatives analyzed in this study are summarized.

1. Comparison of Breeding Performance Between Oxide, Carbide and Metal Fuels: The performance characteristics of the reference oxide, carbide and metal designs for the $\mathrm{Pu} / \mathrm{U}$ cycle can be summarized as:

$\begin{array}{lrrrr} & \text { Oxide } & & \text { Carbide } & \text { Metal } \\ \text { Breeding Ratio } & 1.33 & & 1.48 & 1.58 \\ \text { CSDT, yr } & 17 & 10 & 9\end{array}$

For a range of feasible designs with same ground rules and constraints, there is an inherent difference of $10-15$ points in the breeding ratio for the reference $\mathrm{Pu} / \mathrm{U}$ cycle between the oxide and the carbide fuels, and also between the carbide and the metal fuels (Ref. Fig. 13).

The breeding performance improvements for the carbide fuel over the oxide fuel, and for the metal fuel over the carbide fuel are traceable directly to the basic neutronic properties of each fuel type associated with the neutron energy spectrum that is characteristic of each. About one-half of the breeding ratio improvement for the carbide fuel and the metal fuel is due to increases in the $\eta$-values of the fissile isotopes and the other half to the increase in the fertile fission bonus as the spectrum is hardened.

2. Breeding Performance of Alternative Fuel Cycles: Varying degrees of thorium use were assumed for the alternative cycles. There are neutronic and other advantages in confining thorium usage to blanket regions. Configurations were analyzed for thorium in the radial blanket only, in both axial and radial blankets, and in internal blankets as well in heterogeneous core designs. At the extreme thorium can be utilized in the core as well with the thorium totally replacing $238 \mathrm{U}$ as the fertile material. In this study the same fuel pin mechanical design features as used for the reference $\mathrm{Pu} / \mathrm{U}$ cycle were assumed for all alternative fuel cycle options so the effect of various fueling options could be compared in evolutionary steps.

The breeding ratio is not affected much when thorium is utilized only in the blankets in place of uranium. For the oxide design the breeding ratio is reduced by only 1 point if thorium is used in the radial blanket, and by 2 points if thorium is used in both axial and radial blankets. The reason for the small breeding ratio penalty for the thorium blanket is that the breeding ratio is primarily dictated by the core neutronic properties -- the n-value of fissile isotopes, which depends only on the core fissile material, and by the fertile fission bonus, which is largely determined by the core fertile material. 
For carbide cores the breeding ratio penalty for thorium blankets is somewhat greater than that for oxide and the penalty is further increased for metal cores. This is because the thorium densities for carbide and metal fuels, but particularly for metal, are considerably less than the corresponding uranium fuel densities, resulting in a further reduction in the blanket fertile fissions and an enhanced neutron leakage.

The situation for all fuels worsens rapidly when thorium is introduced into the core itself. Even if plutonium fueling is maintained, if thorium is used as the core fertile material, the breeding ratio penalty is substantial, due mainly to the reduction of the fertile fission bonus. The breeding ratio for the $\mathrm{Pu} / \mathrm{Th}$ cycle is reduced by 14 points for oxide fuel, 26 points for carbide fuel, and 28 points for metal fuel, as compared to the $\mathrm{Pu} / \mathrm{U}$ cycle.

For the alternative cycles discussed above, plutonium fueling was assumed. Two additional alternative cycles were analyzed in this study, neither of which involve plutonium fresh fuel: ${ }^{23{ }^{3}} \mathrm{U} / \mathrm{Th}$ cycle and the denatured ${ }^{23} \mathrm{U} / \mathrm{U}$ cycle.

When ${ }^{23} \mathrm{U}$ is substituted for plutonium in addition to the fertile substitution of thorium, the $n$-value is decreased and there is additional decrease in the fertile fissions (due to the absence of the ${ }^{240} \mathrm{Pu}$ and ${ }^{242} \mathrm{Pu}$ ). The breeding ratios for all fuel types are reduced to the range of 1.1 for the $2{ }^{3} \mathrm{U} / \mathrm{Th}$ cycle. The breeding ratio and the doubling time for the $233 \mathrm{U} / \mathrm{Th}$ cycle could be improved if the design is reoptimized. However, the optimum fuel volume fraction, with respect to the minimum doubling time, for the ${ }^{233} \mathrm{U} / \mathrm{Th}$ cycle is much higher than for the $\mathrm{Pu} / \mathrm{U}$ cycle. The initial fissile inventory requirements would increase substantially for a reoptimized design. Initial inventory startup considerations for the ${ }^{233} \mathrm{U} / \mathrm{Th}$ cycle differ somewhat from the $\mathrm{Pu} / \mathrm{U}$ cycle case. With the $\mathrm{Pu} / \mathrm{U}$ cycle, the initial startup of breeder economy is based on the plutonium discharged from LWRs. In the case of the $2{ }^{3} \mathrm{U} / \mathrm{Th}$ cycle, such initial fissile stockpiles are not available, and a tradeoff will exist between the doubling time and initial inventory, whether $2{ }^{3} \mathrm{U}$ is supplied based on a symbiotic system or from other sources.

For the ${ }^{233} \mathrm{U} / \mathrm{U}$ cycle (denatured fresh fuel), the breeding performance is much better than for the $\mathrm{Pu} / \mathrm{Th}$ cycle. In fact, the breeding ratio for the $23^{3} / \mathrm{U}$ cycle is about half-way between the reference $\mathrm{Pu} / \mathrm{U}$ cycle and the $\mathrm{Pu} / \mathrm{Th}$ cycle. The reason is due to the fast fission contribution of ${ }^{238} \mathrm{U}$ and the improved $n$-value due to the buildup of ${ }^{239} \mathrm{Pu}$.

3. Breeding Performance of Heterogeneous Cores: The relationship between the breeding ratio and the effective core fuel volume fraction is similar for both homogeneous and heterogeneous designs. If we compare a homogeneous and a tightly coupled heterogeneous design on the basis of effective core fuel volume fraction, the breeding performance is about the same. Slight deviations could occur because of different structure/coolant volume ratio and design assumptions. The breeding performance of the heterogeneous design with thorium internal blankets is inferior to that with uranium blankets for two reasons: the reduced thorium physical density and a reduced fertile fission effect. However, this option may be considered as a compromise between the $\mathrm{Pu} / \mathrm{U}$ core with thorium blanket and the $\mathrm{Pu} / \mathrm{Th}$ core, depending on particular symbiotic system applications. 
4. Breeding Perforamcne of GCFR Fuel Cycles: The differences in the neutronic characteristic between the oxide fueled LMFBR and the GCFR, derived form the change in coolant type, are due to a harder GCFR spectrum caused by the absence of sodium moderation. However, because of the heat transfer characteristics of helium cooling, GCFR designs can not easily achieve fuel volume fractions as high as those of LMFBR designs. The net effect is that the breeding ratio is somewhat higher for the GCFR than for the oxide-fueled LMFBR, but the fissile inventory is higher as we1l, resulting in a longer doubling tine.

5. Safety-Related Physics Parameters: For the Pu/U core, the sodium void reactivity effect and the Doppler coefficient are about the same for the oxide and carbide fuels. However, the metal fuel has a significantly higher void reactivity and a lower Doppler coefficient. For the heterogeneous cores the sodium void reactivity is reduced to less than half of that for the corresponding homogeneous designs. For thorium-based fuel cycles, the sodium void reactivity is sharply reduced. For the $\mathrm{Pu} / \mathrm{Th}$ core, the void reactivity is reduced by $30-40 \%$. For $233 \mathrm{U} / \mathrm{Th}$ cores, for all fuel types, the sodium void reactivity becomes slightly negative.

6. Uncertainties in Breeding Performance: The issues associated with oxide fuel breeding performance are not in its technical feasibility. There has been enough irradiation experience accumulated to date to support viable design and a reasonable breeding performance. However, the breeding potential for the oxide fuel is intrinsically inferior to other advanced fuels, and to substantially improve the breeding performance with oxide fuels, it is necessary to push designs to the limit.

Even though carbide fuel development has been more actively pursued in recent years, the irradiation data base is rather sparse and additional work is required to bring the carbide fuel to a stage of development equivalent to the oxide fuel. Nevertheless, the incentive for development is there, for if carbide fuel can be satisfactorily developed, the expected breeding performance characteristics should be considerably better than for oxide fuel.

The irradiation data base is weakest for the metal fuel. There is very little data on plutonium-containing alloys, of the type required for reference design analysis prototypic of commercial application. Thus much greater uncertainties must be assigned to the technical feasibility of such metal fuels than are present for either oxide for carbide fuel.

However, the implications for the INFCE considerations of the superior breeding potential of advanced fuels is that they may provide more flexibility in fast breeder deployment options under various non-proliferation constraints than other fuel types. In the high-breeding-gain fuel designs the doubling time is not affected greatly by design variations that may be necessary under deployment constraints or simply for reasons of conservatism.

There are still greater uncertainties in the performance characteristics of the thorium-based alternative cycles than for the reference $\mathrm{Pu} / \mathrm{U}$ cycle. The irradiation performance data base for the thorium-based fuel types under fast reactor conditions is almost non-existent; and the nuclear cross section data for the thorium chain isotopes in a fast spectrum are also considerably more uncertain. 


\section{ACKNOWLEDGMENTS}

The authors are deeply indebted to W. P. Barthold, H. H. Hummel, J. R. Honekamp, P. R. Huebotter and V. W. Lowery for critical reviews and helpful discussions. We also wish to thank $\mathrm{H}$. Henryson II and B. J. Toppel for their contributions to parts of the write-up as well as their technical contributions. 


\section{REFERENCES}

1. C. E. Till, Y. I. Chang, and R. R. Rudolph, Altemative Fuel Cycle and Deployment Strategies: Their Influence on Long-Term Energy Supply and Resource Usage, Part 1 of this report.

2. J. H. Kittel et al., Status of Fuels and Materials Dovelopment, Part 3 of this report.

3. H. K. Fauske, Safety Implications of Altemative fuel Types, Part 4 of this report.

4. J. C. Chandler et a1., The Proliferation Resistant Preconceptual Core Design Study, HEDL-TM-1083 (March 1978).

5. TID-2666, Nuclear Systems Materials Handbook.

6. Evaluated Nuclear Data File B, Version IV, National Nuclear Data Center, Brookhaven National Laboratory (1975).

7. J. Meadows, W. Poenitz, A. Smith, D. Smith, J. Whalen, and R. Howerton, Evaluated Nuclear Data File of Th-232, Argonne National Laboratory, ANL/NDM-35 (February 1978).

8. H. Henryson II, B. J. Toppe1, and C. G. Stenberg, MC2-2: A Code to Calculate Fast Neutron Spectra and Multigroup Cross Sections, Argonne National Laboratory, ANL-8144 (June 1976).

9. H. Henryson II, B. J. Toppel, and C. G. Stenberg, ETOE-2MC $-2 / S D X$ Multigroup Cross-Section Processing, Proceedings of Seminar-Workshop on Multigroup Cross Sections, March 14-16, 1978, Radiation Shielding Information Center, Oak Ridge, Tennessee.

10. T. A. Daly, G. K. Leaf, and A. S. Kennedy, The ARC System TwoDimensional Diffusion Theory Capability, DARC2D, Argonne Nationa1 Laboratory, ANL-7716 (May 1972).

11. R. P. Hosteny, The ARC System Fuel Cycle Analysis Capability, REBUS-2, Argonne National Laboratory, ANL-7721 (1978).

12. W. P. Barthold and Y. I. Chang, Breeding Ratios and Doubling Time Definitions Used for Advanced Fuels Performance Characterization, Trans. Am. Nuc1. Soc., 26, 588 (1977).

13. Clinch River Breeder Reactor Plant: Preliminary Safety Analysis Report, Project Management Corporation.

14. 750-MWe Gas-Cooled Fast Breeder Reactor Demonstration Plant, GA-A10459 (January 1976).

15. PLBR Phase II; GEFR-00099, Conceptual Design, (June 1977).

16. ERDA-EPRI LMFBR Design Projects Phase it Final Report, TID-27690-1, (June 1977). 
17. LMFBR Conceptual Plant Design, TID-2779Z-I, (May 1977).

18. Y. I. Chang, C. E. Till et al., Altemative Fuel Cycle Options: Performance Characteristics and Impact on Nuclear Power Growth Potential, ANL-77-70 (September 1977).

19. K. J. Baylor et a1., GCFR Fuel Cycle Information for the ORNL Nonproliferation Study, GA-A14753 (January 1978).

20. D. Okrent, Neutron Physics Considerations in Large Fast Reactors, Power Reactor Technology, 7, 107 (1964). 
APPENDIX: Detailed Mass Flow Data 


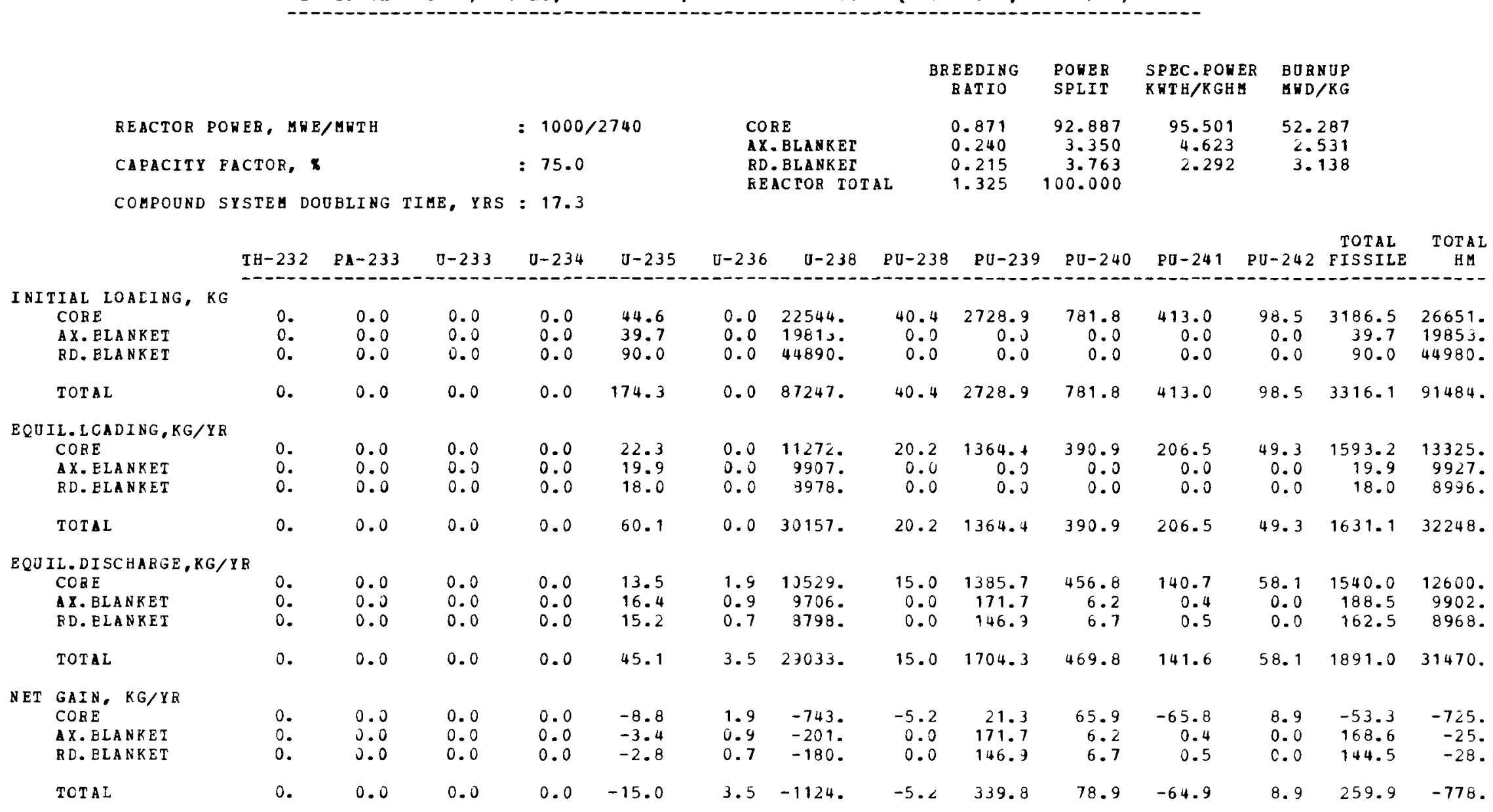

NOTE: 1. EISSILE = EA233+U233+U235+PU239+PU241

2. BR AND CSDT CALCULATED WITH EQUAL FISSILE ISOTOPE WEIGHTING AND LQEDIT FOR PA-233

3. CSDT CALCULATED WITH 1-YEAB EXIERNAL CYCLE TIME AND $2 \%$ GEPROCESSING/FABRICATION LOSSES 
EEACTOR PERFOE

LAFBR-OXIDE: PU/O CORE, U AB, TH RB; REFEKENCE DESIGN (0.29" PIN, $14 \mathrm{KH} / \mathrm{FT})$

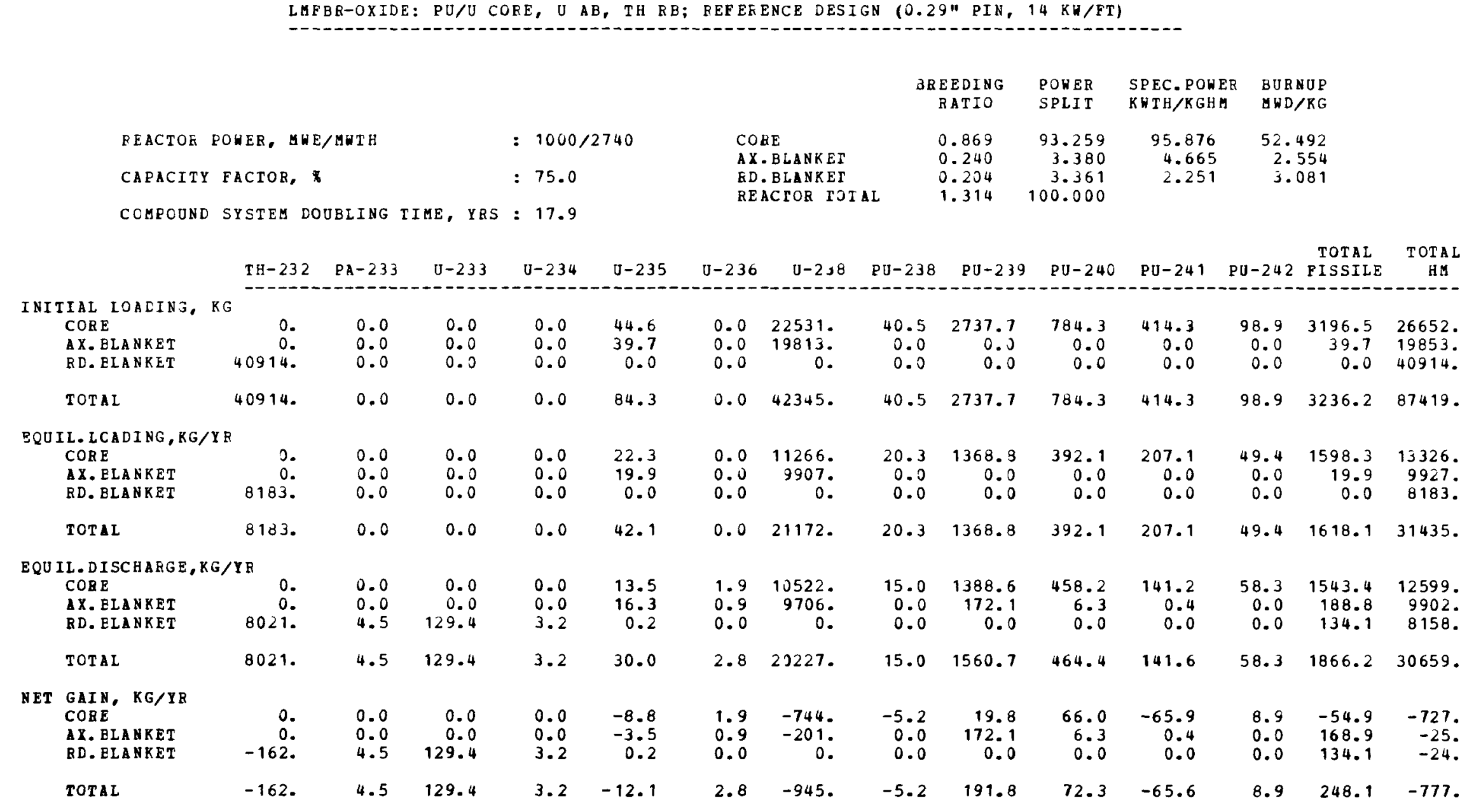

NOTE : 1. FISSILE $=$ PA233+U233+U235+PU239+PU241

2. BR AND CSDT CALCOLATED WITH EQOAL FISSILE ISOTOPE HEIGHTING AND CREDIT FOR PA-233

3. CSDT CALCOLATED RITH 1-YEAR EXTERAL CYCLE TIUE AND 2X REPROCESSING/FABRICATIOS LOSSES 


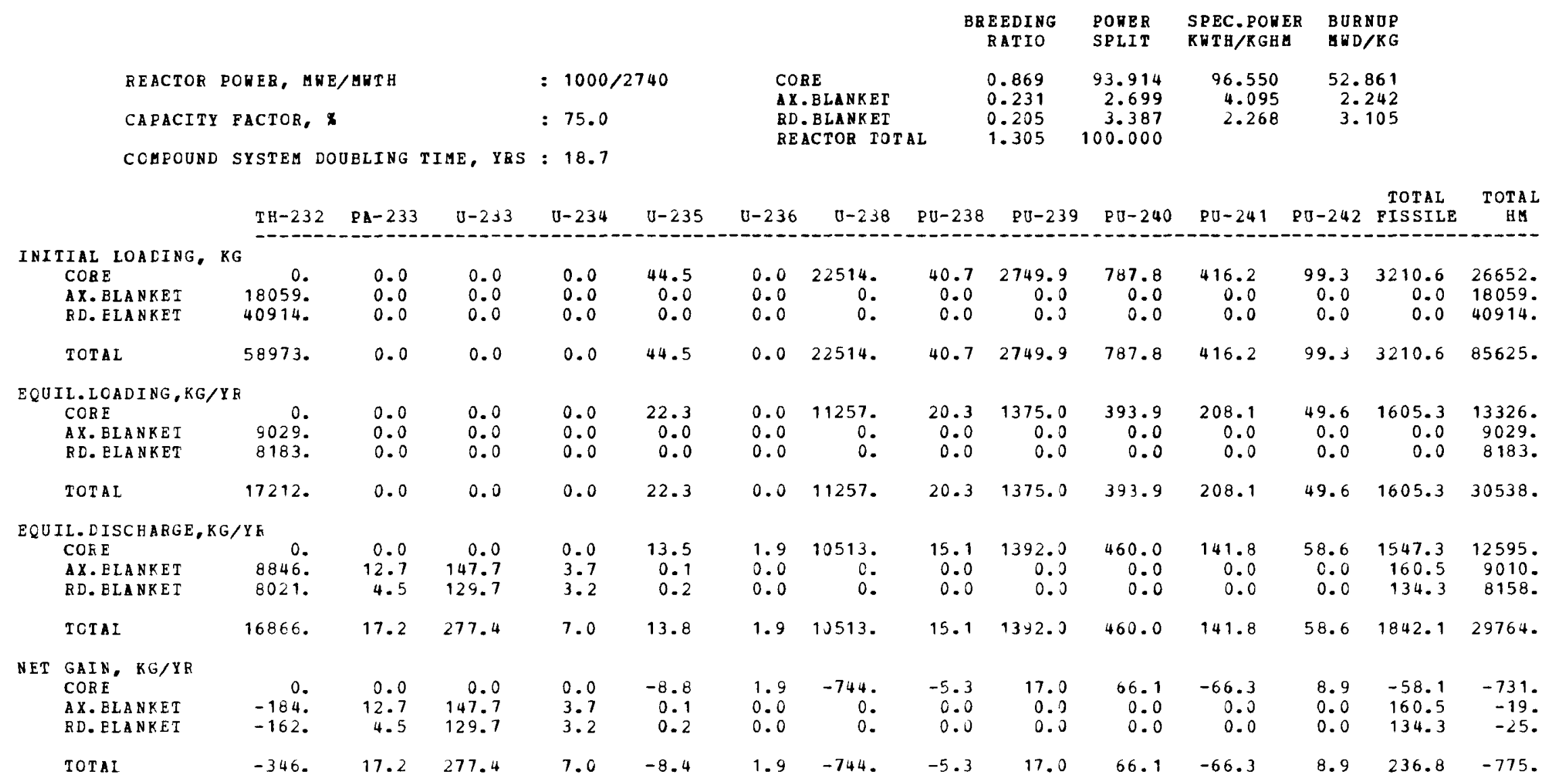

NOTE : 1. FISSILE $=$ PA233+U233+U235+PU239+PU241

2. BR and CSDT CALCULATED WITH EQJAL FISSILE ISOTOPE WEIGHTINi ANL CREDit FOR PA-233

3. CSDT CALCULATED WITH 1-YEAR EXTEKNAL CYCLE TIME AND $2 \%$ BEPROCESSING/FABRICATION LOSSES 
BEACTOR PERFOKMANCE AND MASS FLOW DATA

LIFER-OXIDE: PU/TH CORE, TH AB E RB; EEFERENCE DESIGN $(0.29 n$ PIN, 14 KW/FT)

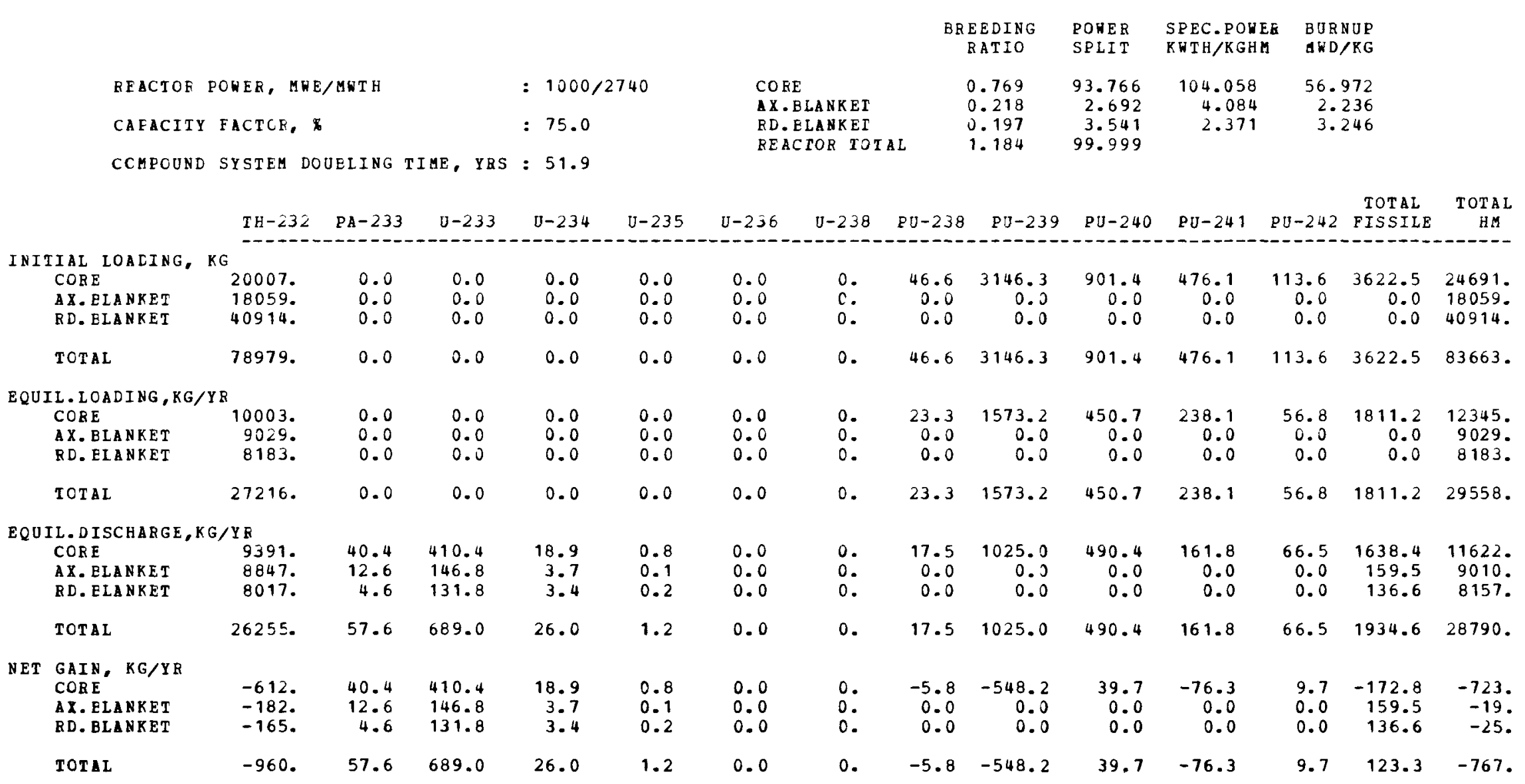

NOTE : 1. FISSILE $=$ FA233 + $2233+0235+$ P0239+P0241

2. BR AND CSDT CALCULATED HITH EQDAL FISSILE ISOTOPE NEIGHTING AND CREDIT FOR PA-233

3. CSDT CALCOLATED IITH 1-YEAR EXTERHAL CYCLE TIUE AND $2 \%$ BEPBOCESSIMG/FABRICATION LOSSES 
REACTOR PERFORMANCE AND MASS FLOH DATA

LHFBE-OXIDE: U233/TH CORE, TH AB E RE; REFERENCE DESIGN (0.29" PIN, 14 KW/FT)

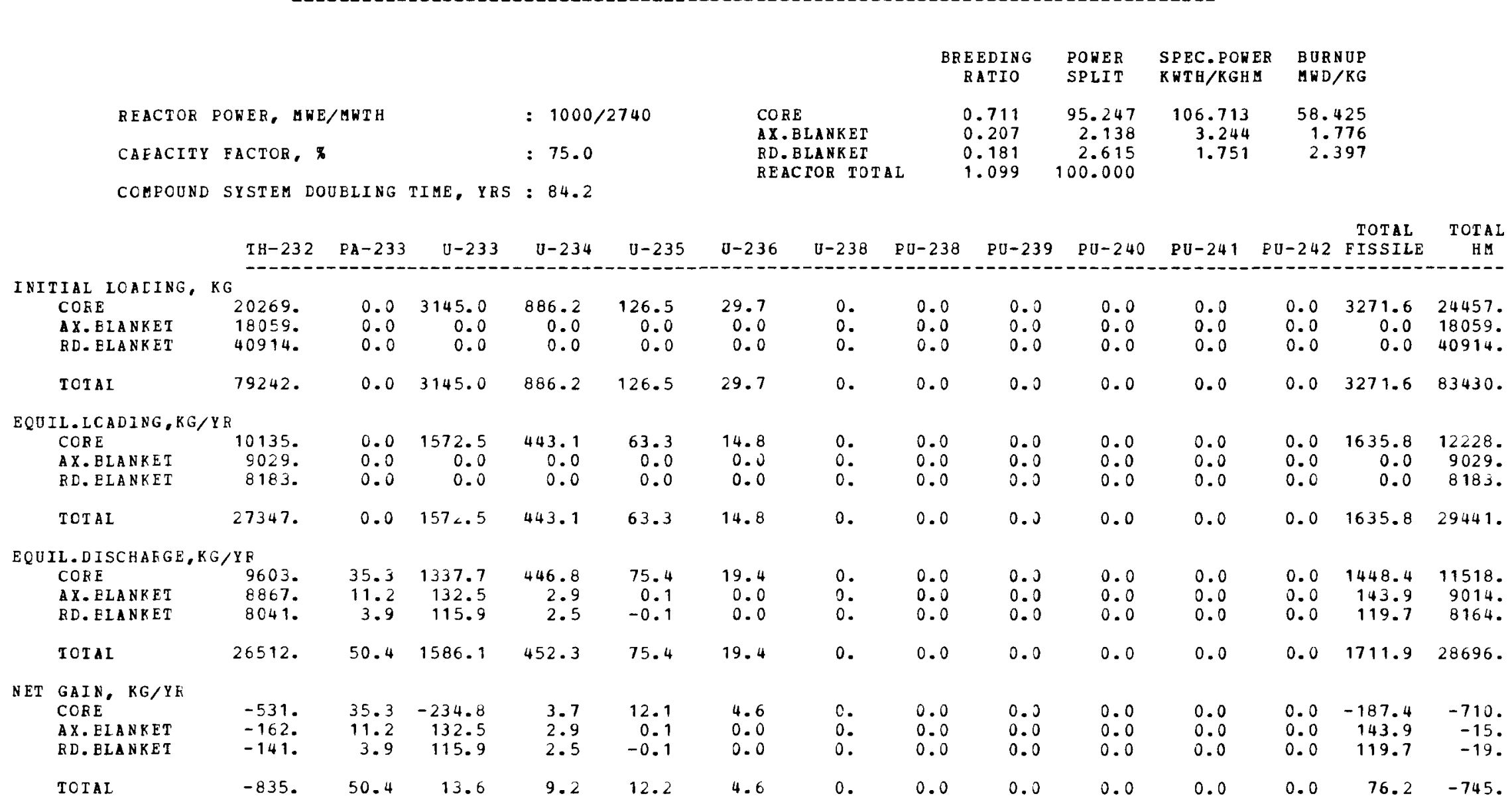

NOTE : 1. FISSILE $=$ FA233+U233+U235+ PU239+ PU 241

2. BR AND CSDT CALCULATED WITH EQUal. FISSILE ISOTOPE heighting and CREDIT For Pa-233

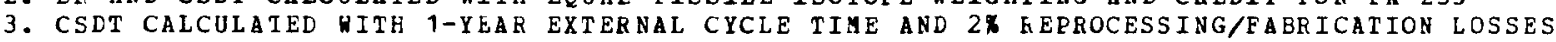




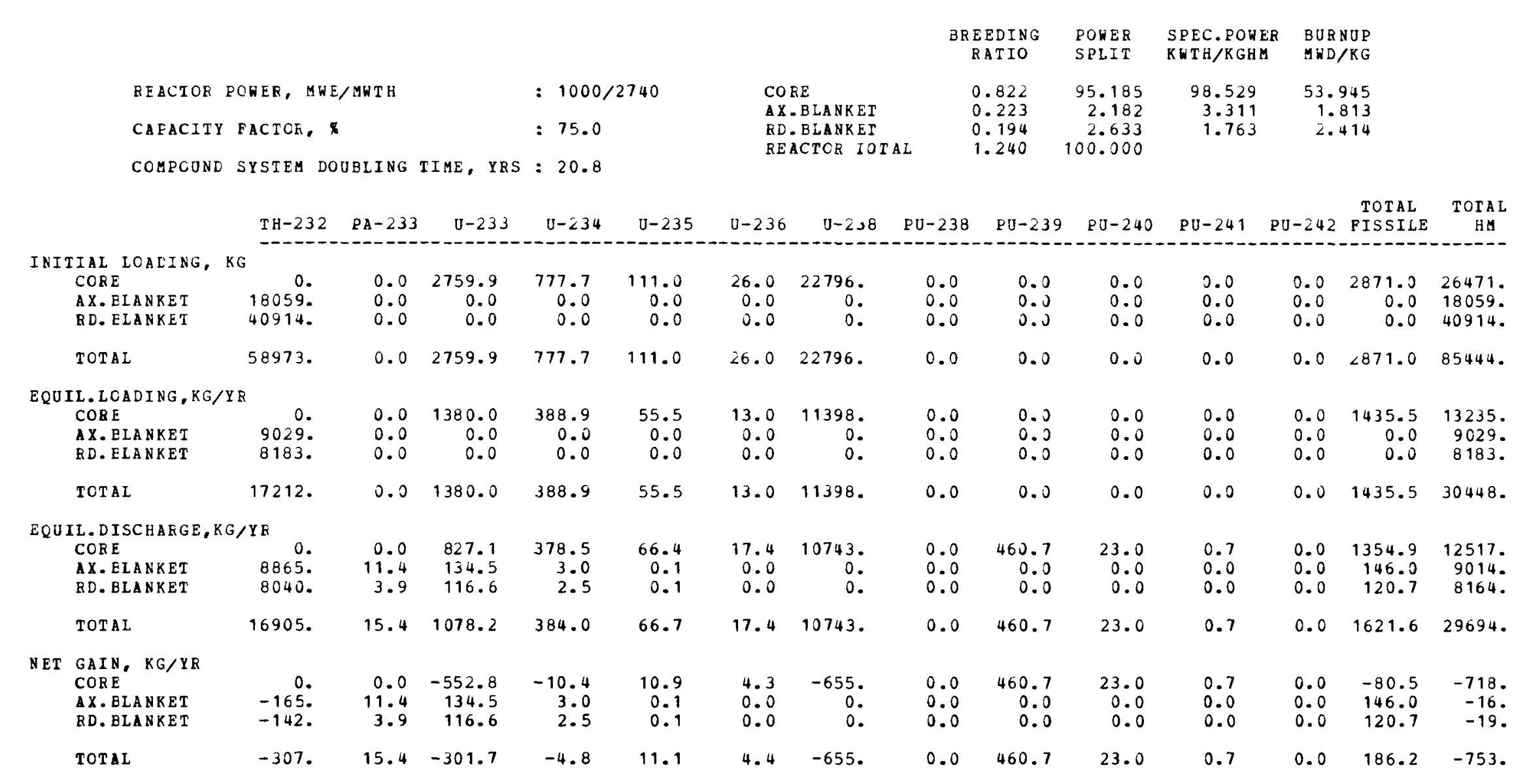

NOTE : 1. FISSILE $=$ PA233+U233+U235+PU239+ PU241

2. BR AND CSDT CALCULATED WITH EOUAL FISSILE ISOTOPE VEIGHTING AND CREDIT FOR PA-233

3. CSDT CALCULATED WITH 1-YEAR EXTERNAL CYCLE TIME AND $2 \pi$ REPROCESSING/FABRICATION LOSSES 


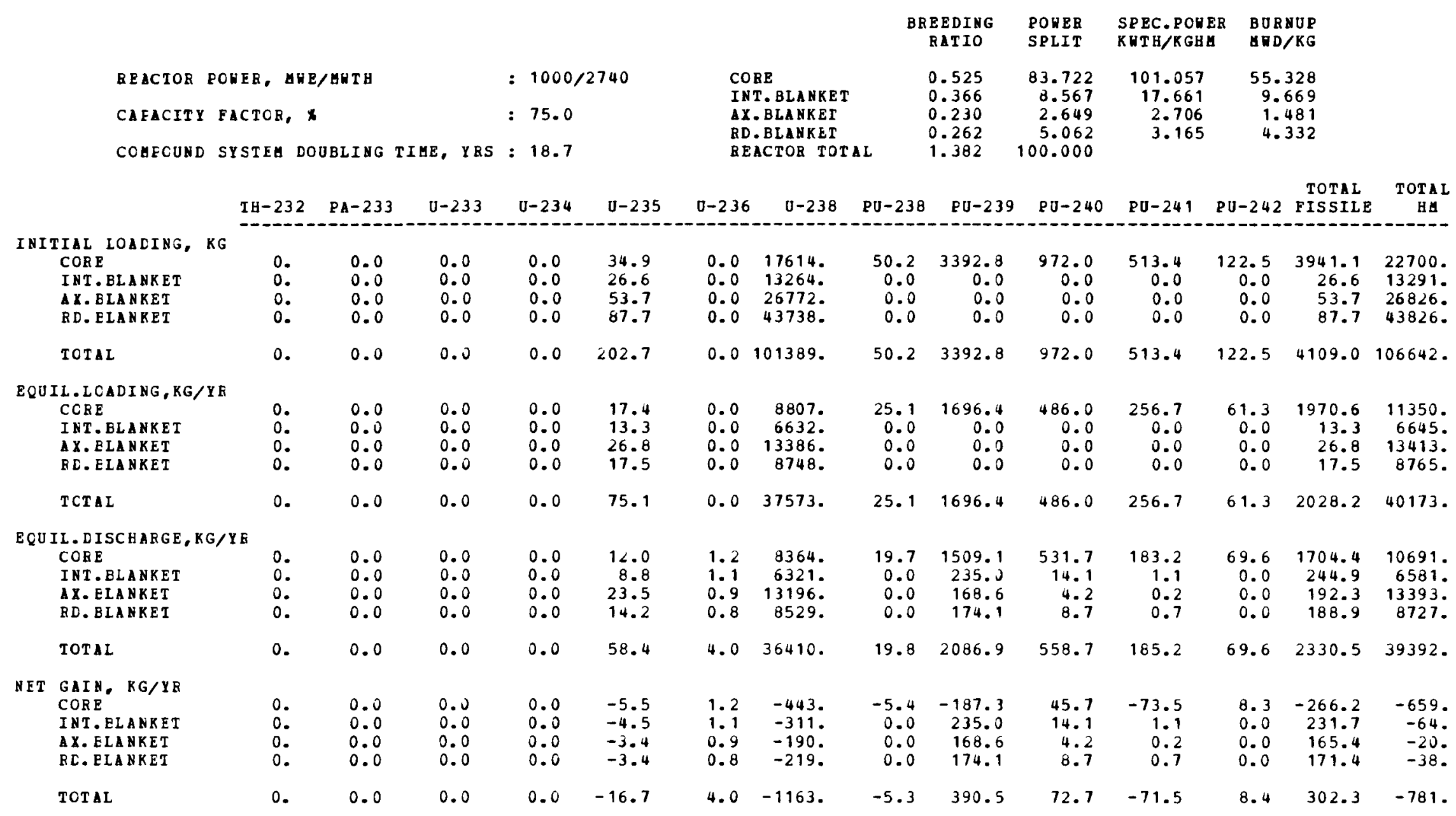

NOTE : 1. FISSILE $=$ FA233+U233+U235+PU239+PU241

2. BR AND CSDT CALCULATED HITH EQUAL FISSILE ISOTORE NEIGHTING AND CREDIT FOR PA-233

3. CSDI CALCULATED WITH 1-YEAR EXTERNAL CYCLE TIHE AND 2X KEPROCESSING/FABRICATION LOSSES 
REACTOE PERFORMANCE AND MASS FLOH DATA

LMFBR-OXIDE HETEKOGENEOUS: PU/U CORE, TH BLANKET: REFERENCE DESISN (0.29" PIN)

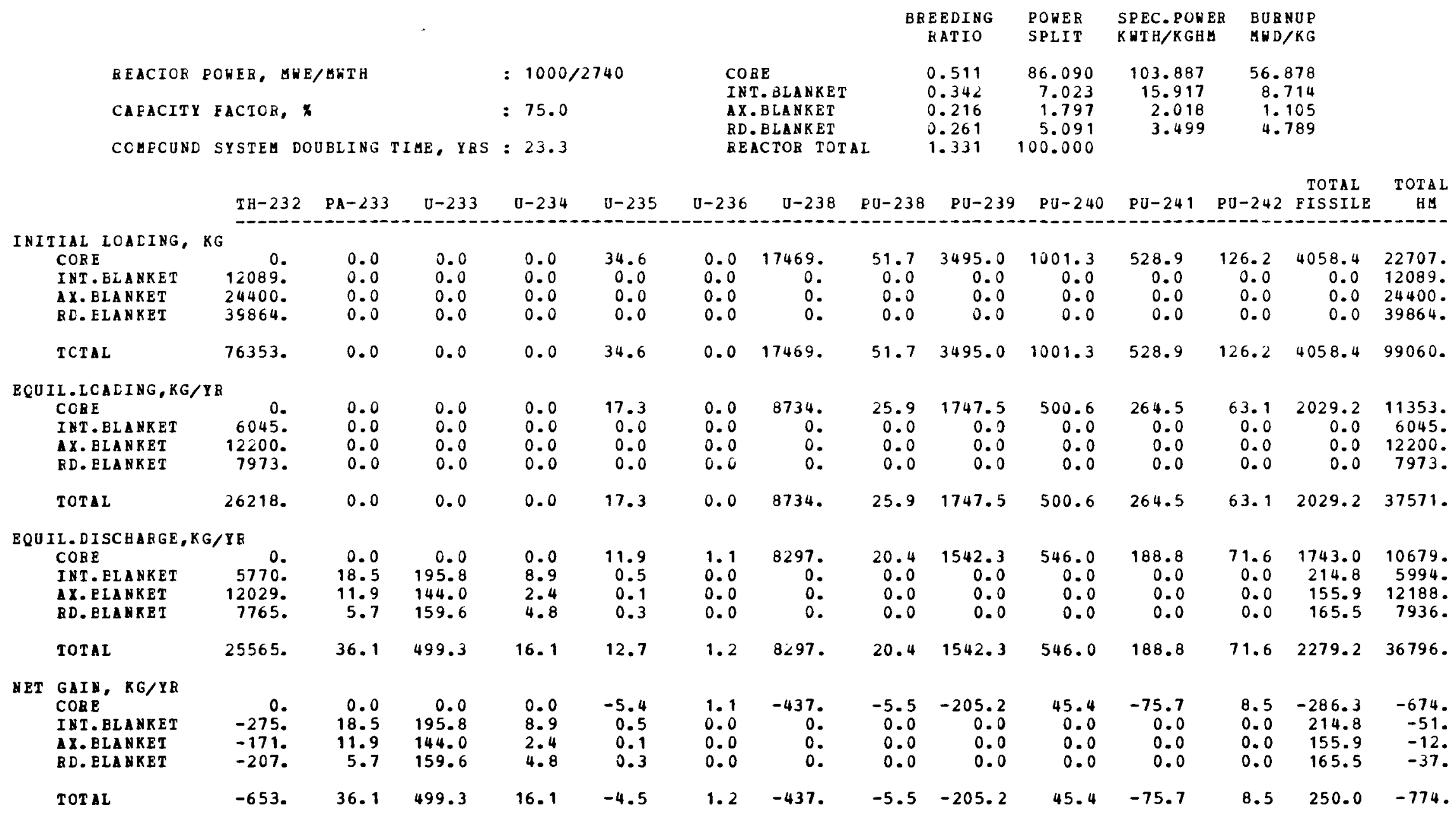

HOTE : 1. FISSILE $=$ FA $233+0233+0235+$ PU239+ PU241

2. BR AND CSDT CALCULATED HITH EQUAL FISSILE ISOTORE WEIGHTING AHD CREDIT FOR PA-233

3. CSDT CALCULATED HITH 1-YEAB EXTERBAL CICLE TIAE AHD 2\$ REPROCESSIHG/FABRICATION LOSSES 


\section{REACTOR PERFORAANCE AND MASS FLOH DATA}

LMFBR-CARBIDE: PU/U CORE, J AB $\varepsilon$ RB; REFERENCE DESIGN (0.37" PIN, $28 \mathrm{KW} / F T)$

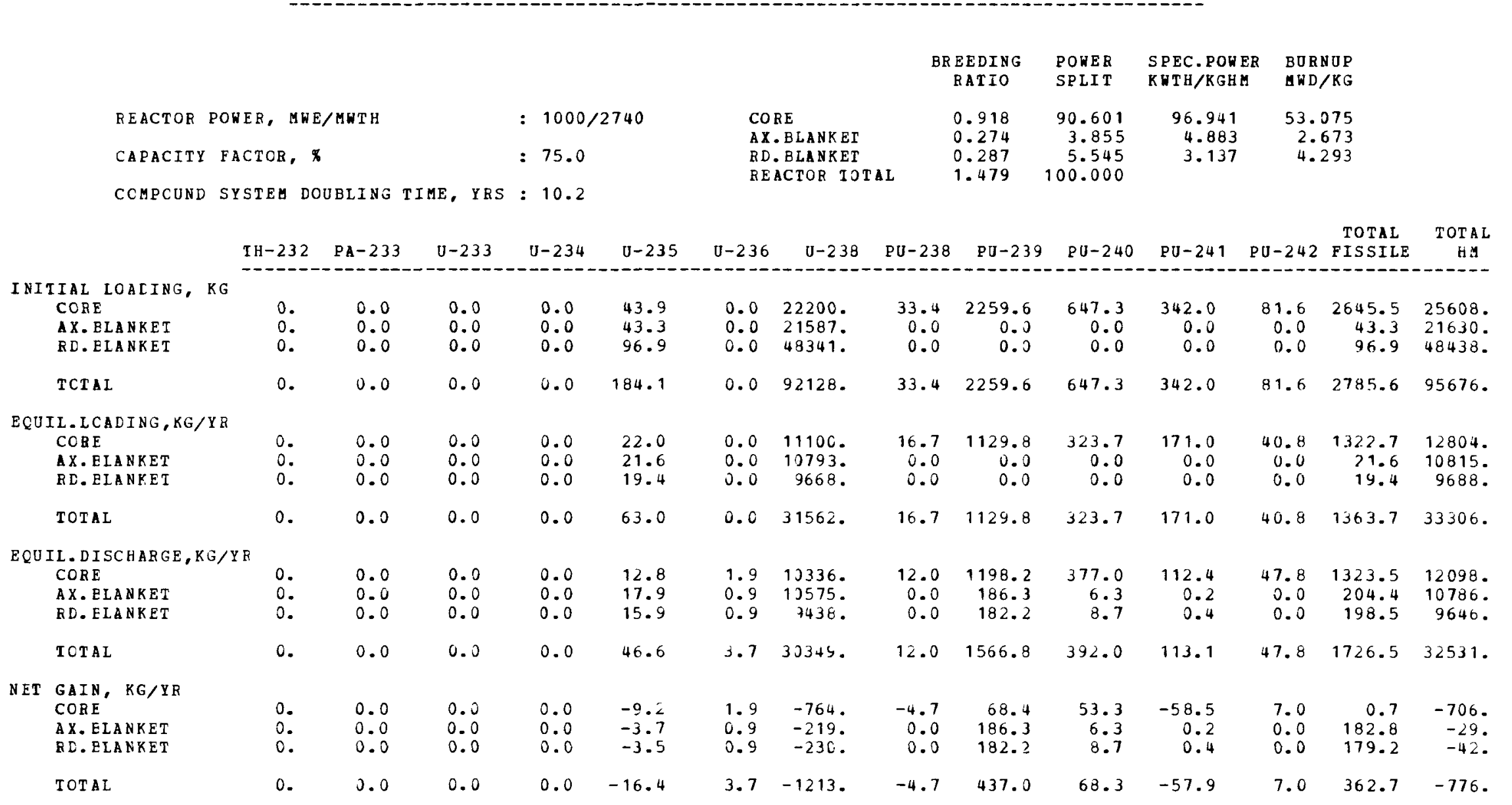

NOTE : 1. FISSILE $=$ EA233+U233+U235+PU $239+$ PU241

2. ER AND CSDT CALCULATED WITH EQUAL FISSILE ISOTOFE NEIGHIING AND CREDIT FOR PA-233

3. CSDT CALCULATED hiTh 1-YEAR EXTERNAL CYCLE TIME AND $2 \%$ KEPROCESSING/FabRiCATIOA LOSSES 
REACTOR PEEFORMANCE AND MASS FLOH DATA

LAFBE-CARBIDE: PU/O CORE, U AB, TH RB; REPEQENCE DESIGN (0.37" PIN, 28 KW/FT)

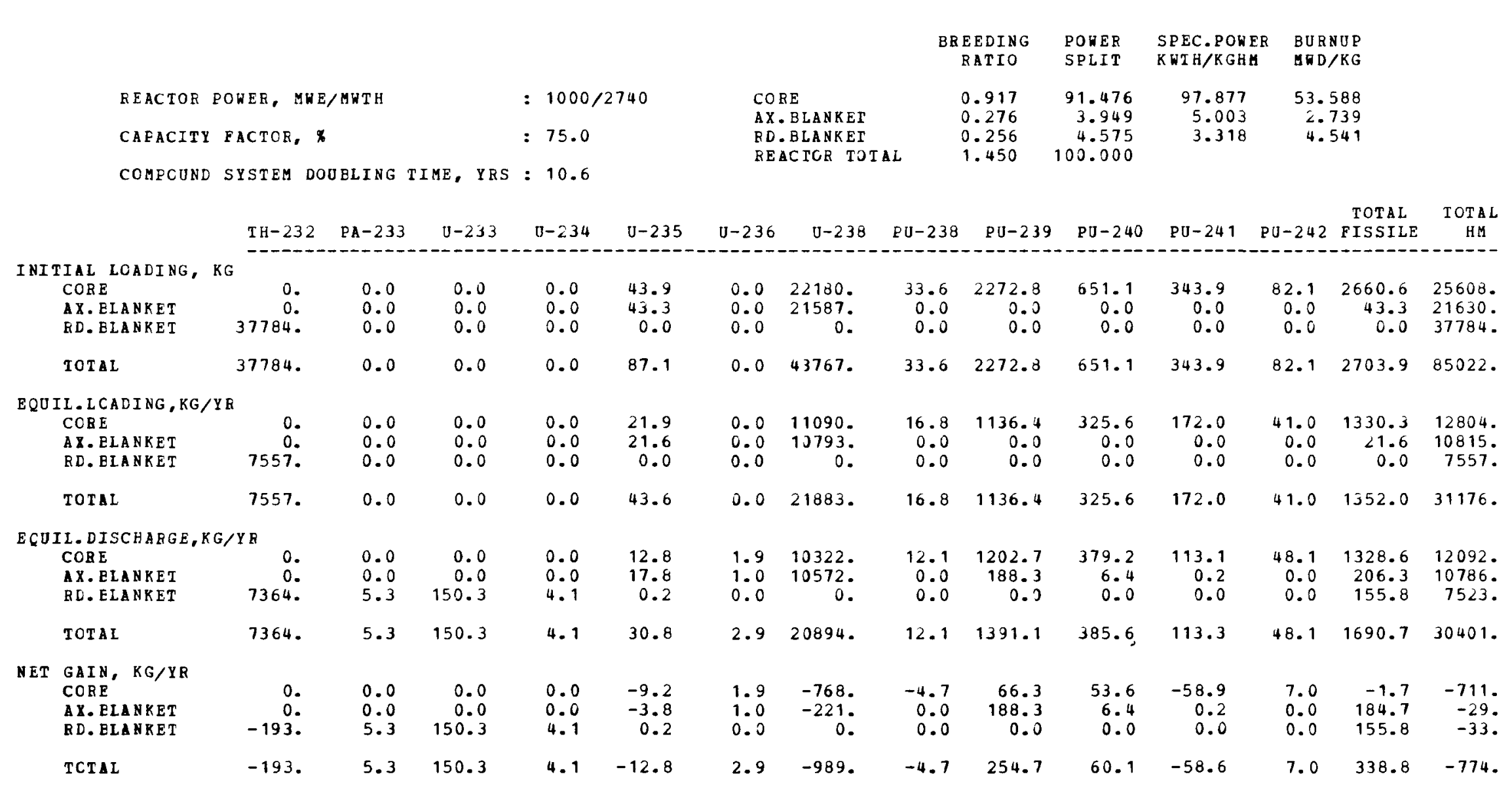

NOTE : 1. FISSILE = PA233+ U233+ U235+PU239+ PU241

2. BR AND CSDT CALCDLATED WITH EQUAI FISSILE ISOTOPE WEIGHTING AND CREDIT FOB PA-233

3. CSDT CALCULATED UITH 1-YEAR EXTERAL CYCLE TIME AND 2\% RERROCESSING/FABRICATION LOSSES 


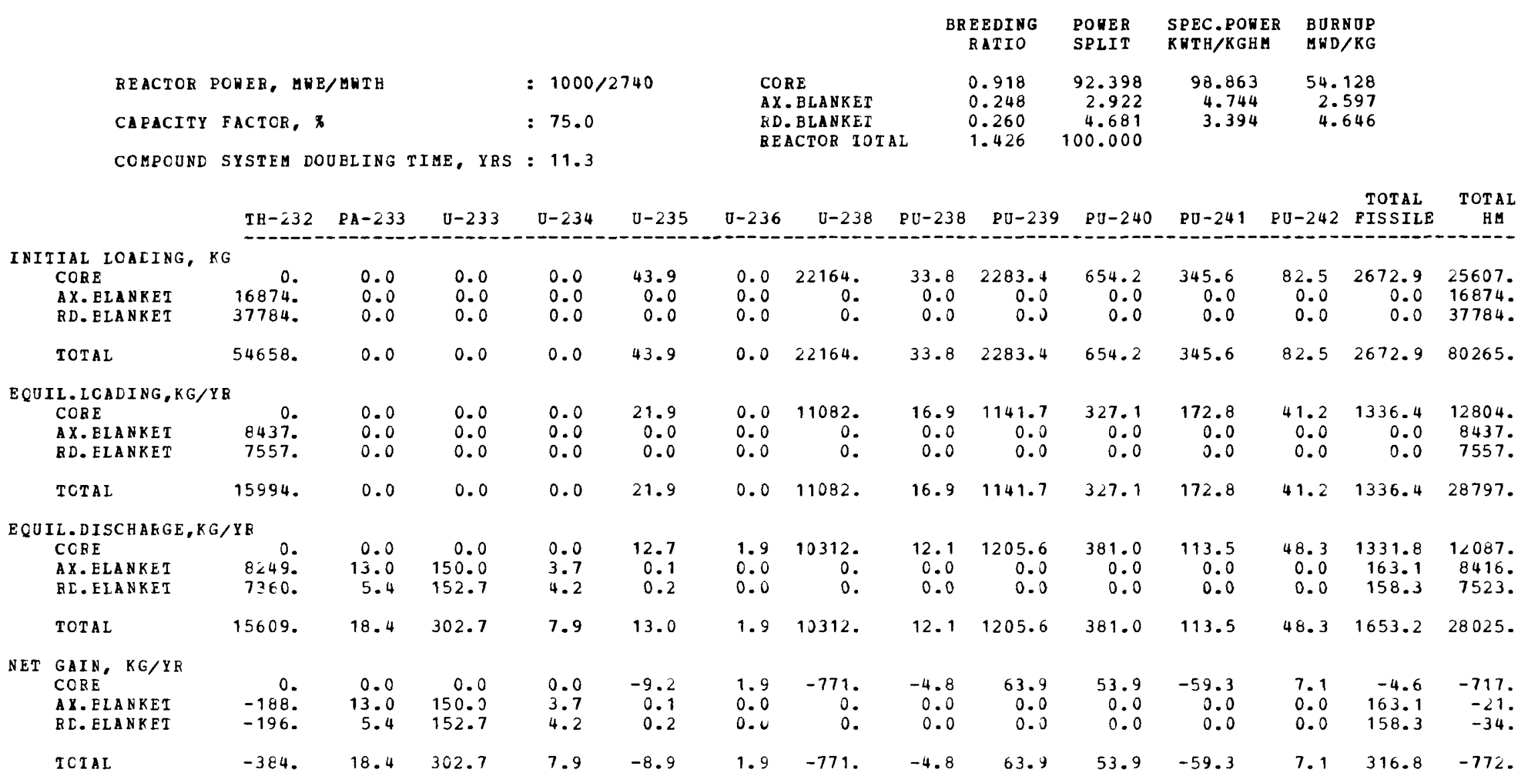

NOTE : 1. FISSILE $=\mathrm{FA} 233+\mathrm{U} 233+\mathrm{U} 235+\mathrm{PU} 239+\mathrm{PU} 241$

2. ER AND CSDT CALCOLATEL WITH EQUAL FISSILE ISOTOPE REIGHTING AND CREDIT FOR PA-233

3. CSDT CALCULATED WITH 1-YEAR EXTERNAL CYCLE TIME AND $2 \%$ REPROCFSSING/FaBRICATION LOSSES 
REACTOR PERFOEMANCE AND MASS FLOW DATA

LMFBR-CARBIDE: PU/TH CORE, TH AB $\varepsilon$ RB; REFERENCE DESIGN $(0.37 "$ PIN, 28 KW/FT)

LMFBR-CARBIDE: PU/TH COKE, TH AB E RB; REF ERENCE DESIGN (0.37n PIN, 28 KW/FT)

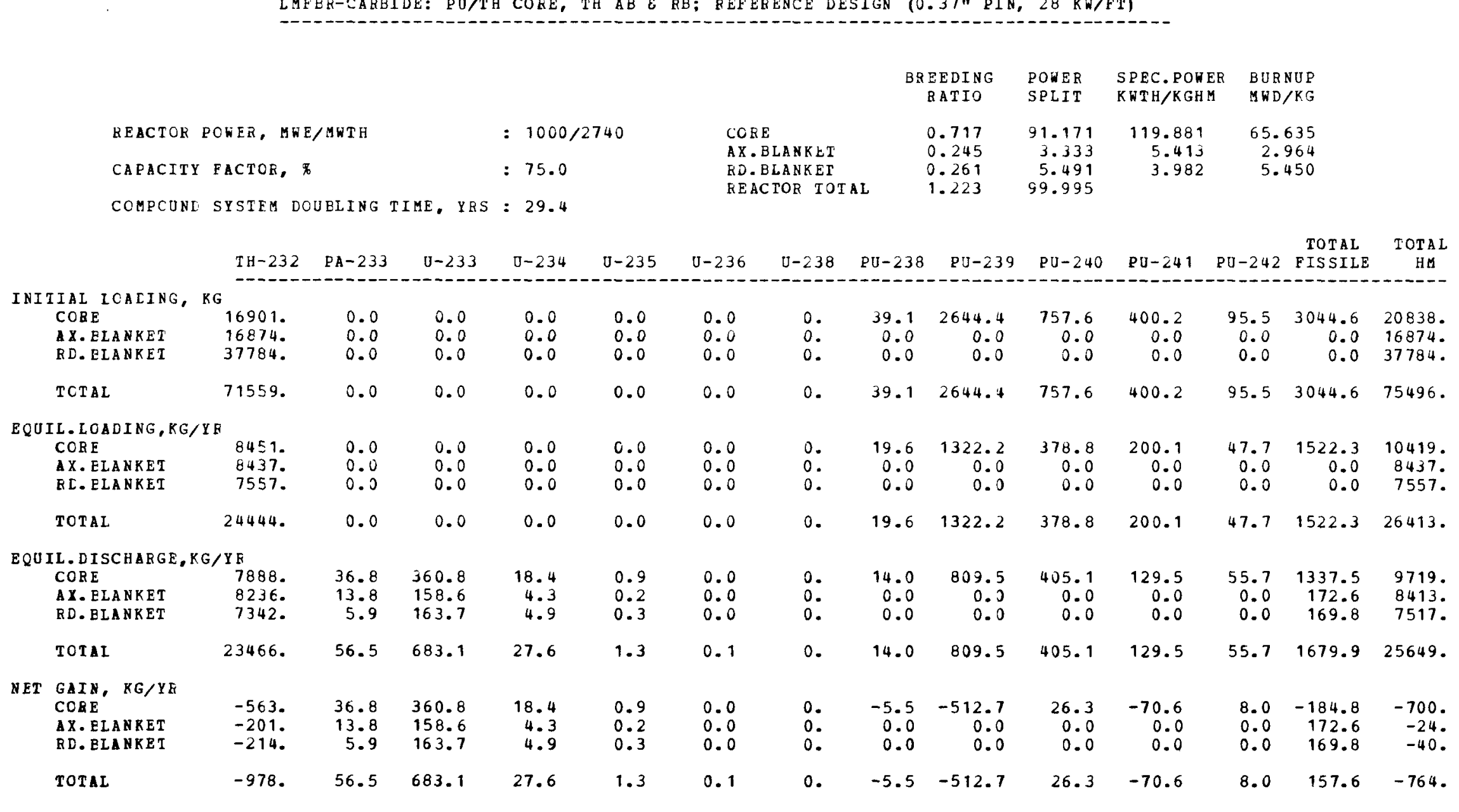

NOTE : 1. FISSILE $=$ PA233+U233+U235+ PU239+PU241

2. BE AND CSDT CALCULATEd WITH EQUAL FISSILE ISOTOPE WEIGHTING AND CREDIT FOR PA-233

3. CSDT CALCULATED ITH 1-YEAR EXTERNAL CYCLE TIME AND $2 \pi$ REPROCESSING/FABRICATION LOSSES 
LMFBR-CARBIDE: U233/TH CORE, TH AB E RB; REPERENCE DESIGN (0.37" PIN, $28 \mathrm{KH} / \mathrm{FT}$ )

\begin{tabular}{|c|c|c|c|c|c|c|c|c|c|c|c|c|c|c|c|}
\hline & & & & & & & & & $\begin{array}{r}B 8 E \\
B\end{array}$ & $\begin{array}{l}\text { EDING } \\
\text { ATIO }\end{array}$ & $\begin{array}{l}\text { PONER } \\
\text { SPLIT }\end{array}$ & $\begin{array}{l}\text { SPEC.PONE } \\
\text { KWTH/KGHU }\end{array}$ & $\begin{array}{l}\text { BURN } \\
\text { UWD/ }\end{array}$ & $\begin{array}{l}\text { NOP } \\
\text { KKG }\end{array}$ & \\
\hline & $\begin{array}{l}\text { REACTOR } \\
\text { CAPACITY }\end{array}$ & $\begin{array}{l}\text { FOWER, } \\
\text { FACTCR, }\end{array}$ & Q UW T H & & $\begin{array}{l}=1000 / \\
=75.0\end{array}$ & 2740 & $\begin{array}{l}\text { COR } \\
\text { AX. } \\
\text { RD. } \\
\text { RE A }\end{array}$ & $\begin{array}{l}\text { LANKET } \\
\text { LANKET } \\
\text { TOR IOT }\end{array}$ & & $\begin{array}{l}.653 \\
.227 \\
.234 \\
.114\end{array}$ & $\begin{array}{r}93.391 \\
2.609 \\
4.000 \\
100.000\end{array}$ & $\begin{array}{r}122.977 \\
4.237 \\
2.901\end{array}$ & $\begin{array}{r}67.3 \\
2.3 \\
3.9\end{array}$ & $\begin{array}{l}330 \\
320 \\
970\end{array}$ & \\
\hline & & $\mathrm{TH}-232$ & $P A-233$ & $0-233$ & $v-234$ & $\mathrm{U}-235$ & $0-236$ & $U-238$ & $\mathrm{PU}-238$ & $\mathrm{PU}-239$ & $P D-240$ & $P U-241$ & $\mathrm{PU}-242$ & $\begin{array}{l}\text { TOTAL } \\
\text { FISSILE }\end{array}$ & $\begin{array}{c}\text { TOTAL } \\
\text { HA }\end{array}$ \\
\hline & $\begin{array}{l}\text { TIAL LOACING, } \\
\text { CCBE } \\
\text { AX.ELANKET } \\
\text { RD. ELANKET }\end{array}$ & $\begin{array}{l}\text { KG } \\
17128 . \\
16874 . \\
37784 .\end{array}$ & $\begin{array}{l}0.0 \\
0.0 \\
0.0\end{array}$ & $\begin{array}{r}2763.5 \\
0.0 \\
0.0\end{array}$ & $\begin{array}{r}778.7 \\
0.0 \\
0.0\end{array}$ & $\begin{array}{r}111.2 \\
0.0 \\
0.0\end{array}$ & $\begin{array}{r}26.1 \\
0.0 \\
0.0\end{array}$ & $\begin{array}{l}0 . \\
0 . \\
0 .\end{array}$ & $\begin{array}{l}0.0 \\
0.0 \\
0.0\end{array}$ & $\begin{array}{l}0.0 \\
0.0 \\
0.0\end{array}$ & $\begin{array}{l}0.0 \\
0.0 \\
0.0\end{array}$ & $\begin{array}{l}0.0 \\
0.0 \\
0.0\end{array}$ & $\begin{array}{l}0.0 \\
0.0 \\
0.0\end{array}$ & $\begin{array}{r}2874.7 \\
0.0 \\
0.0\end{array}$ & $\begin{array}{l}20808 . \\
16874 . \\
37784 .\end{array}$ \\
\hline & TOTAL & 71786 & 0.0 & 2763.5 & 778.7 & 111.2 & 26.1 & 0. & 0.0 & 0.0 & 0.0 & 0.0 & 0.0 & 2874.7 & 75465 . \\
\hline EQU & $\begin{array}{l}\text { IL.ICADING,KG/ } \\
\text { CORE } \\
\text { AX.EIANKET } \\
\text { RD.ELANKET }\end{array}$ & $\begin{array}{l}8564 . \\
8437 \\
7557\end{array}$ & $\begin{array}{l}0.0 \\
0.0 \\
0.0\end{array}$ & $\begin{array}{r}1381.7 \\
0.0 \\
0.0\end{array}$ & $\begin{array}{r}389.4 \\
0.0 \\
0.0\end{array}$ & $\begin{array}{r}55.6 \\
0.0 \\
0.0\end{array}$ & $\begin{array}{r}13.0 \\
0.0 \\
0.0\end{array}$ & $\begin{array}{l}0 . \\
0 . \\
0 .\end{array}$ & $\begin{array}{l}0.0 \\
0.0 \\
0.0\end{array}$ & $\begin{array}{l}0.0 \\
0.0 \\
0.0\end{array}$ & $\begin{array}{l}0.0 \\
0.0 \\
0.0\end{array}$ & $\begin{array}{l}0.0 \\
0.0 \\
0.0\end{array}$ & $\begin{array}{l}0.0 \\
0.0 \\
0.0\end{array}$ & $\begin{array}{r}1437.3 \\
0.0 \\
0.0\end{array}$ & $\begin{array}{r}10404 . \\
8437 . \\
7557 .\end{array}$ \\
\hline & TOTAL & 24558 . & 0.0 & 1381.7 & 389.4 & 55.6 & 13.0 & 0. & 0.0 & 0.0 & 0.0 & 0.0 & 0.0 & 1437.3 & 26397. \\
\hline $\mathrm{EQU}$ & $\begin{array}{l}\text { II.DISCHARGE, K } \\
\text { CORE } \\
\text { AX.ELANKET } \\
\text { RD. BIANKET }\end{array}$ & $\begin{array}{l}G / Y E \\
8080 . \\
8200 \\
7375\end{array}$ & $\begin{array}{r}31.9 \\
12.2 \\
5.0\end{array}$ & $\begin{array}{r}1123.1 \\
142.2 \\
143.5\end{array}$ & $\begin{array}{r}389.2 \\
3.3 \\
3.6\end{array}$ & $\begin{array}{r}66.3 \\
0.1 \\
0.2\end{array}$ & $\begin{array}{r}17.3 \\
0.0 \\
0.0\end{array}$ & $\begin{array}{l}0 . \\
0 . \\
0 .\end{array}$ & $\begin{array}{l}0.0 \\
0.0 \\
0.0\end{array}$ & $\begin{array}{l}0.0 \\
0.0 \\
0.0\end{array}$ & $\begin{array}{l}0.0 \\
0.0 \\
0.0\end{array}$ & $\begin{array}{l}0.0 \\
0.0 \\
0.0\end{array}$ & $\begin{array}{l}0.0 \\
0.0 \\
0.0\end{array}$ & $\begin{array}{r}1221.3 \\
154.5 \\
148.6\end{array}$ & $\begin{array}{l}9707 . \\
8418 . \\
7528 .\end{array}$ \\
\hline & TOTAL & 23715 & 49.1 & 1408.8 & 396.1 & 66.6 & 17.3 & 0 . & 0.0 & 0.0 & 0.0 & 0.0 & 0.0 & 1524.4 & 25653 . \\
\hline NET & $\begin{array}{l}\text { GAIN, KG/YR } \\
\text { CORE } \\
\text { AX. ELANKET } \\
\text { RD. ELANKET }\end{array}$ & $\begin{array}{l}-485 \\
-177 \\
-181\end{array}$ & $\begin{array}{r}31.9 \\
12.2 \\
5.0\end{array}$ & $\begin{array}{r}-258.6 \\
142.2 \\
143.5\end{array}$ & $\begin{array}{r}-0.2 \\
3.3 \\
3.6\end{array}$ & $\begin{array}{r}10.7 \\
0.1 \\
0.2\end{array}$ & $\begin{array}{l}4.3 \\
0.0 \\
0.0\end{array}$ & $\begin{array}{l}0 . \\
0 . \\
0 .\end{array}$ & $\begin{array}{l}0.0 \\
0.0 \\
0.0\end{array}$ & $\begin{array}{l}0.0 \\
0.0 \\
0.0\end{array}$ & $\begin{array}{l}0.0 \\
0.0 \\
0.0\end{array}$ & $\begin{array}{l}0.0 \\
0.0 \\
0.0\end{array}$ & $\begin{array}{l}0.0 \\
0.0 \\
0.0\end{array}$ & $\begin{array}{r}-216.0 \\
154.5 \\
148.6\end{array}$ & $\begin{array}{r}-697 . \\
-19 . \\
-29 .\end{array}$ \\
\hline & TCTAL & -843 & 49.1 & 27.0 & 6.7 & 11.0 & 4.3 & 0. & 0.0 & 0.0 & 0.0 & 0.0 & 0.0 & 87.1 & -744. \\
\hline
\end{tabular}

NOTE : 1. FISSILE $=$ FA233+U233+U235+ PU239+ PU241

2. BR AND CSDT CALCOLATED WITH EOUAL FISSILE ISOTOPE WEIGHTING AND CREDIT FOR PA-233

3. CSDI CALCUIATED HITH 1-YEAR EXTERNAL CYCLE TIUE AND 2 R REPROCESSING/FaBRICATION LOSSES 
REACTOR PERFORAANCE AND MASS FLON DATA

LMFER-CARBIDE: U233/U CORE, TH AB \& RB; REFERENCE DESIGN (0.37" PIN, $28 \mathrm{KH} / \mathrm{FT}$ )

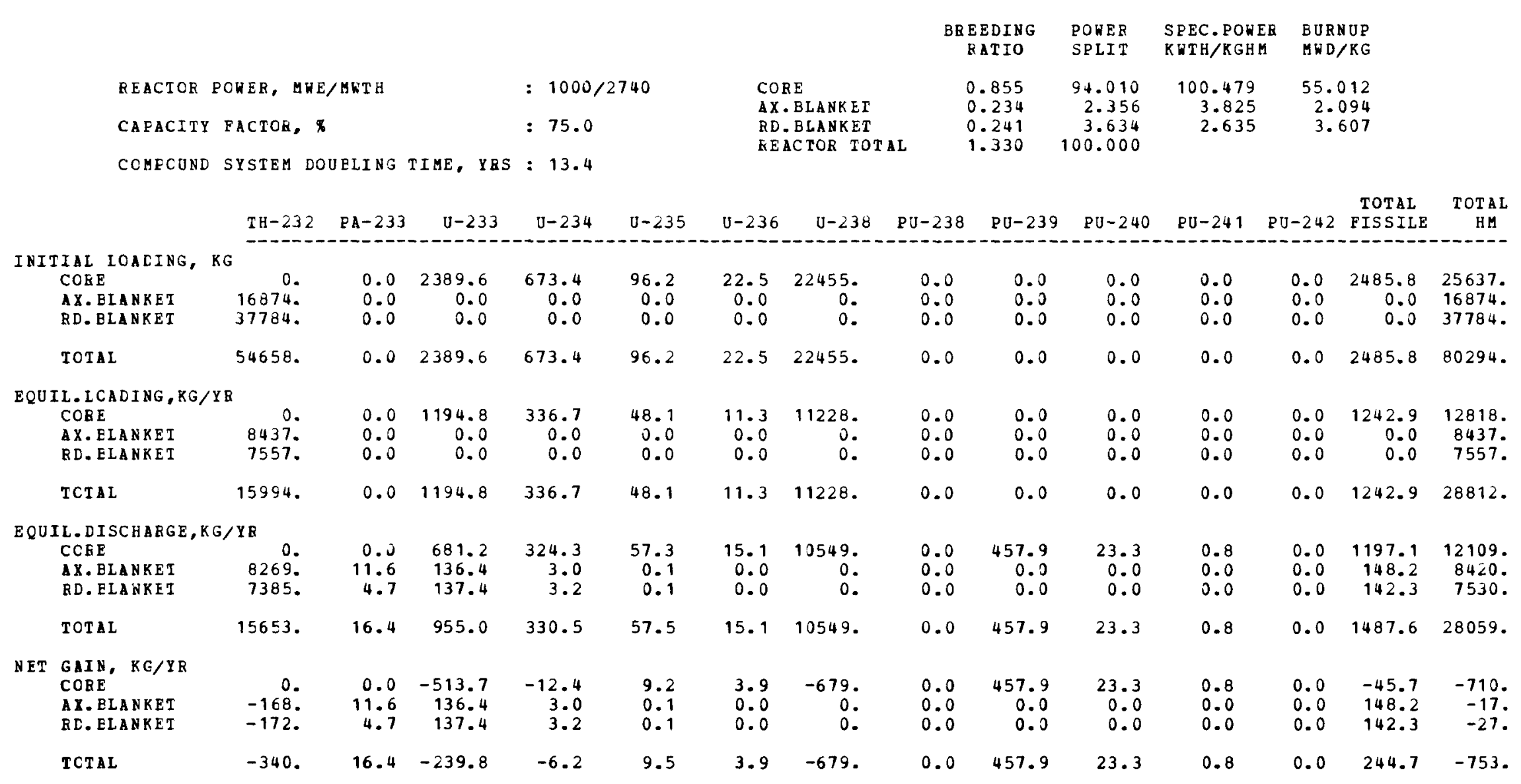

NOTE : 1. FISSILE $=$ PA233+U233+U235+ PU239+PU241

2. BR AND CSDT CALCULATED WITH EQUAL FISSILE ISOTOPE neIghting AND CREDIT FOR PA-233

3. CSDT CALCULATED WITH 1-YEAB EXTERMAL CYCLE TIME AND 2X REPROCESSING/FABRICATION LOSSES 


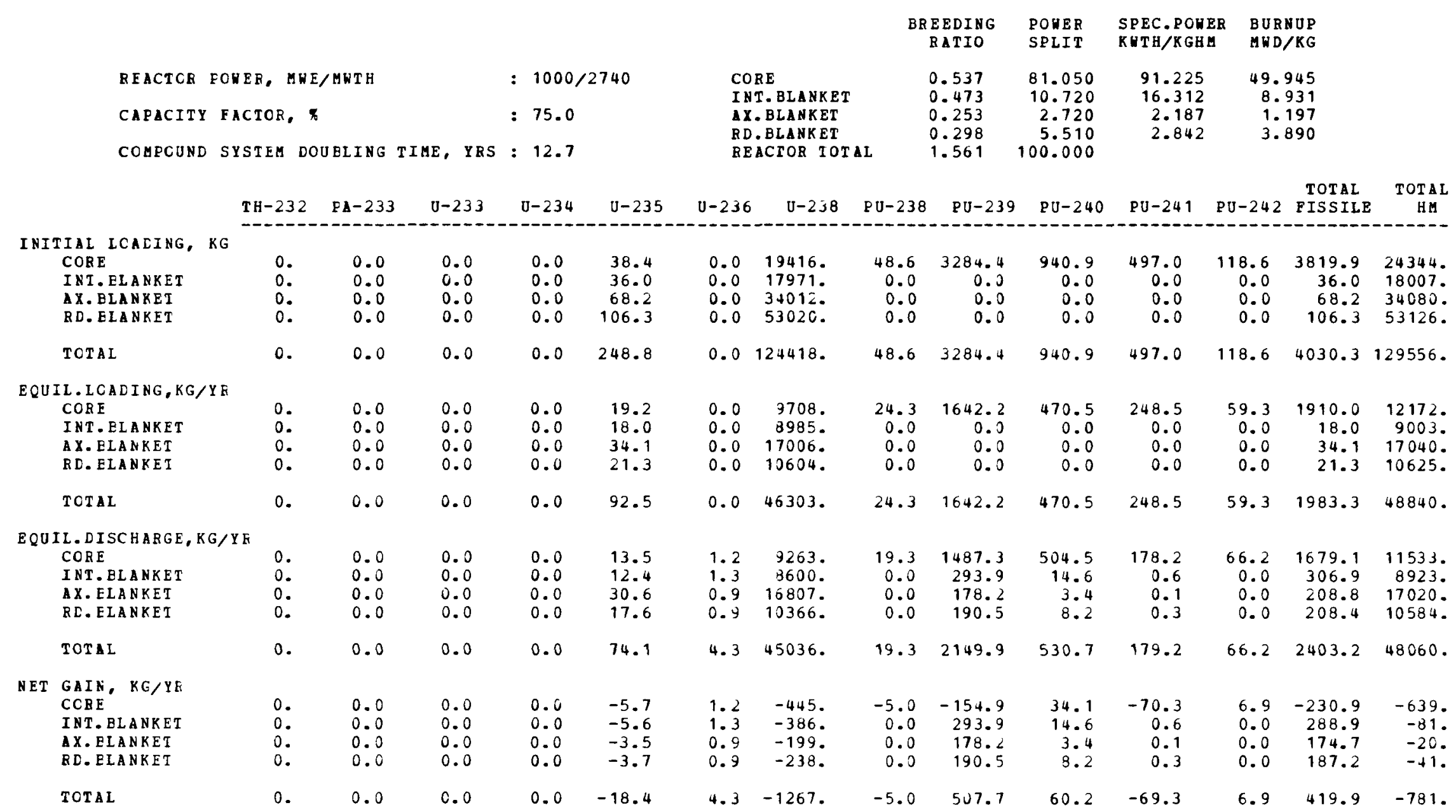

NOTE: 1. EISSILE $=$ PA $\angle 33+U 233+U 235+$ PU $239+$ PU 241

2. BE AND CSDT CALCULATED WITH EQUAL FISSILE ISOTOPE LEIGHIINJ AND CREDIT FOR PA-233

3. CSDT CALCULATED WITH 1-YEAR EXTERNAL CYCLE TIME AND $2 \%$ REPBOCESSING/FABRICATION LOSSES 
REACTOR PERFORMANCE AND HASS FLOW DATA

LMFER-CARBIDE HETEROGENEOUS: PU/U CORE, TH BLANKET; REFERENCE DESIGN (0.37" PIN)

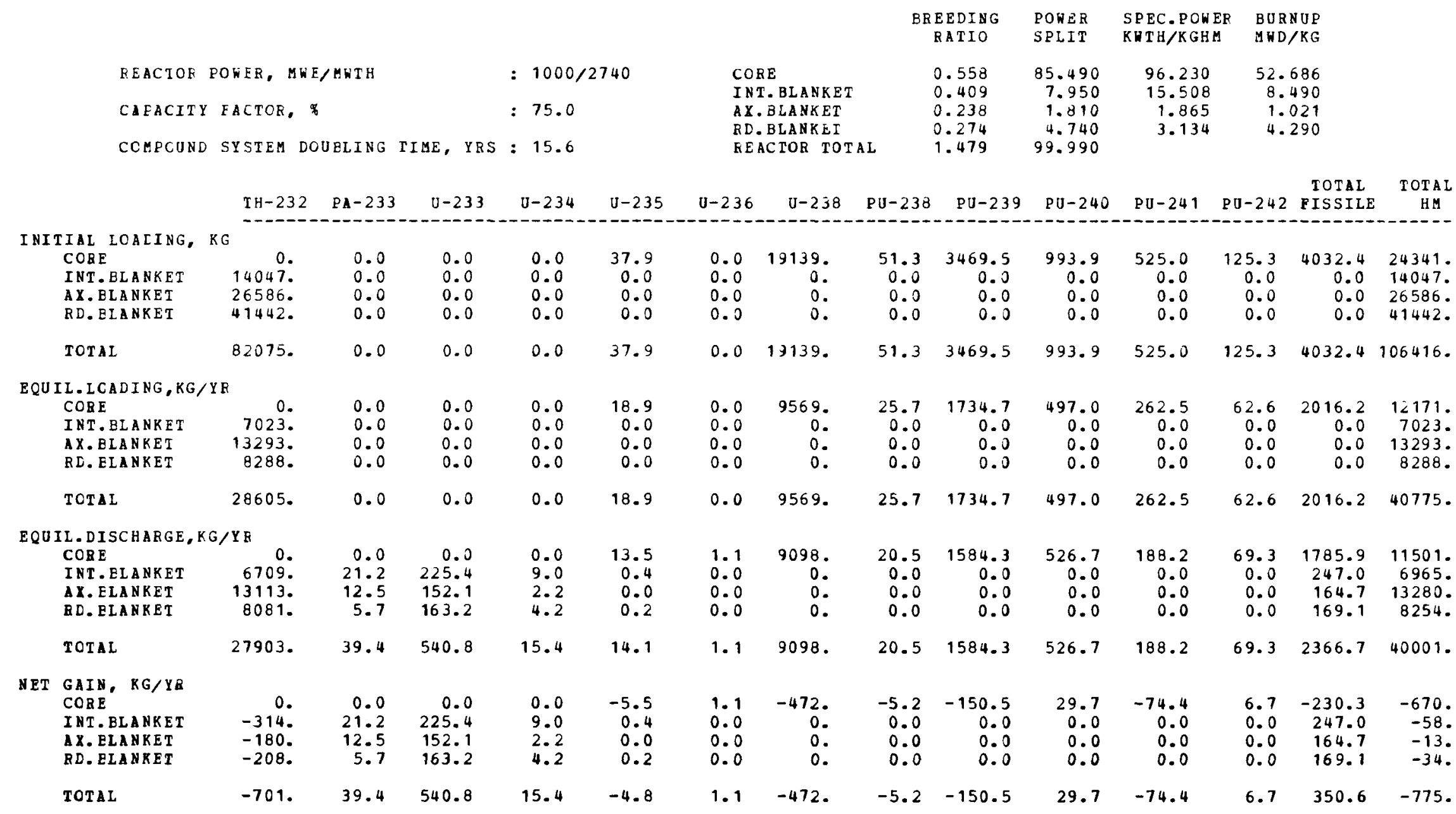

NOTE : 1. FISSILE $=$ PA233+ $2333+\mathrm{U} 235+\mathrm{PU} 239+\mathrm{PU} 241$

2. BR AND CSDT CALCULATED WITH EQUAL FISSILE ISOTOPE WEIGHTING AND CREDIT POR PA-233

3. CSDT CALCULATED NITH 1-YEAR EXTERUAL CYCLE TIBE AND 2X BEPROCESSING/FABRICATION LOSSES 
LMPBR-METAL: PO/U CORE, O AB $\&$ RB; REFERENCE DESIGN (0.31n PIN, $20 \mathrm{KH} / \mathrm{PT})$

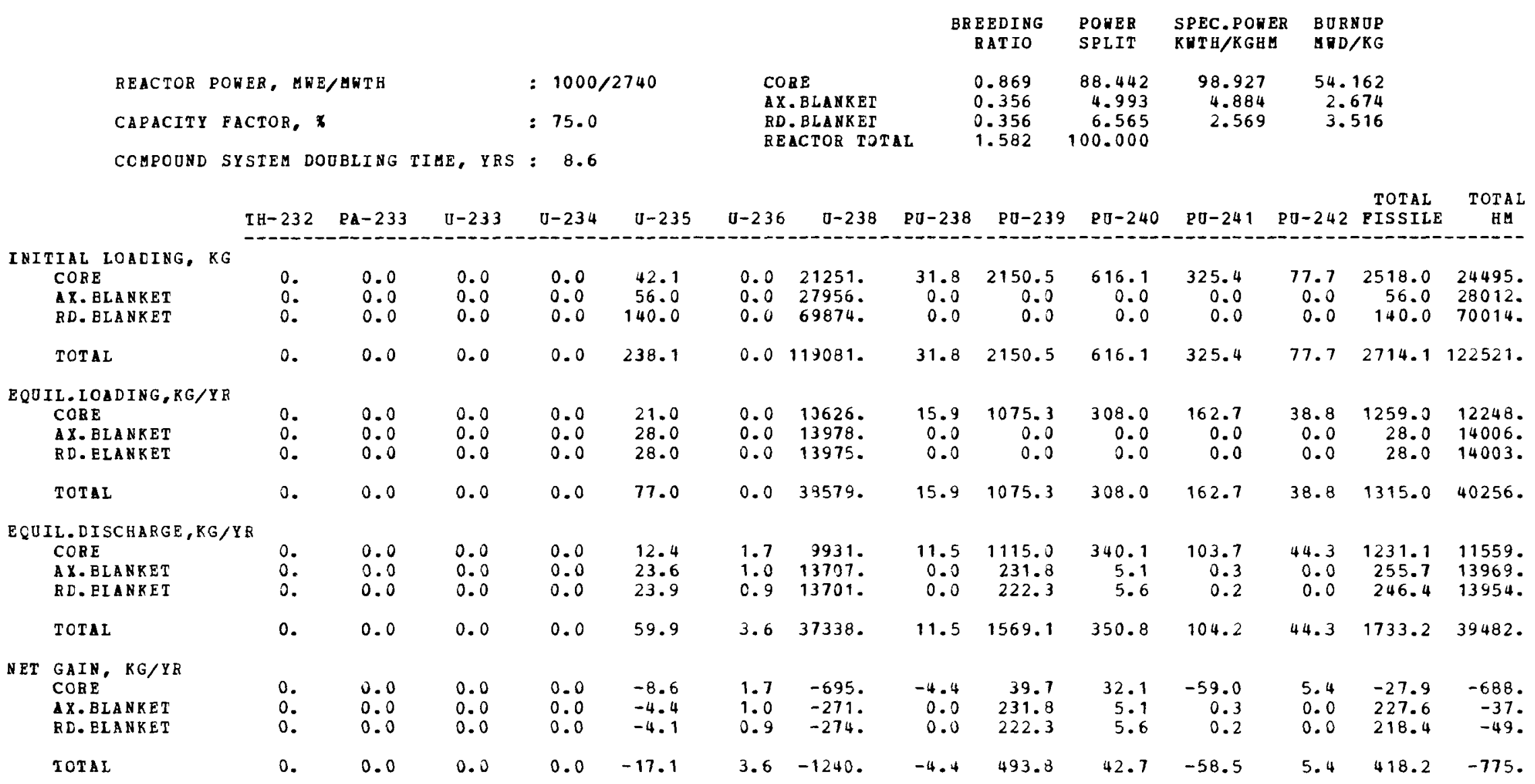

NOTE : 1. FISSILE $=$ FA233+0233+U235+PU239+PU241

2. BR AND CSDT CALCULATED WITH EQUAL FISSILE I SOTOPE HEIGHTING AND CBEDIT FOR PA-233

3. CSDT CALCULATED WITH 1-YEAR EXTERNAL CYCLE TIUE AND 2\% REPROCESSING/FABRICATION LOSSES 
REACTOR PERFORHANCE AND MASS FLON DATA

LAFER-METAL: PU/O CORE, U AB, TH RB; REFERENCE DESIGN $(0.31 "$ PIN, $20 \mathrm{KH} / \mathrm{FT})$

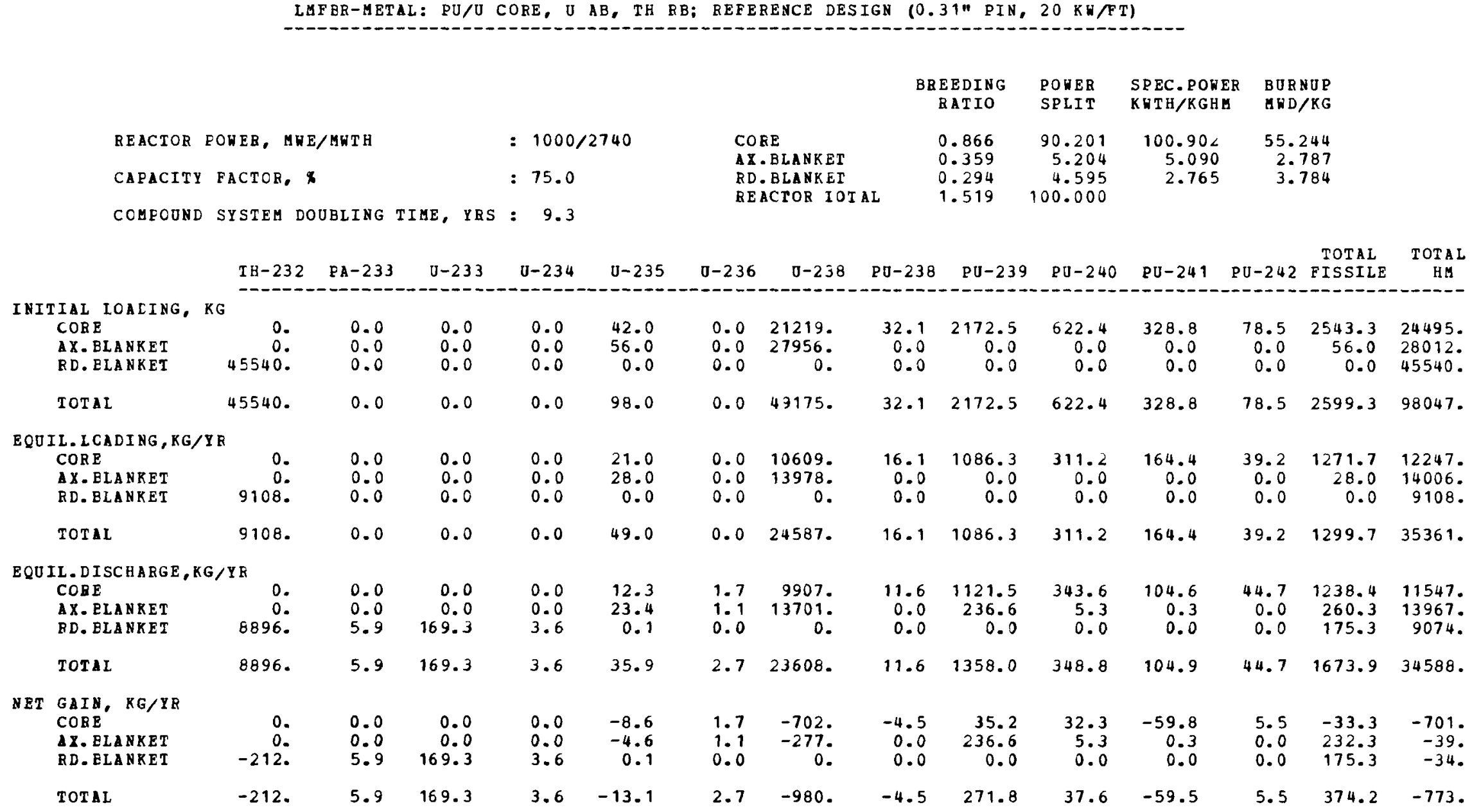

NOTE : 1. FISSILE $=$ PA $233+0233+U 235+$ PU $239+$ PU 241

2. BR AND CSDT CALCULATED RITH EQUAL FISSILE ISOTORE HEIGHTING AND CREDIT FOR PA-233

3. CSDT CALCOLATED WITH 1-YEAR EXTERHAL CYCLE TIUE AND $2 \%$ REPROCESSING/FABRICATION LOSSES 


\section{REACTOR PERFORHANCE AND MASS FLOH DATA}

LMFER-METAL: PU/U CORE, TH AB $E$ RB; REFERENCE DESIGN (0.31" PIN, 20 RH/FT)

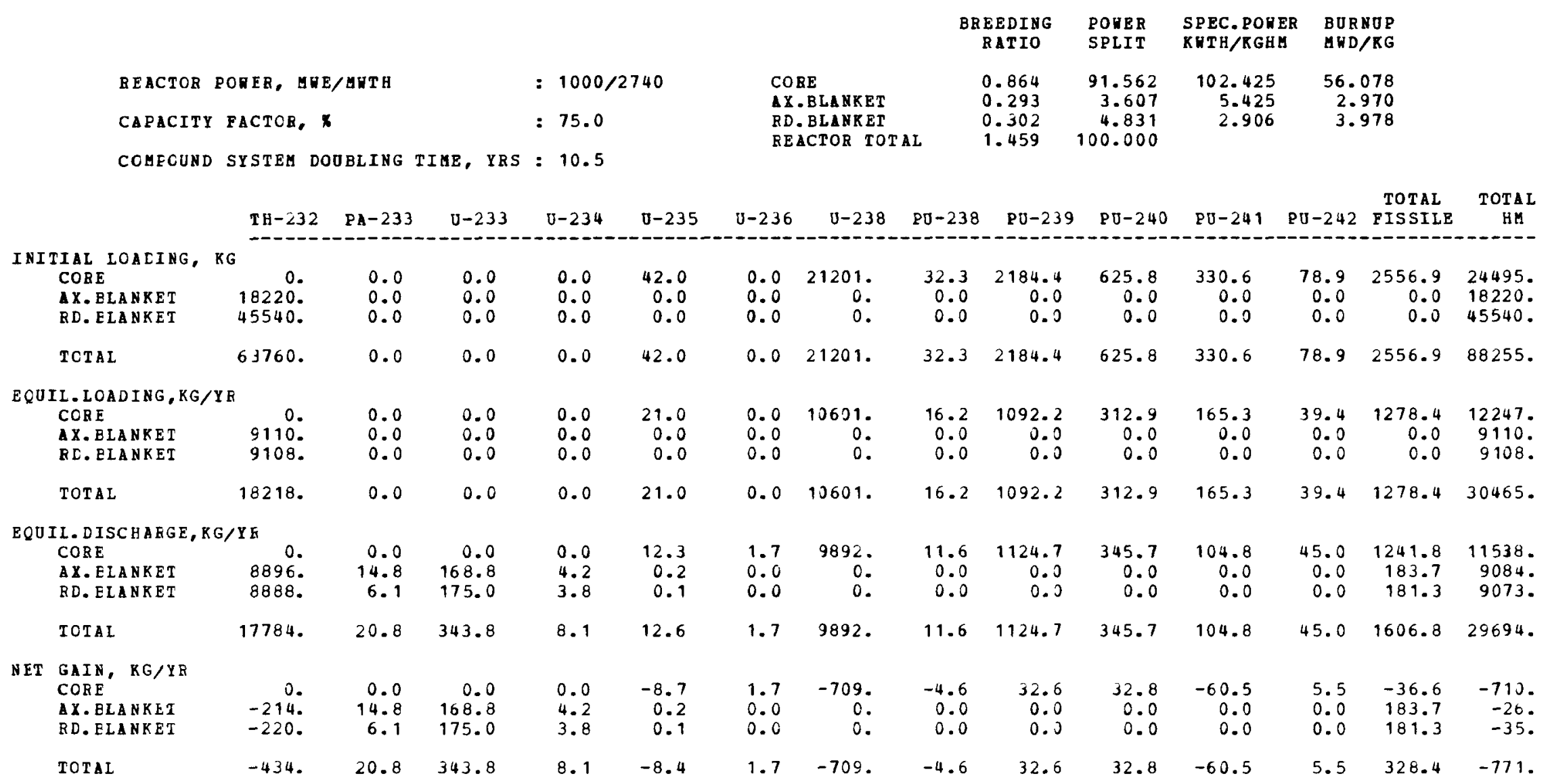

NOTE : 1. FISSILF $=$ PA $233+U 233+0235+$ PU239+PU 241

2. BE AND CSDT CALCULATED WITH EQUAL FISSILE ISOTOPE WEIGHTIN 3 AND CBEDIT FOR PA-233

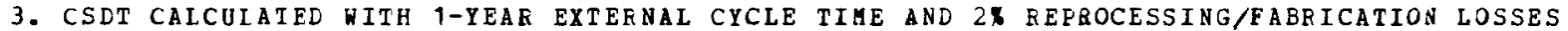


REACTOR PERFORMANCE AND MASS FLON DATA

LMFER-GETAL: PO/TH CORE, TH AB E RB; REFERENCE DESIGN (20 KH/PT, 0.31" PIN)

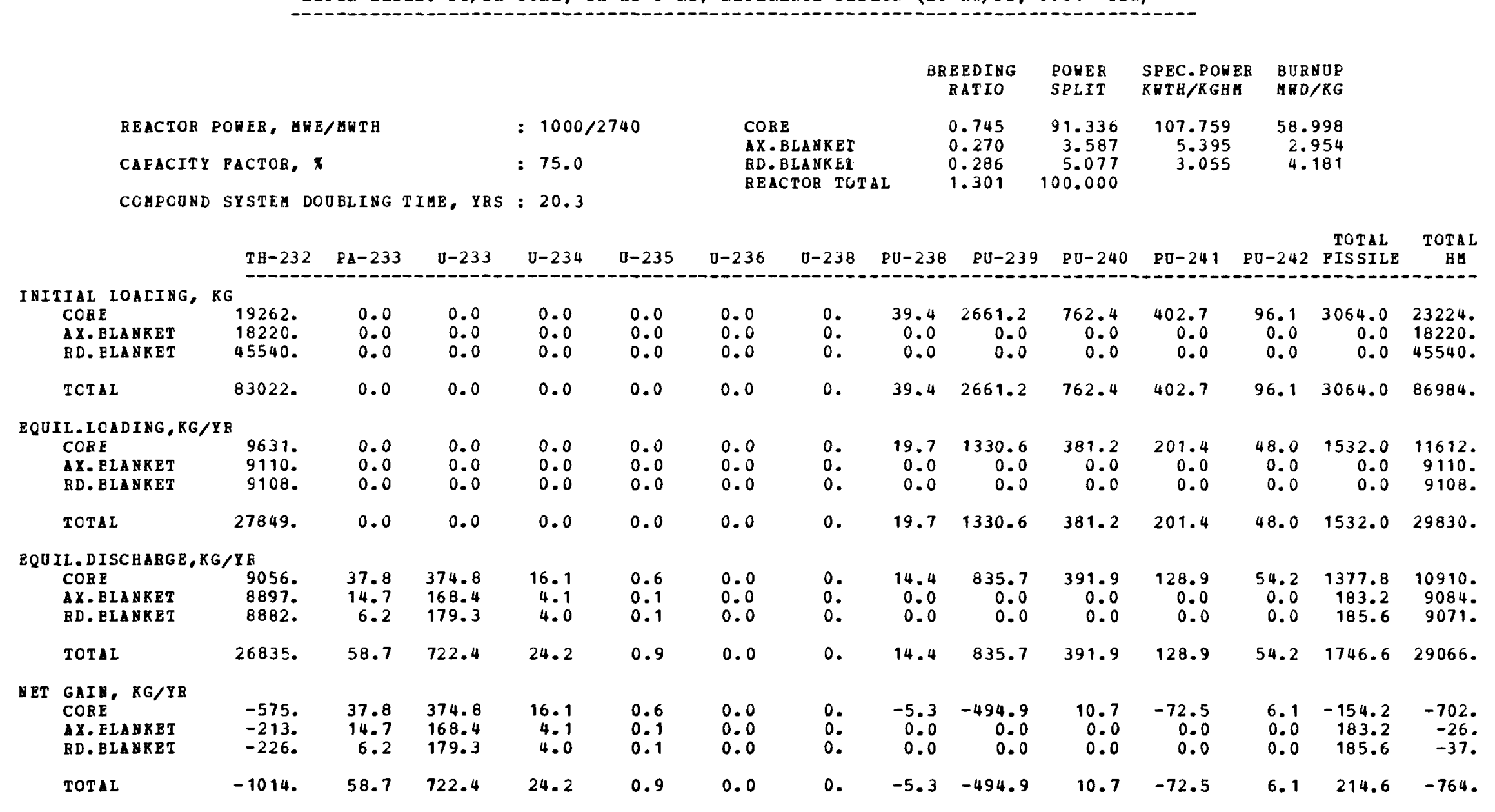

HOTE : 1. FISSILE $=$ PA233+0233+ U235+PU239+PU241

2. BR AHD CSDT CALCOLATED HITH EQUAL FISSILE ISOTOPE WEIGHTIHG AND CREDIT FOB PA-233

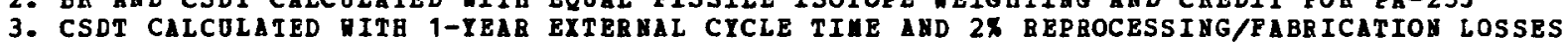




\section{REACTOR PERFORMANCE AND MASS FLOH DATA}

LUFBR-METAL: U233/TH CORE, TH AB E RB; REFERENCE DESIGN (0.31" PIN, $20 \mathrm{KN} / \mathrm{FT}$ )

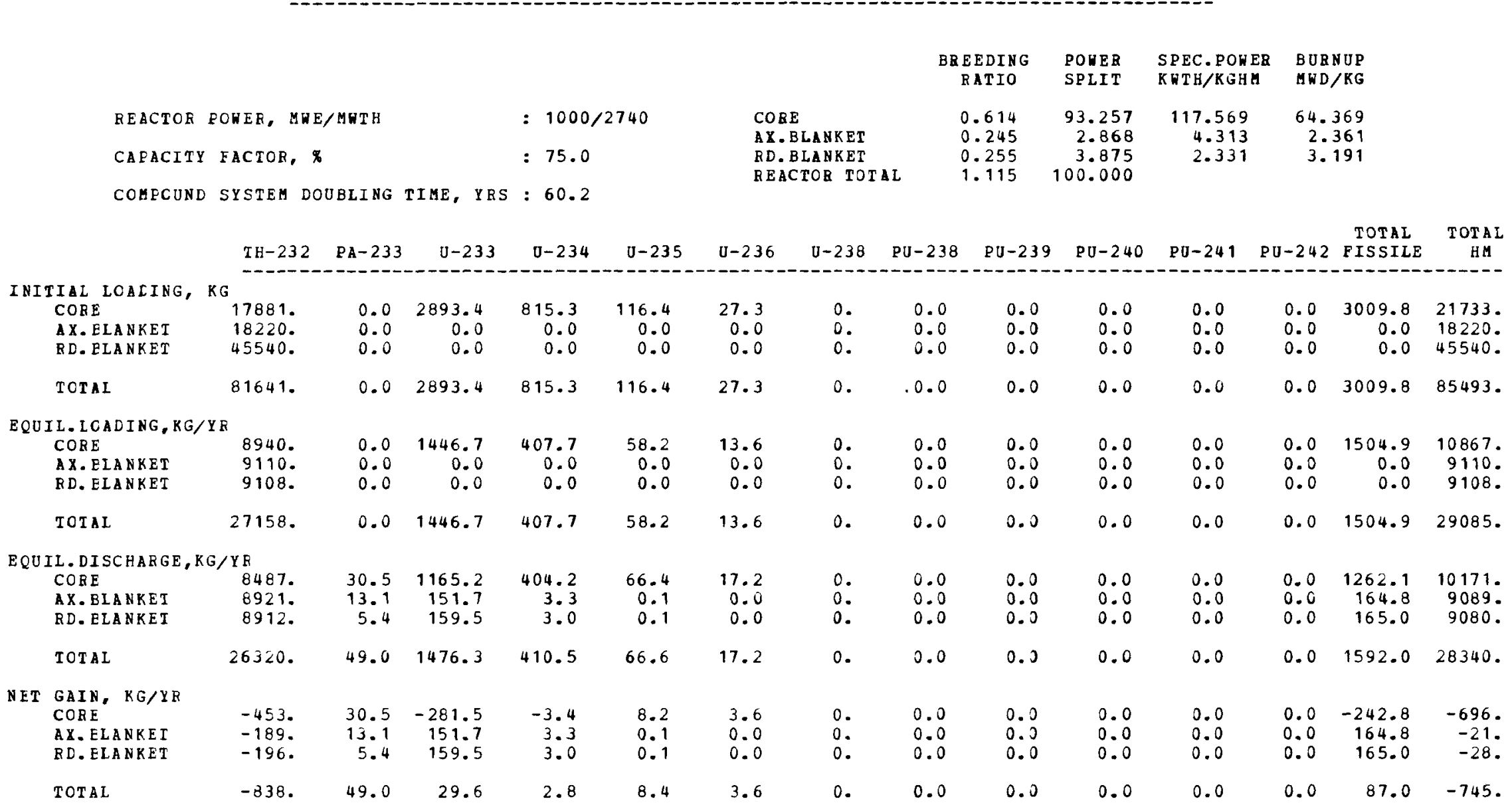

NOTE : 1. FISSILE $=$ EA $233+\mathrm{U} 233+\mathrm{U} 235+\mathrm{PU} 239+\mathrm{PU} 241$

2. BE AND CSDI CALCULATED WITH EQUAL FISSILE ISOTOPE WEIGHTIN3 AND CREDIT FOR PA-233

3. CSDT CALCULATED WITH 1-YEAE EXTERAAL CYCLE TIME AND $2 \%$ EERROCESSING/FABRICATION LOSSES 
REACTOR PERFORMANCE AND MASS FLON DATA

LMFER-METAL: U233/U COKE, TH AB E RB: REFERENCE DESIGN (0.31" PIN, $20 \mathrm{KH} / \mathrm{FT}$ )

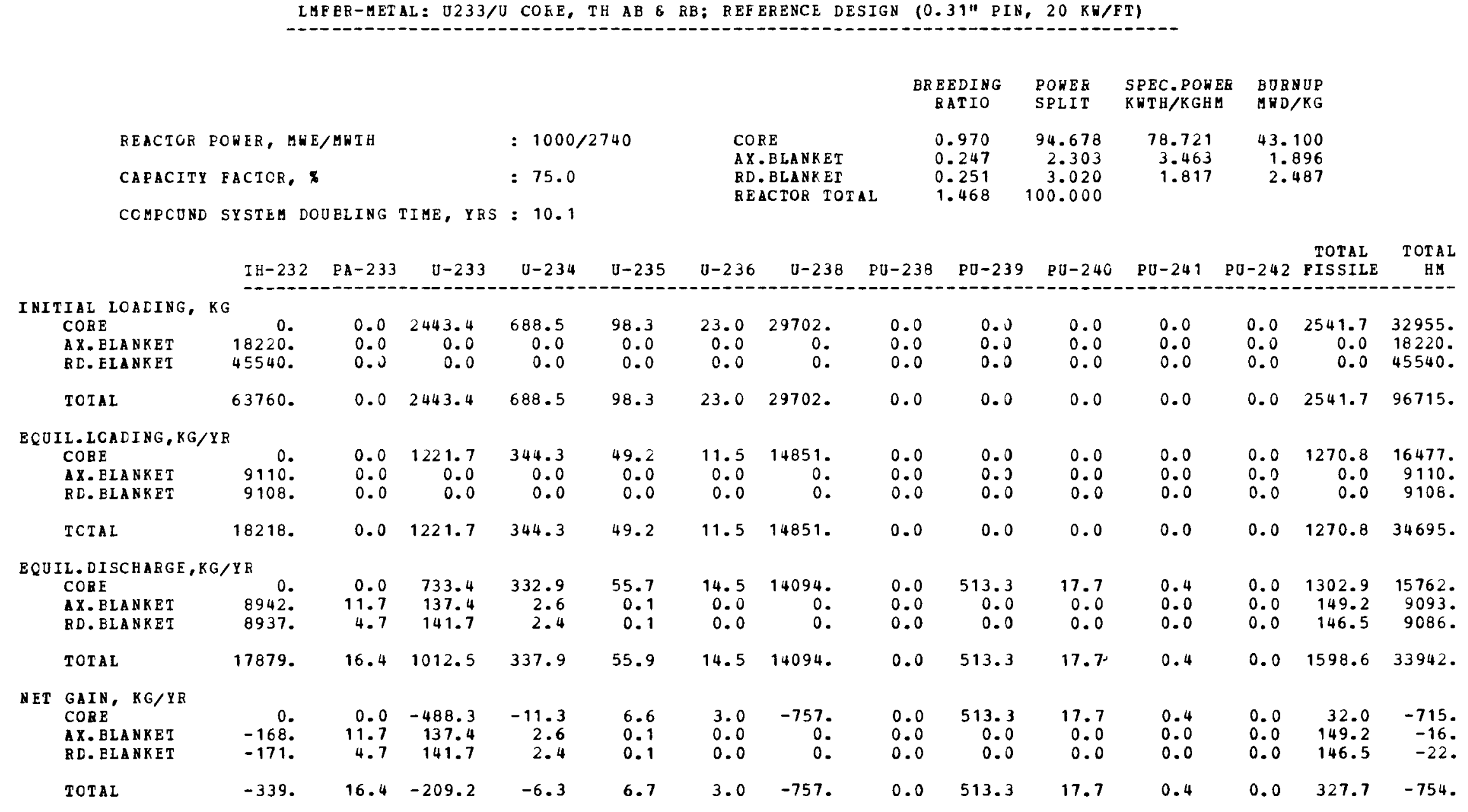

NOTE : 1. FISSILE $=$ PA233+U233+U235+PU239+PU241

2. BR ANL CSDT CALCULATED HITH EQUAL FISSILE ISOTOPE WEIGHTING AND CREDIT FOR Pa-233

3. CSDT CaLCULATED ITH 1-YEAR EXTERnal CYCLE TIHE and $2 \%$ EEPBOCESSING/Fabrication LOSSES 


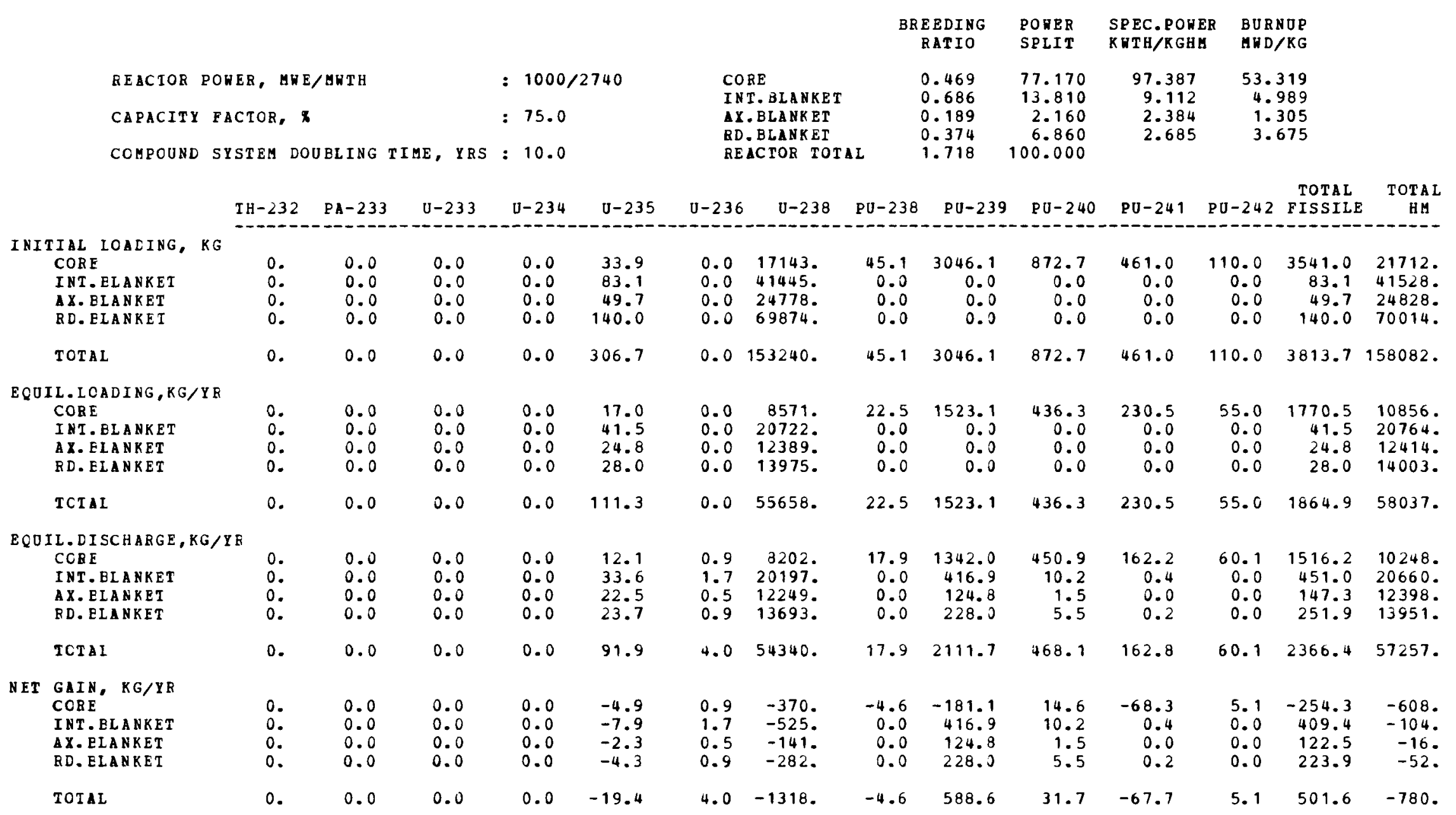

NOTE : 1. FISSILE $=$ PA233+U233+U235+PU239+PU241

2. BF AND CSDT CALCULATED WITH EQUAL FISSILE ISOTOPE WEIGHTING AND CREDIT FOR PA-233

3. CSDT CaLCULATED HITH 1-YEAR EXTERNAL CYCLE TIME AND 2X REPROCESSING/FABRICATION LOSSES 
REACTOR PERFOEMANCE AND MASS FLON DATA

LMFBR-METAL HETEROGENEOUS: PU/U CORE TH BIANKET; REPERENCE DESIGN (0.31" PIN)

LMPBR-HETAL HETEROGENEOUS: PU/U CORE TH BIANKET; REPERENCE DESIGN (0.31N PIN)

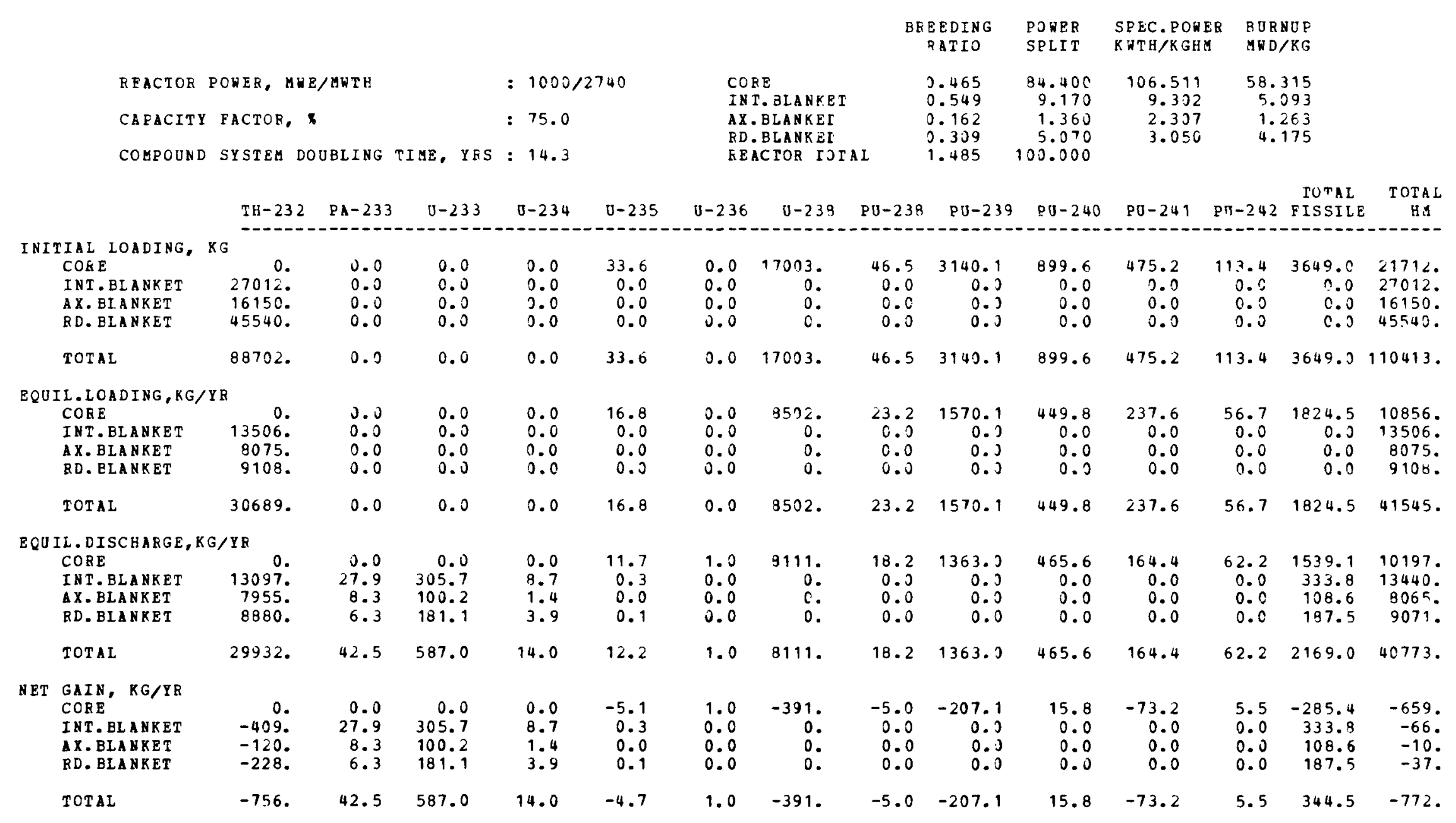

NOTE : 1. FISSIIE $=$ FA233+0233+U235+ PU239+PU241

2. BR AND CSDT CALCOLATED ITH EOUAL FISSILE ISOTORE HEIGHTINA AND CBEDIT FOB PA-233

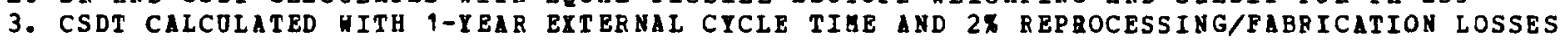




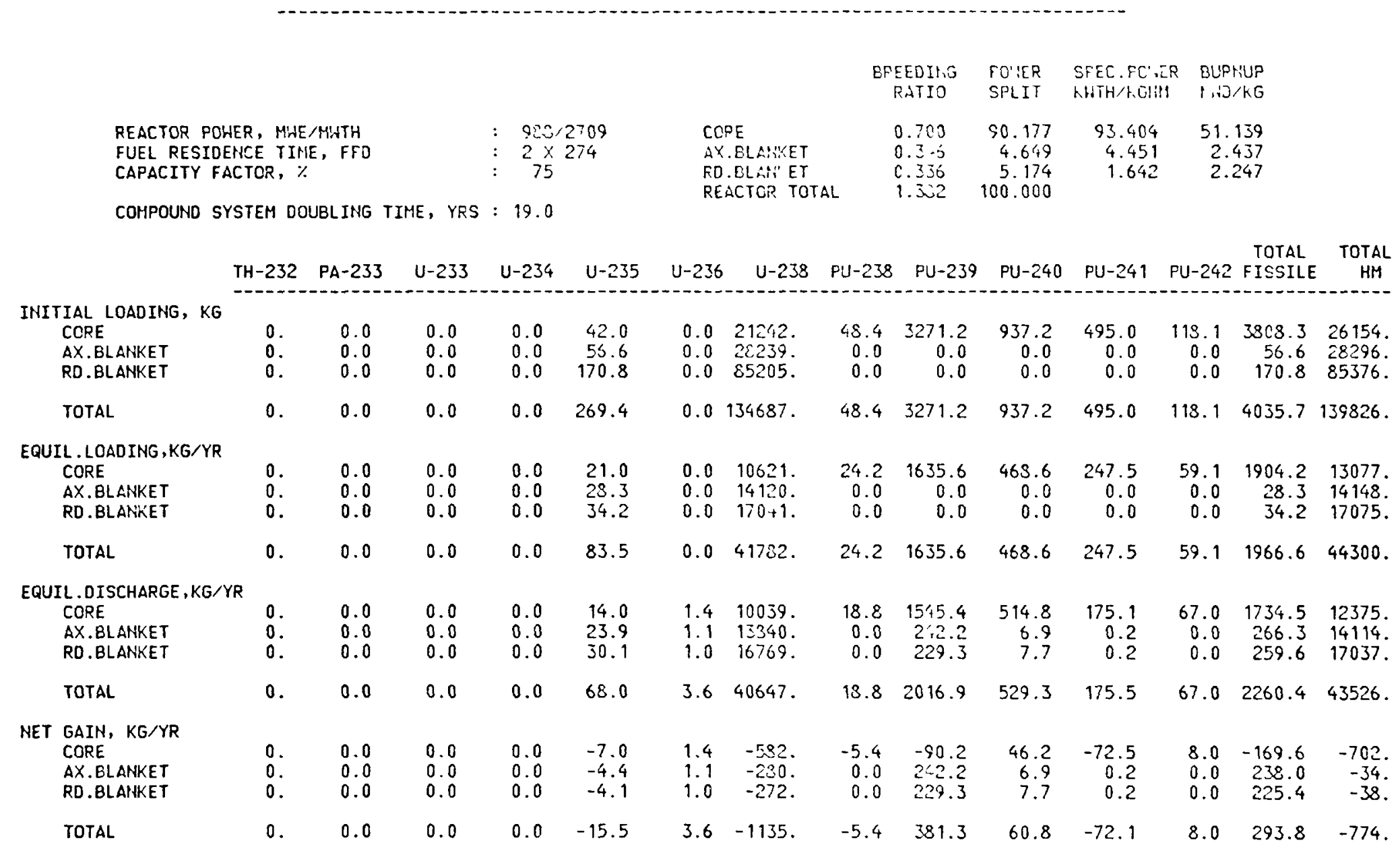

NOTE : 1. FISSILE $=$ PA233 + U233 + U235 + FU239 + PUL41

2. BR ATID CSDT CALCULATED WITH ETJAL FISSILE ISTTOPE WEIGHTINIS AHD CHEDIT FOR PA-233

3. CSDT CALCULATED WITH 1-YEAR EXTEPAHL CYCLE TIME GHO $2 \%$ TEFROCESSITIS FAENICATICIA LOSSES

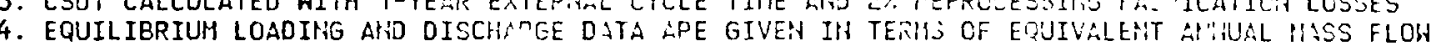


REACTOR PERFORHANCE AND MASS FLOIN DATA

GCFR: PU/U CORE, U AB, TH RB; GA REFERENCE DESIGN HOR:IALIZED TO $14 \mathrm{~kW} / \mathrm{FT}$

REACTOR POHER, MWE/MWTH
FUEL RESIDENCE TIME, FPD

FUEL RESIDENCE TIME,
CAPACITY FACTOR, $\%$

COMPOUND SYSTEM DOUBLING TIME, YRS : 20.0

$$
\begin{aligned}
& : \quad 983 / 2709 \\
& : \quad 2 \times 274 \\
& 75
\end{aligned}
$$

\section{BREEDINS$$
\text { RATIO }
$$

PCHER

STEC. PCINER BUTNUP

\section{CORE}

AX.BLANKET

RD. BLANKET

$0.699 \quad 91.151$

$\begin{array}{rr}0.659 & 91.151 \\ 0.3 \div 6 & 4.719\end{array}$

$\begin{array}{rr}0.3 .6 & 4.719 \\ 0.316 & 4.130\end{array}$

$1.361 \quad 100.000$
STEC.PCINER BURNUP

\begin{tabular}{|c|c|c|c|c|c|c|c|c|c|c|c|c|c|c|}
\hline & $T H-232$ & $P A-233$ & $u-233$ & $U-234$ & $U-235$ & $u-236$ & $U-238$ & PU-238 & PU-239 & PU-240 & PU-241 & $P U-242$ & $\begin{array}{l}\text { TOTAL } \\
\text { FISSILE }\end{array}$ & $\begin{array}{c}\text { TOTAL } \\
\text { HM }\end{array}$ \\
\hline $\begin{array}{l}\text { NITIAL LOADING, } \\
\text { CORE } \\
\text { AX.BLANKET } \\
\text { RD.BLANKET }\end{array}$ & $\begin{array}{r}0 \\
0 \\
0 \\
77660\end{array}$ & $\begin{array}{l}0.0 \\
0.0 \\
0.0\end{array}$ & $\begin{array}{l}0.0 \\
0.0 \\
0.0\end{array}$ & $\begin{array}{l}0.0 \\
0.0 \\
0.0\end{array}$ & $\begin{array}{r}42.0 \\
56.6 \\
0.0\end{array}$ & $\begin{array}{l}0.0 \\
0.0 \\
0.0\end{array}$ & $\begin{array}{r}21211 \\
28239 \\
0\end{array}$ & $\begin{array}{r}48.7 \\
0.0 \\
0.0\end{array}$ & $\begin{array}{r}3293.6 \\
0.0 \\
0.0\end{array}$ & $\begin{array}{r}943.6 \\
0.0 \\
0.0\end{array}$ & $\begin{array}{r}498.4 \\
0.0 \\
0.0\end{array}$ & $\begin{array}{r}118.9 \\
0.0 \\
0.0\end{array}$ & $\begin{array}{r}3834.0 \\
56.6 \\
0.0\end{array}$ & $\begin{array}{l}26156 \\
28296 \\
77660\end{array}$ \\
\hline TOTAL & 77660 . & 0.0 & 0.0 & 0.0 & 98.6 & 0.0 & 49450 . & 48.7 & 3293.6 & 943.6 & 498.4 & 118.9 & 3890.6 & 132112 \\
\hline $\begin{array}{l}\text { EQUIL.LOADING, KG } \\
\text { CORE } \\
\text { AX.BLANKET } \\
\text { RD.BLANKET }\end{array}$ & $\begin{array}{r}\mathbf{R} \\
0 \\
0 \\
15532\end{array}$ & $\begin{array}{l}0.0 \\
0.0 \\
0.0\end{array}$ & $\begin{array}{l}0.0 \\
0.0 \\
0.0\end{array}$ & $\begin{array}{l}0.0 \\
0.0 \\
0.0\end{array}$ & $\begin{array}{r}21.0 \\
28.3 \\
0.0\end{array}$ & $\begin{array}{l}0.0 \\
0.0 \\
0.0\end{array}$ & $\begin{array}{r}10605 . \\
14120 . \\
0 .\end{array}$ & $\begin{array}{r}24.4 \\
0.0 \\
0.0\end{array}$ & $\begin{array}{r}1646.8 \\
0.0 \\
0.0\end{array}$ & $\begin{array}{r}471.8 \\
0.0 \\
0.0\end{array}$ & $\begin{array}{r}249.2 \\
0.0 \\
0.0\end{array}$ & $\begin{array}{r}59.5 \\
0.0 \\
0.0\end{array}$ & $\begin{array}{r}1917.0 \\
28.3 \\
0.0\end{array}$ & $\begin{array}{l}13078 . \\
14148 . \\
15532 .\end{array}$ \\
\hline TOTAL & 15532. & 0.0 & 0.0 & 0.0 & 49.3 & 0.0 & 24725 & 24.4 & 1646.8 & 471.8 & 249.2 & 59.5 & 1945.3 & 42758. \\
\hline $\begin{array}{l}\text { EQUIL. DISCHARGE, } \\
\text { CORE } \\
\text { AX.BLANKET } \\
\text { RD.BLANKET }\end{array}$ & $\begin{array}{r}\text { AYR } \\
0 \\
0 \\
15291\end{array}$ & $\begin{array}{l}0.0 \\
0.0 \\
6.7\end{array}$ & $\begin{array}{r}0.0 \\
0.0 \\
201.6\end{array}$ & $\begin{array}{l}0.0 \\
0.0 \\
3.6\end{array}$ & $\begin{array}{r}14.0 \\
23.9 \\
0.1\end{array}$ & $\begin{array}{l}1.4 \\
1.1 \\
0.0\end{array}$ & $\begin{array}{r}10021 \\
13838 \\
0\end{array}$ & $\begin{array}{r}19.0 \\
0.0 \\
0.0\end{array}$ & $\begin{array}{r}1553.0 \\
243.6 \\
0.0\end{array}$ & $\begin{array}{r}518.1 \\
7.0 \\
0.0\end{array}$ & $\begin{array}{r}176.2 \\
0.2 \\
0.0\end{array}$ & $\begin{array}{r}67.5 \\
0.0 \\
0.0\end{array}$ & $\begin{array}{r}1743.2 \\
267.6 \\
208.4\end{array}$ & $\begin{array}{l}12370 . \\
14113 . \\
15503 .\end{array}$ \\
\hline TOTAL & 15291. & 6.7 & 201.6 & 3.6 & 38.0 & 2.5 & 23858 & 19.0 & 1796.6 & 525.1 & 176.4 & 67.5 & 2219.2 & 41986. \\
\hline $\begin{array}{c}\text { NET GAIH, KG/YR } \\
\text { CORE } \\
\text { AX.BLAIKET } \\
\text { RD.BLANKET }\end{array}$ & $\begin{array}{r}0 \\
0 . \\
-241\end{array}$ & $\begin{array}{l}0.0 \\
0.0 \\
6.7\end{array}$ & $\begin{array}{r}0.0 \\
0.0 \\
201.6\end{array}$ & $\begin{array}{l}0.0 \\
0.0 \\
3.6\end{array}$ & $\begin{array}{r}-7.0 \\
-4.4 \\
0.1\end{array}$ & $\begin{array}{l}1.4 \\
1.1 \\
0.0\end{array}$ & $\begin{array}{r}-585 . \\
-2 \varepsilon 2 . \\
0 .\end{array}$ & $\begin{array}{r}-5.4 \\
0.0 \\
0.0\end{array}$ & $\begin{array}{r}-93.8 \\
243.6 \\
0.0\end{array}$ & $\begin{array}{r}46.3 \\
7.0 \\
0.0\end{array}$ & $\begin{array}{r}-73.0 \\
0.2 \\
0.0\end{array}$ & $\begin{array}{l}8.0 \\
0.0 \\
0.0\end{array}$ & $\begin{array}{r}-173.8 \\
239.3 \\
208.4\end{array}$ & $\begin{array}{r}-708 \\
-35 \\
-29\end{array}$ \\
\hline TOTAL & -241. & 6.7 & 201.6 & 3.6 & -11.3 & 2.5 & -867 & -5.4 & 149.8 & 53.3 & -72.9 & 8.0 & 273.9 & -772 \\
\hline
\end{tabular}

$94.406 \quad 51.687$

$4.518 \quad 2.474$

NOTE : 1. FISSILE $=$ PA233 + U233 + U235 + PU239 + PU241

2. BR AND CSOT CALCULATED HITH EQUAL FISSILE ISOTOPE HEIGHTING AND CREDIT FOR PA-233

3. CSDT CALCULATED WITH 1-YEAR EXTEPNAL CYCLE TIME AND 2\% REFROCESSIIIS/FABRICATION LOSSES

4. EQUILIBRIUM LOADING AND DISCHARGE DATA ARE GIVEN IN TERHS OF EQUIVALENT AFHIUAL MASS FLOH 
REACTOR PERFORMANCE ANID MASS FLON DATA

GCFR: PU/U CORE, TH AB \& RB; GA REFERENCE DESIE!N NJPIIALIZED TO $14 \mathrm{~kW} / F T$

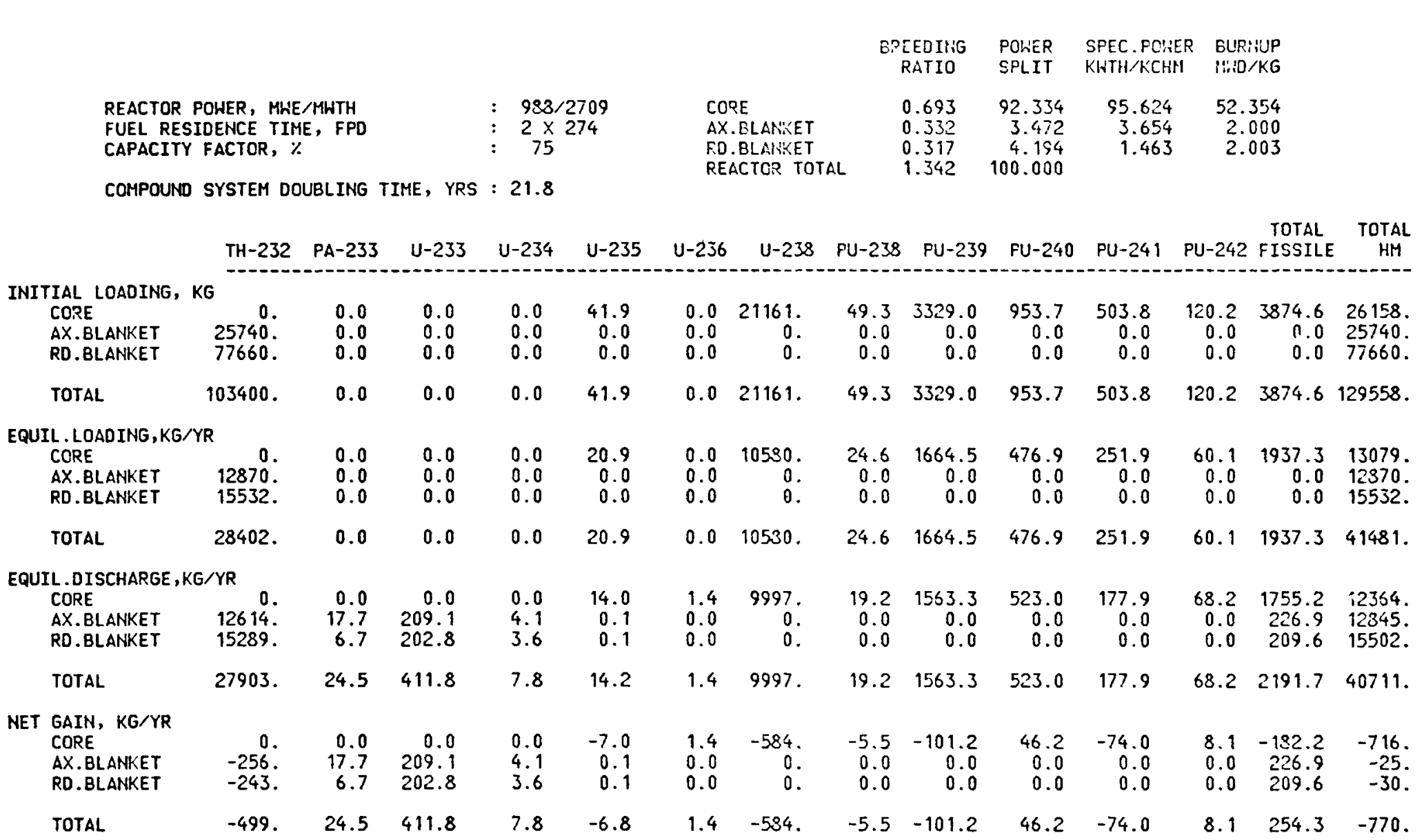

NOTE : 1. FISSILE $=$ PA233 + U233 + U235 + PU239 + PU241

2. BR AID CSDT CALCULATED HITH EGUAL FISSILE ISOTOPE WEIGHTINIG ARD CREDIT FOR PA-233

3. CSDT CALCULATED WITH 1-YEAR EXTERNAL CYCLE TIME ANID 2\% REPROCESSINIG/FABRICATION LOSSES

4. EQUILIBRIUM LOADING AND DISCHARGE DATA ARE GIVEN IN TERMS OF EQUIVALENT ALINUAL MASS FLOW 
REACTOR PERFORIIANCE ARID MASS FLOH DATA

GCFR: PU/TH CORE, TH AB \& RB; GA REFERENCE DESIG: HORIWLIZED TO $14 \mathrm{~kW} / \mathrm{FT}$

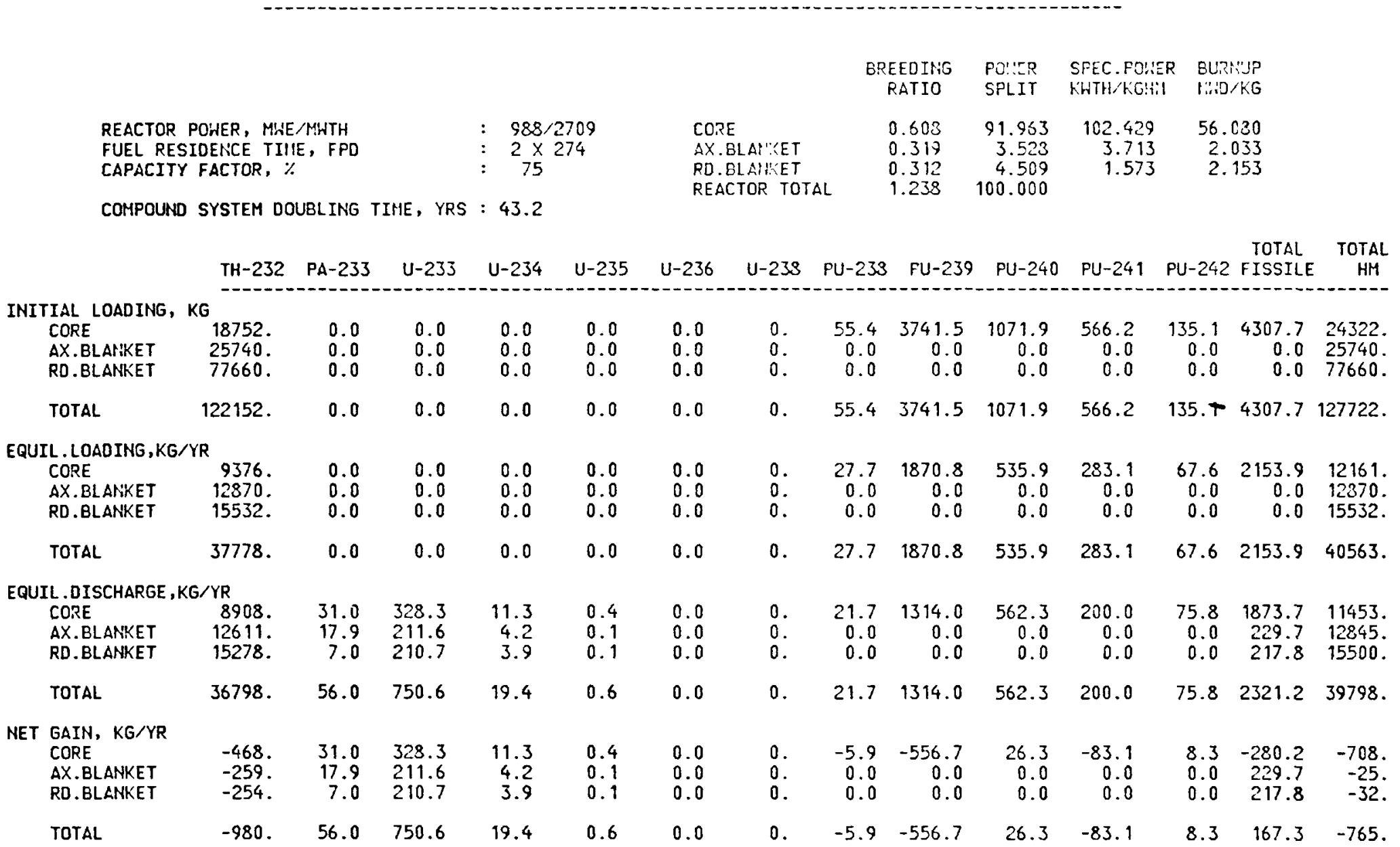

NOTE : 1. FISSILE $=$ PA233 + U233 + U235 + PU239 + PU241

2. ER AIIO CSDT CALCULATED WITH EQUAL FISSILE ISOTOPE HEIGHTIYG AT'D CREDIT FOR PA-233

3. CSDT CALCULATED WITH 1-YEAR EXTERNAL CYCLE TIME LiD $2 \%$ REFROCESSIRIG/FACRICATIOH LOSSES

4. EQUILIBRIUM LOADING ATID OISCHAREE DATA ARE GIVEN IN TERHS GF EQUIVALEHT AHHiUAL HIASS FLOW 


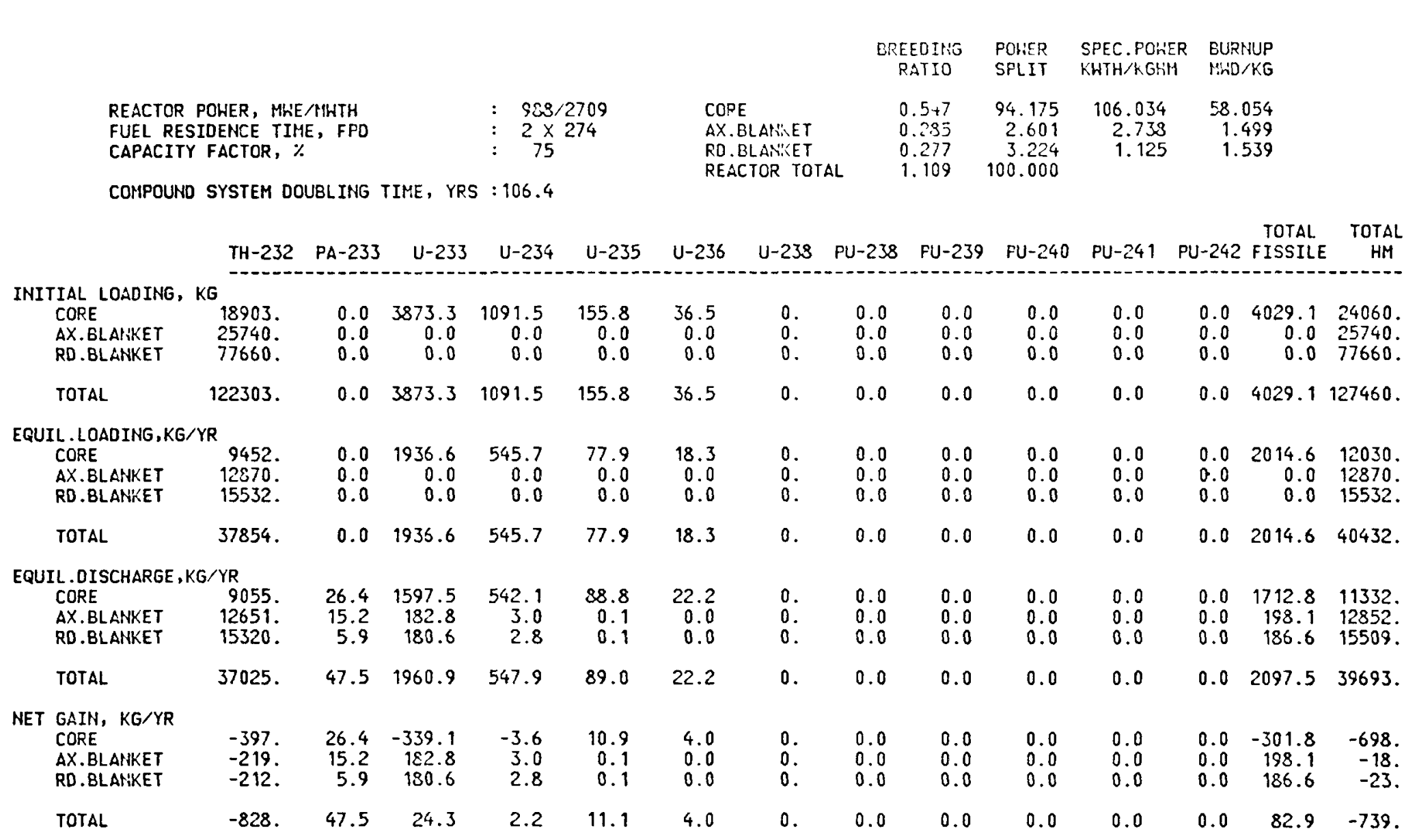

NOTE : 1. FISSILE $=$ PA233 + U233 + U235 + PU239 + PU249

2. BR AHD CSOT CALCULATED HITH ECINAL FISSILE ISOTOPE HEIGHTIHG 1 HO CREDIT FCD FA-233

3. CSDT CALCULATED HITH 1-YEAR EXTERKN:L CICLE TI'E AHD 2\% RETRCCESSI:'S/FARRICATICIH LOSSES

4. EQUILIBRIUM LOADING AND DISCHARGE DATA ARE GIVEN IN TERIIS OF EUUIVALENT AWIU:L MASS FLOW 
REACTOR PERFORMAIICE AFID MASS FLC'A DATA

GCFR: U233/U CORE, TH AB \& RE; GA REFERENCE DESIGH HORMALIZED TO $14 \mathrm{KW} / \mathrm{FT}$

\begin{tabular}{|c|c|c|c|c|c|c|c|c|c|c|c|c|c|c|}
\hline \multirow{3}{*}{$\begin{array}{l}\text { REACTOR } \\
\text { FUEL RES } \\
\text { CAPACITY }\end{array}$} & & & & & & & & \multicolumn{2}{|c|}{$\begin{array}{l}\text { BREEDING } \\
\text { RATIO }\end{array}$} & $\begin{array}{l}\text { PC:.ER } \\
\text { SPLIT }\end{array}$ & $\begin{array}{l}\text { SPEC . FO!.ER } \\
\text { KWTH KC:III! }\end{array}$ & \multicolumn{2}{|c|}{$\begin{array}{l}\text { EURINLP } \\
\because \because D / K G\end{array}$} & \\
\hline & $\begin{array}{l}\text { POHER, MHE } \\
\text { IOENCE TI } \\
\text { FACTOR, }\end{array}$ & $\begin{array}{l}\text { MWTH } \\
\text { : FPD }\end{array}$ & & $\begin{array}{l}: \text { 928 } \\
: \quad 2 \times \\
: \quad 75\end{array}$ & $\begin{array}{l}2709 \\
274\end{array}$ & \multicolumn{3}{|c|}{$\begin{array}{l}\text { COSE } \\
\text { AX.BLA:KET } \\
\text { RD.CLAAKET } \\
\text { REACTOR TOTAL }\end{array}$} & $\begin{array}{l}0.637 \\
0.311 \\
0.234 \\
1.242\end{array}$ & $\begin{array}{r}94.078 \\
2.715 \\
3.207 \\
100.000\end{array}$ & $\begin{array}{r}98.257 \\
2.857 \\
1.119\end{array}$ & \multicolumn{2}{|c|}{$\begin{array}{r}53.796 \\
1.554 \\
1.531\end{array}$} & \\
\hline & TH-232 & PA-233 & $U-233$ & U-234 & $U-235$ & U-236 & $4-238$ & PU-238 & PU-239 & PU-240 & $P U-241$ & $P U-242$ & $\begin{array}{l}\text { TOTAL } \\
\text { FISSILE }\end{array}$ & $\begin{array}{c}\text { TOTAL } \\
\text { HII }\end{array}$ \\
\hline $\begin{array}{l}\text { INITIAL LOADING, } \\
\text { CORE } \\
\text { AX.BLANKET } \\
\text { RD.BLAIKET }\end{array}$ & $\begin{array}{l}\text { KG } \\
0 . \\
25740 \\
77660\end{array}$ & $\begin{array}{l}0.0 \\
0.0 \\
0.0\end{array}$ & $\begin{array}{r}3403.6 \\
0.0 \\
0.0\end{array}$ & $\begin{array}{r}959.1 \\
0.0 \\
0.0\end{array}$ & $\begin{array}{r}136.9 \\
0.0 \\
0.0\end{array}$ & $\begin{array}{r}32.1 \\
0.0 \\
0.0\end{array}$ & $\begin{array}{r}21407 . \\
0 \\
0\end{array}$ & $\begin{array}{l}0.0 \\
0.0 \\
0.0\end{array}$ & $\begin{array}{l}0.0 \\
0.0 \\
0.0\end{array}$ & $\begin{array}{l}0.0 \\
0.0 \\
0.0\end{array}$ & $\begin{array}{l}0.0 \\
0.0 \\
0.0\end{array}$ & $\begin{array}{l}0.0 \\
0.0 \\
0.0\end{array}$ & $\begin{array}{r}3540.5 \\
0.0 \\
0.0\end{array}$ & $\begin{array}{l}25939 . \\
25740 . \\
77660 .\end{array}$ \\
\hline TOTAL & 103400 & 0.0 & 3403.6 & 959.1 & 136.9 & 32.1 & 21407. & 0.0 & 0.0 & 0.0 & 0.0 & 0.0 & 3540.5 & 129339. \\
\hline $\begin{array}{c}\text { EQUIL. LOADING ,KG/ } \\
\text { CORE } \\
\text { AX.BLAMKET } \\
\text { RD.BLANKET }\end{array}$ & $\begin{array}{r}Y R \\
0 \\
12870 \\
15532\end{array}$ & $\begin{array}{l}0.0 \\
0.0 \\
0.0\end{array}$ & $\begin{array}{r}1701.8 \\
0.0 \\
0.0\end{array}$ & $\begin{array}{r}479.5 \\
0.0 \\
0.0\end{array}$ & $\begin{array}{r}68.5 \\
0.0 \\
0.0\end{array}$ & $\begin{array}{r}16.0 \\
0.0 \\
0.0\end{array}$ & $\begin{array}{r}10703 . \\
0 \\
0\end{array}$ & $\begin{array}{l}0.0 \\
0.0 \\
0.0\end{array}$ & $\begin{array}{l}0.0 \\
0.0 \\
0.0\end{array}$ & $\begin{array}{l}0.0 \\
0.0 \\
0.0\end{array}$ & $\begin{array}{l}0.0 \\
0.0 \\
0.0\end{array}$ & $\begin{array}{l}0.0 \\
0.0 \\
0.0\end{array}$ & $\begin{array}{r}1770.3 \\
0.0 \\
0.0\end{array}$ & $\begin{array}{l}12969 . \\
12870 . \\
15532 .\end{array}$ \\
\hline TOTAL & 28402 & 0.0 & 1701.8 & 479.5 & 68.5 & 16.0 & 10703. & 0.0 & 0.0 & 0.0 & 0.0 & 0.0 & 1770.3 & 41371. \\
\hline $\begin{array}{l}\text { EQUIL.DISCHARGE, } \\
\text { CORE } \\
\text { AX.ELANKET } \\
\text { RD.BLANKET }\end{array}$ & $\begin{array}{r}G / Y R \\
0 \\
12645 \\
15320\end{array}$ & $\begin{array}{r}0.0 \\
15.6 \\
5.9\end{array}$ & $\begin{array}{r}1126.2 \\
186.7 \\
180.0\end{array}$ & $\begin{array}{r}468.6 \\
3.2 \\
2.8\end{array}$ & $\begin{array}{r}78.7 \\
0.1 \\
0.1\end{array}$ & $\begin{array}{r}19.8 \\
0.0 \\
0.0\end{array}$ & $\begin{array}{r}10201 . \\
0 . \\
0 .\end{array}$ & $\begin{array}{l}0.0 \\
0.0 \\
0.0\end{array}$ & $\begin{array}{r}358.9 \\
0.0 \\
0.0\end{array}$ & $\begin{array}{r}12.7 \\
0.0 \\
0.0\end{array}$ & $\begin{array}{l}0.3 \\
0.0 \\
0.0\end{array}$ & $\begin{array}{l}0.0 \\
0.0 \\
0.0\end{array}$ & $\begin{array}{r}1554.1 \\
202.4 \\
186.0\end{array}$ & $\begin{array}{l}12266 . \\
12851 . \\
15509 .\end{array}$ \\
\hline TOTAL & 27965. & 21.5 & 1492.9 & 474.5 & 78.9 & 19.8 & 10201. & 0.0 & 358.9 & 12.7 & 0.3 & 0.0 & 1952.5 & 40626. \\
\hline $\begin{array}{l}\text { NET GAIN, KG/YR } \\
\text { CORE } \\
\text { AX.BLANKET } \\
\text { RD.BLANKET }\end{array}$ & $\begin{array}{r}0 \\
-225 \\
-212\end{array}$ & $\begin{array}{r}0.0 \\
15.6 \\
5.9\end{array}$ & $\begin{array}{r}-575.6 \\
186.7 \\
180.0\end{array}$ & $\begin{array}{r}-11.0 \\
3.2 \\
2.8\end{array}$ & $\begin{array}{r}10.3 \\
0.1 \\
0.1\end{array}$ & $\begin{array}{l}3.8 \\
0.0 \\
0.0\end{array}$ & $\begin{array}{r}-503 . \\
0 . \\
0 .\end{array}$ & $\begin{array}{l}0.0 \\
0.0 \\
0.0\end{array}$ & $\begin{array}{r}358.9 \\
0.0 \\
0.0\end{array}$ & $\begin{array}{r}12.7 \\
0.0 \\
0.0\end{array}$ & $\begin{array}{l}0.3 \\
0.0 \\
0.0\end{array}$ & $\begin{array}{l}0.0 \\
0.0 \\
0.0\end{array}$ & $\begin{array}{r}-206.1 \\
202.4 \\
186.0\end{array}$ & $\begin{array}{l}-703 \\
-19 \\
-23\end{array}$ \\
\hline TOTAL & -437 & 21.5 & -208.9 & -5.0 & 10.4 & 3.8 & -503 & 0.0 & 358.9 & 12.7 & 0.3 & 0.0 & 182.2 & -746. \\
\hline
\end{tabular}

NOTE : 1. FISSILE $=$ PA233 + U233 + U235 + FU239 + FU241

2. ER AHD CSDT CALCULATED HITH EQ'JAL FISSILE ISOTOPE WEIGHTIRIS AND CREDIT FCR FA-233

3. CSOT CALCULATED HITH 1-YEAR EXTERHAL CYCLE TIRIE AYID $2 \%$ REFROCESSIRG/FARICATIOII LOSSES

4. EQUILIBRIUH LOADING AYID DISCHARGE DATA ARE GIVEN IN TERISS CF EQUIVALEHT ATIIUAL MIAS FLC!A 
REACTOR PERFORMANCE AND MASS FLON DATA

CURRENT OXIDE: PO/O CORE, U AB E RB; SHALL PIN DESIGH $(0.2 \mathrm{~s}$ N OD, 12 KH/FT)

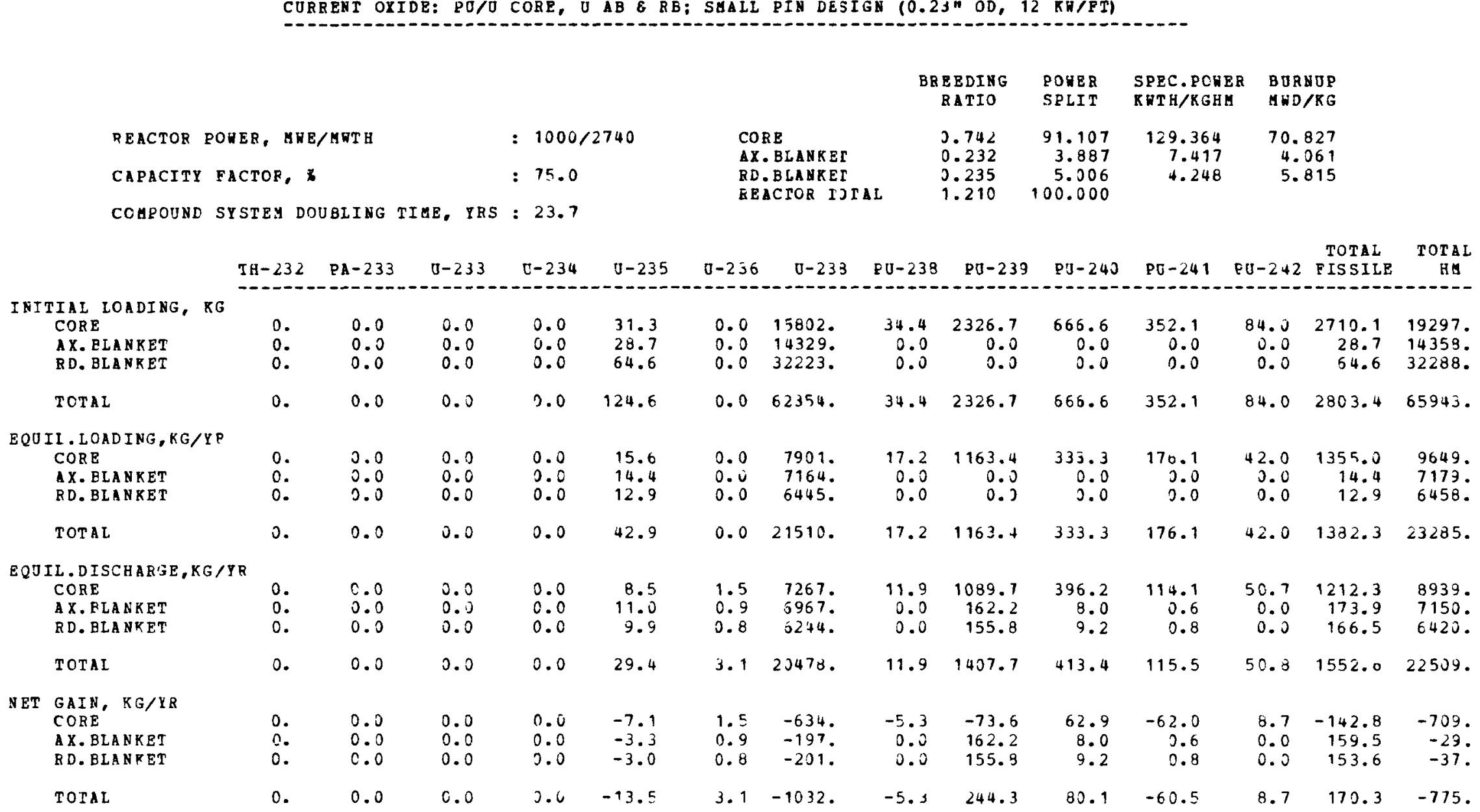

NOTE : 1. FISSILE $=$ PA233+U233+ 1235+EV239+P0241

2. BR AND CSDT CALCULATED WITH EQUAL FISSILE IJOTOPE WEIGHTING AND ZREDIT FOR PA- $\angle 33$

3. CSDT CALCJIATED WITH 1-YEAK EXTZRNAL CYCLE TIME AND $2 \%$ REPROCESSING/PABRICATION LUSSES 
REACTUR PERFOEMANCE AND MASS ELOW DATA

CURRENI OXIDS: PU/T COAE, U AB, TH RB; SAALL PIN DESIGN (0.23" OD, 12 KW/EI)

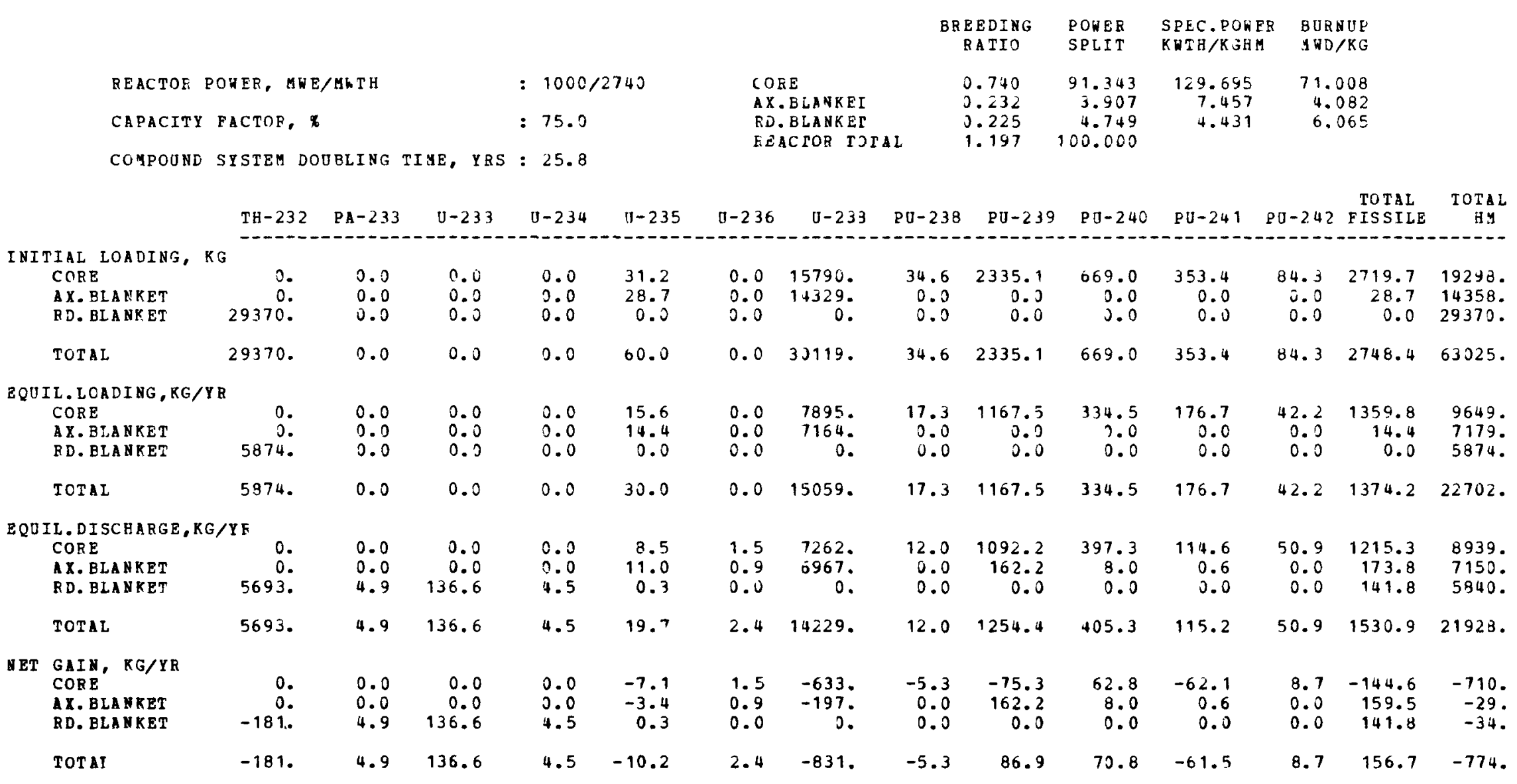

HOTE : 1. FISSILE $=$ PA233+ $2233+0235+$ PU239+P0241

2. BR AMD CSDT CALCILATED NITH EQJAL FISSIIE ISOTOPE NEIGHTIMS AND CBEDIT FOR PA-233

3. CSDT CALCULATED WITE 1-YBaR EXIERMAL CYCLE TIUE AND $2 \%$ REPROCESSING/FABRICATION LOSSES 


\section{REACTOR PERPORHANCE AND MASS FLON DATA}

CURRENT OXIDE: PU/U CORE, TH AB E KB; SMALL PIN DESIGN (0.23N OD, $12 \mathrm{KH} / \mathrm{PT})$

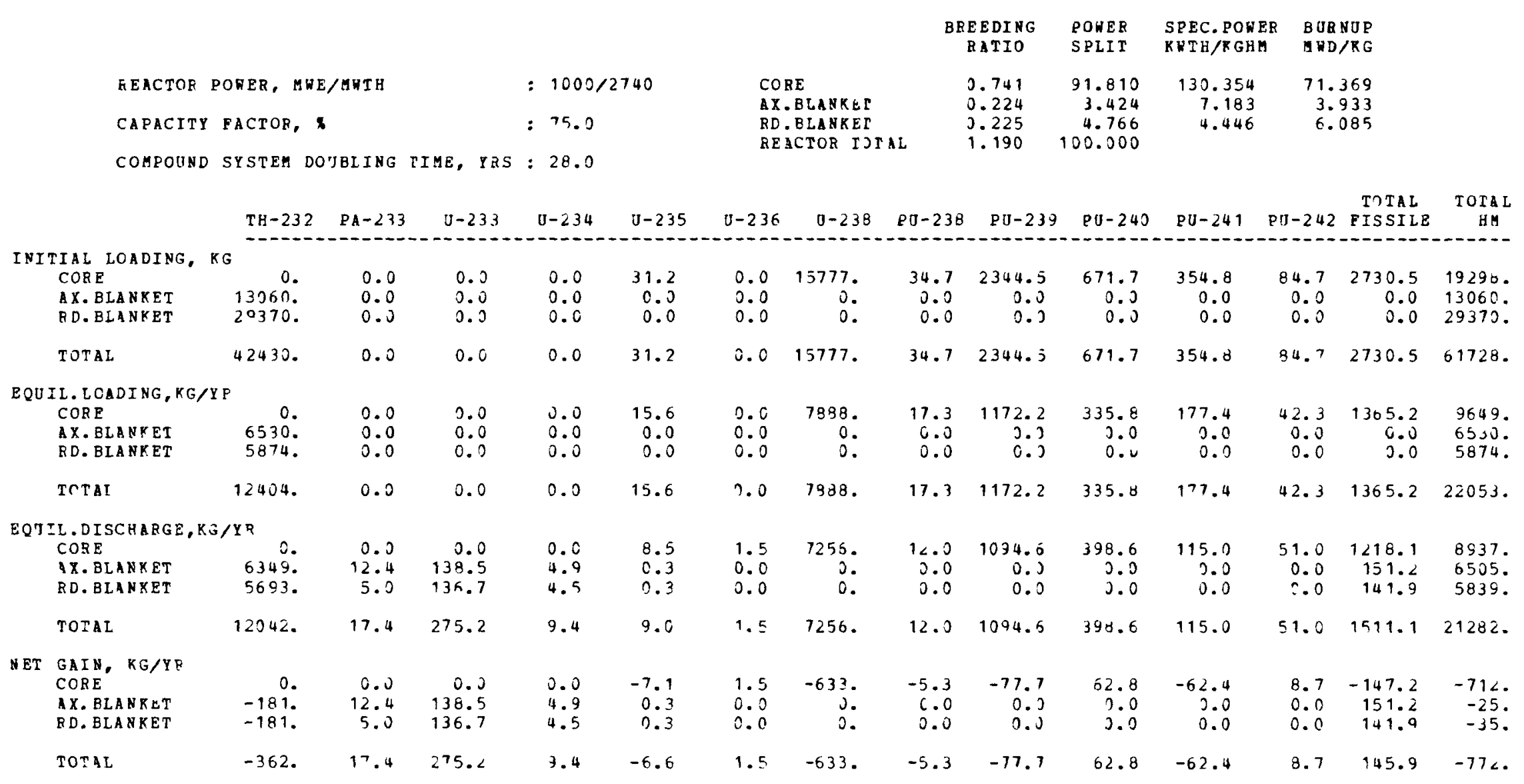

NOTE: 1. FISSILE $=$ PA233+ $2333+U 235+$ PII239+PU249

2. BR AYD CSDT CALCULATED ITH EQUAL FISSILE ISOIORE WEIGHTING AND CREDIT FOR RA-233

3. CSDT CALCULATED WITH 1-YEAR EXTERNAL CYCLE TIUE AND 2 X PEPROCESSING/FAgRTCATION LOSSES 
REACTOE PERFOPMANCE AND MASS FLON DATA

CJRRENT OXIDE: PU/TH COKE, TH AB E RB: SHALI PIN DESIGN $(0.23 "$ OD, 12 KN/FT)

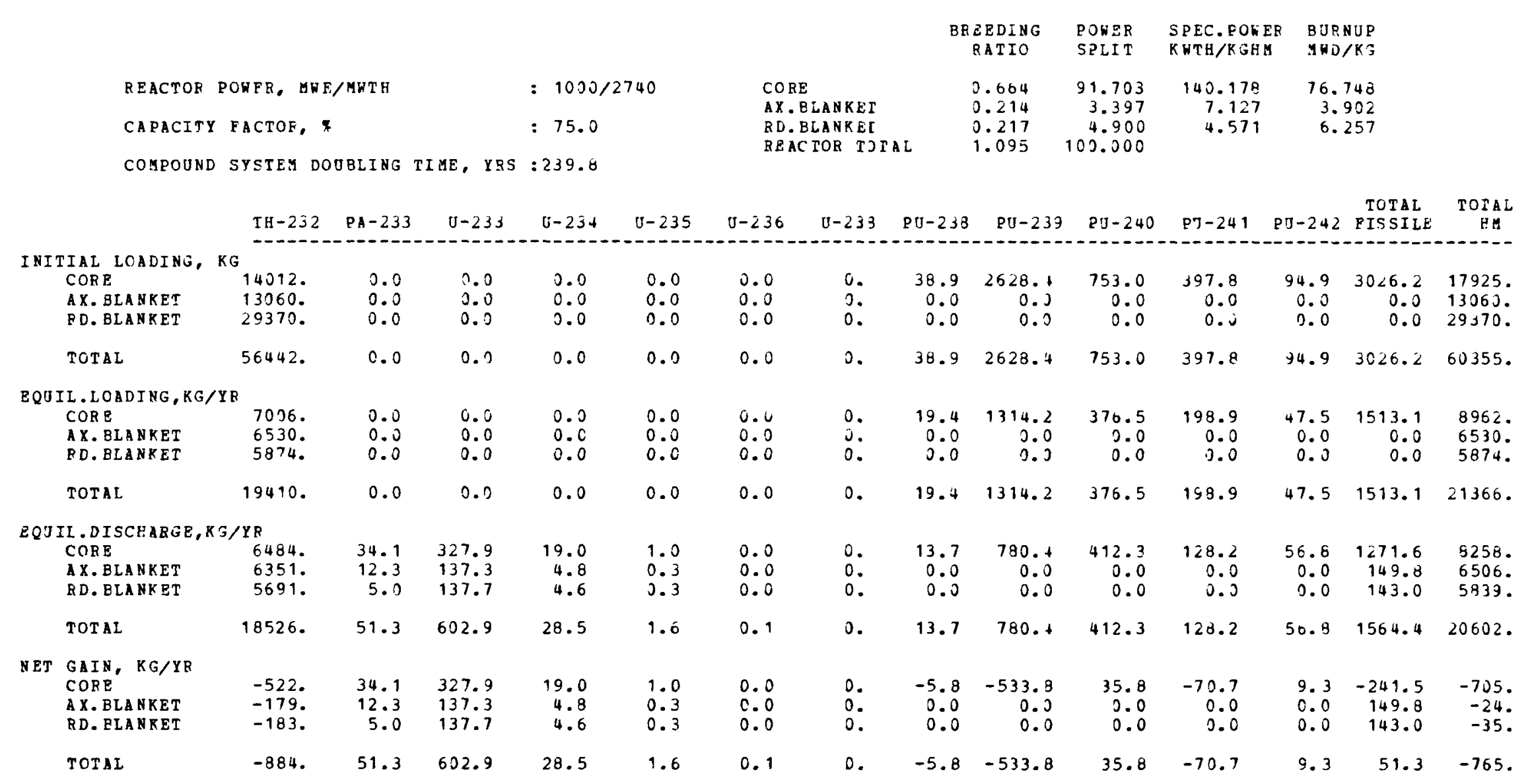

NOTE : 1. FISSILE $=$ PA233+ $2233+U 235+$ PU239+PU241

2. BR AND CSDT CALCDLATED nITH EQOAL FISSILE ISOTOPE nEIGHTIHa AND EREDIT POE Pa-233

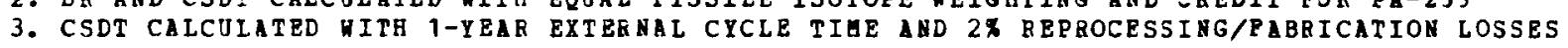




\section{BEACTOR PERFORAANCE ABD HASS FLOR DATA}

CORRENT OXIDE: D233/TH CORE, TH AB E RB: SHALL PIN DESIGN $(0.23 "$ OD, $12 \mathrm{KH} / \mathrm{PT})$

\begin{tabular}{|c|c|c|c|c|c|c|}
\hline & & & $\begin{array}{c}\text { BREEDING } \\
\text { RATIO }\end{array}$ & $\begin{array}{l}\text { PONER } \\
\text { SPLIT }\end{array}$ & $\begin{array}{l}\text { SPEC.PONER } \\
\text { KWTE/KGHM }\end{array}$ & $\begin{array}{l}\text { BORNOP } \\
M Y D / K G\end{array}$ \\
\hline $\begin{array}{l}\text { PFACTOR POHER, MUE/HWTH } \\
\text { CAPACITY FACTOR, }\end{array}$ & $\begin{array}{l}: 1000 / 2740 \\
: 75.0\end{array}$ & $\begin{array}{l}\text { COKE } \\
\text { AX.BLANKEI } \\
\text { RD.BLANKEI } \\
\text { FEACTOR TJTAL }\end{array}$ & $\begin{array}{l}0.616 \\
0.222 \\
0.202 \\
1.020\end{array}$ & $\begin{array}{r}93.573 \\
2.699 \\
3.728 \\
100.000\end{array}$ & $\begin{array}{r}144.596 \\
5.663 \\
3.478\end{array}$ & $\begin{array}{r}79.166 \\
3.101 \\
4.760\end{array}$ \\
\hline
\end{tabular}

\begin{tabular}{|c|c|c|c|c|c|c|c|c|c|c|c|c|c|c|}
\hline & $\mathrm{TH}-232$ & $P A-233$ & $0-233$ & $0-234$ & $0-235$ & $0-236$ & $0-233$ & $\mathrm{PO}-238$ & $\mathrm{PU}-239$ & $\mathrm{PU}-240$ & $\mathrm{PD}-241$ & $\mathrm{PO}-242$ & $\begin{array}{l}\text { TOTAL } \\
\text { FISSILE }\end{array}$ & $\underset{\text { HAL }}{\text { TOTAL }}$ \\
\hline $\begin{array}{l}\text { INITIAL LOADING, } \\
\text { CORE } \\
\text { AX. BLANKET } \\
\text { RD. BLANKET }\end{array}$ & $\begin{array}{l}K G \\
14212 \\
13050 \\
29370\end{array}$ & $\begin{array}{l}0.3 \\
0.0 \\
0.0\end{array}$ & $\begin{array}{r}2642.9 \\
0.0 \\
0.0\end{array}$ & $\begin{array}{r}744.8 \\
3.0 \\
0.0\end{array}$ & $\begin{array}{r}106.3 \\
0.0 \\
0.0\end{array}$ & $\begin{array}{r}24.9 \\
0.0 \\
0.0\end{array}$ & $\begin{array}{l}0 . \\
0 . \\
0 .\end{array}$ & $\begin{array}{l}0.0 \\
0.0 \\
0.0\end{array}$ & $\begin{array}{l}0.0 \\
0.0 \\
0.3\end{array}$ & $\begin{array}{l}0.0 \\
0.0 \\
0.0\end{array}$ & $\begin{array}{l}0.0 \\
0.0 \\
0.0\end{array}$ & $\begin{array}{l}0.0 \\
0.0 \\
0.0\end{array}$ & $\begin{array}{r}2749.3 \\
0.0 \\
0.0\end{array}$ & $\begin{array}{l}17731 . \\
13060 \\
29370\end{array}$ \\
\hline TOTAL & 56642 & 0.0 & 2642.9 & 744.8 & 106.3 & 24.9 & 0 . & 0.0 & 0.0 & 0.0 & 0.0 & 0.0 & 2749.3 & 60161. \\
\hline $\begin{array}{l}\text { EQOIL . LOADING, KG } \\
\text { CORE } \\
\text { AX. BLANKET } \\
\text { RD.BLANKET }\end{array}$ & $\begin{array}{l}\text { YR } \\
7106 . \\
6530 . \\
5974 .\end{array}$ & $\begin{array}{l}0.0 \\
0.0 \\
0.0\end{array}$ & $\begin{array}{r}1321.5 \\
0.0 \\
0.0\end{array}$ & $\begin{array}{r}372.4 \\
0.0 \\
0.0\end{array}$ & $\begin{array}{r}53.2 \\
0.0 \\
0.0\end{array}$ & $\begin{array}{r}12.5 \\
0.0 \\
0.0\end{array}$ & $\begin{array}{l}0 . \\
0 . \\
0 .\end{array}$ & $\begin{array}{l}0.0 \\
0.0 \\
0.0\end{array}$ & $\begin{array}{l}0.3 \\
0.3 \\
0.3\end{array}$ & $\begin{array}{l}0.0 \\
0.0 \\
0.0\end{array}$ & $\begin{array}{l}0.0 \\
0.0 \\
0.0\end{array}$ & $\begin{array}{l}0.0 \\
0.0 \\
0.0\end{array}$ & $\begin{array}{r}1374.6 \\
0.0 \\
0.0\end{array}$ & $\begin{array}{l}8866 . \\
6530 . \\
5874 .\end{array}$ \\
\hline TCTAL & 19510 & 0.0 & 1321.5 & 372.4 & 53.2 & 12.5 & 0. & 0.0 & 0.0 & 0.0 & 3.0 & 0.0 & 1374.6 & 21270 \\
\hline $\begin{array}{l}\text { EQTIL. DISCHARGE, } \\
\text { CORE } \\
\text { AX. BLANKET } \\
\text { PD. BLANKET }\end{array}$ & $\begin{array}{l}G / Y R \\
5651 . \\
6371 . \\
5715 .\end{array}$ & $\begin{array}{r}30.0 \\
11.0 \\
4.4\end{array}$ & $\begin{array}{r}1031.0 \\
124.7 \\
123.4\end{array}$ & $\begin{array}{r}373.5 \\
3.8 \\
3.6\end{array}$ & $\begin{array}{r}65.3 \\
0.2 \\
0.2\end{array}$ & $\begin{array}{r}17.3 \\
0.0 \\
0.0\end{array}$ & $\begin{array}{l}0 . \\
0 . \\
0 .\end{array}$ & $\begin{array}{l}0.0 \\
0.0 \\
0.0\end{array}$ & $\begin{array}{l}0.0 \\
0.0 \\
0.0\end{array}$ & $\begin{array}{l}0.0 \\
0.0 \\
0.0\end{array}$ & $\begin{array}{l}0.0 \\
0.0 \\
0.0\end{array}$ & $\begin{array}{l}0.0 \\
0.0 \\
0.0\end{array}$ & $\begin{array}{r}1126.2 \\
135.8 \\
1 \angle 8.0\end{array}$ & $\begin{array}{l}8168 . \\
6511 . \\
5847 .\end{array}$ \\
\hline TOTAL & 18737 & 45.3 & 1279.1 & 380.8 & 65.7 & 17.3 & 0 . & 0.0 & J. 0 & 0.0 & 0.0 & 0.0 & 1390.1 & $205 \angle 5$. \\
\hline $\begin{array}{ll}\text { NET GAIN, KG/YR } \\
\text { COPE } \\
\text { AX.BLANRET } \\
\text { BD. BLANKET }\end{array}$ & $\begin{array}{l}-455 . \\
-159 . \\
-159\end{array}$ & $\begin{array}{r}30.0 \\
11.0 \\
4.4\end{array}$ & $\begin{array}{r}-290.5 \\
124.7 \\
123.4\end{array}$ & $\begin{array}{l}1.1 \\
3.8 \\
3.6\end{array}$ & $\begin{array}{r}12.1 \\
0.2 \\
0.2\end{array}$ & $\begin{array}{l}4.9 \\
0.0 \\
0.0\end{array}$ & $\begin{array}{l}0 . \\
0 . \\
0 .\end{array}$ & $\begin{array}{l}0.0 \\
0.0 \\
0.0\end{array}$ & $\begin{array}{l}0.3 \\
0.3 \\
0.3\end{array}$ & $\begin{array}{l}0.0 \\
0.0 \\
0.0\end{array}$ & $\begin{array}{l}0.0 \\
3.0 \\
3.0\end{array}$ & $\begin{array}{l}0.0 \\
0.0 \\
0.0\end{array}$ & $\begin{array}{r}-248.4 \\
135.8 \\
129.0\end{array}$ & $\begin{array}{l}-698 . \\
-19 \\
-27\end{array}$ \\
\hline TOTAL & -773 & 45.3 & $-4<.3$ & B. 5 & $1 \alpha .5$ & 4.9 & c. & 0.0 & 0.0 & 0.0 & 0.0 & 0.0 & 15.4 & -745. \\
\hline
\end{tabular}

NOTE : 1. FISSILE $=$ P1233+U233+U235+PJ239+PJ241

2. PF AND CSDT CALCULATED WITH EQUAL FISSILE ISOTOPF WEIGHTINS AND CREDIT FJR PA-233

3. CSDT CALCULATED WITH 1-YEAR EXTERNAL CYCLE TIME AND 2 P PEPROCESSING/FABEICATION LOSSES 
REACTOE PFRFORMANCE AND MASS FLON DATA

CJREENT OYIDE: U233/0 COFE, TH AB \& RE; SMAIL PIN DESIGN $(0.23 "$ OD, $12 \mathrm{KH} / \mathrm{FT}$

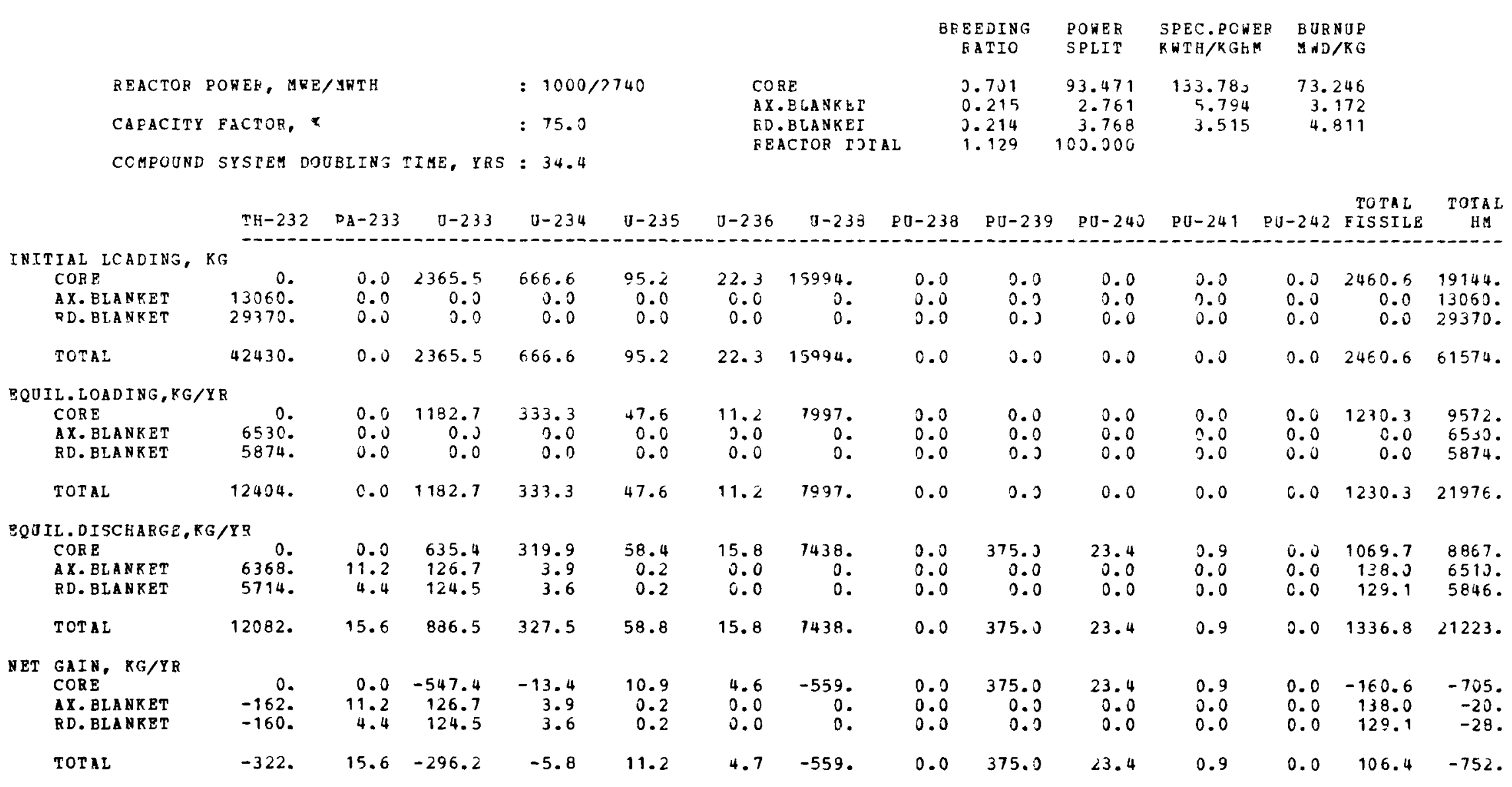

NOTE : 1. PISSILF $=$ PA233+0233+0235+PJ239+PU241

2. BR AND CSDT CALCULATED ITH EQUAL FISSILE ISOTOPE WEIGHTING AND CREDIT FOR PA-233

3. CSDT CALCOLATED HITH T-YEAR EXTERNAL CYCLE TIUE AND 2X REPBOCESSING/FABRICATION LOSSES 


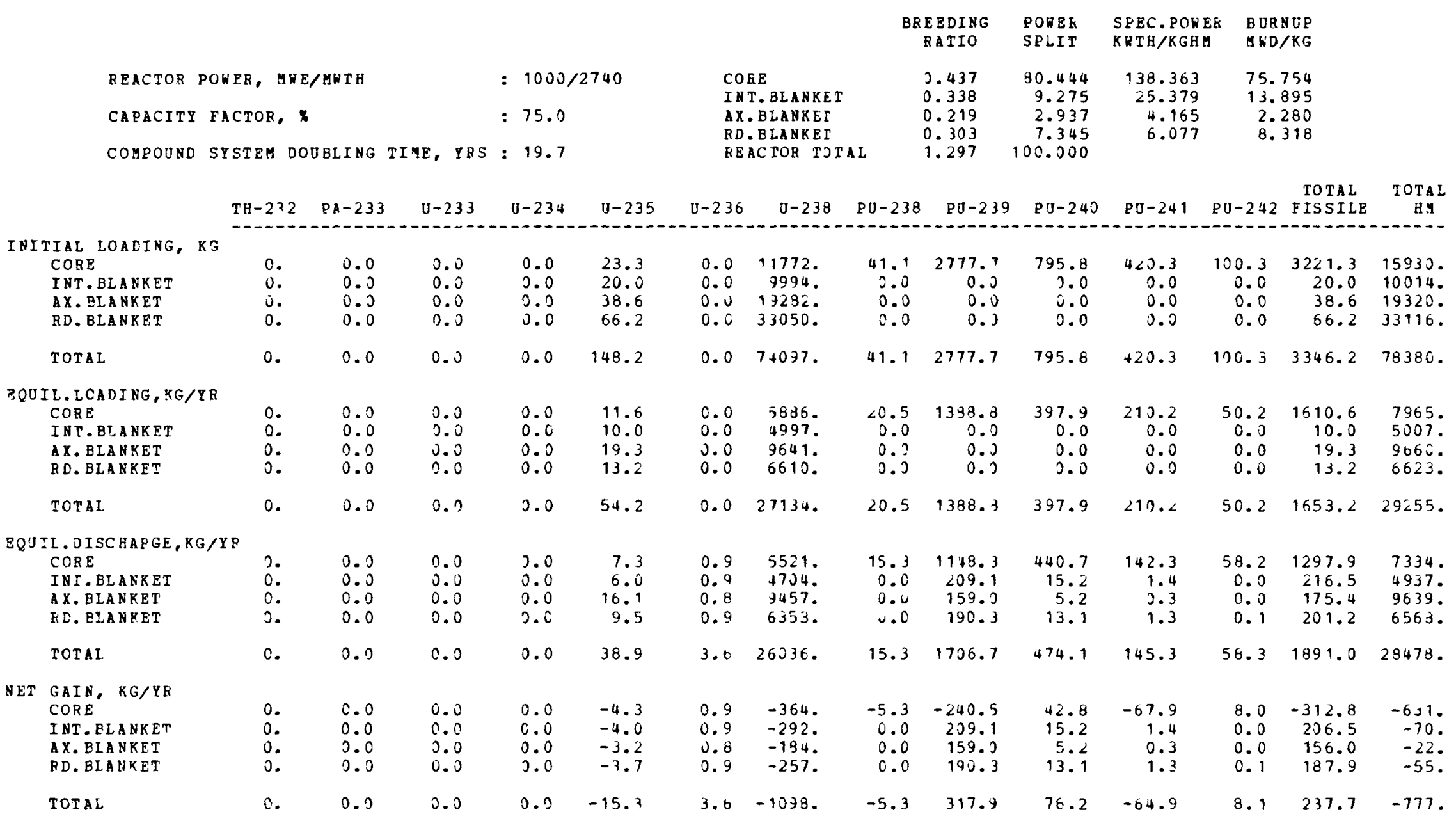

NOTE : 1. FISSIF $=$ PA $233+0233+U 235+P J 239+P U 241$

2. BF AND CSDI CALCULATED WIIH EQUAL FISSILE ISOTOPE NEIGHTIN3 AND ZREDIT FJR PA-233

3. CSDI CAICULATED WITH 1-YEAF EXTERNAL CYCLE IIUE AND 2L EEPROCESSING/FABRICATION LOSSES 
REACTOR PEAFOEMANCE AND MASD FLON DATA

CURRENT OXIDE HETEKOGENFOUS: PU/U COFE, Th BLANKETS: SMALL PIN DESIGN, 12 KH/FT

CURRENT OXIDE HETEKOGENFOUS: PU/O COFE, Th BLANKEIS: SHALL PIN DESTGN, 12 KH/FT

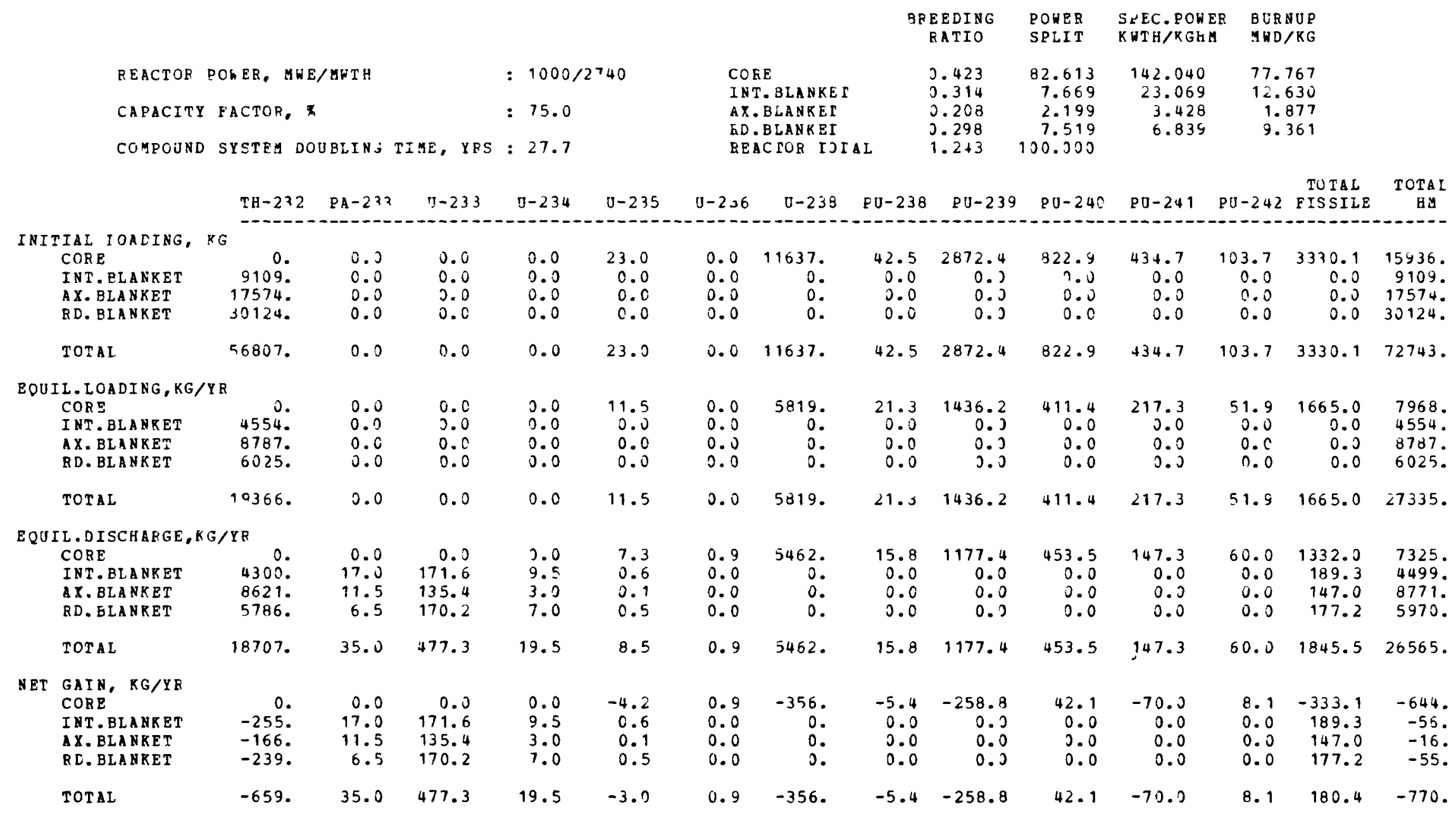

NOTE: 1. FISSILE $=$ PA $233+U 233+0235+P U 239+$ PU 241

2. BR AND CSDT CALCOLATED WITH EQUAL FISSILE ISOTOPE HEIGHTINS AND EREDIT FOR PA-233

3. CSDT CALCOLATED WITH 1-YEAE EXIERHAL CYCLE TIME AND 2X REPROCESSING/FABRICATION LOSSES 
PART 3

\title{
STATUS OF LMFBR FUELS AND MATERIALS DEVELOPMENT
}

J. H. Kittel, L. A. Neimark, L. G. Walters,

R. E. Einziger, and D. E. Mahagin*

(Argonne National Laboratory)

\begin{abstract}
The status of development of the candldate LMFBR fuel type oxide, carbide and metal, cladding/duct alloys, and absorber material is reviewed. The threefuel types are discussed for the reference breeder cycle, transmuter cycle, denatured cycle, and blanket fuel applications. The preferred design concepts for each fuel type are identifled, with discussion of the more significant factors that control burnup and thermal performance for each design and fuel type. The key technical issues for each fuel and material are reviewed and the required effort to resolve the key issues is identified.
\end{abstract}

\section{INTRODUCTION}

The fuels and materials specified for use in LMFBRs have been influenced both by technical developments and by programmatic objectives. Thus, the first LMFBRs (EBR-I, EBR-II, DFR, and FERMI) all used metal fuels because such fuels were relatively better known and because of the programmatic objective of demonstrating maximum breeding performance. With continued LMFBR development other objectives became more important. These objectives included achievement of high fuel burnups, on the order of $10 \mathrm{a} / \mathrm{o}$, and a high sodium outlet temperatures, on the order of 540 to $650^{\circ} \mathrm{C}\left(1000\right.$ to $\left.1200^{\circ} \mathrm{F}\right)$. Metal fuel development had not yet reached a stage where these more demanding objectives could be satisfied, and metal fuel emphasis was therefore curtailed.

The large body of experience that had meanwhile been gained on use of uranium oxide fuel in LWRs provided strong evidence, since corroborated by LMFBR experience, that mixed uranium-plutonium oxide would meet the burnup

*Hanford Engineering Development Laboratory. 
and temperature requirements specified for LMFBRs. Oxide fuel was therefore selected for use in all succeeding LMFBRs including FTR, PFR, Phenix, SNR-300, and $\mathrm{BN}-350$. It was generally felt that the reduced breeding performance associated with oxide fuel could be accepted until more advanced fuels were adequately developed. Mixed oxide fuel has therefore become identified as the current reference fuel for LMFBRs. Furthermore, it is apparent that the major breeder development programs will exploit oxide fuel to the fullest possible extent in advanced element designs before the programs are committed to other more advanced fuel types.

The more advanced fuel specified in all LMFBR fuel development programs is mixed uranium-plutonium carbide. Carbide combines the desirable properties of high metal atom density, high thermal conductivity, excellent compatibility with sodium, and a high melting point. It has become apparent, nevertheless, that more effort than was originally anticipated is needed to bring carbide fuel to the stage of development where it could displace the reference oxide fuel. Additional required work on carbide fuel elements includes development of fuel forms and designs that can satisfactorily accommodate the strong fuelcladding mechanical interactions resulting from the high creep strength of carbide, demonstration of commercially feasible fabrication, demonstration of satisfactory steady state and transient irradiation performance capability under prototypic design basis hot spot conditions and transient service conditions, and resolution of safety issues relating to molten fuel-sodium interaction.

Modest renewed interest in metal fuels has developed recently, primarily because of the demonstrated adaptability of the EBR-II driver fuel alloy to a diversion-resistant fuel cycle. This renewed interest is supplemented by the fact that the basic metal fuel element design, applied to the EBR-II Mark II driver fuel, has achieved goal burnups of 10 a/o with high reliability, and by the apparent ability of candidate LMFBR metal fuels to operate under currently specified reactor sodium outlet temperatures of 470 to $510^{\circ} \mathrm{C}$ $\left(875\right.$ to $\left.950^{\circ} \mathrm{F}\right)$. Planning is currently under way for possible resumption of irradiation testing of LMFBR candidate metal fuels.

This report was prepared as part of the U.S. studies for the International Nuclear Fuel Cycle Evaluation (INFCE) Working Group 5 on Fast Breeders. The report summarizes the status of development of each of the major LMFBR fuel types (oxide, carbide, and metal) and of cladding/duct alloys and neutron absorbers. Key issues related to fuel element design, performance, and licensing are identified, along with the activities required to resolve the key issues.

\section{OXIDE FUELS}

Of the LMFBR fuel candidates, the most extensive fabrication and testing experience exists for mixed uranium-plutonium oxide fuels. The technological base upon which this experience was built was provided by the prior development and manufacture of large numbers of uranium oxide fuel elements for LWRs. Other than providing plutonium-handling capabilities, relatively few major changes were necessary in extrapolating LWR oxide fuel technology into LMFBR fuel areas. 
$\underline{\text { Status of Development }}$

1. Candidate Oxide Fue1 Types: The candidate oxide fuel types under consideration for breeder cycles of current interest ${ }^{1}$ are shown in Table $I$.

TABLE I. Oxide Fuel Types under INFCE Consideration for lise in Fast Breeder Cycles ${ }^{1}$

\begin{tabular}{lcc} 
Breeder Cycle & Core Fuel & Planket Fuel \\
\hline Reference & $\mathrm{UO}_{2}-\mathrm{PuO}_{2}$ & $\mathrm{UO}_{2}$ \\
Transmuter & $\mathrm{UO}_{2}-\mathrm{PuO}_{2}$ & $\mathrm{ThO}_{2}$ \\
& $\mathrm{ThO}_{2}-\mathrm{PuO}_{2}$ & $\mathrm{ThO}_{2}$ \\
Denatured & $\mathrm{UO}_{2}$ & $\mathrm{ThO}_{2}$ \\
\hline
\end{tabular}

Oxide fuels have been under development for use in fast breeder reactors for over 20 years. As noted above, this development has built on the extensive technological base established for $\mathrm{UO}_{2}$, and to a lesser degree $\mathrm{ThO}_{2}-\mathrm{UO}_{2}$, for 1 ight water reactors. The basic oxide fuel for LMFBRs has been $\mathrm{UO}_{2}-\mathrm{PuO}_{2}$, although $\mathrm{UO}_{2}$ has been used in the BOR-60 and $\mathrm{BN}-350$ reactors and for some of a core loading of the Phenix reactor. Although the development of mixed oxide has a firm foundation in the $\mathrm{UO}_{2}$ technology, mixed oxide has had

a significant development program in its own right, principally because of the more stringent operating demands of the LMFBR and significant differences in the thermal, chemical, and mechanical behavior of the oxide owing to the addition of plutonium. The intensive 20-year, multinational development of $\mathrm{UO}_{2}-\mathrm{PuO}_{2}$ has brought this fuel type to near the point of commercialization in 1000 MWe-sized plants. As a fuel, only a few issues remain for $\mathrm{UO}_{2}-\mathrm{PuO}_{2}$; as a fuel/cladding system, demonstration of fuel performance with design parameters optimized to achieve desired breeding performance and economic goals must still be accomplished.

In the U.S., "reference" oxide fuel is defined as the $\mathrm{UO}_{2}-\mathrm{PuO}_{2}$ fuel pin developed originally for use in the FTR and CRBR. "Advanced" oxide refers to fuel element designs with larger diameters, higher smeared fuel densities, and lower cladding thickness/diameter ratios. "Alternative" oxide denotes $\mathrm{ThO}_{2}-\mathrm{UO}_{2}, \mathrm{ThO}_{2}-\mathrm{PuO}_{2}$, and $\mathrm{UO}_{2}$ enriched in ${ }^{23} \mathrm{U}$ (denatured $\mathrm{UO}_{2}$ ) as core fuels, and $\mathrm{ThO}_{2}$ as blanket fuel.

Of the potential oxide fuel materials, the least is known about $\mathrm{ThO}_{2}-\mathrm{PuO}_{2}$. After some early work on this material as a potential light water reactor recycle fuel, little work has been done on it in the past twenty years. It is believed that $\mathrm{ThO}_{2}-\mathrm{PuO}_{2}$ will behave in-reactor similarly to $\mathrm{UO}_{2}-\mathrm{PuO}_{2}$ because of their similarities in properties.

2. Feasible Element Designs: Oxide fuels have been used in a number of developing fuel systems for breeder reactors. The most common form has been solid pellets of various densities, helium-bonded to stainless steel cladding. Combined with the space in the fuel-cladding gap, the as-fabricated porosity in the fuel provides free volume to accommodate fuel swelling with burnup. Fuel smeared densities currently in use range from 80 to $88 \%$ of theoretical density, depending on the design philosophy, with a fuel-cladding gap on the order of $0.14 \mathrm{~mm}$. While the burnup potential of the reference oxide system is not of concern, the advanced oxide systems with their more stringent operating demands and less conservative design parameters may be more pressed to achieve their goals. Typical design parameters and operating conditions for reference and advanced oxide systems ${ }^{2}, 3$ are shown in Table II. 
TABLE II. Comparison of U.S. Reference and Advanced $\mathrm{UO}_{2}-\mathrm{PuO}_{2}$ Design and Operating Parameters ${ }^{2}, 3$

\begin{tabular}{|c|c|c|}
\hline Parameter & $\begin{array}{c}\text { Reference } \\
\text { Design }\end{array}$ & $\begin{array}{l}\text { Advanced } \\
\text { Design }\end{array}$ \\
\hline \multicolumn{3}{|l|}{ Cladding } \\
\hline o.d., mm & 5.84 & $6.6-9.1$ \\
\hline Wall thickness, mm & 0.38 & $0.30-0.38$ \\
\hline Material & $20 \%$ CW 316 SS & $\begin{array}{c}\text { Advanced } \\
\text { Alloys, } \\
20 \% \cdot C W 316\end{array}$ \\
\hline Fuel smeared density, \% T.D. & 85 & $85-92$ \\
\hline Nominal peak linear power, $\mathrm{kW} / \mathrm{m}$ & 43 & $40-50$ \\
\hline Nominal peak cladding temp., ${ }^{\circ} \mathrm{C}$ & 600 & $540-650$ \\
\hline Peak burnup, a/o & 8 & $>10$ \\
\hline
\end{tabular}

A variation of the solid pellet concept of interest in the U.K. is annular fuel containing a pre-formed central hole. Annular fuel is claimed to have advantages in fabrication (easier to control high density), less fuel-cladding mechanical interaction (FCMI) than solid pellets, lower operating temperatures, and higher linear power to cause melting on startup of fresh fuel. These features have become less important, however, as the technology to fabricate low-density pellets became available, stronger claddings became available through the effort to develop lower swelling materials, and interest grew in vibratorily-compacted particulate fuels to solve other fabrication problems. With the wider realization that either LWR recycle plutonium, or ${ }^{233} \mathrm{U}$ fuels, or purposely doped diversion-resistant fuels will be too radioactive for hands-on fabrication, vibratorily-compacted particulate oxide, especially spherical particles, is again receiving careful consideration for remote fabrication. Spherical particulate fuel has had considerably more development in Europe than in the U.S., but a significant technological base also exists in the U.S.4,5 The existing technological base, however, includes few irradiations at operating or design conditions of advanced oxide systems. In this respect, particulate $\mathrm{UO}_{2}-\mathrm{PuO}_{2}$ is only somewhat more advanced than particulate forms of $\mathrm{ThO}_{2}-\mathrm{UO}_{2}, \mathrm{ThO}_{2}-\mathrm{PuO}_{2}$, and $\mathrm{UO}_{2}$.

Current designs for all oxide systems assume near $100 \%$ release of fission gas which is accommodated in a sealed plenum either above or below the fuel column, or both. Previous interest in venting the gases to the reactor coolant has waned for licensing, maintenance, and operating reasons. Only in the Gas Cooled Fast Reactor is venting being used to reduce the mechanical loading on the cladding.

3. Irradiation Performance: The irradiation data base of $\mathrm{UO}_{2}-\mathrm{PuO}_{2}$ fuels is very extensive. It includes steady-state endurance tests over a variety of operating conditions, instrumented and uninstrumented tests to investigate specific phenomena such as short-term fuel restructuring and power-to-melt, transient overpower and undercooling experiments, and tests 
of breached fuel elements. The objective of most of these tests was to provide design and reliability data for near-term reactor missions such as the FTR, PFR, and Phenix. In the U.S. alone over 800 pins prototypic of the FTR have been irradiated in EBR-II; some 2400 experimental $\mathrm{UO}_{2}-\mathrm{PuO}_{2}$ pins have been irradiated in that reactor. ${ }^{2}$ A burnup of 12.7 a/o at a fast fluence of $2.0 \times 10^{23} \mathrm{n} / \mathrm{cm}^{2}$ has been achieved in the U.S. reference oxide program. Extensive transient testing of PPS-terminated emergency and upset events has also been done in the TREAT reactor in support of FTR licensing; only a few tests on low-burnup fuel remain to be done to satisfy now-perceived licensing issues. In Phenix, over 7000 mixed-oxide fuel pins have achieved their goal exposure of $6 \mathrm{a} / \mathrm{o}$, some reaching a maximum burnup of $7.8 \mathrm{a} / 0.6$ In Rapsodie Fortissimo, mixed-oxide fuel pins have achieved 15 a/o burnup. The French data base provides them confidence that a goal burnup of 11.7 a/o is attainable in Super Phenix. In PFR, mixed-oxide has been irradiated to $4 \mathrm{a} / \mathrm{o}$ burnup. This was preceded by an irradiation program in DFR in which approximately 1200 fuel pins were successfully irradiated under PFR conditions to burnups as high as $21.5 \mathrm{a} / 0 .{ }^{7}$ These results support the design goal of 10 a/o for PFR. In $\mathrm{BOR}-60$ and $\mathrm{BN}-350$, the $\mathrm{UO}_{2}$ fuel has achieved maximum burnups of $13.2 \mathrm{a} / \mathrm{o}$ and $5.8 \mathrm{a} / \mathrm{o}$, respectively, apparently without problems. ${ }^{6}$

With most of the work nearing completion on the reference $\mathrm{UO}_{2}-\mathrm{PuO}_{2}$ systems for the near-term missions, work on $\mathrm{UO}_{2}-\mathrm{PuO}_{2}$ over the past few years has been directed at advanced oxide systems which have evolved from the reference design data base. The advanced oxide systems are principally being designed to achieve lower doubling times. In pin design this is being accomplished by increasing pin diameter, increasing fuel smeared density, and reducing the cladding thickness-to-diameter ratio. The larger diameter pins, higher burnup capability $(>10 \mathrm{a} / \mathrm{o})$, and higher linear power rating (up to $50 \mathrm{~kW} / \mathrm{m}$ ) will also reduce fuel cycle costs. A summary of some of the Irradiation tests conducted in support of advanced $\mathrm{UO}_{2}-\mathrm{PuO}_{2}$ systems is given in Table III. The P-40 experiment successfully achieved 13 a/o burnup with high density fuel in thin cladding. The Mk-VIIA experiment with spherical particles, however, suffered 54 failures out of 60 highly-rated wirewrapped pins. A number of factors could have affected the behavior of this experiment, and the cause of the large number of failures is not obvious.

Thoria-urania has been developed for the Light Water Breeder Reactor (LWBR) and to a lesser extent for other water-cooled thermal reactors. The LWBR irradiation experience is marginally applicable to LMFBRs because of the low power density, Zircaloy cladding and nonprototypic thermal operating conditions. The irradiations did indicate the stronger nature of the fuel compared with $\mathrm{UO}_{2}$, however. Irradiations of $\mathrm{ThO}_{2}-\mathrm{UO}_{2}$ for watercooled thermal reactor application indicated that thermally activated processes occur at higher temperatures than in $\mathrm{UO}_{2}$, and therefore, in $\mathrm{UO}_{2}-\mathrm{PuO}_{2}$. The swelling rate of $\mathrm{ThO}_{2}-\mathrm{UO}_{2}$ has been found to be less than that of $\mathrm{UO}_{2}$. Irradiation of $\mathrm{ThO}_{2}-\mathrm{UO}_{2}$ in stainless steel cladding in a light water reactor suggested the possibility of a fuel/cladding chemical interaction. No other issues relevant to the performance of $\mathrm{ThO}_{2}-\mathrm{UO}_{2}$ in LMFBRs have appeared. Very few irradiations have been conducted on $\mathrm{ThO}_{2}-\mathrm{PuO}_{2}$, but the limited results suggest behavior no worse than other oxides. 
TABLE III. Typıcal Design and Operatıng Parameters for Advanced Oxide Fuel Experiments ${ }^{8-10}$

\begin{tabular}{|c|c|c|c|c|c|c|c|c|c|}
\hline \multirow[b]{2}{*}{ Country } & \multirow[b]{2}{*}{ Test } & \multicolumn{3}{|c|}{ Cladding } & \multirow{2}{*}{$\begin{array}{l}\text { Smeared } \\
\text { Density, } \\
\text { T.D. }\end{array}$} & \multirow[b]{2}{*}{$\begin{array}{l}\text { Tuel } \\
\text { Form }\end{array}$} & \multirow{2}{*}{$\begin{array}{c}\text { Nominal } \\
\text { Peak Power } \\
\mathrm{k} w / \mathrm{m}\end{array}$} & \multirow{2}{*}{$\begin{array}{c}\text { Nominal } \\
\text { Peak Clad } \\
\text { Temperature, } \\
{ }^{\circ} \mathrm{C}\end{array}$} & \multirow[b]{2}{*}{$\begin{array}{l}\text { Peak Burnup } \\
\text { Achieved, a/o }\end{array}$} \\
\hline & & Material & $\underset{\mathrm{mm}}{o . d .,}$ & $\begin{array}{c}\text { Wall, } \\
\mathrm{mm}\end{array}$ & & & & & \\
\hline \multirow[t]{10}{*}{ USA } & $P-40$ & 316 & 5.8 & $0.38,0.25$ & 85,92 & $\mathrm{P}$ & 52 & 660 & 13 \\
\hline & $P-41$ & 316 & 6.9 & 0.28 & 92 & $\mathrm{P}$ & 46 & $760-815^{c}$ & 1 \\
\hline & $P-42$ & $31 \mathrm{~F}$ & 6.9 & 0.28 & 92 & $\mathrm{p}$ & 46 & $760-815^{c}$ & 2 \\
\hline & $P-43$ & $316, \mathrm{D}-9, \mathrm{I}-706$ & 5.8 & 0.38 & 85,91 & $\mathrm{P}$ & 33 & 660 & 6 \\
\hline & $P-50$ & 316 & 7.4 & 0.41 & 90 & $\mathrm{P}$ & 43 & 610 & 3 \\
\hline & $P-51$ & 316 & 7.4 & 0.41 & 90 & $\mathrm{P}$ & 23 & 610 & - \\
\hline & $P-52$ & 316 & 7.4 & 0.30 & 85,90 & $\mathrm{P}$ & 43 & 610 & 4 \\
\hline & $P-53$ & 316 & 7.4 & 0.30 & 85,90 & $\mathrm{P}$ & 23 & 610 & 2 \\
\hline & $P-60$ & $P E-16, \quad I-706$ & 7.4 & 0.30 & 85,90 & $\mathrm{P}$ & 46 & 700 & 2 \\
\hline & $P-61$ & $P E-16, I-706$ & 7.4 & 0.30 & 85,90 & $\mathrm{P}$ & 26 & 690 & - \\
\hline \multirow[t]{2}{*}{ UK } & Mk-III & M316, FV548, PE-16 & 8.3 & 0.64 & 80 & PA, V & 62 & 625 & 7,10 \\
\hline & $M k-V I I A$ & M 316 & 6.6 & 0.43 & 70,80 & V & 59 & 590 & 9 \\
\hline \multirow[t]{2}{*}{ Japan } & Joyo $\mathrm{Mk}-\mathrm{II}^{\mathrm{b}}$ & 316 & 5.6 & 0.36 & 85 & $\mathrm{P}$ & 39 & 650 & - \\
\hline & Monju ${ }^{b}$ & 316 & 6.5 & 0.48 & 80 & $\mathrm{P}$ & 46 & 675 & - \\
\hline
\end{tabular}

$\mathrm{a}_{\mathrm{P}}=$ pellet; $\mathrm{PA}=$ annular pellet, $\mathrm{V}=$ vibratorilv-compacted particulate.

${ }^{b}$ Not a specific test. Several tests in DRF and Rapsodie are near these conditions.

${ }^{c}$ Concluded from PIE data. 
4. Modeling of Fuel Element Behavior: A number of fuel-element modeling codes have been developed to predict the thermal, mechanical, and irradiation performance of oxide fuels. These range from fast-running correlations codes to more detailed first-principles codes. Considerable effort over the past ten years has been focused on developing the analytical capabilities to predict steady-state performance using detailed models and hypotheticalaccident performance using simplistic models. More recently, the steadystate codes have been modified to include heat capacity effects and transient deformation models to allow the analysis of design-basis transient events.

The major first-principles codes for fast-reactor oxide fuels are: LIFE (USA), FRUMP (UK), COMETHE (Belgium), SATURN (Germany) and ACTIVE (Japan). These codes are used to assist in planning and post-test analysis of irradiation experiments, in design sensitivity studies, and in benchmarking simpler, faster-running codes. Many in-house correlations-type codes exist at commercial and government laboratories and have been used more often than the detailed codes for experimental planning and analysis and design studies (e.g. deterministic model for probabilistic analysis). In order to standardize analysis methods, either direct or indirect (e.g. benchmarking) use of the first-principles codes is being encouraged.

Code development is an ongoing activity, guided by the results of the experimental program. In general, the codes are quite good in predicting thermal performance, reasonably good at predicting nominal (1-D) mechanical performance, weak in predicting cladding deformation due to FCMI, and poor in predicting fuel element lifetimes. Efforts are being made to overcome these shortcomings.

\section{B. Key Issues}

Five major issues exist in the development of advanced and alternate oxide fuels for application in LMFBRs. These issues are: thermal performance, mechanical behavior, chemical behavior, run-beyond-cladding-breach performance and blanket rod performance. As stated previously, more is known about these issues for $\mathrm{UO}_{2}-\mathrm{PuO}_{2}$ than for the alternative fuels, and less is known about particulate fuel than pellet fuel. A significant data base generated from irradiation performance data is needed for all of the fuel systems before justifiable comparisons can be made.

1. Thermal Performance: Fuel-cladding gap conductance, gap closure kinetics, fuel restructuring, and fuel thermal conductivity interact to establish fuel thermal behavior and its performance limits. Testing has established with reasonable reliability the linear power rating for centerline melting in fresh and irradiated $\mathrm{UO}_{2}-\mathrm{PuO}_{2}$ pins of 5.84 and $6.35 \mathrm{~mm}$ diameter. This information, which is needed for safety and steady-state margin analysis and to determine whether changes in fuel properties with extended irradiation lead to lower power capability, is not available for the alternate fuel systems. Gap conductance and gap closure kinetics as functions of burnup are also not available for the alternate systems. Gap closure kinetics depend sensitively on the mechanical properties of the fuel and the fuel swelling characteristics, neither of which are known with any degree of assurance for the alternate fuels. Once these parameters are determined experimentally, fuel-element behavior codes are available to treat the synergistic behavior of the variables and for extrapolation to larger pin 
diameters. It should be noted that a programmed approach to full power can be used to close the fuel/clad gap and increase the thermal performance capability.

The consideration of particulate fuels focuses attention on their relative thermal performance compared to pellet fuel. Figure 1 shows a transverse section of an irradiated spherical particle fuel rod that illustrates restructuring typical in fuel of this type. Instrumented irradiation tests have been conducted which indicate the early-life "effective thermal conductivity" of the packed bed is even better than that of a pellet fuel having a comparable smeared density. ${ }^{4}$ Because thermal performance is a sensitive function of smeared density, the ability to attain uniform highsmeared density, i.e., $\sim 90 \%$ of theoretical, in long fuel columns must be demonstrated if particulate fuel is to be a long-range option. A definitive power-to-melt experiment with particulate fuel is needed.

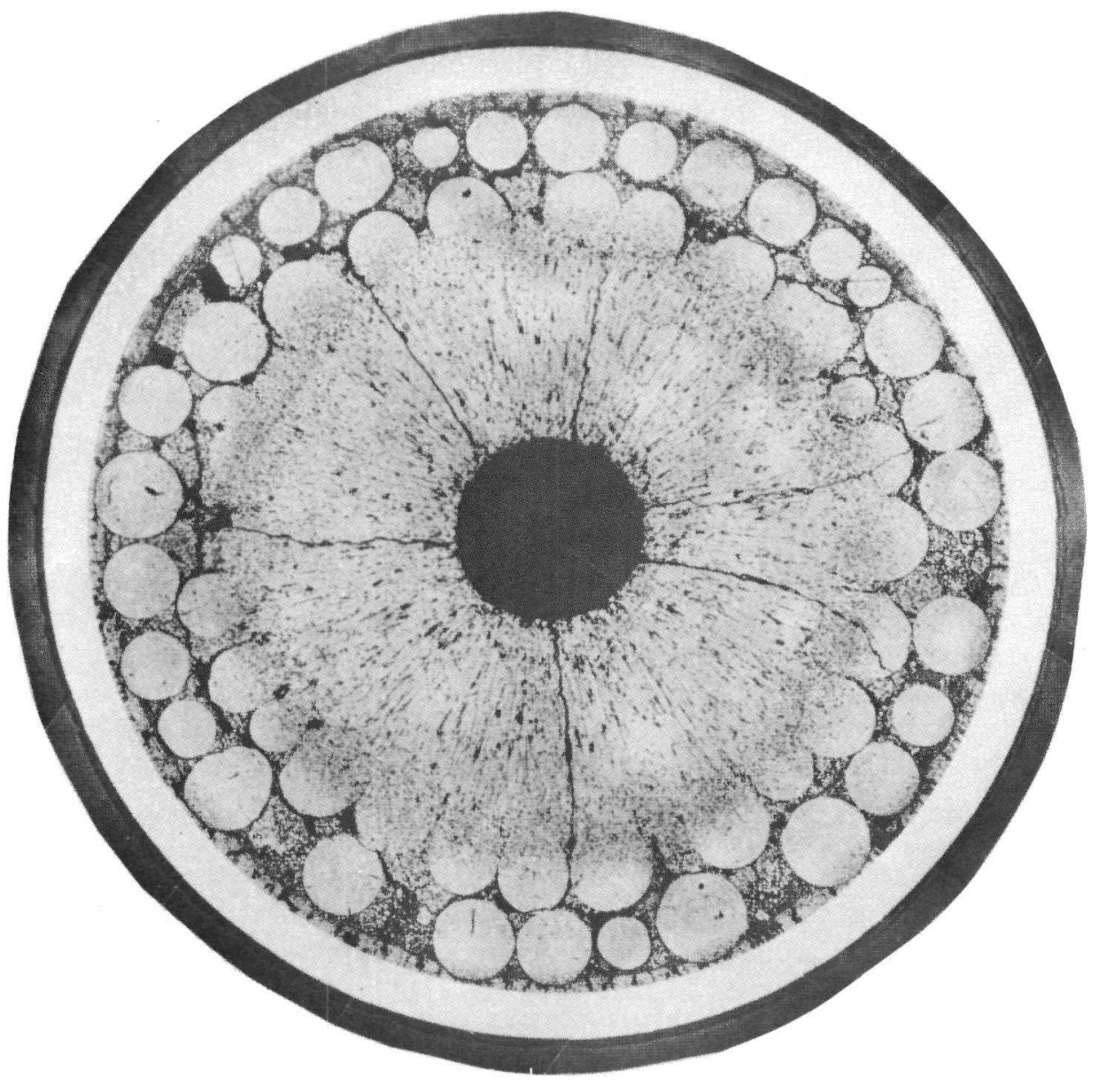

Fig. 1. Transverse Section of Spherical Partical $\mathrm{JO}_{2}-2.0 \mathrm{w} / \mathrm{O} \mathrm{PuO}_{2} 316$ stainless steelClad Fuel Rod After $3 \mathrm{w} / \mathrm{o}$ Burnup at $36 \mathrm{~kW} / \mathrm{m} .^{4}$ The initial smeared fuel density was $81.3 \%$ of theoretical. 
2. Mechanical Performance: The design practice for many years with oxide fuels has been to assume only gas pressure loading on the cladding and no FCMI. The release of fission gas as a function of burnup and power rating, therefore, has always been, and will continue to be, an issue in the performance of oxide fuels. Also, the extent and location of gases remaining in the fuel are important because of their role in the mechanical behavior of the fuel during overpower and overtemperature events. Irradiation tests with highswelling (annealed) claddings indicate limited FCMI with fuel smeared densities below $90 \%$ of theoretical. Cold-worked Type 316 cladding is also expected to exhibit limited FCMI in large LMFBRs where the high fluence-to-burnup ratio may result in the cladding swelling away from the fuel. However, the economic need for low swelling claddings coupled with fuel smeared densities of $90 \%$ and greater and higher linear power ratings may result in significant FCMI with $\mathrm{UO}_{2}-\mathrm{PuO}_{2}$ fuel. $\mathrm{UO}_{2}-\mathrm{PuO}_{2}$ with an $0 / \mathrm{M}$ (oxygen-to-metal ratio) of 1.94 has a $19 \%$ higher coefficient of thermal expansion than fuel of an $0 / M$ of 1.98, thus suggesting a potential lower limit on $\mathrm{O} / \mathrm{M}$ because of FCMI caused by differential thermal expansion. Therefore, for viable advanced $\mathrm{UO}_{2}-\mathrm{PuO}_{2}$ systems, the optimization of fuel pin design variables and the demonstration of acceptable operating power and temperatures and of burnup limitations remain issues in the steady-state and transient overpower mechanical performance of the pin.

The mechanical behavior of LMFBR oxide fuel pins during powercycling, or load-following operating modes is also an issue that remains to be resolved. 11 Experience with oxide fuels in LWRs has shown that FCMI plays at least a contributory role in cladding failure after increases in reactor power. While the stress-corrosion aspect of this behavior is not now an identified concern in iron- or nickel-base cladding materials, LMFBR oxide pins may be susceptible to the FCMI component alone. Analys is has shown that the cladding of an oxide fuel pin suffers a significant fraction of its cumulative damage during transient overpower events, albeit more severe than the slower ramp rates associated with power cycling. Nevertheless, advanced and alternate oxide fuel types would be suspect in this area until experimental data are available to satisy the concern.

Coincidental with the issue of mechanical behavior is the selection of the optimum oxide fuel form. Particulate fuel, especially spherical particles, may offer relief from detrimental FCMI at smeared fuel densities $>88 \%$. The limited information that is available suggests that the FCMI will be reduced by minimizing stress concentration points at the cladding surface and by the accommodation within the fuel column of short-range fuel movements. These mechanisms are highly dependent on the thermal performance of the particulate fuel and whether particle sintering precludes the realization of the claimed benefits.

For the alternate $\mathrm{ThO}_{2}-\mathrm{UO}_{2}, \mathrm{ThO}_{2}-\mathrm{PuO}_{2}$, and $\mathrm{UO}_{2}$ fuels, the issue is much the same, with even less data in hand. Compared to $\mathrm{UO}_{2}-\mathrm{PuO}_{2}$, the alternate fuels are expected to be stronger, have lower creep rates, and lower thermal expansion. Little is definitively known about their fuel swelling rates or fission-gas behavior under fast flux, high power density conditions. The above attributes, however, portend greater FCMI than $\mathrm{UO}_{2}-\mathrm{PuO}_{2}$ at comparable temperatures and heat ratings. Advanced cladding materials might therefore be desirable for these fuels. 
3. Chemical Behavior: Oxide fuels are complex chemical systems that become more complex with irradiation and the generation of fission products. The chemical behavior is sensitive to the original $\mathrm{O} / \mathrm{M}$, or system oxidization potential, and the change in the oxidizing potential with burnup. The mechanisms affected by the fuel chemistry are chemical attack of the cladding, migration of cesium and its reaction with the fuel and blanket material, redistribution of uranium and plutonium, and reaction with coolant sodium. In $\mathrm{UO}_{2}-\mathrm{PuO}_{2}$, the chemical attack of stainless steel cladding by cesium and tellurium is known to be a function of the initial fue $10 / M$, cladding temperature, and burnup. Slight variations in local cladding chemistry may also play a role. The attack is favored at initial o/Ms between 1.97 and 2.00 but is adequately suppressed below 1.96 . One of the major incentives to go to an $\mathrm{O} / \mathrm{M}$ less than 1.96 in the U.S. has been the reduced cladding wastage, although European experience has thus $f$ ar indicated no problems in the upper $\mathrm{O} / \mathrm{M}$ range. Unfortunately, low $\mathrm{O} / \mathrm{M}$ favors the axial migration of cesium and its reaction with fuel and the $\mathrm{UO}_{2}$ blanket pellets. The result of this reaction is a local stress on the cladding which has been shown to cause failures in EBR-II and DFR experiments. For $\mathrm{UO}_{2}-\mathrm{PuO}_{2}$, then, an issue is the optimum $\mathrm{fuel} O / \mathrm{M}$ to yield minimum cladding wastage, minimum FCMI (see previous section, also), maximum thermal performance (reducing the $0 / M$ lowers the fuel solidus temperature and thermal conductivity), and minimum reaction with sodium (favored by high system oxidizing potential). The fact that fuels that will be fissioning only ${ }^{239} \mathrm{Pu}$ will create a higher oxidizing potential than the ${ }^{235} \mathrm{U}$-fissioning fuels from which the existing wastage data base has been generated must be considered in establishing the optimum initial $0 / M$ ratio.

Heterogeneous cores may require fuel compositions with $\mathrm{PuO}_{2}$ contents higher than those for which significant irradiation performance data exist. The chemical behavior of high plutonia content fuels is a virtual unknown. While this may not be an overriding issue, it does affect cladding wastage considerations and fuel thermal performance.

The chemistry of the $\mathrm{ThO}_{2}-\mathrm{PuO}_{2}$ fuel system is expected to be similar to that of $\mathrm{UO}_{2}-\mathrm{PuO}_{2}$, i.e., $0 / \mathrm{Ms}$ of less than 2.00 will be possible. However, in $\mathrm{ThO}_{2}-\mathrm{UO}_{2}$ and $\mathrm{UO}_{2}$ the initial $0 / \mathrm{M}$ will be $\geq 2.00$ and the oxidizing potential will likely increase with burnup. The effects on cladding wastage portend to be the more serious; cesium migration and the detrimental effects of fuel-cesium chemical reactions may actually be reduced. Figure 2 shows, in one fuel rod, differences in the wastage of stainless steel cladding owing to the differences in oxidizing potential between $\mathrm{UO}_{2}$ and $\mathrm{UO}_{2}-\mathrm{PuO}_{2}$ fuels.

\section{Run-Beyond-Cladding-Breach: The ability of fuel pins to operate} with breached cladding is important if reasonable reactor operating efficiency is to be obtained. Irradiation data on the behavior of breached $\mathrm{UO}_{2}-\mathrm{PuO}_{2}$ pins are inconclusive. Some experiments have shown little fuel/sodium reaction and fuel washout while others have shown significant effects. This behavior in $\mathrm{UO}_{2}-\mathrm{PuO}_{2}$ is still a concern in the U.S. and is receiving significant attention. Low $\mathrm{O} / \mathrm{M}$ fuel and control of the sodium chemistry tend to alleviate the problem. The behavior of the alternate oxide fuels, however, is not known. Spherical particulate fuel has apparently behaved well after extended irradiation following cladding breach. However, this fuel was irradiated at relatively high linear power and the spheres were likely well sintered together. Questions still remain whether a lightly sintered or unsintered fuel column will behave as benignly, or whether fuel particles will escape through the clad breach. 


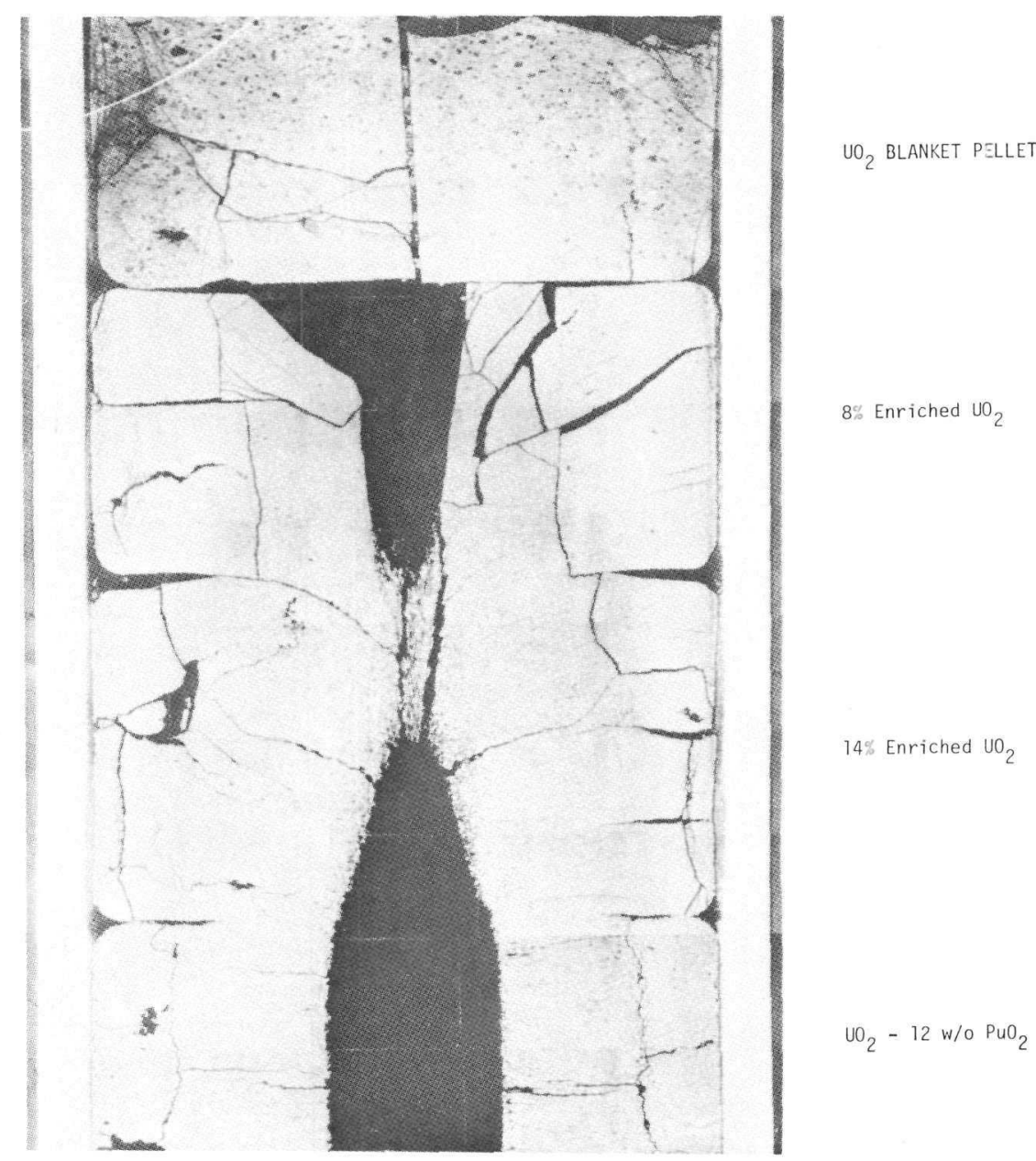

Fig. 2. Longitudinal Section of Upper End of 316 Stainless-Steel-Clad $\mathrm{UO}_{2}-\mathrm{PuO}_{2}$ Euel Rod Containing, from Top to Bottom of Section: $\mathrm{UO}_{2}$ blanket pellet, two annular half-length pellets of enriched $\mathrm{UO}_{2}(\mathrm{O} / \mathrm{M}=2.005)$, and a fuel pellet of $\mathrm{UO}_{2}-12 \mathrm{PuO}_{2}(0 / \mathrm{M}=1.99)$. The figure illustrates the higher oxidizing potential of $\mathrm{UO}_{2}$ (note increased cladding reaction) and vapon transport of $\mathrm{UO}_{2}$ into central void.

5. Blanket Rod Performance: Limited data exist for the irradiation of $\mathrm{UO}_{2}$ radial or internal blanket rods under expected operation conditions, and essentially no data exist for $\mathrm{ThO}_{2}$. A sub-set of issues to be resolved exists for blanket rods, which are similar to those issues for the fuel materials. They are: 1) confirmation of the power-to-melt capability as a function of design parameters, 2) confirmation of high-exposure steadystate irradiation behavior, including power jumps, which are expected to be more severe for internal blankets, 3) demonstration of transient irradiation performance, including undercooling events, and 4) operation beyond cladding breach. Of particular concern, as with $\mathrm{UO}_{2}$ fuel, is the potential for disruptive $\mathrm{UO}_{2}$-sodium reaction in breached pins with resulting enlargement of the breach and subsequent loss of $\mathrm{UO}_{2}$ from the rod. 
In axial blankets of rods operating at the higher linear power of advanced oxide systems, significant axial migration of cesium can be expected with the potential for a deleterious $\mathrm{Cs}-\mathrm{UO}_{2}$ reaction resulting in cladding breaching. Methods to accommodate the cesium-uranate reaction product are being investigated (e.g. void deployment in either the pellet or in the gap, or cesium traps), but only preliminary results are available and a concensus agreement on the solution does not exist.

\section{Activities Required to Resolve Key Issues}

The issues that exist for oxide fuels can only be resolved by an irradiation testing program of integral performance, endurance-type tests, and special purpose steady-state and transient tests. The necessary tests are described below.

1. Thermal Performance: Definitive in-reactor power-to-melt tests are necessary for the alternative oxide fuel types under consideration. These should be done initially for unirradiated fuel but repeated later with irradiated fuel to assess burnup effects. Also, the power-to-melt for spherical particulate fuel should be determined for $\mathrm{UO}_{2}-\mathrm{PuO}_{2}$ as a basis for evaluating the potential limiting thermal performance of this design variable. Fuel density should be a variable to assess potential density inhomogeneities along a long fuel column. Of secondary importance is the generation of experimental data on gap closure and fuel restructuring kinetics. These data can be obtained from interim examinations of steady-state integral performance tests.

2. Mechanical Performance: A series of steady-state integral performance tests in a fast flux are needed to evaluate the potential for FCMI between the alternate fuels and advanced alloy claddings. These tests should cover the expected ranges of linear power ratings and operating temperatures and be irradiated to burnups greater than $10 \mathrm{a} / 0$ and on to cladding failure. Spherical particulate fuel should be included to evaluate its potential to minimize FCMI with $\mathrm{UO}_{2}-\mathrm{PuO}_{2}$ and at least one alternate fuel. Fission-gas release data should also be collected from these tests. Experiments already in place should define the ability of $\mathrm{UO}_{2}-\mathrm{PuO}_{2}$ to achieve the goals of advanced systems. The experiments include both steady-state and transient tests; the transient tests will be only proof tests, as the reference $\mathrm{UO}_{2}-\mathrm{PuO}_{2}$ program has defined the relevant phenomena. In consideration of heterogeneous cores, additional steady-state irradiation tests of high plutonia-content fuels will be needed. Screening-type transient overpower tests should be conducted with the alternate fuels to determine their behavior relative to $\mathrm{UO}_{2}-\mathrm{PuO}_{2}$. Depending on the degree of coincidence, the transient testing program would change to either phenomenological testing (low coincidence) or limited proof-testing (high-coincidence).

Most of the required data from the steady-state tests can be obtained from nondestructive examinations during interim experiment removals. Destructive examinations would be required to generate the fission-gas release data. While thermal reactor experiments might be satisfactory to obtain comparative FCMI data on the alternate fuels, integral performance tests in a fast flux would provide the most useful information on many other phenomena that are flux-spectrum dependent, such as fission-gas release, and fuel chemistry. 
Power cycling is a difficult, but necessary issue to address for LMFBR fuel systems. However, power cycling is not an issue that requires immediate resolution and experimentation can probably be delayed until an appropriate facility is available.

3. Chemical Behavior: The issues raised on the chemical behavior of $\mathrm{UO}_{2}-\mathrm{PuO}_{2}$ and the alternate fuels can be resolved with data obtained from the destructive examination of the integral performance pins mentioned earlier under Mechanical Behavior. This includes data on fuel-cladding chemical interaction, cesium migration and reaction tendencies, and thermal performance (including fissile-constituent segregation). Laboratory thermodynamic data on the alternate fuels are considered necessary in evaluating the in-reactor chemical behavior.

4. Run-Beyond-Cladding-Breach: Run-beyond-cladding-breach should be conducted to evaluate the effects of sodium in reaction with alternate fuels after greater than 8 a/o burnup, and to evaluate the wash-out behavior of particulate fuel operated at low linear power rating. The latter tests need not use high-burnup fuel initially; only thermal conditioning of the fuel would be required. Thus, early data could be obtained on this option with $\mathrm{UO}_{2}-\mathrm{PuO}_{2}$ and alternate fuels.

5. Blanket Rod Performance: The issues raised concerning the performance of blanket fuel rods require extended steady-state irradiation testing as well as shorter specialized irradiation experiments. In particular, long-term steady-state irradiation tests are needed to confirm design burnup capability, including power jumps. Specialized tests are also needed to confirm predicted power-to-melt capability, transient overpower and undercooling capability, and to confirm capability for post-cladding breach operation.

D. Summary of Oxide Fuel Status

$\mathrm{UO}_{2}-\mathrm{PuO}_{2}$ pellet fuel, helium-bonded to $20 \%$ cold-worked Type 316 stainless steel cladding is the most highly developed oxide fuel element for LMFBRs. Current development is aimed at use of larger element diameters, higher smeared fuel densities, and thinner cladding. Alternate oxide fuels, including $\mathrm{ThO}_{2}-\mathrm{UO}_{2}, \mathrm{ThO}_{2}-\mathrm{PuO}_{2}$ and $\mathrm{UO}_{2}$, are expected to perform similarly to $\mathrm{UO}_{2}-\mathrm{PuO}_{2}$. Particulate fuel appears to be a viable option. The most significant key issues are thermal performance limits for alternate fuel forms, fuel-cladding mechanical interaction in elements with high smeared fuel densities, fuel-cladding chemical interaction, operation with failed cladding, and blanket rod performance. Resolution of the key issues requires both steady-state and transient irradiation tests.

\section{CARBIDE FUELS}

\section{A. Status of Development}

Carbide fuel has not been studied as intensively as the reference oxide fuel, and its stage of development is correspondingly lower. It is apparent that the major breeder development programs in most countries now envisage the exploitation of oxide fuel in LMFBRs to the fullest possible extent before possible commitment to use of carbide fuel. This circumstance can be attributed to the large commitments that the breeder nations have in oxide production and manufacturing facilities, to their natural caution in moving from 
use of a widely studied and relatively well understood fuel to a less well known fuel, to the fact that irradiation testing of carbide fuel elements has

TABLE IV. Carbide Fuel Types under INFCE Consideration for Use in Fast Breeder Cycles ${ }^{1}$

\begin{tabular}{lcc}
\hline Breeder Cycle & Core Fuel & Blanket Fuel \\
\hline Reference & (U,Pu C & UC \\
Transmuter & $(\mathrm{U}, \mathrm{Pu}) \mathrm{C}$ & ThC \\
& (Th, Pu C & ThC \\
Denatured & UC & ThC \\
\hline
\end{tabular}
not yet demonstrated an adequate state of development, and to the fact that significant improvement in oxide fuel performance seems to be possible.

1. Candidate Carbide Fuel Types: The candidate carbide fuel types under consideration for breeder cycles of current interest ${ }^{l}$ are shown in Table. IV. In all cases the fuel is hyperstoichiometric, i.e., monocarbide containing up to $10 \mathrm{v} / \mathrm{o}$ sesquicarbide.

2. Fuel Properties: The thermophysical properties of carbide fuels that are of particular interest are their relatively high thermal conductivities, metal atom densities, and melting points. Although the data base on thermophysical properties for (Th, U) C and (Th, $\mathrm{Pu}$ ) C is relatively small, these compounds are isomorphous with the more widely studied (U, Pu)C and $\mathrm{UC}$; the thorium-base carbide fuel compositions are therefore generally assumed to possess the desirable thermophysical properties that characterize the uranium-base carbides.

Laboratory tests show that the compatibility of carbide fuels with cladding materials is sensitive to the stoichiometry of the carbide, the carbon transport medium to the cladding, and the cladding alloy type. Slightly hyperstoichiometric fuel with $\sim 10 \mathrm{v} / 0 \mathrm{M}_{2} \mathrm{C}_{3}$ is commonly specified to provide an optimum combination of acceptable fuel-cladding compatibility and ease of fabrication. Somewhat greater carburization occurs with a sodium fuel-clad bond than with a helium bond. Alloys containing nickel in greater amounts than in Type 316 stainless steel generally show greater amounts of carbide precipitation. The transfer of carbon to the cladding in sodium-bonded elements is impeded to some extent by stainless steel shroud tubes around the fuel, as illustrated in Fig. 3.

The creep strength of carbide fuels is much higher than that of oxide fuels. This characteristic is of great significance because of the influence of fuel cracking and fuel creep strength on fuel-cladding mechanical interaction (FCMI). There is some evidence that ( $T h, U) C$ is even harder than $\mathrm{UC}$ or $(\mathrm{U}, \mathrm{Pu}) \mathrm{C}$. This circumstance could increase FCMI in (Th,U)C fuel elements, particularly in helium-bonded designs.

3. Feasible Element Designs: Three basic design concepts for carbide fuel elements are recognized: (a) sodium-bonded high-density pellets, (b) helium-bonded low-density pellets, and (c) helium-bonded high-density particle fuel. None of the three designs is universally acknowledged to have overriding advantages. As a result, each of the three designs is under development in LMFBR fuel programs in several different countries. ${ }^{12}$ For example, France has selected sodium-bonded pellet fuel for development, 13 Germany helium-bonded pellet fuel, 14 and the U.K. and Switzerland heliumbonded particulate fuel.15,16 U.S.S.R. studies include both helium-bonded 


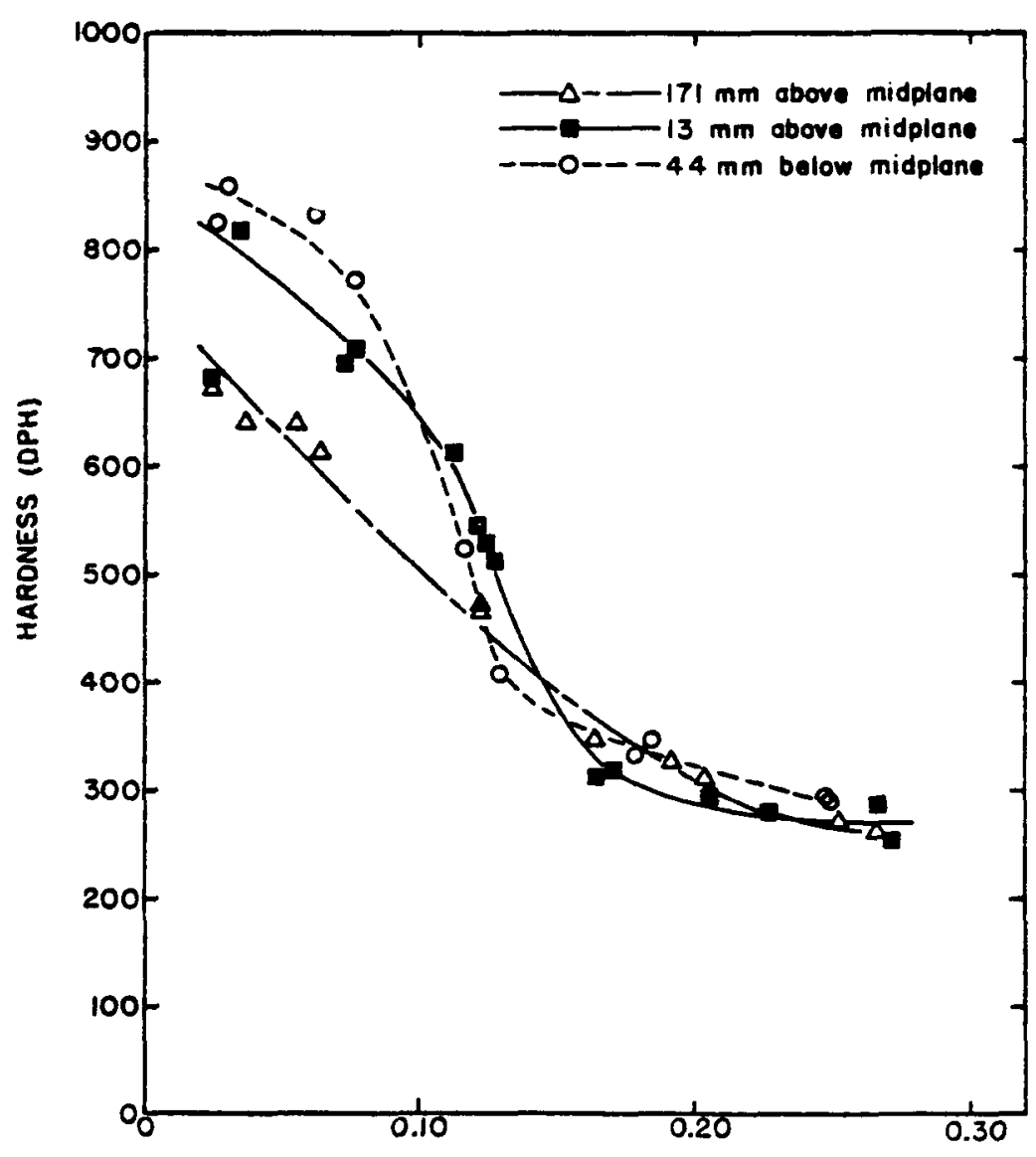

DISTANCE FROM INSIDE CLADDING SURFACE $(\mathrm{mm})$

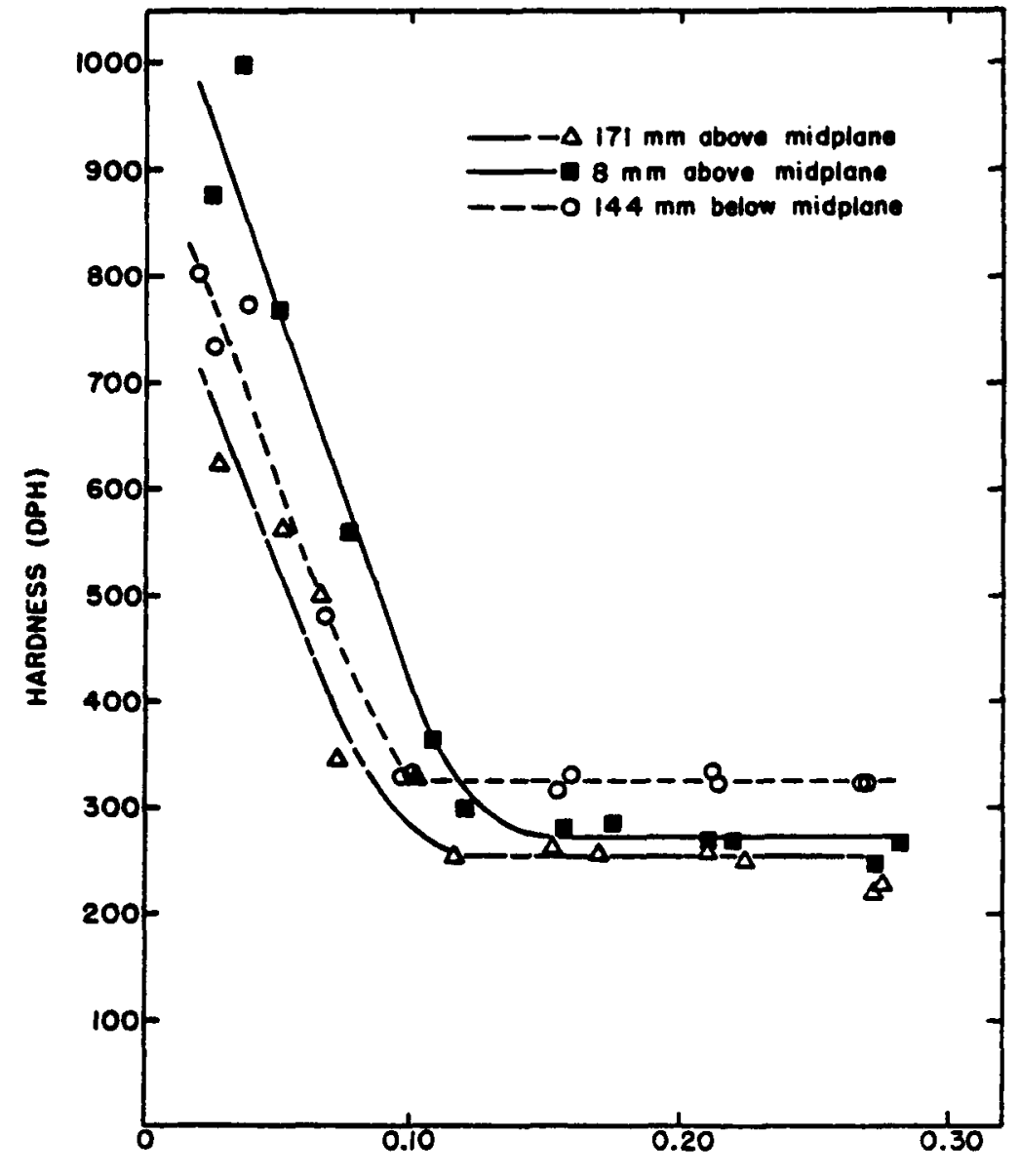

DISTANCE FROM INSIDE CLADDING SURFACE $(\mathrm{mm})$

Unshrouded

With 316 SS Shroud

Fig. 3. Hardness Profiles of 20\% Cold-Worked Stainless Steel Cladding from Sodium-Bonded Hyperstoichiometric Carbide Elements Irradiated in EBR-II to $\sim 8.0 \mathrm{a} / 0$ Burnup at $\sim 80 \mathrm{~kW} / \mathrm{m}$ (from LASL work). 
and NaK-bonded fuel elements. ${ }^{17}$ The U.S. program presently includes approximately equal emphasis on sodium-bonded and helium-bonded pellet fuel. 18

Sodium-bonded carbide fuel operates at relatively low temperatures so that the fuel swelling rate is minimized. High-density ( $98 \% \mathrm{~T} . \mathrm{D}$.$) pellets$ are normally specified; the necessary voidage to accommodate fuel swelling is all placed in the fuel-clad gap. The fuel-clad gap is sized so that the fuel does not forcibly contact the cladding until the end of the desired life of the fuel element. The cladding can be relatively thin, since the element design is not intended to accommodate significant FCMI. Modifications include (a) a thin sleeve or shroud around the fuel pellet column to prevent pellet fragments from wedging against the cladding and causing high local strains that can ultimately breach the cladding, (b) a vent so that the gas plenum cannot become pressurized and eject the sodium bond should a cladding leak occur, and (c) addition of 1 to $1.5 \%$ oxygen to the fuel to reduce the carbon potential and corresponding possibility of unacceptable cladding carburization.

Helium-bonded pellet fuel has the advantage of somewhat simpler fuel rod assembly compared to sodium-bonded fuel because the complications of providing a sodium bond and inspecting the bond quality are absent. Possible carbon transport from the fuel to the cladding is less efficient with a helium bond than with sodium. Fuel swelling in helium-bonded elements is greater than in sodium-bonded elements because of the higher fuel temperature and must be restrained by the cladding. The fuel pellets for helium-bonded fuel must be fabricated with low densities and uniformly distributed porosity to provide the necessary voidage to accommodate fuel swelling. The pellets must also be ground to close dimensional tolerances to assure the proper fuel/clad gap.

Particulate fuel element designs have been tested in smaller numbers to date than pellet fuel rods. However, vibratorily compacted particulate fuel is currently receiving increasing attention because of several considerations: (a) wet processes can be used to minimize dusting problems, (b) fuel/cladding mechanical interaction is lower than is the case with pellet fuel, and (c) compared to pellets, particulate fuel is more amenable to diversion-resistant fuel cycles requiring remote fabrication operations. Particulate fuel has been investigated both as solidsolution $(\mathrm{U}, \mathrm{Pu}) \mathrm{C}$ particles and as physically mixed particles of UC and PuC. 19

4. Irradiation Performance: Items of particular interest in assessing the irradiation performance of carbide fuel elements include transport phenomena and $\mathrm{f}$ ission product behavior, carbon activity and carburization of the cladding, fuel swelling and fission gas release, fuel restructuring and movement with accompanying FCMI, and characterization of cladding breaches.

Steady-state and transient irradiation tests are in progress in several countries to investigate the influence of the above factors on fuel element performance, and to test element designs that have developed based on results obtained from the irradiation studies. EBR-II is being used in the U.S. program to irradiate both sodium-bonded and helium-bonded fuel under steady-state conditions as nearly identical as possible, so that direct comparisons of fuel element performance can be made for the two element design 
concepts. Plans are also being made for comparison experiments in FTR. Vibratorily-compacted particulate fuel may be included in the FTR tests so that direct comparisons may be possible for all three candidate fuel element designs. TREAT is being employed in the U.S. program for transient overpower tests.

Gamma scanning and radiographic examinations of irradiated pellet and particulate carbide fuel elements show evidence of only modest migration of plutonium and fission products. Carbon and oxygen transport to the fuel surface by carbon monoxide has been observed with formation of free $(\mathrm{U}, \mathrm{Pu})$ metal phases in the fuel center. Second phases formed at least partially from segregated fission products have been observed in irradiated pellet and particulate fuels. Carbide fuel pins appear to be exempt from fission-product/cladding and fuel/coolant reactions. 20 However, enhanced fission product migration to the fuel/clad interface has been observed in single-phase monocarbide fuel which appeared to increase adhesion of the fuel to the cladding. ${ }^{1}$ Single-phase carbide, however, is not in the current U.S. test matrix.

Possible changes in the carbon/metal ratio during burnup are important because of their effects on carbon activity and cladding carburization. The carbon/metal ratio appears to decrease in hyperstoichiometric fuel because of carbide formation by the rare earth fission products. ${ }^{2}$ The carbon activity will decrease correspondingly with burnup. No fuel element failures have been attributed to excessive carburization in the U.S. studies, which have been on carbide fuels containing up to $20 \mathrm{v} / 0(\mathrm{U}, \mathrm{Pu})_{2} \mathrm{C}_{3}$. This experience applies to both helium- and sodium-bonded pellet fuel and to vibratorily compacted particulate fuel. Swiss irradiation studies of particulate fuel containing up to $40 \mathrm{v} / 0(\mathrm{U}, \mathrm{Pu})_{2} \mathrm{C}_{3}$ showed instances of severe cladding carburization that led to cladding failure. ${ }^{23}$ The U.S. and Swiss programs currently specify upper limits of $\mathrm{M}_{2} \mathrm{C}_{3}$ in carbide fuel at 10 and $5 \mathrm{v} / \mathrm{o}$, respectively.

The rate of fission gas release from carbide fuel is associated with those burnup and temperature factors that control the fuel swelling rate. Thus, at temperatures below $1100^{\circ} \mathrm{C}$ where swelling rates are low, gas release is correspondingly low and is in accordance with recoil and diffusion mechanisms. Above $1100^{\circ} \mathrm{C}$, or at high burnups where "breakaway" swelling begins from accelerated fission gas bubble growth, gas release is increased and is associated with fission gas bubble linkup.

Sodium-bonded fuel shows comparatively low fission gas release rates because of the lower fuel operating temperatures provided by the sodium bond. Fission gas release is usually in the range of 3 to $20 \%$. Fission gas release is higher (typically 15 to $35 \%$ ) in helium-bonded fuels because of higher fuel operating temperatures and internal fuel porosity. Gas release is also sensitive to fuel smeared density because of the influence of internal voidage on the effective thermal conductivity of the fuel, and because the increased porosity in low density fuel provides more fuel surface area for gas release and shorter paths for gas diffusion and bubble interconnection. Vibratorily compacted particulate fuel releases fission gas at rates comparable to helium-bonded pellets. A direct comparison of physically mixed UC and PuC particulate fuel with solid-solution $(\mathrm{U}, \mathrm{Pu}) \mathrm{C}$ particulate fuel showed comparatively low release for the latter fuel form. 19 
Sodium-bonded pellets tend to fragment into relatively large pieces during irradiation. The fracturing behavior is due to thermal stresses that are especially severe during power transients such as those from reactor scram. The rate of fuel surface temperature change during such transients is maximized by the thermally efficient sodium fuel/clad bond. Subsequent movement and separation of the fuel fragments is facilitated by the large fuel/clad gap in sodium-bonded fuel elements. The relatively low fuel temperature in sodium-bonded elements minimizes crack healing or resintering of fuel fragment interfaces.

The higher central fuel temperatures in helium-bonded fuel produce more extensive microstructural changes than in sodium-bonded fuel. In the case of pellet fuel, a central porous zone is observed that may be surrounded by an intermediate annulus of high-density fuel and by a peripheral annulus of unrestructured fuel that contains circumferential as well as radial cracks. Crack healing which reduces pellet fragmentation is of en evident. Similar restructuring is noted in vibratorily compacted particulate fuel. The fuel density changes that occur in helium-bonded pellets are fuel densification, followed by swelling of the fuel to the cladding. These changes, which first increase and then close the fuel/clad gap, cause corresponding changes in fuel/cladding gap conductance. ${ }^{24,2} 5$

Most of the FCMI effects in sodium-bonded fuel are caused by the movement of fuel fragments that result in wedging of the fragments against the cladding. Figure 4 shows a longitudinal section of a fractured sodiumbonded carbide fuel pellet with a fuel chip that has wedged pellet fragments against the fuel element cladding. This in turn leads to cladding ovalities or other non-uniform cladding strains due to local stress concentrations. Promising initial results have been obtained on elements containing shroud tubes to restrain fuel fragment movement and to thereby minimize development of clad ovalities. 26

FCMI in helium-bonded pellet fuel is associated with fuel swelling and is generally more uniform than that observed in sodium-bonded fuel. Cladding diameter increases ranging from 1 to $3 \%$ have been observed for fuel elements irradiated to 10 a/o burnup with smeared fuel densities in the range of approximately 80 to $90 \%$ of theoretical. However, the increases in cladding diameter are less than $1 \%$ if smeared fuel density ranges from 70 to $80 \%$ of theoretical. FCMI in helium-bonded pellets may be enhanced by extensive fuel/ clad bonding that has been observed, particularly in single-phase monocarbide fuel. Radial fuel cracks in the bonded areas result in local cladding stress concentrations. Other evidence of local clad stress concentrations is provided by profilometry traces of irradiated elements that show circumferential ridging at each fuel pellet interface. No clear advantage is evident in using annular pellets; both poorer and better element performance have been reported.

Limited information to date indicates that, compared to pellet fuel elements, FCMI in vibratorily compacted elements is relatively $10 \mathrm{w}(<1 \%)$ and is highly uniform. Tests at high linear powers indicate that the benefits from higher fuel temperature and plasticity are outweighed by the adverse effects of high cladding thermal stresses, higher fission gas release, and greater susceptibility to power cycles. 20 , 


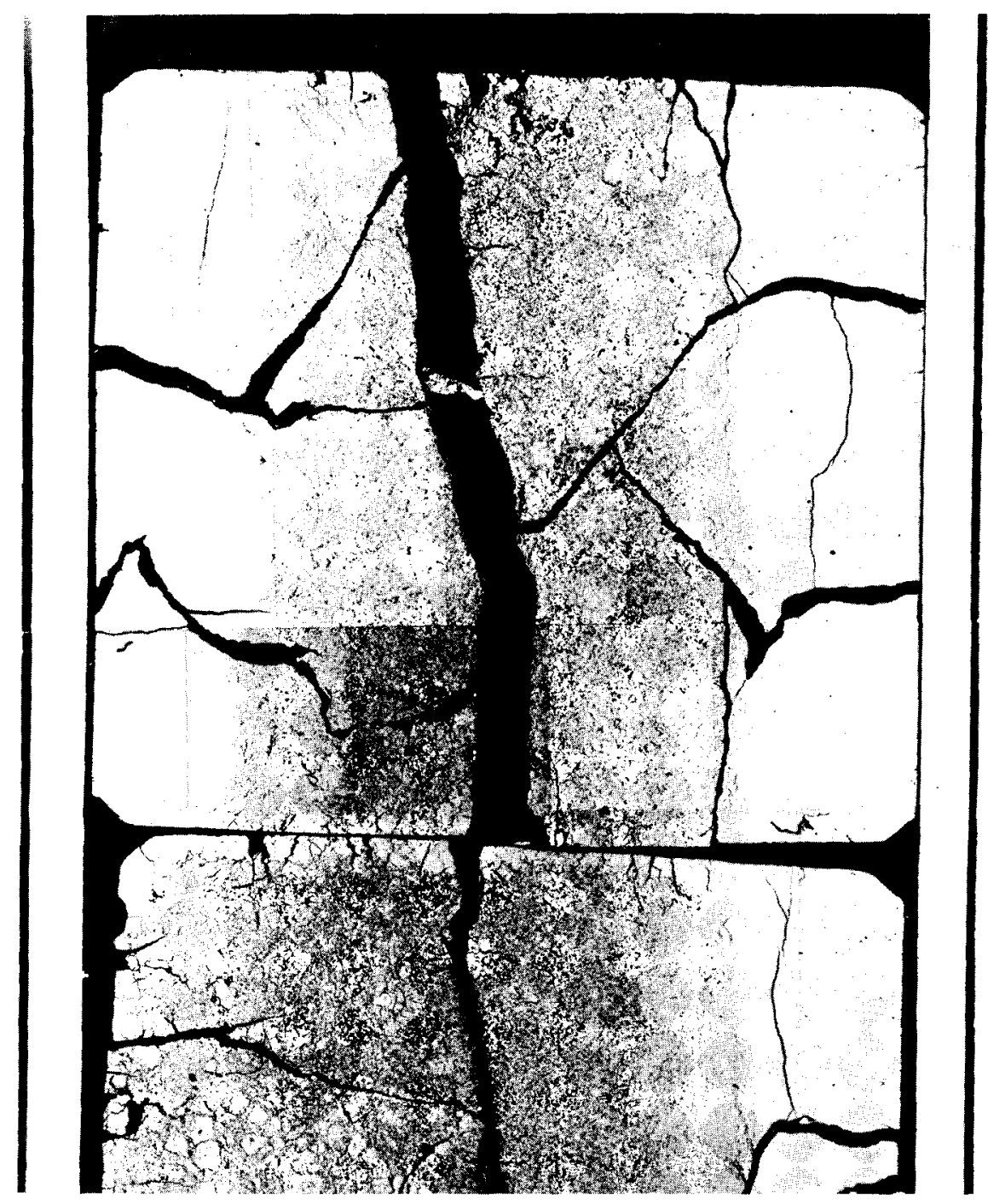

Fig. 4. Longitudinal Section of a Sodium-Bonded Carbide Euel Element Showing a Fuei Chip that Wedged Between the Major Fragments of the Jpper Fuel Pellet, and Asymmetric Swelling in the tower Fuel Pellet. 21

Cladding failures in carbide fuel elements are relatively benign and are characterized by small grain-boundary separations that are often so small they cannot be located by ordinary visual examination techniques. Continued operation beyond failure apparently results in very slow crack propagation. The fuel does not react with the coolant and fuel. loss is not observed.

The principal mechanisms that are believed to initiate failure in sodium-bonded elements are wedging of fuel pellet fragments against the cladding as shown in Fig. 4 which can cause local cladding strains, and discontinuities in the sodium bond from fission gas bubble collection that may cause local overheating of the fuel and cladding. No failures have yet been reported in sodium-bonded elements that contain fuel shroud tubes. 
Cladding failures in helium-bonded pellet elements (Fig. 5) are often found near the ends of radial fuel cracks which are frequently located near pellet/pellet interfaces. Grain-boundary cavitation and separations are associated with the cladding cracks. The observed microstructural changes are typical of those observed in creep-rupture tests. Larger clad cracks were noted in a group of failed vibratorily compacted elements, but those failures were attributed to cladding carburization and embrittlement resulting from excessively high amounts of sesquicarbide in the fuel. ${ }^{23}$
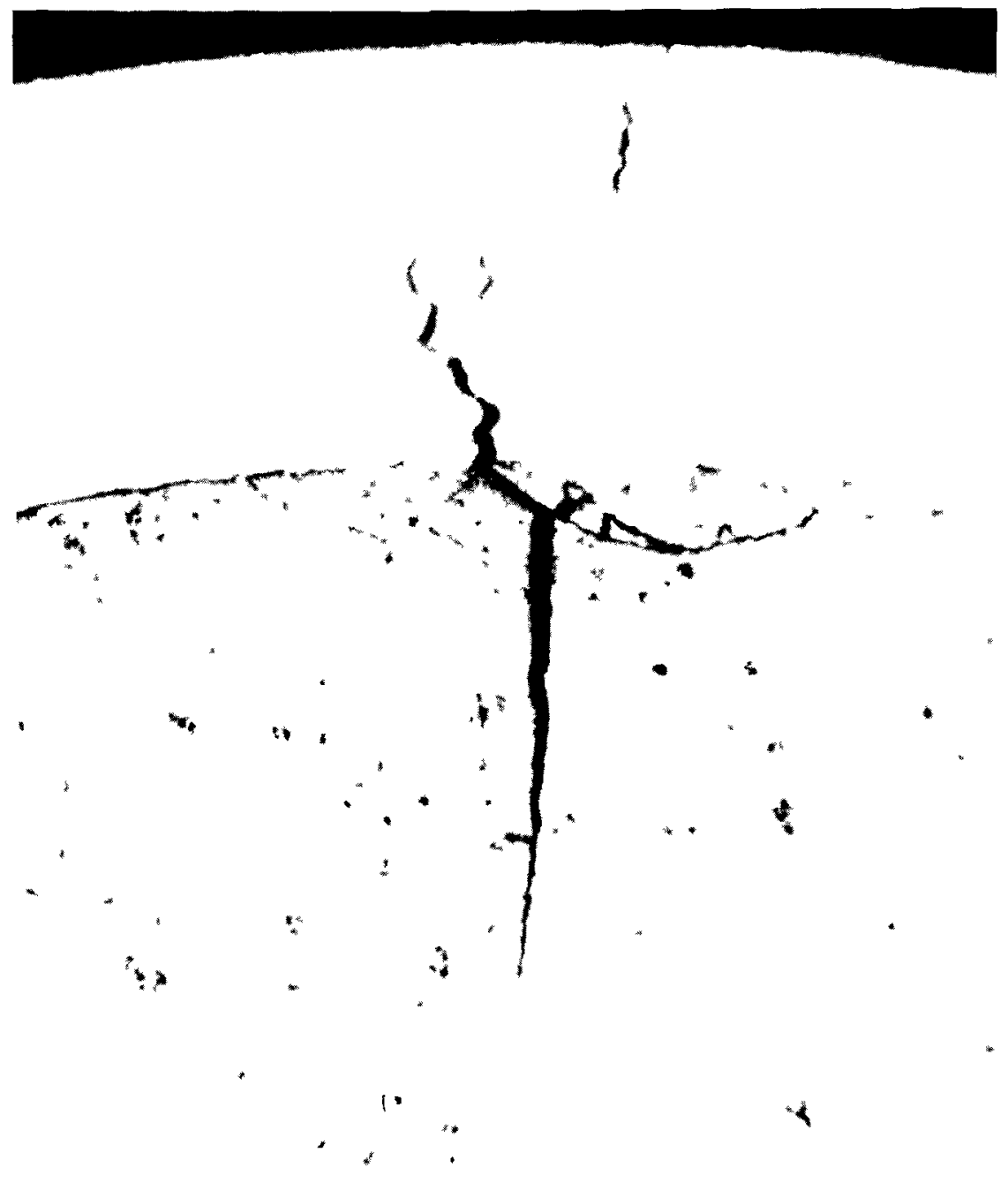

Fig. 5. Cladding Crack Appearing as an Extension of a Fuel Crack in an Element containing Single-Phase Carbide Fuel Bonded to the Cladding. 21 
The thermal performance of carbide fuel is not limited by center melting considerations, as is the case with oxide fuels, but primarily by fuel/cladding chemical and mechanfcal interaction effects. These effects are presently difficult to model so that direct experimentation is relied upon to establish both thermal and burnup performance limits. Interpretation of the guidance provided by such testing may vary, depending upon the investigator. As a consequence, the performance limits selected by different groups for the same fuel element design concept may vary considerably. Design and thermal performance objectlves currently accepted in various national programs are shown in Table $\mathrm{V}$. The three fuel element types are specified in the national programs to operate at fuel burnups up to 12 a/o with maximum cladding temperatures ranging from 620 to $655^{\circ} \mathrm{C}$, and at linear powers in the range of 80 to $110 \mathrm{~kW} / \mathrm{m}$. Smeared fuel densities for sodium-bonded designs are somewhat higher ( 81 to $86 \%$ T.D.) than those specified for helium-bonded designs (72-84\% T.D.).

TABLE V. Carbide Fuel Flement Design and Performance objectives ${ }^{1}$

\begin{tabular}{|c|c|c|c|c|c|c|}
\hline Fucl Form & $\begin{array}{l}\text { Fue1- } \\
\text { C1ad } \\
\text { Eond }\end{array}$ & $\begin{array}{c}\text { Smeared } \\
\text { Fuel } \\
\text { Density, } \\
\% \text { T.D. }\end{array}$ & $\begin{array}{c}\text { Nominal } \\
\text { Peak } \\
\text { Clad } \\
\text { Temperature, } \\
{ }^{\circ} \mathrm{C}\end{array}$ & $\begin{array}{l}\text { Nominal } \\
\text { Peak } \\
\text { Linear } \\
\text { Power, } \\
\mathrm{hk} / \mathrm{m}\end{array}$ & $\begin{array}{c}\text { Peak } \\
\text { Burnup } \\
\text { at. } \%\end{array}$ & Country \\
\hline \multirow[t]{2}{*}{ Pellet } & $\mathrm{Na}$ & $81-86$ & 655 & 100 & 12 & U.S. \\
\hline & & 85 & NA & 80 & 5 & France \\
\hline \multirow[t]{2}{*}{ Pellet } & He & $75-84$ & 655 & 100 & 12 & U.S. \\
\hline & & 75 & 620 & 80 & 7 & Germany \\
\hline \multirow[t]{2}{*}{ Particulate } & He & $72-80$ & $\mathrm{NA}$ & 110 & NA & $\mathrm{L} \cdot \mathrm{K}$. \\
\hline & & $75-80$ & 650 & 80 & $>7$ & Swit zer 1 and \\
\hline
\end{tabular}

The initial translent overpower tests of carbide fuels were intended to provide information relevant to safety issues. Sodium-bonded pellets, helium-bonded pellets, and vibratorily compacted fuel elements were subjected to transient irradiations in TREAT that, in some cases, were severe enough to cause melting of the fuel and cladding. Bond ejection was noted in a test on preirradlated sodium-bonded fuel at $220 \mathrm{~kW} / \mathrm{m}$ but cladding failure did not follow. A similar test of pretrradiated heliumbonded pellet fuel caused cladding failure. It should be noted that these early tests were on non-prototypic fuel pins. The fuel density was higher than currently specified, a different cladding material was used, and the highly-stringent QA fuel speciffcations adhered to today were not utilized. A transient overpower test on vibratorily compacted PuC in stainless steel cladding showed a cladding fallure because of 11quid-phase formation between free plutonium metal and the stainless steel cladding.

Milder transient overpower tests are currently in progress on sodium- and helium-bonded pellet $(\mathrm{U}, \mathrm{Pu}) \mathrm{C}$ fuel elements. ${ }^{27}$ These tests are intended to evaluate the ability of candidate carbide fuel element designs to withstand design-basis transients, and to determine the transient overpower threshold conditions that result in cladding failure. Unirradiated 
shrouded sodium-bonded fuel has been subjected to peak linear powers up to $385 \mathrm{~kW} / \mathrm{m}$ without cladding fallure, although extensive bond boiling and shroud melting occurred. A test of $120 \mathrm{~kW} / \mathrm{m}$ on an unirradiated heliumbonded fuel element showed no significant effects, as was the case in a test at $165 \mathrm{~kW} / \mathrm{m}$ on a preirradiated helium-bonded element.

Virtually all of the information summarized above on the irradiation behavior of carbide $\mathrm{fuel}$ pertains to (U,Pu)C elements. However, because of the known similarities in properties and structure of uraniumand thorium-base carbides, it is belleved that the irradiation behavior of the two carbide systems will be correspondingly similar. An irradiation experiment has been placed in EBR-II to confirm this assumption. The 19-pin assembly contains helium-bonded elements of (U,Pu)C, (Th, Pu) $\mathrm{C}$ and UC that will be irradiated under essentially identical conditions so that direct comparisons of fuel element performance will be posstble.

5. Modeling of Fuel Element Behavior: Modeling the in-reactor behavior of carbide fuel elements is being done by several different groups in the U.S. and abroad. The objectives of the modeling efforts are to obtain a better understanding of the basic materials properties and behavior

mechanisms that combine to determine fuel element performance, to interpolate or extrapolate existing experimental results with increased confidence, and to assess the sensitivity of element performance to specific materials properties, design parameters, and operating conditions. Reliable models will help identify, for example, the most feasible design changes that could be needed to accommodate the possibly higher creep strength of $(\mathrm{Th}, \mathrm{U}) \mathrm{C}$.

The modeling codes presently being used for performance analyses of carbide fuels have been generally derived from earlier first-principles codes developed for oxide fuel performance. For example, the UNCLE-S and UNCLE-T codes have been developed to predict the steady-state and transient performance of carbide fue1. ${ }^{2}$ These codes are based on the LIFE-3 code structure with appropriate carbide properties and behavior models substituted for the oxide ones originally in LIFE-3. UNCLE-S is intended to analyze fuel-element performance for reactor histories that include normal startups, steady power, gradual power changes, and shutdowns. The code includes options for sodium and helium fuel/clad bonds with stainless steel and a variety of advanced alloy claddings. UNCLE-T is designed for continuous analysis of both steady-state operation and design transient events. It includes all the UNCLE-S options along with capabilities for transient heat transfer analysis with inclusion of high strain rate deformation models. blanket fuel behavior.

Efforts are just being started to develop codes to model carbide B. Key Issues

The key issues for continued carbide fuels development are associated with: (a) the tendency of carbldes to carburize fuel cladding under certain conditions, (b) proving out element designs that can satisfactorily accommodate the relatively high fuel/cladding mechanical interaction aspects of carbide fuels, (c) the potential consequences of the loss of bond in sodium-bonded elements, (d) blanket development, and (e) development 
of improved codes for predicting fuel element performance. The key issues apply to all candidate carbide fuel types -- (U,Pu) C, (Th, U) C, and (Th, Pu) C, and UC.

1. Cladding Carburization and Embrittlement: The transfer of carbon from fuel to cladding lowers the ductility of the cladding, as indicated by changes in microhardness such as those shown in Fig. 3 and by brittle failures observed in heavily carburized cladding. Carbon transfer occurs most effectively in sodium-bonded elements. In principle, carburization of the element cladding and its embrittlement should not be of great significance in sodium-bonded elements because the element design concept assumes that the useful fuel lifetime ends when the fuel contacts the cladding. Nevertheless, prudent reactor operation with sodium-bonded carbide fuel must include the assumption that there will be some instances where fuel element operation is extended beyond initial contact of fuel and cladding. While the ability of heavily carburized cladding in sodium-bonded elements to contain swelling fuel without cladding rupture has not been reliably determined, moderately carburized cladding in sodium-bonded pins has demonstrated its ability to perform reliably without breaching.

2. Fuel/Cladding Mechanical Interaction: The relatively high creep strength of carbide fuel tends to provide an inexorable aspect to its swelling behavior. Compared to oxide or metal fuel, carbide therefore requires stronger cladding if its swelling tendencies are to be restrained, or if swelling is to be redirected into internal void volumes such as the central hole in annular pellets. Although high-strength cladding may be desirable to restrain carbide fuel swelling, adequate cladding ductility is needed in any case to accommodate local strains. As noted in preceding sections, three different fuel element designs have evolved to accommodate carbide fuel swelling -- sodium-bonded high-density pellets, helium-bonded low-density pellets, and helium-bonded particulate fuel. Several hundred fuel elements representing the three element designs have been irradiated to date in the U.S. and abroad, but as yet with no clear indication of the best approach for accommodating carbide fuel swelling. Sodium-bonded carbide pellets characteristically fracture into a few large pieces which tend to become wedged against the cladding, as shown in Fig. 4. This movement of fuel fragments in turn produces severe local stress concentrations that are manifested as cladding ovalities or other non-uniform radial cladding strains which are conductive to cladding failure. Helium-bonded fuel causes stress concentrations to develop in the cladding at the base of radial fuel cracks, as illustrated in Fig. 5. In the case of vibratorily compacted fuel, preliminary experiments show less FCMI with physically mixed particles than with solid-solution particles. No data are available on comparative FCMI effects in elements with spherical or angular fuel particles.

3. Loss of Sodium Bond: The consequences of loss of sodium bond because of cladding failure or bond displacement by gas bubbles are a recurring issue with sodium-bonded fuel. The potential seriousness of such an event is greatest at the start of life, when the fuel/clad gap is largest. Calculations for sodium-bonded elements operating at normal heat ratings $(\sim 100 \mathrm{~kW} / \mathrm{m})$ indicate that loss of bond in such cases may cause the fuel to melt but that, as long as coolant flow is maintained, the molten fuel will not penetrate the cladding. The possibility of molten fuel /coolant interaction must be considered if the cladding should be penetrated. In any case, if the sodium bond is lost, fuel swelling will be 
accelerated by the increase in fuel temperature. This in turn may fail the relatively thin cladding that is normally specified for sodium-bonded elements.

4. Blanket Development: Smeared fuel densities specified for carbide blanket elements are $90 \%$ or more of theoretical. Carbide blanket elements have not been irradiated so that their capability for reaching goal burnups, which are in the range of 1 to $2 \mathrm{a} / \mathrm{o}$, is undetermined.

5. Fuel Element Performance Predictions: Extensive efforts are in progress to model the performance of carbide fuel elements. To date, however, the models have been handlcapped by the relatively small existing data base for the irradiation behavior of carbide fuels. This is especially true for transient overpower events. In addition, many of the early irradiation studies of carbide fuels were made under non-prototypic irradiation conditions and on poorly characterized materials. As a result, the computer models cannot be calibrated reliably so that the performance of carbide fuel elements can not be predicted with the degree of confidence than can be applied to predictions of the reference oxide fuel behavior.

\section{Activities Required to Resolve Key Issues}

All the key issues identified for carbide fuels require resolution through irradiation tests of integral fuel elements. Both steady-state and transient testing is needed, plus supporting out-of-reactor studies.

1. Cladding Carburization and Embrittlement: Continued irradiation studies are needed to determine the maximum amount of cladding carburization that can be accommodated without incurring early cladding failure because of changes in mechanical properties. The use of high-nickel cladding alloys should be avoided unless such alloys are essential because of cladding strength considerations. If use of such alloys appears desirable, it may be advisable to investigate the use of fuel additives to reduce carbon activity, and the use of barrier layers between the fuel and cladding to reduce carbon transfer.

2. Fue1-Cladding Mechanica1 Interaction: Steady-state and transient tests are needed on the three princlpal carbide fuel element design concepts to determine which design is best able to accommodate FCMI from fuel swelling, as well as from movement of fuel fragments. Vibratorily compacted particulate fuel appears to offer a promising solution to FCMI effects. The unrestructured annulus of fuel particles that adjoins the cladding in such fuel elements cannot develop large cracks and fragments that cause corresponding stress concentrations in the cladding. If particulate fuels are not added to the U.S. program, meaningful comparisons of fuel element performance may nevertheless be possible by evaluating results from U.K. and Swiss irradiations of vibratorily compacted fuels in the PFR.

For sodium-bonded elements, comparative tests are also needed between shrouded elements clad with stainless steel and unshrouded elements with high-strength alloy cladding to detemine the best method of accomodating movement of fuel fragments. Helium-bonded fuel should be tested in highstrength alloy cladding to determine if such cladding is capable of preventing cladding failures from high-temperature fuel swelling. In the case of 
vibratorily compacted fuels, comparisons are also needed between angular and spherical particles, and between solid-solution particles and physically mixed particles of fissile and fertile carbides.

Transient irradiation tests should be performed on elements with ranges of prior steady-state reactor exposure extending from unirradiated fuel to elements that have reached discharge burnups.

3. Loss of Sodium Bond: Irradiation tests at full linear power (nominal power plus $3 \sigma$ uncertaint1es plus $15 \%$ overpower) are needed to determine the size of unbonded area that can be accommodated without producing fuel melting or adversely affecting fuel element performance. Tests with complete loss of bond under the above power conditions are also needed to determine the possible consequence of extensive fuel melting. Both unirradiated and previously irradiated fuel elements should be tested to reflect respectively the influence of maximum fuel/clad gap and stored fission gas in the fuel. If the consequences of sodium bond loss are judged unacceptable, then vented designs should be considered, as well as reduced operating powers and fuel/cladding gaps so that fuel melting cannot occur with loss of sodium bond.

4. Blanket Development: Blanket irradiations of ThC and UC should be started as early as practicable because of the long residence time to reach goal burnups. The smeared densities should be varied upwards from $90 \%$ of theoretical to determine the maximum feasible value.

5. Fuel Element Performance Predictions: Continued efforts are needed to improve the prediction capabilitles of existing computer models for carbide fuel element performance. Opportunities should become available to calibrate the codes more reliably as additional results become available from postirradiation examinations of steady-state irradiations in EBR-II and transient overpower tests in TREAT. Code development is also needed for carbide fuel performance in internal, radial, and axial blanket element designs.

\section{Summary of Carbide Fuel Status}

Hyperstoichiometric (U, Pu)C pellets, helium- or sodium-bonded to $20 \%$ cold-worked Type-316 stainless steel cladding, are the most highly developed carbide fuel elements for LMFBRs. Alternate carbide fuels, including $(\mathrm{Th}, \mathrm{U}) \mathrm{C},(\mathrm{Th}, \mathrm{Pu}) \mathrm{C}$, and $\mathrm{ThC}$ are expected to perform similarly to $(\mathrm{U}, \mathrm{Pu}) \mathrm{C}$. Helium-bonded particulate carblde element designs are also being actively developed. Current development is largely centered on determining the relative capabilities of the candldate element designs to reach goal burnups under design conditions. The most significant key issues are cladding carburization, local fuel /cladding mechanical interaction from fuel cracking and from wedging of fuel fragments, consequences of loss of sodium bond, blanket fuel development, and development of improved fuel element performance models. Resolution of the key issues requires continued steady-state and transient irradiation tests. 
IV. METAL FUELS

A. Status of Development

Renewed interest in metal fuels for LMFBRs is due to several developments. The EBR-II Mark I metal driver fuel is the only type of LMFBR fuel to have demonstrated a closed, diversion-resistant fuel cycle. ${ }^{29}$ System design studies of large commercial LMFBRs during the past few years have specified steadily decreasing requirements for reactor sodium outlet temperatures. At current temperatures of interest, the candidate metal fuels have adequate compatibility with cladding materials. Also, a basic design for an LMFBR metal fuel element has been developed that has been demonstrated to be capable of achieving fuel burnups greater than 10 a/o with high reliability. The high burnup capability appears to be independent of fuel composition, provided that adequate fuel/cladding compatibility exists.

TABLE VI. Metal Fuel Types under INFCE Consideration for Use in Fast Breeder Cycles ${ }^{1}$

\begin{tabular}{lll}
\hline Breeder Cycle & Core Fuel & Blanket Fuel \\
\hline Reference & $\mathrm{U}-\mathrm{Pu}-\mathrm{Zr}$ & $\mathrm{U}, \mathrm{U}-\mathrm{Mo}$ \\
Transmuter & $\mathrm{U}-\mathrm{Pu}-\mathrm{Zr}$ & $\mathrm{Th}$ \\
& $\mathrm{Th}-\mathrm{Pu}-\mathrm{Zr}$ & $\mathrm{Th}$ \\
& $\mathrm{Th}-\mathrm{U}$ & $\mathrm{Th}$ \\
Denatured & $\mathrm{U}, \mathrm{U}-\mathrm{MO}$ & $\mathrm{Th}$ \\
\hline
\end{tabular}

1. Candidate Metal Fuel Types:

The candidate metal fuel alloy types under consideration for breeder fuel cycles of current interest ${ }^{l}$ are shown in Table VI. Zirconium is used in the plutonium alloys to improve the compatibility of the alloys with cladding materials and to raise the solidus temperature of the alloys. Uranium, or uranium alloyed with molybdenum, is specified for the denatured cycle to provide a fuel with perform-

ance at least equal to the metallurgically similar but more complicated uranium-5 w/o-fissium* alloy used as the EBR-II driver fuel. 30

2. Fuel Properties: The fuel alloys shown in Table VI generally reflect the properties of the fertlle matrix (thorium or uranium). The thorium-base alloys are characterized by high melting points, isotropic dimensional behavior, and high thermal conductivities. ${ }^{31,32}$ The isotropic dimensional behavior of the thorium-base fuel alloys reflects the isotropic properties of the face-centered cublc lattice of the thorium matrix. On the other hand, the uranium-base alloys are subject to anisotropic growth if preferred grain orientations exist, and have high densities and thermal expansion coefficients. ${ }^{3}$ Because of their anisotropic properties, the uranium-base alloys must be fabricated with random grain orientations to avoid anisotropic dimensional changes under irradiation and thermal cycling.

\footnotetext{
*Fissium (Fs) is a term used to denote the equilibrium concentration of fission-product elements left by the pyrometallurgical reprocessing cycle used for EBR-II. The simulated equilibrium composition now used as the EBR-II driver fuel consists of uranium with $2.4 \%$ molybdenum, $1.9 \%$ ruthenium, $0.3 \%$ rhodium, $0.2 \%$ palladium, $0.1 \%$ zirconium, and $0.01 \%$ niobium.
} 
The metallurgical compatibility of metal fuels with cladding alloys is of particular interest and is based on two areas of consideration -- solidstate diffusion and eutectic formation. Solid-state diffusion rates are of particular application to steady-state irradiation performance, while eutectic formation rates apply to transient overtemperature situations. Based primarily on out-of-reactor fuel/cladding compatibility data and assuming that a Cumulative Damage Fraction of 0.5 is a reasonable design basis, the 1imiting cladding temperatures for steady-state operation to 10 a/o burnup were calculated as shown in Table VII.

TABLE VII. Limiting Cladding Temperatures for Steady-State Operation to $10 \mathrm{a} / 0$ Burnup at a Cumulative Damage Fraction of 0.5

\begin{tabular}{lll}
\hline Fuel, w/o & Cladding & $\begin{array}{r}\text { Limiting Cladding } \\
\text { Temperature, }{ }^{\circ} \mathrm{C}\end{array}$ \\
\hline Th-20U & Type 316 SS & 670 \\
Th-20Pu & & 658 \\
U-15Pu-10Zr & D9 Alloy & 668 \\
U-5Mo & \\
Th-20U & & 668 \\
Th-20Pu & 711 \\
U-15Pu-10Zr & 688 \\
U-5Mo & & 709 \\
& & 709 \\
\hline Based on results obtained from U-5 w/o Fs.
\end{tabular}

3. Feasible Element Designs: A solid fuel pin, sodium-bonded to the cladding, has proved to be the most feasible design for LMFBR metal fuel elements. The sodium bond can accomodate fuel swelling without corresponding FCMI, while maintaining an efficient thermal bond between the fuel and cladding. It has been found that the fission gas release characteristics of metal fuels could be turned to advantage in extending the burnup capability of sodiumbonded metal fuel elements. When swelling from fission gas bubble growth in metal fuels is allowed to exceed $\sim 25 \%$, the larger fission gas bubbles begin to touch and become interconnected among themselves and with the fuel surface. A large fraction of the fission gas is released from the fuel if it is permitted to swell more than $30 \%, 33,34$ as shown in Fig. 6 . The gas is released to the sodium bond where it then rises to the element gas plenum. The fuel swelling causes the original void volume, which exists as the sodiumfilled annulus around the solid metal fuel pin at the start of irradiation, to become redistributed throughout the fuel volume in the form of finely divided porosity. The porous fuel is restrained from further swelling by the cladding, so that significant FCMI is eliminated. The porosity in the fuel is available to accommodate solld fission product swelling with continued fuel burnup. Analyses of fuel element behavior and initial tests of prototype elements indicated that metal fuel elements with $75 \%$ smeared fuel density, which allows $33 \mathrm{v} / \mathrm{o}$ swelling, should be capable of achieving burnups 


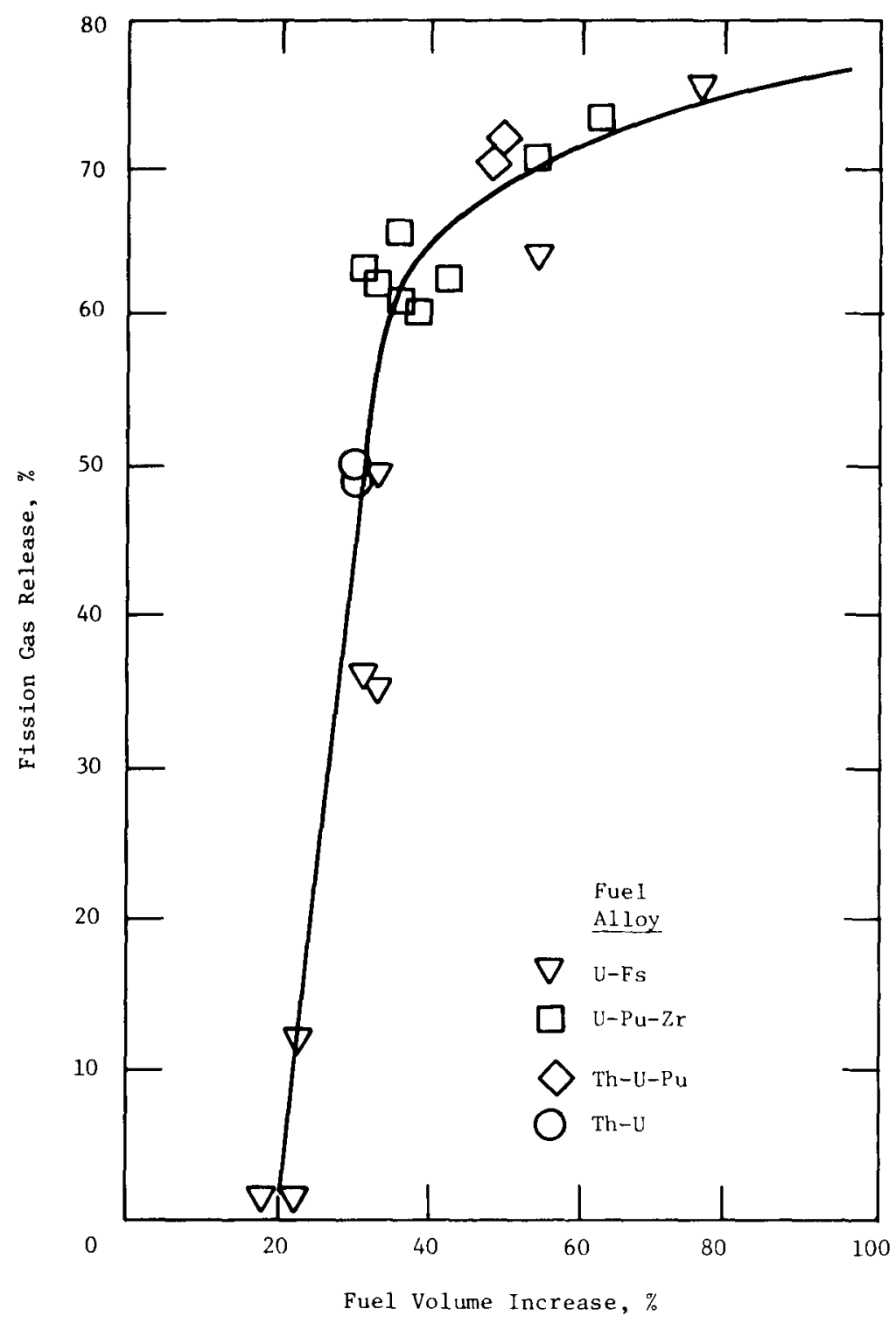

Fig. 6

Effect of Fuel Swelling on Fission Gas Release in Metal Fuels. 34

of at least $10 \mathrm{a} / \mathrm{o}$, independently of the fuel composition. A basic element design concept for LMFBR use was accordingly developed with design parameters and operating conditions shown in Table VIII.

4. Irradiation Performance: Th-U and Th-Pu alloys have been tested as sodium-bonded fuel elements to high burnup in only a few cases. However, extensive information under other conditions exists on the irradiation behavior of a wide range of Th-U alloys. The conditions include sodium-bonded fuel elements at low burnup but at high heat ratings in the SRE reactor, unclad specimens in thermal reactor capsules, and large tubular elements operating at relatively low temperatures in pressurized water reactors. $\mathrm{U}-\mathrm{Pu}-\mathrm{Zr}$ alloys have been investigated in the form of prototype fuel elements and as full-size EBR-II experimental elements. U-Mo alloys have been irradiated extensively, primarlly to determine the optimum heat treatment to minimize high-temperature swelling. It is believed, however, that information on U-Mo alloy that is more applicable for application in the 
TABLE VIII. Design and Operating Parameters of Reference Metal Fuel Element Design for LMFBR Applications

\begin{tabular}{lc}
\hline \multicolumn{1}{c}{ Parameter } & Value \\
\hline Cladding & $4.5-9.4$ \\
o.d., mm & $0.31-9.65$ \\
Wall thickness, mm & 0.069 \\
Thickness/diameter & $20 \% \mathrm{CW} 316 \mathrm{SS}$ \\
Material & 75 \\
Fuel smeared density, $\% \mathrm{~T} . \mathrm{D}$. & 65 \\
Nominal peak linear power, $\mathrm{kW} / \mathrm{m}$ & 600 \\
Nominal peak cladding temperature ${ }^{\circ} \mathrm{C}$ & 10 \\
Peak burnup, a/o & \\
\hline
\end{tabular}

reference metal fuel element design shown in Table VIII is provided by the metallurgically similar U-Fs alloy used in the Mark II driver fuel element in EBR-II. The observed behavior of the EBR-II Mark II driver fuel elements will therefore be relied upon in this report to evaluate the expected irradiation performance of comparable U-Mo alloy elements.

Significant restructuring and movement of solid fission products is noted in $\mathrm{U}-\mathrm{Pu}-\mathrm{Zr}$ alloys. 33,34 During irradiation with normal radial temperature distributions, three distinct concentric annular zones develop, as shown in Fig. 7, that are due to the alloy phases

in equilibrium over the corresponding temperature ranges. Zirconium and gamma-active fission products migrate from the middle annular zone to the center and outer annular zones. Uranium moves in the opposite direction. No significant plutonium movement is noted. The alloy restructuring and constituent movement in U-Pu-Zr fuel elements have had no discernible effect on fuel element performance.

Compared to other fuels, metal fuels swell at lower temperatures from the nucleation and growth of fission gas bubbles. Metal fuels containing non-cubic phases may also exhibit grain boundary separations due to anisotropic dimensional changes in adjoining grains. The threshold or "breakaway" swel1ing temperature, where accelerated fission gas bubble growth occurs, is proportional in some degree to the melting point of the fuel. Thus, thoriumbase fuel alloys, which are characterized by relatively high melting points, are also characterized by relatively high breakaway swelling temperatures, on the order of 600 to $700^{\circ} \mathrm{C} .31$ Figure 8 shows the comparative swelling rates of uranium- and thorium-base alloys. The swelling temperature of Th-U alloys also appears to be sensitive to the size and distribution of the fissile uranium-rich phase. The highest swelling temperatures are obtained if the alloy is prepared so that the urantum-rich phase has a particle size of less than $\sim 5 \mu \mathrm{m}$. Most of the fission recolls can thereby escape from the uraniumrich phase into the higher-melting thorlum-rich phase. The threshold temperature for breakaway swelling of Th-Pu alloys has not been determined. The microstructural considerations for Th-U alloys do not apply for Th-Pu fuel alloys because Th-Pu alloys are single-phase. It is likely, however, that the swelling temperatures of $\mathrm{Th}-\mathrm{Pu}$ alloys are relatively high because of the high melting point of the thorium matrix in which the plutonium is dissolved. Uranium-base fuel alloys generally show breakaway swelling temperatures at lower temperatures, in the range of 400 to $600^{\circ} \mathrm{C}$. 31 Finely-dispersed insoluble particles of U-Al-Fe intermetallic particles in essentially unalloyed uranium have been found effective in delaying to higher temperatures grain boundary tearing and the growth of fission gas bubbles. This type of uranium, known as "adjusted" uranium, is of particular interest for blanket fuel where burnup requirements are relatively low. 


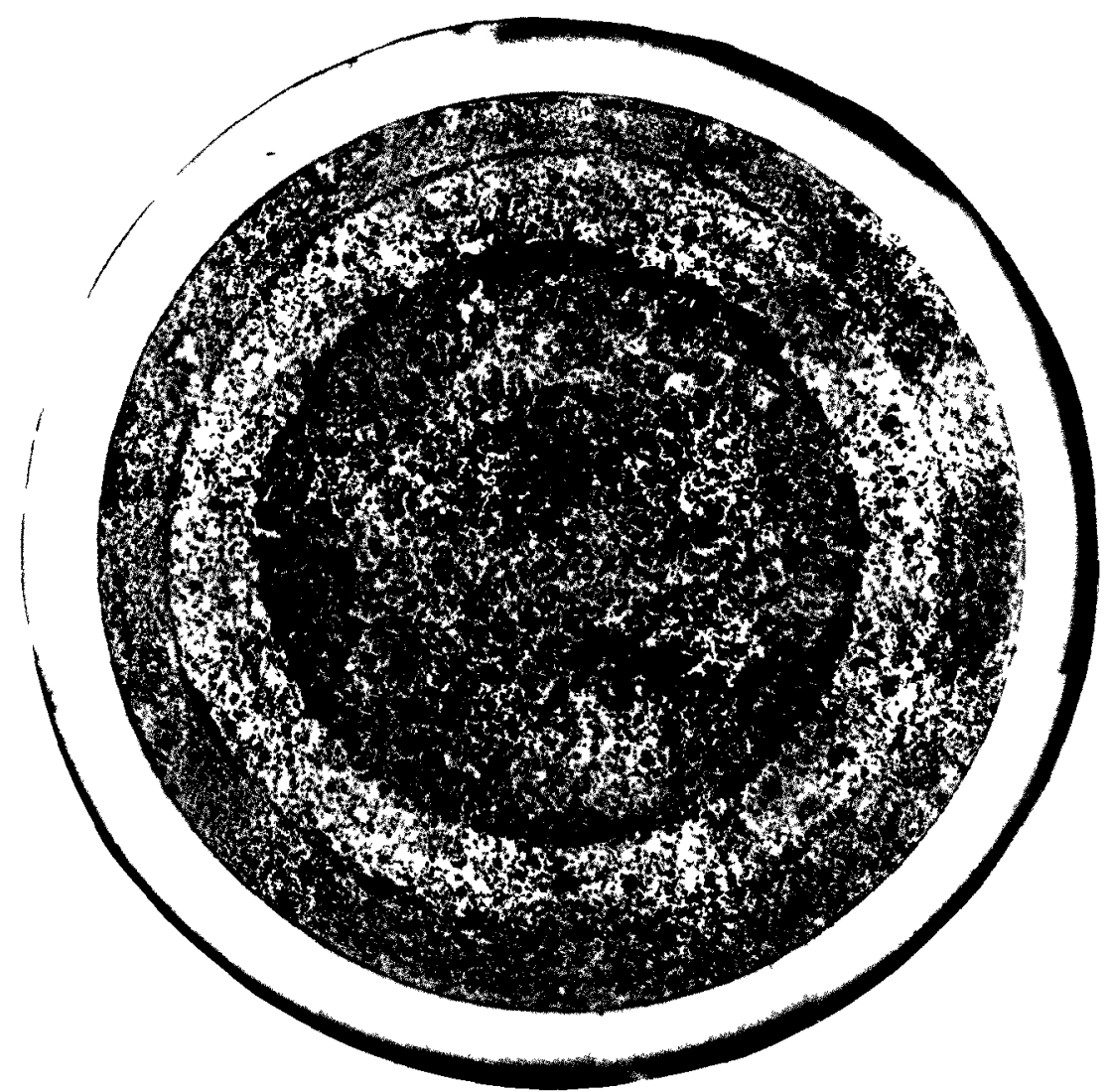

Fig. 7. Transverse Section of U-15 w/O Pu-12 w/O Ir Alloy Prototype Fuel Element with Hastelloy-X Cladding after 2.4 a/o Burnup at a Maximum Cladding Temperature of $610^{\circ} \mathrm{C} .{ }^{34}$ The concentric bands in the fuel are due to the alloy phase distributions that existed during irradiation because of the nomal temperature gradient in the fuel element.

Observations on the steady-state irradiation behavior of metal fue 1 elements closely similar to the basic design concept include extensive experience with the EBR-II Mark II driver fuel and more limited experiments with $\mathrm{U}-\mathrm{Pu}-\mathrm{Zr}$ alloy fuel elements. No significant FCMI has been noted. No information presently exists on FCMI effects in elements with lower cladding thickness/diameter ratios, in elements with thorium-base alloys that swell at relatively high temperatures, or in elements with $20 \%$ cold-worked instead of annealed 316 stainless steel. Providing that adequate fuel/clad compatibility exists, the high burnup capability of the basic element design shown in Table VIII has been found to be independent of the composition of the fuel, as evidenced by tests of the design with a variety of uranium- and thoriumbase fuel alloys. The most extensive related experience exists with the EBR-II Mark II driver fuel element. This element uses U-5 w/o Fs alloy and annealed Type 316 stainless steel cladding in a design that conforms to the dimensional specifications listed in Table VIII. To date, over 700 Mark II 


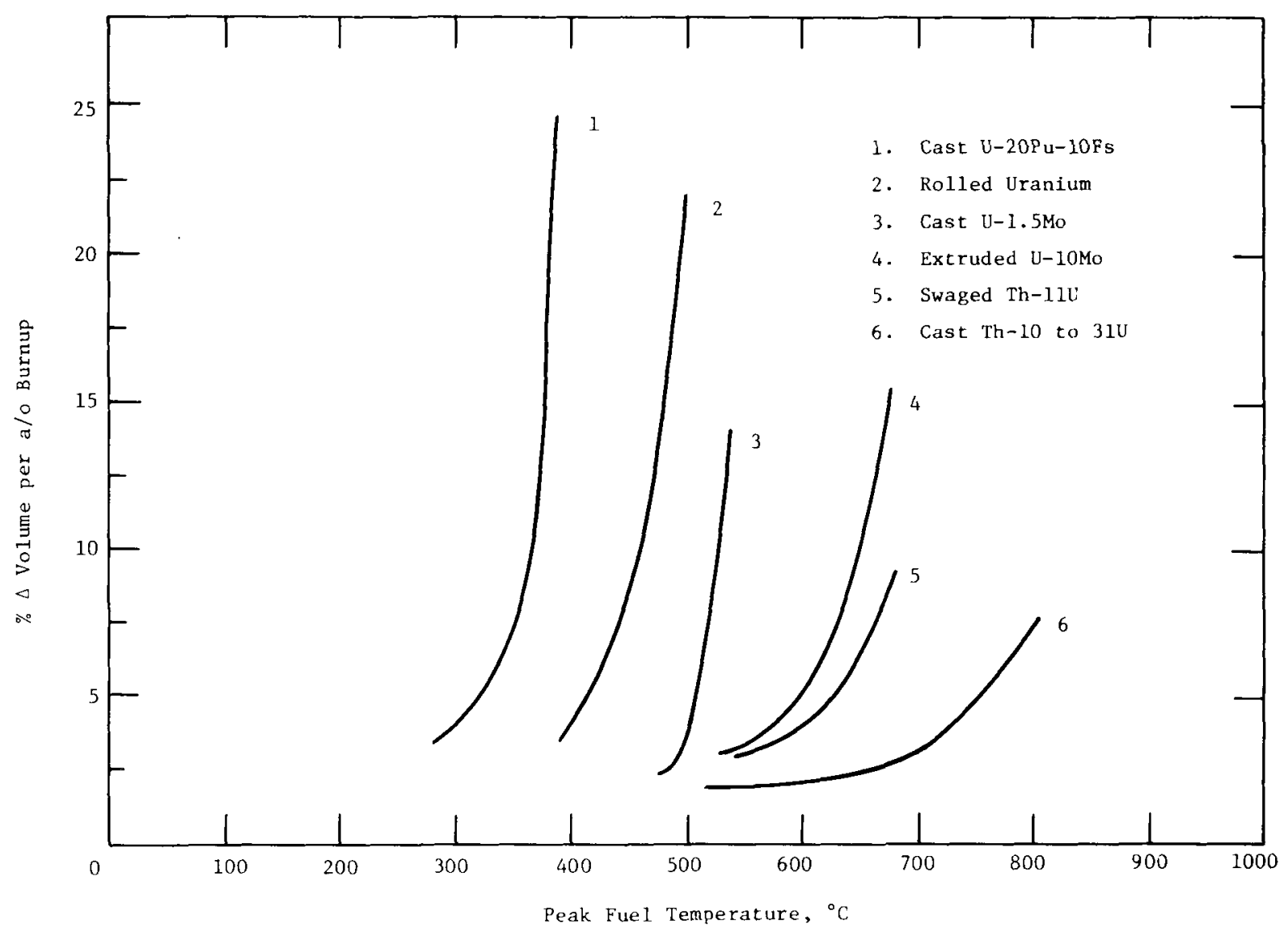

Fig. 8. Effect of Irradiation Temperature on the Swelling Rate of Metal Fuels. ${ }^{31}$

fuel elements have achieved fuel burnups of $10 \mathrm{a} / \mathrm{o}$ or more, with no cladding failures below 10 a/o burnup.

Uncertainties regarding the steady-state irradiation performance capability of the metal fuel types shown in Table VI should be resolved in possible FTR tests of metal fuels, now in the planning stage.

No information currently exists on the behavior of metal fuel elements with the reference design concept under transient irradiation conditions. Possible FCMI under transient overtemperature conditions may depend on the condition of the fuel element prior to the transient. Three conditions are envisaged: (a) immediately prior to fuel/cladding contact with no interconnected fuel porosity, fission-gas release, or cladding degradation, (b) fuel/cladding contact at the midplane of the element with limited interconnected porosity, fission gas release, and cladding degradation, and with sodium isolated in the lower part of the element, and (c) complete fuel/cladding contact with maximum interconnected fuel porosity, fission-gas release, and cladding degradation, and with all bond sodium displaced into the element plenum. Useful conclusions concerning the first two conditions can be drawn from transient overpower tests that were performed on U-5 w/o Fs alloy elements with up to 2.5 a/o burnup and which had a smeared fuel density of $85 \%$ of theoretical and a cladding thickness/diameter ratio of 0.052 . No FCMI occurred from fuel swelling or sodium entrapment. Preparations are underway to test condition (c). 
The only information on the cladding breach characteristics of elements closely similar to the reference design under steady-state conditions was obtained in preliminary run-to-clad-breach irradiations of EBR-II Mark II fuel elements. The irradiations included elements that were clad with relatively weak Type $304 \mathrm{~L}$ stainless steel as well as with Type 316 stainless steel. All clad breaches were in the elements clad with the lowstrength Type 304L cladding and occurred at burnups between 9.2 and 16.2 a/o. The clad breaches were located between the core midplane and the upper end of the fuel column. The cladding breaches developed gradually from grain boundary separations and were not enlarged by fuel/coolant interaction.

Both thorium- and uranium-base alloy fuel elements have been subjected to transient overpower tests in TREAT. 35,36 Although in both cases the element designs tested had $85 \%$ smeared fuel densities and 0.052 cladding thickness/diameter ratios and were clad with relatively low-strength annealed Type $304 \mathrm{~L}$ stainless steel, the test results are nevertheless believed applicable to the more conservative reference fuel element design. The thorium alloy tests, which were on Th-20 w/o U alloy, showed that the highmelting thorium matrix contained the molten uranium phase without cladding failure until the melting point of the cladding itself was approached, near $1360^{\circ} \mathrm{C}$. The uranium alloy tests, which were on $\mathrm{U}-5 \mathrm{w} / \mathrm{o} \mathrm{Fs}$ alloy, developed cladding breaches from eutectic formation at cladding temperatures of 860 to $1020^{\circ} \mathrm{C}$, depending upon the level of prior steady-state irradiation.

5. Modeling of Fuel Element Behavior: The status of metal fuel element performance modeling is much less advanced than is the case for oxide and carbide fuels. For metal fuels the only existing code of significance is BEMOD, a correlation-type code. The more sophisticated codes such as LIFE-3, UNCLE-S, and UNCLE-T that are used for oxide and carbide fuels are first-principles type codes. Development of a first-principles code for metal fuels has recently been started using applicable parts of both the LIFE- 3 and BEMOD codes.

\section{B. Key Issues}

The known irradiation behavior of the candidate metal fuels is based in part on information obtained both from irradiations of small prototype fuel elements and from fuel element irradiations for non-LMFBR applications. The key issues that exist for the metal fuels therefore reflect the lack of an adequate data base on the performance of the candidate metal fuels when used in the reference metal fuel element design.

1. Thermal Performance: Existing information on the metal fuel candidates indicates that the thermal performance of the fuel alloys is generally adequate to meet the criteria being applied in current LMFBR core design studies. These criteria assume a $500^{\circ} \mathrm{C}\left(930^{\circ} \mathrm{F}\right)$ sodium outlet temperature and apply prescribed procedures for analytical treatments such as the calculation of cumulative damage fractions, uncertainties in cladding temperatures and fuel element linear powers, design power transients, etc. However, analyses of the thermal performance of metal fuels are currently based largely on out-of-reactor properties data, such as eutectic temperatures, that may be subject to changes from the effects of high fuel burnup. Although such changes may not be significant nor deleterious, greater confidence 
could be placed on the determinations of thermal performance limits of metal fuels if in-reactor properties data were available to enable the analyses to be based entirely on the propertles of irradiated fuel (and cladding). Fuelcladding compatibility tests are needed on Th-Pu and U-Mo alloys with Type 316 stainless steel, and compatibility tests are needed on all fuel alloy candidates with selected advanced cladding alloys. The bases for the relatively high fuel/cladding eutectic temperatures and improved metallurgical compatibility observed in the U-Pu-Zr-stainless steel system are not wellunderstood and need further investigation. Oxygen levels in the fuel and/or cladding appear to be associated with the high eutectic temperature, but a fundamental understanding of the bases for the high eutectic temperature and improved compatibility should be obtalned.

2. Mechanical Performance: Significant FCMI does not occur in the basic metal fuel element design with annealed Type 316 stainless steel clading up to the goal burnup of $10 \mathrm{a} / \mathrm{o}$. This implies that the specified cladding thickness/diameter ratio of 0.069 may be too conservative. Thinner cladding might therefore be feasible without compromising fuel element lifetime and with favorable effect on breeding ratios. Axial restraint of metal fuel has not yet been accommodated in an entirely satisfactory manner. Restrainers that extend to the fuel from the upper end plug of the fuel element occupy much of the available plenum volume. Improperly designed fuel restrainers, e.g., dimpling the cladding, have caused cladding damage and led to premature failure. The behavior of the basic fuel element design under transient overpower conditions has not yet been investigated. Tests are needed to determine if the transient behavior is at least as good as that shown by early tests on metal fuel elements with higher smeared fuel densities and lower fuel burnups, cladding fluences, and cladding thickness/diameter ratios. While the early tests showned that benign cladding failures occur in transient events at low burnups, it is presently thought that with the basic metal fuel element design the most damaging transient would be at high burnup. The possible significance to fuel element performance of the upper axial blanket resting on the fuel has not been determined. The potential effects include fuel slumping from the weight of the blanket.

3. U-Pu-Zr Alloy Restructuring: Significant restructuring occurs in $\mathrm{U}-\mathrm{Pu}-\mathrm{Zr}$ alloy under reactor operating conditions. The three annular zones that form in this alloy exhibit varlous degrees of mechanical separation and relative movement, as well as local migration of alloy constituents and fission products. While there is no evidence that the changes adversely affect fuel element performance, and even some possibility that the observed migration of zirconium may further improve fuel compatibility with the cladding, the possible effects of the restructuring are presently undetermined in the reference element design at fuel burnups greater than $4.5 \mathrm{a} / \mathrm{o}$.

4. Blanket Development: Smeared fuel densities specified for metal blanket elements are on the order of $85 \%$ of theoretical. Metal blanket elements have been irradiated to fuel burnups of only a few tenths atom percent, so that their capability for reaching goal burnups, which are on the order of 1 to $2 \mathrm{a} / \mathrm{o}$, is presently undetermined.

5. Fuel Element Performance Prediction: There are no adequate modeling codes for metal fuels that enable detailed cladding stress-temperature 
histories to be calculated and used for end-of-life prediction. A calibrated, first-principles code based on materlals properties and known materials behavior would enable more realistic fuel element performance for specific reactor applications. The sensitivity of design and operating parameters on metal fuel element performance could also be evaluated more quantitatively so that optimization of fuel element designs could proceed with fewer irradiation experiments.

\section{Activities Required to Resolve Key Issues}

The key issues that exist for the candidate metal fuels can only be resolved by a steady-state irradiation testing program to goal burnups, and by special-purpose steady-state and transient tests.

1. Thermal Performance: Irradiation tests of the candidate metal fuels to goal burnups at nominal and $2 \sigma$ cladding temperatures are needed to provide required information on the possible influence of fission products, constitutent migration, and other irradiation effects on fuel-cladding compatibility. If the Th-Pu alloy is selected for development, largescale irradiations should be preceded by an alloy development program to raise the solidus temperature of the Th-Pu-U fuel alloy that will exist at the end of life of the fuel element. Zirconium additives are a logical approach, based on experience in related U-Pu alloys. The predicted capability of advanced cladding alloys to extend the thermal performance of metal fuels by permitting larger amounts of fuel penetration into the cladding should be verified by reactor testing. The predicted capability of the candidate alloy fuel elements to accommodate design transients should also be verified by transient tests on both unirradiated and highly-irradiated fuel elements.

2. Mechanical Performance: Irradiation tests to goal burnups at nominal and $2 \sigma$ cladding temperatures are needed to determine the extent, if any, to which the cladding thickness/diameter ratio of 0.069 can be reduced without compromising fuel element performance. The basic element design concept must be demonstrated to goal fuel burnups with thorium-base candidate alloys. Improved means of restraining axial fuel movement should be developed. The fuel restrainer should occupy minimum plenum volume and should not adversely affect cladding integrity. Coincident with this effort, the optimum mode for supporting the upper axial blanket should be determined. An irradiation test should then be performed to confirm the effectiveness of the axial restraint approach and the absence of significant fuel slumping if the upper blanket is to rest on the fuel column.

3. U-Pu-Zr Alloy Restructuring: U-Pu-Zr alloy elements should be irradiated to goal burnups at $2 \sigma$ cladding temperatures to determine whether fuel performance is adversely affected by the three annular zones that form under normal operation. Transient overpower tests are also needed on restructured highly-irradiated elements to ascertain if the annular fuel zones significantly affect fuel element behavior.

4. Blanket Development: Blanket fuel irradiations based both on thorium and uranium should be started as early as practicable because of the long residence times required to reach goal burnups. Unalloyed thorium is expected to perform without difficulty. Uranium, on the other hand, 
requires special consideration because of its anisotropic properties. The irradiation tests should not only include $U-5$ w/o Mo alloy, but also "adjusted" uranium containing small additions of iron and aluminum.

5. Fuel Element Performance Predictions: The LIFE-3 code should be evaluated to determine which parts of the code structure can be used as a framework upon which to base a metal fuels performance code. Modeling of the metal fuels code can be calibrated from results obtained from the steady-state and transient irradiations of metal fuel elements recomended above.

\section{Summary of Metal Fuel Status}

The most highly developed metal fuel element design concept is a solid metal fuel pin sodium-bonded to $20 \%$ cold-worked Type 316 stainless steel cladding with sufficient voidage in the fuel/clad gap to permit the metal fuel to swell and release its fission gas. Although the high-burnup capability of the basic element design has been indicated by the closely similar EBR-II Mark II driver fuel, the design has been tested to only 4.5 a/o burnup with the candidate U-Pu-Zr metal fuel, and has not yet been tested with the other candidate metal fuels, Th-U, Th-Pu, U-Mo, and $U$. The most significant key issues are the demonstration of in-reactor thermal performance of the candidate fuel compositions, potential reduction in cladding thickness/ diameter ratio, potential effects of restructuring in U-Pu- $\mathrm{Yr}$ alloy, blanket fuel development, and development of improved fuel element performance models. Resolution of the key issues requires extensive steady-state and transient irradiation testing.

\section{CLADDING/DUCT ALLOYS}

\section{A. Status of Development}

At an early stage in the development of materials for cladding and duct applications in fast breeder reactor fuel systems, it was determined that substantial property changes can occur under the environmental conditions in which these systems are required to function. Initial work was concentrated on the properties of 300-serles austenitic stainless steels, with the findings that the materials are subject to significant volume increases ("swelling") under high-fluence neutron irradiation. In addition, the process of creep is enhanced by irradiation, so that creep rates at low temperatures approach those rates observed ex-reactor only at very much higher temperatures. It was also found that irradiation can lead to marked reduction in the ability of a material to sustain plastic deformation, with unexpected reductions in ductility observed at temperatures formerly thought to be above the range at which these effects should occur.

The choice of 300-series stainless steels, or other equivalent designations, for initial fuel systems was clearly in order, because of the broad base of related technology associated with these materials and the limited irradiation testing experience which indicated them to have the appropriate combination of strength, irradiation resistance and compatibility with reactor coolant. Accordingly, intensive U.S. development efforts were focused on $20 \%$ cold-worked AISI 316, the materlal chosen for use as the cladding and 
duct material in the Fast Test Reactor (FTR). This choice was based on the swelling resistance, creep strength and sodium compatibility offered by this material. Attention was directed to a thorough characterization of the behavior of this reference material, with the objectives of: (1) verifying the ability to meet the FTR fuel systems performance goals, and (2) assessing the capabilities of the material for operation to higher burnup levels. However, extrapolations from the current data base have indicated that swelling and in-reactor creep can become excessively large if the reference material is carried to fluences and burnup levels thought to be necessary for economic operation of breeder reactor power stations.

This potential limitation on the performance of the reference material led, in 1974, to the implementation of a program in the U.S. to develop cladding and duct alloys with performance capabilities superior to $20 \%$ coldworked AISI 316. A screening process was initiated to reduce the number of materials for detailed study from several hundred possible alloys to a selected few. Twenty-nine commercial alloys were selected in the initial screening, and thirty-four newly deslgned alloys (known as the "developmental" alloys) were also subjected to further examination. The contending alloys were chosen to represent three general alloy classes considered to offer potential for further expolitation: (1) ferritic steels, (2) austenitic stainless steels, and (3) iron-rich superalloys. The number of alloys under consideration was reduced to eleven in June 1977. The elimination process up to this point was largely subjective, since high fluences had not yet been achieved in tests with the advanced alloys, and was based primarily on swelling behavior, since this was throught to be a major criterion. Some alloys, however, were rejected on the basis of insufficient creep resistance or poor sodium corrosion resistance. The schedule for the screening decisions was tied to fabrication schedules which would allow early tests of the selected alloys in FTR fuel and absorber assemblies, and a decision was made to retain representatives from each of the three general alloy classes. This was necessary in order to maintain responsiveness to future requirements for advanced and alternate fuel systems and to subsequent reactor plant design decisions.

The selected advanced alloys are currently undergoing intensive evaluation in EBR-II tests, and components are being fabricated for a wide variety of FTR tests, both fueled and non-fueled. Further reductions in the number of alloys under test will be made as clear evidence for superior performance develops and as reactor or fuel systems design decisions dictate.

\section{B. Key Technical Issues}

Work with the reference materlal is in a final phase, but several key issues remain to be resolved in order to provide an adequate description of material behavior for use in-core performance analyses. Issues include heat-to-heat variability of properties; the interrelationship of swelling and creep, particularly in duct-bowing effects; the effect of stress, stress state, stress history and temperature history on swelling and creep; the effect of adjacent fuel on the properties of cladding; and several other concerns. These issues apply equally well to advanced alloys. 
Many technical issues remain to be resolved before advanced alloys can be considered for utilization. In the case of the ferritic steels, it remains to ensure that the materlals will provide sufficient strength over the entire temperature range of application without serious elevation of the ductile-brittle transition temperature. It is also necessary to evaluate the compatibility of ferritic core components with an austenitic heat transport system. A major issue with the austenitic stainless steels is suppression of deleterious phase transformations which lead to a loss of resistance to swelling and creep. The high-strength advanced alloys are suspected to be subject to irradiation embrittlement, and means must be found to ensure the retention of adequate ductility at very high fluences.

\section{Activities Required to Resolve Key Issues}

Programs are in place to resolve the key technical issues. Testing in EBR-II should provide the means for achieving resolution in case of the reference material, and these results will help to facilitate an understanding of irradiation effects in the more complex advanced alloys. The performance capabilities of the advanced alloys will not be fully assessed until extensive experience is gained through FTR testing; this experience is expected to be at hand in 1983.

\section{NEUTRON ABSORBERS}

\section{A. Status of Development}

The choice of absorber materials for control applications in LMFBRs is extremely limited. To date, only boron carbide, europium sesquioxide, and tantalum have been given serious consideration. 37 of these, boron carbide possesses the best combination of nuclear properties and performance capability. It has thus emerged as the leading candidate for LMFBR control applications. ${ }^{38}$ Interest has developed recently in the U.S. and Europe in use of europium hexaboride as an alternate to boron carbide. Studies of its properties and irradiation behavior have been initiated.

1. Boron Carbide: Boron carbide is used in the control systems of every operating LMFBR in the world. In the U.S., a nine-year testing program in EBR-II has provided a data base that includes burnup levels exceeding $1 \times 10^{22}$ captures $/ \mathrm{cm}^{3}$ (equivalent to three years' operation in the FTR control system) at temperatures in the range $500-1000^{\circ} \mathrm{C} .{ }^{39}$ Some specimens have been irradiated at temperatures greater than $1800^{\circ} \mathrm{C}$. To date, no absorber pin performance limitations have been identified by the testing program. Sealed boron carbide absorber elements become pressurized under irradiation because of helium production from boron-10. It is possible to gain design flexibility and alleviate lifetime limitations by incorporating vents in the elements. Such components are already being used in PFR and Phenix. Vented boron carbide test pins have been irradiated in EBR-II for periods as long as 22 months, during which time all vents functioned perfectly.

In summary, the performance of boron carbide in breeder reactors has been exceptionally good and its irradiation behavior poses no insurmountable design problems. The existing data base indicates that much of the conservatism in existing designs can be eliminated. 
2. Other Neutron Absorbers: Both tantalum and europium sesquioxide have been irradiated in fast neutron spectra to fluence levels exceeding $10^{22} \mathrm{n} / \mathrm{cm}^{2}$ (E > $\left.0.1 \mathrm{MeV}\right)$. Both materials swel1 during irradiation and, in the case of europia, pellet cracking and degradation have been observed. It is not the irradiation behavior of these materials, however, that restricts their utility in breeder reactors. Both have low reactivity worth relative to enriched boron carbide and both require substantial shutdown cooling due to decay heating. At best, they should be considered only for isolated low-worth applications.

Only a small amount of work has been done with europium hexaboride. It has been irradiated in RAPSODIE 40 to an exposure of $1.2 \times 10^{21}$ captures $/ \mathrm{cm}^{3}$ and in EBR-II to an exposure of $24 \times 10^{21}$ captures $/ \mathrm{cm}^{3}$. Preliminary data indicate high gas release rates and possibly reduced swelling relative to boron carbide. The fact that this material has no reactivity-worth limitations, like tantalum and europia, and has materials properties similar to boron carbide provide strong incentives for continued development.

\section{B. Activities Required to Resolve Key Issues}

Existing programs on absorber matertal development should be continued in order to provide required information on material behavior and pin performance under high exposures. EBR-II and eventually FTR should be used to provide the test environment. Work should be concentrated on boronbearing materials to avoid reactivity-worth deficiencies. Absorber materials development should be integrated with design and performance analyses. An effective method for accomplishing this is by implement development of advanced absorber assemblies. Such effort could culminate with a threeor four-year performance demonstration in the FTR control system, after which the component assembly could be considered qualified for breeder reactor service.

\section{Summary of Absorber Materials Status}

Boron carbide is currently the most widely used control material for LMFBRs. This control material has performed quite satisfactorily. Limited development work is in progress on other materials, including tantalum, europium sesquioxide, and europium hexaboride. The latter compound appears to be the only material that may provide better long-term performance than boron carbide.

\section{SUMMARY AND CONCLUSIONS}

of the LMFBR fuel candidates (oxide, carbide, and metal), the most extensive fabrication and testing experience relevant to current reactor designs exists for $\mathrm{UO}_{2}-\mathrm{PuO}_{2}$ fuel elements. A relatively conservative $\mathrm{UO}_{2}-\mathrm{PuO}_{2}$ element design has been developed and extensively tested for FTR and CRBR applications. This reference oxide element, as a result of the intensive 20-year, multinational development of $\mathrm{UO}_{2}-\mathrm{PuO}_{2}$, has been brought to near the point of commercialization in 1000 MWe-sized plants.

Compared to oxide fuel, improved breeding performance is possible with carbide and metal fuels that are in various stages of development and testing. It is apparent, however, that the major breeder development programs 
will exploit oxide fuel to the fullest possible extent before possible commitment to other fuel types. In the U.S. for example, advanced oxide fuel element development is underway to obtain improved breeding performance compared to that possible with the reference oxide element. The advanced oxide element designs include larger diameters, thinner cladding, and higher smeared fuel densities.

Carbide fuel development is being pursued in all major breeder development programs as a potential option to ultimately replace oxide fuel. The carbide fuel element concepts under development include helium-bonded pellets, sodium-bonded pellets, and hellum-bonded particulate fuel. The principal developmental efforts are concerned with determination of the optimum element design that avoids development of the unduly severe fuelcladding mechanical interaction effects commonly observed in carbide fuel elements. Promising approaches include use of fuel shroud tubes in sodiumbonded elements and high-strength cladding for helium-bonded elements.

A metal element concept has been developed that is based on a sodiumbonded fuel pin which, under irradiation, is converted to a porous structure that does not develop significant fuel-cladding mechanical interaction. The burnup capability of the design appears to be independent of the fuel composition and can evidently achieve the burnup goal of 10 a/o or more with high reliability, as indicated by the extensive experience being obtained with the closely-related EBR-II Mark II element. The principal recommended developmental effort is to verify the expected performance of the design concept with metal fuels of current interest for LMFBR fuel cycles. 


\section{REFERENCES}

1. Y. I. Chang and C. E. Till, Design and Performance Characteristics of Alternative Fuels and Fuel Cycles, Part 2 of this report.

2. C. M. Cox and T. T. Claudson, LMFBR Fuel Design, Fabrication, and Irradiation, HEDL-SA-1195 (paper presented at 1977 WATTec Meeting, Knoxville, Tennessee, February 22-24, 1977).

3. J. C. Chandler, et a1., The Proliferation Resistant Preconceptual Core Design Study, HEDL-TC-1082 (March 1978).

4. A. R. Olsen, R. B. Fitts, and W. J. Larkey, In-Reactbr Restmucturing

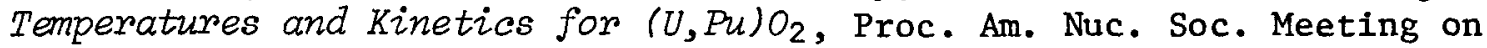
Fast Reactor Fuel Element Technology, New Orleans, Louisiana, pp. 579-600 (April 1971).

5. C. M. Cox, D. R. Cuneo, and E. J. Manthos, Performance of Sphere-Pac and Pelletized (U,Pu) $\mathrm{O}_{2}$ During Severe Overpower Transients, Ib1d., pp. 701-723.

6. S. Rippon, IAEA Symposium On LMFBR, Nuclear News, 21(8), pp. 126-138 (June 1978).

7. K. Q. Bagley and J. A. Gatley, The App Zication of Core and Fue I Performance Experience in British Reactors to Commercial Fast Reactor Design, Int. Symp. on Design, Construction, and Operating Experience of Demonstration Liquid Metal Fast Breeder Reactors, Bologna, Italy, Apri1 10-14, 1978.

8. C. M. Cox, R. F. Hilbert, and A. Biancheria, U.S. Experience in Irradiation Testing of Advanced Oxide Fuels, Proc. Am. Nuc. Soc. International Meeting on Advanced LMFBR Fuels, Tucson, Arizona, pp. 136-148 (October 10-13, 1977).

9. K. M. Swanson, W. Sloss, and W. Batey, U.K. Irradiation Experience Relevant to Advanced Oxide Fuel Concepts for LMFBR's, Ibid., pp. 95-109.

10. K. Uematsu, Y. Ishida, and J. Komatsu, Experience and Future Plan of Fast Reactor Oxide Fuels Irradiation in Japan, Ibid., pp. 110-121.

11. L. S. Golovnin and Y. L. Likhachev, Predicting the Performance of Oxide Fuel Elements for Fast Sodirm Reactors, Atomnaya Energia, 40, pp. 27-37 (1976).

12. Proceedings of International Meeting on Advanced LMFBR Fuels, October 10-13, 1977, Tucson, Arizona, Am. Nuc. Soc., ed. by J. A. Leary and J. H. Kittel.

13. R. Pascard, The French Advanced Fuels Program, Ibid., pp. 52-60. 
14. G. Karsten, The SNR-Carbide Program - Its Position Between Present and Future, Ibid., pp. 26-50.

15. J. F. W. Bishop, A. Chamberlain, and Gatby, The U.K. Strategy and Progrommes for Advanced LMFBR Fuels, Ib1d., pp. 15-25.

16. R. W. Stratton, Development of Advanced Fuels in SwitzerZand, Ibid., pp. 74-85.

17. V. A. Tsykanov et al., Results of Testing Carbide Fuel Elements in the BOR-60 Reactor, Atomnaya Energia, 42, pp. 378-382 (1977).

18. J. M. Simmons, J. A. Leary, J. H. Kittel, and C. M. Cox, The U.S. Advanced LMFBR Fuels Development Program, Proc. Am. Nuc. Soc. International Meeting on Advanced LMFBR Fuels, Tucson, Arizona, pp. 2-14 (October 10-13, 1977).

19. T. W. Latimer, F. L. Brown, and L. A. Neimark, Performance in EBR-II of Carbide Fuel Elements Irradiated to 7 at.\% Burnup, Trans. Am. Nuc. Soc. 12, pp. 87-88 (1969).

20. K. Q. Bagley, et al., U.K. Irradiation Experience Relevant to Advanced Carbide Fuel Concepts for LMFBR's, Proc. Am. Nuc. Soc. Int. Meeting on Advanced LMFBR Fue1s, Tucson, Arizona, pp. 313-325, (October 10-13, 1977).

21. J. 0. Barner, et al., Advanced Carbide Fuels - U.S. Experience, Ibid., pp. 268-298.

22. H. Kleykamp, The Chemical State of Imadiated Carbide Fuel Pins, Ibid., pp. 166-178.

23. R. W. Stratton and L. Smith, The Irradiation Behavior of Sphere-Pac Carbide Fuel, Ibid., pp. 348-360.

24. P. Combette, French Irradiation Test Experience for Carbide Fuels, Ibid., pp. 343-347.

25. K. R. Kummerer, The German Irradiation Test Experience for Fast Reactors, Ibid., pp. 326-342.

26. J. F. Kerrisk, J. 0. Barner, and R. L. Petty, Design and Performance of Shroud Tubes in Sodium-Bonded Advanced Fuel Elements, Ibid., pp. 648-649.

27. H. C. Tsai and L. A. Neimark, Behovior of Unirradiated Sodium-Bonded Carbide During Mild Overpower Transients, Trans. Am. Nuc. Soc. 28, pp. 478-479 (1978).

28. M. C. Billone, V. Z. Jankus, J. M. Kramer, and C. I. Yang, Progress in Modeling Carbide and Nitride Fuel Performance in Advanced LMFBRs, Proc. Am. Nuc. Soc. Int. Meeting on Advanced LMFBR Fuels, Tucson, Arizona, pp. 516-536, (October 10-13, 1977). 
29. M. J. Feldman, N. R. Grant, D. C. Hampson, and R. M. Fryer, Experience in Remotely Fabricating EBR-II Fuel, Trans. Am. Nuc. Soc. 30, pp. 309-310 (1978).

30. B. R. Seidel and R. E. Einzinger, In-Reactor Cladding Breach of $E B R$-II Driver-Fuel Elements, Radiation Effects in Breeder Structural Materials, M. L. Bleiberg and J. W. Bennett, Eds., TMS-AIME, New York, p. 139 (1977).

31. J. H. Kitte1, J. A. Horak, W. F. Murphy, and S. H. Paine, Effects of Irradiation on Thorium and Thorium-Uranium AlZoys, Argonne National Laboratory Report, ANL-5674 (1963).

32. B. Blumentha1, J. E. Saneck1, D. E. Busch, and D. R. O'Boyle, ThoriumUranium-Plutonium Alloys as Potential Fast Power-Reactor Fuels, Argonne National Laboratory Report, ANL-7259 (1969).

33. C. M. Walter, G. H. Golden, and N. J. Olson, U-Pu-Zr MetaZ AZZoy: A Potential Fuel for LMFBR's, Argonne National Laboratory Report, ANL-76-28 (1975).

34. W. N. Beck, R. J. Fousek, and J. H. Kittel, The Irradiation Behavior of High-Burnup Uranium-Plutonium Alloy Prototype Fuel Elements, Argonne National Laboratory Report, ANL-7388 (1968).

35. A. B. Rothman, C. J. Renken, R. R. Stewart, A. K. Chakraborty,

C. E. Dickerman, G. G. Dewy, S. Matias, R. V. Strain, and

D. R. Hutchinson, Transient Behavior of High SweZling EBR-II Mark-IA Driver Fuel in TREAT, Nucl. Eng. and Design, 15, pp. 187-207 (1971).

36. C. E. Dickerman, L. E. Robinson, B. Blumenthal, and R. Stewart, Behavior of Th-20 wt \% U Fast Reactor Fuel Under Transient Heating to Failure, Nuc1. Applications, 3, pp. 9-17 (1967).

37. K. R. Birney, A. L. Pitner, and R. D. Bourquin, Absorber Materials for Fast Reactor Control Applicatons, Trans. Am. Nuc. Soc. 26, p. 173 (June 1977).

38. D. E. Mahagin and R. E. Dah1, Nuclear Application of Boron and the Borides, Boron and Refractory Borides, V. I. Matkovich, Ed., Springer-Verlag, Heidelberg (1977).

39. J. A. Basmajian and A. L. Pitner, Correlations for Boron Carbide Helium Release in Fast Reactors, Trans. Am. Nuc. Soc. 26, p. 174 (June 1977).

40. M. Hörle, et al., DAtF, Reaktortagung, Dusseldorf (1976). 


\title{
PART 4
}

\author{
SAFETY IMPLICATIONS OF ALTERNATIVE FUEL TYPES \\ Hans K. Fauske \\ (Argonne National Laboratory)
}

\begin{abstract}
This report provides an assessment of safety implications associated with alternatives relative to the reference (U,Pu) oxide fuel in fast breeder reactors. The alternatives considered include thorium- and uranium-based oxide, carbide and metal fuel types for the LMFBR and oxide fuel types for the GCFR. Major emphasis is put on low probability, but potentially large-consequence accidents, e.g., core-disruptive accidents (CDAs).
\end{abstract}

\section{INTRODUCTION AND SUMMARY}

The purpose of this report is to discuss safety implications associated with alternatives relative to the reference (U,Pu) oxide fuel. It was prepared as a part of the U.S. Study for the International Nuclear Fuel Cycle Evaluation (INFCE) Working Group $V$ on Fast Breeders. ${ }^{l}$ The alternatives considered include thorium- and uranium-based oxide, carbide and metal fuel types for the liquid metal fast breeder reactor (LMFBR) and oxide fuel types for the gas cooled fast reactor (GCFR). ${ }^{2}$ Safety related parameters (delayed neutron fractions, Doppler, and sodium void coefficients) of alternative fuels are given in Ref. 2. Implications of alternatives relative to fuel performance during normal operation as well as operational and anticipated transients including design basis transient events and run-beyond-cladding-breach are discussed in Ref. 3. In this report we put major emphasis on low probability, but potentially large consequence accidents, e.g., core disruptive accidents (CDAs), since the issue of significant risk from fast reactors as for thermal reactors, becomes only of concern in the case of a CDA capable of breaching the containment. The potential causes of containment failures under CDA conditions include 1) rapid failure due to CDA energetics and 2) relatively slower failures due to CDA fuel debris resulting in long-term pressurization.

In discussing CDAs, it is important to emphasize that the basic protection to the public from fast reactors, as from all other reactor types, against the escape of radioactive material is through a multiplicity of barriers, e.g., pin cladding, subassembly structures, the reactor primary system, cleanup systems, and the secondary containment system. To provide this assurance in the U.S. Fast Breeder Reactor Safety Program, a balanced approach based upon four levels of protection are provided which are aimed at reducing both probability and 
consequences of a core disruptive accident (CDA). ${ }^{4}$ These levels of protection are referred to as lines of assurance (LOAs): LOAI - prevent accidents, LOA2 limit core damage, LOA3 - maintain containment integrity, and LOA4 - attenuate radiological consequences.

While much attention has been given to detailed mechanistic calculations of CDA energetics using accident analysis computer codes (SAS, ${ }^{5}$ MELT, 6 SIMMER $^{7}$ ), these codes do not readily lend themselves to an assessment of safety characteristics of the alternative fuel candidates. This is because the available codes are usually developed to specifically handle the reference oxide fuel and/or they are still largely in a developmental stage. Hence, in this study it was deemed necessary to rely upon arguments largely based upon physical principles supported by the extensive experience with the reference oxide fuel in assessing safety implications of the alternative fuels.*

Following this approach we find that significant differences in safety characteristics are much more dependent on whether the fuel is in the oxide, carbide, or metal form, than on whether the fuel is ${ }^{23} 3 \mathrm{U}$ or ${ }^{23} 9 \mathrm{Pu}$ or the fertile material is ${ }^{238} \mathrm{U}$ or thorium, with the exception of the sodium void effect. A summary of these differences are given below.

Relative to accident prevention, e.g., the ability to safely shut the reactor down when called upon and to subsequently remove decay heat, no significant safety implications of other fuel types relative to the reference (U, $\mathrm{Pu}$ ) oxide fuel appear to be present. Based upon inherent prompt negative feedback characteristics, the metal and carbide fueled reactors would place similar demands upon required response of the plant protection system as the reference oxide fuel. The lower Doppler coefficient of the metal fuel ( 0.003 as compared to $\sim 0.008$ for oxide fue1) ${ }^{2}$ is offset at least to a certain extent by a more reliable and better characterized axial-expansion coefficient of reactivity for the metal fuel. ${ }^{8}$ However, for highly-irradiated, swollen fuel there is a question as to whether the clad would restrain this expansion.

In the area of shutdown heat removal, the potentially added safety feature of sodium boiling being capable of removing decay heat power levels ${ }^{9}$ (in the case of insufficient time for establishing single-phase natural circulation) may not be available for the metal fuel to the same degree as for the oxide and carbide fuel types, because the eutectic temperature between the metal fuel and cladding is less than the boiling temperature of the sodium. However, it is likely that it can be shown that the time duration of sodium boiling prior to reestablishing single-phase natural circulation of relatively low temperature sodium is short compared to the required time for any significant clad penetration.

\footnotetext{
*As a result, very much greater uncertainty must be assigned to suggested safety implications of the alternatives considered in this report than for the much better established reference oxide fuel type.
} 
Relative to CDA accommodation, arguments for benign energetics become easier with a fuel element (fuel, bond, and cladding) which becomes dispersive*10 upon disruption and which does not display explosive characteristics**10 upon contacting the coolant. These requirements lead to increased safety concerns with the carbide fuels because of less favorable characteristics relative to timely fuel dispersal and benign fuel-coolant interactions as compared with the oxide types (uranium as well as thorium based).

For oxide fuels, the cladding boiling point is roughly equal to (uraniumplutonium) or somewhat lower (thorium) than the melting point of the fuel suggesting that steel vapor from clad boiling can provide an effective dispersal mechanism. Explosive sodium vapor formation is not likely to be involved for oxide-fuel/sodium systems. U-Pu metal fuels which are bonded with and have become logged with sodium have a potentially similar dispersive mechanism through the fact that sodium bond would begin boiling very nearly coincident with initiation of fuel disruption (i.e., at the metal fuel melting temperature which is below the cladding melting temperature). If this fuel dispersal by sodium bond vaporization can be demonstrated, the U,Pu metal fuel appears at least as favorable as the $\mathrm{U}, \mathrm{Pu}$ oxide fuel with respect to benign energetics arguments. Some less likely phenomena (e.g., extensive fuel slumping) would be required to raise the fuel temperature sufficiently to achieve an explosive fuel-coolant interaction. The dispersal potential appears less favorable for thorium-based metal fuels since the cladding melts at a lower temperature than does the fuel which would allow sodium bond to escape prior to fuel disruption; the safety concerns then become similar to those to be noted for carbide fuels.

The potential for monotonic fuel dispersal characteristics of carbide fuels would appear less favorable, $\dagger$ since the clad boiling point is well above the carbide melting point. Furthermore, for temperatures where extended carbide fuel dispersal becomes possible, a strong argument on the basis of physical principles can no longer be used to eliminate the concern for explosive formation of sodium vapor. $\Phi$ In particular, the potential for a pressure-driven recriticality event would appear to be more difficult to rule out for the carbide fuel. Therefore, in comparison with the oxide fuel, more detailed mechanistic descriptions of core-disruptive accident phenomena are likely to be required to assess accident mitigation and consequences.

*Dispersive implies the presence of a volatile material (sodium or steel) which is able to do work by receiving heat from the disrupted fuel. This effect will provide extended or long-term dispersal as compared to possible short-term dispersal by fission-gas release.

**Explosive characteristics imply "spontaneous" vapor formation upon contact between the molten fuel and the coolant, which can lead to mixing and subsequent sustained pressurization.

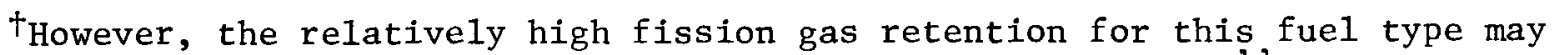
lead to extended fuel dispersal as compared to oxide fuel. 11

In the case of the carbide-sodium system, spontaneous nucleation is satisfied upon contact. However, while considerable experimental support is available, ${ }^{12}$ we note that the spontaneous nucleation criterion as a guide for assessing the possibility of an energetic fuel-coolant interaction is not universally accepted. 13 
We further note that for ( $U, P u$ ) metal fuel, the low melting temperature and favorable dispersive characteristics provided by the sodium bond at least partially offset the fact that the sodium void coefficient tends to be more positive than for oxide and carbide fuel. However, if in some way a large positive reactivity ramp rate could be introduced before the fuel was molten, the possibility would exist for significant conversion of fuel thermal energy to work by the sodium bond. Also for very high ramp rates the lower Doppler coefficient for the metal fuel would become a problem. However, the reactivity ramp rates likely to be introduced by sodium are not large enough for this to be a problem; some less likely phenomenon would be required. Energy release in the fuel for more probable ramp rates would not be much larger for the lower Doppler coefficient of the metal fuel.

In regard to the sodium void effect in general, we note that the void coefficient is much smaller in ${ }^{23} \mathrm{U}$ fueled systems* which largely eliminates the incentive for heterogeneous cores. This is particularly true for the metal fuel where the ${ }^{233} \mathrm{U}$-Th system hardly has a central positive sodium void region and it is clearly negative for the bulk of the core.

In the case of a postulated loss-of-heat-sink accident, $* *$ oxide and carbide fuel would experience disruption only after the coolant level drops below the core, since sodium boiling would appear capable of removing decay-heat power levels. It therefore follows that the damage potential from a loss-ofheat-sink accident is sma1l even if an energetic recriticality event is postulated, since there is no liquid sodium to transmit the kinetic energy to the reactor vessel head components. This favorable safety characteristic may not be available for the metal fuels because the low-melting eutectic temperature between the fuel and clad is such that fuel disruption may occur in the presence of coolant. However, in this case continued sodium vaporization may provide fuel dispersal, thereby preventing energetic recriticalities.

Relative to the potential for breach of the barriers in the absence of an energetic CDA due to thermal meltthrough, the postulated loss-of-heat-sink accident** appears to rule out in-vessel coolability arguments, i.e., the fuel debris melts through the primary reactor vessel wall in the absence of decay heat removal. We note that based upon the ex-vessel postaccident heat removal approach with an explicit core retention device (passive or active), the metal fuels would appear to have advantage because of their low melting points and high thermal conductivities, if question over oxidic fission product migration can be solved by material and design studies. However, with the inherent retention in the concrete approach (i.e., in the absence of an explicit fuel debris retention device), a moderate advantage appears with the oxide fuels because no additional heat or gas are generated by fuel reactions. These phenomena may pose additional requirements on possible containment and/or confinement combined with filtered purge systems relating to mitigation of radiological consequences.

\footnotetext{
*Fue1s with predominantly ${ }^{23}{ }^{3} \mathrm{U}$ fissile composition will have an inherently lower sensitivity to the effects of sodium-voiding reactivity because of the relative insensitivity to changes in neutron-energy spectrum of the ratio of capture to fission cross sections.

**For this accident class, which by definition leads to whole-core involvement, the core meltdown process occurs at low power (decay heat) and is therefore treated separately from unprotected accidents.
} 
The above comments relate specifically to the LMFBR design. In the case of the GCFR design, no significant differences in safety implications are noted for the alternatives considered, since the property characteristics of oxide fuels are quite similar. Relative to LMFBRs, GCFR designs offer the advantages of essentially eliminating the positive void coefficient problem and completely eliminating the fuel-coolant thermal interaction problem, but the high pressure and the use of gas coolant provides for less favorable fuel dispersal characteristics and inability to remove decay heat by natural convection.

Section II reviews key energetics issues and desirable safety characteristics. Details of accident energetics related to oxide fueled LMFBRs are given in Section III, including a discussion of accident initiators, potential for core disruption and energetics, reactor disassembly and structural design considerations, and $R \& D$ requirements to resolve the remaining issues. Sections IV and V discuss carbide and metal fuels, respectively. Various proposed postaccident heat removal options and their relationships to fuel type are briefly discussed in section VI. Section VII provides a brief description of safety implications of alternative fuels relative to the GCFR design, and overall conclusions are given in section VIII.

\section{KEY ENERGETICS ISSUES AND DESIRABLE FUEL CHARACTERISTICS}

Unlike LWRs, LMFBRs can be very sensitive to dimensional changes or relocation of core materials since the intact LMFBR core is not in its most reactive configuration. Therefore, it is theoretically possible that rearrangement of geometry can lead to prompt-critical reactivity excursions and to hydrodynamic disassembly* of the reactor, resulting in large quantities of vaporized fuel, as first discussed by Bethe and Tait in 1956, 16 which raises the general issue of energetic recriticality accidents.

A typical idealized configuration used to produce an upper-bound limit on the recriticality excursion is shown in Fig. 1, where the upper portion of the core following an arbitrary separation is assumed to fall by gravity onto the lower portion of the molten core. The relatively greater concern voiced over LMFBR core-meltdown accidents results therefore principally from its significantly increased potential for producing vaporized plutonium (airborne fuel particles) and breach of the engineered barriers due to a violent disassembly accident. Only the recriticality issue is unique to the fast breeder reactors.

Also, even if a core meltdown occurs without an energetic neutronic excursion, the possibility of an energetic fuel-coolant interaction (vapor explosion) where the sodium becomes the working fluid must be considered in LMFBRs, as first discussed by Hicks and Menzies in 1965.17 An upper-bound estimate as used by Hicks and Menzies requires the idealized configuration illustrated in Fig. 1 where the molten fuel and liquid sodium must be finely mixed to result in optimum and instantaneous transfer of energy.

*The rapid heating and vaporization of the fuel produces sufficiently high pressures that the core can be treated as a homogeneous fluid and the material motion during disassembly calculated using a hydrodynamic approach. 


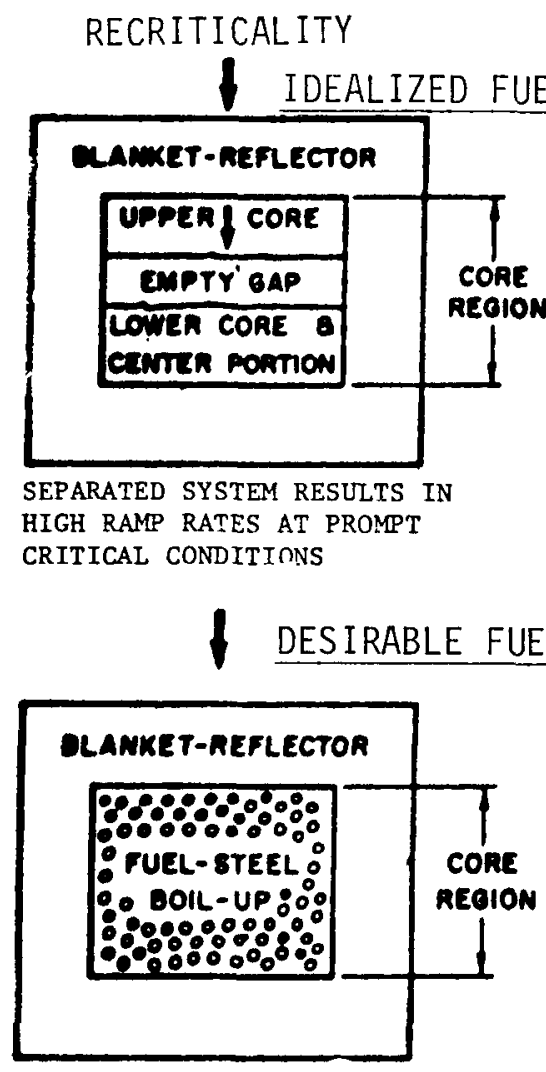

FUEL DISPERSAL PREVENTS ENERGETIC RECRITICALITY
FUEL-COOLANT INTERACTION

\section{CONFIGURATIONS}

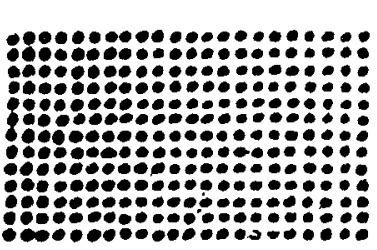

MOLTEN FUEL AND LIQUID SODIUM FINELY MIXED PRIOR TO HEAT EXCHANGE RESULTS IN LARGE SUSTAINED PRESSURIZATION (VAPOR EXPLOSION).

\section{Fig. 1. Accident Energetics - Generic Issues.}

However, the most serious concern over the energetics comes from much less idealized configurations than either of those just discussed but occuring simultaneously, i.e., some initial separation of the core which results in a localized vapor explosion which subsequently drives the fuel back into the core region. This situation is genera11y referred to as a pressure-driven recriticality. 18

Ever since Bethe-Tait and Hicks-Menzies studies, the assessment of CDAs, including recriticality and fuel-coolant interaction events, has been a major consideration in LMFBR safety analysis and development. This is because it is generally not considered practical to accommodate upper "theoretical" bounds resulting from idealized configurations as illustrated in Fig. 1. Furthermore, since the levels of energetics resulting from hydrodynamic disassembly are rather sensitive to small variations in the core peak and average temperatures (the work is essentially proportional to fuel vapor pressure, which is an exponential function of temperature) and hence to initial conditions like the driving ramp rate, it follows that it is desirable to be able to rule out energetic hydrodynamic disassembly conditions altogether. For example, Fig. 2 illustrates slightly different idealized recriticality configurations including both gravity and pressure-driven collapse modes and associated work potential*

*The work potential in this case is from fuel vapor expansion rather than from an energetic fuel-coolant interaction. 

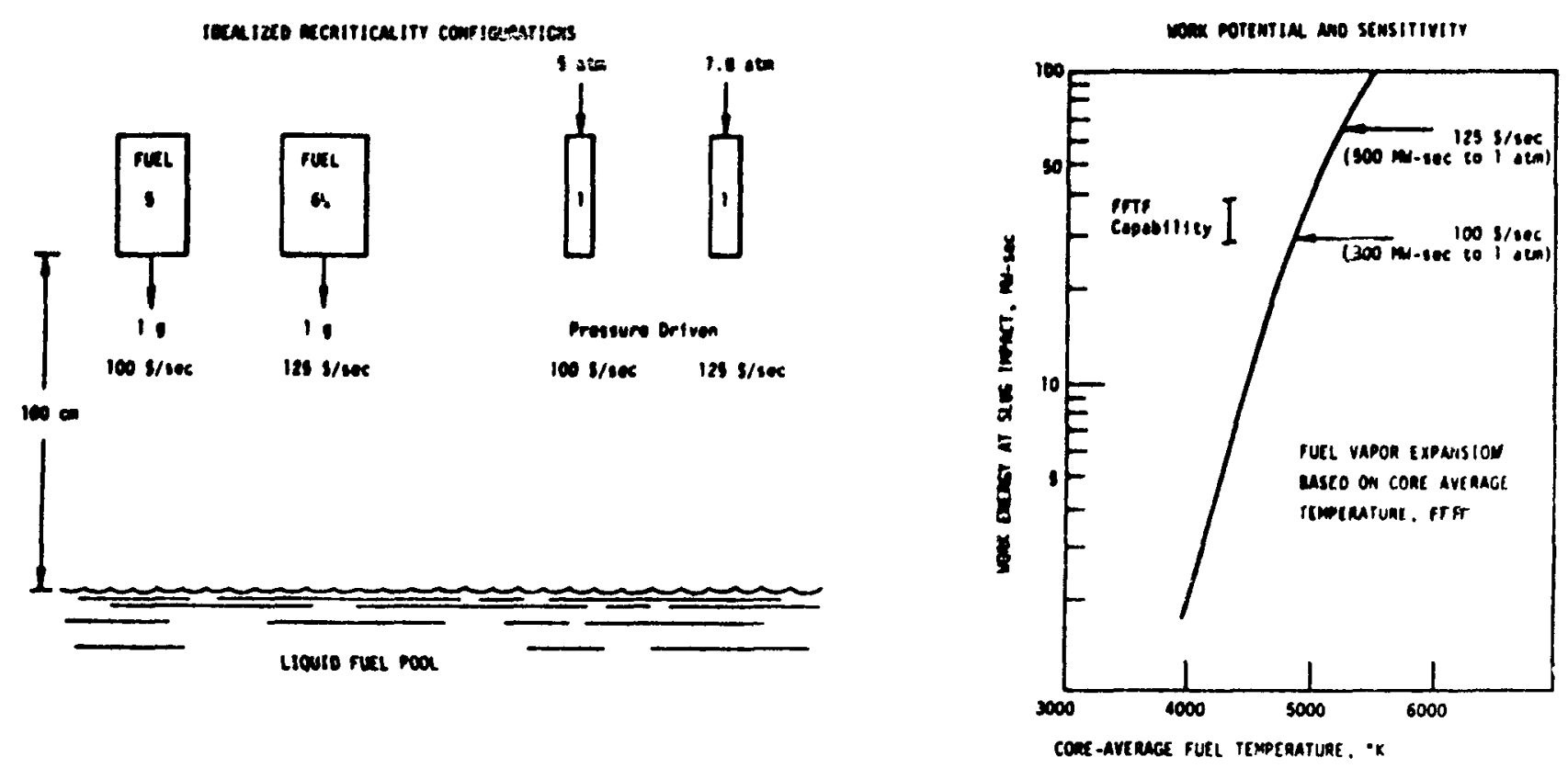

Fig. 2. Illustration of Energetic Recriticality Events (Gravity and Pressure Driven) and Associated Work Potentials. Illustrations are made for FFTF where 1 unit of fuel represents the fuel inventory in one subassembly. For CRBR, 1 unit would correspond to 23 subassemblies.

for the Fast Flux Test Facility (FFTF). If these conditions were indeed realistic, it would be difficult to sort out the difference between ramp rates of $100 \$ / \mathrm{s}$ and 125 \$/s which lead to an increase in work potential by a factor of 2. It would therefore be correspondingly unrealistic to claim that FFTF is providing any significant safety margin for the conditions illustrated in Fig. 2. Adequate safety margins are rather assured by izlustrating that highly energetic gravity or pressure-driven recriticality events are very unlikely. Similar arguments can be made relative to large-scale energetic fuel-coolant interaction events. Therefore, from a safety point of view, it would appear difficult to make reasonable convincing arguments without a fuel possessing the following desirable characteristics:

- Upon fuel dismption the system should display dispersive characteristics (see Fig. 1) capable of driving the fuel to a permanent subcritical state, i.e., preclude gross fuel compaction and energetic gravity-driven recriticalities.

- Upon fuel melting or conditions required for displaying dispersive characteristics, the system should not satisfy conditions which may lead to explosive vapor formation, i.e., prevent overall energetic fuel-coolant thermal interactions and the energetic pressure-driven recriticalities (see Fig. 1).

In addition to the above two generic accident-energetics issues, the design-dependent issue related to the positive sodium-void worth in LMFBRs 
needs resolution.* This problem is of little or no concern for ${ }^{23}{ }^{3} \mathrm{U}$-based fuel, ** but with a large homogeneous core of ${ }^{239} \mathrm{Pu}$-based fuel the net sodiumvoid reactivity may be 5 to 8 dollars. ${ }^{2}$ Following a postulated unprotected loss-of-flow accident, high-power, fuel-failure conditions may be reached due to sodium voiding in the high power subassemblies alone with the reactor near prompt critical and a substantial fraction of the core still not voided. Following pin failures in voided and nonvoided channels much higher ramp rates leading to superprompt burst conditions due to fuel densification near the midplane and/or accelerated sodium voiding are theoretically possible, but fuel dispersal may also override further reactivity due to sodium voiding. The problem here is that the level of energetics becomes sensitive to details of competing material motions on a millisecond time scale in a highly disrupted geometry if near prompt burst condition is established. The physical characteristics of the problem are illustrated in a conceptual manner in Fig. 3 . Again, from a safety point of view, the following additional desirable safety characteristics emerge:

- Subjected to unprotected loss-of-flow or transient overpower conditions, the fuel should display early dismption and dispersive characteristics to cancel sodium-void reactivity well before reaching prompt-critical condition (see Fig. 3).

The availability of these desirable safety characteristics relative to fuel type are indicated in Table $I$. The breeding ratio along with such important safety parameters as Doppler and void worth are also listed together with an assessment relative to the abi-ity to tolerate sodium boiling at decay heat power level.

It is concluded from Table $I$ as well as considering the available data base that relative to accident energetics the strongest case can be made for the oxide fuel. The main area of question relates to fuel dispersal in connection with the positive sodium void worth. Consideration of heterogeneous designs should largely eliminate this concern. A less favorable situation appears for carbide and metal; for the carbide fuel increased potential exist for pressure driven recriticality, and while this potential would appear less for metal fuel, the higher void worth and much lower Doppler coefficient raises concern over the metal fuel. Further details of these characteristics are given below relative to the potentials for core disruption and accident energetics.

*This problem may be largely eliminated through heterogeneous designs, but with the penalty of increasing the fuel inventory and thus increasing the doubling time.

**For ${ }^{233} \mathrm{U}$-based fuel the fuel capture-to-fission ratio is relatively insensitive to energy-spectrum variations, while this effect is significant for ${ }^{23} \mathrm{Pu}$ fuel. 

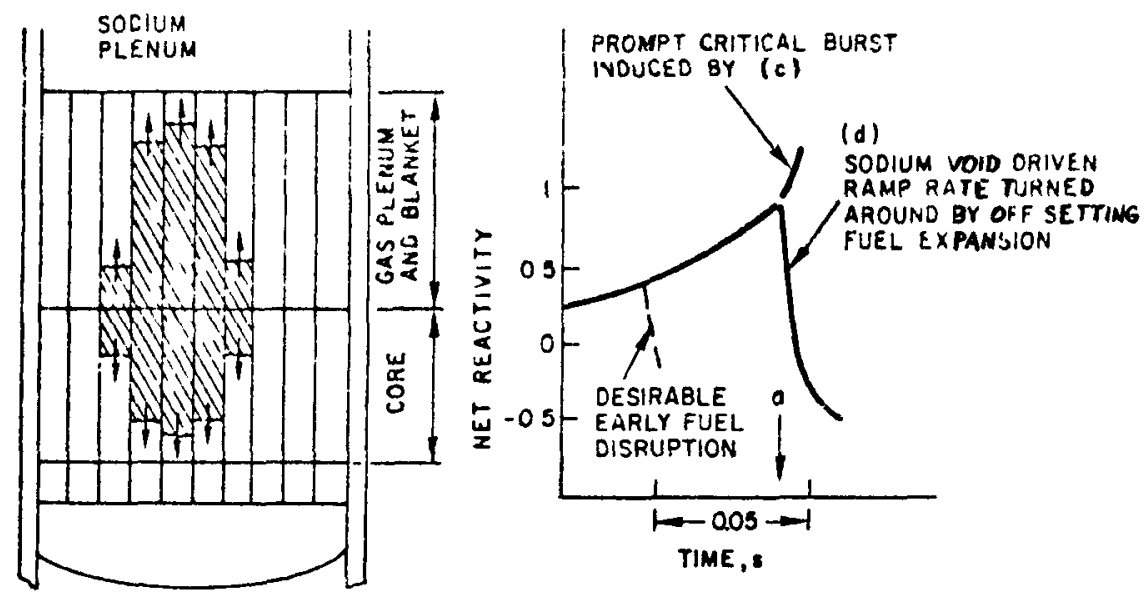

(a) SOOIUM VOIOING IN CORE AT

(b) REACTIVITY EFFECTS POSSIBLE AT TIME OF FUEL FAILURE CONDITIONS ILLUSTRATED IN (a)
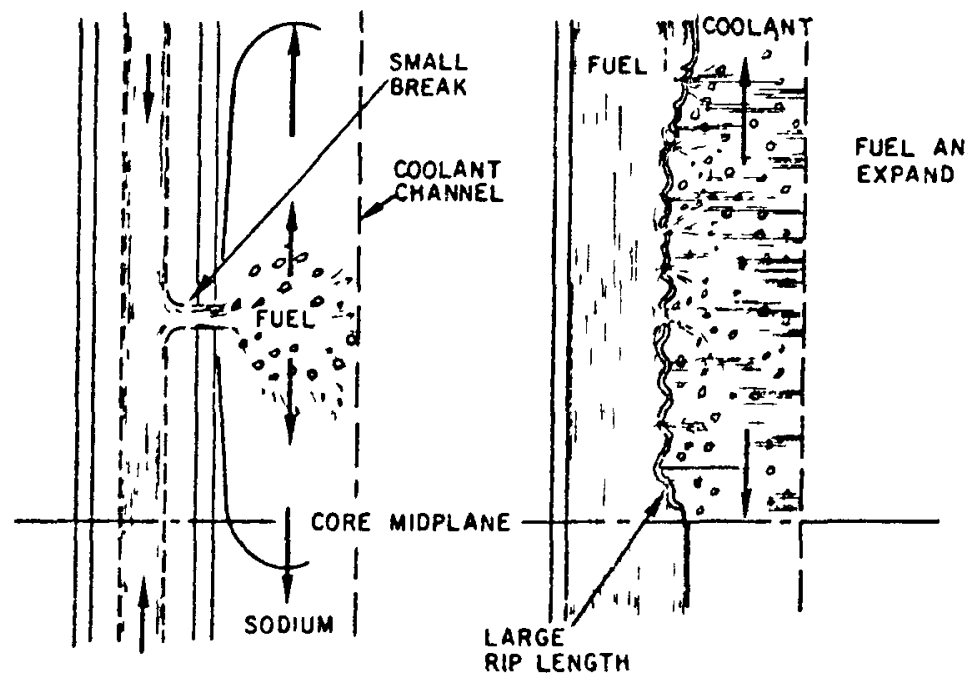

(c) AUTOCATALYTIC CONDITIONS FUEL MOVING II.SIDE CENTRAL VCID TOWARD MIDPLANE SOOIUM VOIDING FASTER THAN FUEL IN COOI ANT CHANNEL

(d) LARGE RUPTURE MIMIMIZES FUEL MOTION INSIDE PIN FUEL AND SODIUM EXPAND TOGETHER FUEL MOTION OFF SETS SOOIUM VOID REACT VITY INCREASE

Fig. 3. Illustration of Fuel-motion Possibilities as a Consequence of a Large Positive Sodium-void Coefficient. 
Table I. Relationship between Desirable Safety Characteristics and Fuel Type

\begin{tabular}{|c|c|c|c|c|c|c|c|}
\hline Fue1 Type & $\begin{array}{c}\text { Breeding } \\
\text { Ratio }\end{array}$ & Dopp1er & $\begin{array}{l}\text { Void } \\
\text { Worth }\end{array}$ & $\begin{array}{l}\text { Dispersal } \\
\text { Potential }\end{array}$ & $\begin{array}{l}\text { Absence } \\
\text { of Vapor } \\
\text { Explosion }\end{array}$ & $\begin{array}{l}\text { Early } \\
\text { Fuel } \\
\text { Dispersal }\end{array}$ & $\begin{array}{l}\text { Ability } \\
\text { to Tolerate } \\
\text { Sodium Boiling } \\
\text { (Decay Heat) }\end{array}$ \\
\hline Oxide & 1.33 & 0.0063 & 5.7 & Favorable & Favorable & $\begin{array}{l}\text { Less } \\
\text { Favorable }\end{array}$ & Favorable \\
\hline Carbide & 1.48 & 0.0062 & 5.3 & $\begin{array}{l}\text { Less } \\
\text { Favorable }\end{array}$ & $\begin{array}{l}\text { Less } \\
\text { Favorable }\end{array}$ & $\begin{array}{l}\text { Less } \\
\text { Favorable }\end{array}$ & Favorable \\
\hline Metal & 1.58 & 0.0022 & 8.2 & Favorable? & Favorable? & Favorable? & $\begin{array}{l}\text { Less } \\
\text { Eavorable }\end{array}$ \\
\hline \multicolumn{8}{|l|}{ Metal } \\
\hline${ }^{233} \mathrm{U} / \mathrm{Th}$ & 1.1 & - & - & - & - & - & - \\
\hline
\end{tabular}




\section{ACCIDENT ENERGETICS - OXIDE FUELED LMFBRS}

A. Initiators of Core-disruptive Accidents

Classes of possible initiating conditions have been identified as follows: (1) those resulting in a reactivity insertion at a rate so great that the reactor plant-protection system would be unable to respond in time, (2) malfunctions or faults within the design basis of the reactor plant-protection system but in combination with failure of the plant-protection [these can be broken down into fuel-failure propagation, whole-core loss-of-flow (LOF), and transient overpower (TOP)], and (3) malfunctions or faults leading to interruption of heat-removal capability even with shutdown, such as loss-of-heat sink. From a probabilistic point of view, it would appear, appropriate to consider only the second and third class of initiators since the first class (including control-rod ejection, gas-bubble intake, and failure of core-support structure or core-restraint system can be discounted on the grounds that they can be effectively precluded by design. ${ }^{19}$ It is therefore common to discuss core-disruptive accidents in terms of three general initiating classes:

1. Fuel-failure Propagation;

2. Loss of P1ant-protection Systems (Unprotected Transients);

3. Loss of Heat Sink.

\section{B. Potential for Core Disruption}

1. Fuel-failure Propagation: With multiple subassembly inlets subassembly disruption with (U,Pu) oxide fuel need only be considered as a hypothetical event, since extensive efforts have been unable to identify any sequences of events which could result in disruption. 20 The principal reasons for this conclusion are: 1) local faults (including fission-gas release, molten-fuel release, and localized boiling) have been shown to be isolated events (no rapid propagation) and 2) slow blockage propagation is not expected, particularly in wire-wrapped subassemblies, but it still remains to be finally verified.

A similar claim can be made for thorium based oxide fuel. We note that damaging blockage formation by fuel debris is unlikely in the flux zone because of the self-disruptive nature of heat-generating fuel beyond a certain critical size (this size would appear well below any damaging blockage size that could lead to sufficient flow starvation, i.e., produce bulk coolant temperatures approaching the saturation value). An additional line of defense against core disruption from local faults can be provided by detection. Here it is important to note that our current understanding of material-behavior interactions suggest that at least several tens of grams of molten fuel could be released into the coolant without approaching the threshold for rapid subassembly disruption. Delayed-neutron detectors would appear adequate and could therefore be set at very high levels to avoid spurious trips from leaking fuel pins, etc. 
Finally, we note that if an unprotected subassembly meltdown is postulated, it becomes difficult to rule out the possibility of subassembly-tosubassembly propagation. The concern here is not an energetic fue1-coolant interaction since these would appear to be absent in the oxide-sodium system (see Fig. 4). Instead, a significant potential exists for fuel freezing and

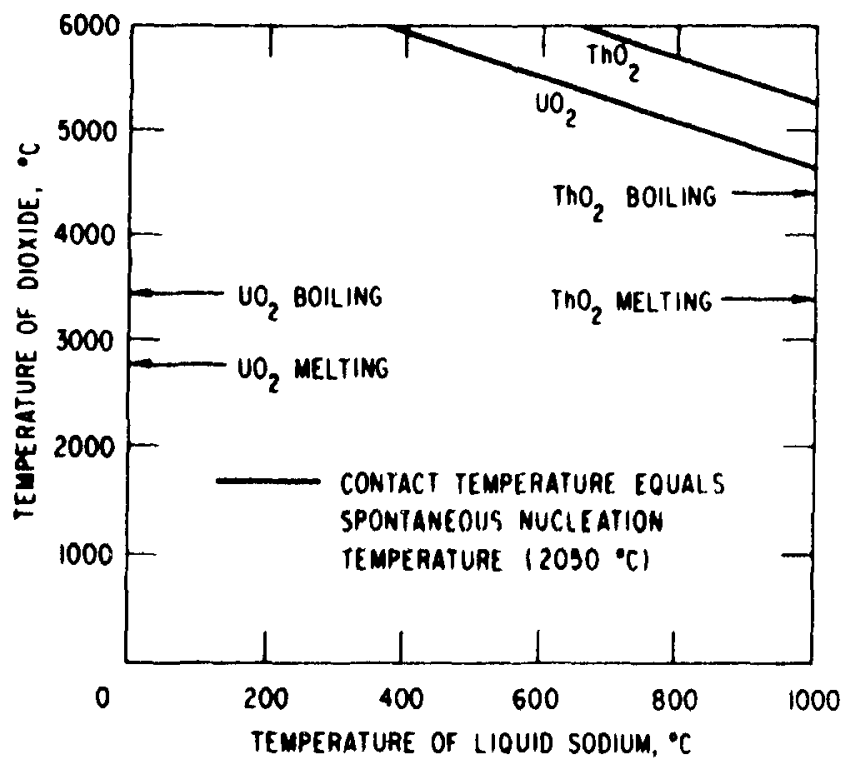

Fig. 4. Illustration of Necessary Temperatures for Oxide Fuels to Cause Spontaneous Nucleation (Explosive Boiling) upon Contact with Liquid Sodium. ${ }^{2}$ A large body of experimental data supports the necessity for satisfying this condition in order to have an energetic langescale fuel-coolant interaction. However, we note that this criterion is not yet universally accepted in the technical community. 13

plugging as the fuel-steel mixture expands into the cold structures outside the flux zone. If complete blockage and bottling-up of the fuel should occur, radial propagation by thermal meltthrough would appear unavoidable if the reactor still remains at full power. Under these conditions, the incident hexcan wall as well as the adjacent hexcan walls provide little or no defense against propagation, implying that any significant line of defense against whole-core disruption from local faults must be based upon ruling out an unprotected subassembly meltdown. (In the case of reactor scram, propagation appears unlikely).

2. Loss of Plant Protection Systems: This category of accidents can be generically associated to either a loss-of-flow (LOF) or a transient overpower (TOP) sequence. In case of normal protective-system response, these events will not result in core damage. Only in the case one postulate total plantprotection system failure, does the potential for core disruption exist.

a. Unprotected TOP: The principal areas of interest for this accident class relative to the potential for whole-core involvement includes fuelfailure phenomenology, pin-failure incoherencies (in space and time), and postfailure fuel motion. 21 In the first area, available analytical and experimental data generally support axial failure location well above the core 
midplane (this is definitely the case where the reactivity rate is limited to the maximum speed of the contro1-rod drive [several cents per second]), suggesting that there is sufficient negative reactivity feedback for neutronic shutdown by axial fuel motion inside the fuel pin to the failure location. Fuel sweepout in the coolant channels, while desirable, apparently is not necessary for shutdown, and the key remaining concern relative to limited coredamage termination is the potential for fuel plugging and its effect upon coolability, which relates to the second and third areas of interest. Evidence is available from TREAT fuel-pin disruption tests with (U,Pu) oxide fuel that plugging can occur ${ }^{22}$ (although these have generally been carried out with less than prototypic hydraulic conditions and fuel sample sizes). However, arguments based upon intrasubassembly temperature incoherencies, and hence incoherencies of fuel-pin failure, may prevent complete subassembly blockages.

Finally, it should be noted that it is important to be able to rule out coherent fuel-coolant interactions as the fuel is ejected into the coolant stream, which appears to be the case for oxide fuel (see Fig. 4). (Only small-scale incoherent interactions seem possible as demonstrated by all the TREAT (U,Pu) tests). ${ }^{22}$ If energetic interactions could take place, flow reversal and downward voiding (and downward fuel motion toward the midplane since initial fuel failures are expected well above the midplane) could occur, leading to positive reactivity addition, resulting in midplane failure and possible autocatalytic effect, particularly in a large core with a sizable positive sodium-void coefficient. We note that this concern is considerably decreased for fuels with predominantly ${ }^{23}{ }^{3} \mathrm{U}$ fissile composition which have an inherently lower sensitivity of the ratio of capture to fission cross sections with changes in neutron energy spectrum (see Fig. 5).

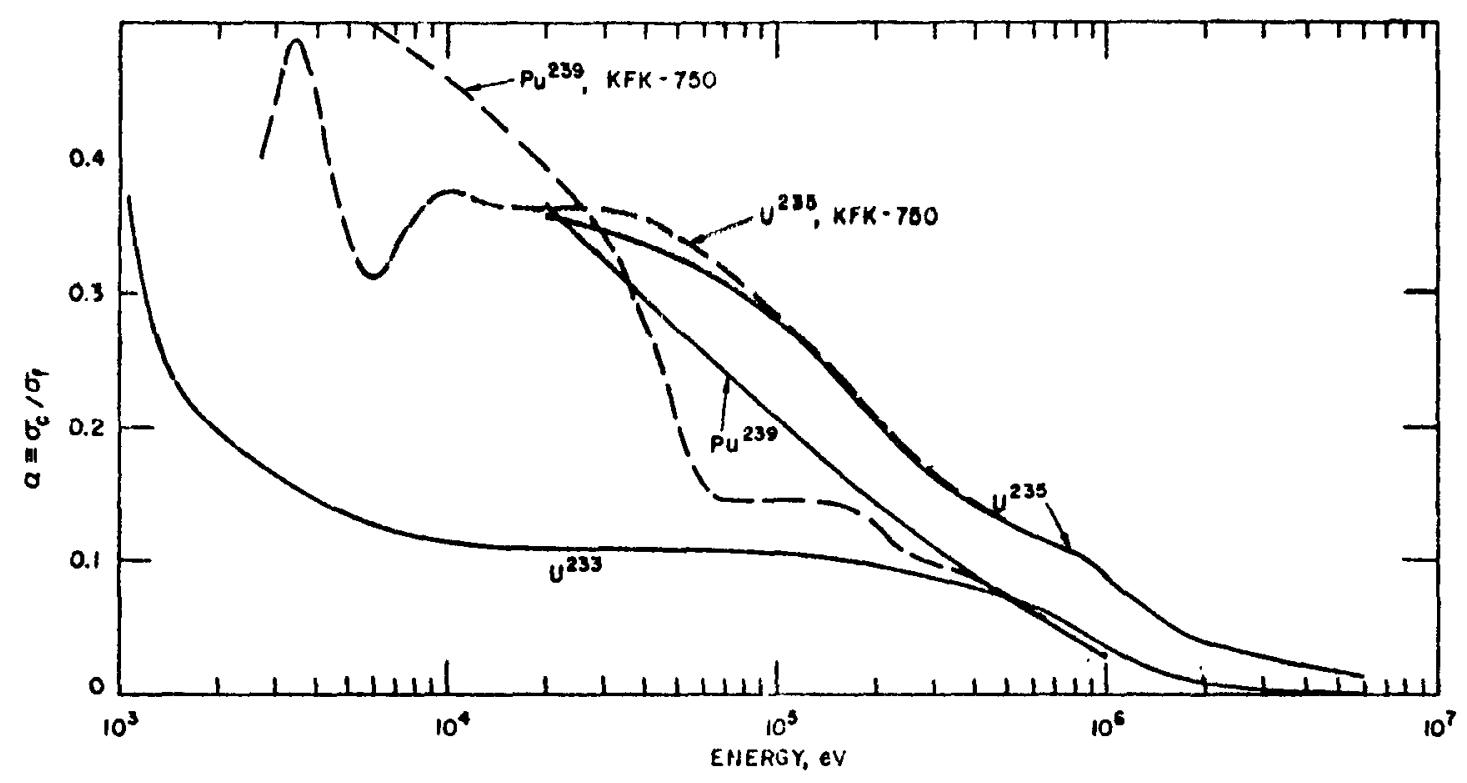

Fig. 5. Ratios of Capture to Fission Cross Sections. (Taken from Ref. 23). 
b. Unprotected LOF: Current technology applied to current reactors (FFTF) does not indicate that early termination with limited core damage and largely coolable geometry of the transient undercooling accident is possible. ${ }^{24}$ The combination of rapid flow coastdown and relatively high coherence in subassembly power-to-flow ratios leads to voiding in a large fraction of the core prior to fuel disruption in the lead subassemblies. One-dimensional voiding is predicted, which may add significant positive reactivity in CRBR-size or larger cores prior to fuel disruption. The resulting power excursion aggravates the situation relative to the potential for early termination. Furthermore, the structure located above the active fuel region in current designs (reflector or blanket and fission plenum) appears to result in plugging by fue1 and steel being expelled by the excursion, and hence makes it difficult to argue for extensive and timely fuel relocation as well as coolability of the damaged subassemblies.

\section{Potential for Energetics}

1. Core Disruption at High Power Levels: Since early termination is not indicated of the unprotected loss-of-flow accident for current U.S designs, detailed considerations have been given to the potential for energetic events associated with extensive core disruption. Accident analysis computer codes such as SAS, ${ }^{5}$ MELT, ${ }^{6}$ and SIMMER $^{7}$ have been used for this purpose. However, since these codes have been largely developed for the oxide fuel type, it was deemed necessary in this study to rather rely upon a number of physical principles and characteristics, in order to produce a timely qualitative assessment of safety implications relative to the alternate fuel candidates. An example of such an approach to the resolution of generic accident energetics issues* can be based on the following two physical principles which are not sensitive to the many complex details which are present in the core disruption phase:

1. A self-heated liquid becomes dispersive. At nominal as well as decay heat power levels, the oxide fuel would appear to be monotonically dispersive by steel boiling (clad boiling point s fuel melting point - see Fig. 6).

2. Fine mixing of a hot and cold fluid, a necessary condition for developing sustained pressures, requires spontaneous nucleation on contact. The contact temperature for the mixed oxide-fuel-sodium system is well below the spontaneous nucleation temperature for liquid sodium (see Fig. 4).

Application of the two physical principles summarized above lead to the following result:

- Principle 1 rules out gravity-driven recriticality and Principle 2 rules out pressure-driven recriticality.

- Principle 2 rules out energetic fuel-coolant thermal interactions (vapor explosions).

*In addition to the generic accident energetics issues of recriticality and fuel-coolant interaction, attention is currently given to heterogeneous core designs to mitigate sodium-void effects. 


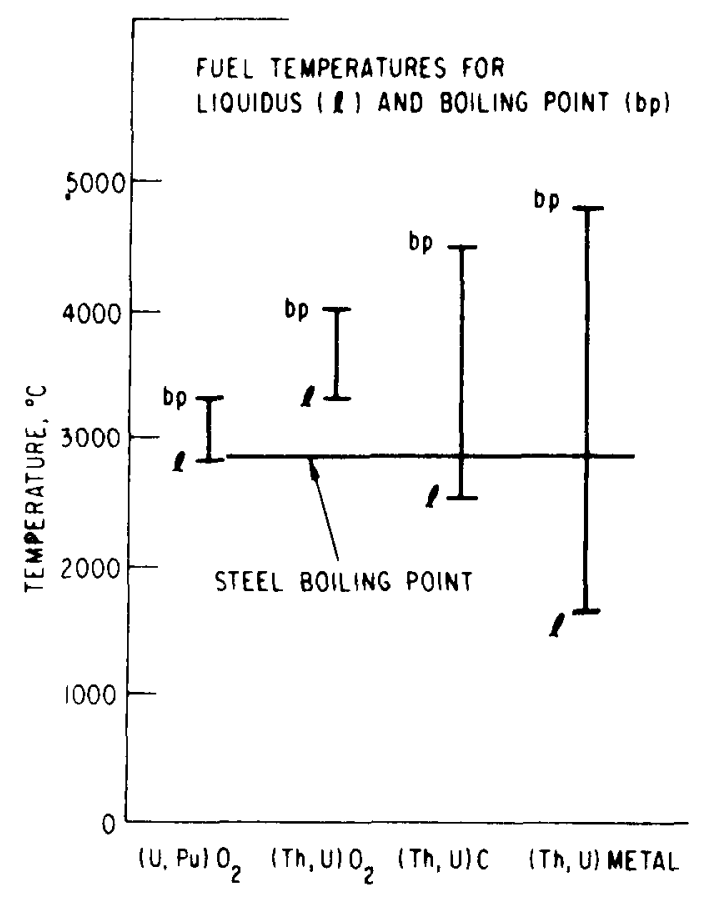

Fig. 6. Comparison between Melting and Boiling Points of Different Fuel Cycles Relative to the steel Boiling Point.

2. Core Disruption at Low Power Level: For the protected loss-of-heatsink accident, * the power level is reduced to decay-heat levels following scram, and the subsequent heatup therefore occurs over hours as compared to seconds for the unprotected accidents. Because of the low power level, boiling stability is maintained, and clad melting and fuel relocation will not occur as long as liquid sodium is available for vaporization. For subcooled plenum conditions (below and above the core), analysis ${ }^{9}$ and simulation experiments ${ }^{27}$ indicate that $5 \%$ of nominal power can be safely removed without resulting in dryout and overheating in the absence of forced flow conditions. But even with saturated plenum conditions, dryout is very unlikely for power levels of interest. A simple conservative bounding calculation based upon top flooding can be provided by assuming no communication between the inlet and exit plenums. In this case refluxing of saturated liquid sodium from the top is calculated to remove heat corresponding to $3 \%$ of nominal power level. It folzows that fuel melting is initiated only if the coolant level drops below the core.

The significance of the above conclusion relative to damage potential from a postulated core disassembly driven by fuel vapor pressure is illustrated in Fig. 7. If no corrective action is assumed (considerable time is available), fuel melting would proceed at a very slow rate (minutes rather than seconds) due to the low power levels. Although effective fuel dispersal under these conditions may be difficult to demonstrate, the probability of a recriticality occurring which would lead to significant energy releases during the fuel

*The loss-of-heat-sink accident has received little attention. Yet for some of the current design concepts, this accident would appear to have significantly higher probability of occurrence than the failure to scram accidents. ${ }^{26}$ 


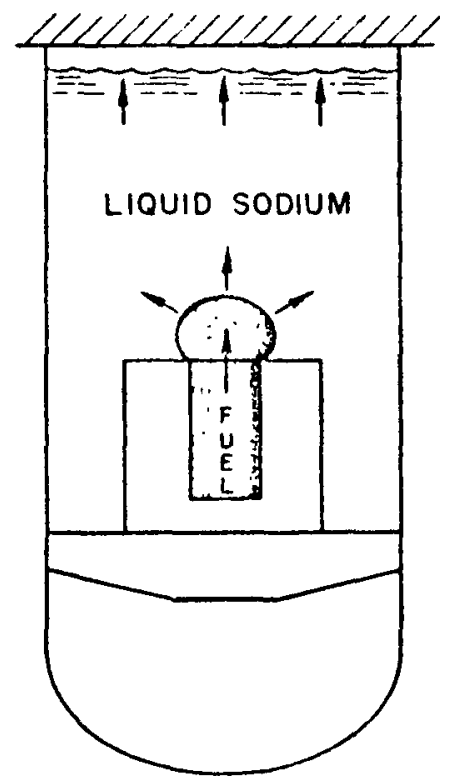

(a) FAILURE TO SCRAM

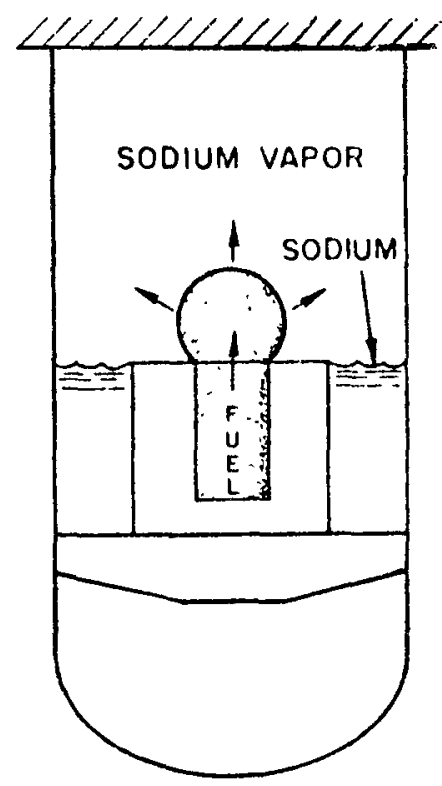

(b) WITH SCRAM

Fig. 7. Illustration of Liquid Sodium Level at the Time of Postulated FueIvapor Expansion for Two Accident Classes: (a) Loss-of-Plant-Protection Systems and (b) Loss-of-Heat Sink.

melting, draining, and removal processes is judged to be low because of the presence of large incoherencies in the core-wide fuel-melting pattern. However, even if a severe compaction of the core fuel is postulated, resulting in large fuel vapor pressures, the available kinetic energy cannot be transmitted to the vessel head or other critical components so as to produce missiles and damage to the containment, because of the absence of liquid sodium above the core region. This is in contrast to the situation of the unprotected accidents, where the liquid sodium is still above the core at the time of fuel melting (see Fig. 7). In this case the energy release is transmitted by the kinetic energy of the sodium slug at impact on the head. It follows that the damage potential from a heat-sink accident is small even if an energetic recriticality event is postulated.

\section{Reactor Disassembly and Structural Design Considerations}

Based upon the above discussion, it would appear that unrealistic physical processes must be postulated in order to achieve highly energetic prompt-burst conditions leading to a true hydrodynamic disassembly of the reactor core. Such calculations are, however, useful in establishing pressure-volume relationships to be used to upgrade any weak links in the design established principally from functional requirements as well as assessing safety margins provided by the resulting design. Figure 8 illustrates such calculations for the FFTF and CRBR. There the core average temperature is related to prompt-critical excursion and associated ramp rate resulting from postulating various amounts and rates of collapsing fuel in a largely molten core (recriticality accident). The mode of energy release considered is the expansion of fuel vapor, resulting 


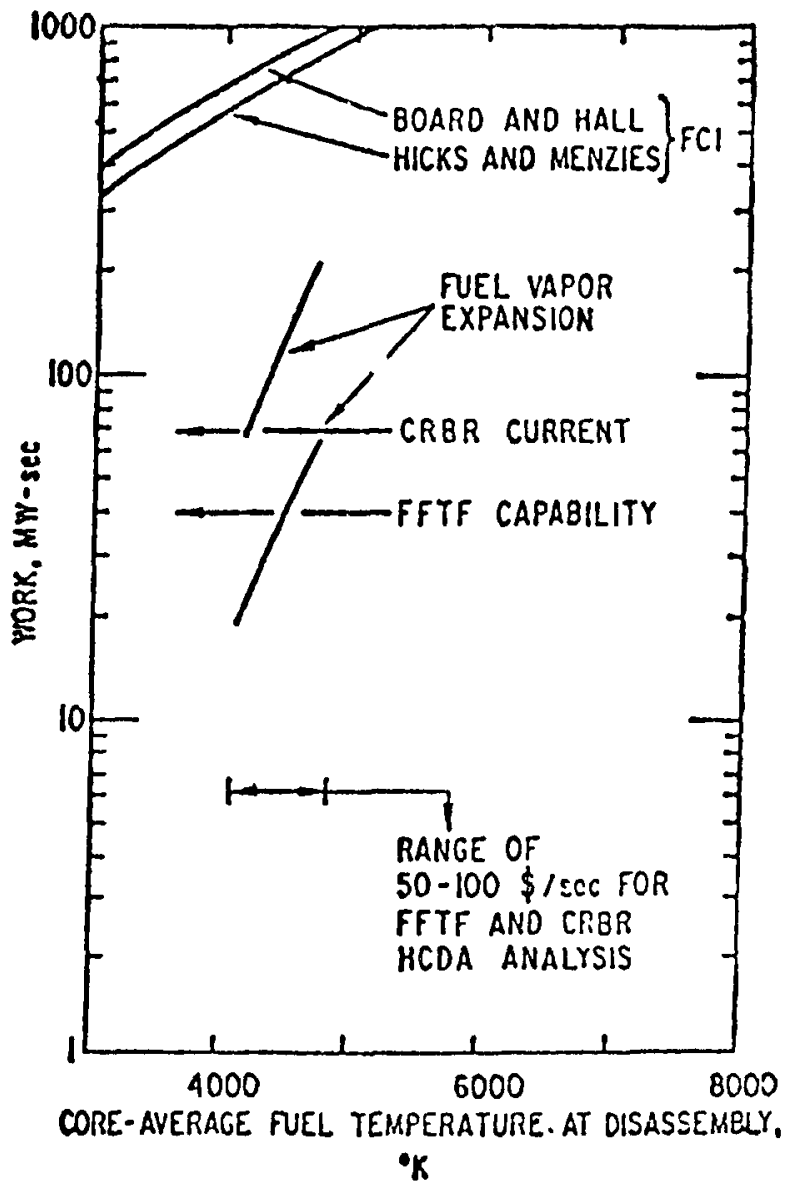

Fig. 8. Illustration of Work Potential (at Slug Impact) from Two Different Source Terms Including Fuel-vapor and Sodium-vapor Expansions.

in sodium-slug impact on the reactor vessel head (see Fig. 7a). The VENUS-II $\operatorname{code}^{28}$ can be used to calculate the disassembly motion and power histories during disassembly. Elementary thermodynamic calculations provide the source term based upon expansion of the fuel from either an initial temperature distribution specified by VENUS calculations or a corresponding mass-average core temperature; ${ }^{29}$ the REXCO codes $^{30}$ provide a hydrodynamic calculation of the pressure propagation coupled with an analysis of the structural response of the important system components. (For a detailed discussion of the main techniques that have been used to develop pressure-volume relationships and the corresponding work potential see Ref. 31). If we consider the arbitrary assumption and uncertainty in specifying the source term (the value of the ramp rate at prompt-critical condition), the above codes can be considered we11-developed and sufficiently accurate. It should be noted that a higher work potential can be obtained by postulating rapid energy transfer from the high-temperature fuel to the sodium, as illustrated 17,32 in Fig. 8 . However, considerations of the requirements for bulk mixing ${ }^{12,33}$ lead to the conclusion that heat transfer from oxide fuels to sodium cannot occur on a time scale short enough to increase significantly the work potential above that obtained by the expanding fuel vapor. ${ }^{29}$ These considerations are also consistent with experimental observations. 34 
Even if energetic prompt-burst conditions are postulated, the chances for developing a significant work potential may still be small for some limited range of ramp rates. 35 In the case of the largely voided core, the high-pressure fuel-steel mixture must expand through the reflector, blanket, and fission-gas plenum regions prior to significantly accelerating the liquid sodium. This geometry, which together with a very low initial temperature $\left(2900^{\circ} \mathrm{C}\right)$ relative to the expanding fuel, gives rise to a highly dispersed flow configuration and large temperature gradients resulting in rapid melting and entrainment of cold cladding and blanket fuel with the hot fuel (ablation). These features may result in a highly effective mechanism for thermal or equivalent mechanical energy loss from the expanding fluid, if potential adverse effects from the presence of liquid sodium films adhering to the upper structures can be ruled out. With reference to the fuel boiling temperature at $1 \mathrm{~atm}$, this mechanism could represent a thermal energy absorption capability of $25000 \mathrm{MW}-\mathrm{s}$. Therefore, if early plugging of these structures should not occur, little or no work potential may be developed even if energetic disassembly conditions are postulated.* Recent analysis and experiments would suggest that substantial fuel penetration up through the upper FFTF subassembly structure may be possible but would appear less likely in the presence of blanket material. 39

Finally, we note that this mitigating effect may only be effective for a rather limited range of ramp rates, i.e., ramp rates and corresponding work potentials that may significantly challenge the primary system, are also likely to push the upper core structure out of the way as the high pressure fuel expands. Therefore, in view of the noted sensitivity of work potential to small variations in ramp rates, the ultimate argument for adequate safety margins with current designs would still appear to require ruling out the likelihood of energetic prompt critical excursions.

\section{E. Resolution of Key Issues}

In addition to further long-term operating experience with failed fuel, experiments relating to the potential for blockage propagation and means for detection, and experiments to obtain additional fuel failure data and subsequent fuel behavior under transient overpower conditions, the principal need for experiments falls in the area of demonstrating monotonic and extended fuel dispersal down to the decay heat level. These experiments relate to early accident termination, resolution of the longstanding sodium void coefficient problem, and the ability to rule out energetic recriticalities. Safety test facility requirements are therefore largely determined by the need to demonstrate fuel dispersal. Such tests are therefore further discussed below. A summary of recommended experiments in terms of key issues and facilities is given in Table II.

In addition to further analysis and creative laboratory experiments, demonstration with real reactor materials (in-pile tests) appears desirable in order to achieve general acceptance of the inherent dispersive nature of oxide fuel and the absence of the potential for energetic recriticality events.

\footnotetext{
*Ear1y considerations of this potential can be found in Ref. 36. For more recent detailed and elaborate considerations of various interactive transport processes which can lead to radical reduction in system kinetic energy, see Refs. 37 and 38 .
} 
Table II. Experimental Resolution of Key Issues - Oxide Fuels

\begin{tabular}{|c|c|c|c|c|c|}
\hline ISSUE & CAMEL & EBR-II & TREAT & TREAT-UPGRADE & SLSF \\
\hline $\begin{array}{c}\text { FUEL } \\
\text { FAILURE } \\
\text { PROPAGATION }\end{array}$ & & 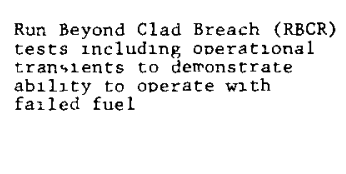 & & & 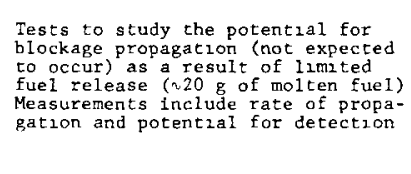 \\
\hline $\begin{array}{l}\text { LIMITED } \\
\text { CORE } \\
\text { DAMAGE }\end{array}$ & 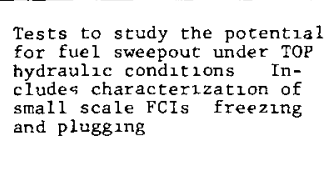 & & 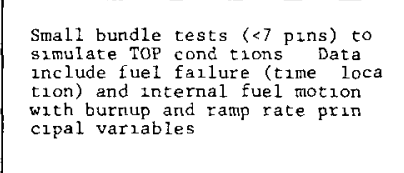 & 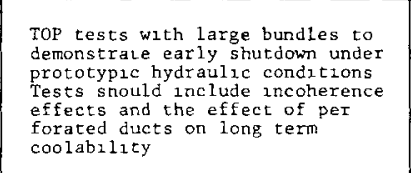 & $\begin{array}{l}- \text { Top tests with small ramp rates } \\
(\times 10 \% / s) \text { des } r \text { rable }\end{array}$ \\
\hline $\begin{array}{l}\text { ENERGETICS } \\
\text { Na VOID }\end{array}$ & & & 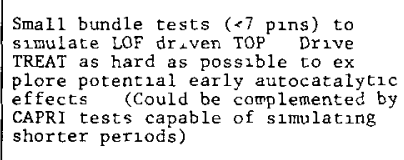 & & \\
\hline $\begin{array}{l}\text { ENERGETICS } \\
\text { RECRITICALITY }\end{array}$ & & & 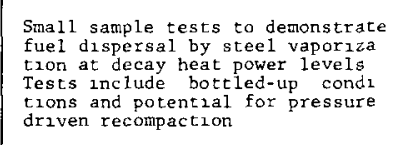 & 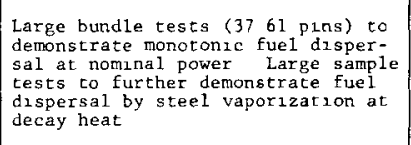 & \\
\hline $\begin{array}{l}\text { ENERGETICS } \\
\text { FUEL-COOLANT } \\
\text { INTERACTIONS }\end{array}$ & & & $\begin{array}{l}\text { See Energetscs- at Vold } \\
\text { Additional proof testing nay be } \\
\text { necessary to completely close } \\
\text { this issue. }\end{array}$ & & \\
\hline $\begin{array}{l}\text { LOSS OF } \\
\text { HEAT SINK }\end{array}$ & & & & & \\
\hline
\end{tabular}


The objective of the in-pile tests would be to verify the dispersive behavior of the oxide system starting from 1) the initial pin structure configuration (at nominal power or above) and 2) an initially separated state (at decay heat power levels). The question of early monotonic fuel dispersal can be adequately assessed by TREAT with modest improvements (TREAT Upgrade).14,15

For demonstration of boilup at decay heat power levels it is of utmost importance to recognize the inherent effect of boundary heat losses which are controlled by the presence of the fuel crust.* As seen from Table III, for any significant portion of the core undergoing a hypothetical disruption, the

Táble III. Characteristics of Fuel Crust

\begin{tabular}{ccccc}
\hline & & \multicolumn{2}{c}{ Fraction of Fuel Inventory as Crust } \\
\cline { 3 - 5 } $\mathrm{P}_{\mathrm{O}}$ & $\delta_{\max , \mathrm{cm}}$ & FFTF Core & 1 Subassembly & 7-pin Bundle \\
\hline 1 & 0.16 & 0.03 & 0.18 & 1.1 \\
0.1 & 0.5 & 0.09 & 0.57 & 3.5 \\
0.05 & 0.7 & 0.13 & 0.82 & 5.0 \\
0.01 & 1.6 & 0.30 & 1.82 & 11.2 \\
\hline
\end{tabular}

material associated with the fuel crust at the confinement boundary represents only a small fraction of the disrupted fuel. However, this ratio is highly dependent on the surface-to-volume ratio of the sample in question and indeed becomes quite large or even exceeds 1 for fuel sample sizes of the order of a single LMFBR subassembly (i.e., in the range of the capability provided by the planned SAREF Program).14,15 Melting down fuel-pin samples of this size (much larger samples are not considered practicable), with the objective of verifying fuel dispersal at decay-heat power levels, most likely would lead to highly nonprototypic and highly undesirable results. This objective can, however, be achieved with reasonable sample sizes by including as part of the makeup of the test fuel sample (see Fig. 9) the nonboiling fuel layer at the confinement boundary, as it is believed to be present in hypothetical core-meltdown situations as discussed above. By providing for the fuel crust prior to boilup in the small sample (geometric dimensions illustrated in Fig. 9 corresponds approximately to an equivalent 61 -pin bundle test) an essentially adiabatic system is established much like that in the hypothetical large system. Because of the large time constant of the fuel, the required energy deposition in both the crust and the fuel sample (should approach the melting point of the crust prior to boilup of the fuel sample) can be achieved by a power burst prior to the flattop simulating decay-heat power level (see Fig. 9).

* Since the melting point of the steel confinement boundary is well below the melting point of fuel, this necessitates the presence of a solid fuel crust. Furthermore, since the boiling point of steel is approximately equal to the melting point of fuel, the maximum nonboiling layer (open system) is determined by the ability to conduct away the generated decay heat. 


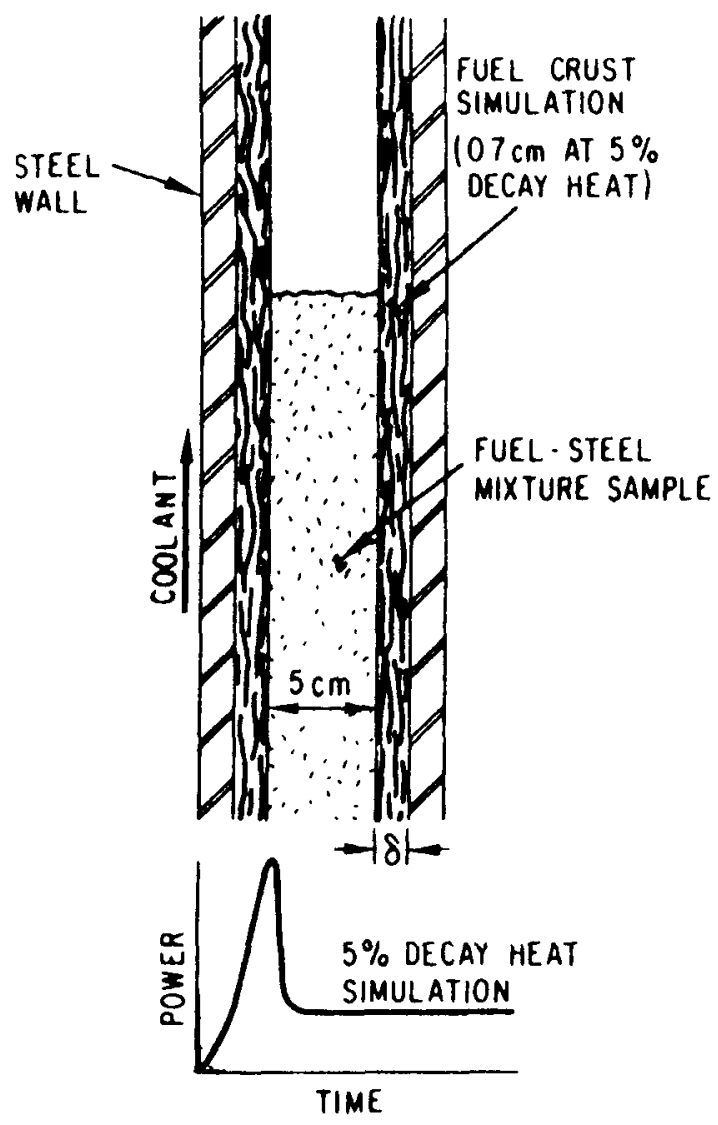

Fig. 9. Proposed In-pile Test Sample for Resolution of Key Recriticality Issues.

It is suggested that the proposed test sample in Fig. 9 can be used as a reference for a test matrix that could include separate effects prooftests of the following nature: 1 ) boilup in an initially open system, including measurements of the rate of fuel dispersal and fuel penetration into the upper simulated blanket and fission-gas plenum regions to verify current analysis; ${ }^{2}, 25$ out-of-pile experiments as they relate to boilup tests with simulant materials; 40 freezing and plugging tests using the thermite method to produce molten fuel; 39 2) the potential for pressure-driven compaction by including the presence of liquid sodium in the simulated blanket and fission-gas plenum regions to verify current analysis and out-of-pile experiments using the thermite method; ${ }^{4}{ }^{1}$ and 3) boilup in a "bottled-up" system, including measurements of potential pressurization and rate of unplugging to verify current analysis and out-of-pile experiments. 12,40

The above proposed test matrix should provide adequate resolution (public acceptance) to the recriticality question for LMFBRs and would not appear to require fuel sample sizes exceeding the capability being provided by the proposed SAREF Program.14,15 
F. Summary

The apparent dispersive nature of oxide fuel and the likely absence of recompaction forces (inherent physical characteristics) can be used to rule out energetic events in case of postulated unprotected accidents leading to major core disruption.

The postulated 1oss-of-heat-sink accident is treated separately, since whole-core disruption appears unavoidable. Here generic considerations suggest that fuel melting is initiated only if the coolant level drops below the core. It follows that the damage potential from a loss-of-heat-sink accident is small even if an energetic recriticality event is postulated, since liquid sodium is not present to transmit the kinetic energy to the vessel head and other critical components.

\section{ACCIDENT ENERGETICS - CARBIDE FUELED LMFBRS}

A. Introduction

As summarized in Table I, Section II, and illustrated in Table IV, the carbide fuels appear less dispersive than the oxide fuels, although the relatively high fission gas retention for the carbide fuel may provide extended

Table IV. Temperature Characteristics for Carbide and Oxide Fuels

\begin{tabular}{lll}
\hline \multicolumn{1}{c}{ Material } & Carbide, ${ }^{\circ} \mathrm{C}$ & Oxide, ${ }^{\circ} \mathrm{C}$ \\
\hline Na coolant boiling temperature & $\sim 950$ & $\sim 950$ \\
Na-bond boiling temperature & $\sim 1150$ (fresh & - \\
C1ad melting temperature & $\sim 1400$ & $\sim 1400$ \\
Fuel melting temperature & $\frac{2400}{2800}$ & $\sim \underline{2800}$ \\
Clad boiling temperature & $\underline{2800}$ & $\sim \underline{2800}$ \\
Fuel boiling temperature & $\sim 4500$ & $\sim 3300$ \\
\hline
\end{tabular}

fuel dispersal as compared to oxide fuel.11 This is because the melting point for the carbide fuel is well above the melting point for the cladding (ruling out the sodium bond as a dispersive agent) and is also well below the boiling point for the cladding material (see Fig. 6), ruling out early dispersal by steel vaporization and, hence, increases the time for fuel mobility relative to oxide fuel. Furthermore, it should be recognized that fuel temperatures associated with extended dispersal $\left(>2800^{\circ} \mathrm{C}\right)$ are such that they no longer preclude the possibility of satisfying the requirements for explosive thermal interactions based upon spontaneous nucleation contact conditions (see Fig. 10). We note that this requirement appears necessary but is not a sufficient requirement by itself for energetic large scale fuel-coolant interactions, and that other characteristics may possibly be present to largely prevent energetic events. 


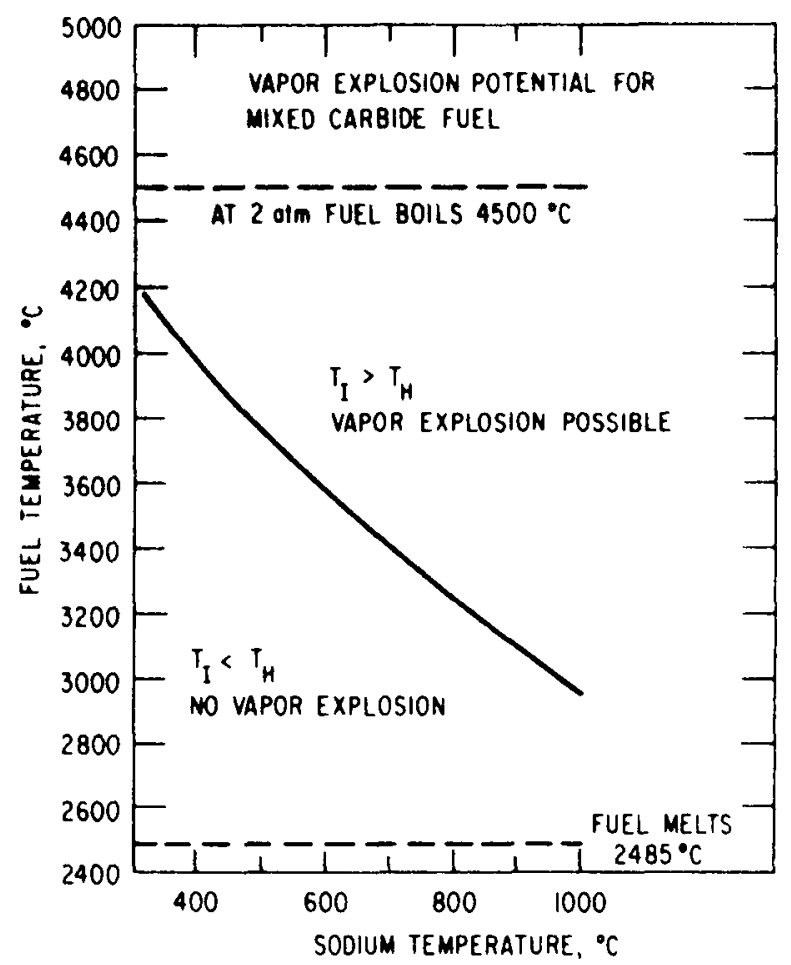

Fig. 10. Illustration of Necessary Temperatures for Carbide Fuels to Cause Spontaneous Nucleation Upon Contact with Liquid Sodium.

\section{B. The Potential for Core Disruption}

1. Fue1-failure Propagation: As for the oxide fuel, favorable conclusions can be made relative to the potential for rapid pin-to-pin propagation as well as blockage propagation. Loss of sodium bond would not appear to be a serious problem, and cladding failures observed during the steady-state irradiation of sodium-bonded elements have not been related to loss of bond. ${ }^{42}$

However, relative to a postulated unprotected subassembly-meltdown accident, the conditions would appear even more unfavorable relative to the potential for subassembly propagation. In particular, we note the concern over fuel-coolant interactions and potential core damage which possibly could lead to reactivity insertion and whole-core involvement.

\section{Loss of Plant-protection Systems}

a. Unprotected TOP: Relative to oxide fuel, the smaller time constant for heat transfer of the high thermal conductivity fuel favors fuel failure toward the top of the active fuel zone, at least in moderate reactivity insertions. However, the increased concern over fuel-coolant interactions for the carbide fuel suggests the possibility of adverse reactivity effects.

b. Unprotected LOF: The increased potential for fuel collapse following initial fuel disruption of carbide fuel (the relatively high retention 
of fission gas for carbide fuel may lead to early dispersal) relative to oxide fuel and the existence of significant potential for pressure-driven recompaction upon achieving extended fuel-dispersal conditions make it more difficult to argue for early termination via limited fuel removal.

\section{Potential for Energetics}

1. Core Disruption at High Power Level: The increased potential for energetic fuel-coolant interaction for the (U, Pu) carbide system in connection with the problem of the positive sodium-void coefficient has been illustrated by some recent Sandia tests. A test series with single pins of 15.24-cm 1ength was carried out under U.S. NRC sponsorship in the ACPR reactor subjected to prompt-burst transients. 43 The oxide-fuel-pin tests confirmed the benign results obtained with the earlier TREAT tests. ${ }^{22}$ However, limited testing with carbide fuel pins subjected to essentially same conditions as the oxide fuel pins in the ACPR resulted in relatively energetic fuel-coolant interactions. 44 This difference may be related directly to the requirement for spontaneous nucleation upon contact in order to establish an energetic interaction. This criterion was likely satisfied in the carbide tests (see Fig. 10). However, it is of interest to note that the efficiency obtained in the carbide tests was considerably lower than the maximum thermodynamic value. ${ }^{7}$ In this regard, it is important to recognize certain inherent features present in the current LMFBR design, including the facts that 1 ) the boiling point of liquid sodium is well below the fuel-clad melting temperature and 2) the time constant for the clad is much larger than the period associated with the nuclear transient of interest (prompt burst). Molten fuel and liquid sodium therefore cannot be both present in the core without being largely separated by solid cladding ${ }^{10}$ (see Fig. 11). This condition could restrict considerably the potential for mixing, although the condition for film boiling, a necessary requirement for intermixing, is satisfied for the carbide system.

On the other hand, an ideal mixing condition for a large-mass, and highly energetic, explosive interaction may be illustrated by considering the final test of the SPERT-I Destructive Series ${ }^{45}$ (see Fig. 12). In this test a violent pressure pulse occurred about $15 \mathrm{~ms}$ after peak power, when the excursion had been self-terminated and the power had returned to a nominal level. The pressure pulse, which destroyed the reactor core, was attributed to "a selfpropagating steam explosion that resulted from the dispersal of the molten fuel plates (Al/U alloy) into the water throughout the core." 45 An analysis of the power trace indicated that approximately $12 \mathrm{l}$ of steam void were present in the core at the time of the observed steam explosion. If it is assumed that the fuel plates were uniformly blanketed by the void volume, it is seen that at the time of the explosion, 1.5-mm-thick molten fuel plates (in the SPERT-ID excursion, the thermal response time of the aluminum cladding was about $1 \mathrm{~ms}$, and it is believed that the cladding melted during the nuclear transient while the water coolant underwent film boiling) were interleaved with 3-mm-thick water layers with a $0.6-\mathrm{mm}$-thick intervening vapor layer between them. Thus, the premixing situation for the postulated LMFBR accident is different from that for the SPERT-ID excursion* in that the molten fuel is separated from liquid sodium

*It is widely believed that similar steam explosions occurred in the BORAX-1 destructive test ${ }^{46}$ and in the SL-1 accident. 47 


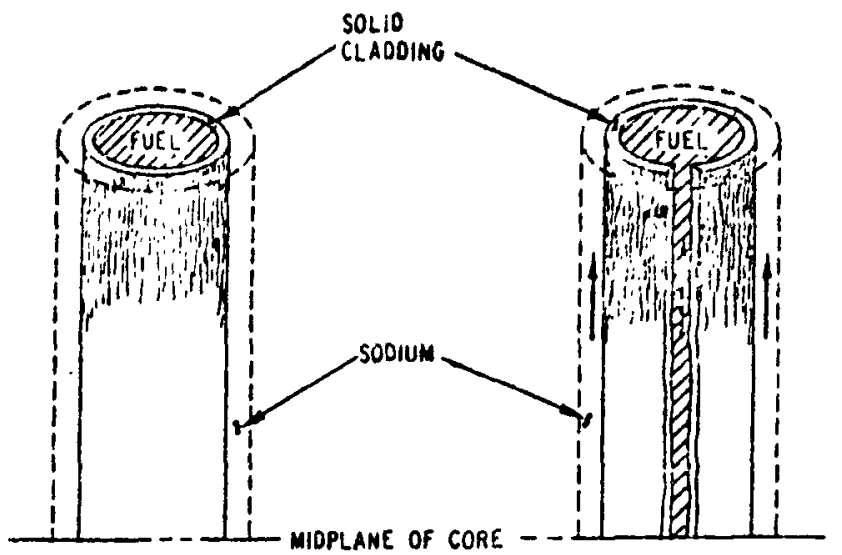

BEFORE FAILUAE
AFTER FAILURE
PROMPT RIIRST PERION 11 MSEC

ACOUSTIC RELLEF TIME थSEVERAL MSEC

CLADDIMG TIME CONSTANT ? TENS OF MSEC
Fig. 11 .

Illustration of an LMFBR Fuel Pin and Its Anticipated Behavior Near Prompt-critical Conditions with Sodium In, Showing that Presence of Molten Fuel and Liquid Sodium in the Core Always Requires the Presence of Solid Cladding.

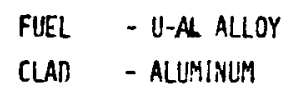

COOLANT - WATER

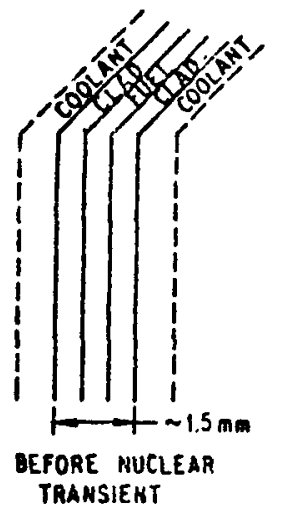

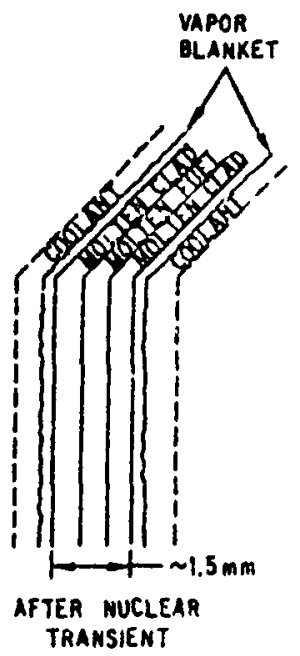

FERIOD 3 MSEC

CLAD TIME CONSTAMT I I MSEC

CLADDING MELTING POINT $2620^{\circ} \mathrm{C}$

CLADDING THERILLL CONOUCTIVITY/COOLANT THERMAL CONDILCIIVITT 4 SO

$T_{1}>T_{s} \rightarrow$ FILM BOILING
Fig. 12 .

Illustration of a SPERT-I Fuel Element and Its Behavion Following the Nuclear Transient in Run 54, Showing that Molten Fuel and Molten Clad Can Be Present in the Core Together with Liquid Water and These Are Only Separated by Thin Vapor Blankets. These conditions according to current understanding favor a highly energetic steam explosion. 
by a solid steel layer, not by a vapor layer. This difference would appear to be fundamentally important in producing highly energetic interactions.

However, the most significant difficulty in assessing the coredisassembly energetics for high-thermal-conductivity carbide fuels is likely to be associated with external pressure-driven compaction. If a high-thermal conductivity carbide core undergoes a mild disassembly, then conditions favorable for a pressure-driven recompaction induced by a fuel-coolant interaction -- on a scale much less than the whole core -- are present and must be considered along with potential barriers to this possibility.

2. Core Disruption at Low Power Level: The arguments made for oxide fuel should also apply to the carbide system (see section III, B.2). However, the increased potential for fuel-coolant interactions should be noted.

\section{Resolution of Key Issues}

The test facilities being planned for oxide fuel14,15 should also be adequate for carbide fuel. However, considerably more detailed testing may be required for the carbide fuel in view of relatively unfavorable safety characteristics as compared to the oxide fuel. A summary of desirable experiments in terms of key issues and facilities is given in Table $\mathrm{V}$.

\section{E. Summary}

The apparent lack of timely and extended fuel-dispersal characteristics and the relatively large potential for explosive fuel-coolant interactions make it more difficult to argue for a nonenergetic core-meltdown situation for the carbide system when compared to the oxide system.

\section{ACCIDENT ENERGETICS - METAL FUELED LMFBRS}

\section{A. Introduction}

As summarizer in Table I, Section II, the (U,Pu) metal fuel appears to have the potential of satisfying all the desirable safety characteristics relative ti accident energetics. As illustrated in Table VI, sodium-bond vaporization would appear available to disperse the fuel when it becomes molten, assuming the cladding material remains intact so as to prevent escape of the sodium bond prior to fuel melting. The latter condition would appear to be assured since the rates of cladding penetration upon exceeding the eutectic temperature for the metal-clad alloy is relatively slow compared to the time scale for unprotected transients of interest (see Table VII). It should also be noted that upon exceeding the melting temperature of fuel, penetration becomes very rapid, allowing the sodium to disperse the fuel in a relatively short period. (This favorable fuel dispersal characteristic would not appear to be available for the thorium based metal fuel since the fuel melting temperature is somewhat higher than the clad melting temperature - see Fig. 6). 
○

Table V. Experimental Resolution of Key Issues - Carbide Fuels

\begin{tabular}{|c|c|c|c|c|c|}
\hline $\begin{array}{c}\text { FUEL } \\
\text { FAILURE } \\
\text { PROPAGATION }\end{array}$ & & 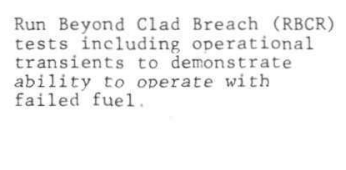 & & & 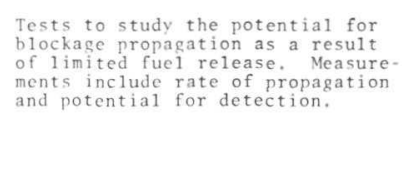 \\
\hline $\begin{array}{l}\text { LIMITED } \\
\text { CORE } \\
\text { DAMAGE }\end{array}$ & 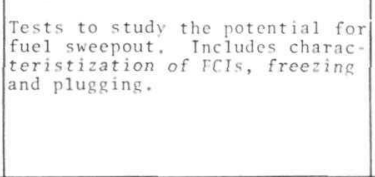 & & 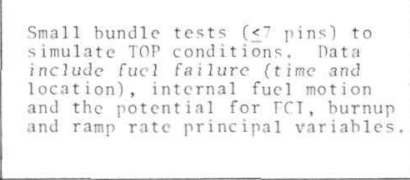 & 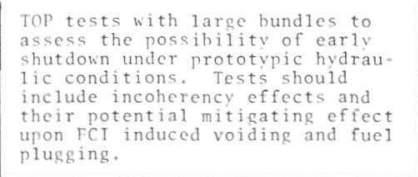 & $\begin{array}{l}- \text { Top tests with smal1 ramp rates } \\
(<10 \leftarrow / s) \text { desirable. }\end{array}$ \\
\hline $\begin{array}{l}\text { ENERGETICS } \\
\mathrm{Na} \mathrm{VOID}\end{array}$ & & & 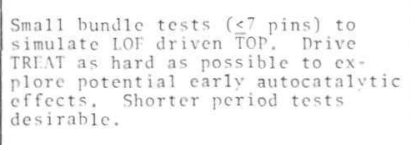 & $\begin{array}{l}\text { Lareer bund 1e tests desirable to } \\
\text { expiore incoherence effects. }\end{array}$ & \\
\hline $\begin{array}{l}\text { ENERGETICS } \\
\text { RECRITICALITY }\end{array}$ & & & 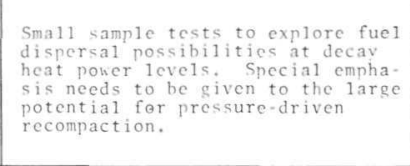 & 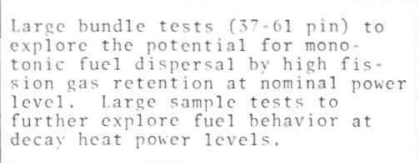 & \\
\hline $\begin{array}{l}\text { LOSS OF } \\
\text { HEAT SINK }\end{array}$ & & & & & \\
\hline
\end{tabular}


Table VI. Temperature Characteristics for the Metal Fuel

Material Temperature, ${ }^{\circ} \mathrm{C}$

Na coolant boiling temperature

Na-bond boiling temperature

Fuel melting temperature

Clad melting temperature $\sim 950$

1150 (fresh fue1 - can be regulated by fuel pin fill pressure)

$\sim \underline{1150}$

$\sim 1400$

Table VII. Cladding Penetration Rates above the Eutectic Temperature for (U,Pu) Metal $(10 \mathrm{w} / 0 \mathrm{Zr}$ ). (Inferred from results obtained on the $\mathrm{U}-5 \mathrm{wt} \%$ Fs/SA 304 stainless-stee1 system). ${ }^{8}$

\begin{tabular}{|c|c|}
\hline Temperature, ${ }^{\circ} \mathrm{C}$ & Rate, mils/min \\
\hline$\sim 800$ & $\sim 0.1 \leftarrow$ eutectic temperature \\
\hline$\sim 900$ & $\sim 0.5 \leftarrow \mathrm{Na}$ boiling temperature \\
\hline$\sim 1020$ & $\sim 3.0$ \\
\hline$\sim 1100$ & $\sim 8.0$ \\
\hline$\sim 1150$ & $10 \mathrm{mils} / \mathrm{s} \leftarrow$ fuel melting temperature \\
\hline
\end{tabular}

Furthermore, following 25-30\% fuel swelling, interconnection of porosity occurs. ${ }^{8}$ As a result of the interconnected porosity, substantial fission-gas release occurs $(\sim 60 \%)$, and it allows the thermal-bond sodium to move into the porous fuel and $\log$ it. ${ }^{8}$ Because of the excellent wetting characteristics between metal and sodium, the ability of sodium to penetrate the cracks increases with decreasing crack size. This effect also increases the effective boiling point for the liquid sodium. This entrapped sodium is not only expected to provide early and prompt dispersal ${ }^{8}$ but is likely to provide extended fuel dispersal because of the large liquid-to-vapor density ratio for liquid sodium. Flow-regime boundaries associated with dispersal for the metal-sodium system are shown in Fig. 13 relative to the oxide-steel system. Because of the order-ofmagnitude increase in the ratio of metal-fuel density to the sodium-vapor density relative to the oxide-steel vapor system, fuel dispersal with the metal should be more effective at low power levels than with the oxide system. It follows that the concern over energetic fuel-coolant interactions is considerably decreased if the sodium bond is effective in permanently dispersing the fuel, since the melting temperature of the fuel is only slightly above the boiling point of the coolant. Again we note the higher melting point for thorium based metal fuel which is likely to remove the sodium bond as a potentially effective dispersive agent, and hence brings about the same concerns as for the carbide based fuels. 


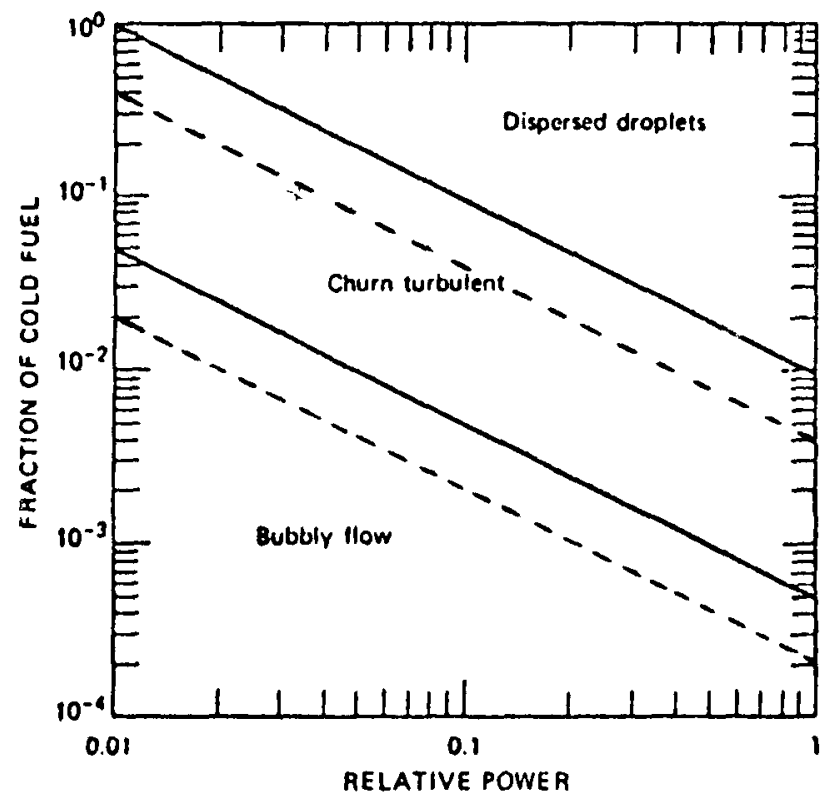

Fig. 13. Illustration of Flow-regime Boundaries Associated with Extended Fuel Dispersal. Solid and open lines represent oxide-steel and metal fuel-sodium systems, respectively, assuming equivalent power generation per unit mass of fuel.

\section{B. The Potential for Core Disruption}

1. Fue1-failure Propagation: As for the oxide fuels, rapid pin-to-pin propagation can be precluded and slow propagation (blockage propagation) is not expected, but it still remains to be verified. Based upon considerations of loss of the sodium bond, direct release of molten fuel appears very unlikely, ${ }^{8}$ and if arbitrarily postulated, the potential for energetic interaction with the coolant appears low. The existence of the eutectic alloy between the metallic fuel and stainless steel cladding must be taken into account in the evaluation. Slow attack of cladding material may occur for $\mathrm{T}>800^{\circ} \mathrm{C}$ (see Table VII), increasing the potential for slow blockage propagation. However, recent improved understanding relative to fluid mechanics and heat transport associated with various blockage types suggests that incredible blockages must be postulated in order to exceed the eutectic temperature of fuel. ${ }^{20}$ As an example, $30 \%$ of the subassembly flow area would have to be blocked by an internal planar blockage in order to exceed $800^{\circ} \mathrm{C}$ in the downstream wake of the blockage. Such a blockage would be considered incredible in a wire-wrapped bundle.

Finally, as for oxide fuel, in the case of a postulated unprotected subassembly-meltdown accident, propagation becomes difficult to rule out. The problem of thermal propagation is enhanced by the formation of a low-temperature eutectic. However, this effect may be canceled by the decreased potential for fuel plugging as noted below. 


\section{Loss of Plant-protection Systems}

a. Unprotected TOP: The small time constant associated with metal fuel ( $0.5 \mathrm{~s}$ as compared to 3-4 $\mathrm{s}$ for oxide fuel) and the low melting temperature should assure fuel disruption at the top of the active fuel zone, at least for moderate reactivity insertions, thereby resulting in neutronic shutdown. The possibility of such fuel removal without the occurrence of cladding breach deserves further attention. The absence of fuel-coolant interaction also favors early shutdown with metal fuel. In particular, we note that the sodium vapor pressure corresponding to the metal-fuel melting temperature is less than the core inlet pressure.

b. Unprotected LOF: Early termination for metal fuel may also be possible for the loss-of-flow accident. Again there exists the possibility of fuel relocation by fission gas release and early shutdown without significant fuel failure. The low eutectic temperature may become a problem, however, in assuring intact cladding geometry.

\section{Potential for Energetics}

1. Core Disruption at High Power Levels: If effective fuel dispersal by sodium-bond vaporization can be demonstrated, the conditions for benign core meltdown would appear even more favorable than for the oxide system. In particular the low melting temperature of the fuel suggests early disruption and dispersal so as to essentially mitigate any positive reactivity addition due to sodium voiding, thereby preventing prompt-burst conditions.* [Note that this is of no concern for the ${ }^{233} \mathrm{U}$-fuel type (see Fig. 5)]. The time from fuel-pin dryout to fuel disruption for the metal fuel is estimated to be $\sim 1.0 \mathrm{~s}$ as compared to $4-5 \mathrm{~s}$ for the oxide fuel under loss-of-flow conditions. This is a particularly important point, because if large reactivity insertion rates at prompt-critical conditions were likely with the metal fuel, the potential exists for developing a significant work potential due to the presence of sodium bond.

2. Core Disruption at Low Power Levels: As indicated in Section III, B.2, sodium boiling is expected to be stable at decay-heat power levels, i.e., extended dryout will not occur. However, since the eutectic alloy temperature for the fuel-clad is less than the sodium boiling temperature, fuel disruption may take place despite the presence of liquid sodium. In this case extended sodium vaporization may be available to mitigate fuel collapse and hence, energetic recriticalities. In particular, the large density ratio of metal fuel to sodium vapor may provide effective dispersal at relatively low power levels. This is particularly the case, if foaming should be the prevailing flow regime. 25

\footnotetext{
* Since in unprotected loss-of-flow accidents, the sodium boiling temperature represents the upper limit of operation prior to ultimate fuel disruption for a11 fuel types, the low melting temperature associated with metal fuel should not be interpreted as leading to any higher probability for fuel disruption than for the higher melting oxide and carbide fuels.
} 


\section{Resolution of Key Issues}

Safety test facilities being planned for testing oxide fuel ${ }^{14,15}$ should also be adequate for providing resolution to key issues associated with metal fuels. Because of the much lower melting temperature of metal fuel relative to oxide fuel, the demand for a large test-sample size may be considerably reduced. Early fuel-dispersal characteristics for the metal fuel also suggests less demand on safety test facilities relative to short-period testing. Recommended near-term tests in terms of key issues and facilities are summarized in Table VIII. The magnitude of projected R\&D efforts to resolve the key safety issues associated with the metal fuel is not considered to be significantly different than that required for the oxide fuel. This is because the already existing data base and analytical capability for the oxide fuel is largely offset by the reduced demand on safety test facilities for the metal fuel.

\section{E. Summary}

Since desirable safety characteristics (early fuel dispersal and absence of fuel-coolant interactions) appear to be provided by the sodium-bonded meta1fuel system, benign core-meltdown characteristics relative to both unprotected accidents and postulated loss-of-heat-sink accidents are suggested.

\section{POSTACCIDENT HEAT REMOVAL - OXIDE, CARBIDE, AND METAL FUELED LMFBRs}

In the absence of an energetic CDA, breach of the engineered barriers may also be postulated to result from thermal meltthrough due to continued decay heat generation.* There are three general categories of approaches to postaccident heat removal, including: ${ }^{4}$ (1) in-vessel retention, (2) ex-vessel retention, and (3) inherent retention in concrete. In this section, each approach is reviewed briefly relative to the effects of fuel type on postaccident heat removal and core debris accommodation.

\section{A. In-vessel Retention}

Successful in-vessel fuel debris retention requires availability of longterm heat removal systems. If such systems can be assured (this is not the case in the loss-of-heat-sink accident), effective heat removal from the fuel may be argued if sufficient surfaces are (or made) available. The ejected fuel debris from the core (formed either by the dispersal process as discussed earlier or upon quenching in sodium ${ }^{49}$ ) would be expected to settle on horizontal surfaces to form particulate beds. The stability of a particulate bed on a horizontal surface depends primarily on the ability to transfer the internally generated heat upward to the overlying sodium by conduction and/or boiling. In the case of heat removal by sodium vaporization, fuel properties are likely to be a second order effect. However, we note that this form of heat removal may not

*In this case radioactive release will occur at a relatively later time, and it has been argued ${ }^{48}$ that the potential harm to the environment is not greatly different from that which could arise from a core meltdown accident in a light water reactor of the same size. 
Table VIII. Experimental Resolution of Key Issues - Metal Fuels

\begin{tabular}{|c|c|c|c|c|c|}
\hline ISSUE & CAMEL & EBR-II & TREAT & TREAT-UPGRADE & SLSF \\
\hline $\begin{array}{c}\text { FUEL } \\
\text { FAILURE } \\
\text { PROPAGATION }\end{array}$ & $\begin{array}{l}\text { Tests to study the potential } 1 \text { for fuel sweepout under TOP } \\
\text { fydraulic conditions. }\end{array}$ & 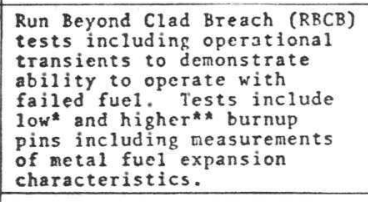 & & & 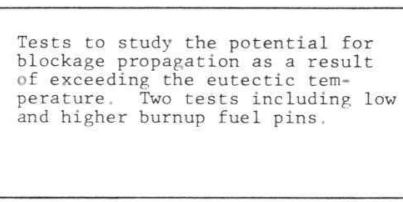 \\
\hline $\begin{array}{l}\text { LIMITED } \\
\text { CORE } \\
\text { DAMAGE }\end{array}$ & & & $\begin{array}{l}\text { TOP and LOF tests to demonstrate } \\
\text { that metal fuel favors top fuel } \\
\text { renoval and ear1y shutdown. } \\
\text { Tests include low and hidher } \\
\text { burnup pins including fuel pins } \\
\text { with upper blanket removed. }\end{array}$ & 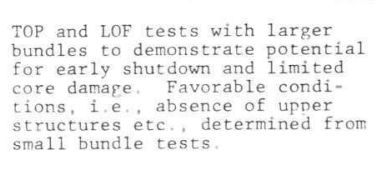 & 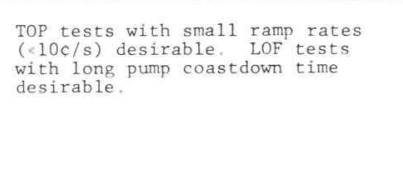 \\
\hline $\begin{array}{l}\text { ENERGETICS } \\
\mathrm{Na} \mathrm{VOID}\end{array}$ & & & 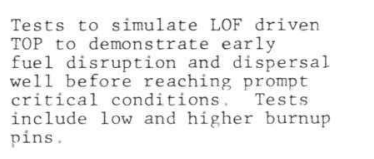 & $\begin{array}{l}\text { Larger bundle tests for further } \\
\text { demonstration. }\end{array}$ & \\
\hline $\begin{array}{l}\text { ENERGETICS } \\
\text { RECRITICALITY }\end{array}$ & & & 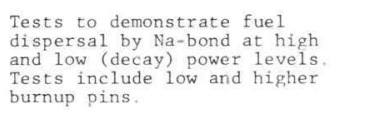 & $\begin{array}{l}\text { Larger bundle tests for further } \\
\text { demonstration. }\end{array}$ & \\
\hline $\begin{array}{l}\text { ENERGETICS } \\
\text { FUEL- COOLANT } \\
\text { INTERACTIONS }\end{array}$ & & & & & \\
\hline $\begin{array}{l}\text { LOSS OF } \\
\text { HEAT SINK }\end{array}$ & & & & & \\
\hline
\end{tabular}

* Wow burnup refers to insufficient swelling; large fission gas retention in fuel

**Higher burnup refers to sufficient swelling resulting in large fission gas release
and sodium-1ogged fuel pins. 
be applicable to the metal fuel unless a refractory metal or another system is installed in the vesse1, since the eutectic temperature between metal fuel and steel is less than the boiling point for sodium. On the other hand, for conduction controlled heat removal, on the basis that subcooled sodium is present, coolable bed loadings are increased by a factor of $n 3$ for the metal fuel relative to the oxide fuel, and becomes equivalent to coolable bed loadings obtained with boiling. Therefore, based upon avai ıbility of a long-term decay heat removal system, we conclude that no sign, cant differences are anticipated relative to in-vessel heat removal considerations.

\section{B. Ex-vessel Retention}

For sma11 reactors, such as FFTF, it has been shown to be very likely that the core debris would achieve a coolable configuration within the reactor vessel, and the core debris would remain stable as long as heat removal from the reactor vessel continued. 49 However, for larger reactors in the absence of explicit core-debris retention devices* (example, CRBR), in-vessel coolability arguments become difficult. ${ }^{49}$ The most likely reason for failure of the reactor vessel would be because of the gradual buildup of fuel debris to depth exceeding dryout limits. Following failure of the reactor vessel bottom, the flow of core debris into the reactor cavity is anticipated to occur almost simultaneously with the flow of sodium from the vessel. If the reactor cavity is converted into a cooled crucible** (active system) as recommended in Ref. 51, metal/carbide/oxide is order of fuel preference because increased conductivity will keep the temperature lower.

Passive core debris retention devices also appear feasible based upon the reactor cavity bed concept, where the major portion of the decay heat would be removed by vaporization of sodium. ${ }^{49}$ If sodium refluxing could be established (would appear feasible), this method could provide long-term stability of the core debris without active cooling. In the case of a magnesia bed, the metal fuel has a potential advantage because of the lower melting point and higher conductivity; however, complicating factors such as transference of oxidic fission products to ceramic phase could convert the main heat source into an oxide ceramic and become similar to the oxide fuel case. The carbide fuel has disadvantage of possible carbon monoxide gas release, and in the case of air or water influx chemical heat release would result for the metal and carbide fuels. For a graphite-bed concept, the metal and carbide fuel would appear to have advantage over oxide fuel since no carbon monoxide will be generated. In summary, it would appear therefore, that the metal fuel has a potential advantage because of the lower melting point and higher conductivity if question over oxidic fission product migration can be solved by material and design studies.

\section{Inherent Retention in Concrete}

The current CRBRP approach suggests that an explicit core-debris retention system (active or passive) in the reactor cavity is not necessary because of the

\footnotetext{
*Pool-type reactors are particularly well-suited for in-vessel retention of core debris because of the greater area available for the installation of a tray or system of trays (example: Super-Phenix reactor and the British PFR). 50

$* *$ The current design of the German SNR-300 reactor includes a cooled corecatcher tank in the cavity. 50
} 
inherent retention capability of the base mat (concrete) below the reactor cavity. ${ }^{9}, 50$ However, it has been found necessary to include a number of engineered systems which are needed mostly to deal with the release of gases from the concrete base which comes under attack from the heat-generating core debris. These include a containment purge system to prevent hydrogen-oxygen detonation, containment vent and cleanup systems to prevent excessive pressure from developing and an annulus cooling system is provided which assures structural integrity of the containment-confinement system. In this approach, the oxide fuel would appear to have moderate advantage over metal and carbide fuel types because no additional heat or gas are generated by fuel reactions; carbide will be converted to oxide with evolution of heat and carbon monoxide gas and metal will be converted to oxide with evolution of heat and hydrogen gas.

In summary, the apparent advantage offered by a given fuel type relative to postaccident heat removal and core-debris accommodation would appear to depend on the selected approach. Based upon ex-vessel coolability arguments with an explicit core retention device (passive or active), the metal fuel has a potential advantage if question over oxidic fission product migration can be solved by material and design studies. However, in the case of the inherent retention approach a moderate advantage appears with the oxide fuel relative to carbide and metal fuel types.

\section{GCFR CONSIDERATIONS}

\section{A. Introduction}

In this study the alternative fuels considered for the GCFR are all oxide fuels. ${ }^{2}$ As such, no significant differences in safety implications relative to the reference ( $\mathrm{U}, \mathrm{Pu}$ ) oxide fuel are noted, since the property characteristics of uranium and thorium based oxide fuels are quite similar as discussed earlier in this report. The comments provided below therefore apply equally well to both the $(\mathrm{U}, \mathrm{Pu})$ oxide and the alternative fuel types.

\section{B. Accident Energetics}

Relative to CDA prevention, the GCFR design would put similar demands upon required response of the plant-protection system as the LMFBR design, since the Doppler coefficient in the two systems are similar. In regard to shutdown decay heat removal, we note that the GCFR coolant requires forced circulation to remove decay heat as compared to the LMFBR coolant where natural convection alone may be adequate. Furthermore, the high pressure associated with the GCFR design would appear to lead to less favorable dispersal characteristics of the oxide fuels. This is because the cladding material no longer provides a timely vapor source at elevated pressures at the time of fuel disruption as would appear to be the case for the low pressure LMFBR oxide design.

Relative to CDA consequences, the GCFR design offers the advantages of essentially eliminating the positive void coefficient problem and completely eliminating the question of energetic fuel-coolant interactions, two major safety concerns in the LMFBR design.

Relative to the potential of gravity driven recriticalities occurring in the GCFR design, three classes of initiators are generally considered: ${ }^{52,53}$ 
1) loss of coolant flow with scram, 2) loss of coolant flow or depressurization without scram, and 3) transient overpower without scram. The first two classes of initators generally result in whole-core involvement, but nominal estimates suggest that the mechanical work from such events is orders of magnitude smaller than the strength of the prestressed concrete reactor vesse1 (PCRV). $53,54 \%$ The general behavior expected in the transient overpower without scram accident is very similar to that of LMFBR (see Section III), i.e., limited fuel removal leading to neutronic shutdown appear likely. The potential for either mechanical work or fuel aerosol generation in such an accident is therefore believed to be sma11. 53,54

\section{Postaccident Heat Remova1}

In view of the strength of the PCRV and the unlikelihood of generating energetic recriticality events, ${ }^{53}$ the question of long-term coolability of fuel debris would appear to be the central issue relative to CDA consequences in the GCFR. Here we note that cooling of postaccident fuel debris in a GCFR appears to be feasibly done within the reactor vessel. The reactor vessel employs coolant coils around the entire reactor cavity with the purpose of keeping the concrete sufficiently cool during normal operation. This coolant system, with a certain amount of increased capacity, particularly in the lower regions of the core cavity, may prevent meltthrough at the bottom of the reactor vessel. A significant amount of the total decay heating from the debris would be radiated upward and received by the cooled walls of the reactor cavity, by the radial blanket and radial shields, and by the gridplate at the top of the reactor cavity. The large heat capacity of these overlying structures would permit absorption of heat in a heat capacity mode, i.e., without melting for many hours following an accident.

\section{Resolution of Key Issues}

The safety test facilities available or are being planned for LMFBR oxide fuels should also be adequate for GCFR oxide fuels. Furthermore, some of the work which has been done or is being planned in the LMFBR program finds direct application in the GCFR program. We note that certain further in-pile testing on accident features unique to a GCFR are required. However, because of the close similarity of behavior of accidents for a wide range of sizes of GCFRs and the absence of positive void and fuel-coolant interaction problems, a rather smaller total testing program than that required for the LMFBR should be possible.

\section{E. Summary}

In the case of the GCFR design, no significant differences in safety implications are noted for the alternatives considered, since the property characteristics of oxide fuels are quite similar. Relative to LMFBRs, GCFR designs offer the advantages of essentially eliminating the positive void coefficient

*It is important to note that the strength of the PCRV is considerably greater than for the current LMFBR vessel designs, and that in the GCFR design the absence of a largely incompressible coolant as compared to the LMFBR makes it much more difficult to couple the structural components to the potential energy source. 
problem and completely eliminating the fuel-coolant thermal interaction problem, but the high pressure and the use of gas coolant provides for less favorable fuel dispersal characteristics and inability to remove decay heat by natural convection.

\section{CONCLUSIONS}

The above evaluation dealing with the effects of fuel type on safety considerations is based upon the assessment that besides accident prevention, core-disruptive accidents and accident energetics in particular, will continue to represent the key safety issues in the licensing of the fast breeder reactors. With this as a guideline, the following conclusions are made relative to fuel type and licensability:

- Relative to accident prevention, no significant safety implications of other fuel types relative to the reference (U,Pu) oxide fuel appear to be present. The lower Doppler coefficient of the metal fuel is offset at least to a certain extent by a more reliable and better characterized axial-expansion coefficient of reactivity for the metal fuel. However, for highly-irradiated, swollen fuel there is a question as to whether the clad would restrain this expansion.

- Relative to CDAs and the case for benign accident energetics, the strongest case can be made for the oxide fuel. This is based upon both favorable dispersal characteristics and absence of energetic fuel-coolant interaction together with a rather extensive available data base for this fuel type.

- There are increased safety concerns with the carbide fuels, because of less favorable characteristics relative to timely fuel dispersal and fuel-coolant interactions, as compared with the oxide fuel types. In particular, the potential for a pressure-driven recriticality event would appear to be more difficult to rule out for this fuel type.

- If extended fuel dispersal by sodium bond vaporization can be demonstrated, the (U,Pu) metal fuel appears at least as favorable as the oxide fuels relative to the generic accident energetics issues (recriticality and fuel-coolant interaction). Some less likely phenomenon would be required like extensive fuel slumping to raise the fuel temperature sufficiently to achieve an explosive fuel-coolant thermal interaction condition. For the thorium-based metal fuel, the dispersive potential appears less favorable. In this case the safety concerns become similar to that noted for the carbide fuels.

- On the other hand, for (U,Pu) metal fuel, the sodium void coefficient tends to be more positive than for oxide and carbide. If in some way a large positive reactivity ramp rate could be introduced before the fuel was molten, the possibility would exist for significant conversion of fuel thermal energy to work by the sodium bond. It is also only for very high ramp rates that the lower Doppler coefficient 
for the metal fuel may become a problem. In regard to the sodium void effect in general, the void coefficient is much smaller in ${ }^{23} \mathrm{U}$ fueled systems which largely eliminates the incentive for heterogeneous cores.

- Based upon ex-vessel postaccident heat removal approach with an explicit core retention device (passive or active), the metal fuel would appear to have advantage because of its low melting point and high thermal conductivity, if question over oxidic fission product migration can be solved by material and design studies. With the inherent retention in the concrete approach, a moderate advantage appears with the oxide fuel because of no additional heat or gas are generated by fuel reactions.

- While the existing data base is considerably less for metal fuels, the magnitude of effort required to resolve key safety issues for the oxide and metal fuel types is considered to be about the same. This is because the lack of data base for the metal fuels is 1argely offset by less demand on safety test facility requirements. Relative to carbide fuels more detailed analysis and testing may be required in view of less favorable safety characteristics as compared to the oxide fuels. The test facilities being planned for oxide fuels should also be adequate for carbide fuels.

In the case of the GCFR design, no significant differences in safety implications are noted for the alternatives considered, since the property characteristics of oxide fuels are quite similar. Relative to LMFBRs, GCFR designs offer the advantages of essentially eliminating the positive void coefficient problem and completely eliminating the fuel-coolant thermal interaction problem, but the high pressure and the use of gas coolant provides for less favorable fuel dispersal characteristics and inability to remove decay heat by natural convection.

\section{ACKNOWLEDGMENTS}

Many individuals have contributed comments and technical suggestions throughout the preparation of this report including: R. Avery, W. P. Barthold, Y. I. Chang, D. H. Cho, L. W. Deitrich, M. Epstein, D. R. Ferguson, G. H. Golden, M. A. Grolmes, R. E. Henry, J. R. Honekamp, P. R. Huebotter, J. H. Kittel, J. F. Marchaterre, D. Rose, J. I. Sackett, and C. E. Till. The author is particularly grateful to the many valuable suggestions and clarifications made by P. B. Abramson, P. L. Garner, and H. H. Hummel during their extensive review of the report, and the technical contributions provided by L. Baker, Jr. and R. H. Sevy in the areas of postaccident heat removal and GCFR considerations, respectively. 


\section{REFERENCES}

1. C. E. Till, Forword to this report.

2. Y. I. Chang and C. E. Till, Reactor Design and Performance Characteristics of Altermative Fuels and Fuel Cycles, Part 2 of this report.

3. J. H. Kittel et a1., Status of Fuels and Materials Development, Part 3 of this report.

4. J. D. Griffith et a1., U. S. Approach to LMFBR Risk and Safety R\&D Cost Benefit Assessment, see Brusse1s Conf. Proc. ENS/ANS Int. Topical Mtg. on Nuclear Power Reactor Safety, Brussels, Belgium, October 16-19, 1978.

5. D. R. Ferguson et a1., The SAS4A LMFBR Accident Analysis Code System: A Progress Report, Proc. Fast Reactor Safety and Related Physics, CONF761001, Chicago, I11inois, October 5-8, 1976.

6. N. P. Wilburn, Comparison of SAS3A and MELT-III Predictions for a Transient Overpower Hypothetical Accident, Proc. Fast Reactor Safety and Related Physics, CONF-761001, Chicago, Illinois, October 5-8, 1976.

7. L. L. Smith et a1., SIMMER-I, An LMFBR Dismuted Core Analysis Code, Proc. Fast Reactor Safety and Related Physics, CONF-761001, Chicago, I1linois, October 5-8, 1976.

8. C. M. Walter, G. H. Golden, and N. J. Olson, U-Pu-Zr Metal AZZoy: A Potential Fuel for LMFBRs, ANL-76-28, Argonne National Laboratory, November 1975.

9. F. E. Dunn, Fuel Pin Coolability in Low Power Voiding, Trans. Am. Nuc1. Soc., 28, 1978 .

10. H. K. Fauske, The Role of Core Dismuptive Accidents in Design and Licensing of LMFBRs, Nuclear Safety, 17(5), September-October 1976.

11. J. F. Kerrisk, Experience Related to the Safety of Advanced LMFBR Fuel Elements, LA-6028, November 1975.

12. H. K. Fauske, Assessment of Accident Energetics in LMFBR Core-dismptive Accidents, Nuclear Eng. \& Design, 42, 19, 1977.

13. S. J. Board and L. Caldarola, "Fuel-Coolant Interactions in Fast Reactors," Thermal and Hydraulic Aspects of Nuclear Reactor Safety, Volume 2: Liquid Metal Fast Breeder Reactors, The American Society of Mechanical Engineers, 1977 .

14. R. Avery et a1., The SAREF Program, Proc. Fast Reactor Safety and Related Physics, CONF-76001, Chicago, Illinois, October 5-8, 1976.

15. M. A. Grolmes et al., In-pize Experiments and Test Facizities Proposed for Fast Reactor Safety, Proc. Fast Reactor Safety and Related Physics, CONF-761001, Chicago, Illinois, October 5-8, 1976. 
16. H. A. Bethe and J. H. Tait, An Estimate of the Order of Magnitude of the Explosion When the Core of a Fast Reactor Colzapses, UKAEA-RHM (56)/113, 1965.

17. E. P. Hicks and D. C. Menzies, Theoretical Studies on the Fast Reactor Maximum Accident, Proc. Safety, Fuels and Core Design in Large Fast Power Reactors, ANL-7120, Argonne National Laboratory Report, 1965.

18. J. E. Boudreau and J. F. Jackson, Recriticality Considerations in LMFBR Accidents, Proc. Fast Reactor Safety Meeting, CONF-740401-P3, Apri1 2-4, 1974, Beverly Hills, California.

19. Final Safety Analysis Report, Fast Flux Test Facility, October 1976.

20. H. K. Fauske, M. A. Grolmes, and S. H: Chan, Assessment of Fuel Failure Propagation in LMFBRs, Proc. Fast Reactor Safety and Related Physics, CONF-761001, Chicago, Illinois, October 5-8, 1976.

21. N. P. Wilburn et al., An Updated Assessment on the Unprotected Transient Overpower Accident in the FTR, HEDL-T1 75285, October 1977.

22. C. E. Dickerman et al., Status and Surmary of TREAT In-pile Experiments on IMFBR Response to Hypothetical Core-dismptive Accidents, Symp. on the Thermal and Hydraulic Aspects of Nuclear Reactor Safety, Vol. 2: Liquid Metal Fast Breeder Reactors, edited by O. C. Jones, Jr. and S. G. Bankoff, ASME publication, 1977.

23. G. H. Golden, Elementary Neutronics Consideration in LMFBR Design, ANL-7532, Argonne National Laboratory, 1969.

24. H. K. Fauske and D. R. Ferguson, An Updated Assessment of the Unprotected Loss-of-flow Accident in the FTR, ANL/RAS 77-42, October 1977.

25. M. Epstein and D. W. Condiff, Foom Flow Regime in a Volume Heated Boiling Pool, ANL/RAS 77-34, October 1977.

26. CRBRP Risk Assessment Report, Vol. 1, Main Report, CRBRP-1, March 1977.

27. W. D. Hinkle, Water Tests for Determining Postvoiding Behavior of the LMFBRs, MIT-EL 76-005, June 1976.

28. J. F. Jackson and R. B. Nicholson, VENUS-II: An LMFBR Disassembly Program, ANL-7951, Argonne National Laboratory, September 1972.

29. D. H. Cho, M. Epstein, and H. K. Fauske, Work Potential Resulting from a Voided-core Disassembly, Trans. Am. Nuc1. Soc., 18, 220, June 1974.

30. S. H. Fistedis et al., Fast Reactor Containment Analysis, Recent Improvements, Applications, and Future Developments, Proc. Fast Reactor Safety, Beverly Hills, California, Apri1 1974, CONF-740401-P2, Vo1. 2, 763-782.

31. J. F. Marchaterre et a1., Work Energy Characterization for Core-dismuptive Accidents, Proc. Fast Reactor Safety and Related Physics, CONF-761001, Chicago, Illinois, October 5-8, 1976. 
32. S. J. Board, R. W. Hall, and R. S. Hall, Detonation of Fuel-coolant Explosions, Nature, 254, 319-321, March 27, 1975.

33. D. H. Cho, H. K. Fauske, and M. A. Grolmes, Mixing Considerations for Large-Mass Energetic Fuel-coolant Interactions, Proc. Fast Reactor Safety and Related Physics, CONF-761001, Chicago, I1linois, October 5-8, 1976.

34. R. E. Henry et al., Large-scale Vapor Explosions, Proc. Fast Reactor Safety Meeting, Beverly Hills, California, April 1974, CONF-740401-P2, Vo1. 2, 922-934.

35. H. K. Fauske, Summary of Accident Energetics, Including Coolant Dynamics, Cladding and Fuel Relocation, and Molten Fuel-coolant Interactions, Proc. Fast Reactor Safety and Related Physics, Chicago, Illinois, October 5-8, 1976.

36. T. G. Theofanous and H. K. Fauske, An Energy Dissipation Mechanism Due to the Cladding of the Fission-Gas Plenum During an HCDA, ANL/RAS 72-31, September 1972.

37. C. R. Bell and J. E. Boudreau, Application of STMMER-I to the Postdisassembly Fluid Dynamic Behavior within an LMFBR Reactor Vessel, to be published.

38. S. J. Hakim, P. B. Abramson, and R. J. Henninger, On the System Damage Potential for CRBR, 1977 Winter ANS Meeting, San Francisco, California, November 27-December 2, 1977.

39. M. Epstein eta1., Analytical and Experimental Studies of Transient Fuel Freezing, Proc. Fast Reactor Safety and Related Physics, CONF-761001, Chicago, Illinois, October 5-8, 1976.

40. M. Farahat, R. E. Henry, and J. Santori, Fuel Dispersal Experiments with Simulant Fluids, Proc. Fast Reactor Safety and Related Physics, CONF-761001, Chicago, Illinois, October 5-8, 1976.

41. R. E. Henry et a1., Experiments on Pressure-driven Fuel Compaction with Reactor Materials, Proc. Fast Reactor Safety and Related Physics, CONF761001, Chicago, Illinois, October 5-8, 1976.

42. J. 0. Barnes, Advanced Carbide Fuels - U. S. Experience, Proc. Advanced LMFBR Fuels Topica1 Meeting, Tucson, Arizona, October 1977.

43. T. R. Schmidt, LMFBR Prompt Burst Excursion (PBE) Experiments in the Annular Core Pulse Reactor (ACPR), Proc. Fast Reactor Safety and Related Physics, CONF-761001, Chicago, Illinois, October 5-8, 1976.

44. K. 0. Reil, M. F. Young, and H. Plitz, Prompt Burst Energetics Experiments - Uranium Carbide Series, Trans. Am. Nucl. Soc., 28, 487, 1978.

45. R. W. Miller, A. Sola, and R. K. McCardell, Report of the SPERT-I Destructive Test Program on an Aluminum, Plate-type, Water Moderated Reactor, IDO-16883, 1974 . 
46. J. R. Deitrich, Experimental Investigation of the Self-limitation of Power during Reactivity Transients in a Subcooled Water-moderated Reactor - BORAX-1 Experiments, 1954, AECD-3668, 1965.

47. SL-1 Project, Final Report of SL-1 Recovery Operations, IDO-19311, 1962.

48. L. Cave, D. Ilberg, and D. Okrent, Designing for Safety in Fast Reactors in the Presence of Uncertainties, Proc. Fast Reactor Safety and Related Physics, Chicago, Illinois, October 5-8, 1976.

49. L. Baker, Jr., Core Debris Behavior and Interactions with Concrete, Nuclear Eng. \& Design, 42, 137, 1977.

50. E. L. Gluekler and L. Baker, Jr., Postaccident Heat Removal in LMFBRs, Symp. on the Thermal and Hydraulic Aspects of Nuclear Reactor Safety, Vo1. 2: Liquid Metal Fast Breeder Reactors, edited by 0. C. Jones, Jr. and S. G. Bankoff, ASME publication, 1977.

51. E. L. Gluekler, Ex-vessel Core Retention Concept for Early Sized LMFBRs, GEAP-14121, August 1976.

52. Project Staff, 300 MWe Gas-Cooled Fast Breeder Reactor Demonstration Plant, GA-A13045, July 1974.

53. Project Staff, Gas-Cooled Fast Reactor Core Dismutive Accidents, ANL/RAS/GCFR-76-1, November 1976.

54. R. H. Sevy and T. Y. C. Wei, Posttransient Phenomena in Gas-Cooled Fast Reactor Core-dismuptive Accidents, September 1977. 


\title{
PART 5
}

\section{FUEL CYCLE OPTIONS}

M. J. Lineberry, H. F. McFarlane, P. I. Amundson, R. W. Goin, and D. S. Webster

(Argonne National Laboratory)

Organizational Contributors:

Hanford Engineering Development Laboratory

Los Alamos Scientific Laboratory

Oak Ridge National Laboratory

Non-Proliferation Alternative Systems Assessment Program

\begin{abstract}
The results of the FBR fuel cycle study that supported U.S. contributions to the INFCE are presented. Fuel cycle technology is reviewed from both generic and historical standpoints. Technology requirements are developed within the framework of three deployment scenarios: the reference international, the secured area, and the integral cycle. Reprocessing, fabrication, waste handling, transportation, and safeguards are discussed for each deployment scenario. Fuel cycle modifications designed to increase proliferation defenses are described and assessed for effectiveness and technology fcasibility. The present status of fuel cycle technology is reviewed and key issues that require resolution are ldentified.
\end{abstract}

\section{INTRODUCTION}

This chapter describes the results of a fast breeder reactor (FBR) fuel cycle study which supported U.S. contributions to the INFCE. The analysis covers the major fuel cycle activities required to support fast reactors, with a variety of constraints assumed on deployment of reactors and fuel cycle facilities. The emphasis is on the technical aspects of proliferation issues, and we seek to answer:

i. Where in FBR fuel cycles should proliferation concerns be focused?

ii. What is the feasibility and effectiveness of alternatives to increase proliferation resistance?

iii. Given this spectrum of possibilities, what is the current state of development, and what key issues can be identified? 
A. Deployment Scenarios

The approach to this study of fast breeder reactors, and more broadly the U.S. view of the INFCE, was that it should include a study of a full range of alternatives in addition to the traditional concepts. To explore this range of alternatives, three main scenarios were developed with different constraints on deployment of reactors and fuel cycle facilities.

\section{Reference International System}

In this deployment scenario FBRs are assumed to be deployable anywhere, according to national decision. The supporting fuel cycle facilities are assumed to be deployable anywhere, but with:

i. Varying degrees of collocation between elements of the FBR system (no collocation; collocation of reprocessing and fabrication, and collocation of fuel cycle facilities with a few FBRs), and

ii. Varying levels of adminstrative controls, from national to multinational to international operation of the fuel cycle.

\section{Secured Area System}

Here FBRs fueled with chemically-separable materials (e.g., U-Pu or ${ }^{233} \mathrm{U}-\mathrm{Th}$ fuel cycles) are assumed to be located in secured, multinationaly or internationally controlled enclaves which would also contain the fuel cycle facilities. ${ }^{2}{ }^{3} \mathrm{U}$ would be produced by the breeders in the secured area, and when denatured with $238 \mathrm{U}$, would be used to fuel dispersed reactors sited by national decision. This concept would impose two major proliferation barriers on the fuel cycle, the secured area itself and the denaturant in the fuel for the dispersed reactors.

\section{Integral Cycle System}

In this scenario, FBRs and fuel cycle facilities would be sited by national choice, but with constraints on the technology. A few (perhaps 6-10) FBRs would be collocated with fuel cycle facilities dedicated to only those reactors. What is envisioned here is a scale-up of the early operation of the Experimental Breeder Reactor-II (EBR-II), where fuel was removed from the reactor, reprocessed and fabricated while intensely radioactive, and quickly returned to reactor usage. The technology used in fuel cycle activities could be substantially different in this scenario than in the other two. The technical proliferation barrier in this concept would be the high radiation level that is consistently present with the fuel.

Fuel cycle impacts in each of these scenarios will be discussed.

\section{B. Content of this Chapter}

This chapter consists of seven sections, including this introduction. Section II discussed the breeder fuel cycle generically, and includes a brief review of historical developments, proliferation defenses and sensitive elements in the cycle, and concludes with an overview of safeguards concepts and 
techniques. Sections III-V describe feasible fuel cycle technologies for the reference international, secured-area, and integral cycle deployment scenarios. Included are analyses of basic approaches as well as discussions of the feasibility of alternatives which might enhance proliferation resistance. Section IV summarizes the status of the various technologies introduced in earlier sections, while Section VII identifies the key technical issues, sumarizes the findings, and presents the conclusions.

\section{GENERIC REVIEW OF THE FUEL CYCLE}

Fue1 reprocessing, fabrication and attendant transportation and waste management systems are the back end of the fuel cycle. In this report, these activities will be referred to simply as the fuel cycle. They are as important to FBR development as the breeder reactor itself, and their implementation requires the solution to a number of technical and political problems. These include problems in process and proliferation control, safety, and environmental impact.

Technically, the non-reactor part of the FBR cycle is similar to that of the light-water reactor. Many operational techniques and processes used in the light-water reactor fuel cycle have been accepted as a basis for further development for the FBR. 1

\section{A. Generic FBR Fuel Cycle Description}

A generic FBR fuel cycle is shown in Fig. 1. Regardless of the particular fuel cycle technology employed, fuel recovery operations are composed of the illustrated steps.

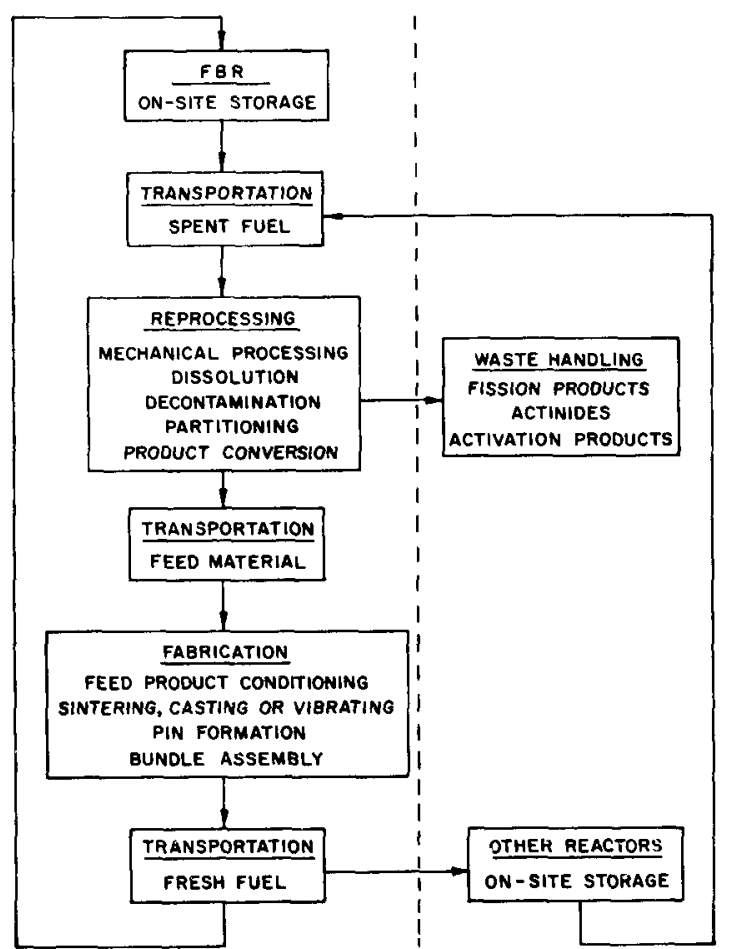

Fig. 1

Generic Fuel Cycle. ANL Neg. No. ID-103Cl1053 
At the reactor site, storage is provided for both fresh and spent fuel. For spent fuel, storage provides sufficient time for fission-product decay until the heat generation is low enough to allow shipping in shielded casks. Periodic storage of fresh fuel insures that fuel will be available when needed for refueling the reactor. After the spent fuel has cooled sufficientIy, it is transported to the reprocessing facility.

Once at the reprocessing facility the spent fuel is dissassembled and the fuel material is converted to a liquid form. Some of the fission products are separated from the fuel-bearing material, and the fissile and fertile materials are completely or partially separated from each other. Finally, the product is converted to the required fuel compound (e.g., oxides) and is transported to the fabrication facility.

In the fabrication plant, bulk feed materials are blended to the required fuel composition, fuel pin components are fabricated, the components assembled into pins, and the pins into bundles. Finished fuel assemblies are then transported to the reactor to complete the fuel cycle. Extra bred fuel is used by other reactors, either converters or breeders.

Radioactive wastes are generated at various stages of the fuel cycle in solid, liquid and gaseous forms. These wastes, which are contaminated with radioactive fission products, activation products, and actinides, are converted to forms suitable for disposal.

\section{B. Fue1 Reprocessing}

Fuel placed in FBRs must be periodically removed and processed to remove at least some of the accumulated fission products, to repair radiation damage and to readjust the amount of fissile and fertile materials. The operations to recover the fissile and fertile materials from spent fuel have followed two general avenues of development. The first is aqueous separation and includes various techniques to extract the fuel materials from an initial aqueous solution. The second, non-aqueous separation, covers all other techniques. These are generally high temperature separations utilizing differences in solubility, volatility, melting point, or valence.

\section{Aqueous Processes}

Aqueous separation of plutonium from irradiated reactor fuel began in the early 1940 s when a laboratory separation process based on the coprecipitation of plutonium with bismuth phosphate and lanthanum fluoride was simply scaled-up several orders of magnitude. The bismuth phosphate batchtype process was slow and inefficient. ${ }^{2}$ It was superceded in 1951 by the Redox process which was based on the extractability of the higher oxidation states of plutonium and uranium in methyl-isobutyl-ketone (hexone) from concentrated aqueous nitrate solutions. Although the Redox process lent itself to continuous reprocessing, it produced large volumes of radioactive waste and used flammable solvents. 3

The Purex process ${ }^{4}$ corrected these deficiencies. This process uses the extractability of uranium and plutonium into a tributyl phosphate solution, and has been under continuous development since the late 1940 s. Purex plants at Savannah River and Hanford went into operation in the 
mid-1950s. The designs were based on the extensive laboratory and pilotplant studies of the previous decade and on the design, maintenance, and operating experience gained with predecessor radiochemical processes at Hanford. The Purex plants were operated successfully, and the process has been internationally pre-eminent ever since. 5 Further development of the Purex process continues today to extend its application to breeder reactor fuels. ${ }^{6}$

The Thorex process to treat thorium-based fuels evolved from Purex. Like Purex, it utilizes tributyl phosphate extraction. ${ }^{7}$ Although initially developed for thorium-uranium fuels, Thorex appears to be applicable to fuels containing thorium, uranium, and plutonium.

\section{Non-Aqueous Processes}

The potential for separating fissile, fertile, and fission product elements by means of dry reactions of a metallurgical nature was initially investigated in the mid-1940s. Several basic investigations led to the initiation, in the early 1950s, of considerable bench-scale work toward the development of high-temperature processes.

In the mid-1950s, a process was developed for the melt refining of EBR-II metal fuel. This process, described in Section $V$, was used for several years to process discharged fuel and recycle it to the reactor. 8 However, melt refining in EBR-II was an incomplete process because noble metal fission products were retained with the fuel. Application to current FBR fuels would require an auxiliary process to remove the noble metals.

Pyrochemical processes were subsequently investigated, in which separations were effected by selective transfer between molten metal and molten salt phases using appropriate oxidizing and reducing agents.9 Separations also can occur as a result of volatilization and selective precipitation of certain elements. Although a significant amount of bench-scale work was done on pyrochemical processes between the mid-1950s and the ear1y 1970s, process development has not proceeded beyond this point.

Conversion of uranium and plutonium to volatile fluorides was the basis of a process developed for FBR fuels. The fluoride volatility process produced separated and decontaminated plutonium and uranium from spent oxide fuels. Considerable laboratory-scale work was completed before development of this process was terminated in the early 1970 s.

Dry processes, such as Airox 10 and Carbox, 11 have been investigated in the laboratory. These processes utilize repeated hot gas oxidation and reduction of fuel to disintegrate the fuel matrix and release gaseous and volatile fission products. The non-volatile fission products, however, remain with the fuel and build up continuously as the fuel is recycled, requiring an auxiliary process to remove these fission products.

\section{Fuel Fabrication}

Fabrication experience for solid FBR fuels exists primarily for oxide and metal fuels. Carbide and nitride development activities have been largely devoted to preparation of fuel pins for irradiation testing. The 
principal early development work centered on metal fuels, but research and irradiation testing of these fuels was considerably reduced during the mid1960s when oxide fuels were selected as the reference fuel for developing FBRs. Since that time, development activities and irradiation testing have mainly involved oxide fuels.

\section{Oxide Fue1 Fabrication}

Much of the FBR fuel development work done over the last 18 years has focused on a fuel design utilizing uranium-plutonium mixed oxides (MOX) clad in stainless stee1.12 This fuel has been adopted by most countries for their operating or planned fast reactor demonstration plants. The choice of oxide fuel for first-generation demonstration plant loadings stemmed naturally from the well-established technology and experience gained with $\mathrm{UO}_{2}$ in the light-water reactor programs. 13

Pellet fuel fabrication techniques are basically similar throughout the world: mechanically-blended powders are pressed and sintered resulting in mixed-oxide fuel pellets. This is the reference FBR fuel fabrication technique. In the U.S. development of MOX pellet fabrication has been toward a goal of automatic operation of the process line, but with direct access possible for equipment maintenance. 14

Other fabrication techniques have been less developed. In the mid$1960^{\prime}$ 's there was interest in fabrication of pins from vibratory compaction of spherical or angular fuel particles. 15 There appears to be a new interest in these techniques, both in the U.S. and abroad.16,17

\section{Metal Fuel Fabrication}

Several U.S. fast reactors have been fueled with solid metallic uranium and plutonium alloys. These include CLEMENTINE, EBR-I, EBR-II, and the Enrico Fermi Fast Breeder Reactor. ${ }^{8}$ A number of fabrication techniques were utilized to produce fuel for these reactors. Of these, the principal fabrication experience and the only experience in hot fuel fabrication was associated with EBR-II and its integral pyrometallurgical reprocessing facility. The injection casting process used for pin fabrication was successful, and remains the reference for fabrication of EBR-II driver fuel.9

\section{Waste Management and Disposal}

High-level waste solidification by calcination was developed to treat defense-related wastes. These methods have been in use for about 15 years to reduce waste volume. An effort is being made now to develop a production process to reduce high-level wastes to a glass form. No fundamental differences are apparent in treating wastes from either defense or commercial reactors. Since FBR wastes will differ only slightly from those of the LWR, it appears that the development of FBR waste management procedures will call heavily on the techniques now developed or under development. 20 Lowlevel waste materials characteristically do not contain significant quantities of special nuclear materials (SNM). Consequently, these waste materials are of no proliferation concern, and will not be considered. High-level wastes, from the separation phase of fuel reprocessing plants, may contain significant quantities of actinide elements (i.e., elements in the periodic table from 
actinium and above).21,22 Proliferation aspects of these will be discussed under specific deployment strategies.

\section{E. Transportation}

Since the late $1940 \mathrm{~s}$, DOE and its predecessor agencies, AEC and ERDA, have transported large quantities of special nuclear materials by a variety of armed courier-escorted commercial and government transportation modes. In the late 1960s, governmental perceptions of diversion threats in both the national and international transportation of nuclear materials caused the AEC to review its safeguarding procedures. ${ }^{23}$ The review resulted in a considerable amount of upgrading of domestic transportation patterned after elements of the nuclear weapons program.

In the early 1970s, the weapons program developments were extended to encompass strategically-important shipments (uranium of $20 \%$ enrichment or more or plutonium weighing 2 kilograms or more) of special nuclear materials in the civilian program. These developments included requirement for armed courlers with sophisticated transport vehicles and communications systems, resulting in an improvement in the physical protection of domestic shipments of special nuclear materials. $24-26$

Both fresh and spent light-water power reactor fuel has been characteristically transported by unescorted private licensed carriers in utilityowned casks. There is no commercial FBR fuel transportation history for comparison.

The FBR research and development program has depended heavily on the government transportation system for the movement of large quantities of enriched uranium and plutonium. This experience with both irradiated and nonirradiated materials could form the basis for development activities leading to secure transport of plutonium and uranium for a commercial FBR industry.

F. Fuel Cycle Proliferation Defenses and Vulnerable Points

Depending on their location within a breeder fuel cycle, nuclear materials have varying degrees of attractiveness for diversion. As materials pass through the fuel cycle, they take on different chemical and physical forms and are found in various degrees of purity. In this section, some general features of a breeder fuel cycle proliferation defense are discussed; more detailed analyses will be incorporated in later sections.

\section{Elements of Proliferation Defenses}

Policies to strengthen proliferation defenses must address the motivating forces behind the threat of proliferation. These forces are numerous and complex, and inevitably involve judgements that exceed the scope of this report. Proliferation defenses here will be investigated, for each of the deployment scenarios mentioned, from a technical viewpoint.

From this technical viewpoint, proliferation defense certainly includes procedures (technical and administrative) to account for and physically protect the sensitive materials in any fuel cycle deployment scenario. Proliferation defense might include, depending on the deployment scenario, 
modifying fuel cycle processes. This could make it more difficult to acquire sensitive materials even if unauthorized access is gained to fuel cycle facilities or materials. Accounting and physical protection are generally referred to as safeguards and are discussed in Section II.F.3 and elsewhere in this report. Safeguards, in fact, play a prominent role in this study. Modifications of some fuel cycle processes will be addressed in later sections of this chapter dealing with different deployment scenarios.

\section{Sensitive Elements of the Fuel Cycle}

Fuel reprocessing, fabrication, waste management, and transportation activities have four elements in common. They all handle SNM process materials, using specialized process techniques, using relatively complex equipment, and operations are located in dedicated facilities.

\section{a. Process Materials}

A number of physical and chemical characteristics of the process material determine the ease with which it could be converted to nuclear weapons.

Uranium or plutonium with high percentages of ${ }^{233} \mathrm{U}, 235 \mathrm{U}$ or ${ }^{239} \mathrm{Pu}$ would be more sensitive than fuels with low fissile isotope purity. Generally, the higher the fissile isotope purity, the easier it would be to use for nuclear weapons material.

Fuel that has only small quantities of gamma-ray emitters in the material would be more sensitive than those that are highly radioactive. Fuel with a low radiation level could be converted to bomb material with standard laboratory equipment, while highly radioactive fuel would require shielded facilities.

Chemically pure fuel forms would be more sensitive than impure forms. Plutonium oxide would be easier to convert to bomb-usable metal than would a mixture of plutonium oxide and uranium oxide. Also fuel that is in the elemental form (as plutonium metal) would be more sensitive than compounds of that chemical.

High specific-activity alpha emitters are also highly radiotoxic. Small quantities ingested or inhaled can have severe, but generally slow, impact on health. Ranked in decreasing order of toxicity are plutonium, ${ }^{233} \mathrm{U}$ and $235 \mathrm{U}$. Thus, for this characteristic, plutonium would be less sensitive than ${ }^{23} \mathrm{U}$ which would be less sensitive than ${ }^{235} \mathrm{U}$.

\section{b. Process Techniques}

The process techniques used determine the physical and chemical form of the process material, could influence accountability, and in certain cases could impact physical security.

Because of reduced accessibility, diversion from a continuous flow process would be more difficult if the process used automated equipment. In accounting for the materials in a continuous flow process, monitoring 
could be nearly continuous with the results obtained quickly; however, accounting balances would not be as accurate as slower batch-process accounting.

Low temperature process steps (for example, those steps involving completed fuel pellets) would provide more opportunity for diversion than high temperature steps and consequently would require more sophisticated accounting methods.

Chemical processes that are not hazardous would be more sensitive than those that contain chemicals difficult to contain or handle.

Processes that have large holdup times make it difficult to apply timely accounting procedures, and they would be more diversion-sensitive if the process were accessible.

Shipping and receiving and their attendant inspection processes would be especially sensitive for materials having low radiation levels. These processes also represent potential interfaces between the automated materials measurements and accounting system (MMAS, which provides on-line process accounting) and the physical protection system (plant entrance and exit contro1). In the defined safeguards system (Section II.F.3.b) the computerized safeguards coordination unit would handle information from both systems, potentially cross checking for added diversion resistance.

\section{c. Process Equipment}

Process equipment design has been generally determined by laboratory or bench-scale development of the process technique or from performance data of like process equipment in other facilities. Many characteristics of in-place process equipment could impact accountability and physical securfty.

Process equipment that proves easy to modify might facilitate the processing of high-quality SNM in an overtly-seized plant originally designed to produce fuel for reactors.

Nuclear facilities can include equipment designed for hands-on, fully remote, or zero maintenance. 27 Hands-on maintenance requires shutdown and decontamination of part of the plant prior to beginning process maintenance. Remote maintenance is done with special devices designed to repair or replace process elements remotely. Zero maintenance systems are designed not to be maintained. The ability to modify a facility is in part related to the ease with which it could be maintained.

Access to inner segments of a process could result in sensitivity to frequent covert diversions of small quantities of material. This would be especially true of numerous sample points in continuous-flow aqueous reprocessing plants, ${ }^{28}$ and SNM storage locations. Automatic monitoring of sample lines, as part of the safeguards system covered in Section II.F.3.b., would be necessary to reduce the sensitivity of this process element.

\section{d. Facilities}

Present facilities that contain elements of the fuel cycle have been designed to optimize the processes. Although designs generally 
lend themselves to a prescribed level of security, overa11 safeguards considerations have been secondary. Facility characteristics could strongly affect not only physical protection, but also the ability to engineer the process equipment and process techniques for improved safeguards.

A certain amount of access must be included in any facility. Principal need for personnel access include normal operations and for transfers of equipment materials. Historically, access control has been a function of plant security systems utilizing guards and varying levels of identification, radiation monitors, and metal detectors. Recent development activities 29 have brought together a number of sophisticated entrance and exit monitoring devices that use computer-based data assessment with human backup. Ongoing impact assessments (safeguards effectiveness vs. process productivity) with this type of equipment could lead to deployment of these improved access control systems.

All fuel cycle facilities contain various process equipment enclosures designed to protect people from the process. Protection of people from radiation, contamination, toxic chemicals, or high-temperature equipment has long been a goal of facility design for all nuclear facilities. The resulting hardening of structures around process equipment can be taken as a built-in safeguards advantage. However, hardened equipment enclosures (for example, processes contained in thick-walled concrete cells) also may make certain elements of materials accounting more difficult. This is especially true of the highly radioactive, continuous-flow nature of the initial stages of fuel reprocessing facilities. Enclosures designed with safeguards requirements in mind (allowing for sufficient specialized safeguards assay penetrations) will reduce these in-process accountability problems.

The ability of nuclear facilities to withstand attack by armed terrorists with possible subsequent theft of SNM has been seriously questioned. 30 These questions have led to a number of studies of the ability of nuclear facilities to withstand armed intruders long enough to allow deployment of response forces. Activities have already gone beyond the study stage, with efforts to engineer and assemble coordinated systems to increase the protection of certain nuclear facilities. ${ }^{31}$ Penetration alarms, closedcircuit television, and delay systems, in place in certain government facilities, will undergo operational testing in selected FBR research and development facilities starting in 1978.

The physical location of fuel cycle facilities could strongly affect its proliferation resistance. Physically separated fuel cycle processes would require more transportation steps, thus increasing diversion vulnerability.

\section{Overview of Safeguards}

Regardless of the way in which reactors and fuel cycle facilities are deployed, and regardless of the technology used, worldwide safeguarding of sensitive materials is in the interest of all nations. Safeguards must provide a common line of proliferation defense, no matter what the deployment scenario. 
Nowhere in the breeder fuel cycle would safeguards be more important than in the reprocessing and fabrication steps. Thus even though a separate chapter in this report deals with breeder fuel cycle safeguards, the topic will be treated in this analysis for completeness.

In this report an assessment will be made of how the alternatives to the traditional concepts (different deployment scenarios, different fuel cycles, and different engineered systems which might enhance proliferation resistance) might impact the safeguards system.

\section{a. International Safeguards}

The International Atomic Energy Commission (IAEA) safeguards system is defined in two documents. The first, INFCIRC/66/Revision 2, forms the basis for bilateral agreements, transfer agreements, and unilateral submissions under which equipment, facilities, nuclear material, other material, and information are subject to safeguards. 32 The second, INFCIRC/153, forms the basis for agreements between states that are party to the Nuclear NonProliferation Treaty. 33

The IAEA goals for safeguarding include upper limits on both the size of mass flow deviations and the time delay between diversion and detection. The mechanisms of IAEA safeguards consist of three components: nuclear material accountancy, containment, and surveillance.

Nuclear material accountancy is defined ${ }^{34}$ as the continuing knowledge of the material's identity, composition, and quantity, including the statistical uncertainties in these values, and location. Nuclear material accountancy has historically involved perfodic physical inventories and review of records to determine the present book inventory. From these investigations, the difference between a physical inventory and the book inventory is determined.

Containment involves restrictions on the movement of or access to nuclear material and is used for physical protection of the material, safety or personnel, and convenience of operational procedures. 34

Surveillance means instrumental or human observation to indicate the movement of nuclear material. 34 The IAEA does not impose physical restrictions on the movement of or access to material. Operators must, however, provide to the IAEA information as to whether such movement or access occurred while inspectors were not present, in order to preserve the integrity of prior measurements of nuclear material by the IAEA, and to provide the IAEA with knowledge of material flows at important points in a fuel cycle. The IAEA has the responsibility of drawing a conclusion as to the amount of material discrepancles (based on its safeguards procedures) only for the case of facilities subject to IAEA safeguards under the Nuclear NonProliferation Treaty. 33

In the case of facilities subject to IAEA safeguards under bilateral treaties or unilateral submission, the IAEA is not obliged to draw a conclusion about material discrepancies. It is obliged, however, to make a determination of compliance with the safeguards agreement. ${ }^{32}$ 
While the international safeguards system, as presently defined, is responsible for detecting diversion of SNM, domestic safeguards systems are designed to prevent diversion. In addition to the direct physical security and protection role, domestic safeguards include the accounting system which is generally used as the basis for IAEA verification. The international safeguards system must provide verification independently of the domestic safeguards system, and it must also be resistant to tampering by the operator or host country. Although the state is responsible for physical security, the IAEA does provide nonbinding recommendations for physical security programs.

\section{b. National Safeguards}

The effective implementation of international safeguards depends on successful institutional arrangements and on effective technology to verify accountancy and containment of SNM. While the objectives of international and domestic safeguards may differ, the technology for these systems can be essentially identical. Development of the technology will be primarily done in various national safeguards programs.

The goals of the present U.S. safeguards programs are: ${ }^{35}$ (1) to deter diversion of SNM, (2) to provide adequate protection of facilities and materials, (3) to detect diversion, and (4) to quantify diversion. To meet these goals, the domestic safeguards programs are developing integrated systems for safeguards and material control in future large domestic fuel cycle facilities. Postulated integrated-system designs have been analyzed for application to LWR fuel cycle facilities, and similar systems could be designed for FBR fuel cycle facilities. A brief description of such systems is provided here as a background for understanding the present capabilities being developed to deter, detect, and quantify diversion. The techniques and associated instrumentation will, in general, be adaptable to other facilities.

\section{(1) Physical Protection System (PPS)}

A physical protection system performs the IAEA functions of containment and surveillance through control of personnel, material, and equipment movement into, within, and out of a facility. Such systems can include: ${ }^{29}$ (1) automated personnel identification systems to assure that only authorized people are in restricted areas; (2) SNM monitors, metal detectors, and explosives monitors to assure that sensitive materials do not move across barriers that are expected to restrict their passage; (3) presence monitors and closed-circuit television to monitor sensitive areas remotely; (4) delay systems to slow down an overt external attempt to enter a restricted area; (5) doorway monitors and alarms to detect movement of people into sensitive areas; and (6) sufficient personnel to respond to an externally generated overt act of a specified size.

The equipment described is available from commercial sources; ${ }^{36}$ some of it has been available for many years. Most, however, has been engineered specifically for nuclear facilities with the past five years. 
Physical protection systems rely on nuclear monitors to detect small quantities of material. All commercial monitors do this by measuring gamma rays emitted in the monitored space. 37 Regardless of the true source of the gamma rays, it is assumed that they come from special nuclear material. Although this assumption may create certain operational problems, it results in highly sensitive monitors. U.S. regulatory specifications ${ }^{38}$ for these monitors include the requirements to detect: (1) one-half gram ${ }^{239} \mathrm{Pu}$ with a $95 \%$ confidence level; (2) one gram of freshly refined ${ }^{23} \mathrm{U}$ (7-10 ppm $232 \mathrm{U}$ within four hours of purification) with a $90 \%$ confidence level, and (3) three grams of $235_{\mathrm{U}}$ contained in uranium enriched to $20 \%$ or more at a $50 \%$ confidence level. All samples are assumed to be encased in and thus shielded by three millimeters of brass.

The natural gamma rays associated with SNM are primarily of low energy and can therefore be relatively easily shielded. Consequently, it is not difficult to move relatively large quantities of shielded SNM through a space monitored only for gamma rays. 39 Therefore, metal detectors capable of detecting $200 \mathrm{~g}$ or more of nonferrous metals 40 are used in conjunction with radiation detectors and are intended to sense the presence of shielding materials.

Other equipment such as radiation monitoring equipment and piece counting equipment can be used at shipping or receiving points as part of a semiautomatic monitoring capability. ${ }^{1}$ Shipping drums, for example, can be placed on a test fixture where appropriate instrumentation can identify the container, perform a nondestructive assay (NDA), and transmit the information to a central accounting system computer. The computer can check the information received against preprogrammed shipping information to provide a check on the manual inspection process. Discrepancy alarms can be incorporated in the system and can be automatically activated if a discrepancy occurs.

Remotely operated radiation and metal-detection instrumentation can also be used to supplement the PPS. Devices such as door locks and television cameras can be controlled by remotely located computers receiving information from the detection instrumentation. These automatic control functions would normally be used on $1 \mathrm{y}$ outside continuous-flow processing lines to avoid unnecessary interruptions of critical process operations.

\section{(2) Materials Management and Accountability Systems (MMAS)}

Throughout the major portion of any fuel cycle, item material accountability can be used by both the facility operator and the IAEA to detect diversion. In facilities such as reprocessing plants, where item accountability cannot be applied, other methods are necessary. Conventional nuclear materials management and accountability systems, both in the U.S. and abroad, rely on plant input-output data with periodic shutdown for inventory. Various forms of materials control and accountability programs have been developed at several U.S. domestic nuclear facilities, both governmentoperated under Department of Energy (DOE) control and privately owned under Nuclear Regulatory Commission (NRC) jurisdiction. The development stages range from simple computerized accounting systems to the use of in-1ine NDA instrumentation linked through a computer network for accounting, materials control, and theft detection and localization. 
To achieve nearly continuous materials control and accountability, a facility can be subdivided into physical areas within which SNM accounting is done. ${ }^{1}$ These physical areas, called unit-process accounting areas (UPAAs), are chosen in such a way that all nuclear material crossing the unit-process boundary can be measured, and a material balance can then be computed. The UPAAs are chosen to localize the material within a given unit process, both in space and in time. On-line computers can then be used to cope with the large quantities of data collected over short periods of time. Materials accounting statistics can be calculated and monitored for each unit process. ${ }^{42}$ If the value of such a statistic (or set of statistics) exceeds a specified alarm level, the materials control system can alert the appropriate authorities and investigative action can be taken.

Successful implementation of an MMAS will be dependent on the availability and/or development of advanced NDA instrumentation. These instruments monitor natural radiation, neutron-induced fission, or radiation-absorption properties of materials in the process stream to determine the identity of these materials and to measure their abundance. This advanced NDA instrumentation has been developed largely for application in LWR fuel cycle applications.

The specific measurement techniques employed and the resultant precision and accuracy obtainable for a given subclass of materials will depend on the size, shape, mass, and to varying degrees, on the SNM cqncentration in the sample. The presence of other radioisotopes such as fission products and/or actinide contaminants, the intensity of fluorescent $x$-rays, the parent-daughter relationships, and the relative SNM abundances also affect the choice of measurement technique and the resulting precision and accuracy. No universal NDA technique exists. The proper choice can be made only after characterizing the material to be analyzed and understanding the inherent strengths and limitations of the available assay techniques.

of nearly equal importance to NDA instrumentation is the capability for direct, automated transfer of data from these NDA instruments to a central computer, and the availability of sophisticated computer programs that do real-time accounting and make quick diversion assessments from vast quantities of NDA and other process data.43,44

\section{(3) System Structure}

The flow of information, authorization, and control data through and between the safeguards structure and the plant process system is given in Fig. 2.28 It is based on a safeguards system implemented at Los Alamos Scientific Laboratory.

Safeguards coordination, materials measurements and accounting, and process control coordination would mainly be computercontrolled, automated functions. The safeguards system automatically couples these functions. 


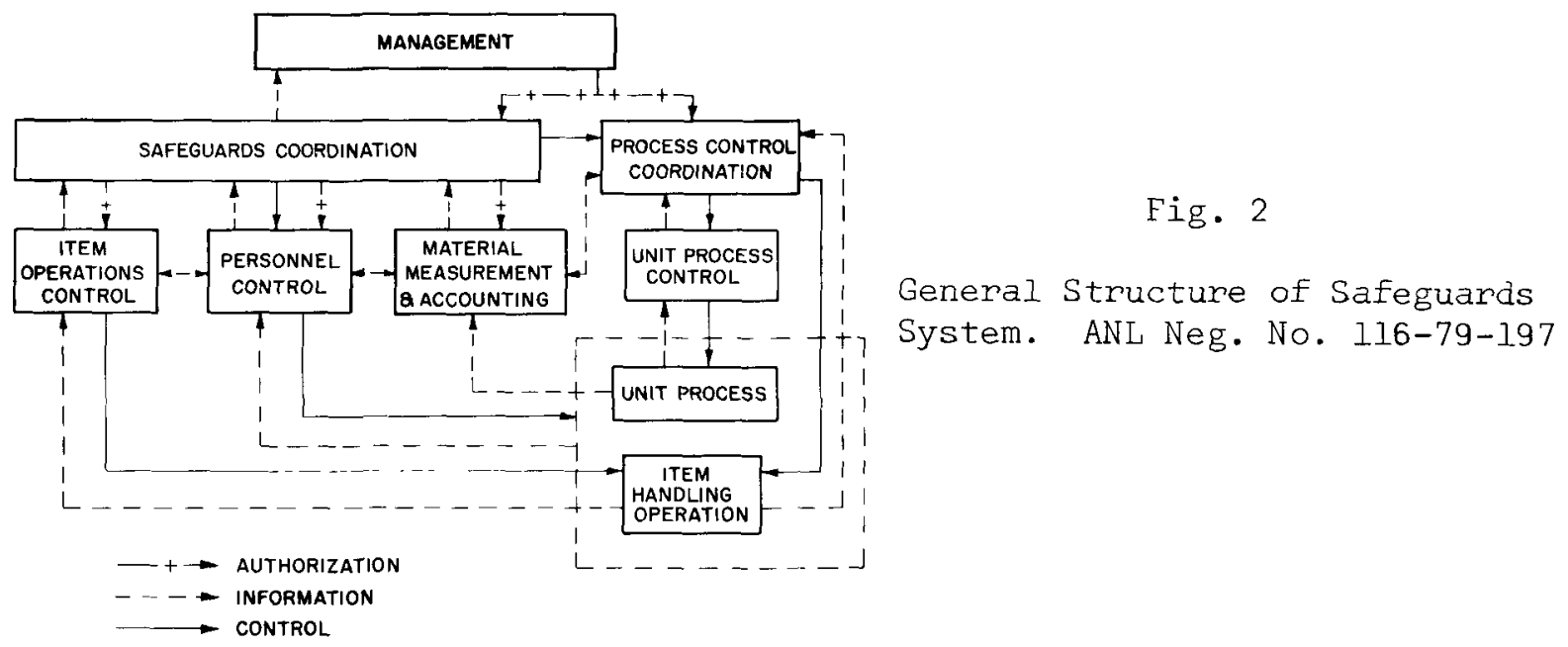

The basic data flow would be from unit process NDA and associated monitoring sensors in the process line to the MMAS. Results of real-time statistical assessments of the data to determine potential diversion would be transmitted to the safeguards coordination area, and at times to the process control coordination area, depending on the presence of, and amount of, useful process information in the assessment.

Some head-end and tail-end operations would be handled by the physical protection system due to the fact that items in these operations could be individually identified. NDA might not be done, but items would be accounted for by automated data transmission to the safeguards coordination area. 29

The components of the safeguards system described above are essentially developed. Systems integration, processing, and logic are now being 1 . oratory tested.

\section{FUEL CYCLE IN THE REFERENCE INTERNATIONAL SYSTEM}

At this time the reference fuel for the international development of FBRs is mixed $\mathrm{UO}_{2} / \mathrm{PuO}_{2}$. Part $\mathrm{A}$ of this section describes reprocessing that fuel, the subsequent fabrication of new fuel assemblies, the waste products generated, and the required transportation of special nuclear materials. Modifications necessary to handle two other candidate fuels, U/Pu metal and $\mathrm{UC} / \mathrm{PuC}$, are considered. Finally, diversion potential in the reference system and the safeguards against it are described.

Several technical modifications to the fuel cycle have been suggested that might increase diversion resistance. These modifications are treated on a one-by-one basis in Part B of this section. Consideration is given to the system changes, to the implications of those changes, and to the effectiveness of those changes in enhancing diversion resistance. Examples of proposed modifications that are addressed include coprocessing of $\mathrm{U}$ and $\mathrm{Pu}$, processing that yields a contaminated product fuel, plant designs that inhibit flexibility or alteration, fuel spiking, pre-irradiation, collocation 
of reprocessing and fuel-fabrication plants, use-denial engineering of materials and facilities, and ${ }^{238} \mathrm{Pu}$ denaturing of plutonium fuels. These modifications would be aimed at reducing the diversion sensitivity of the sensitive elements of the fuel cycle, as was discussed in Section II.F.

A. Reference FBR Fuel Cycle

The following sections describe the current reference technologies for the FBR fuel cycle. The impact of advanced reactor fuels (metals and carbides) is also considered. Safeguards and diversion-resistance are addressed from a technical standpoint.

\title{
1. Reprocessing of FBR Mixed-0xide Fuels by Aqueous Solvent Extraction
}

In the reference international system, the Purex solvent-extraction process* is assumed for reprocessing spent fuel. Purex reprocessing technology for FBR fuels is not fully developed in this country. The processes described below are current or proposed technology for a large FBR plant.

The main steps in reprocessing spent fuel are shown in Fig. 3. In the head-end, steps 2 and 3, the heavy-metal-bearing materials are separated from structural materials and dissolved in nitric acid. During the extraction and purification, step 4, the plutonium and uranium are decontaminated from fission products, separated from each other, and then each is further purified. Finally in step 5, the products are concentrated and converted to $\mathrm{UO}_{2}$ and $\mathrm{PuO}_{2}$ prior to transfer to a fuel fabrication plant. The radioactive wastes, some gaseous, some liquid, and some solid, are concentrated and prepared for disposal in step 6.

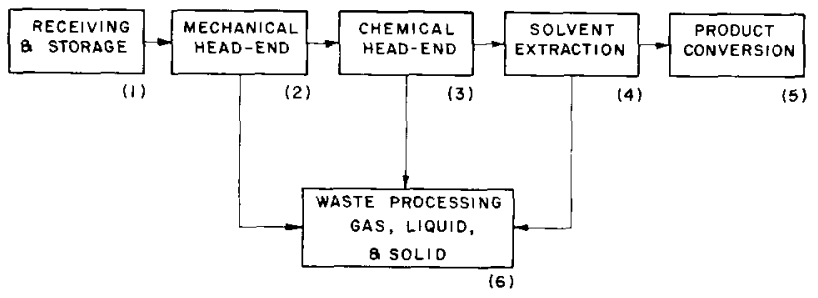

\author{
Fig. 3 \\ Fuel Reprocessing Flow Chart. \\ ANL Neg. No. 116-79-202
}

In the head-end steps, individual fuel assemblies are remotely transferred from the storage pool and are disassembled. The fuel pins are separated from the structural part of the fuel assembly and are chopped into pieces approximately $50 \mathrm{~mm}$ long. The structural part of the assembly is discarded to the waste stream. The fuel segments are dropped into a voloxidizer, which is a rotating calciner, where they are heated for 1-2 hours in an oxidizing atmosphere to produce $\mathrm{U}_{3} \mathrm{O}_{8}$ from $\mathrm{UO}_{2}$. Breakup and expansion of

\footnotetext{
* Large industrial plants using a Purex process started operation at Savannah River in 1954 and at Hanford in 1956. Two reprocessing plants using Purex were built at Dounreay in the north of Scotland. The process was used in France at the Marcoule plant in 1958, and in a later plant at LaHague in 1967. An adaption of the Purex process was used at the Eurochemic plant in Belgium, the WAK plant in Germany, the Trombay plant in India, the Tokai plant in Japan, and the West Valley, Morris, and Barnwell plants in the U.S. 45
} 
the fuel during $\mathrm{U}_{3} \mathrm{O}_{8}$ formation releases tritium for off-gas treatment, neutralizes any residual sodium and reduces the subsequent production of oxide of nitrogen. The fuel segments are then dissolved in nitric acid, and the cladding hulls separated from the solution and sent to the solid waste. Based on bench-scale tests, plutonium losses in the head-end step are expected to be less than 0.1\%, and these losses are primarily in the hulls.

Although the dissolution of low-burnup $\mathrm{UO}_{2} / \mathrm{PuO}_{2}$ fuels is somewhat difficult, highly irradiated $\mathrm{UO}_{2} / \mathrm{PuO}_{2}$ appears to dissolve readily in nitric acid, 46 so this may not be a problem in high-burnup FBR fuel. To reduce plutonium losses, the dissolved mixture is centrifuged and the residual solids are dissolved in concentrated nitric acid. Dilute hydrofluoric acid may have to be added to complete the dissolution process, especially if the fuel is unirradiated scrap from fabrication.

Separation of $\mathrm{U}$ and $\mathrm{Pu}$ from fission products, or separation of plutonium from uranium, is accomplished by a solvent extraction technique (Purex process). The technique utilizes the fact that when an aqueous solution containing uranium, plutonium, fission products and nitrate ions is contacted with an immiscible organic solution of perhaps 10 to $30 \%$ tributyl phosphate (TBP) dissolved in dodecane (essentially kerosene), much of the uranium and plutonium is complexed by the TBP and pulled into the organic phase. Consequently, a distribution of uranium and plutonium exists between the two phases, and the proportion forced into the organic phase can be increased by raising the nitrate ion concentration. Fission products are essentially not complexed and remain in the aqueous phase. Contacting of phases may be done in a variety of counter-current extractors. One type of extractor that has been frequently used is a vertical column that produces droplets of one phase in the other; the more violent the breakup of drops, the faster the transfer of uranium and plutonium is accomplished. The organic phase (1ight) rises and and the aqueous phase (dense) falls in the column to produce a counter-current motion; this mode of operation also results in relatively high concentrations of heavy metals in both phases at one end of the column, and relatively low concentrations in both phases at the other end of the column.

The flow chart for the extraction and purification step is shown in Fig. 4 and is composed of three main steps. In the extraction step (1) the feed solution is contacted with TBP in an organic solvent ( $n$-dodecane is commonly used) to separate most of the fission products from the plutonium and uranium. This is followed by a partition step (2) in which the uranium is separated from the plutonium. Finally, the uranium is stripped back out of the organic extractant (3). Both the uranium and the plutonium product streams are then subjected to one or two further purification steps ( 4 and 5 ) to achieve decontamination factors (DF) -- ratios of initial fission product concentrations to final concentrations - of approximately $10^{7}$.

Two conditions would be present in processing FBR fuel as opposed to fuels which have been processed in existing reprocessing plants.

i. High burnup would result in a higher quantity of fission products, resulting in a higher specific activity and higher chemical concentration of fission products. 


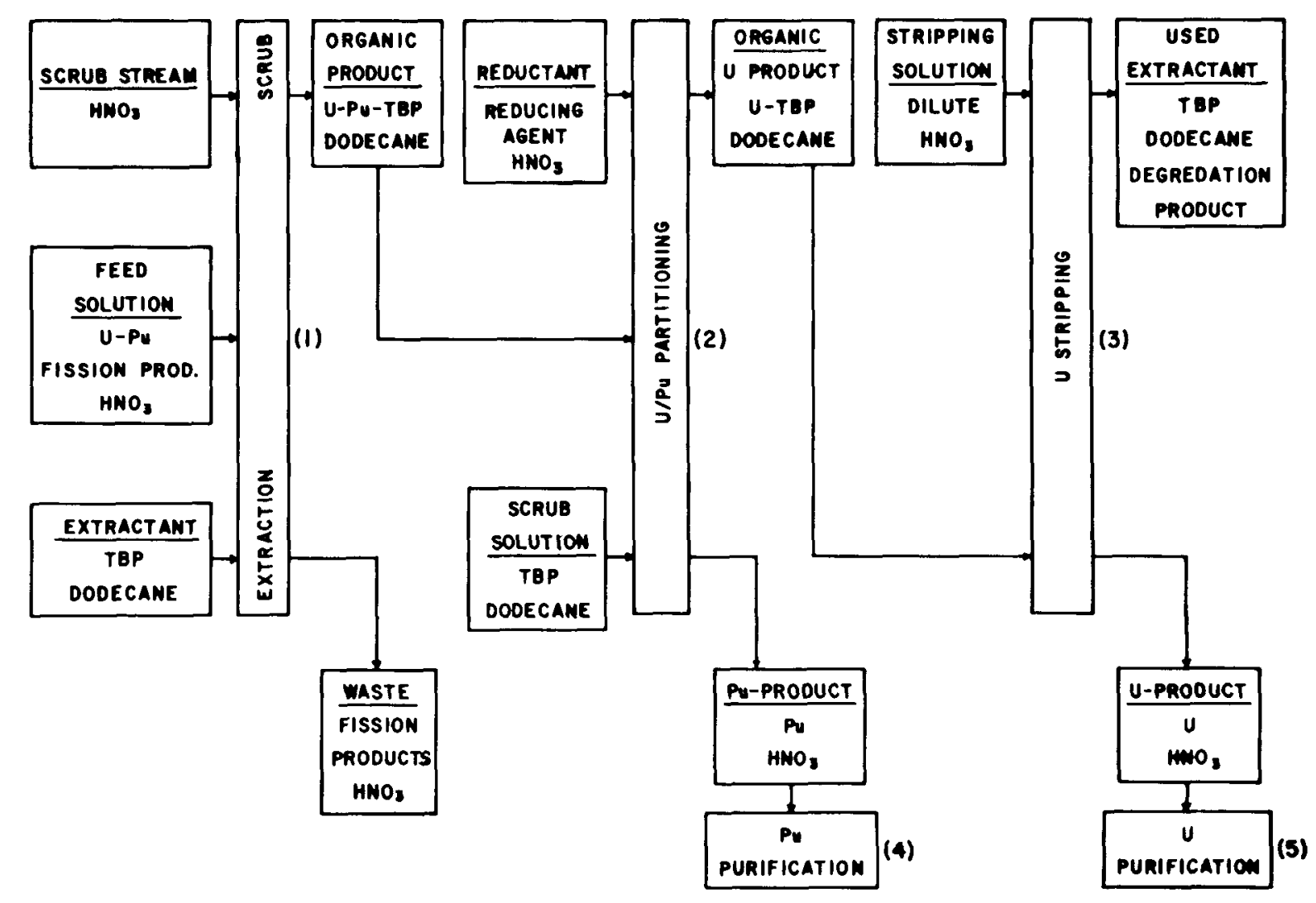

Fig. 4. Purex Solvent Extraction Flowsheet. ANL Neg. No. 116-79-194

ii. The higher plutonium content would require an adjustment of the chemical flow scheme and engineering modifications to provide for criticality safety.

The increased radiation in the dissolved fuel would lead to higher rate of radiolytic decomposition of the organic solvent. Decomposition products include dibutyl phosphoric acid (HDBP) and monobutyl phosphoric acid $\left(\mathrm{H}_{2} \mathrm{MBP}\right)$. $\mathrm{HDBP}$ and $\mathrm{H}_{2} \mathrm{MBP}$ could be removed from the organic solvent before recycling by washing with an alkaline solvent-scrub solution. In addition, the organic diluent could bond with other molecules to form radiolytic products, among which are some long-chained phosphoric acid esters, 47,48 which would not be removed by the alkaline scrub, but could be removed by passing the solvent over such strongly oxidizing absorbers as $\mathrm{PbO}_{2} / \mathrm{SiO}_{2}$. These phosphoric acid esters are especially strong extractants for the tetravalent metallic ions $\mathrm{Pu}$ (IV) and $\mathrm{Zr}$ (IV). $\mathrm{Pu}$ (IV), which is bonded to HDBP, is difficult to strip, so this would lead to Pu losses in the used solvent. Also, insoluble deposits form along the phase boundary between the aqueous and the organic solutions which contain zirconium and dibutyl phosphate.

The problems associated with radiolytic decomposition can be minimized by reducing the contact time between the organic phase and the aqueous 
phase containing the fission products and by completely removing the radiolysis products from the TBP before recycling it. Centrifugal contactors provide very short contact times and have been used in the first extraction cycle of the Savannah River plant for the reprocessing of low burnup fuels. Such innovations have reduced the radiation exposure time of the TBP by two orders of magnitude. Reducing the radiation damage to TBP could allow shorter out-of-reactor times by allowing earlier processing after discharge, with resultant economic and mass-flow benefits. There is no operating experience with centrifugal contactors in processing fuels of high burnup at present, but the French multistage centrifuge is being tested in the plant at Cap de la Hague and was built into the Barnwell plant.

Criticality safety is an important consideration in large-scale reprocessing plants of the higher quantities and concentrations of the plutonium present. For this reason, a poison such as gadolinium nitrate may be added to the dissolved fuel. It is subsequently stripped out with the fission products and is discarded with the highly active waste.

In the U-Pu separation step (step 2 in Fig. 4), the $\mathrm{Pu}$ is reduced to the +3 valence state which is only weakly extractible by TBP. Ferrous sulfamate has been used as a reducing agent, but its use increases the volume of radioactive waste. To overcome this disadvantage, uranium nitrate, in the +4 valence state, has been used as the reducing agent. However, a disadvantage to this procedure for LWR fuels is that a high stoichiometric surplus of U (IV) is necessary, which dilutes the enrichment of the product uranium. Another reducing process which might be used in future reprocessing plants involves electrolytic reduction in the extractor. This process has not yet been demonstrated in a commercial system, but it has been tested in the MILLI plant at Karlsruhe ${ }^{49}$ and has been designed into the AGNS plant at Barnwel1.

In the plutonium purification cycle (step 4 in Fig. 4), the plutonium is first re-oxidized to the +4 state (using $\mathrm{NO}_{2}$, or $\mathrm{N}_{2} \mathrm{O}_{4}$, or $\mathrm{NaNO}_{2}$ ) whereupon it is preferentially extracted into TBP which is scrubbed with $1.0 \mathrm{M} \mathrm{HNO}_{3}$ to remove any extracted ruthenium and zirconium fission products. The maximum plutonium product concentration is approximately $15 \mathrm{~g} / \mathrm{liter}$. It is then introduced to a stripping column where the plutonium is reduced to the +3 valence state and is stripped into the aqueous product stream. After the plutonium stream has been purified, it is in a solution of up to 60 $\mathrm{g} /$ liter, which is usually concentrated to approximately $250 \mathrm{~g} / \mathrm{liter}$.

The uranium product is also passed through one or more purification cycles which are similar to steps 2 and 3 in Fig. 4. In the tail-end step, the uranyl nitrate and plutonium nitrate streams can be "denitrated" by evaporating to dryness and heating to thermal decomposition temperature to form the respective oxides. A more conventional method would be to precipitate the plutonium with oxalic acid. The oxalate is filtered and thermally decomposed to form the oxide, which is then canistered for storage and shipment to a fabrication plant. Although $\mathrm{UO}_{2}$ can also be produced with this method, the present reference method is to precipitate the uranium with ammonia as ammonia diuranate. The $\mathrm{UO}_{2}$ product is then formed by calcination and reduction. 


\section{Reprocessing Differences for Metal and Carbide Fuel}

In the aqueous reprocessing of advanced fuels, most of the steps are identical to those with oxide fuel. The differences are in head-end and conversion steps. The level of development of processing advanced fuels is less than that for the reference oxides.

In the receiving and storage step, carbide fuels could inadvertantly contact and react with water, so different means of cooling and shielding spent elements in storage may need to be developed.

In the head-end steps, there might be some problems associated with shearing carbide fuels. Because the carbide and metal fuels will probably be sodium-bonded, some sodium would pass to the waste stream if it were oxidized during the head-end steps. Tritium is released when the carbides are converted to oxides prior to dissolution. It can then be handled as an off-gas, as in the voloxidation of oxide fuels. No simple process for releasing tritium from metal fuels is now available.

Carbide fuels are oxidized prior to dissolution. Although they could be dissolved directly in nitric acid, resulting organic acids would make solvent extraction difficult. The zirconium in the U-Pu-Zr alloy of metal fuels does not readily dissolve in nitric acid, and its presence in the fuel alloy will inhibit dissolution of the fuel unless dilute hydrofluoric acid is present. When HF is required, there can be corrosion prob-

lems in the dissolver and in subsequent process equipment. Also, the fluoride might complex plutonium if it is carried into the extraction cycle, which could increase plutonium losses into the waste stream.

The off-gas treatment will need to be modified for these alternate fuels. The presence of carbon dioxide in significant quantities as a result of oxidizing carbide fuels might interfere with the xenon and krypton removal process. The metal fuels generate far more nitrogen oxides and heat when they react with nitric acid than do oxide fuels, so additional off-gas treatment capacity will be required for them.

Subsequent steps -- extraction, purification, and conversion -would not be different for carbide and metal fuels once they are present as nitrates. Converting the oxide products to carbides would be done by a carbothermic reduction process. Several methods exist for producing metals from a nitrate product, including conversion to the tetrafluoride followed by reduction with calcium or magnesium.

\section{Diversion Potential in Reprocessing}

In the reference reprocessing facility described in Section III.A.1, plutonium is found in a variety of physical forms and chemical compounds with concentrations and radiation levels that vary by orders of magnitude. As was discussed in Section II.F, the proliferation resistance at various points in the fuel cycle is directly related to these chemical and physical characteristics. Concentrations, chemical form, and radiation levels are the parameters that determine diversion sensitivity. This section characterizes the materials and flow paths in the reprocessing stream to identify potential 
diversion pathways. For this discussion the plant capacity is assumed to be $5 \mathrm{t} /$ day with core and blanket assemblies being processed simultaneously.

Referring to Fig. 3, the receiving and storage steps involve handling spent fuel assemblies. In this form, plutonium would be thoroughly contaminated with fission products; radiation levels would be of the order of $15,000 \mathrm{rem} / \mathrm{hr}$ * Similar conditions exist for the materials in the mechanical and chemical head-end steps.

In the solvent extraction step, plutonium would be in the form of nitrate in solution in varying degrees of purity. The feed solution to the extraction cycle would have a radiation level of about $10,000 \mathrm{rem} / \mathrm{hr}$.* In this stream, the flow would be approximately $200 \mathrm{~kg} / \mathrm{hr}$ of heavy metal of which about $8 \%$ is plutonium.

After the solvent extraction step, in which the heavy metals are separated from most of the fission products, the uranium and plutonium stream is passed into the plutonium partitioning cycle. The aqueous plutonium stream flowing out of the partitioning cycle would have a radiation level of about $8 \mathrm{rem} / \mathrm{hr}$, * with a heavy metal flow of about $17 \mathrm{~kg} / \mathrm{hr}$, of which about $77 \%$ would be plutonium. The radiation level of the uranium-bearing organic stream would be about $600 \mathrm{rem} / \mathrm{hr} *$ with a heavy metal flow of 182 $\mathrm{kg} / \mathrm{hr}(<0.05 \% \mathrm{Pu})$. The waste stream would have a very high radiation level and low fissile content. The output from the plutonium purification cycle would be about $0.05 \mathrm{rem} / \mathrm{hr}$ * in a stream with a plutonium flow of $16 \mathrm{~kg} / \mathrm{hr}$, in a concentration of about $10 \mathrm{~g} / 1$. The output of an additional plutonium purification and concentration cycle is about $0.0005 \mathrm{rem} / \mathrm{hr}$ with a plutonium flow of $16 \mathrm{~kg} / \mathrm{hr}$ at a concentration of about $300 \mathrm{~g} / 1$ in a nitrate solution.

Starting with the first plutonium purification cycle, material could be diverted into the uranium line, out the waste line, out through an analytical chemistry sampling link or into a recycle line to be directed to an upstream sampling port.

In later steps purified plutonium oxide is found in solid form. Diversion of this material could take the form of several thefts of plutonium oxide powder, prior to the canister filling and storage operation or theft of canisters from the storage vault.

It is the protection of plutonium downstream from the first purification cycle where the processing plant safeguards system must play a strong role. That role is discussed in the next section.

\section{Safeguards for Reprocessing}

Except for some head-end receiving and mechanical operations and tail-end storage and shipping functions, the reference reprocessing plant utilizes a continuous flow process. 50 Generally fuel is assayed in the flowing stream; however, in some stages (for example, in hold-up tanks) the flow may be low enough so that assays are more nearly static measurements.

*Unless otherwise noted, all radiation levels are unshielded dose rates at one meter, normalized to one kilogram of plutonium in the source. 
The actual IAEA safeguards requirements that will be in effect when large FBR reprocessing facilities are finally deployed are unknown at this time. The approach taken here is to describe the detection sensitivity of a state-of-the-art safeguards system that could be integrated into the reference reprocessing facility. While the ultimate assurances on SNM accountability will depend on the international safeguards system, examination of a feasible national safeguards system is of interest in its own right. In addition, such technology has the potential for future international applications.

A safeguards system, 28,43 engineered to meet the varying process requirements is described generically in Section II.F.3.b. It utilizes NDA techniques primarily in the flowing process lines and depends on process instrument measurements of liquid level and organic-aqueous phase interface level to determine column (or tank) plutonium quantities. 50 Primary NDA techniques used are alpha, gamma ray analysis, and absorption edge densitometry. ${ }^{43}$ These techniques measure relative quantities of plutonium in the process line. By coupling standard flow meter data and frequent NDA calibration using analytical chemistry techniques, fuel mass flow is determined.

The system has been evaluated ${ }^{28}$ for diversion sensitivity by computer modeling the process streams, the NDA measurements, and the safeguards analysis system. 51,52

The results of these evaluations are given in Table I to show the range of capabilities for diversion detection. The amount of material, the loss of which would be detected within a given time, is presented as a function of material balance frequency and assumed accuracy for measuring fissile content in bulk liquids, as in columns, contactors, and holdup tanks. In the table, the right-hand column is the cumulative mass at which the safeguards computer realizes the diversion is taking place.

TABLE I. Reprocessing Safeguards Diversion Sensitivity

\begin{tabular}{lccc}
\hline $\begin{array}{l}\text { Maximum } \\
\text { Detection } \\
\text { Time }\end{array}$ & $\begin{array}{c}\text { Material } \\
\text { Balances Per } \\
8 \text {-hour Shift }\end{array}$ & $\begin{array}{c}\text { Assumed Column } \\
\text { Measurement } \\
\text { Accuracy }\end{array}$ & $\begin{array}{c}\text { Total at } \\
\text { Time of } \\
\text { Detection, kg }\end{array}$ \\
\hline 8 hour & 1 & $10 \%$ & 4.2 \\
1 week & 1 & $10 \%$ & 6.3 \\
1 hour & 8 & $5 \%$ & 2.6 \\
24 hours & 8 & $5 \%$ & 1.8 \\
\hline $\begin{array}{l}\text { Average detection time for single random diversions is half } \\
\text { of that indicated. }\end{array}$
\end{tabular}

The most marked improvement occurs when there are many balances during a detection period. System improvements could be made by increasing the balance frequency and/or improving measurements methods for the material in columns (or tanks).

It is unlikely that process monitoring sensitivity will ever approach that of the portal monitors, because process monitors must specifically identify the $\mathrm{Pu}$ and measure its quantity, while the doorway monitors 
measure gross gamma or neutron fluxes and assume that the signal is wholly from plutonium. These monitors provide the best safeguards against covert diversion of small quantities of special nuclear material.

Although quantities of SNM below the detection limits presently represent only a tiny fraction of plant throughout, future technical improvements prior to actual deployment of FBR reprocessing could produce a significant reductions. It is important to note, however, that these limits would apply only to rather sophisticated national safeguards systems. Limits on detection of national diversion of SNM will depend not only on implementation of technical systems, but also on institutional arrangements.

\section{Fabrication of Mixed Oxide Fuel for FBRs}

The reference fuel fabrication process in the international system involves the automated, shielded production of reactor-ready MOX fuel assemblies from bulk plutonium and uranium oxides. The generic steps in that process are shown in Fig. 5. This process includes the handling and processing of both special nuclear materials and structural materials. While assembly of the structural hardware is a significant part of the fabrication process, 53 the discussion which follows is limited to those steps in which plutonium-bearing material is handled or processed.



Fig. 5

Fuel Fabrication Process. ANL Neg. No. $116-79-199$

One possible process flowsheet for the fabrication of plutoniumuranium oxide fuel elements for FBRs is shown in Fig. 6.54 The process provides for the capability of sampling and analyzing the process flow steps at each point and allows for the recovery and recycle of material or process products which fail to meet specifications. The process flow steps for the fabrication of FBR fuel are very similar to those in a mixed-oxide fabrication plant for LWR fuel. 


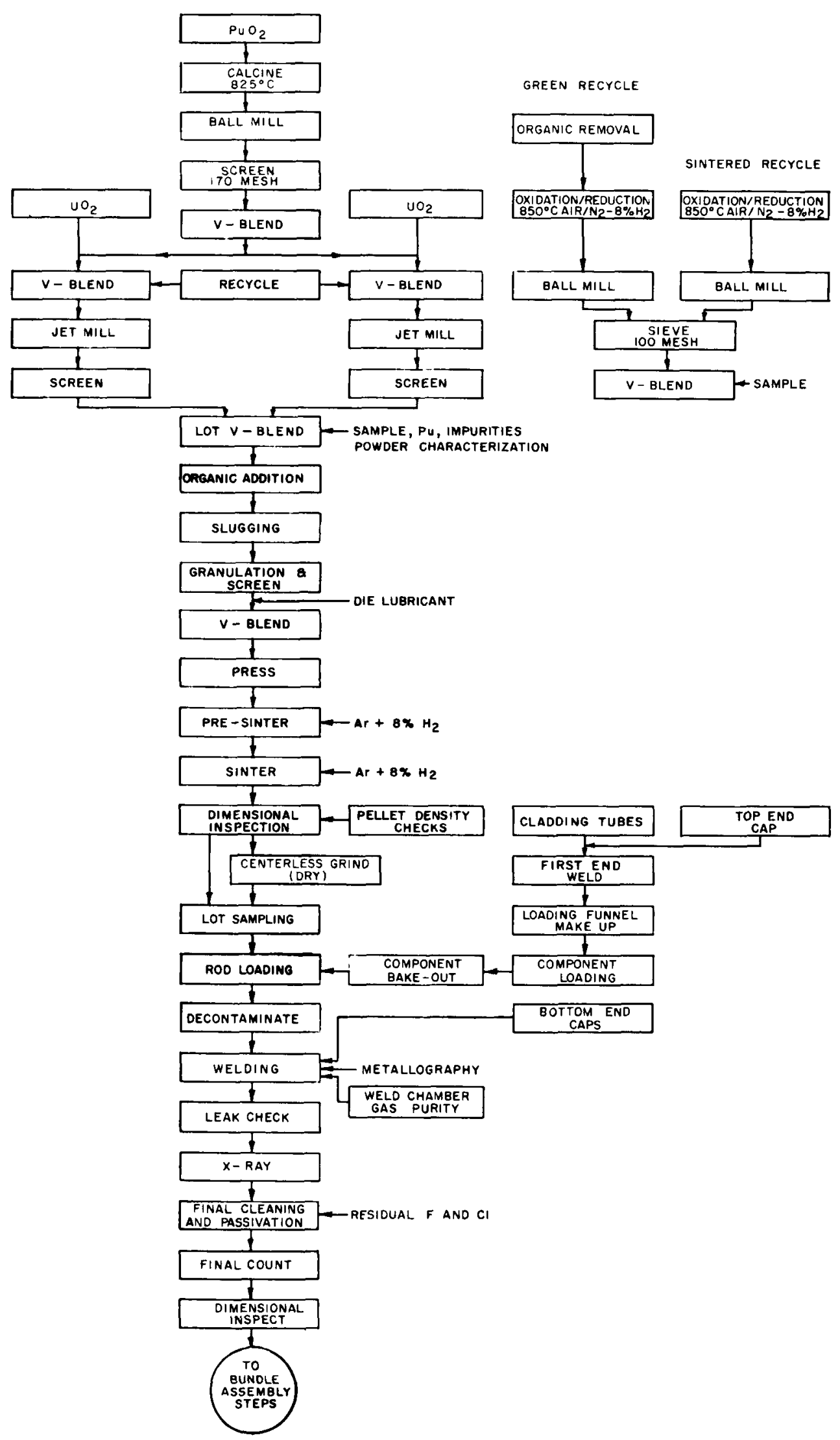

Fig. 6. Flow Diagram for the Fabrication of FBR Oxide Fuels. ANL Neg. No. ID-103-Cl1054 
In the reference process line shown in Fig. 6, separate streams of uranium and plutonium oxide arrive at the plant. The incoming fissile material is assayed and stored. Pellet fabrication begins when plutonium and uranium oxide powders are mechanically blended and compacted. The compacted material is granulated, mixed with a binder and pressed again to form a green pellet. This is sintered in an atmosphere of argon plus $8 \%$ hydrogen gas at a nominal temperature of $1700^{\circ} \mathrm{C}$ until the desired pellet density is achieved. Pellets are inspected for length, diameter, mass, and surface flaws. Non-conforming pellets are rejected to recycle scrap or ground to dimensions in a centerless grinder. Accepted pellets are dried, loaded into trays, and fed into a cladding tube. The loaded pin is welded shut; the surface is decontaminated and inspected for dimensional and structural defects. Each pellet in each pin is assayed for percent ${ }^{239} \mathrm{Pu}$, total fissile content, and time since separation. Data are accumulated for each pin. The completed pins are finally assembled in a completed fuel element.

The reference fabrication plant includes a low throughput recycle system to recover chemically contaminated SNM scrap generated during pellet and pin production operations. This includes all assay streams generated in the process of performing material accountability checks. The system is a scaled-down reprocessing plant employing the same basic process steps previously described.

There are two major differences between the FBR fuel fabrication processes described above and a conventional LWR fuel fabrication plant producing low enrichment fuel. The first is the presence of plutonium which requires that all process steps in which plutonium is handled must be carried out in sealed work spaces (e.g., glove boxes) or sealed containers. The isolation requirements for plutonium-bearing materials result from its radiotoxicity. Low-burnup plutonium containing more than $90 \%{ }^{239} \mathrm{Pu}$ is normally fabricated in sealed glove boxes by contact methods. Production of such plutonium is not thought to be practical for commercial application. Higherburnup plutonium containing up to $25 \% 240 \mathrm{Pu}$ and $24{ }^{1} \mathrm{Pu}$ has been fabricated in glove box facilities with strategically placed local shielding and with careful monitoring of personnel to limit radiation exposures. However, the high neutron and gamma activity of high-burnup plutonium containing up to $40 \%$ ${ }^{240} \mathrm{Pu},{ }^{241} \mathrm{Pu}$ and ${ }^{242} \mathrm{Pu}$ might require semi-remote or remote fabrication techniques. 55 The second difference is that FBR fuel material has a fissile content which is approximately 4 to 8 times greater than that in LWR fuels. Criticality considerations therefore dictate the process equipment and batch sizes. A large throughput FBR fuel fabrication plant would therefore be characterized by multiple parallel process trains.

A11 of the process steps have been demonstrated in the U.S. in low-throughput facilities where pins and fuel bundles have been produced for irradiation experiments. Commercial-sized automated equipment for remote pellet inspection, pellet pressing, powder blending, and pin welding has been developed and demonstrated. It is the intent of the current U.S. program to develop and demonstrate, within the next five years, all of the individual components needed for a commercial-sized mixed-oxide pellet fabrication facility. 
6. Fabrication of Metal Fuel for FBRs

Several U.S. fast-breeder systems have been fueled with metallic uranium and plutonium alloys. These, in the order of their appearance, were: Clementine, 56,57 EBR-I, 58 LAMPRE, 59,60 EBR-II,61,62 and the Enrico Fermi FBR.63,64 Experience was gained with machined plutonium (Clementine); molten $\mathrm{Pu}-\mathrm{Fe}$ (LAMPRE); coextruded elements (EBR-I and Fermi); NaK-bonded gravity cast, rolled, and machined uranium (EBR-I), NaK-bonded centrifugally cast and machined uranium (EBR-I); and Na-bonded injection-cast metallic uranium alloy (EBR-II). The principal experience with sustained metallic fuel fabrication in the United States is that accumulated during the fourteen years of operation of EBR-II. Consequently, the EBR-II experience will form the primary basis for this discussion.

Driver fuel elements for EBR-II consist of enriched uranium alloy fuel slugs. Although the uranium alloy is different than the U-Pu-Zr alloy fuel assumed in the INFCE reactor characteristics study (see Chapter 3), it is believed that the same injection-casting processes can be applied to $\mathrm{U}-\mathrm{Pu}-\mathrm{Zr}$ fuel. 65

Past experience in fabricating of EBR-II fuel has included both contaminated recycle fuel and fresh, unirradiated material. Fabrication of 35,000 radioactive fuel pins was done remotely early in the EBR-II history. This recycle feed material came from melt-refining, a process which left a fraction of the noble-metal fission products in the fuel. These fission products, called fissium,* made up 5\% of the metallic fuel. Fissium was a beneficial additive in that swelling characteristics of the fuel were reduced. Non-radioactive isotopes of fissium were subsequently used to fabricate almost 100,000 EBR-II fuel elements from cold (essentially nonradioactive) fuel material. 66

Figure 7 is an abbreviated flowsheet for injection-casting of metallic fuel. Several separate streams of components are used to produce a finished subassembly. Crucibles, molds, and alloy feed are used in the fuel pin fabrication; the pin, sodium, and jacket components are then used to fabricate finished elements; the finished elements are bundled to form reactor-ready subassemblies. The major loss of fuel material from the fabrication stream is the material accumulated in used crucibles; along with al1 other scrap, it is recycled into the process stream. Many of these processes require enclosure in a shielded facility for handling irradiated fuel.

Using unirradiated feed metal, EBR-II fuel alloy billets are prepared by the direct melting of uranium with fissium in a stabilized zirconia crucible (at $1370^{\circ} \mathrm{C}$ for about two hours) and casting in a graphite mold coated with zirconia, yttria, or thoria. The billet is remelted in a coated graphite crucible within an injection-casting furnace. The injection-casting furnace consists of a vacuum-pressure chamber in which a number of precisionbore Vycor tubes are suspended above the crucible. The furnace and the molds are evacuated during the melting cycle, the crucible is raised to immerse the open ends of the molds, and the furnace is rapidly pressurized with inert

*Fissium consists of Molybdenum (48.9\%), Ruthenium (38.7\%), Rhodium (6.1\%), Palladium (4.1\%), Zirconium $(2.0 \%)$, and Niobium $(0.2 \%)$. 


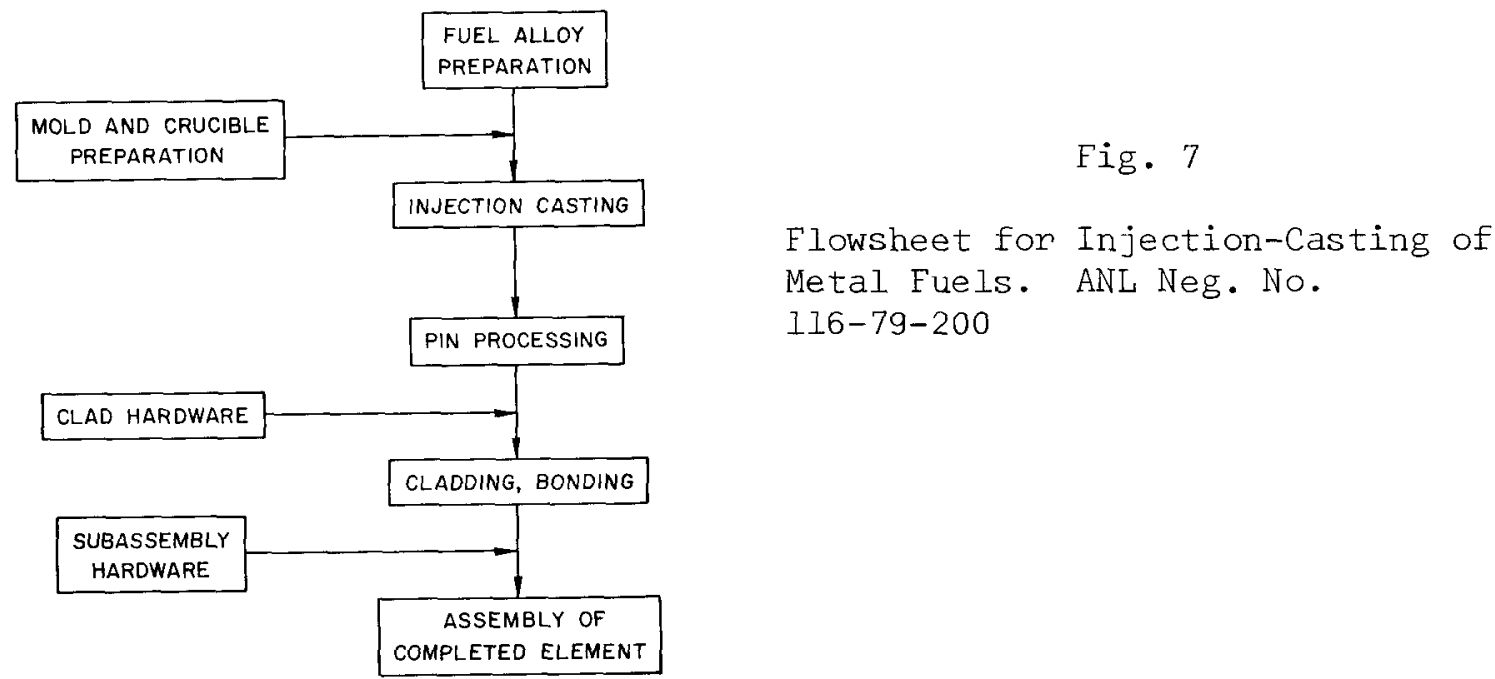

gas, causing the evacuated molds to fill. As soon as the metal in the molds solidifies, the molds are removed from the furnace.

After the molds are broken from the pins, the pins are cut to length, inspected, and loaded along with bond sodium into the fuel jackets. The sodium is melted and allowed to settle; then an end plug is welded in place. Both capacitive-discharge and tungsten-inert gas welding techniques have proven acceptable for this operation. Sodium bonding is accomplished by heating the elements to $510^{\circ} \mathrm{C}$ followed by repeated raising and lowering to work gas bubbles out of the annulus between fuel and cladding.

Performance of fuel fabricated by these techniques has been excellent, with only one failure being traced to a manufacturing defect.

Unirradiated U-Pu-Zr fuels could very likely be fabricated by a variant of the injection-casting technique described above. The major problem at this time is the difficulty of achieving chemical homogeneity in feed billets and pins. Melt-stirring and bottom-pour techniques have been used to reduce billet inhomogeneity. 67 Coatings of $\mathrm{NbC}$ and $\mathrm{Y}_{2} \mathrm{O}_{3}$ that were developed for use on pouring crucibles have proven successful. Problems still remain in coping with segregation of $\mathrm{Zr}$ during billet cooling.

Injection-casting of $\mathrm{U}-\mathrm{Pu}-\mathrm{Zr}$ appears to be feasible, although difficulties have been encountered using Vycor molds, ${ }^{68}$ due in large part to the high temperatures required $\left(1540^{\circ} \mathrm{C}\right)$ for $\mathrm{U}-\mathrm{Pu}-\mathrm{Zr}$ alloys. Compositional adjustments could result in reduced temperatures, and casting parameters could also be adjusted to produce acceptable pins.

Other pin-forming processes have been investigated for $\mathrm{U}-\mathrm{Pu}-\mathrm{Zr}$ alloys; these would also be applicable to uranium alloys. Both extrusion and swaging have been used to fabricate $\mathrm{U}-\mathrm{Pu}-\mathrm{Zr} ;{ }^{69}$ extrusion appears to be the more promising technique. The major uncertainties concerning mechanical forming processes are the remote operation and maintenance of the forming equipment in a hot fabrication operation and the unknown effects of crystallographic and mechanical texturing upon irradiation of the elements. Very 
small amounts of crystallographic texturing have been shown to result in rather substantial anisotropic irradiation growth in metallic fuels. 70

There is incentive to reduce the amount of recyclable scrap in metal fuel fabrication, since recycling results in increased process costs. Scrap results from losses in the injection-casting process; heels remaining in billet molds and injection casting crucibles; material adhering to or absorbed by ingot molds, crucibles, and pin molds; short castings; shards from the shearing operation; and fuel elements that fail to meet specification. All this material except that adhering to or absorbed by the molds and crucibles is recycled back into the fabrication process stream. Based on the EBR-II and Sodium Reactor Experiment (SRE) results, 71 it appears that 40-50\% of the feed material might require recycle back to the billet preparation step. The adhering/absorbing material will amount to $7-10 \%$ and must be chemically recovered. These values are higher than the corresponding numbers in oxide fuel pellet fabrication, where it appears that about $10 \%$ of the material will be recycled to the fabrication head-end, while about 3\% might require a wet recycle technique. This perhaps represents the advanced state of oxide fuels development.

\section{Fabrication of Carbide Fuels for FBRs}

The basic flowsheet for the preparation of uranium-plutonium carbide fuel pellets is similar to that employed with oxide material. The process involves an extra step to convert oxide feed material to carbides and variations in process conditions, but the basic techniques which have been developed for the oxides are applicable to the carbides.

The feed materials in the mixed carbide flowsheet are oxides. The oxides are blended with an unreactive binder and carbon. The mixture is pressed into a briquet form and introduced into a furnace where it rapidiy undergoes a carbothermic reduction at a temperature in the range of $1600^{\circ}$ to $2000^{\circ} \mathrm{C}$. Purging with an inert gas enhances the removal of carbon monoxide. Mechanical conditioning to obtain sinterable powder includes crushing, milling, and sieving. Because the carbide material is chemically reactive, all of the process equipment must be designed to guarantee a suitable inert atmosphere throughout the fabrication process. Helium with a low water and oxygen impurity content is acceptable. The steps in the preparation of green carbide pellets are the same as those used to produce oxide pellets. During pin fabrication, a controlled quantity of molten sodium is loaded to bond the pellets to the cladding. While the techniques and processes have all been demonstrated, the experience in the preparation of carbide fuels for fast reactors has been limited to only small-scale, glove box-type facilities producing test assemblies for irradiation experiments.

\section{Diversion Potential in Fabrication}

In order to identify diversion potential during fuel fabrication, typical quantities of fuel material in a fabrication plant are estimated in Table II. The plant has an assumed capacity of 100 tonnes of heavy metal per year, so scaling to other sizes would be simple. Based on 250 working days per year, this corresponds to an average throughput of $400 \mathrm{~kg} / \mathrm{day}$. Along the process line, this in-process inventory, $400 \mathrm{~kg} \mathrm{HM} /$ day, represents a daily throughput of $64 \mathrm{~kg} \mathrm{Pu}$ metal equivalent. Relative sensitivity of the material at various stages can be determined by referring to Section II.F. 
TABLE II. Process Line Storage Requirements

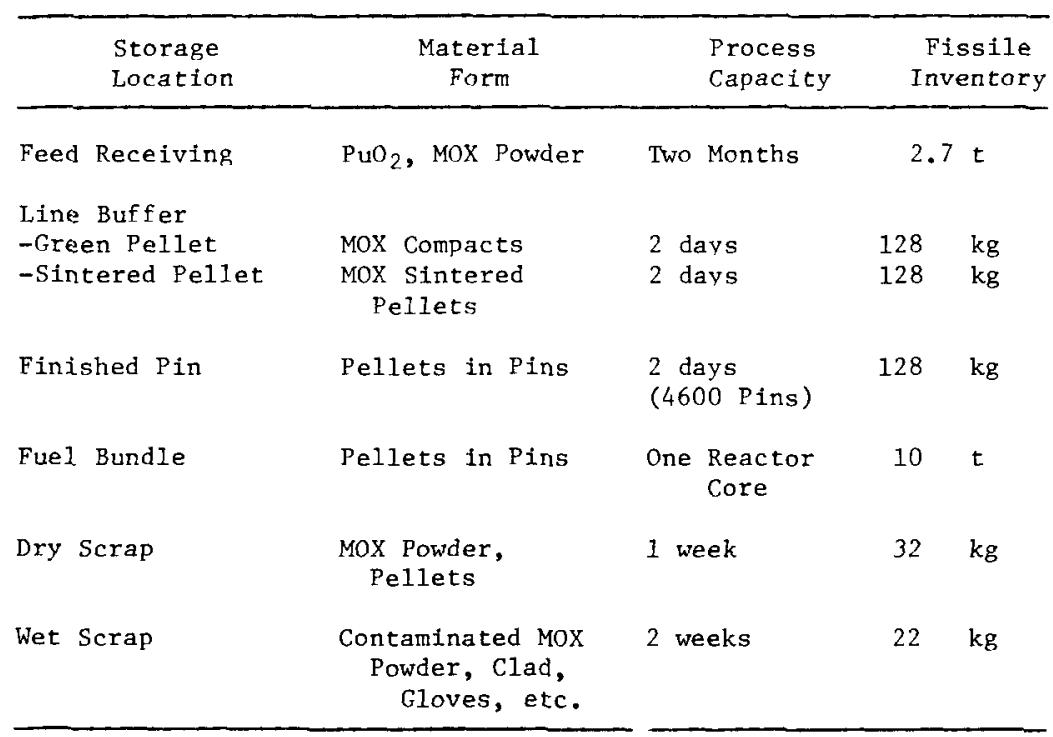

Unlike the reprocessing plant, where the fissile material purity and chemical form changes substantially during processing, the bulk of the fuel material in the reference fabrication plant arrives and remains as oxide throughout processing. The feed material includes a separate stream of $\mathrm{PuO}_{2}$ powder. It is this material, in storage and in the process line, which is the most sensitive. After the powder blending step, separated $\mathrm{PuO}_{2}$ is not handled again in the fabrication process (V-blend; Fig. 6).

After the mechanical blending step, the plutonium component may be partially separable by chemical means as a result of different acid dissolution characteristics for the plutonium and uranium oxides. After sintering, the mixed oxides require acld dissolution and solvent extraction (or an equivalent process) to isolate plutonium. After pin and/or assembly fabrication, the material additionally requires some means of removing the cladding and/or structural hardware of the assembly.

As previously noted, the reference fabrication plant includes lowthroughput acid dissolution and solvent-extraction equipment to recover SNM scrap generated during fabrication. This recycle process produces pure $\mathrm{PuO}_{2}$ for the head-end steps.

\section{Safeguards for Fabrication}

As with reprocessing, the safeguards system that is of primary interest to this evaluation is the IAEA system that will be in place at the time of deployment of large FBR fuel fabrication facilities. Just what that system will be is subject to considerable speculation. Since some of the system components could duplicate or include some of the domestic safeguards technology, the discussion here is limited to a technical discussion of a conceptual system for which the actual hardware exists.

It is assumed that the safeguards accounting system 44 described in Section II.F.3.b. will be used. Clearly, the data-gathering devices 
must be engineeied to the specific processes. For the reference fuel fabrication facility, these are taken from Ref. 44 based on a mixed-oxide fabrication plant using $4 \% \mathrm{PuO}_{2}$ in total mixed oxide. It is assumed that for fabricating $12 \% \mathrm{PuO}_{2}$ (average) mixed oxides, plant design change will not significantly impact the NDA detectors that are required.

Accountability measurements are made at each unit process in the fabrication line. These measurement systems may include weighing stations, gamma analysis NDA detectors, neutron counting NDA detectors, and visual identification and accounting positions. There are also automatic pellet counters and points for extraction of samples for laboratory chemical analyses and isotopic NDA. As an example, an entire fabrication line could have 42 weighing stations, 33 gamma analysis NDA monitors, 20 neutron counting NDA monitors, six sample points for laboratory chemical and NDA isotopic analyses, 28 visual accounting steps, and six automatic pellet counters.

The physical protection subsystem, as described in Section II.F.3.b. (1), involves stringent entrance and exit monitoring of people, materials, and equipment to minimize covert diversion. It emphasizes special facility design and delay systems to impede overt diversion.

The safeguards system has been evaluated for sensitivity ${ }^{4}$ to materials accountability discrepancies by the use of a time-event Monte Carlo simulation of the fabrication lines. ${ }^{72,73}$ The simulated process system was evaluated for sensitivity to discrepancies by the safeguards system methodology. ${ }^{74}$ The results are given in Table III for five sensitive unit processes. Although the indicated detection levels are reasonably low, they are well above the detection levels for exit monitors in the physical protection system (one-half gram $\mathrm{Pu}$ inside $3 \mathrm{~mm}$ of brass).

TABLE III. Results of Monte Carlo Analysis of Sensitivity of Material Management and Accountability System

(MMAS) in an FBR Fuel Fabrication plant

\begin{tabular}{lc}
\hline Unit Process & $\begin{array}{c}\text { Detection Level } \\
\text { (g Pu/Balance Period) }\end{array}$ \\
\hline $\mathrm{PuO}_{2}$ Unloading & 110 \\
$\mathrm{MO}_{2}$ Blending & 130 \\
Pelleting & 150 \\
$\begin{array}{l}\text { Grinding } \\
\text { Clean Scrap } \\
\text { Recovery System }\end{array}$ & 200 \\
\hline $\begin{array}{l}\text { at the 50\% confidence level; multiple events per balance } \\
\text { period precluded. }\end{array}$
\end{tabular}

The evaluated detection levels are based on what is considered to be readily attainable performance from current U.S. accountability methods. Further improvements might be expected in the MMAS prior to actual deployment of large fuel fabrication facilities. However, the role of sophisticated safeguards technology in future international safeguards systems cannot be 
predicted at this time. Therefore, application of limits to national diversion scenarios is dependent on the type of system that is adopted by the IAEA for application to FBR fabrication facilities.

\section{Waste}

Wastes from FBRs would not differ significantly from those generated in present-day LWRs. Basically they would be composed of fission products, actinides, and activation products. For $1000 \mathrm{~kg}$ of spent LWR fuel, about $35 \mathrm{~kg}$ of fission products and $14 \mathrm{~kg}$ of actinides are separated from the remaining $951 \mathrm{~kg}$ of uranium. ${ }^{22}$ The actinides include $9 \mathrm{~kg}$ of plutonium that is available for recycle, a few grams of which would appear in the waste stream. FBR fuel would contain more fission products because more power would be produced from the fuel. The quantity of plutonium and higher actinides would be determined by the initial composition as well as by the burnup.

Since a waste disposal policy has not been adopted in the United States, the reference process for handling high-level wastes is impossible to define at this time. One method that seems feasible and has had some technological development would be to solidify the high-level wastes and to fabricate them into borosilicate glass cylinders for ultimate disposal in deep geological deposits. Such processes are expected to be the same for both LWR and FBR wastes. Solidification of high level defense wastes as calcines has been done for about 15 years.

Estimates for recovery of fissile material from spent reactor fuel by current technology range from 93 to $99.5 \%$ of the $U$ and $\mathrm{Pu}, 75,76$ although anything below $99 \%$ would probably be unacceptable. Feasible improvements in process efficiency might raise the recovery to $99.95 \%$. Fissile material that is not recovered is lost to the waste stream. Estimated quantities of fissile materials that would appear in the high-level wastes are presented in Table IV for three FBR fuel cycle options.

TABLE IV. Estimates of Fissile Material in FBR Waste Streams

\begin{tabular}{|c|c|c|}
\hline \multirow{2}{*}{$\begin{array}{l}\text { Reactor/Fuel } \\
\text { Cycle Type }\end{array}$} & \multicolumn{2}{|c|}{$\begin{array}{c}\text { Fissile Materials in } \\
\text { the Waste Stream, } \\
\mathrm{kg} / \mathrm{Gwe}-\mathrm{a}\end{array}$} \\
\hline & $\mathrm{Pu}^{\mathrm{b}}$ & $U^{c}$ \\
\hline $\begin{array}{l}\text { Reference International } \\
\text { Deslgn (U/Pu) }\end{array}$ & $7.6-9.9$ & - \\
\hline Pu-Th Core & $4.7-5.9$ & $3.2-3.8$ \\
\hline $23^{3}$ U-Th Core & - & $7.1-8.6$ \\
\hline
\end{tabular}


There are two factors inherent in spent fuel and reprocessing wastes which would make them relatively undesirable as a source of SNM: high radiation levels and high internal heat generation. Because of these characteristics, diversion of SNM from the waste stream would require specialized handling techniques and equipment. The activity and thermal power of representative FBR spent fuel elements are presented as a function of time after shutdown in Table $V$.

TABLE V. Representative Thermal Power and Activity of FBR Spent Fuel as a Function of Time After Removal

\begin{tabular}{lrr}
\hline $\begin{array}{l}\text { Time, } \\
\text { Days }\end{array}$ & $\begin{array}{c}\text { Thermal Power, } \\
\mathrm{kW} / \mathrm{t}^{\mathrm{a}}\end{array}$ & $\begin{array}{l}\text { Activity, } \\
\mathrm{MCi} / \mathrm{t}\end{array}$ \\
\hline 0 & 2822 & 237 \\
10 & 118 & 29 \\
20 & 88 & 21 \\
30 & 74 & 18 \\
60 & 53 & 12 \\
90 & 42 & 10 \\
180 & 27 & 6 \\
360 & 14 & 3 \\
720 & 7 & 2 \\
\hline
\end{tabular}

a Tonne of heavy metal.

The presence of a mixture of $\mathrm{Pu}$ isotopes in the reactor fuel would make the total production of higher actinides greater in an FBR than in an LWR using a once-through fuel cycle. However, production in an LWR using recycled plutonium would be comparable to that in an FBR, on the order of $25 \mathrm{~kg}$ of higher actinides per GWe-year.

Because the actinide wastes have very long half-lives, they would persist long after fission product wastes have become insignificant. One proposal to deal with this problem is to partition the actinides from the remainder of the waste stream and then burn them in an FBR.

Higher actinides in the waste stream produce a potential proliferation concern since fissile isotopes occur in their decay schemes. $243 \mathrm{~cm}$ and ${ }^{243} \mathrm{Am}$ decay to ${ }^{239} \mathrm{Pu},{ }^{245} \mathrm{Cm}$ decays to $241^{\mathrm{Pu}}$, and ${ }^{241} \mathrm{Am}$ decays to ${ }^{23}{ }^{3} \mathrm{U}$. However, the half-lives of the parent isotopes are sufficiently long that production of fissile material from actinide decay represents a rather minor resource. In two of the cases, the half-life of the fissile isotope is shorter than that of the actinide parent. As a result, the amounts of ${ }^{241} \mathrm{Pu}$ and ${ }^{233} \mathrm{U}$ present in secular equilibrium would be reduced substantially from the parent concentrations.

\section{Transportation}

The transport of fissile material occurs in four basic forms in the nuclear fuel cycle: (1) shipment of bulk material to a fabrication facility from either a reprocessing center or from an ore processor, (2) 
shipment of fresh fuel from the fabrication facility to the reactor, (3) shipment of spent fuel to a reprocessing facility, and (4) shipment of waste materials to a disposal site. The protection of the fissile materials in these steps relies primarily on security measures, although heavy containers and high radiation levels provide some inherent protection.

SNM has been transported on highways, railroads, and waterways, but air transport of significant quantities of plutonium is currently prohibited by NRC regulation. Potential accidents in the various modes of transport have been studied 77 and shipping casks have been designed to withstand collisions and fire. ${ }^{78}$

The need for accident protection, radiation shielding, and decay heat removal could result in casks as large as 90-100 tonnes ${ }^{79}$ for shipping FBR spent fuel, as opposed to roughly half that mass for LWR spent fuel shipments. Problems which occur to a greater extent with FBR fuel include higher neutron emission from spontaneous fission and higher decay heating rates. The decay heat limits the amount of fuel that can be shipped in a single cask. 79 The most optimistic design would allow roughly $48 \mathrm{~kW}$ of total heat generation. 80

To assess the impact of fuel transportation, a reference design with 318 subassemblies, 2-year residence time, and $10 \mathrm{~kg}$ of fissile plutonium per subassembly has been assumed. Estimated quantities of fissile material that are shipped each year are presented in Table VI.

TABLE VI. Estimated Quantities of Fissile Material Transported Within the U.S. in Tonnes per GWe-year

\begin{tabular}{|c|c|c|c|c|c|}
\hline \multirow{3}{*}{$\begin{array}{l}\text { Transport } \\
\text { Step }\end{array}$} & \multicolumn{5}{|c|}{ Fissile Material Transported, $t / G W e_{-a}^{a}$} \\
\hline & \multicolumn{2}{|c|}{ PWR, $1000 \mathrm{MWe}^{\mathrm{a}}$} & \multicolumn{3}{|c|}{$\mathrm{FBR}^{\mathrm{b}}$} \\
\hline & Once Through & Pu/U Recycle & Blanket & Core & Total \\
\hline $\begin{array}{l}\text { Fuel Material } \\
\text { to Fab. Plant }\end{array}$ & $\begin{array}{l}0.855^{235} \mathrm{U} \\
(3 \% \text { enr. })\end{array}$ & $\begin{array}{l}0.67^{235} \mathrm{U} \\
(3 \% \text { enr. })\end{array}$ & $0.04^{235} \mathrm{U}$ & $\begin{array}{l}0.03235 \mathrm{U} \\
1.59239+241 \mathrm{Pu}\end{array}$ & $\begin{array}{l}0.07 \\
1.59\end{array}$ \\
\hline Fuel to Reactor & $\begin{array}{l}0.84{ }^{235} \mathrm{U} \\
(3 \% \text { enr. })\end{array}$ & $\begin{array}{l}0.66{ }^{235} \mathrm{U} \\
0.27 \mathrm{U} / \mathrm{Pu}\end{array}$ & $0.05^{235} \mathrm{U}$ & $\begin{array}{l}0.033^{235} \mathrm{U} \\
1.59239+241 \mathrm{Pu}\end{array}$ & $\begin{array}{l}0.08 \\
1.59\end{array}$ \\
\hline $\begin{array}{l}\text { Fuel from Reactor } \\
235 \mathrm{U} \\
239+24{ }^{1} \mathrm{Pu}\end{array}$ & $\begin{array}{l}0.22 \\
0.17\end{array}$ & $\begin{array}{l}0.17 \\
0.27\end{array}$ & & & $\begin{array}{l}0.08 \\
1.60\end{array}$ \\
\hline $\begin{array}{l}\text { Recycled Fuel } \\
235 \mathrm{U} \\
239+24 \mathrm{IPu}_{\mathrm{Pu}}\end{array}$ & - & $\begin{array}{l}0.15 \\
0.27\end{array}$ & & & $\begin{array}{l}0.08 \\
1.59^{\mathrm{c}}\end{array}$ \\
\hline
\end{tabular}

a. Domestic Transportation Safeguards

Considerable experience in transportation of material protected by use-denial systems has been gained in the last two years. One of these is the U.S. Department of Energy's Safe Secure Trailer (SST). The SST is a $40 \mathrm{ft} \times 8 \mathrm{ft}$ armored trailer modified to function as a mobile vault. It 
includes digital communications with regional monitoring stations, electronically coded locks, and accident and fire protection. It is usually accompanied by one or two escort vehicles carrying several trained guards. 80 Computer programs which evaluate physical protection systems by simulation of armed attack 81,82 and which evaluate alternate routes with respect to available law enforcement agencies ${ }^{83}$ are being developed.

Cask designs are available $e^{79}$ which provide some deterrent to diversion by requiring special equipment and/or a detailed knowledge of the system in order to gain access to contents. In the case of spent fuel, the size of the cask (90-100 tonnes) in itself would present substantial handling problems.

Transportation of fresh plutonium and enriched uranium in the United States has historically been handled by armed-courier-escorted government leased or owned vehicles. Recent improvements in transportation methods have centered on sophisticated physical security measures. In transit monitoring of SNM is technically feasible but has not been done.

The physical security measures applied to transportation have been primarily aimed at preventing overt seizure of the material. The defense against the couriers covertly diverting material has been through the use of tamper-proof seals placed on the containers.

\section{b. International Transportation Safeguards}

For the purposes of applying IAEA safeguards, nuclear material transportation may be viewed as a moving FBR fuel cycle storage facility. The type of material being transported determines the level of IAEA goals which which the safeguards system should approach. Presented below are three concepts for safeguarding nuclear material in transit which meet IAEA safeguard goals. ${ }^{84}$ These concepts vary not with respect to the distance traveled, but with the time-interval goal for verification and the avallable safeguards measures.

\section{Periodic Shipping/Receiving Comparison}

This concept is based on the comparison and correlation of material transfer records at the origin and destination of shipments, and on the accountacy records maintained at a monitoring agency. The key elements are:

- Notification by the shipper of the transfer,

- Notification by the receiver,

- Use of seals and integrity devices by the shipper/receiver to assure the integrity of the shipping container or cask and the material contained, and

- Periodic on-site inspector verification of shipment records supplemented by physical inventory. 
This system provides for the detection of anomalies in shipment records or in inventories during on-site inspections. The time required for verification depends on the frequency of inspection.

\section{Escorts}

This concept, which is applicable to shipment times averaging more than a few days, assumes continuous IAEA-inspected escort of the transportation vehicle from the point of origin to the destination. The key aspects of this system may include:

- Frequent notification, by standard telephone or radio, of the position of the transportation vehicle and the integrity of material containment,

- On-site observation of loading, unloading, and verification of transported fuel, and

- Use of seals and integrity devices by the shipper/receiver to assure the integrity of shipping container or cask and the material contained.

This concept has a capability for rapid detection of diversion of the shipment during transit.

\section{Remote Surveillance}

This concept is based on a monitoring system which verifies, by a remote communication link, the presence and integrity of the material in its container during its transit between the origin of shipment and the destination. Placement and removal of the material from the container is verified independently at the shipping and receiving facilities. This concept provides the capability for the detection of tampering or removal of material during transit. It would employ high-frequency radio and satellite communication links and other presently available equipment. The speed of detection is dependent only on the time interval chosen for communication between the vehicle and the off-site monitoring facility. Thus, with this system nearly instantaneous detection of diversion could be achieved. It should be noted, however, that this type of surveillance is in only the conceptual stage. Therefore, feasibility evaluations and demonstration will be required before it can be recommended for implementation on an international basis.

B. Modifications to the Reference Processes: Feasibility, Implications and Impact on Diversion Resistance

The following sections contain descriptions of alterations to the reference fuel cycle that have been suggested to make it more acceptable from a proliferation defense standpoint. Technical feasibility and incremental diversion resistance are emphasized.

\section{Alternate Methods of Fue1 Reprocessing}

Several methods for reprocessing spent reactor fuel other than the reference Purex process have been developed or discussed. In addition, some 
variants of the Purex process which retain some uranium and some fission products in the plutonium stream have been suggested. Here we examine some of these alternate concepts from the point of view of diversion resistance and technical feasibility. Batch process methods such as ion exchange and precipitation have not been included because their low throughput and high expense do not make them suitable for the reference deployment scenario. Pyrochemical processes have been deferred until Section $V$ because of their possible suitability for integral cycle deployment. Processes that retain substantial uranium with the plutonium are less sensitive. Processes that employ lowdecontamination factors or spikants leave the fuel physically hot and highly radioactive. The impact of these parameters on proliferation resistance was discussed in Section II.

\section{a. Coprocessing}

The reprocessing of spent U-Pu fuel assemblies under the requirement that the plutonium is never separated from uranium could be done with a modification of the Purex solvent extraction process. A flowsheet for a co-extraction process is shown in Fig. 8. The head-end steps including dissassembly, chopping or shearing, voloxidation, and dissolution, would remain the same as discussed in Section III.A.l. After dissolution the plutonium in the feed solution would be present in the +4 valence state, $\mathrm{Pu}$ (IV), which is extractable in TBP. This would be introduced into the first extraction contactor, where uranium and plutonium would be selectively extracted into the organic phase. The first extraction step would correspond to the first extraction step in the conventional Purex process in which the uranium and plutonium are co-extracted into tributyl phosphate (TBP) and a high decontamination factor is obtained. The aqueous phase containing the fission products would pass out of the contactor to the high-level waste. In the scrub section of the contactor, the organic stream would be washed with $\mathrm{HNO}_{3}$ for additional fission product removal.

From the scrub section, the organic stream carrying the uranium and plutonium would pass to a partitioning contactor (step 2 in Fig. 8). Here the organic stream would be contacted with an aqueous stream containing a reducing agent (as in the reference process) to convert plutonium to its non-extractable state that would be carried with the aqueous flow. However, conditions would be changed from the reference to force some uranium into the aqueous flow. The flow rates of the organic and the aqueous streams, the nitrate-concentration in the aqueous stream, and the temperature could be modified to achieve this end. For example, whereas in the reference process the aqueous flow might be about one-tenth the organic flow and carry only traces of uranium, an increase to a little over half the organic flow would increase the $U$ concentration in the product to about four times the $\mathrm{Pu}$ concentration.

The uranium and plutonium in the aqueous stream could then be passed through one or more purification cycles. The organic stream carrying the remainder of the uranium would be sent to a stripping stage where the uranium would be stripped into an aqueous solution, which would pass on to a uranium purification cycle. The uranium stripping and purification cycles would be similar to those in the conventional Purex process. 


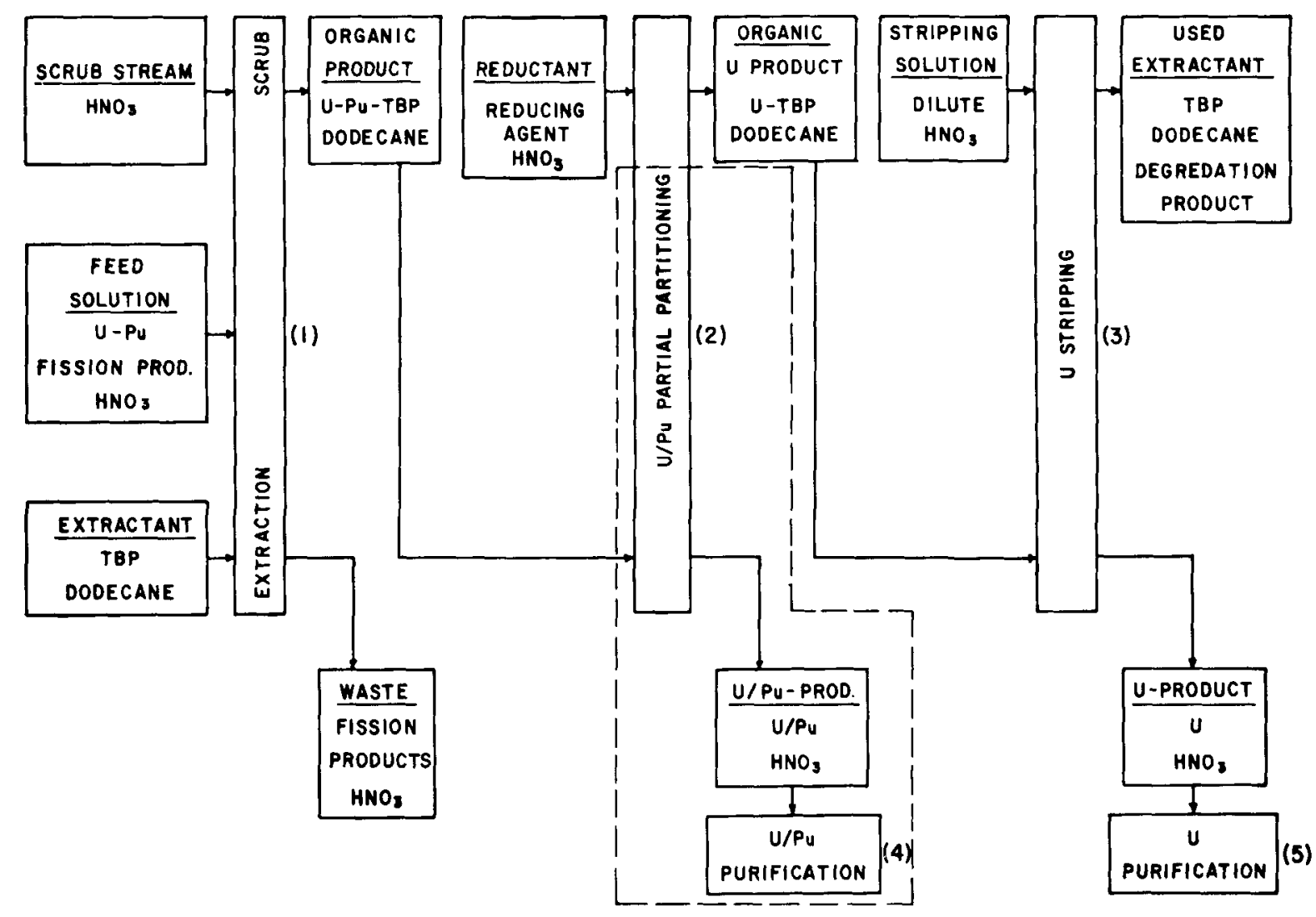

Fig. 8. Coprocessing Solvent Extraction Flowsheet. ANL Neg. No. 116-79-189

If blanket and core material were to be processed separately in campaigns, the coprocessing plant would have to be made very flexible since the plutonium fraction could vary from about $1 \%$ to about $15 \%$, and it would be desirable to produce a coprocessed product which is in the range of $15 \%$ to $25 \%$ plutonium. Development of a tamper-proof process under these conditions would be more difficult than for an operation using uniform feed.

Aqueous coprocessing would have all of the technical problems that the Purex process has, in addition to the optimization of flow rates and mass balances. While it appears that this process would be technically feasible, coprocessing spent FBR fuels with $10 \%$ to $20 \%$ plutonium requires additional study and development work.

In addition, the product conversion step, in which the $U / \mathrm{Pu}$ is converted to oxide, could not utilize the traditional oxalate precipitation process because the precipitation chemistries of uranium and plutonium are different. An alternate conversion technique is under development for coconversion. 85 This conversion process utilizes ammonium hydroxide precipitation step followed by fluid-bed calcination and finally a fluid-bed reduction and stabilization step. This process has been demonstrated on a laboratory scale, but significant development would be required before it would be ready for commercialization. 
Coprocessing would slightly impact the total cost and complexity of the overall fuel cycle. The principal cost impact would be in product conversion, associated with the large increase in throughput volume. The severity of the impact would be dependent upon the amount of uranium left with the plutonium. In a plutonium-only conversion in a 5 tonne/day reprocessing plant, a throughput volume of about $500 \mathrm{~kg} /$ day of $\mathrm{PuO}_{2}$ would be expected. For comparative purposes, the throughput volume increases to about $2000 \mathrm{~kg} / \mathrm{day}$ for a $25 \%$ plutonium product. One estimate of the cost impact of coprocessing on the LWR fuel cycle is about 0.1 mill/kW-hr as an upper bound on the cost penalty. 86 With the smaller relative increase of bulk throughput for FBRs than for LWRs (because of the higher plutonium fraction in FBR fuel), it seems reasonable to conclude that the total cost impact of coprocessing on FBR fuel cycle costs would be less than that for LWRs.

\section{b. Coprocessing with Low Decontamination}

A possible modification to the reference fuel cycle would be to produce recycled fuel in which some of the radioactive fission products are carried through in reprocessing. The fissile material would then always be in a mixture of radioactive elements in all parts of the fuel cycle.

Fuel reprocessing under these conditions would use a variant of the co-extraction process described in the previous section. A flowsheet for this process, shown in Fig. 9, is based upon one (Civex) suggested by EPRI ${ }^{87}$ in their study of proliferation resistant fuel cycles for breeders. To minimize the decontamination, the scrub section in the first extraction contactor would be eliminated. Flow rates would be adjusted so that the saturation level of uranium in the organic solvent would be less than in a normal Purex operation, and the nitric acid in the feed stream would be reduced. These changes would combine to increase the extraction of zirconium and ruthenium into the organic solvent. The steps following extraction would be similar to those in normal coprocessing. Again, the fraction of uranium stripped with plutonium would be controlled by the relative flow rates of the organic and aqueous streams and by the specific design of the extraction equipment. Conversion of the product to MOX must not decontaminate the product further. The conversion process referred to in Section III.B.1.a appears to satisfy this requirement.

A11 of the development problems associated with Purex and with the coprocessing scheme would be present here, in addition to those caused by high levels of radioactivity throughout the plant.

The high radiation levels might interfere with criticality monitoring instrumentation and might make it difficult to provide material accounting. Routine sample analysis would have to be done remotely, with a concomitant reduction in accuracy.

Major losses of some of the residual fission products could occur in the calcining and sintering steps during fabrication. In addition, the product end of the plant will require complete shielding and remote handling because of the radioactive nature of the product.

The cost impact of coprocessing with low decontamination would be primarily determined by the increased shielding requirements in the back 


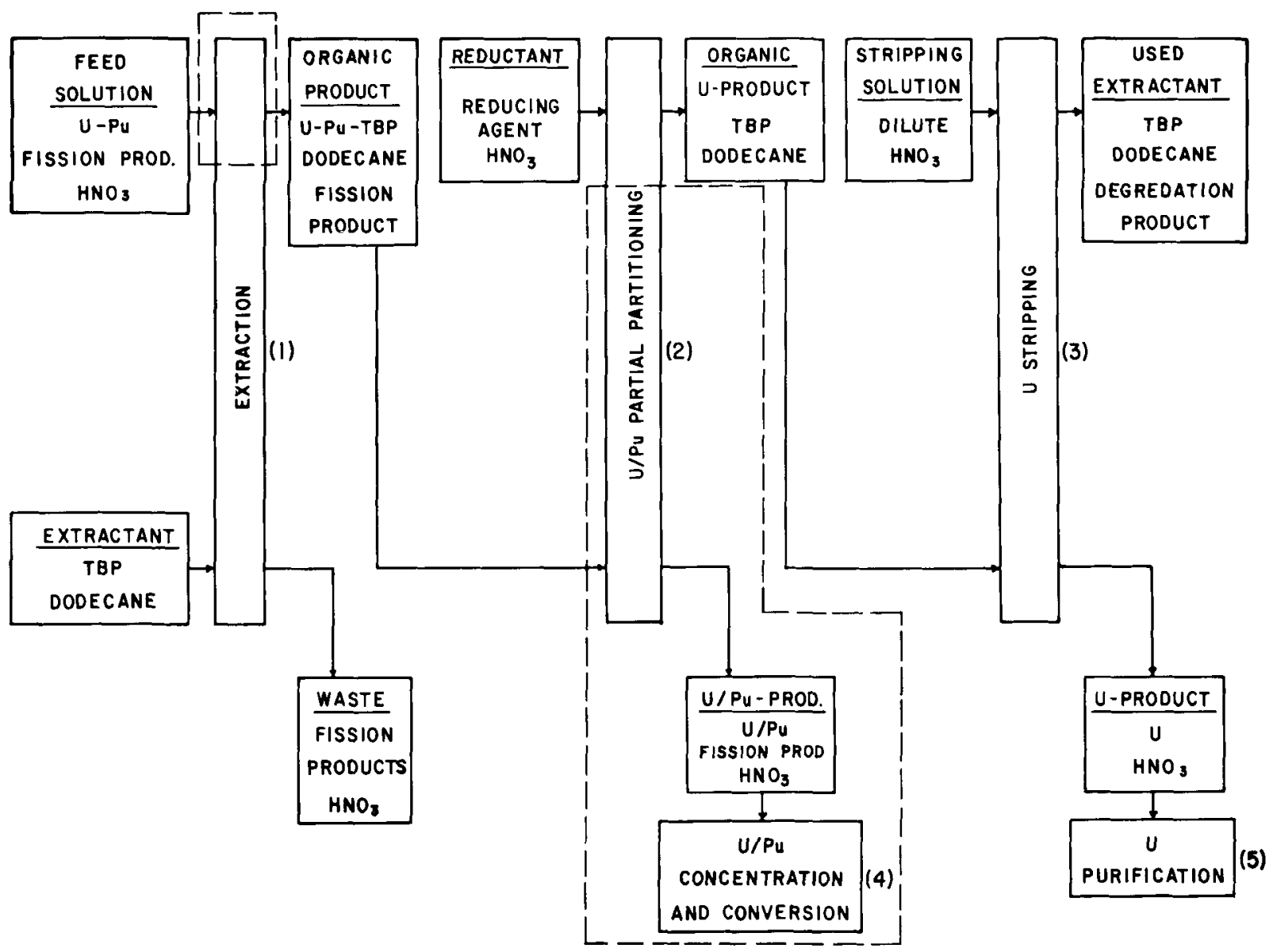

Fig. 9. Solvent Extraction Flowsheet for Coextraction with Low Decontamination Factors. ANL Neg. No. 116-79-190

end of reprocessing and in all of the fabrication portions of the fuel cycle, as well as by added remote handling requirements. One estimate 88 ranges from a $5 \%$ to a $50 \%$ increase in fuel cycle costs.

\section{c. Halide Volatility Processes}

The halide volatility processes form fluorides or chlorides of the fissile and fertile materials and then separate using relative volatilities. The primary expected use of the chloride volatility process would be for the treatment of thorium-based fuels. Since thorium-based fuels are not a part of the reference deployment scenario, chloride volatility will not be treated in this section.

Fluoride volatility seems especially well-suited for uranium fuels. $U_{6}$ is a stable, readily formed fluoride that can be easily handled in a volatility process. Volatile $\mathrm{PuF}_{6}$ can also be formed, but decomposition to non-volatile $\mathrm{PuF}_{4}$ must be controlled to reduce losses and avoid criticality hazards. ${ }^{88}$ Thorium does not form a volatile fluoride.

Fluoride processes suffer from several disadvantages besides the $\mathrm{PuF}_{4}$ problem. Fluoride is an expensive reagent with corrosive properties which could result in an undesirable amount of maintenance and replacement 
of process equipment. Development is only to the bench engineering stage, although extensive laboratory work has been done.

Fluoride volatility could offer certain advantages when used for only a part of the reprocessing steps. Such an approach is taken in the Civex concept. 87 There, fluoride volatility would be used to decontaminate the uranium stream after partitioning. The process was chosen because if plutonium were diverted into the stream, it would be flushed out with the fission products. The process was also used as a uranium purification step in the reprocessing plant at Morris, Illinois.

\section{d. Dry Processes}

The dry processes fit into the category of low decontamination processes. Basically, the fuel is treated with gases to change the chemical composition. During the breakdown of the original structure, fission product gases and volatiles are released and removed. A reduction process follows, which reconstitutes the fuel to the correct chemical form.

Since some classes of fission products always remain with the fuel, the process has limited usefulness in a multiple recycle situation. Eventually residual fission products would have to be removed by some other means.

\section{Fuel Spiking}

The concept of fuel spiking is to add a radiation barrier around some of those parts of the fuel cycle in which the plutonium is not protected by radiation from the decay of fission products. There are at least three motivations for spiking fuel with neutron or high-energy gamma sources: (1) to enhance the detectability of SNM, (2) to aid in locating stolen materia1, and (3) to deter would-be thieves by incapacitating or killing them with a high radiation dose. Although there is a great deal of flexibility about where in the fuel cycle the spikant could be added to the SNM, each choice has some disadvantages. An alternate approach would be to use external, fixed sources rather than mixing a spikant with the material. These concepts have been studied in some detail for LWR and HTGR fue1.89 Much of that work would be applicable to FBR fuel spiking.

Many neutron and gamma emitting materials have been considered as possible spikants. At least four criteria have been applied when selecting candidate materials:

i. a source of supply at reasonable cost, such as a fission product, a higher actinide, or a regularly produced radioisotope;

ii. for neutrons, a copious emitter or for gammas, a relatively hard gamma ray;

iii. a half-life compatible with demands on out-of-reactor time, e.g., >1 year;

iv. compatibility with the reactor fuel. 
Based on these criteria, ${ }^{60} \mathrm{Co}$ would be the current choice. It has two gamma rays with energies exceeding one $\mathrm{MeV}$. However, recent studies have indicated that cobalt might not be totally compatible with the reference oxide fuel. For this reason cerium and stable compounds of cesium are also being considered. No neutron emitters were found which met all the criteria, although some would be useful for purposes of detection and location of SNM.

Spiking for detection requires only that a minute amount of spikant be added to the SNM. These small amounts, on the order of microcuries of ${ }^{60} \mathrm{Co}$ per kilogram of heavy metal, are adequate to ensure that even gram quantities of moderately-shielded SNM could be detected by portal monitors. Neutron emitters would be even more effective because of the inherently low neutron background in most facilities. With its inherent spontaneous fission source, plutonium would probably need no additional spiking if neutron detectors were used in the portal monitors. $235_{\mathrm{U}}$ might require about $0.1 \mathrm{\mu g}{ }^{252} \mathrm{Cf}$ per $100 \mathrm{~g}$ of $235 \mathrm{U}$ if several centimeters of light shielding were assumed.

By using the inherent neutron source of plutonium, and sensitive neutron detectors in the portal monitors, no external spiking would be required and there would be no adverse effect on the fuel cycle. This might require some development of thermal neutron doorway monitors, investigation of fast neutron shields, and maintenance of low neutron background levels in fabrication plants.

The success of spiking to locate stolen SNM would depend on many parameters. As in the case of spiking for detection, neutron emitters seem to have an advantage because of the naturally low and invariant neutron background. In addition, fast neutrons would not be as susceptible to concrete shielding as gamma rays. Again, it might be possible to use the inherent neutron sources in plutonium fuels, especially if the ${ }^{244} \mathrm{~cm}$ (a copious neutron emitter) is recycled. Addition of ${ }^{252} \mathrm{Cf}$ is also a possibility. For this application, about $18 \mu \mathrm{g}{ }^{252} \mathrm{Cf}$ per $\mathrm{kg}$ of $\mathrm{Pu}$ would be required. Such additions would strain the present production capacity of ${ }^{252} \mathrm{Cf}$.

Recycling the curium isotopes could cause some problems. Such problems would include additional alpha heating, special processing of active wastes, an unknown impact on fuel performance, an increase in handling difficulties, and activation in process equipment resulting from neutron capture.

The third level of spiking would involve adding enough spikant to kill or incapacitate after a few minutes of direct exposure to the SNM. The radiation level for deterrence would be in the range of $250 \mathrm{rem} / \mathrm{hr}$ at one meter to $20,000 \mathrm{rem} / \mathrm{hr}$ at one meter for a five-kilogram container of fissile material.90 Because of shielding considerations, this range would be dependent on the gamma energy. Two methods for this level of spiking have been proposed. The first would mix the spikant with the bulk SNM. The second would mechanically attach high-intensity sources to fuel assemblies, shipping casks, and/or bulk storage containers. Neutron emitters do not appear to be feasible for the required radiation levels. Hence, only ${ }^{60}$ Co sources are considered for the rest of the discussion.

Several problems would be associated with mixing large amounts of ${ }^{60}$ Co with SNM in order to achieve a deterrence capability. Such action would result in a substantial increase in fuel costs and electric power costs. Low 
decontamination in the recovery process could achieve essentially the same level of deterrence at less cost and with the added benefit of a reduced number of processing steps. At the high activity levels required, $>5 \mathrm{Ci}\left({ }^{60} \mathrm{Co}\right) / \mathrm{g} \mathrm{Pu}$, the self-heating rate would become a major engineering concern. Circulating cooling systems might be required for all storage and transportation periods. One of the primary deterrent characteristics of the spiked SNM is that heavy containers would be required for safe handling of the material. This advantage could be galned without the addition of a spikant.

The concept of attaching external ${ }^{60} \mathrm{Co}$ sources is quite different from the concept of having the spikant finely mixed with the plutonium. It would have the significant disadvantage of not being a protective measure inherent to the SNM. However, it would have some advantages, including lower projected costs. External sources would probably increase the nuclear electric generating costs by less than one percent. Another advantage would be that these external sources could provide a substantial amount of protection from access to SNM at the most vulnerable points in the fuel cycle. ${ }^{60} \mathrm{Co}$ sources could be temporarily attached to fabricated fuel assemblies from the time that fabrication is complete until just before they were placed in a reactor. Intense sources could be attached to fuel casks. Terrorists attempting to penetrate shipping casks and remove kilogram quantities of plutonium would be exposed to $10,000-100,000 \mathrm{rem} / \mathrm{hr}$ gamma fields. Extensive shielding and remote handling would be required, and the escape vehicles would have to be heavily shielded. Attached sources could also be used for protecting such bulk SNM as $\mathrm{PuO}_{2}, \mathrm{MOX}$, plutonium nitrate solution, and plutonium scrap, either in storage or in transportation.

External ${ }^{60} \mathrm{Co}$ sources could also be used to protect in-process SNM, but there the implications are considerably different than for protection during storage and transportation. Massive shielding required to protect operators would increase costs. High gamma backgrounds could interfere with criticality monitoring. Remotely deployable sources could reduce the impact of protecting SNM during processing. These sources would only be deployed when an attempted theft was signaled. However, accidental deployment of the sources would be a serious hazard for employees. Maintenance of such sources could also be a problem.

\section{Plant Design Features to Inhibit Flexibility or Alteration (Civex Approach)}

One possible component of diversion resistance is the design of fuel reprocessing and fabrication plants that have inherent limits on flexibility and which require major construction projects for alteration. Since such plants have not been built or even designed in detall, this report shall treat the subject in a conceptual manner. The ideas presented here are summarized from a paper by Levenson and Zebroski ${ }^{87}$ dealing with the Civex system.

Those criteria in Civex which have to do with plant design are that there should be: (1) no way to produce pure plutonium by simple process adjustment, (2) no way to produce pure plutonium without equipment modifications, (3) no way to carry out equipment modifications with facilities and components normally on site, and (4) no way to carry out the required equipment modifications without plant decontamination or entry into extremely high radiation fields. 
The intent of the provision for not being able to produce pure plutonium by simple process adjustment is to protect against diversion by the "inside man". This means that no feasible adjustments to acidity, flow rates, or reducing agent concentrations could produce a stream of pure plutonium.

The second and third criteria are intended to ensure that modifications required to produce pure plutonium involve extensive construction projects with materials brought in from the outside. Simple plumbing and/or electrical changes would not be sufficient to produce pure plutonium. New components would be required, but the plant would be designed with no room for new components.

The criterion requiring that equipment modification could not be achieved, nor new equipment installed without extensive decontamination or entry into very high radiation fields would introduce a procedural as well as time deterrent.

Several of the diversion-resistant design features of the system can be demonstrated by the Civex flowsheet, Fig. 10. The key point is that Purex-type processes that produce pure plutonium would be missing in the Civex plant. The diversion-resistant features of such plant designs are summarized below.

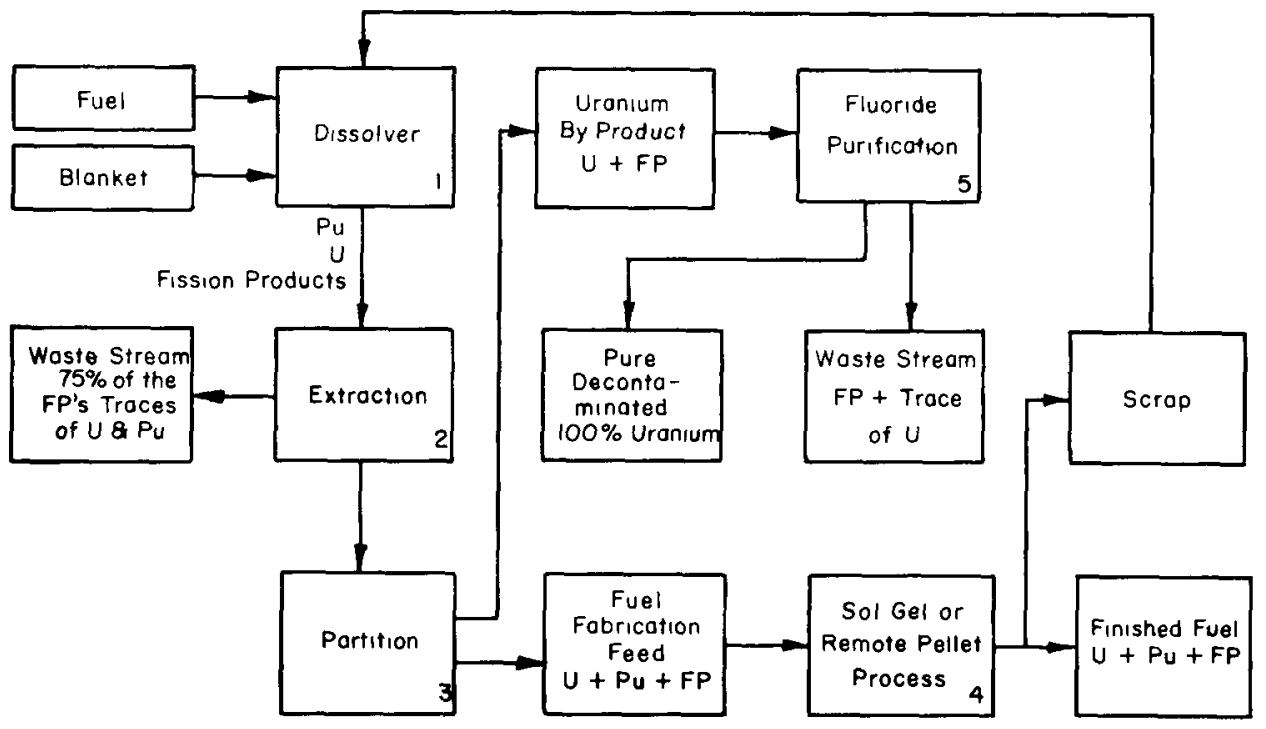

Fig. 10. Civex Flowsheet. ANL Neg. No. 116-79-191

One process feature would be the retention of fission products in the $\mathrm{Pu} / \mathrm{U}$ stream (low DF coprocessing considered earlier). The Civex solvent extraction plant equipment would contain no scrub stages in the extractor, so that after partitioning, the solvent contains $\mathrm{Pu}, \mathrm{U}$ and fission products. None of the equipment necessary for a scrub system (pumps, flowmeters, piping, makeup tanks, etc.) would be present. Hence, it would require a major modification to acquire a scrub system.

On the other side of the partition, the excess uranium would be collected for subsequent purffication by a fluoride volatility process. 
Such a process would not be effective for separating $\mathrm{Pu}$ and fission products. If plutonium were to be diverted to this stage, it would be concentrated with the fission products.

No scrap recovery facilities would be designed into the plant, which would eliminate scrap recovery as a possible sidestream for simple diversion. Fuel fabrication scrap would be recycled along with the spent fuel.

Backward recycle in a Purex plant allows for high decontamination of the plutonium stream. Because fission products would be retained in the stream that contains plutonium, no backward recycle provisions would be made at the CIVEX plant.

Existing plant designs call for such equipment as pumps and flowmeters to be operated in midrange, allowing for maximum flexibility. The Civex approach would be to operate equipment near the limit in order to restrict flexibility. For example, pumps might be operated at $90 \%$ of maximum flow rate and reactions might be required to take place on one end or the other of ambient range. Limiting such capabilities would require equipment modifications or additions in order to significantly adjust the process. Furthermore, pumps could be ganged on a single motor in order to pre-establish flow rates and flow ratios.

Restricting the plant flexibility as described above does not mean that the range of operation need be so narrow that the operation could not proceed on a practical basis. The restrictions would assure that large quantities of decontaminated plutonium would not be produced, while at the same time allowing for reasonable variations in acidity, salt concentrations, flow rates and flow ratios.

A maintenance capability represents a potential for plant alterations for illicit purposes. Hence, the Civex design would make no provisions for in-cell maintenance of chemical separation process equipment which could handle plutonium. Furthermore, no access would be provided for direct maintenance.

The entire chemical process could be housed in two adjacent, heavily-shielded cells. Access would be provided only through a shielding plug in the top of each cell and the number of sample lines would be minimized.

The first cell would contain the loading port, the chopping machine, the dissolver, and a feed makeup tank. Mechanical motions of the chopping machine would operate by shafts extending through the wall. Wearable parts would be replaced by special-purpose, single-function tools. Transfers of solution would be accomplished by airlifts with external controls.

The second cell would contain several pulse columns or centrifugal extractors. Any moving parts would have drive mechanisms located external to the cel1.

One basic deterrent design would be to size extractors and receiving tanks such that nuclear criticality results when more highly purified plutonium is produced. This would thwart such simple diversion tactics as returning product fuel to the dissolver. 
Automated mechanical interrupts would be incorporated into the design. Such interrupts could stop the process whenever process "signatures" deviated substantially from normal operating conditions. Interrupts could be reversed by resident inspectors or coded exogenous actions. The most serious interrupts would not be reversible without extended delays.

The types of inherent design limitations discussed above greatly restrict plant flexibility. While this would serve as a diversion deterrent, it might also place limitations on the types of reactor fuels that could be effectively serviced by such a facility. Furthermore, inherent lack of maintenance capability would increase the engineering risk and would have potential for decreasing plant reliability. On the other hand, removal of some of the Purex process steps would eliminate the need for some types of maintenance. Certain of the design features were aimed at specific potential diversion points. If these points were considered less important under some particular conditions, then plant flexibility could be correspondingly increased.

Considerable engineering development is required with this approach. Most of the processes have not been demonstrated, although they are based on current technology. Specialized equipment as described here does not exist, although the components are state-of-the-art. Cost increments to the fuel cycle are apt to be substantial.

\section{Collocation of Fabrication and Reprocessing Plants}

Collocation of fabrication and reprocessing has been treated in detail for LWR plutonium recycle in the IAEA study project on regional nuclear fuel cycle centers.75,91 Many of the economic and proliferationdefense benefits identified in that study also apply to the FBR fuel cycle. The difficulties that are associated with institutional arrangements are not very dependent on the type of reactor deployed outside the center. On the other hand, each of the processes and facilities for FBR fuel would differ from the reference LWR case. Those differences are identified elsewhere in this report and do not depend on the location of the facilities.

The motivation for collocation of fabrication and reprocessing plants is to take advantage of the economics of scale and to reduce the proliferation risks. Reprocessing plants that are scaled for optimum economic efficiency could support 20-50 FBRs. 75 Few nations could expect to deploy the number of FBRs required to support such plants within a few years. Hence, the incentive exists for multinational cooperation in the development of regional fuel cycle centers. Avallability of and access to such fuel services should encourage nations without national reprocessing capabilities to forego developing such facilities. Multinational participation and management would make national covert diversion of SNM from the plant more difficult. The reduced number of plants and the requisite multinational cooperation would make the job of IAEA inspections much easier. Larger security forces would help insure a credible resistance to terrorist attacks.

Regional fuel cycle centers impact several areas in defending the FBR fuel cycle against diversion. A significant reduction in transportation would result from elimination of shipments from the reprocessing plant to the fabrication plant. Pre-irradiation would then become a more practical deterrent for fuel transportation between the fabrication facility and the reactor. 
One significant benefit in collocation wruld be a reduction of the total security force required. Regional fuel cycle centers would probably require large numbers of armed guards, but fewer than for separate plants and armed transportation escorts.

The IAEA concept for regional fuel cycle centers depends on multinational involvement and cooperation. Precedents for such multinational ventures include Eurochemic, Eurodif, and Urenco. However, the fuel cycle center concept is not limited to multinational arrangements. Countries which are heavy users of nuclear power might want their own fuel cycle centers.

There are some potential disadvantages to regional fuel cycle centers. Depending on the geographical size of the region serviced, transportation costs of fresh and spent fuel could be increased. In addition, transportation routes could be complicated by political instability in either user or non-user nations within the geographical region. Multinational participation would make fuel cycle technology more readily available to participant nations. The greater throughput of material would make more frequent inspections necessary and would increase the threat posed by a seizure of the facility.

\section{Engineering the Use-Denial of Materials and Facilities}

One concept for preventing diversion of SNM is to protect sensitive facilities with systems that are engineered to deny willful misuse of material and facilities. Development of such systems is the goal of the Proliferation Resistant Engineering Program (PREP). As presently envisioned, the system would utilize peripheral and process monitors, a central data collection and logic processing center, and devices for physically interrupting facility use and for converting SNM to a useless form. The present reference is that the complete fuel service center would be owned, controlled and operated by three or more nations. A principal feature of passive use-denial engineering would be the deliberate arrangement of facilities and equipment so as to hinder process modification and access to SNM.

The normal safeguards system would provide real-time data about material balances in the process flow, any breach in perimeter defenses, and any passage of SNM through portal monitors. The data would be collected in a dedicated central control room and processed through various logic tests. Detection of signals indicating a suspected overt diversion attempt would initiate different levels of response depending upon the magnitude of the perceived threat. Some responses would be immediate while others would proceed more deliberately and could be halted by coded interrupts. The most serious response would cause substantial damage to the plant, and might be automatically actuated by the intruder. Response system design and development is oriented toward high system reliability with concern for accidental actuation and personnel safety.

The response mechanisms would depend on the actual physical system, so most present development work is on the required logic, monitors, and overall system requirements. Preliminary investigations indicate that it might be feasible to achieve about a one-month delay of host-nation acquisition of veapons useable materials. Use-denial system capital and operating costs, though substantial, might contribute only a few percent to the cost of electricity. 
6. Fuel Fabrication

Modifications made elsewhere in the fuel cycle can affect fuel fabrication. In addition, alternate processes have been proposed that may prove superior to the reference pellet fabrication method. In this section, some of those alternate methods are discussed and the impact of reprocessing modifications is evaluated.

\section{a. Alternate Fuel Fabrication Processes}

Pressing and sintering pellets from powders has been historically the dominant technology for fabrication of FBR fuel, and it is the reference fabrication process in this report. Yet there is another method of FBR ceramic fuel fabrication, vibratory compaction of particles, which is less mechanically intensive than pellet processes, and is therefore attractive in remote operation of fabrication equipment.

Vibratory compaction of particulate FBR fuel elements was preceded, in the early 1960s, by extensive development to determine optimum particle sizes, particle fractions and vibration conditions for the particle packing operation. ${ }^{15}$ Both spherical and angular particle compaction were studied in the expectation that both types of particles might be available for fabrication and subsequent irradiation testing.

The initial studies were conducted with spherical particles in single and multiple sizes. The results of experiments with spherical particles enabled prediction of achievable packing densities by mathematical calculations, and resulted in theoretical packing fractions for 1-, 2-, and 3-size component systems. 92

The work on spherical particle shapes was then extended to the compaction of angular particles. ${ }^{3}$ The packing efficiency of angular shapes was found to be a function of both particle shape and absolute size. The relation between packing efficiency and particle size has been derived ${ }^{9} 3$ and is similar to that found for spherical systems with the addition of a shape factor. The derived equations allow calculation of packing fractions of multicomponent systems in terms of diameter ratios only.

The development work on spherical and angular packing was sufficient to define the spatial characteristics and limitations of the systems studied. Generally, infiltration time for the smallest particle size in both spherical and angular particle systems varies inversely with acceleration to about $15 \mathrm{G}^{\prime} \mathrm{s}$. Little difference in the infiltration rate was observed between 15 and $20 \mathrm{G}^{\prime} \mathrm{s}$. The rate of infiltration was a maximum at a vibration frequency between 40 and $80 \mathrm{~Hz}$ for all accelerations up to $20 \mathrm{G}$ 's. These findings prompted the use of $60 \mathrm{~Hz}$ for all fabrication work on actual carbide fuel elements. In a typical example, a 560-mm long, 60-mm diameter fuel column was loaded at $60 \mathrm{~Hz}$ vibration and $15 \mathrm{G}$ acceleration. The time for complete infiltration of the smallest size fraction of angular particles was about 25 minutes. About 7 minutes was necessary to complete the infiltration of spherical particles.

There is a fundamental trade-off in the choice between angular or spherical particles for compaction. Angular particles are produced 
by dry processes like pulverizing massive fuel chunks obtained from arc melting or pressing and sintering. Spherical particles are produced by a wet gelatin process (briefly described below) which requires more elaborate equipment. Conversely, higher packing density is achievable with the spherical particles. For carbide fuels, where the desired smear density is about $80 \%$ of theoretical (see Chapter 3 ), the simpler angular particle process might be preferred. For oxide fuels, with a higher density (about $90 \%$ of theoretical), spherical packing may be the only possible choice.

The microsphere-forming ${ }^{94}$ process consists of three major steps, each of which may be accomplished in several ways. In the first step either a suspension of small actide crystallites (so1) is formed or a broth of actinide nitrate and organic additives is produced. Gelation, the second step, is then accomplished by either ammonia gelation or water extraction. In the first method the liquid droplet gels so ammonium diuranate when the droplet is exposed to ammonia. In the second method the liquid droplet gels as water is extracted from the droplet by contact with alcohol in a sphere-forming column. Finally, the remaining volatile constituents in the gel are driven off and, if desired, the fuel particle sintered by drying and firing in a controlled atmosphere. Particles containing $\mathrm{UO}_{2}$ or carbides must be protected from oxygen.

A limited number of fuel elements have been made by both angular and spherical particle compaction, and irradiated in reactor facilities. Their performance has generally been good, but more development would be needed before particle processes could be fairly assessed against the more fully-developed pellet process.

In the United Kingdom, in apparent response to concern over worker radiation exposure to plutonium, development is proceeding on a dry fabrication route yielding angular particulate fuel as the preferred form for remotely-fabricated oxide and carbide FBR fuel elements. 17

b. Impact of High Gamma Fuels

There are a number of different highly-radioactive fuel materials under consideration in the various fuel cycle options. The radiation sources could be mixed with the fuel as in the case of a ${ }^{60}$ Co spikant, carried over from reprocessing as in low decontamination coprocessing, or inherent to the fuel material as in ${ }^{23} \mathrm{U}$-thorium fuels, (i.e., the ${ }^{23} \mathrm{U}$ decay chain).

Highly radioactive gamma sources intimately mixed with the fuel material would provide some diversion protection throughout the fabrication process, but they would have a substantial impact on plant operations. Al1 processing and maintenance would have to be carried out remotely. (Remote processing, less heavily shielded, with contact maintenance is the current reference approach.) Substantial design and development of equipment would be required. Streamlining process steps to minimize the number of manipulations and inspections would also be required and techniques for remote inspection of pins and assemblies would have to be developed. The high radiation levels throughout the plant might significantly damage hydraulic systems, especially seals in hydraulic equipment. Designs might have to be extremely simple; relacement might be frequent and flexibility might be limited. The behavior ff the various spikants and fission products during the fabrication process 
is unknown. This includes behavior of the spikants during precipitation of plutonium and uranium from solution and during sintering. Ruthenium and cesium, for example, will both volatilize during sintering. However, nonvolatile chemical compounds of cesium have been proposed and merit investigation.

Fabrication of high gamma fuels would clearly increase fuel cycle costs. The results of one study are shown in Fig. 11 (Ref. 90). The lower radiation levels require relatively minor changes in process equipment configurations or batch sizes, but as the radiation levels increase, fundamental changes are required which are reflected in the rapidly increasing cost penalty. The higher spikant concentrations require fully remote operation and maintenance. Above this level of spikant concentration the cost penalty is relatively constant.

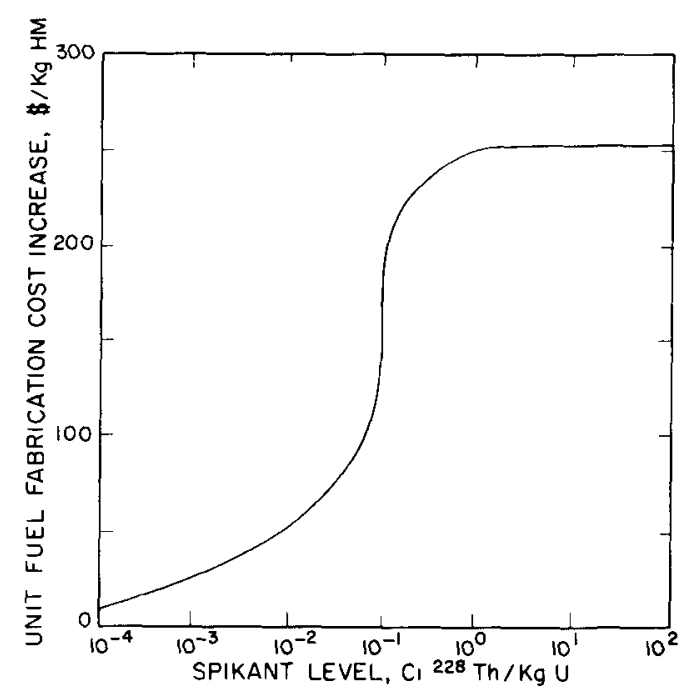

Fig. 11

Fuel Fabrication Costs as a Function of Spikant Level. ANL Neg. No. $116-79-198$

\section{c. Impact of Mixed U/Pu Feed Material}

Powder preparation is one of the first steps in the fabrication process. Powders are proportionally batched, blended, and milled to provide properly conditioned mixed-oxide powder to the next stage. If mixed $\mathrm{U} / \mathrm{Pu}$ is one of the feed materials, it changes the batch proportions and might require additional millings, but impacts little else. The key issue is whether the feed batch has a uniform dispersal of plutonium in uranium. Since there is close-coupled analysis during blending, there is little chance that pre-mixed feed powders can have an adverse impact.

\section{Pre-Trradiation}

Pre-irradiation has been suggested as one method to increase the diversion resistance of fresh FBR fuel assemblies. In this concept fuel material would be fabricated into fuel assemblies as described in Section III.A.5. The fuel elements would then be inserted into an irradiation facility to produce a significant radiation level in the fresh fuel before it is shipped out of the fabrication facility. The increased resistance for the fresh fuel elements would result from the need to ship the pre- 
irradiated assemblies in massive shielded casks and from the increased difficulty and time required to extract plutonium from the hot assemblies. Studies have been conducted to evaluate the radiation level required to achieve the desired diversion resistance, to explore alternative design concepts for the irradiation facility, and to assess the economic and performance impact of the process on the fuel cycle. 95 Because reactor fuel is designed to be irradiated and handled in an irradiated state, there are no obvious technical barriers to the implementation of the primary questions are those relating to cost and effectiveness.

The radioactivity of the pre-irradiated assembly would diminish over time, and so some consideration must be given to the decay time during which the radioactivity would be required as a deterrent. Figure 12 gives the gamma dose rate at a distance of approximately one meter from the midplane of a single unshielded subassembly as a function of decay time and exposure. The irradiation time to achieve a given exposure level would be inversely related to the assembly power level in the irradiation facility; that is, low power levels would correspond to long irradiation times. Shorter irradiation times might be achieved with a higher-cost irradiation facility capable of handling the higher assembly power levels.

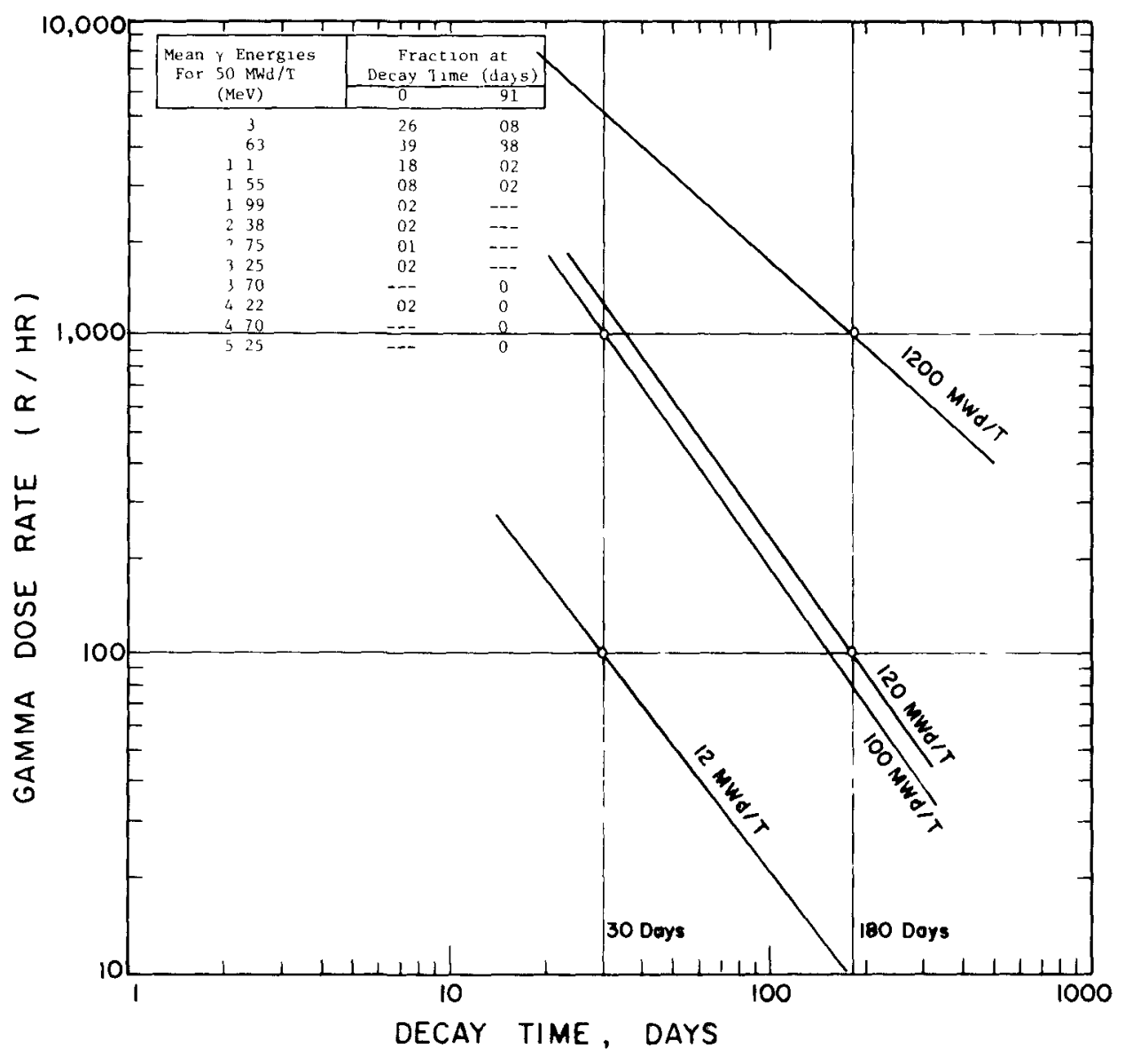

Fig. 12. Gamma Dose Rate from High Gamma Fuels as a Function of Decay Time. ANL Neg. No. 116-79-193 


\begin{abstract}
Various alternatives have been investigated for the irradiation facility. 95 These include both fast and thermal systems, various coolants and "self-driven" and "externally-driven" concepts. In the self-driven concepts the fresh fuel elements being pre-irradiated would be grouped together to form a critical assembly. In the externally driven concept, the target subassemblies would be irradiated external to a host core. The selection of a specific design would be governed by such considerations as incremental cost on the fuel cycle, flexibility of the facility to accommodate a range of different FBR fuel designs, and impact on fuel element performance in the power reactor.
\end{abstract}

The major impact of pre-irradiation on the fuel cycle would be the cost of building and operating the pre-irradiation facility itself. In addition, shipping irradiated fresh fuel assemblies would require shielded casks with provisions for heat removal. Inspection of the fresh fuel assemblies at the power plant prior to insertion in the reactor would require development of a remote, shielded operation.

\title{
8. $\quad 238 \mathrm{Pu}$ Denaturing of Plutonium Fuels
}

One proposal for making plutonium less sensitive is to increase the amount of ${ }^{238} \mathrm{Pu}$ present. This would have two beneficial effects as far as proliferation resistance is concerned. First, ${ }^{238} \mathrm{Pu}$ decays by alpha emission, which generates an appreciable amount of internal heat and would cause handling difficulties. Second, the neutron and gamma emission from ${ }^{238} \mathrm{Pu}$ spontaneous fission would enhance the detectability of diverted materials. Once present, it would be unrealistic to separate the ${ }^{238} \mathrm{Pu}$ from the ${ }^{239} \mathrm{Pu}$.

The scenario of plutonium denaturing was developed for the case of LWR recycle. In an equilibrium FBR system, the fraction of $238 \mathrm{Pu}$ in the plutonium is less than $1 \%$, considerably less than in LWR discharge fuel. Also, since there is little ${ }^{235} \mathrm{U}$ in the system, production of ${ }^{238} \mathrm{Pu}$ precursors would be relatively insignificant. In FBRs, production of $238 \mathrm{Pu}$ precursors occurs primarily from $(n, 2 \mathrm{n})$ reactions in ${ }^{238} \mathrm{U},{ }^{238} \mathrm{Pu}$ is also directly produced by $(n, 2 n)$ reactions in ${ }^{239} \mathrm{Pu}$. In order to make use of plutonium denaturing in FBR systems, makeup ${ }^{238} \mathrm{Pu}$ or its precursors would probably have to be taken from LWR fuel.

From the fuel cycle standpoint, plutonium denaturing would have little impact on the processes. Spent reactor fuel elements received at the reprocessing plant would have to be cooled regardless of the ${ }^{238} \mathrm{Pu}$ concentration. The various reprocessing steps are not dependent on the $\mathrm{Pu}$-isotopic composition. Except for possible blending with ${ }^{238} \mathrm{Pu}-\mathrm{rich}$ material, the impact on fabrication would be minor. Heat generation and radiation problems would be small relative to the various spiked-fuel concepts. As in the case of spiked fuel or pre-irradiated assemblies, fresh fuel assemblies might require special cooling during storage and transportation.

The key issue here is the degree to which the presence of ${ }^{238} \mathrm{Pu}$ would complicate successful fabrication of a weapon. Even if this were judged to be very effective, the problem of how enough ${ }^{238} \mathrm{Pu}$ could be generated remains. 


\section{FUEL CYCLE IN THE SECURED-AREA SYSTEM}

In the secured-area scenario, restrictions are assumed on the location and type of breeder reactors. Breeders utilizing fuels with chemically separable fissile materials (for example, U-Pu or ${ }^{2}{ }^{3} \mathrm{U}-\mathrm{Th}$ cycles) would be located only in secured enclaves; the system is characterized in Fig. 13. The key element is that participating nations would give up a measure of sovereignty over their nuclear fuel cycle in exchange for guarantees of fuel supply. This scenario thus requires the successful negotiation of a complex institutional arrangement. This section addresses the technical feasibility and effectiveness of the system.

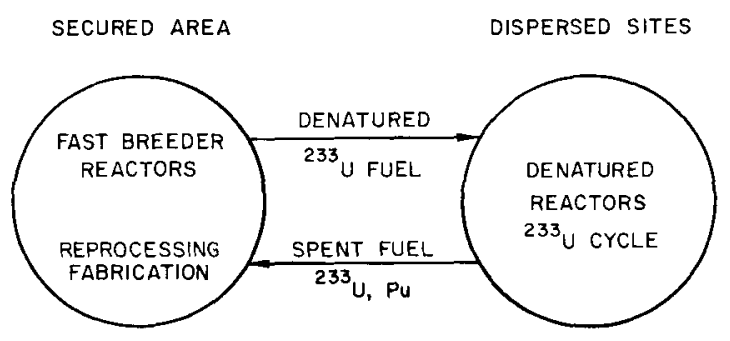

Fig. 13

Secured-Area System. ANL Neg. No. 116-79-196

The secured-area scenario involves international or multinational control of the nuclear fuel cycle, a concept which can be traced to the AchesonLilienthal Report and the Baruch Plan. ${ }^{96}$ As with some of the feasible options discussed for the reference international scenario, global adherence to secured-area deployment of nuclear power facilities would result in a higher resistance to proliferation of nuclear weapons.

One key issue regarding the secured-area system is whether the system could properly function. At least two technical questions about proper functioning can be posed:

\section{Would the system be technically feasible?, and \\ 2. Could the secured enclaves, operating with a mix of fissile materials including ${ }^{23} \mathrm{U}_{2}$ be effectively safeguarded?,}

along with one question that is both political and practical,

3. What would constitute suitable siting criteria for secured areas?

In this chapter the focus will be on the first two questions. Also missing here is a treatment of the problems associated with implementing the securedarea concept, although it is clear that the technical and economic feasibility of the system would be crucial to acceptance.

\section{A. Overview of Reactor and Fuel Cycle Characteristics}

\section{Type of Reactors Deployed}

Because of a large number of potential reactor types in both the secured enclaves and at dispersed sites, the secured-area scenario would have 
a complex fuel cycle. However, the number of options could be significantly reduced by grouping reactor types generically, and eliminating those with either marginal economic or proliferation-defense incentives.

At the dispersed sites reactors would be fueled with ${ }^{23}{ }^{3} \mathrm{U}$, denatured by the presence of ${ }^{238} \mathrm{U}$. Acquisition of purified fissile material from fresh fuel would thus require isotopic separation. Depending on the maximum permissible amount of ${ }^{233} \mathrm{U}$ in ${ }^{238} \mathrm{U}$, * fast breeder reactors might be allowed at dispersed sites. Because of uncertainty in this maximum permissible level, denatured ${ }^{23}{ }^{3} \mathrm{U}$ fast breeders are admitted as one case of dispersed reactors. These FBRs would have ${ }^{23{ }^{3}} \mathrm{U}-{ }^{238} \mathrm{U}$ cores and (most likely) thorium blankets in either oxide, carbide, or metal form. The core fuel discharged from these reactors to the secured reprocessing facility would contain ${ }^{23}{ }^{3} \mathrm{U},{ }^{23}{ }^{8} \mathrm{U}$, and plutonium bred from ${ }^{238} \mathrm{U}$; while the discharged blanket would contain ${ }^{2}{ }^{3} \mathrm{U}$ and thorium.

Whether or not denatured breeders would be allowed as dispersed reactors, denatured converters must also be examined. To span the range of converter performance, both LWRs (the worst case) and CANDUs (the best) were featured in the systems studies (see Chapter 2). Regardless, these reactors would use low-enriched $23{ }^{3} \mathrm{U}$ fuel $\left(1.5-3.0 \%{ }^{23}{ }^{3} \mathrm{U}\right.$ in ${ }^{238} \mathrm{U}$ or a mix of ${ }^{238} \mathrm{U}$ and thorium). Also, with either converter the discharged fuel would contain ${ }^{23}{ }^{3} \mathrm{U}$, ${ }^{238} \mathrm{U}$, plutonium, and possibly thorium.

Next consider the breeders within the secured areas. These reactors must respond to the fuel demands of the dispersed reactors. Thus, they must produce ${ }^{233} \mathrm{U}$. Moreover, for fuel assurances to be credible, the secured reactors must breed enough excess fuel to allow for growth in world demand. The secured FBRs should thus have good breeding characteristics.

Three FBR fuels are initially included as candidates for the secured area: U-Pu, Th-Pu, and Th- ${ }^{23}{ }^{3} \mathrm{U}$. Both the U-Pu and Th-Pu fuels would take advantage of the superior breeding properties of plutonium and hence allow for system growth. Also, both would utilize the plutonium returned to the secured area from fuel discharged by dispersed reactors.** The U-Pu system is the better breeder, and could produce varying amounts of ${ }^{233} \mathrm{U}$ and plutonium depending on blanket composition (thorium or uranium) and arrangement. While the $\mathrm{Th}-\mathrm{Pu}$ is a poorer breeder, it could consume large amounts of plutonium and could produce large amounts of ${ }^{23}{ }^{3} \mathrm{U}$. The $\mathrm{Th}-{ }^{23}{ }^{3} \mathrm{U}$ fuel provides a marginal breeder, and would not utilize the plutonium discharged from dispersed reactors.

Carbide and metal fuels result in significantly better breeding performance than the oxide, and this would be especially important in securedarea deployment. Accommodating a $3.0 \%$ growth rate in nuclear power would require a maximum 23 year doubling time if breeders alone are used, and this could be achieved with a variety of FBRs, including those using oxide fuel. Trying to attain the same system growth with 1-3 dispersed converters per

\footnotetext{
*A current consensus value appears to be $12 \%$ (maximum) ${ }^{23}{ }^{3} \mathrm{U}$ in ${ }^{238} \mathrm{U}$. Fast breeder reactors can be designed at that enrichment, but breeders would be precluded at maximum enrichments much reduced from that level.

**Because the dispersed reactor fuels would a11 be denatured with ${ }^{238} \mathrm{U}$, some plutonium would always be contained in the discharge.
} 
secured breeder would be much more difficult and, in fact, could only be done with carbide or metal fuels, and with advanced converter reactor design.

\section{Demands on the Fuel Cycle Facilities}

The reactors described would discharge material to the secured reprocessing plant, and accept reload material from the secured fabrication plant. Shown in Table VII are all the fuels which might be employed. Certain combinations of the fuels described above are more logical than others, and three cases are representative.

TABLE VII. Types of Fuels in Secured-Area Deployment

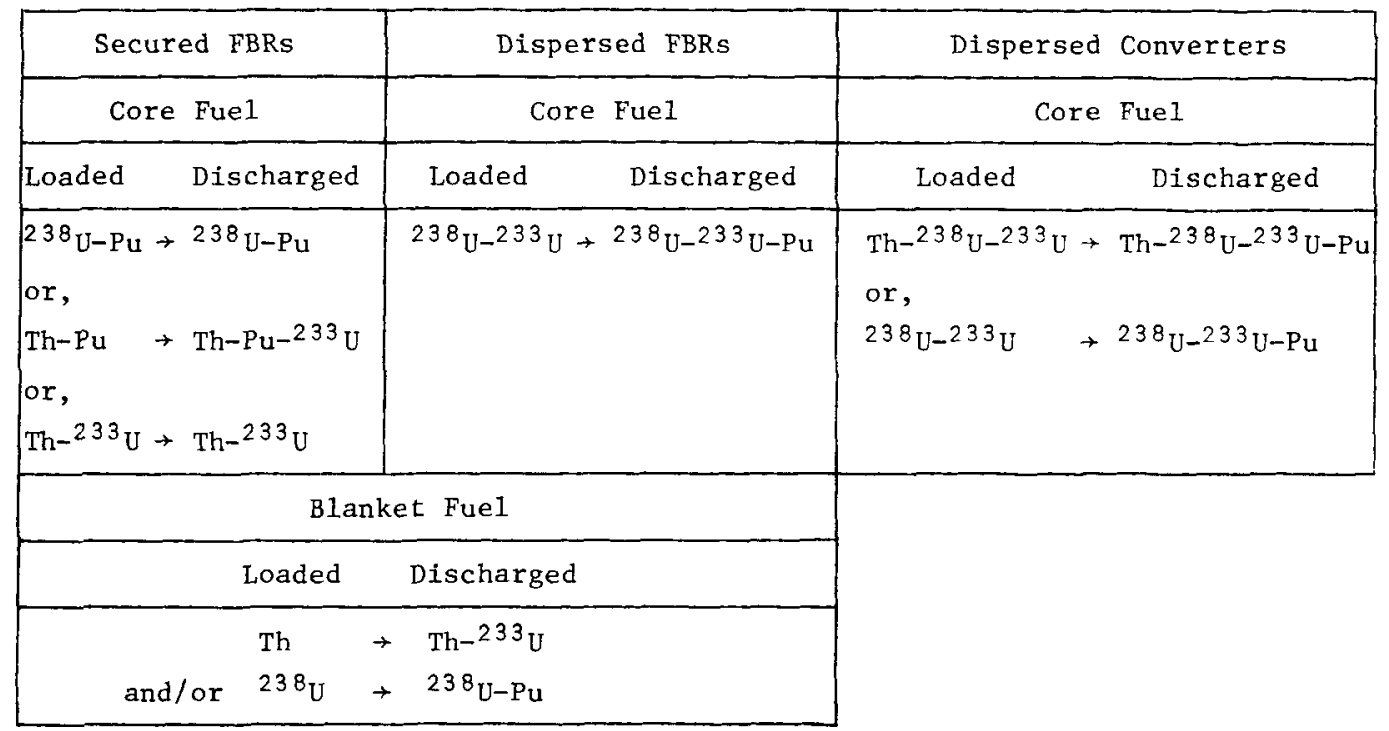

Case I: In Table VIII the unshaded portions would represent the most feasible symbiosis if $\mathrm{U}-\mathrm{Pu}$ were the secured FBR fuel cycle. The attractive features of this combination include the best breeding characteristics of any secured FBR cycle as well as 2-way separations in the reprocessing step; most likely Thorex for Th-U (discussed in detail later) and Purex for $\mathrm{U}-\mathrm{Pu}$.

TABLE VIII. Most Reasonable Symbiosis in Case I (Unshaded Portions)

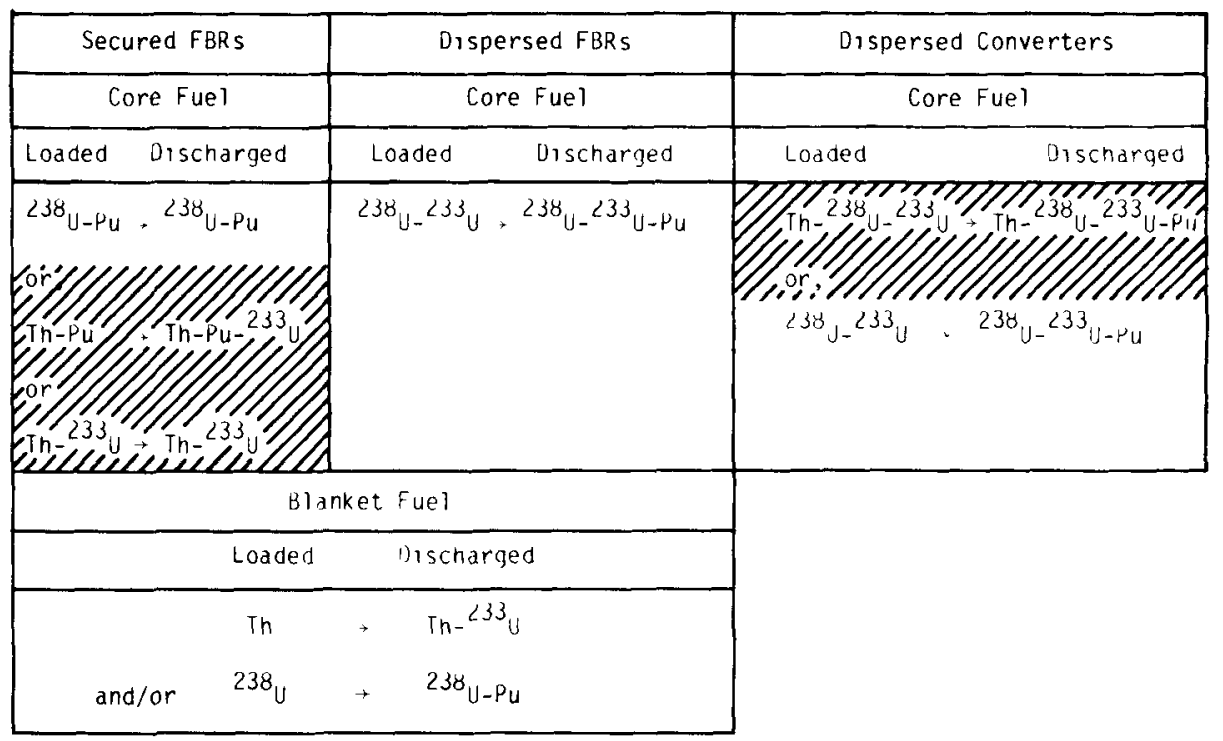


Case II: In this case, Th-Pu would be the fuel cycle of the secured FBR. One attractive feature of this fuel is that it permits substantial production of ${ }^{233} \mathrm{U}$, and one secured FBR could feed 2-3 denatured, dispersed FBRs. Because Th-Pu secured FBRs would consume large quantities of plutonium, they could not operate in equilibrium with dispersed reactors consisting only of denatured converters. Makeup plutonium would be required and could come, for example, from $235 \mathrm{U}$-fueled converters deployed separate from the secured system. The fuel discharged from the secured FBRs would require 3-way chemical separation of thorium, plutonium, and uranium.

TABLE IX. "lost Reasonable symbions in Crese it ( nshader lartions)

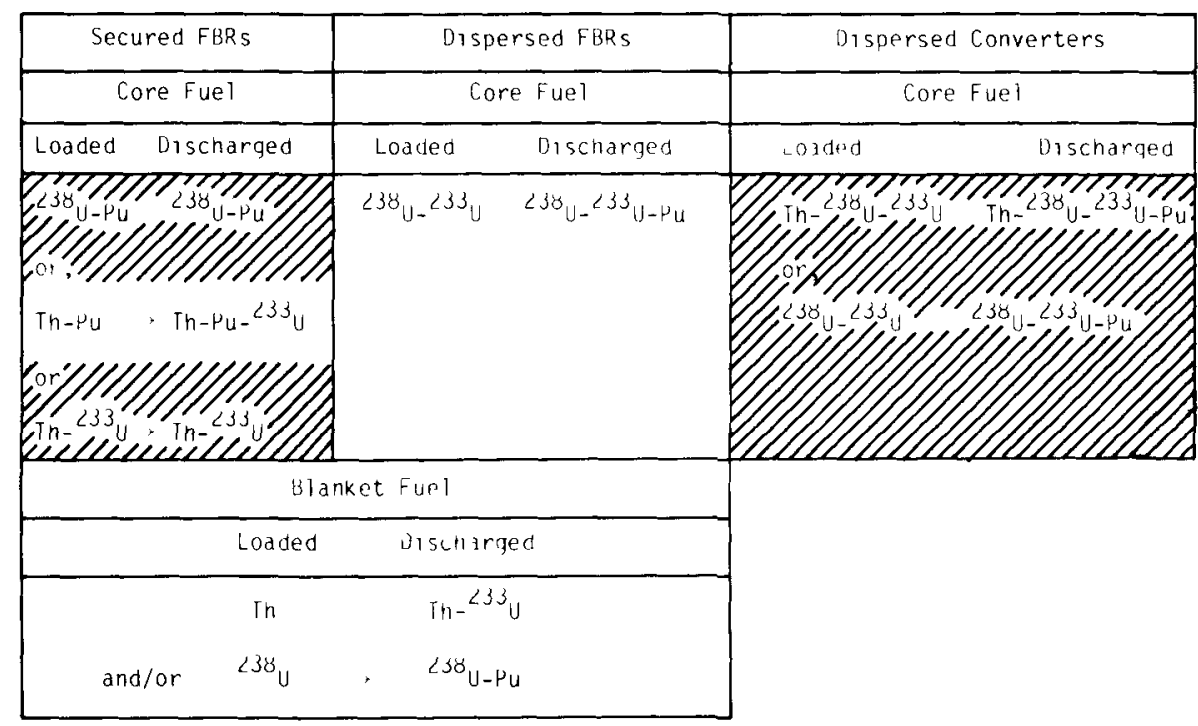

Case III: Here Th- ${ }^{233} \mathrm{U}$ would be the fuel cycle of the secured FBR. Denatured FBRs would not be dispersed because the substantial amounts of plutonium that would be produced would not be utilized in this fuel cycle. Thus, only denatured converters could be dispersed, operating with $\mathrm{Th}-23{ }^{3} \mathrm{U}-23{ }^{2} \mathrm{U}$ fuel (even here there would be an economic penalty unless the relatively small amount of generated plutonium were used in the secured fast reactor). Thorex would be the main reprocessing technique, but again, 3-way separation would be required for the converter fuel.

TABLE X. "nut heasnnab]e sumbiosic an (abe IIT (Unshaded Portions)

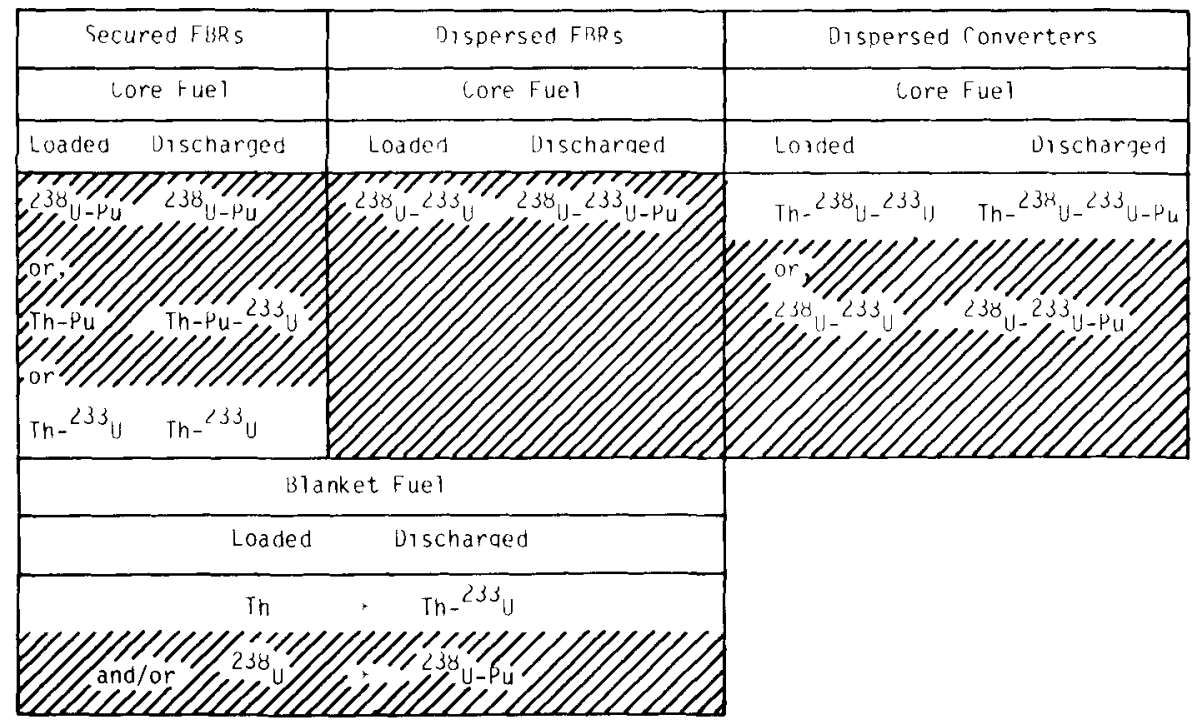




\section{Characteristic Deployments}

Here ranges are specified in the kind and number of facilities that might make up a complete secured-area reactor system. Some observations are useful:

a. The secured enclaves are the only places in the system where chemically-separated fissile materials would be found. Thus, within the enclaves extraordinary security and safeguards measures would be expected. Also, several FBRs would be located inside each area, resulting in a geographical concentration of electrical power. These two facts make it desirable to limit the number of secured areas, and hence to maximize the number of dispersed reactors that each enclave serves.

b. On the other hand, increasing the number of dispersed reactors would generally decrease the system growth potential. This is strictly true for the case with dispersed converters, since they would use fuel that could have been withheld for use in the more efficient secured breeders. It would also be true to a lesser extent for the case when denatured FBRs were dispersed. Thus, a tradeoff exists between increasing the number of dispersed reactors per secured area and increasing the growth potential of the system.

c. The number of sites available for placement of secured areas would become severely restricted as the number of reactors within each area increased. For example, there might be no suitable sites in the U.S. for a concentration of 50 reactors, while there could be several sites capable of accommodating 20 reactors. 97

These observations were used to construct Table XI, which shows ranges of feasible deployments. The number of reactors both inside and outside the secured area is shown along with the time required to produce enough fuel to start a complete new system, and the yearly reprocessing demands. The three different fuel types for the secured FBRs are shown, as are a few variations of fuel form (oxide, carbide, metal). Reprocessing demand was limited to capacity of a single plant of about 1500 tonnes/yr. Increasing this allowable reprocessing throughput would generally have little effect on the number of reactors deployed if a maximum of 20 FBRs per secured area were maintained.

Secured U-Pu, oxide-fueled FBRs of INFCE design would have a doubling time of 17 years. Up to 22 dispersed FBRs could be served in a symbiotic arrangement, with only a modest increase in doubling time. These same secured FBRs could serve 20 denatured LWRs in equilibrium (an infinite doubling time). The CANDU case clearly shows the tradeoff between dispersed reactor quantity and doubling time. Use of metal fuels in the secured breeder would result in a decreased system doubling time.

If Th-Pu were the secured FBR fuel cycle, dispersed FBRs would be the only long term option (see Section IV.A.2). An appreciable number of dispersed FBRs could be served, with a doubling time only slightly in excess of that for the comparable U-Pu case. 
TABLE XI. Characteristic Secured-Area Deployments

\begin{tabular}{|c|c|c|c|c|c|}
\hline $\begin{array}{l}\text { FueI Cycle of } \\
\text { Secured FBRs }\end{array}$ & $\begin{array}{l}\text { Type of } \\
\text { Dispersed } \\
\text { Reactor }\end{array}$ & $\begin{array}{l}\text { No. of Secured } \\
\text { FBRs Within } \\
\text { Enclave }\end{array}$ & $\begin{array}{l}\text { No, of Dispersed } \\
\text { Reactors per } \\
\text { Enclave }\end{array}$ & $\begin{array}{l}\text { System } \\
\text { Doublifing } \\
\text { Time }\end{array}$ & $\begin{array}{c}\text { Yearly Reprocessing } \\
\text { Demand, } b \\
\text { tonnes heavy metal }\end{array}$ \\
\hline $\mathrm{U}-\mathrm{Pu}(\text { oxide })^{\mathrm{C}}$ & $\begin{array}{c}233 \mathrm{U}-238 \mathrm{U} \mathrm{FBR}^{\mathrm{c}} \\
\text { (oxide) }\end{array}$ & 20 & $0-22$ & $17-24$ & $600-1150$ \\
\hline$"$ & LWR & 20 & $0-20$ & $17-\infty$ & $600-1100$ \\
\hline & CANDU & 8 & 26 & $\infty$ & 1540 \\
\hline & " & 12 & 24 & 38 & 1560 \\
\hline$"$ & $"$ & 19 & 19 & 31 & 1520 \\
\hline$"$ & $"$ & 20 & 10 & 22 & 1100 \\
\hline$"$ & $"$ & 20 & 0 & 17 & 600 \\
\hline $\mathrm{U}-\mathrm{Pu}$ (meta1) & $\begin{array}{c}23{ }^{2} \mathrm{U}-238 \mathrm{U} \text { FBR } \\
\text { (metal) }\end{array}$ & 20 & $0-14$ & $9-11$ & $600-1020$ \\
\hline " & CANDU & 12 & 24 & 32 & 1560 \\
\hline Th-Pu (oxide) & $\begin{array}{c}233 \mathrm{U}-238 \mathrm{U} F \mathrm{FBR} \\
\text { (oxide) }\end{array}$ & ------- & 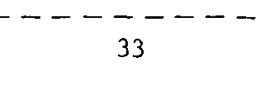 & $-\frac{--}{27}$ & --------- \\
\hline Th-Pu (metal) & $\begin{array}{c}23^{3} \mathrm{U}^{2}{ }^{8} \mathrm{U} U \mathrm{FBR} \\
(\text { meta1) }\end{array}$ & 19 & 32 & 13 & 1530 \\
\hline \multirow{2}{*}{$\begin{array}{l}\text { Th- }{ }^{33} \mathrm{U} \text { (oxide, } \\
\text { carbide, metal) }\end{array}$} & $----\cdots$ & $\begin{array}{c}------- \\
20\end{array}$ & $\begin{array}{c}------- \\
0-6\end{array}$ & $\begin{array}{l}-\cdots-- \\
60-\infty\end{array}$ & $\begin{array}{c}--------- \\
600-750\end{array}$ \\
\hline & CANDU & 20 & $0-17$ & $60-\infty$ & $600-1450$ \\
\hline
\end{tabular}

$a_{\text {Years }}$ required for enough excess fuel to accumulate (compounded continuously) to start a new enclave and the appropriate number of dispersed reactors.

$b_{\text {Assuming }} 25$ tonnes/year for LWRs, 30 for FBRs and 50 for CANDUs.

${ }^{\mathrm{C}} \mathrm{All}$ breeders in this table have Thorium blankets.

Finally, if $T h-233 \mathrm{U}$ were used as the secured FBR fuel, the doubling times would be very long ( 60 years), even with no dispersed reactors. For 6 LWRs or 17 CANDUs, the system would be in equilibrium.

\section{B. Reprocessing in the Secured-Area System}

It is clear from the discussion above that the detalled reprocessing requirements in the secured-area system cannot be specified right now. Moreover, the preferred way in which reprocessing would be accomplished (one universal line handling all fuels in the secured-area; one plant with multiple lines, multiple plants, etc.) is presently unclear. Therefore, this discussion about reprocessing will have to be confined to general approaches.

Referring to the cases outlined in the previous section, and assuming that the reprocessing options are Purex for U-Pu fuels, Thorex for Th-U, and a combination called 3-way for U-Pu-Th, Table XII outlines the processes required.

TABLE XII. Processes Required in Secured-Area system

\begin{tabular}{lcc}
\hline & $\begin{array}{c}\text { Processes for Secured } \\
\text { FBR Cores and Blankets }\end{array}$ & $\begin{array}{c}\text { Processes for } \\
\text { Dispersed Reactors }\end{array}$ \\
\hline Case I (U-Pu secured FBR) & Purex, Thorex & Purex, Thorex \\
Case II (Th-Pu secured FBR) & 3-way, Thorex & Purex, Thorex \\
Case III (Th-233 U secured FBR) & Thorex & 3-way \\
\hline
\end{tabular}


The Purex process, required in two of the three cases, has been discussed in detail in the previous section. Thorex and 3-way separation, one or the other of which is required in all cases, are described below.

\section{A Thorex Process Description}

Although the Thorex process is not nearly as we11-developed as Purex, it has been under development for several years $98,99,100$ and a pilotplant at Julich, Germany is nearly ready for startup. 101 Thorium fuels have been processed in the U. S. on a campaign basis in Purex plants modified to a Thorex flowsheet 102,103 . Thorex is quite similar in principle to Purex, both being solvent-extraction processes.

A general flowsheet for one Thorex process is given in Fig. 14 for oxide fuels. Irradiated thorium fuel is dissolved in a nitric acid solution containing fluoride ion as a catalyst. The thorium nitrate solution is adjusted to feed specifications and introduced into the extraction contactor where the thorfum and ${ }^{23} \mathrm{U}$ are extracted into diluted tributyl phosphate (TBP). $2{ }^{33} \mathrm{~Pa}$ and fission products remain in the aqueous phase, and leave the bottom of the column. This solution can be concentrated and stored for about one year to allow the ${ }^{233} \mathrm{~Pa}$ to decay to ${ }^{233} \mathrm{U}$, then processed to recover the uranium before disposing of the waste. The organic stream, containing the decontaminated thorium and ${ }^{23} \mathrm{U}$, flows continuously to the middle of the partitioning column, where thorium is preferentially stripped into the dilute nitric acid solution. An organic scrub stream is introduced to re-extract small amounts of ${ }^{23} \mathrm{U}$ from the aqueous stream. The aqueous stream carrying the thorium goes to an evaporator for concentration of the thorium product. The ${ }^{233} \mathrm{U}$ product is stripped into a slightly acidic water solution and is then passed through an ion-exchange resin column for concentration and final purification. The organic stream goes to a solvent recovery stage where the decomposition products of TBP are removed, and the purified solvent is recycled.

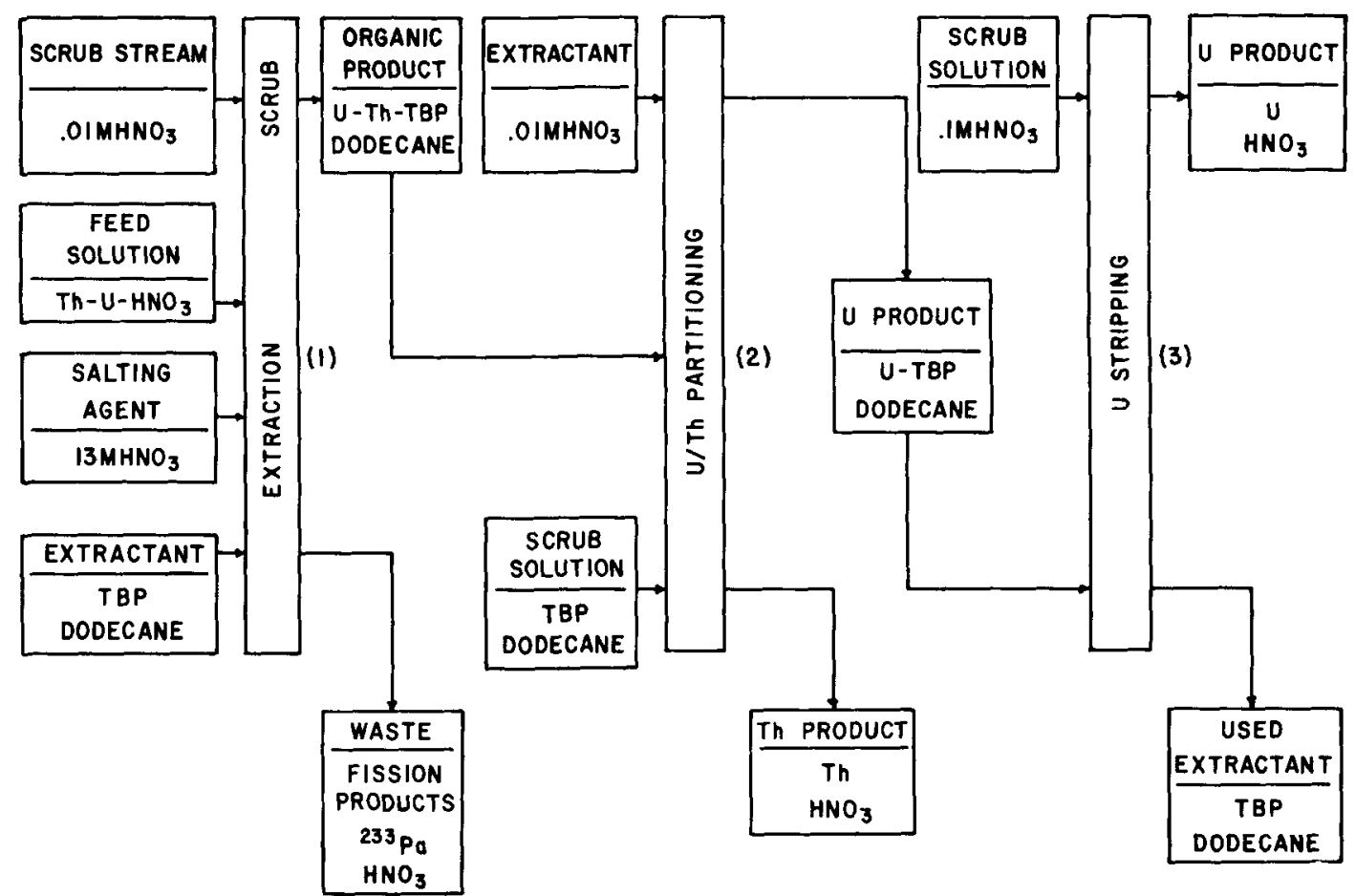

Fig. 14. A Thorex Flowsheet. ANL Neg. No. 116-79-195 


\section{3-Way Separation Process}

The application of the Thorex process to fuels containing thorium, uranium and plutonium appears to be technically feasible from the sparse data available, but has not been demonstrated. Dilute hydrofluoric acid would probably be necessary to aid in dissolution; and aluminum nitrate would have to be added to the dissolver solution to complex the excess fluoride.

The first extraction cycle would be similar to the corresponding step in Thorex: the three actinides would be extracted from the aqueous dissolving solution by an organic extractant, TBP. This partlally-decontaminated organic solution carrying $\mathrm{Th}, \mathrm{Pu}$, and $\mathrm{U}$ would then be treated with a reducing agent to reduce plutonium to the extractable +3 valence form $\mathrm{Pu}$ (III), which would then be scrubbed out of the organic stream with dilute nitric acid. This plutonium stream would then go to a plutonium purification process similar to the corresponding step in Purex. The organic stream carrying the $U$ and Th would again be scrubbed with dilute nitric acid, and the thorium (which is less soluble in organic than uranium) transferred to the aqueous phase. This thorium stream would then be passed to a thorium purification cycle. Finally, the uranium would be transferred to the aqueous phase by stripping with a slightly acid water solution, and passed through an ionexchange column for concentration and final purification.

\section{Unique Features in Reprocessing of Thorium-Based Fuels}

While many items in the reprocessing of thorium-based fuels are similar to the case with uranium-plutonium fuels, there are significant uncertainties which would require investigation before a thorium fuel cycle could be considered technically mature.

First, in the head-end operations, it is not known whether voloxidation would be effective in releasing radioactive tritium from thorium-based fuels. When $\mathrm{UO}_{2}$ is heated sufficiently in the presence of oxygen, it oxidizes to $\mathrm{U}_{3} \mathrm{O}_{8}$, resulting in a fracturing of the original ceramic. This fracturing releases essentially all of the tritium contained in the fuel. $\mathrm{ThO}_{2}$, on the other hand, is stable. While it is not clear what would happen in voloxidation of a mixed Th-U oxide, it appears that a significant amount of tritium could be dissolved with the fuel, thus contaminating aqueous solutions in the plant. Development of a water-retention/ isotope-separations system might then be required.

Next, dissolution of thorium-based fuels is more difficult than uranium fuel. To dissolve thorium oxide, for example, it appears that hydrofluoric acid must be added. HF is extremely corrosive and can cause corrosion of the process equipment unless preventative steps are taken. If thorium-based fuels were to be used in thermal reactors with the standard zircaloy cladding, further problems could be encountered since the zirconium would partially dissolve, complex the fluoride, and inhibit dissolution of the thoria.

In the solvent extraction step, partitioning the thorium from the uranium is more difficult than with plutonium-uranium, where a plutonium valence change is effected and exploited. Also, thorium precipitates with 
the decomposition products of TBP (as does zirconium), so it would be important to minimize radiation damage to the TBP and to purify it before recycling.

There are several problems in 3-way separation which require significant development efforts. The problems noted in Thorex are also present in the 3-way separation process. In addition to these problems, data are not yet available to closely predict the performance of a solvent extraction system in which the three elements uranium, plutonium and thorium are all present in significant quantities.

When fuel containing ${ }^{233} \mathrm{U}$ is irradiated in an $\mathrm{FBR},{ }^{232} \mathrm{U}$ is generated from the high energy $(n, 2 n)$ reaction with ${ }^{23}{ }^{3} \mathrm{U}$. Because of uncertainties in cross sections, the precise amount of ${ }^{232} \mathrm{U}$ is not well known, but 500$3000 \mathrm{ppm}{ }^{232} \mathrm{U}$ in ${ }^{23} \mathrm{U}$ might be expected in equilibrium operation of FBRs. ${ }^{232} \mathrm{U}$ is radioactive with a lengthy decay chain involving emission of numerous alpha, beta and gamma rays:

${ }^{232} \mathrm{U} \underset{70 \mathrm{a}}{-\frac{\alpha}{228} \mathrm{Th}} \frac{\alpha}{1.9 \mathrm{a}}{ }^{224} \mathrm{Ra} \frac{\alpha}{3.6 \mathrm{~d}} \rightarrow^{220} \mathrm{Rn} \frac{\alpha}{50 \mathrm{~s}} \rightarrow . .{ }^{208} \mathrm{~Pb}$ (stable).

When fuels containing ${ }^{232} \mathrm{U}$ are reprocessed, the ${ }^{232} \mathrm{U}$ stays with the ${ }^{23}{ }^{3} \mathrm{U}$, the ${ }^{228} \mathrm{Th}$ follows the bulk ${ }^{232} \mathrm{Th}$ and the remainder of the isotopes in the decay chain (called $232 \mathrm{U}$ daughters) follow the fission products and end up in the waste stream.

After separation, the uranium product initially has a low rate of gamma-ray emission. But the decay of the ${ }^{232} \mathrm{U}$ immediately starts a new buildup of radioactive daughters, and within a short time the fuel becomes too active to handle directly. Figure 15 shows the dose rate at $0.3 \mathrm{~m}$ from a thin disc of $1 \mathrm{~kg}{ }^{23} \mathrm{U}$ containing $1000 \mathrm{ppm}{ }^{232} \mathrm{U}$ (taken from Ref. 104). The fuel becomes too radioactive to handle within a few days, and poses a severe, though not incapacitating, handling hazard within a few months. The ${ }^{228} \mathrm{Th}$ which follows the bulk thorium also makes that material radioactive following separation. In the case of bulk thorium, the gamma radiation level peaks within a few days after separation, and then decays with the 1.9 year half-life of ${ }^{228} \mathrm{Th}$.

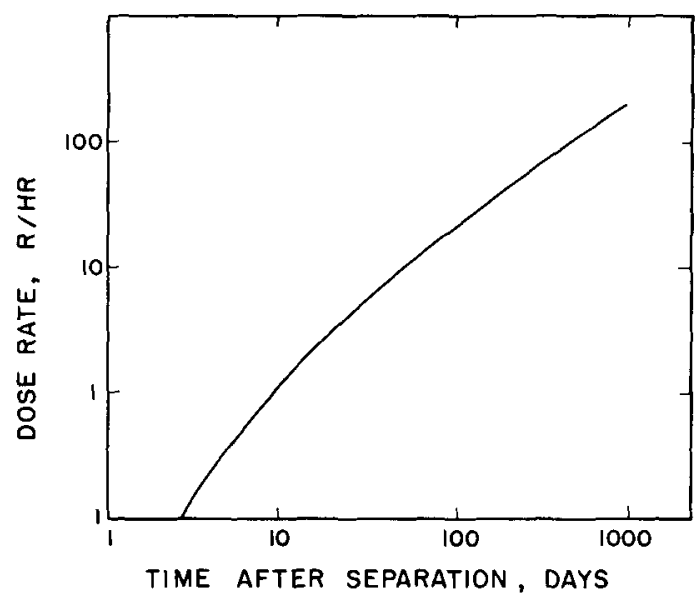

Fig. 15

Dose Rate at $30 \mathrm{~cm}$ from a Thin Disc of $1 \mathrm{~kg}$ of ${ }^{233} \mathrm{U}$ with $1000 \mathrm{ppm}{ }^{232} \mathrm{U}$. ANL Neg. No. 116-79-201 


\section{Fabrication of Thorium-Based Fuels}

The basic processes required to prepare thorium-based fuel elements from powders are similar to those processes used in uranium-plutonium fuel fabrication. There would be a major change, however, in process equipment design to accommodate heavily shielded remote operation and remote maintenance. This must be done whenever

i. $\quad 23{ }^{3} \mathrm{U}$ is used as a fissile component of the fuel, or

ii. recycled thorium is used as a fertile component.

Again referring to the three general cases of fuels which could be used in secured-area deployment, remote fuel fabrication would be required for all dispersed reactors. Completely remote fuel fabrication for secured FBRs would be required in Case III $\left({ }^{233} \mathrm{U}-\mathrm{Th}\right)$, might be required in case II (Pu-Th) if recycled thorium were used, but would not be needed in Case I (Pu-U fuel, which would be fabricated in an automated facility as in Section III.A.5).

\section{Oxide Fuel Pellets}

The bulk of the fabrication experience for thorium-based fuels has been gained in connection with various thermal reactor programs. Most of these programs have sought to exploit the advantages of ${ }^{23}{ }^{3} \mathrm{U}$ in a thermal system and therefore have been based on ${ }^{23} \mathrm{U}$-Th fuels in the oxide form. Some experience has also been gained, however, in the fabrication of $\mathrm{PuO}_{2}-$ $\mathrm{ThO}_{2}$ fuels. These fuels have been fabricated using the same basic techniques previously described for the reference international system employing $\mathrm{PuO}_{2}-$ $\mathrm{UO}_{2} \cdot 105$

Much of the recent experience in the fabrication of thoria-based fuel pellets has been acquired in the light-water breeder reactor project (LWBR). The development effort for the LWBR fuel indicates that the basic reference processes are adaptable to any thoria-based fuel system, requiring remote or total-containment fabrication, but the actual experience was limited to 1 ow ${ }^{232} \mathrm{U}(<10 \mathrm{ppm})$ feed material. $106^{\circ}$

As indicated above, the fabrication process description for $\left({ }^{23} \mathrm{U}, \mathrm{U}\right) \mathrm{O}_{2},(\mathrm{U}, \mathrm{Th}) \mathrm{O}_{2}$, or $(\mathrm{Pu}, \mathrm{Th}) \mathrm{O}_{2}$ fuels is essentially identical with those for $(\mathrm{U}, \mathrm{Pu}) \mathrm{O}_{2}$. The feed materials would be purified powders of $\mathrm{UO}_{2}$, $\mathrm{ThO}_{2}$ and $\mathrm{PuO}_{2}$ while the scrap recycle material for the mixed oxide cases would be an appropriate blend of coprecipitated $(\mathrm{U}, \mathrm{Th}) \mathrm{O}_{2}$ or $(\mathrm{Pu}, \mathrm{Th}) \mathrm{O}_{2}$. It is likely that minor changes would be required in the powder specifications to ensure proper blending and eventually homogeneity in the sintered pellets, but these could be accommodated in the conversion processes at the reprocessing plant.

The balance of the processing up to the sintering step would be identical. The only change at the sintering step would be the possible need for an increase in the sintering temperature where $\mathrm{ThO}_{2}$ is one of the material constituents. For the $(\mathrm{U}, \mathrm{Pu}) \mathrm{O}_{2}$ materials, this is set at $1700^{\circ} \mathrm{C}$. This temperature would be adequate for properly conditioned powders of $\mathrm{UO}_{2}$ mixed with $\mathrm{ThO}_{2}$ as defined in the LWBR program. However, the higher concentrations of fissile materials in the mixed oxide core materials for the fast breeder 
reactors might require higher temperatures, longer sintering times, etc., to assure adequate homogeneity in the finished fuel pellets. Experimental determination is needed.

The need for remote operation and maintenance of fabrication equipment requires a different approach to process equipment design. These equipment modifications would be most extensive in the areas of fuel element assembly and inspection. Significant modifications in plant and equipment design would occur in three process support areas. These are the sample analysis system for process control, the scrap recovery systems, and the process and facility off-gas systems.

The sample analysis techniques would be in large measure identical to the case with U-Pu fuels, and techniques have been or are being developed to provide equivalent accuracy. However, the significant increase in penetrating gamma activity associated with the samples would require that all equipment be designed for remote operation. The facility would also have to include shielded analytical cells to receive and perform some of the analyses. Shielded storage would be required for analysis of wastes as well as for storage of the required archive samples.

The scrap recovery system would be similar in structure to that with U-Pu fuels. For clean (U,Th) $\mathrm{O}_{2}$, the material would be pulverized and recycled as a powder. Contaminated scrap would be returned to the reprocessing plant or to a special processing line for recovery of fissile and fertile elements.

Finally, the off-gas systems from all areas dealing with exposed fuel materials would have to incorporate either radon traps or sufficient process delay to ensure the decay of the short-lived radon in the ${ }^{232} \mathrm{U}$ decay chain before the usual filtration to remove all particulate contaminants. The facility design would have to incorporate remote handling of these filters to prevent over-exposure of maintenance personnel.

\section{Impact of Carbide and Metal Fuel}

Thorium-based carbide fuels containing either ${ }^{233} \mathrm{U}$ or ${ }^{239} \mathrm{Pu}$ fissile isotopes and uranium carbide which contains ${ }^{23} \mathrm{U}$ are prepared by the same method used to make $\mathrm{UC}$ and $(\mathrm{U}, \mathrm{Pu}) \mathrm{C}$ feed material; that is, by carbothermic reduction of oxides of the heavy metals. As with UC and (U,Pu)C, the chemical reactivity with oxygen and water vapor of the thorium-based fuels and uranium-carbide containing ${ }^{23} \mathrm{U}$ would require that a suitable inert atmosphere be used during fuel fabrication. The production of thorium-based carbide fuel pellets for use in FBRs has, however, been very limited. Further development would draw on experimental work with uranium carbides, and would require a major effort.

The technology for the fabrication of thorium-based metal fuels (Th-U, Th-Pu, Th-Pu-U) has been demonstrated on a limited basis and is based on the experience with uranium metal fuels discussed earlier. Mechanical methods of fabrication have been investigated, but injection casting would likely be the favored technique because casting equipment is normally smaller, easier to service and easier to operate than mechanica1-working equipment. 107 All thorium-based alloys of interest have liquidus and solidus 
temperatures higher than their uranium or mixed U-Pu counterparts, and as a result pin fabrication would be more difficult. Although limited experimental information exists, significant additional work would be required to upgrade the technology to handle the higher melting temperature of thorium metals and to develop more suitable mold materials.

\section{Particle Methods}

The radioactive nature of fuels containing recycled thorium or ${ }^{23} 3_{\mathrm{U}}$ provides a strong incentive to develop remote fabrication techniques. Also, remote maintenance of the fabrication process equipment would be probable. It was noted in Section III.B.6. that particle methods using vibratory compaction offer some attractive features. There are uncertainties associated with the engineering of a remotely operated and maintained pellet fabrication facility. The mechanical complexity of the fabrication equipment is reduced in going from pellets to particles, but more complex fuel feed preparation is required. Also there are significant uncertainties associated with irradiation performance and large-scale production of fuels fabricated with any of the particle methods. More development of remote pellet processes and particle fabrication processes would be required before the favored approach could be determined.

\section{Waste}

The reprocessing waste streams in the secured-area system would differ from those in reference international systems in that ${ }^{23}{ }^{3} \mathrm{U}$ and $\mathrm{Th}$ would be present along with the fluorides necessary for the dissolution of $\mathrm{ThO}_{2}$. The fluoride and aluminum which result from the Thorex process might cause significant modifications to present approaches. At a minimum, the additional materials would cause an increase in the volume of solidified product per unit of fuel reprocessed.

The wastes from the fuel fabrication steps should be much the same as for the U-Pu cycle. The remote operation and maintenance of fabrication equipment would very likely increase the volume of waste from this step. 108

The fissile materials that would be present in the secured-area wastes, although different in isotopic content, are similar in total amount (see Table IV in Section III.A.10). Thus any proliferation concerns associated with nuclear waste are essentially the same as in the reference international system.

\section{E. Transportation}

One of the principal benefits of the secured-area deployment scenario would be the reduction in transport of SNM. In the reference international system, for each GWe-yr of FBR operation, the reactor would discharge 125160 core assemblies containing $11-12 \mathrm{~kg}$ of fissile plutonium and 40-45 blanket assemblies containing 4-6 kg fissile plutonium. These data are shown in Table XIII with results when three different dispersed, denatured reactors are deployed in various combinations with secured breeders. 
TABLE XIIr. Fissile Materials Transported for 1 GWe-year Total Electrical Production

\begin{tabular}{|c|c|c|c|}
\hline & $\begin{array}{l}\text { Spent Fuel } \\
\text { Discharged, } \\
\text { kg fissile }\end{array}$ & $\begin{array}{l}\text { Fresh Fuel } \\
\text { Loaded, } \\
\mathrm{kg} \text { fissile }\end{array}$ & \\
\hline Reference Internationa1 System & $1700-1900$ & $1300-1600$ & ( $\mathrm{Pu}$ at $9-12 \%$ average enrichment) \\
\hline \multicolumn{4}{|l|}{ Secured-Area System } \\
\hline $\begin{array}{l}\text { 1. Denatured FBRs dispersed } \\
\text { at } 1: 1 \text { ratio to secured } \\
\text { FBRs. }\end{array}$ & $730-800$ & $620-720$ & ( ${ }^{233} \mathrm{U}$ at $9-12 \%$ average enrichment) \\
\hline $\begin{array}{l}\text { 2. Denatured LWRs dispersed } \\
\text { at } 1: 1 \text { ratio to secured } \\
\text { FBRs. }\end{array}$ & 130 & 280 & $\left({ }^{233} \mathrm{U}\right.$ at $2.4 \%$ enrichment $)$ \\
\hline $\begin{array}{l}\text { 3. Denatured CANDUs dis- } \\
\text { persed at } 1.5: 1 \text { ratio } \\
\text { to secured FBRs. }\end{array}$ & 460 & 500 & $\left({ }^{233} \mathrm{U}\right.$ at $1.5 \%$ enrichment $)$ \\
\hline
\end{tabular}

The only chemically-separable fissile materials that appear outside of the secured enclaves would be in spent fuel elements and in treated wastes. In both cases the fissile isotopes would be protected by a matrix of highly radioactive materials. The only exception to this situation would occur during transportation of fresh core material for startup of a new secured area.

Because of the multinational or international control of the fuel transportation system, seizure of SNM in transport would be a clear proliferation signal, quickly known to the international community. This timely warning is significant, because it might allow international response before diverted material could be converted to weapons use.

\section{F. Safeguards}

It was noted in the introduction to Section IV that safeguards measures must be relied on for an adequate proliferation defense in the secured-area fuel cycle.

Safeguards concerns in the secured-area fuel reprocessing are similar to those in the reference system if the same techniques are used (see Section III.A.4). Some technique-development work might be necessary for nondestructive assay of ${ }^{23} \mathrm{U}$. The characteristic gamma ray analysis techniques used to assay plutonium might not work for the weaker gamma rays from ${ }^{23}{ }^{3} \mathrm{U}$. Absorption edge densitometry techniques, although more complex and costly, could overcome these problems in streams where the density is not excessive. 110 Plutonium fuel fabrication safeguards in the secured area would be essentially the same as in the reference system (see III.A.9). ${ }^{23}{ }^{3} \mathrm{U}$-thorium fuel fabrication may represent more complex materials accounting problems due to the ${ }^{232} \mathrm{U}$ decay chain. ${ }^{228} \mathrm{Th}$ (daughter from the alpha decay of ${ }^{232} \mathrm{U}$ ) will be in equilibrium as will its decay products, and these are highly gamma-radioactive. During separation these decay products will be stripped out, but ${ }^{228}$ Th will be carried over with the bulk thorium. The highly gamma-active daughters of $228 \mathrm{Th}$ grow back in very quickly (rate controlled by its daughter -3.64 day $224 \mathrm{Ra}$ ). 
Basically the problem is that nuclear methods of non-destructive assay are invariably less accurate when a high background level of radiation exists. 110 Thus, the safeguards issues here are not unlike those encountered when fuel is processed with incomplete fission product removal (Section III.B.1.b.) or when fuel is spiked with a radioactive isotope (Section III.B.2). It appears that NDA techniques will either work or can be made to work ${ }^{11}$ in gamma radiation fields. However, the uncertainties in material. balances will be higher, perhaps considerably so. Thus, confident identification of diversion would occur at a higher threshold value of lost material.

It was mentioned before that, even in facilities handling relatively cold U-Pu material, on-line assessments would likely never approach the diversion sensitivity of perimeter (portal) monitors. In the secured-area system, this perimeter control would take on even greater significance. Interesting1y, the ${ }^{23} \mathrm{U}$-thorium materials, with their active decay chain, are considerably easier to detect with portal monitors. Thus, the reduced on-line diversion sensitivity in secured-area systems is offset to some degree by increased boundary control.

\section{G. Feasibility of Alternatives in Reprocessing or Fabrication to Enhance Proliferation Resistance}

As in the reference international system, there are alternatives to the reference processes which might enhance proliferation resistance, particularly the resistance of the system with respect to subnational groups acquiring weapons-usable materials. Here these alternatives will be given considerably less attention than in the previous scenario, mainly because the existence of a functioning secured-area system is seen as a major proliferation deterrent in itself.

Coprocessing of fissile and fertile materials is one possibility. It was noted before that uranium and plutonium could be stripped together in the reprocessing step. Incomplete partitioning could be applied to mixtures of plutonium and thorium and to mixtures of uranium and thorium. While these approaches to coprocessed materials might be feasible, there are some practical limitations.

Referring to the three cases introduced in Section IV.A.2, coprocessing would cause difficulties in Case $I$. In avoiding the need for 3-way separation, the dispersed reactor fuel was chosen to be denatured uranium. If coprocessed with thorium, the $233_{U}$ produced in secured FBR blankets would not be suitable for use in the dispersed reactors. Coprocessing here would only work if dispersed breeders were abandoned and if dispersed converters operated on a denatured uranium-thorium cycle (requiring 3-way separation). Coprocessing of plutonium with uranium would, however, be feasible.

Similarly in Case II, coprocessing of uranium and thorium could not be used, although coprocessed plutonium-thorium appears feasible. For an adequate level of denaturing, the fuel for the dispersed FBRs must contain little or no thorium. Hence, the ${ }^{23} \mathrm{U}$ generated in the blankets of the secured FBRs must be separated and mixed with $238 \mathrm{U}$.

In Case III, coprocessed uranium-thorium mixtures could be used in both the secured and dispersed reactors. 
The use of radiation barriers, either through low-decontamination of the processed fuel or through addition of a spiking material, might be used. It is true, however, that most of the ${ }^{233} \mathrm{U}$ stored in the secured area would have passed enough time since separation to provide a significant level of radiation from the ${ }^{232} \mathrm{U}$. Although not quickly incapacitating, this level would be sufficient to require heavy shielding and special handling techniques.

\section{H. Summary of the Secured-Area Fuel Cycle}

There are a number of fuels and reactor concepts which could be used to make up a system of secured FBRs and fuel cycle facilities, and dispersed, denatured reactors. Should any of these be developed, there would be an incentive toward those systems with the better breeding characteristics given that international acceptance of the secured-area approach would depend, in some measure, on perceptions of the credibility of fuel assurances. Secured FBRs with U-Pu cores of advanced fuel design (carbides, metals) and thorium blankets head the list, followed by $\mathrm{Pu}$-Th cores of advanced fuel design. ${ }^{23} \mathrm{U}-\mathrm{Th}$ cores would be marginal from this point of view.

Reprocessing any of the candidate secured-area fuels would require development of thorium-based reprocessing technology, probably the Thorex process. Some options would involve Purex in addition, and some would involve a more speculative 3-way separation of uranium, thorium and plutonium. The dissolution and separation steps in the reprocessing of thorium-based fuels would be more difficult than in the uranium-plutonium case.

The relatively small amounts of ${ }^{232} \mathrm{U}$ that would build into an FBR fueled with ${ }^{23} \mathrm{U}$ would cause major difficulties due to its very active decay chain. Remote fabrication and remote maintenance of fabrication equipment would be required, and this would require extensive development. Safeguards techniques using nuclear interrogation would be compromised to some degree, perhaps greatly, by the gamma radiation which would accompany such a level of ${ }^{232} \mathrm{U}$. This would impact safeguarding of the fabrication plant more than the reprocessing facility.

Coprocessing of uranium-thorium, while apparently technically feasible, is not very practical in the secured-area system. For some of the candidate fuels bearing plutonium, coprocessing with uranium does have some attraction. The latter case, coupled with the moderate gamma fields attendant to the ${ }^{23} \mathrm{U}$ fuels, might be considered to enhance the resistance to diversion of materials inside the secured enclaves.

Transportation of sensitive materials would be considerably reduced in the secured-area system, relative to some options in the reference international case. Waste management considerations would not be greatly impacted.

In most, if not a1l, areas of reactor and fuel cycle development, significant levels of effort would be needed to bring the status of the technology to a state comparable to that of the uranium-plutonium fuel cycle in a reference international deployment scenario. This will be discussed in more detail in Section VI. 


\section{FUEL CYCLE IN THE INTEGRAL SYSTEM}

The reference international scenario would allow FBRs to be sited by national decision and would admit varying degrees of constraint on the administrative and technical aspects of the fuel cycle. More severe constraints would occur in the secured-area scenario, where FBRs would not be sited by national choice, but would exist in enclaves and produce fuel for denatured reactors sited by national decision. The integral cycle scenario would again allow breeders to be sited by national choice, but only when accompanied by a proliferation-resistant fuel cycle technology.

The idea includes fuel cycle facilities dedicated exclusively to a few collocated FBRs. This collocation would be coupled with use of a reprocessing technology (pyrochemical or aqueous Civex) which would result in fission product contamination of the processed fuel, and which would be difficult to modify to yield a highly-decontaminated product. Moreover the fuel would be processed quickly, reducing the out-of-reactor period (hence inventory).

Although the integral cycle system is presented here as a separate deployment scenario, the technology employed in the integral cycle could be used as a component within either of the other two deployment scenarios.

Since the elements of the Civex approach were discussed in Section III.B., the focus here will be on pyrochemical processes. Moreover, the cost penalties of using aqueous reprocessing to serve a few integral-cycle FBRs may be severe. Pyrochemical techniques are compatible with metal fuels. Oxides or carbides could be pyrochemically processed, but as a first step might require conversion to metal and as a last step a tail-end reconversion. The conversion step might be accompanied by large volumes of waste materials. The discussion in this section will thus be limited to pyrochemical processes and metallic fuels. Specifically, the fuel will be taken as the U-Pu-Zr design adopted in the INFCE reactor characteristics study (see Chapter 3).

\section{A. Integral Cycle Operation of EBR-II}

An early and partial version of the integral cycle concept was demonstrated in the operation of EBR-II and its associated Fuel Cycle Facility. ${ }^{19}, 67,112$ For a period of about five years, the reactor was operated with fuel returned from a collocated facility where hot fuel was reprocessed and fabricated remotely.

The EBR-II fuel cycle reprocessing step was a simple pyrometallurgical operation of melt-refining. The process succeeded in removing not only gaseous fission products but also most of the other fission products, with the notable exception of the noble metals ( $\mathrm{r}, \mathrm{Ru}$, Mo, etc.). However, the process was not truly complete in that the noble metals accumulated in the alloy, and required removal of a portion of the melt each cycle to suppress noble metal buildup. The removal (drag-out) was a small fraction of the melt in EBR-II because of the 1ow burnup of the fuel (1-2\%) but would be greater with the high burnups (7-10\%) demanded in current FBR development programs. Actual removal fractions are dependent on the tolerance level of noble metal fission products in an FBR and this has not been established. 
The dragout material from EBR-II was stored, with the intention of recovering the uranium at a later date by a pyrochemical process. Pyrochemical processes were explored, but never used, because the FBR emphasis was shifted to oxide fuels.

In principle, advanced pyrochemical procedures could be expected to duplicate the one-month turnaround time of the melt-refining technique, while providing more versatility in rejection or retention of fission products with plutonium in a U-Pu cycle. Their primary weakness is lack of complete development and demonstration; at this point they are promising but somewhat speculative.

\section{B. A Pyrochemical Process}

The metallic constituents of a fuel can be separated by, for example, manipulating their movement between a molten metallic solvent phase (copper, zinc, cadmium, magnesium, etc., or alloys of them) and a molten salt phase (frequently a chloride). The movement is accomplished by oxidation or reduction reactions, the choice of which is guided by the relative values of free energy of the metal chlorides to be moved and the chloride salts available as reagents. For example, U-Pu metal containing fission products can be dissolved in zinc. If the reactive alkali metals (Cs, $\mathrm{Rb}$ ) and alkaline earth metals ( $\mathrm{Ba}, \mathrm{Sr}$ ) of the fission products, for example, are to be removed from the melt, then a salt should be added such as $\mathrm{CaCl}_{2}$, whose free energy lies below the alkali metals, but above those of uranium and plutonium, the rare earths and the noble metals. The alkalis and alkaline earths are chlorinated by the $\mathrm{CaCl}_{2}$, to become salt and enter the salt phase; the calcium becomes metal and enters the metal phase.

Other separations include precipitation of a chosen (usually major) constituent by lowering melt temperature, or changing the solvent metal composition, or converting the constituent to an insoluble component such as a hydride. A filtration, or at least a decanting, would follow. A very useful consideration in choosing the proper solvent metal composition is to assure that it is sufficiently volatile to be distillable (retorted) from the product. Zinc, magnesium, and cadmium have this property. These manipulalations, and others, are presented in the literature. ${ }^{,}, 11^{\circ}$

The fission products (FP) fall into four groups, defined by their behavior in pyrochemical reactions:

FP-1: The gases that do not react: $\mathrm{T}_{2}, \mathrm{Xe}, \mathrm{Kr}$.

FP-2: A miscellany of elements that are sufficiently active to take $\mathrm{Cl}^{-}$from $\mathrm{CaCl}_{2}$ or $\mathrm{KCl}$ and enter the Salt Phase: I, Br; Cs, $\mathrm{Rb} ; \mathrm{Ba}, \mathrm{Sr} ; \mathrm{Sm}, \mathrm{Eu}$; $\mathrm{Se}, \mathrm{Te}$.

FP-3: The rare earths, or lanthanides (except $\mathrm{Sm}$ and Eu) and yttrium: $\mathrm{Y}, \mathrm{La}, \mathrm{Ce}, \mathrm{Pr}, \mathrm{Nd}, \mathrm{Pm}, \mathrm{Gd}, \mathrm{Tb}$. These elements can take $\mathrm{Cl}^{-}$from $\mathrm{MgCl}_{2}$, e.g., and enter the salt phase.

FP-4: The "noble metals," which are too inert to take $\mathrm{Cl}^{-}$from $\mathrm{MgCl}_{2}$ or even $\mathrm{ZnCl}_{2}: \mathrm{Zr}, \mathrm{Nb}, \mathrm{Mo}, \mathrm{Te}, \mathrm{Ru}, \mathrm{Rh}, \mathrm{Pd}, \mathrm{Ag}, \mathrm{Cd}, \mathrm{In}, \mathrm{Sn}, \mathrm{Sb}$. 
There are several potential approaches to pyrochemical reprocessing of fast reactor fuels. All of these share the attribute of being inherently difficult to force to production of a highly decontaminated fuel product. One possible approach will be detailed. The process chosen for illustration includes steps that have been demonstrated on laboratory or bench-scale, and some that have not; the latter are usually of an operational or engineering nature. Uncertainties will be noted as the process is described.

\section{Reprocessing with Pyrochemical Techniques}

The process would have sufficient capacity to support several collocated FBRs. Taking eight FBRs, a typical daily feed of core material might consist of $400 \mathrm{~kg}$ of uranium, $50 \mathrm{~kg}$ of zirconium, $45 \mathrm{~kg}$ of plutonium ( $60 \%$ fissile), and $14 \mathrm{~kg}$ of mixed fission products $(1.9 \mathrm{~kg} \mathrm{FP-1}, 2.8 \mathrm{~kg} \mathrm{FP-2}, 3.0 \mathrm{~kg} \mathrm{FP-3}$, $6.3 \mathrm{~kg} \mathrm{FP}-4$ ).

After the clad has been removed and the fuel elements chopped into small segments, the fuel would be dissolved in a $\mathrm{Cu}-5 \% \mathrm{Mg}$ alloy at about $950^{\circ} \mathrm{C}$, as shown in Fig. 16. The dissolver vessel, tungsten backed with graphite, would be $1 \mathrm{~m}$ in diameter and $1 \mathrm{~m}$ high with a cover sealed in place by a fusible metal seal. The FP-l gases leaving the dissolver would pass to a treatment train. The FP-2 elements and perhaps half of the FP-3s would be oxidized and trapped by a cover salt of $\mathrm{CaCl}_{2}-\mathrm{KCl}$ with enough $\mathrm{MgCl}_{2}$ for partial oxidation of the FP-3s; at completion of dissolution the cover salt would be pressuretransferred to waste.

P1utonium, half of the FP-3s, all of the FP-4s and some of the uranium would enter the metal phase as a solution; most of the uranium would precipitate as $\mathrm{UCu}_{5}$. A melt of $\mathrm{MgCl}_{2}-\mathrm{MgF}_{2}$ stored in a second vessel would then be transferred by pressure through a pipe to the bottom of the metal phase in the dissolver. As the salt rises through the metal and is agitated, it would reduce a portion of the plutonium, uranium and FP-3 to their respective chloride salts and dissolve them; FP-4s would be unaffected and remain in the metal solvent. At completion of the operation, the salt would be transferred to the bottom of a second vessel containing a $\mathrm{Zn}-17 \% \mathrm{Mg}$ alloy. Here the uranium, plutonium and FP-3s would be reduced back to metal, driven largely by the metal-complexing action of zinc. (For every gram-equivalent of $\mathrm{U}-\mathrm{Pu}$ moved into the $\mathrm{Zn}-17 \% \mathrm{Mg}$ alloy, a g-equivalent of magnesium would be transferred back to the copper alloy). This two step operation is called salt transport.

The loading of plutonium, uranium and and FP-3s in the transport salt is low, so the operation would need to be repeated a number of times. The plutonium and FP-3s would transfer faster than the uranium (greater reactivity, smaller quantity), so that by the time $99+\%$ of the plutonium and FP-3s present have transferred, only about $50 \%$ of the uranium would have moved. The operation would be stopped at this point and the $\mathrm{Zn}-17 \% \mathrm{Mg}$ containing uranium, plutonium and FP-3 would be transferred to a hydrider vessel for further treatment.

The uranium left in the copper solvent would be recovered into a third vessel by a similar salt transport step, and most of the copper could then be used for dissolving the next batch of fuel. A portion of the copper must be sent to waste (drag-out) and replaced with fresh copper, to avoid excessive accumulation of the large quantity of zirconium from the fuel and the lesser quantity of $\mathrm{FP}-4 \mathrm{~s}$. 


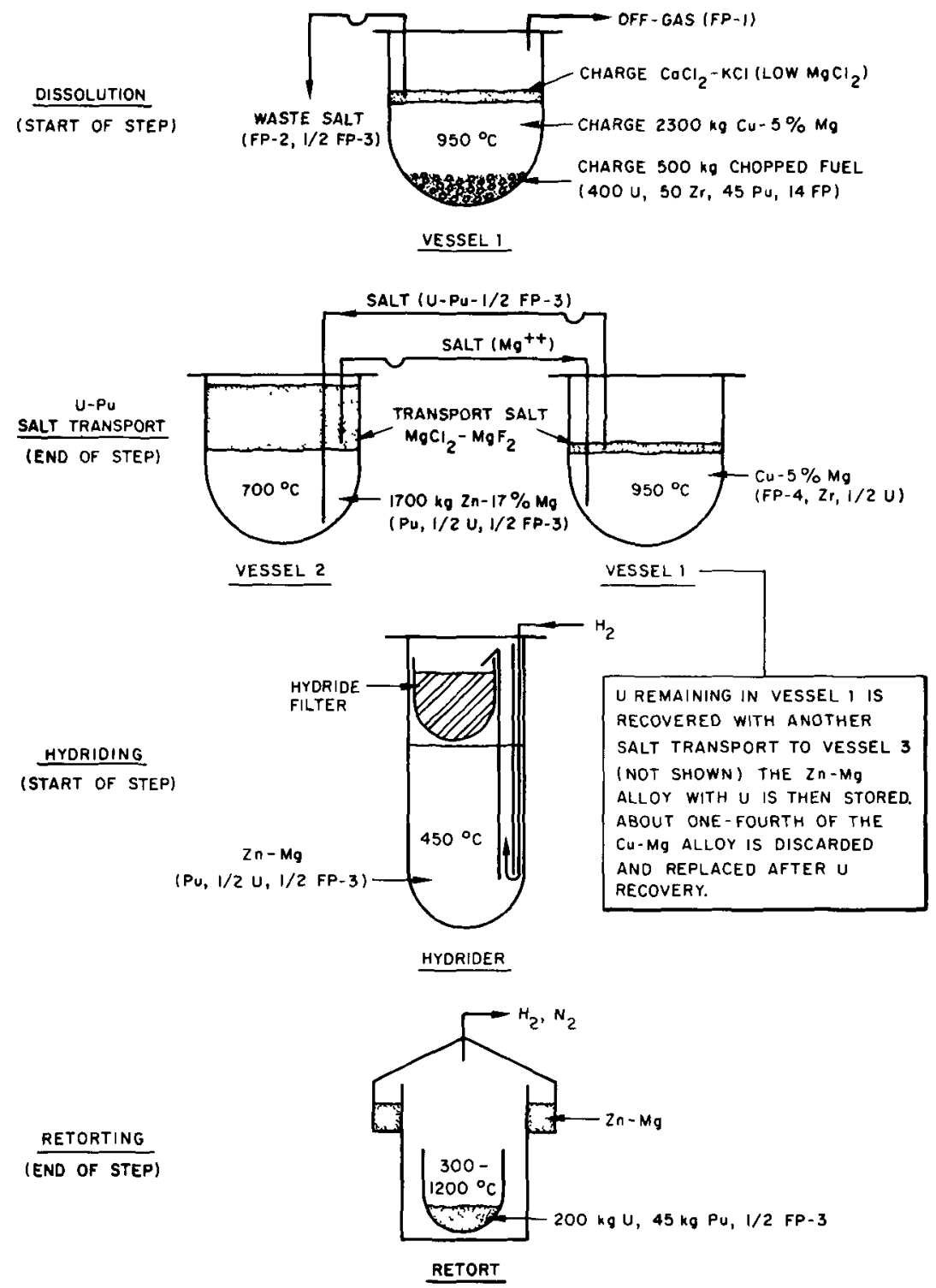

Fig. 16

Potential Pyrochemical Process. ANL Neg. No. $116-79-192$

The $\mathrm{Zn}-17 \% \mathrm{Mg}$ containing uranium, plutonium and $\mathrm{FP}-3 \mathrm{~s}$ could conceivab1y be retorted to drive off the $\mathrm{Zn}-\mathrm{Mg}$, but the time required is impractically long. A preliminary concentrating operation would consist of hydriding the uranium, plutonium and $\mathrm{FP}-3$ in the alloy and filtering the hydrides from the $\mathrm{Zn}-\mathrm{Mg}$. The filtration operation is thought to be achievable with a beryllia crucible having bottom holes over which a particle layer of a compound such as magnesium nitride does the filtering. The alloys and hydrides are to be carried to the filter with a $\mathrm{H}_{2}$ gas 1ift; the engineering details of the operation are speculative.

At the completion of hydriding, the filter and its collection of hydrides and interstitial $\mathrm{Zn}-\mathrm{Mg}$ would be transferred (inside a whole crucible) to a retort and the residual $\mathrm{Zn}-\mathrm{Mg}$ distilled, the hydrides and nitrides decomposed, and the resulting metal melted into an ingot. The composition of the ingot 
should be about $18 \%$ plutonium and $0.3 \%$ FP-3 in uranium. A final step of zirconium adjustment would be necessary to attain the $10 \%$ zirconium level required for recycled fuel.

\section{Fuel Fabricated in the Integral Cycle}

The development of remote fabrication of radioactive metallic fuel would be based on the EBR-II experience, outlined in Section III.A.6.

\section{E. Safeguards in the Integral Cycle}

Since integral cycle systems are identified for world-wide deployment, the safeguards defenses would take on much of the structure of internationally deployed LWR safeguards.

The structure of the national safeguards imposed on the systems would be largely up to the nation or organization purchasing them, although it is likely that the buyer would be contractually required to employ a specified minimum of physical security and follow IAEA requirements for accountability.

Although the likely structure of the physical security system is well understood (see Section II.F.3.b.(1)), the level of its deployment and workability is likely to be nation-dependent. The application of physical protection for the purpose of protecting the facilities from physical damage and limiting theft by employees would establish a base level of SNM protection.

However, the international system of safeguards control would need to retain responsibility for assurance of SNM security. This system, administered by the IAEA (also see Section II.F.3.a for a more detailed treatment), requires (for NPT nations) that the nation establish and maintain a system of accountability and control of SNM in a manner that enables IAEA inspectors to verify that there has been no diversion of the material. The verification is by independent measurements and observations. In practice this is performed by checking accounting records, and making visual checks and NDA measurements of random samples of the SNM.

For the integral cycle, present IAEA techniques would have reduced effectiveness due to the high radiation level of the SNM in all phases of the fuel cycles. However the period for deployment of the integral cycle might be sufficiently distant to allow IAEA application of advanced NDA techniques capable of measurements in the expected gamma radiation fields for reprocessed or fabricated fuel.

In the integral cycle the amount of SNM would constantly increase due to the employment of high breeding gain FBRs. The resulting IAEA accounting approach would likely rely on modeling techniques to predict expected inventory levels. The required techniques are presently available and could be routinely applied well before any conceivable first integral cycle deployment. 
F. Transportation in the Integral Cycle

There would be less transportation of nuclear materials in the integral cycle system than in any other type of FBR deployment. Collocation of reprocessing and fabrication with the reactors would eliminate shipments of spent fuel from the reactor to the reprocessing plant, shipments of bulk SNM from the reprocessing plant to the fabrication plant, and shipments of fresh fuel from the fabrication plant to the reactor. If the national waste depository were located off-site, then shipment of nuclear wastes from the energy center to the depository would be the only normal transport of potentially hazardous nuclear material in the integral cycle deployment scenario.

Startup of new facilities would involve some transportation of fresh fuel assemblies during the initial phases. The number of assemblies involved would depend on the number of reactors in the energy center, the delay between startup of the reactors, and the system doubling time. Total shipments of this type would be at least a factor of 10 below what they would be in the reference international deployment scenario.

A mature energy center would have the capability of accumulating a large stockpile of processed plutonium. Reprocessing would leave fission products in the fuel, but the actual radiation level associated with the stockpiled fuel would depend on the decontamination factor and the elapsed time since reprocessing. Eventually this stockpiled material would be sent from the center for use elsewhere, in the form of either bulk material or fabricated fuel elements. The impact on transportation would depend on the physical form, the radiation level, and the destination of the material.

\section{G. Overt Diversion Potential in the Integral Cycle}

In addition to the issues of safeguards and covert diversion addressed above, two observations can be made in an assessment of diversion potential with integral cycle systems.

The first is that pyrochemical reprocessing, with its incomplete partitioning of uranium and plutonium and its partial decontamination of the product fuel, can be altered. In this respect pyrochemical reprocessing is similar to the proliferation defense offered by aqueous Civex. It may be inherently more difficult to pyrochemically remove all fission products, but it is likely that a relatively high decontamination could be accomplished. Similarly, plutonium could be fairly completely separated from uranium with some process modifications. Thus the diversion barrier offered by pyrochemical reprocessing in the integral cycle is primarily a barrier to subnational groups on 1y.

Secondly, deployment of integral cycle systems implies deployment of versatile, shielded hot cells. Diversion of these facilities to weaponsrelated activities would be quickly known to inspectors; nonetheless, the presence of numerous integral cycle facilities can be viewed as potentially tempting to a non-weapons state. 


\section{STATUS OF FBR FUEL CYCLE TECHNOLOGY}

In the last five sections the technology of feasible FBR fuel cycles was reviewed. In this section the discussion will focus on the status of the development of the major elements in each process. Because the time required to develop some of the processes needed in FBR fuel cycles can be quite long, estimates of the development times required for a mature industry will be made where feasible or appropriate.

\section{A. Reprocessing}

Since a commercial fast reactor fuel cycle has yet to be established anywhere in the world, full scale reprocessing, including equipment and processes, is not an accomplished fact. However, many of the individual processes are developed though not applied to FBR fuels. Demonstration of a fullyintegrated plant of practical size is needed, and will require a substantial commitment over the next several years.

\section{Aqueous Solvent Extraction}

\section{a. $\quad$ Purex}

Purex reprocessing has been under development in the U.S. for more than 25 years. The chemical processes are well understood and have been applied in large scale production plants around the world. In general, extrapolation of present-day Purex technology to FBR fuels is thought to be feasible, in that the approach is similar to that for LWR fuels. Those areas that require continued development are the head-end steps (for example, the reliability of shears), retention of gaseous radioactive materials, and the design of low-cost remote maintenance systems. Although development work has largely been for oxide fuels, most of the process steps are the same for metals and carbides once they have been dissolved. Final product conversion is, of course, specific to the fuel. Although a specific product conversion step has been developed and demonstrated, alternative methods that require further development may be more promising.

For carbide fuels, storage in water pools is an unresolved problem area. Placement in individual cans within the storage pool has been laboratory tested. The ability to shear the carbides has not been satisfactorily demonstrated. Additional work on the conversion of carbides to oxides is required.

As with carbides, the head-end steps for metal fuels need development. In addition to storage, shearing, and inactivation of the sodium bond, dissolution of $\mathrm{U}-\mathrm{Pu}-\mathrm{Zr}$ fuels is still a problem whose solution has yet to be demonstrated. However, proposed methods appear to be feasible.

\section{b. Coprocessing}

Coprocessing requires moderate additional development beyond that which is needed for Purex. However, a requirement for low decontamination would add additional uncertainty to the chemical processes. Retention factors for the fission products have to be developed at the laboratory 
level. The ability to control these factors at the production level has to be demonstrated. It is believed that limiting the decontamination factors for ruthenium and zirconium fission products to $\sim 100$ will require only modest changes to present technology. The extra heat production (factor of 4-5) will require development of end-product cooling processes.

c. Thorex

Development of the Thorex process for U/Th fuels is considerably behind that of Purex. In this country, about 1000 tonnes of thorium fuels have been processed on a campaign basis in Purex plants modified to a Thorex flowsheet. In the Federal Republic of Germany, a Thorex pilot plant is ready for startup.

Al1 chemical processes in Thorex require further laboratory development. The required addition of $\mathrm{HF}$ to the nitric acid for fuel dissolution might cause operational problems due to corrosion if adequate control of the fluoride ion cannot be effected. Partitioning and solvent extraction steps are not developed to a satisfactory level even in the laboratory.

\section{Fluoride Volatility Processes}

The Civex reprocessing flowsheet, which is conceptual only, uses fluoride volatility after the extraction step of the pure uranium stream. Demonstration of fluoride volatility has proceeded to the bench-scale experiment stage for discharged reactor fuels. As with other processes, no FBR fuel experience exists. The process is suitable for neither plutonium nor thorium-bearing fuels, but for different reasons. Thorium does not form a volatile fluoride. Plutonium does form the volatile $\mathrm{PuF}_{6}$, but it decomposes readily to non-volatile $\mathrm{PuF}_{4}$, which plates out in equipment and causes losses and criticality problems. A solution to the instability has not been found. However, fluoride technology has been well established at the laboratory level through years of development.

\section{Pyrochemica1 Processes}

The metal-salt processes have been developed to the point of demonstration of some process steps for U/Pu fuels in bench-scale equipment. Another subset of pyro processing, melt refining, was successfully used for recycling enriched-uranium fuels in the EBR-II pilot plant facility. A pyrochemical process will be installed to recycle plutonium scrap and recover americium at Rocky Flats, Colorado. In general, considerable development would be required for a practical demonstration of complete processes in a large plant. Materials selection and equipment fabrication for pyrochemical processes would be a major development requirement; processing equipment requires inert materials with a high melting point such as tungsten. These materials are difficult to fabricate.

\section{B. Fabrication}

Fabrication of mixed (U-Pu) oxide FBR fuel elements from pressed and sintered pellets is the reference technology in the United States and in most other countries with FBR development programs. The approach in the U.S. is 
that the fabrication process will be automated and contained in shielded cells, but that contact-maintenance of process equipment will be done.

Some process steps have been commercially demonstrated on an engineering scale. Methods for automating such processes as powder metering, pellet pressing and inspection, and fuel-pin welding have been demonstrated on an engineering scale. All other development activities for fabrication equipment have progressed to or beyond the proof-of-feasibility stage.14,115 The remaining key issue is whether prototypic equipment can be successfully demonstrated in an integrated fabrication line.

Fabrication of mixed U-Pu carbide pellets would require essentially the same steps outlined above for oxides. Additional development would involve some head-end processes to convert oxide powder to carbide.

Completely remote fabrication, including remote maintenance of equipment, would be required in several fuel cycle options (spiked fuel, fuel reprocessed with fission product retention, thorium-based fuels). Fabrication of pellets is a mechanically-intensive operation, and development of completely remote processes would require a major effort. Remotely maintainable pellet inspection systems have been practically demonstrated. Design of fabrication equipment to operate with remote maintenance is just beginning. Completion of the design/construction/testing/evaluation/scale-up cycle would require a large investment.

Less mechanically intensive fabrication processes involving vibratory compaction of particulate fuel have been investigated in the laboratory, but is considerably behind pellet processes in development. Major uncertainties in reactor performance of particulate fuel elements need resolution, in addition to development of the process itself.

For metal fuels, several fabrication technologies have been tried, with varying degrees of success. The injection-casting process developed for uranium alloy fuels at EBR-II is in the most advanced state of development, both for hands-on and completely remote fabrication. Laboratory investigations are needed to investigate the casting of longer pins required in large FBRs.

The technology of fabricating thorium-based FBR oxides and carbides is not as well developed as for the U-Pu counterpart. However, essentially all of the process equipment designed for fabrication with remote operation and maintenance would be applicable to the thorium-based fuels. Laboratory investigations are required to develop a well-defined set of feed powder specifications and time and temperature requirements for pellet sintering.

Metallic thorium-based fuels received considerable attention from 1950 to 1968, but interest has been dormant since then. Most processes would be similar to the case with $\mathrm{U}-\mathrm{Pu}-\mathrm{Zr}$ fuels, but because of the higher melting points of thorium-based fuels, development of metallic thorium-based pin fabrication techniques would be more difficult.

Finally, radioactive spiking or fission-product retention could impact the development of fabrication technology beyond requiring completely remote 
operation. As an example, laboratory investigations are needed to determine the impact of conversion and pelletizing processes on spikants.

In summary, LWR reactor fuels and research FBR fuels have undergone continuous development for almost 30 years. Commercial-scale fabrication of FBR fuels requires the development of automated and integrated fabrication equipment. Several of the concepts suggested to enhance proliferation resistance of the FBR fuel cycle would increase the demands on fabrication technology, and increase both the time and expense of development.

\section{Transportation}

Shipping cask development for FBR fuels is basically at the design stage. Although the U.S. has commercial experience in shipping spent LWR fuel, FBR fuels are sufficiently different that much of the present technology will not be applicable. Higher burnup in FBR fuel plus the economic incentives for earlier shipment following discharge from the reactor result in much higher heat sources. Internal cooling of the shipping cask is then a major development area. Laboratory tests with helium cooling and individual elements encased in sodium have been conducted. It is estimated that present cask design concepts could handle 8-10 CRBR assemblies 30 days after discharge.

Shipping casks for high level wastes are essentially undeveloped in this country. ${ }^{77}$ The design goals are to provide adequate shielding to protect the population from radiation while not introducing an unmanageable weight penalty. Casks designed for LWR Pu-recycle wastes should be adequate for FBR wastes.

D. Waste Handling

FBR waste handling will not differ from LWR waste handling. Waste handling in the U.S. is at the stage where conversion from high-level liquid waste to solid waste has been demonstrated. A pilot plant for calcining liquid wastes has run since the early 1960s. A production plant is being built. 113

Waste disposal policy in this country has become a major political issue. Although there has been much discussion in the public sector of the need for demonstration of safe, permanent disposal of high-level reactor wastes, no permanent disposal site has yet been selected. Demonstration of this final phase of waste handling will not be forthcoming until the political decisions are made. Such a demonstration will require several years and substantial effort.

One totally undeveloped concept is to separate the actinides from other high level wastes and fission them in an FBR. 14 Development of this concept would require a great deal of effort starting at the research level, but is considered to be technically feasible.

\section{E. Safeguards}

The components of the safeguards systems described in this report are essentially developed. Systems integration, processing and logic are being laboratory-tested. Complete safeguards systems will have to be specifically 
engineered for a given plant so that demonstration of safeguards should proceed concurrently with prototype demonstration of reprocessing and fabrication.

Real-time accountability will have to be demonstrated for the reference fuel cycle. Some of the proposed antiproliferation technical fixes would impose operating conditions that would necessitate substantial additional development of NDA systems.

\section{SUMMARY, KEY TECHNICAL ISSUES AND CONCLUSIONS}

Years of research, development, and demonstration will be required to go from the present FBR fuel cycle technology to a viable commercial industry. Many individual chemical processes and mechanical components have to be developed to prototypic scale before FBR fuel cycle technology will be completely established. The direction of that technological development during the next few years will be influenced by the issue of proliferation resistance, which could greatly complicate FBR fuel cycle development if large technical modifications result from proliferation-defense criteria. The focus here has been on the key technical issues in establishing the reference FBR fuel cycle and on the additional technical issues raised by suggestions for making the FBR fuel cycle more proliferation-resistant.

The two major fuel cycle technologies, reprocessing and fabrication, will require substantial commitments to establish mature commercial facilities for the reference U-Pu system. There is a consensus within the technical community that both technologies could be successfully developed for oxide fuels. Most components and processes are in a state where they require only scale-up and testing, though possibly through several stages. The proof-of-principle development work is mostly required in the less important areas. General technological developments that need to be demonstrated include reduced personnel exposure, improved safeguards, reduced fuel costs, increased plant throughput, and improved fuel performance.

Aqueous reprocessing technology has been in some stage of development for more than 30 years. There is little question that some variant of the present-day Purex process could be used to process large quantities of FBR fuels. The key to this development is continuation of the engineering, testing, and systems integration that are required. Most of the areas that are in need of development are in the head-end steps up to and including fuel element dissolution. Individually they do not represent make-or-break issues, but rather areas where cost-effective processes that are operationally satisfactory must be developed. Establishing a total U.S. reprocessing capability for FBR fuels would require a strong commitment of technical personnel and facilities for up to 20 years.

Fabrication experience with FBR oxide fuels has been limited to small glovebox operations in the U.S. Scale-up of these processes to completely automated fabrication has been under development and engineering evaluation for the past four years. Many unit operations are expected to undergo practical demonstration of prototypes during 1979. A key issue here is the integrated control of remote operation and maintenance of a fabrication line. As with reprocessing, development of a full fabrication capability would require substantial commitment, but no technological breakthroughs. 
Introducing metal or carbide FBR fuels would result in additional uncertainties in establishing the fuel cycle. Carbides have less impact than metals because the basic reprocessing and fabrication technologies are extensions of those required by oxides. This requires additional conversion steps at each end of the reprocessing plant, but in the fabrication plant the carbides are formed into ceramic pellets in essentially the same way as oxides. Metal fuels would require basic development in the dissolution step of aqueous reprocessing; corrosive $\mathrm{HF}$ is needed to dissolve the zirconiumbearing fuel. Pyrochemical processes are also candidates, but need much more development. Fabrication of metal fuels requires completely different techniques from those required by oxides. Although considerable experience has been gained with EBR-II, fabricating full-sized fuel pins of U-Pu-Zr alloy is essentially unproven.

In summary, fuel cycle technology for reference deployment involves many processes and many pieces of equipment that are in different states of development. The research and development paths to successful demonstration of the reference FBR fuel cycle seem straightforward, though an appreciable commitment is yet required. Modifications to the reference fuel cycle would increase the $R \& D$ requirements, resulting in increased uncertainty as to the time and cost required for demonstration of a working fuel cycle.

The concerns that gave birth to the INFCE have raised many suggestions for strengthening the FBR fuel cycle against proliferation. Some of these suggestions have to do with such deployment scenarios as secured areas and integral cycles. Other suggestions involve technical modifications to the reference processes or introduction of a thorium fuel cycle. Implementation of any of these suggestions would complicate the establishment of the fuel cycle, and many would add a cost penalty beyond the additional money required for research and development. The key issue is whether any of the alternate concepts would offer sufficient incremental proliferation defenses, above the safeguards that would normally be imposed, to justify the additions in cost, operational difficulty, and personnel exposure.

Most of the suggested modifications are aimed at increasing the proliferation-resistance of the fuel cycle. Use of radiation barriers is a recurrent theme in these alternate concepts. While these radiation barriers might present substantial diversion-resistance to terrorists, they would be less effective in thwarting proliferation by a nation with an industrial base capable of supporting FBRs. However, such barriers could increase the difficulty of plutonium separation and lengthen the time between material diversion and weapons fabrication. Unfortunately, in some cases these barriers also reduce the effectiveness of materials accounting procedures.

Several of the alternative approaches deal with reprocessing modifications. Generally these have to do with leaving uranium and/or fission products in the plutonium stream. Retention of the desired proportion of these materials would be very sensitive to the exact operating conditions. Maintenance of consistent proportions throughout the reprocessing and refabrication steps, especially for the case of multiple recycle, is the key technical issue. However, the key issue overall may be whether knowledgeable people $h$ control of the plant could modify processes in any of the concepts to produce a stream of uncontaminated, uranium-free plutonium. The residual issue 
of whether the increased time, difficulty, and probability of detection would provide an adequate level of defense is beyond the scope of this report.

There are several schemes for retaining hard-gamma emitters with the plutonium throughout the fuel cycle. As a class, these schemes raise several technical issues. The first is that the impact on fabrication would be extreme from a technology and cost standpoint. Fully remote, heavily shielded fabrication lines would be required. Remote maintenance would also be required. Development of the latter to a point of commercial confidence would demand a substantial effort. Development of particulate fuel elements, which involve fewer mechanical fabrication processes than pellets, might improve the reliability of high-gamma fuel fabrication, but raise additional issues about fuel performance. Whether the gamma-emitters could be retained in a known and constant quantity from the selected point in the reprocessing stream to the finished fuel element is another issue. Using reference methods it is probable that some retained fission products could be lost during certain process steps (pellet sintering, for example). The concept of an externally-supplied gamma source (e.g., ${ }^{60} \mathrm{Co}$ ) raises a host of problems, but one key issue is whether an adequate production capacity could be developed.

Pre-irradiation is a high-gamma concept that is designed to protect only a limited part of the fuel cycle - fresh fuel transportation and storage. This concept would require a development effort to design and demonstrate an irradiation facility. A key issue is whether this additional cost penalty should be imposed to protect a limited part of the fuel cycle.

The Civex approach to plant design is essentially based on present-day components. There are some key issues other than those involved with the chemical processes. Since the engineering goal is inflexibility, one key issue is whether the plant could successfully operate with a variety of fuel compositions. The other is whether the requisite reliability could be achieved. With no maintenance capability built into the plant, even infrequent breakdowns could be severely penalizing. Another issue that might be important is the cost that would be added to the fuel cycle. At present the range of estimates of incremental costs is wide, but if the correct value is near the upper end, the cost impact would be substantial.

Safeguards provide a common element of defense in any of the fuel cycle technologies. Safeguards development programs are well under way in this country, and safeguards concepts and instrumentation are reasonably well established, though they are not being demonstrated in sensitive facilities. The key issue here is that safeguards discussions have been based on present-day technology. Improved instrumentation and methods, developed concurrently with the rest of the fuel cycle, could have a significant and beneficial impact. This approach could be less costly than some of the exotic fuel cycle technologies that have been proposed. Another issue is the probable detrimental effect of high-gamma fuels on NDA analysis for safeguards. Degradation of this on-line material accountability system would partially offset the diversion resistance gained by retention of high radiation levels throughout the fuel cycle.

Transportation technology is a key factor in determining out-of-reactor time for the fuel. Since this impacts doubling time, required inventories, and ultimately fuel cycle costs, development of shipping casks that are 
capable of handling high heat loads is an important component of overall fuel cycle technology. Moreover, reducing the total amount of fissile material in transit by increased collocation of fuel cycle facilities appears to offer increased proliferation resistance.

Alternative deployment scenarios would have a substantial impact on the fuel cycle. In the secured area concept, only denatured reactors would be allowed for general deployment, with fuel supplied from secured FBRs which would use more sensitive fuels. The requirement for balanced fissile production/consumption would greatly restrict the allowable combinations of reactor types. Denaturing would automatically introduce the undeveloped thorium cycle.

Thorium cycles would introduce all the problems of other high-gamma fuels. In addition, Thorex is behind Purex in development. The complications to the total fuel cycle, including mining and milling, would be enormous because the uranium cycle would still be required. Hence, separate and parallel development of reprocessing and fabrication facilities for each cycle would be required. Three-way separation (U, Th, Pu) is presentIy a concept that has not been demonstrated.

Integral cycle deployment would rely on highly radioactive fuel and elimination of most transportation of sensitive materials as primary diversion deterrents. Although metal fuels and pyrochemical reprocessing are well suited to the integral cycle, other technologies could be operated in this deployment scenario. Perhaps more important1y, integral cycle technology would be used in other deployment scenarios. The capability for quick turn-around time would have a beneficial effect in that relatively less special nuclear material would exist outside the reactor.

Pyrochemical reprocessing would require a much greater development effort than Purex. Reliable techniques for unit operations such as filtration must be devised. Fabrication of such process equipment as the dissolver represents a major development. Present knowledge of fabrication techniques for candidate materials (tungsten or ceramic linings) suggests that substantial problems would be encountered.

Obviously, all of the FBR fuel. cycle options will not be developed to the point of commercialization. Economics, resource utilization, timeliness of implementation, feasibility and proliferation resistance will each be considered in the selection of promising fuel cycle options.

\section{ACKNOWLEDGMENT}

A large number of people were instrumental in the preparation of this chapter. G. A. Ducat and R. E. Kaiser (Argonne National Laboratory) were very helpful in arranging the fabrication and transportation-waste discussions, respectively. V. P. Charyulu (Idaho State University) provided assistance with the generic review of FBR fuel cycles. M. C. J. Carlson and R. Hennig (Hanford Engineering Development Laboratory) were responsible for arranging for a substantial input from the Non-proliferation Alternative bystems Assessment Program (NASAP), and for a review of the fabrication sections of the report. W. O. Harms (Oak Ridge National Laboratory) coordinated 
the assembly of fuel cycle data for INFCE support group 5, and some of that data appears in this report. W. D. Burch (Oak Ridge National Laboratory) provided reprocessing information and assisted in the review of the reprocessing sections. Careful and thoughtful reviews were provided by L. Burris, P. L. Garner, W. B. Seefeldt, M. J. Steindler, D. C. Wade, B. S. Yarlagadda (Argonne National Laboratory) and K. L. Rohde (Allied Chemical Corp.). J. Cassady and $J$. Wissmueller were responsible for preparation of the manuscript through the several drafts. The assistance of all these people was sincerely appreciated and is gratefully acknowledged.

\section{REFERENCES}

1. IMF'BR Program Plan, Vol, 8, Fuel Recycle, WASH-1108, USAEC (August 1968).

2. S. Lawroski, Survey of Separation Processes, Proceedings of the International Conference on the Peaceful Uses of Atomic Energy, 9, p. 575, United Nations, New York (1956).

3. F. L. Culler, Reprocessing of Reactor Fuel and Blanket Materials by Solvent Extraction, Proc. of the Int1. Conf. on the Peaceful Uses of Atomic Energy, 9, pp. 464-483, 560-569, United Nations, New York, (1956).

4. M. Benedict, T. H. Pigford, Nuclear Chemical Engineering, pp. 320337, McGraw-Hi11 Book Co., Inc., New York, NY (1957).

5. E. J. Detilleux, A. Schneider, B. F. Warner, Chemical Reprocessing of Nuclear Fuels: A Technical Status Review, Proc. of the Intl. Conf. on World Nuclear Energy - A Status Report, American Nuclear Society, Hinsdale, IL (November 1976).

6. W. D. Burch, A. L. Lotts, Developments in Reprocessing Technology for High Temperature and Fast Breeder Fuel, Proc. Of IAEA Symposium on Nuclear Power and Its Fuel Cycle, IAEA-CN-36/14 (1977).

7. A. T. Guesky, Solvent Extraction Separation of ${ }^{233} U$ and Thorizon from Fission Products by Means of Tributyl Phosphate, Proc. Int1. Conf. on Peaceful Uses of Atomic Energy, 9, p. 505, United Nations, New York (1956).

8. C. E. Stevenson, M. J. Feldman, D. C. Hampson, D. M. Paige, N. J. Suauron, Operations of a Pyrochemical Processing-Remote Refabrication Plant: The EBR-II Fuel Cycle Facility, Recent Advances in Reprocessing of Irradiated Fue1, Chem. Engr. Prog. Symp., Series 94, 65 (1969).

9. R. K. Steunberg, R. D. Pierce, L. Burris, Progress in Nuclear Energy, Series III, Process Chemistry, 4, Pergamon Press - Oxford of New York (1969).

10. G. E. Brand, E. W. Murbach, Pyrochemical Reprocessing of vo by AIROX. Summary Report, NAA-SR-11389 (August 1965). 
11. L. Burris et a1., Pyrometallurgical and Pyrochemical Fuel Processing, Proc. of Third Intl. Conf. on the Peaceful Uses of Atomic Energy, 10, p. 500 (1965).

12. P. Murray, Fast Breeder Fuel, Reactor Technol., 15, (1), pp. 6-58 (Spring, 1972).

13. M. H. Lloyd, W. T. McDuffee, O. K. Tallent, L. E. Morse, R. G. Haire, Sol-Gel Processes for $\mathrm{PuO}_{2}$ and $\mathrm{UO}_{2}-\mathrm{PuO}_{2}$, Proc. of the Symp. on Sol-Gel Processes and Reactor Fuel Cycles, Gatlinburg, TN, pp. 100112, May 4-7, 1970.

14. D. H. Nyman, D. W. Bennett, T. T. Claudson, R. E. Dah1, R. A. Graham, J. J. Keating et al., U.S. Technology for Mechanized/Automated Fabrication of Fast Reactor Fuel, Proc. NUCLEX 1978 Technology Meeting A1, to be published October 1978.

15. J. E. Ayer, (U-PulC Particulate Fuel Fabrication, Proceedings of International Symposium on Plutonium Fuels Technology, AIME, ed. by K. E. Horton, R. E. Macherey, and R. J. Allio, Scottsdale, Arizona, pp. 249-262 (October 4, 1967).

16. R. A. Bradley, Oak Ridge National Laboratory, private communication (1978).

17. J. F. Bishop, A. Chamberlain, J. A. Gatley, The UK Strategy and Progrommes for Advanced LMFBR Fuels, Proc. International Meeting on AdLMFBR Fuels, Am. Nucl. Soc., Tucson, Arizona, pp. 15-25 (October 10, 1977).

18. J. G. Yevick, East Reactor Technology Plant Design, MIT Press, Cambridge, MA (1966).

19. M. J. Feldman et al., Remote Fabrication of EBR-II Fuels, 1969 Nuclear Metallurgy Sympoisum, Reprocessing of Nuclear Fuels, Ames, IA, 15, (August 1969).

20. T. R. Clark, E. E. Kintner, F. K. Pittman, W. R. Voight, Jr., Nuclear Fuel Cyle, Energy Research and Development Administration Report ERDA-33 (March 1975).

21. E. E. Augino, High-Level and Long-Lived Radioactive Waste Disposal, Sctence, 198, (4320), p. 885 (December 1977).

22. B. L. Cohen, The Disposal of Radioactive Wastes from Fission Reactors, Scientific American, 236, (6), p. 21 (June 1977).

23. R. G. Page, Features and Requirements of the United States Nuclear Matemial Control System, Safeguarding Nuclear Materials, Vol. I, p. 37, IAEA publications, Vienna, Austria (1976).

24. K. P. Chapman, NRC Perspective on Fuel Cycle and Safeguards, Nuc1. Matl. Mgmt., V(III), p. 29 (Fall, 1976). 
25. H. E. Lyon, The Role of Material Control and Devezopment in ERDA's Safeguards Progrom, ibid, p. 63 (Fall, 1976).

26. R. Rometsch, C. Bennett, Nuclear Safeguards and Transportation, Trans. Int1. Conf. on World Nuclear Energy - A Status Report, Am. Nucl. Soc., Hinsdale, IL (1976).

27. A. Stoller, R. Richards, Reactor Handbook, Vol. II, Fuel Reprocessing, Interscience Publishers, New York (1961).

28. E. A. Hakkila et al., Coordinated Safeguards of Matemials Management in a Fuel Reprocessing Plant, LA-6881, Vo1. I (September 1977).

29. L. D. Chapman et a1., Development of an Engineered Safeguards System Concept for a Mixed Oxide Fuel Fabrication Facility, SAND 76-0180 (August 1976).

30. M. Willrich, T. B. Taylor, Nuclear Theft: Risks and Safeguards, Ballinger Publishing Co., Cambridge, MA (1974).

31. J. M. de Montmollier, R. B. Walton, The Design of Integrated Safeguards for Nuclear Facilities, Nucl. Matl. Mgmt., V(II), pp. 317-332 (1976).

32. The Agency's Safeguards System, International Atomic Energy Agency, INFCIRC/66/Rev. 2 (September 1968).

33. The Structure and Content of Agreements Between the Agency and States Required in Connection with the Treaty on the Non-Proliferation of Nuclear Weapons, International Atomic Energy Agency, INFCIRC/153 (May 1971).

34. Regional Nuclear Fuel Cycle Centers, Vo1. II, Appendix 5A, International Atomic Energy Agency (April 1977).

35. Nuclear Safeguards Technology Handbook, U.S. DOE Report, HCP/D6540-01 (December 1977).

36. Entry-Control Systems Handbooks, SAND 77-1033, Chapter 1 (September 1977).

37. Ibid., Chapter 4.

38. USAEC Regulatory Guide, 5.27, (June 1974).

39. T. E. Sampson, P. E. Fehlau, Sodium Iodide and Plastic Scintizlator Doomway Monitor Response to Shielded Reactor Grade Plutonium, LA-6566-M5 (November 1976).

40. USAEC Regulatory Guide, 5.7, (June 1973).

41. J. P. Shipley, D. D. Cobb, R. J. Dietz, M. L. Evans, E. P. Schelonka, D. B. Smith, R. B. Walton, Coordinated Safeguards for Materials Monagement in a Mixed-Oxide Fuel Facizity, LA-6536 (February 1977). 
42. J. E. Lovett, Concepts of Real-Time and Semi-Real-Time Material Control, Nuc1. Mat1. Mgmt., IV(III) pp. 24-33 (1975).

43. R. H. Augustson, Development of In-Plant Real Time Materials Control: The DYMAC Progrom, Nuc1. Mat1. Mgmt., V(III), pp. 302-316 (1976).

44. G. R. Keepin, W. J. Maraman, Nondestmuctive Assay Technology and InPlant Dynamic Materials Control-DYMAC, Safeguarding Nuclear Materials, Proc. Symp., Vienna, 1975, paper IAEA-SM-201/32, pp. 305-320 (1976).

45. J. A. Williams, Nuclear Fuel Cycle: (5) Reprocessing of Irradiated Fuel, Journal of the Institute of Fue1, 50, pp. 153-160 (September 1977).

46. J. H. Goode, C. L. Fitzgerald, V. C. A. Vaughen, The Dissolution of Unirradiated and Irradiated (U,Pu) $\mathrm{O}_{2}$ in Nitric Acid, ORNL-5015 (February 1975).

47. F. Baumgartner, W. Ochsenfeld, DeveZopment and Status of LMFBR Fuel Reprocessing in the Federal Republic of Germany, KFK-2301 (May 1976).

48. H. Goldacker, H. Schnieder, F. Steinbrunn, L. Stieglitz, A Newly Developed Solvent Wash Process in Nuclear Fuel Reprocessing Decreasing the Waste Volume, Kerntechnik, 18, p. 426 (1976).

49. W. Ochsenfeld, F. Baumgartner, H. J. Bleyl, D. Ertel, G. Koch, E. Warnecke, Versuche zur Aufarbeitung von Schnell-Bruter Brennstoffen in der Anlage MILLI, KFK-2396 (February 1977).

50. Bamwelz Nuclear Fuels Plant Separations Facility-Final Safety Analysis Report, Docket 50-332, Allied-General Nuclear Services (October 10, 1973).

51. E. A. Hakkila et al., Coordinated Safeguards for Materials Management in a Fuel Processing Plant, LA-6881, Vo1. II (September 1977).

52. J. L. Jaech, Statistical Methods in Nuclear Material Control, TID26298 (1973).

53. D. E. Ferguson, A. L. Lotts, Fast Reactor Fuel Reprocessing, International Conference on Nuclear Solutions to World Energy Problems (1972).

54. W. J. Ross, Fabrication of FFTF Fuel pins at Babcock \& Wilcox, Trans. Am. Nuc1. Soc., 22, p. 248 (1975).

55. A. B. Shuck, A. L. Lotts, K. Drumheller, The Remote Fabrication of Reactor Fuels, Reactor Technology, Selected Reviews 1965, Leonard E. Link, ed., TID-8541 (1965).

56. E. T. Jurney et a1., The Los Alamos Plutonizm Reactor, TID-10048 (1954).

57. J. G. Yevick, Fast Reactor Technology, Plant Design, MIT Press, Cambridge, MA (1966). 
58. W. H. Zinn, H. V. Lichtenberger, M. Novick, Feasibility Report: Fast Neutron Pile for a Test of Conversion, ANL-4356 (1949).

59. H. G. Barkman et a1., LAMPRE Hazard Report, LA-2327 (1959).

60. R. E. Peterson, R. L. Corbett, Operation of the Plutonium Fueled Fast Reactor, LAMPRE, Transactions of a Topical Meeting on Fast Reactors, Am. Nuc1. Soc., San Francisco, California (April 10-12, 1967).

61. L. J. Koch et a1., Hazard Summary Report, EBR-II, ANL-5719 (May 1957).

62. L. J. Koch et al., Addendum to Hazard Summary Report, EBR-II, ANL5719 Addendum (June 1962).

63. E. L. Alexanderson et al., Operating Experience at the EFBR, Transactions of a Topical Meeting on Fast Reactor Technology, Am. Nucl. Soc., Detroit, Michigan (April 26, 1968).

64. C. E. Branyan, U.S. Experience with Fast Power Reactors, FERMI-I, American Power Conference, Chicago, Illinois (April 20, 1971).

65. C. M. Walter et al., U-Pu-Zr Metal AlZoy, A Potential Fuel for LMFBR's, ANL-76-28 (November 1975).

66. M. Haas et a1., Driver-Fuel Element Fabrication for the EBR-II, ANL report, to be published.

67. L. Burris et a1., The Melt Refining of Irradiated Uranium: Application to EBR-II Fast Reactor Fuel. I. Introduction, Nuc1. Sci. \& Eng., 6, pp. 493-495 (1959).

68. D. R. Harbur et al., Studies on the U-Pu-Zr AZloy System for Fast Breeder Reactor Applications, LA-4512 (1970).

69. H. F. Jelinek, A. G. Hins, Fabrication of Experimental Metal Fueled Irradiation Test Rods, Annual Progress Report for 1965: Metallurgy Division, ANL-7155, pp. 66-68 (1966).

70. E. F. Sturcken, C. M. Walter, Texture and Irradiation Growth in EBR-II Driver Fuel, J. Nuc1. Mater., 50, (1), pp. 69-82 (February 1964).

71. B. R. Hayward, P. Corzine, Th-U Fuel Elements for SRE, Proc. 2nd Geneva Conf., 6, pp. 438-442 (1958).

72. J. P. Shipley, Coordinated Safeguards for Materials Management in a Mixed-Oxide Fuel Facility, LA-6536 (February 1977).

73. J. Kleijnen, Statistical Techniques in Simulation, Marce1 Dekker, Inc. (1974).

74. T. Naylor, J. L. Balintfy, D. S. Burdick, Kong Chu, Computer Simulation Techniques, Wiley (1966). 
75. V. Mechoni, R. J. Catlin, L. L. Bennett, Regional Nuclear Fuel Cycle Centers: 2977 Report of the IAEA Study Project, Vols. I and II, International Atomic Energy Agency, Vienna (1977).

76. J. J. Cohen, Why Partition Nuclear Waste, Workshop on Nuclear Waste Partitioning, CONF-760642-5, Seattle (1976).

77. S. H. Sutherland et al., Waste Transportation Systems, Trans. Am. Nuc1. Soc., 28, pp. 347,348 (June 1978).

78. H. R. Yoshimura et al., High-Speed Impact and Fire Test of a Spent Fuel Raiz Cask System, Ibid, p. 348 (June 1978).

79. R. B. Pope et al., Conceptual Designs for LMFBR Spent Fuel Shipping Casks, SAND 77-1483 (March 1978).

80. D. P. Dickson, The Department of Energy (DOE) System for the Transportation of Strategic Quantities of Special Nuclear Materials, Proceedings of the International Symposium on Packaging and Transportation of Radioactive Materials, May 1978, to be published.

81. J. R. Gallagher et al., The Evaluation of Road Transit Physical Protection Systems, Ibid.

82. S. C. Keeton, R. J. Gallagher, A Tactical Gome for Use in Development and Evaluation of Road Transit Physical Protection Systems, Ibid.

83. K. P. Berkbigler, Estimates of LLEA Officer Availability, Ibid.

84. C. S. Sonnier and M. N. Cravens, Preliminary Concepts for Detecting National Diversion of LWR Spent Fuel, SAND-77-1954 (April 1978).

85. R. S. Sloat, W. A. Graf, Jr., G. P. Miller, Criteria and Concepts for Coprecal Conversion in an LWR Fuel Reprocessing-Refabrication Plant Complex, NEDO-21822 (1977).

86. R. W. Lambert, D. W. Wilson, The Coprocessing Option in the Nuclear Fuel Cycle, NEDG-21856-1 (Apri1 1978).

87. M. Levenson, E. Zebroski, A Fast Breeder System Concept, Proceedings of the 5th Energy Technology Conference, Washington, D. C. (1978).

88. B. A. Hutchins, Denatured Plutonizm: A Study of Deterrent Action, EPRI-310 (July 1975).

89. E. V. Weinstock, Coordinator, The Spiking of Special Nuclear Materials as a Safeguards Measure, Vols. I and II, BNL Draft Report (1975).

90. R. E. Brooksbank et a1., Fuel Cycles Using Adulterated Plutonium, ASME Symposium on Non-Proliferation: Reality and Illusion of a Plutonium-Free Economy, Albuquerque, NM (March 16, 1978).

91. V. Meckoni et a1., Regional Nuclear Fuel Cycle Centres, Energy Policy, pp. 267-281 (December 1977). 
92. J. E. Ayer, F. E. Soppet, Vibratory Compaction: I, Compaction of Spherical Shapes, J. Am. Ceram. Soc., 48, pp. 180-183 (1965).

93. J. E. Ayer, F. E. Soppet, Vibratomy Compaction: II, Compaction of Angular Shapes, J. Am. Ceram. Soc., 49, pp. 207-210 (1966).

94. W. J. Lackey and J. E. Sells, Assessment of GeZ-Sphere-Pac FueZ for Fast Breeder Reactors, ORNL-6568, October, 1978.

95. H. S. Bailey, N. A. Deane, B. Talwar, Preliminary Evaluation of PreIrradiation as a Means of Increasing the Diversion and Proliferation Resistance of the LMFBR Plutonizm-Uranizm Fuel Cycle, GEFR-00300 (October 1977).

96. C. M. Roberts, The Nuclear Years; The Arms Race and Arms Control, 29452970, Praeger, New York (1970).

97. Nuclear Energy Center Site Survey - 2975, USNRC Report NUREG-0001 (January 1976).

98. Gas-Cooled Reactor Progroms, Thorium Utilization Program Progress Report for July I, 2975 through September 30, 2976, ORNL-5266 (July 1977).

99. A. L. Lotts, F. J. Homan, E. Blthesen, R. F. Turner, HTGR Fuel and Fuel Cycle Technology, paper IAEA-CN-36/578, International Conference on Nuclear Power and Its Fuel Cycle, Salzburg, Austria (May 2, 1977).

100. HTGR Fuel Recycle Progrom Quarterly Progress Report for the Period Ending November 30, 2977, GA-A14738 (December 1977).

101. E. Merz, The Thorium Fuel Cycle, paper IAEA-CN-36/96, International Conference on Nuclear Power and Its Fuel Cycle, Salzburg, Austria (May $2,1977)$.

102. G. F. Smith, Purex Plant Chemical Flowsheet for the 2970 Thorium Compaign, Atlantic Richfield Hanford Company, ARH-1748 (July 1970).

103. D. A. Orth, SRP Thorium Processing Experience, Trans. Am. Nuc1. Soc., 28, pp. 340-341 (June 1978).

104. F. E. Owen, Beta and Gomma Dose Rates from ${ }^{232} \mathrm{U},{ }^{23}{ }^{3} \mathrm{U}$, HW-8196U (April 1964).

105. S. Goldsmith, D. W. Brite, Fabrication of Metal-Clad Thorium Ceramic Recycle Fuels, Trans. Am. Nucl. Soc., 28, p. 341 (1978).

106. W. A. Weinreich et al., Fabrication of High Density, High Integrity Thoria-Base Fuel Pellets, Trans. Am. Nucl. Soc., 37, p. 309 (1977).

107. J. H. Kittel, J. K. Bates, Recycle Technology for Thorizm Metal Fuels, Trans. Am. Nuc1. Soc., 28, p. 342 (1978). 
108. J. 0. Blomeke, D. W. Tedder, Waste Management Aspects of Altemative Thorium Fuel Cycles, Trans. Am. Nuc1. Soc., 28, pp. 344-346 (1978).

109. E. P. Bertin, R. J. Longoloucco, R. J. Carver, A Simplified Routine Method for $X$-Ray Absorption Edge Spectrometric Analysis, Anal. Chem., 36, pp. 641-655 (1964).

110. F. Brown, D. R. Terry, J. B. Hornsby, R. G. Monk, F. Morgan, J. Herington, P. T. Good, K. C. Steel, V. M. Sinclair, Application of Instmmental Methods to the Determination of Nuclear Fuel Materials for Safeguards, Safeguards Techniques, Proc. IAEA Symp., Karlsruhe, Vol. II, pp. 125-142 (July 1970).

111. T. R. Canada, E. R. Martin, J. W. Tape, W. B. Tippens, T. D. Reilly, J. L. Parker, Gomma-Ray Densitometry, LA-6040-PR, pp. 9-12 (August 1975).

112. D. C. Hampson et al., MeZt Refining of EBR-II FueZ, 1969 Nuclear Metallurgy Symposium, Reprocessing of Nuclear Fuels, Ames, Iowa, p. 15 (August 1969).

113. G. E. Bingham, B. R. Wheeler, A Production Facility for Solidificating of High-Level Radioactive Wastes, Trans. Am. Nucl. Soc., 28, pp. 353-354 (1978).

114. S. L. Beaman, Plutonizm and Actinide Bumout as a Waste Management Altemative, Trans. Am. Nucl. Soc., 28, pp. 351-352 (1978).

115. D. H. Nyman, D. R. McLemore, R. S. Sturges, Handling System for Nuclear Fuel Pellet Inspection, Trans. Am. Nucl. Soc., 28, pp. 370-371 (1978). 


\title{
PART 6
}

\section{INTERNATIONALIZATION AND COLLOCATION \\ OF FBR FUEL CYCLE FACILITIES}

\author{
M. G. Stevenson \\ (Los Alamos Scientific Laboratory) \\ P. B. Abramson and L. G. LeSage \\ (Argonne National Laboratory)
}

Technical Contributors:

H. H. Henryson II $\quad$ D. C. Wade
$\begin{aligned} & \text { J. R. Honekamp } \\ & \text { B. S. Yarlagadda }\end{aligned}$

W. R. Rhyne

(Science Applications, Inc.)

\begin{abstract}
This report examines some of the non-proliferation, technical, and institutional aspects of internationalization and/or collocation of major facilities of the fast Breeder Reactor (FBR) fuel cycle. The national incentives and $d$ isincentives for establishment of FBR Fuel cycle Centers are enumerated. The technical, legal, and administrative considerations in determining the feasibility of FBR Fuel Cycle Centers are addressed by making comparisons with light water Reactor (LWR) centers which have been studied in detail by the IAEA and UNSRC.
\end{abstract}

\section{INTRODUCTION}

A basic objective of the International Nuclear Fuel Cycle Evaluation (INFCE) is to evaluate alternatives for the nuclear fuel cycle in terms of both proliferation resistance and ability to meet energy needs. It has been suggested that collocation of some or all of the elements of a Fast Breeder Reactor (FBR) fuel cycle under international ownership, operation, and management makes significant advances toward both of these objectives. This report is directed at evaluation of the technical and institutional feasibility of collocation and/or internationalization and of the contributions these may make toward non-proliferation goals. 
In this report the term collocation is used interchangeably with the term Fuel Cycle Center (FCC) to mean collocation of two or more of the major elements of the FBR fuel cycle: spent fuel storage for either thermal reactors or FBRs, reprocessing, fabrication, or power generation. Collocation has safeguards and non-proliferation advantages even for national facilities. Similarly, internationalization has non-proliferation advantages for dispersed as well as for collocated facilities. In this report, the term internationalization is used to mean any participation of more than one nation in the ownership, management, and operation of a facility. This includes both multinational (a specific set of nations) and internation (open enrollment) as used in the International Atomic Energy Agency (IAEA) study of regional Fuel Cycle Centers.l

Three alternative deployment strategies for FBRs have been considered throughout the preparation of the U.S. contribution to the INFCE Working Group 5 (WG5) study:

1. Integral Cycle Deployment confines all facilities, including reactors, within a well secured site selected by national option. Design constraints on the facilities (e.g., CIVEX) and strong international safeguards are relied on to provide proliferation resistance. Such a constrained and (perhaps) economically suboptimally sized facility might nonetheless be attractive in view of the autonomy of national action it offers.

2. Secured Area Deployment confines fresh fuel which contains chemically separable fissile material to within a secure area containing the reactors which burn this fuel and the reprocessing/refabrication plants for producing it. The secured area center relies on collocation, international safeguards, and perhaps internationalization for proliferation resistance. Denatured fresh fuel would be shipped to dispersed reactors to provide the autonomy of national choice in reactor siting.

3. The Reference International Deployment places no constraint on breeder fuel cycle type or breeder reactor location. Autonomy of national action is maximized for this scheme. Proliferation defenses always include international safeguards and could (but need not) include:

- collation of reprocessing/refabrication plants

- internationalization of collocated reprocessing/ refabrication plants or

- a number of technical modifications including:

- coprocessing,

- spiking, or

- preirradiation

This report discusses the use of collocation and internationlization in conjunction with breeder reactor deployment. In Chapter II, the evolutionary steps which might lead to implementing these options are traced, and the underTying incentives are identified. In Chapter III, the prospects for internaional coopertion on FCCs are evaluated. In Chapters IV and V, the non-prolifertion features and technical features of breeder FCCs are discussed. Legal and 
administrative aspects are discussed in Chapter VI. The results are summarized and conclusions are drawn in Chapter VII.

\section{INCENTIVES AND EVOLUTIONARY TRENDS TOWARD COLLOCATION AND INTERNATIONALIZATION}

A. Evolution

A number of alternative deployment scenarios for FBRs have been considered in preparing the U.S. contribution to INFCE Working Group 5. (Ref. 2) These have started from the current deployment of thermal reactors and have included the future deployment of both breeder and symbiotic breeder/converter cycles after the year 2000. The studies were made to assess the resource utilization, energy supply potential, and economic implications of breeder deployment, and have shown strong incentives for breeder introduction after the year 2000 .

To consider collocation and internationalization of FBR facilities it is necessary to assume that breeders in some form will ultimately be deployed. In this report it is further assumed that breeder reactors will not provide a significant fraction of electrical energy needs for at least three decades. The deployment studies referenced above suggest that a transition from the existing thermal reactor (largely Light Water Reactor (LWR)) economy to a symbiatic economy will contain the following elements:

1. Thermal reactor spent fuel storage, for several decades initially, and for at least several years during the period of breeder introduction,

2. Reprocessing to create breeder reactor fuel from thermal reactor spent fuel (reprocessing may also be in use for recycle of uranium and plutonium in thermal reactors),

3. Breeder Reactor spent fuel storage, possibly long term, but more likely short term if full advantage is taken of breeder introduction,

4. Development or modification of commerical reprocessing to include feedstock from spent breeder fuel, and

5. Eventual establishment of a symbiotic thermal and breeder reactor economy with the mixture ratio dependent on the growth rate demand, the relative economics of the sytems, and possible non-proliferation advantages of certain mixes.

It may be desirable to incorporate collocation or internationalization into the evolutionary transition from an LWR to a symbiotic FBR/LWR economy. Subsequent sections discuss the incentives and disincentives and the institutional and technical feasibility of the use of collocation or internationalization in a breeder economy.

Primary among immediate needs is a means to accommodate the spent fuel from LWRs currently in operation or under construction. It has been estimated by the IAEA l that in the absence of reprocessing, the total amount of spent 
fuel will have reached 40,000 tonnes in 1985, growing to over 90,000 tonnes by 1990. These projections also indicate that spent fuel in storage can be expected to rise from its current level of roughly 5,000 tonnes to nearly 20,000 tonnes in 1985, if all the reprocessing plants both planned and authorized are operating in that time frame.

This prospect is one of the reasons that the recent United States Nuclear Non-Proliferation Act (NNPA) requires the President to promptly udertake discussions directed toward "the establishment of repositories for the storage of spent nuclear reactor fuel under effective international auspices and inspection". The creation of an international spent fuel repository if it were to occur could provide the needed relief while at the same time providing a basis for subsequent operations such as reprocessing, recycle and final disposal of wastes could be conducted under some form of international auspices.

Since spent fuel from thermal converter reactors contains significant fissile content which could be recycled in these reactors, some states are considering reprocessing. Such reprocessing may also simplify the management of long-term LWR wastes. However, to improve safeguards and minimize proliferation risk and to proved economic benefits compared to national reprocessing, collocation and internationlization of large reprocessing refabrication plants for a group of nations with common needs could be considered. The development of such Fuel Cycle Centers for LWR fuel in the next several decades could provide (as with an internationalized spent fuel facility) a starting point upon which the implementation collocation or internationalization of FBR facilities might be developed. In this regard the IAEA has recently distributed a paper on international management of plutonium and spent fuel.

In summary, in the near-term evolution of the LWR economy, several opportunities may arise for the introduction of collocation and internationalization of elements of the LWR fuel cycle. These are:

a. The possibility of international facilities for Away From Reactor (AFR) storage of LWR spent fuel,

b. The possibility of regional Fuel Cycle Centers for reprocessing/ fabrication of LWR spent fuel, and

c. The possibility of further international management and storage of plutonium.

Any of these possibilities, if it occurs, could provide a base upon which collocation and internationalization of elements of future FBR or FBR/LWR symbiotic fuel cycles could be developed.

\section{B. Incentives}

This section summarizes some of the factors that may influence a nation in making a decision either to participate in an international FCC or to develop national fuel cycle facilities. These factors fall generally into the categories of non-proliferation goals, economies of scale, accessibility of technology already developed, net balance of trade, and assurances of supply. 
The proliferation advantages and disadvantages of international FCCs are discussed in more detail in section IV of this report. Proliferation considerations are one, $1,3,4,5$ but not the only incentive for participation in international FCCs.

The cost advantages of regional FCCs relative to dispersed national facilities have been examined in some detail by the IAEA. 1 These studies indicate that the unit costs of fuel reprocessing, fuel fabrication and waste management are significantly reduced with larger facilities relative to smaller national facilities. The unit total cost of reprocessing and recycling operations was calculated to approximately 40 percent less for a 1500 tonne/year plant relative to a 500 tonne/year plant. The IAEA study further indicated that a large reprocessing plant may be necessary for the levelized net costs to be positive for the reprocessing and recycling of mixed oxide fuel into LWR plants. The lower cost of fuel recycling in large international FCCs results from both lower capital costs and lower operation costs per unit output. There are many factors that influence the lower capital costs, but they largely result from the economies of scale. For example there will be lower total land requirements. Lower operating costs would be somewhat less certain but could result, for example, from an expectation of more efficient use of personnel, better trained and more specialized personnel, and the availability of more and better quality support services. For example, the safeguards cost per unit output are expected to slowly decrease with increasing plant size. This behavior is expected for many of the other support services.

Another possible incentive for a nation to decide to participate in an international Fuel Cycle Center rather than developing national facilities is the accessibility to the advanced fuel cycle services not available domestically. The FCC offers to participating nations its services; thereby eliminating the need for costly and uncertain national development. For some countries a national development program to develop a commercial fuel cycle technology may be out of the question. In this case the only option may be participation in some form of international FCC or entry into a commerical agreement for fuel cycle services in another country. Given only these two options it may be that many nations would feel that participation in an international FCC would offer more assurance of a continued supply of fuel cycle services, since the commercial agreement would be dependent upon the stability of a private company or the policy of a single nation. These concerns could be mitigated if there were several private companies or nations offering fuel cycle services. The questions of assured supplies of fuel and fuel cycle services are discussed in somewhat more detail in section IV of this report and in much more detail throughout the INFCE studies.

Given the choice between an international FCC and national facilities a nation may decide that the national facilities provide the better assurance of continued long-term fuel cycle services. This would depend somewhat on how the nations views the long-term stability of the international FCC and possibly on the choice of host country. Confidence in the international FCC could be weakened if significant international institutional problems are encountered in the organization or operation of the facility. These issues are discussed in Section VII of this report. 


\section{INTERNATIONAL COOPERATION IN THE BREEDER FUEL CYCLE}

In considering international cooperation related to $F B R$ fuel cycles, it is useful to examine existing cooperation agreements. The commerical LWR reactor industries of all major supplier nations except the USSR and Sweden are based upon commerical license agreements with U.S. reactor manufacturers. In the past, the U.S. has been the major supplier of enrichment service for the commerical LWR industry. However, in recent years intergovernmental joint ventures have led to the construction of several commercial scale enrichment plants. This has led to particularly strong interdependencies in which most nations have agreed to purchase enrichment from another (USDOE, CEA, TECHSNAB, URENCO, or BNFL), and nearly half have arrangements with more than one supplier. These arrangements are given in Ref. 6 of this report. Joint ventures in reprocessing include Eurochemic (whose facility operated from 1967 to 1974) and United Reprocessors which was formed in 1971 by British Nuclear Fuels, the French Atomic Energy Commission, and Kernbrennstoff-Wiederaufarbeitungsgesellschaft (KEWA) of the FRG. This commerical company, with headquarters in Karlsruhe, FRG, offers a complete range of irradiated oxide fuel reprocessing services including transportation and fabrication of mixed oxide fuel.

The most ambitious international nuclear development agreements in effect today are involved with commercialization of the Liquid Metal Fast Breeder Reactor (LMFBR). With the obvious motivation of cost sharing, interdependent FBR research, development, and demonstration programs have been established in Western Europe. Following the successful operation of the prototype breeder reactor Phenix, a company, NERSA, was established by the main utilities in France, Italy and FRG to build a European demonstration plant, the 1200 MWe FBR Super Phenix. A detailed cooperative arrangement between France and FRG led to establishment of a joint company, SERENA, which also includes Belgium, the Netherlands and Italy. A commercial sized LMFBR, SNR-2, is planned by the FRG in cooperation with Italy, France, Belgium and the Netherlands. A company, ESK, was formed by the main utilities of these countries in support of this reactor project. Smaller cooperative programs have also been established between the European nations, Japan, UK and the US. A number of European nations continue to support and actively participate in gas-cooled fast reactor development through the Gas-Cooled Breeder Reactor Association, headquarted in Brussels.

The incentives which led to the examples of international cooperation noted above may be different from those which would be applicable in the case of international breeder Fuel Cycle Centers. However, such examples demonstrate the feasibility of establishing an institutional and administrative basis for cooperation in development and deployment of many of the technologies which are relevant to an FBR FCC scenario.

A more complete discussion of international co-operative efforts in Breeder Reactor research, design \& development is found in Ref. 7.

\section{NON-PROLIFERATION FEATURES}

Non-proliferation features of interest here are: 1) collocation, 2) internationalization and 3) deployment strategy. The last is given brief attention here (Section IV.C) and is more thoroughly discussed in another 
report. 8 The advantages and disadvantages of collocation and internationalization are discussed in Section IV.A and IV.B respectively.

\section{A. Collocation Considerations}

\section{Potential Advantages}

1) Collocation of the major FBR fuel cycle facilities reduces the number of offsite transportation links between facilities. Elimination of the external shipments between reprocessing and fabrication is especially important if separated plutonium or mixed uranium/plutonium are shipped in low radiation bulk form,

2) A larger security force would probably be available at large, collocated sites. This is important in resisting over subnational diversion,

3) The site perimenter can be reduced relative to the total perimeter of dispersed sites, thus making possible increased boundary protection for a given expenditure,

4) Safeguards activities can be more effective as a result of more efficient use of personnel, better trained and more specialized personnel, and the availability of more and better equipped support services.

Potential Disadvantages

1) A subnational group including insiders might have more opportunities for diversion of small amounts of material due to possible accessability to more facilities,

2) In the case of seizure of collocated facilities, more material and facilities would be available.

B. Internationalization Considerations

$\underline{\text { Potential Advantages }}$

1) The availability of international facilities provides an alternative to developing national facilities.

2) The susceptibility to national level diversion is reduced by international participation. National level diversion or covert operations within the facility would be more difficult to carry out with internatonal participation in operations and management.

3) Internationalization would introduce legal and political barriers to abrogation of non-proliferation commitments by the particpating nation and to misuse of the facility by the host country.

4) With international management of the facility committed to safeguards, there might be a greater level of cooperation with IAEA, both in the negotiati of the initial safeguards agreements and in the day-to-day interactions among IAEA inspectors and the facility management and operators. 
5) Operation under international auspices might make the services of the facility more attractive to some countries that might be reluctant to rely upon the unilateral control of a single nation.

6) The potential exists for the IAEA to perform the material accountability and surveillance functions and thus rely on advanced safeguard systems.

Potential Disadvantages

1) International participation in the ownership, management, or operation of a facility could make the fuel cycle technology more available to the participating countries, thereby reducing the technical difficulties in developing national facilities.

2) Any division in physical protection responsibilities between the international centers and the host state could result in problems which might reduce security effectiveness.

3) With large international centers there might be increased need for longdistance international transport of nuclear materials resulting in some increased risk.

\section{Deployment Strategy}

A key proliferation defense aspect of a fuel cycle center is the security of its location. As an obvious example, a national FCC located in a nuclear weapons state (NWS) has no direct national proliferation problem. If such a national FCC entered into assured fuel services agreements with non-nuclear weapons states (NNWS), it would provide an incentive for the NNWS to forego national reprocessing. This option, as long as it continued, would be a more secure situation with respect to national proliferation, while still providing needed fuel services. Internationalization of an FCC located in an NWS but including direct NNWS participation could offer an even stronger perceived assurance of fuel services to an NNWS.

It is reasonable to assume that NNWS currently having substantial FBR development programs have the technological capacity to produce weapons useable materials by routes other than through the FBR cycle. For these countries, an increased emphasis on strong international safeguards and an increased international interdependency with implied sanctions may provide the most relatistic proliferation deterrents.

There are many other NNWS not yet vigorously pursuing FBR development but already deploying or now considering deploying thermal reactors on a lowenriched uranium cycle. Many of these are not likely to have sufficient indigenous uranium reserves to meet their expected needs. These nations may be willing to participate in international Fuel Cycle Centers, wherever located, because of economic incentives.

The three deployment scenarios, Integral Cycle, Secured Area, and Reference International, considered in preparing the U.S. contribution to INFCE Working Group 5 are different ways of addressing the siting issue. 


\section{TECHNICAL ISSUES}

A. Technical Considerations in Selecting a Specific Collocation Configuration

The advantages and disadvantages of collocation have been discussed earlier in this report. The technical issues involved in the degree of collocation are treated here, introduced by a brief discussion in this section of differences in the characteristics of FBR and thermal reactor fuel cycles. Using this as technical background, some collocation configurations which may enhance proliferation resistance are identified and discussed with respect to their siting and resource requirements and to transmission cost penalties if substantial reactor generating capacity is collocated. A more detailed discussion on siting and resource requirements is given in a separate report ${ }^{9}$ which is summrized in Section $B$ below.

The conclusions of quantitative and comprehensive studies 1,10 on LWR FCCs are summarized here to lay a framework for considerations specific to FBR FCCs which will be discussed relative to it.

The IAEA $^{l}$ studied thermal reactor regional Fuel Cycle Centers with collocated back-end facilities and pointed out that it is economically advantageous for a nation to be a participant in a large scale multinational national regional FCC rather than either establishing small scale national reprocessing facilities or storing the spent fuel until the time when a large scale plant could be justified. The economic analysis covered the time period through 2010, and the optimum capacity for the reprocessing plant was found to be 1500 tonne/yr of LWR spent fuel with the regional FCC containing the other back-end facilities of matching size. Such a facility would reprocess the spent fuel from 40-50 LWRs. The Nuclear Energy Center Site Survey 10 performed by the US Nuclear Regulatory Commission (USNRC) considered three different FCCs: those involving reactors alone, those involving back-end facilities and those involving a combination of reactors and back-end facilities. This study showed that collocation of a set of four 1200 MWe reactors is optimum in the U.S. from the point of view of capital investment if existing construction methods and transmission lines are to be utilized, and they point out that this is the current trend in the U.S. nuclear power industry. Advanced construction techniques were also considered with the conclusion being that these could lead to an optimum size larger than four plants. Transmission costs were concluded to be significant, but not overriding, as summarized in Sectin $B$ of this chapter. They also concluded that the net additional fuel cycle costs would be minimal when reactors that utilize all mixed oxide fuel produced on site are collocated with the back-end facilities at and FCC, in comparison with the dispersed reactor case. These conclusions in conjunction with the different characteristics of FBR spent fuel will have a significant effect on degree of collocation at an FCC.

1. FBR Spent Fuel Characteristics: Detailed discussion of reprocessing of FBR spent fuel is given in a companion report on fuel cycles.ll Those differences between LMFBR spent oxide fuel and that of LWR spent oxide fuel which may have some effect on degree of collocation or the optimum size of facilities are summarized here. 
a. Large Throughput of Plutonium: As shown in Table I, the amount of plutonium in FBR (reference U/Pu oxide system) spent fuel is about an order of magnitude larger than for an equivalent LWR, although the annual discharges (tonnes of heavy metal) are about the same.

b. High Fissile Content: The fissile content, i.e. $\left({ }^{235} \mathrm{U}+{ }^{239} \mathrm{Pu}+\right.$ ${ }^{24} \mathrm{Pu}$ ) is about 4 times larger for FBR spent fuel than that of LWR spent fuel

TABLE I. Spent Fuel Data of Different Types of Reactors

\begin{tabular}{|c|c|c|c|c|c|}
\hline SPENT FUEL CHARACTERISTICS & $\begin{array}{l}1000 \mathrm{MW}(\mathrm{e}) \\
\mathrm{LWR}^{\mathrm{l}}\end{array}$ & $\begin{array}{l}1000 \mathrm{MW}(e) \\
\text { LWR w1th } \\
\text { Pu recycle }\end{array}$ & $\begin{array}{c}1000 \mathrm{MW}(\mathrm{e}) \\
\text { HWR }\end{array}$ & $\begin{array}{r}1000 \mathrm{MW}(\mathrm{e}) \text { LMFBR } \\
\text { Core UO }{ }^{2} \text { and PUO } \\
\mathrm{AB}+\mathrm{RE} \text { DEPLETED Uranium } \\
\end{array}$ & $\begin{array}{l}1000 \mathrm{NW(e)} \\
\text { LMF BR + } \\
1000 \mathrm{MW(e)} \\
\text { HWK MIX }\end{array}$ \\
\hline $\begin{array}{l}\text { Annual discharge } t / y r \text { of } \\
\text { (HM) Heavy Metal }(U+P u)\end{array}$ & 26.6 & 26.5 & 100 & $\begin{array}{c}31.47 \\
(\text { Core }+\mathrm{AB}+\mathrm{RB})\end{array}$ & 131.47 \\
\hline$\%$ wt Plutonium/HM & 0.97 & $\begin{array}{l}0.97 \text { in U assembly } \\
3.4 \text { in Pu assembly }\end{array}$ & 0.38 & $\begin{array}{c}7.0 \\
(\text { core }+A B+K B)\end{array}$ & 2.1 \\
\hline $\begin{array}{l}\% \text { wt Fissile Pu/HM } \\
\left(23{ }^{\mathrm{Pu}}+241 \mathrm{Pu}\right)\end{array}$ & 0.7 & $\begin{array}{l}0.7 \text { in U assembly } \\
1.94 \text { in Pu assembly }\end{array}$ & 0.28 & $\begin{array}{c}5.866 \\
(\text { Core }+A B+R B)\end{array}$ & \\
\hline z we ${ }^{235} \mathrm{U} / \mathrm{HM}$ & 0.9 & $\begin{array}{l}0.8 \text { in } \mathrm{U} \text { assembly } \\
0.37 \text { in Pu assembly }\end{array}$ & 0.23 & $\begin{array}{c}U .143 \\
(\text { Core }+A B+R B)\end{array}$ & \\
\hline Annual Pu discharge $\mathrm{Kg} / \mathrm{Yr}$ & 258 & 386 & 380 & $2,388.7$ & \\
\hline \% wt Pu in Core & 0.97 & $\begin{array}{l}0.97 \text { in U assembly } \\
3.4 \text { in Pu assembly }\end{array}$ & 0.38 & 16.32 & \\
\hline$\%$ wt Pu in (Core $+A B$ ) & - & - & - & 9.93 & \\
\hline
\end{tabular}

aThe plant capacity factor used for LWR and HWR calculations was 0.70 and for LMFBR was 0.75 .

as shown in Table I. Furthermore, the weight percent of fissile material in HWR spent fuel is about a factor of 3 lower than LWR spent fuel. Criticality considerations will have an effect on the design and optimum capacity of an FBR reprocessing plant.

c. Decay Heat and Activity: The decay heat and activity of FBR spent fuel is not significantly different from that of LWR spent fuel on the average (although the core fuel has higher activity) when cooled for the same time period. However, the rapid recycle required in the equilibrium FBR fuel cycle may necessitate reprocessing short cooled FBR spent fuel, while in the case of LWR longer cooling periods are expected. Short cooled spent fuel has higher decay heat and activity and thus has effects on the sizing of head end equipment in a reprocessing plant, on the effluent control systems and perhaps on site selection.

It is of interest to consider the possibility of reprocessing FBR spent fuel in an LWR reprocessing plant. The high fissile content and resulting criticality requirements require, in general, a reprocessing plant specifically designed for FBR spent fuel. However, the IAEA studyl pointed out that in 
thermal recycle, the LWR mixed oxide fuel and HWR spent fuel could be mixed so that the reduced plutonium percentage in the mix would allow reprocessing in an LWR uranium fuel reprocessing plant. An extrapolation of this idea to that of mixing $1: 1 \mathrm{FBR}$ and HWR spent fuels would reduce the plutonium content of the mix to the same order of magnitude as that of LWR spent fuel, as shown in Table I. Even though this is a conceptually feasible method to permit reprocessing of LMFBR spent fuel in an LWR reprocessing plant, the practicality cannot be ascertained without further study.

2. FCC Configurations: An evolutionary sequence of feasible FCC configurations, beginning with thermal reactor fuel cycle elements is described below. Some of these configurations are an extension of the fuel cycle center concept for the back-end facilities by collocating either the reactors that supply the spent fuel or the reactors that are fueled by mixed oxide fuel at the center.

a. Reference Centers: In this scheme the reactors are dispersed and are served by an optimum sized FCC containing the back-end facilities. An FCC reprocessing LWR spent fuel might supply the mixed oxide back to LWRs or supply the mixed oxide fuel to dispersed FBRs. FBR back-end facilities could also be collocated at the center to serve the dispersed FBRs in an equilibrium situation. Al1 plants would be of optimum size fresh and spent and mixed oxide fuel transportation would be required.

b. Transition Centers: Transition centers represent an intermediate stage in the evolution from a system of thermal reactors to the final equilibrium situation involving FBRs. In this scheme, reactors that completely uti1ize the mixed oxide fuel would be collocated at an FCC reprocessing LWR spent fuel. The USNRC's nuclear energy center survey ${ }^{10}$ considered plutonium burners (thermal reactors fueled by $100 \%$ mixed oxide fuel) for collocation. An optimum sized LWR reprocessing plant of capacity 1500 tonnes/yr could support 10-15 1000 MWe plutonium burners.

An alternative transition center of optimum size could be achieved if FBRs were collocated rather than thermal plutonium burners. In this case a 1500 tonnes/yr themal FCC would support roughly 51000 Mwe FBRs (reference oxide design). The FBR spent fuel would not be reprocessed but would be sent to spent fuel storage on site for eventual reprocessing and recycle later in FBRs. This retains the option to move toward a complete FBR system while enhancing long-term fuel utilization. In this transition period, by using thorium in the FBR blankets, a reserve of ${ }^{233} \mathrm{U}$ could also be developed to supply denatured fuel to thermal reactors at a later time. This scheme has enhanced overall diversion resistance since mixed oxide fuel transportation would be eliminated.

c. Integral Center: This constrains the FBRs to be collocated with dedicated fuel reprocessing and fabrication facilities. The technology would be constrained to promote proliferation resistance such that the location and fuel cycle type could be unconstrained. Elimination of transport of mixed oxide fuel is an objective, however, net breeding will necessitate either an increase in the number of collocated reactors, or some form of controlled off-site shipment. Technology constraints on processes and mixed oxide fuel transport might lead to higher costs, and the reprocessing capacity might be smaller than optimum. 
The concept confirms fresh fuel which contains chemically sparable fissile material within a secured area containing the reactors which burn this fuel and the reprocessing/fabrication plants for producing it. Denatured fresh fuel is shipped to dispersed reactors.

The reprocessing of spent fuel from FBRs operated on alternate fuels and technical options for proliferation resistance, i.e., spiking, coprocessing, etc., are discussed in detail in another companion report.11 These alternatives have similar effects on collocation and internationalization as the reference FBR fuel cycle case described here.

\section{B. Technical Considerations Related to Siting of Collocated Facilities}

With respect to site related technical considerations, the various collocation options discussed previously can be grouped into two categories:

1) collocation of the fuel fabrication facility with a facility of matching capacity for fuel reprocessing, nitrate conversion, and waste solidification, and

2) collocation of the above fuel cycle facilities with power production facilities.

In the second case the power production facilities may or may not match the capacity of the fuel cycle facilities, although the integral cycle FCC concept requires that all reactors utilizing the fuel cycle facilities be collocated.

Major technical considerations which could impose significant siting constraints are:

1) radiological and chemical effluents,

2) thermal effluents, and

3) land and water requirements. are:

In the case of power generation facilities, two additional considerations

1) transmission cost penalties, and

2) power reliability considerations.

The key consideration with respect to collocation of fuel fabrication and fuel reprocessing facilities is the availability of sites (number and size) that meet national criteria for radiological effluents. For the same dose commitment at the boundaries of the collocated and dispersed sites, the collocated site would require less total land. In addition, since the number of sites is reduced by collocation this could in some cases reduce the exposure to the population beyond the site boundary or lead to less difficulty in finding sites that meet a given population exposure criteria. There would be an increase in the local socioeconomic impact with respect to the dispersed case, but the impact would be no more than that frequently associated with other major industrial facilities.

Power generation at an FCC may produce heat dissipation constraints. If the number of reactors on the FCC site is relatively smal1 (four to eight) then heat dissipation either by once-through cooling or by evaporative cooling would 
not introduce constraints more limiting than siting them elsewhere. As the number of reactors collocated at a site increases to match the capacity of a large reprocessing facility then the potential effects of heat dissipation on climatic conditions could lead to increased land requirements relative to dispersed siting. The total land and water requirements associated with collocating a large number of reactors could become a siting constraint.

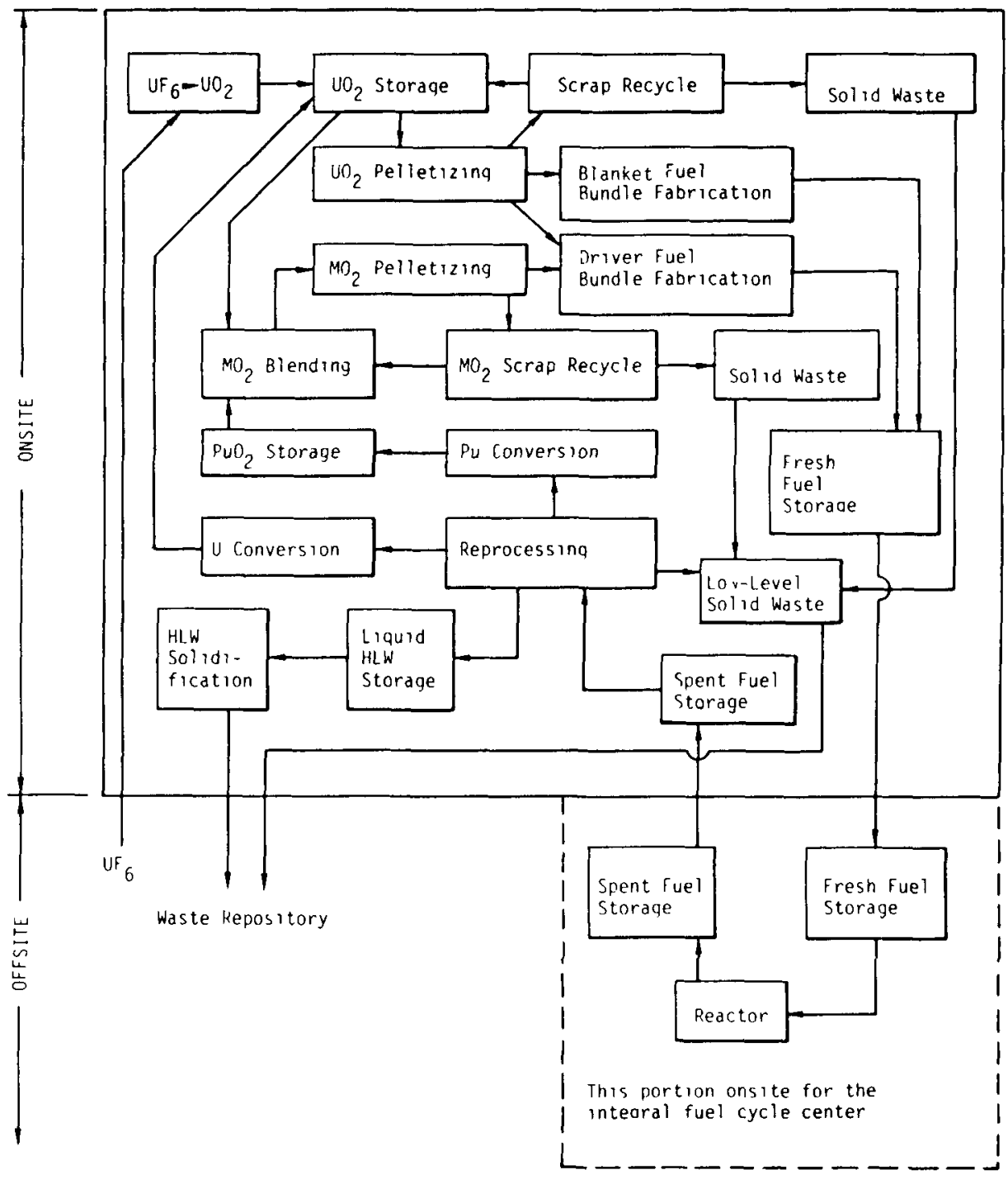

Fig. 1. Reference U/Pu Fuel Cycle Schematic

1. Collocation of Fuel Fabrication, Reprocessing, Nitrate Conversion, and Waste Solidification: A schematic of the typical FBR reference fuel cycle process components is shown in Figure 1, and the process steps are described elsewhere. ${ }^{12}$ The reference facilities in the following discussion have a capacity of 1500 tonnes per year. 
a. Chemical Effluents: No process liquid effluents will be released to the environment from reprocessing, nitrate conversion, and waste solidification facilities since all process liquids are recycled for treatment to recover chemicals and fertile and fissile elements. Current fuel fabrication plants have not found it economic to include the same level of process liquid treatment. Therefore, fluoride and nitrogen in the form of ammonia and nitrates are contained in liquid effluents, but concentrations still meet applicable U.S. criteria. For a large FCC, additional ammonia recovery might be necessary, but would not impose a major economic penalty.

The most significant gaseous chemical effluent is hydrogen fluoride arising from the conversion of $\mathrm{UF}_{6}$ to $\mathrm{UO}_{2}$. Current U.S. fuel fabrication plants meet the applicable criteria at the site boundary, and the additional treatment that might be required for a large FCC would not impose a major economic penalty. Other major gaseous effluents are nitrogen oxides and sulfur dioxide arising primarily from the burning of fossil fuel in process boilers. At the site boundary the concentrations of these effluents would be expected to meet U.S. air pollution requirements by about a factor of ten.

b. Water Requirements: Approximately $3.5 \times 10^{8} \mathrm{Btu} / \mathrm{hr}$ of heat must be dissipated for $1500 \mathrm{MTHM}$ throughput or $2.3 \times 10^{5} \mathrm{Btu} / \mathrm{hr} / \mathrm{MTHM}$. Dissipating this heat with wet evaportive cooling towers combined with the process water requirements results in a total water consumption of about $5 \times 10^{3} \mathrm{gpd} / \mathrm{MTHM}$.

TABLE II. Comparison of Dose Commitment from Collocated Reprocessing and Fabrication Facilities with other Common Sources of Radiation in the U.S.

\begin{tabular}{|c|c|c|}
\hline $\begin{array}{l}\text { Exposure } \\
\text { Source }\end{array}$ & $\begin{array}{l}\text { Individual } \\
\text { Exposure } \\
\text { (mrem/yr) }\end{array}$ & $\begin{array}{l}\text { Population } \\
\text { Exposure } \\
\text { (mrem/yr) }\end{array}$ \\
\hline Natural Background & 100 & $2.1 \times 10^{7}$ \\
\hline Fallout & 4 & $8.4 \times 10^{5}$ \\
\hline Medical (diagnostic) & 72 & $1.6 \times 10^{7}$ \\
\hline Television & 0.1 & $2.1 \times 10^{4}$ \\
\hline Total & 176.1 & \\
\hline LMFBR-FCC $a, b$ & 200 & $1.4 \times 10^{4}$ \\
\hline LWR-FCC $a, b$ & 70 & $7.9 \times 10^{3}$ \\
\hline \multicolumn{3}{|c|}{$\begin{array}{l}\text { These figures are estimates of the maximum dose received by } \\
\text { an individual residing continuously at the site boundary. } \\
\text { b These represent pure LMFBR or LWR FCCs. A mixed operation } \\
\text { will result in exposures between those of the individual } \\
\text { species operation. }\end{array}$} \\
\hline
\end{tabular}

$$
\text { c. Radiological }
$$

Effluents: Technology is available to ensure essentially zero radiological release of 1iquid effluents and to achieve an atmospheric release fraction for particulates of $10^{-9}$. In the time frame that an FBR FCC might be built, release fractions of $10^{-2}$ will likely be achieved economically for $\mathrm{H}-3, \mathrm{C}-14$, and $\mathrm{Kr}-85$, and $10^{-4}$ for iodines.16,17 However, using present technology (no reduction for $\mathrm{H}-3, \mathrm{C}-14$ and $\mathrm{Kr}-85$; a release fraction of $5 \times 10^{-2}$ for $\mathrm{I}-129$; a release fraction of $2.5 \times 10^{-2}$ for I-131; and a particulate release fraction of $2 \times 10^{-7}$ ) the annual dose commitment

from a collocated FBR facility having 1500 MTHM throughput is given in Table II for several exposure pathways. The corresponding values are also shown for a collocated FCC processing LWR fuel. The largest exposures result from and inhalation, ingestion pathway involving the thyroid. Table II compares this exposure to other common sources of radiation in the U.S. The population 
exposure resulting from either FCC is a small fraction of the population exposure attributable to other sources. The exposure to an infant located at the site boundary is comparable to that received from other sources. However, as stated earlier, by the time FBR FCCs might be built, it is expected that additional reductions in radionuclide effluent releases could be obtained economically so that all FCC doses would be less than those from other sources.

TABLE III. Annual Dose Commitment from Collocated Reprocessing and Fabrication Facilities

\begin{tabular}{|c|c|c|c|c|}
\hline \multirow[t]{2}{*}{$\begin{array}{l}\text { Exposure } \\
\text { Pathway }\end{array}$} & \multicolumn{2}{|c|}{$\begin{array}{c}\text { Individual at the } \\
\text { Site Boundary } \\
\text { (mren/yr) }\end{array}$} & \multicolumn{2}{|c|}{$\begin{array}{c}\text { Population within } 80 \mathrm{~km} \text { a } \\
\text { of a Model Site } \\
\text { (mrem/yr) }\end{array}$} \\
\hline & LMFBR & LWR & LMFBR & LWR \\
\hline Total body ${ }^{b}$ & 17 & 13 & $3 \times 10^{3}$ & $2.3 \times 10^{3}$ \\
\hline Thy roidc & 89 & 52 & $1.4 \times 10^{4}$ & $7.9 \times 10^{3}$ \\
\hline Infant Thyroidd, & 200 & 70 & $d$ & $d$ \\
\hline Bone $e^{c}$ & 40 & 51 & $2.2 \times 10^{3}$ & $2.6 \times 10^{3}$ \\
\hline
\end{tabular}

apopulation average used was $3.5 \times 10^{6}$ people residing within 50 miles of the site.

birect irradiation of the total body.

${ }^{c}$ Inhalation plus ingestion of effluents specific to the organ plus direct external irradiation.

$\mathrm{d}_{\mathrm{An}}$ average distribution of infants has been included in the population for the model site.

could be as close as $0.9 \mathrm{~km}$ and achieve the necessary exclusion distance on the $23 \mathrm{~km}^{2}$ site. The dose commitment to an individual at the site boundary could be made essentially the same as dispersed siting by improved Pu particulate effluent control and/or by moving the two plants closer together on the site.

Table III was based on the use of $(\mathrm{U}, \mathrm{Pu}) \mathrm{O}_{2}$ fuel, but the use of $(\mathrm{U}, \mathrm{Th}) \mathrm{O}_{2},(\mathrm{U}, \mathrm{Pu}) \mathrm{C}$ or $(\mathrm{U}, \mathrm{Th}) \mathrm{C}$ as the fuel material would not increase the dose commitment significantly unless the U-232 content greatly exceeds about $1200 \mathrm{ppm}$ (of uranium). If the U-232 content increases from $1200 \mathrm{ppm}$ to $5000 \mathrm{ppm}$, the total body dose, for example, increases about 30\%. For comparison, the Clinch River Breeder Reactor Plant (CRBRP) thorium cycle design showed a maximum U-232 concentration of less than $700 \mathrm{ppm}$ anywhere in the cycle.11

\section{Collocation of Power Generation and Fuel Cycle Facilities}

The incremental effects of collocating power generation with the fuel cycle facilities are discussed in this section.

a. Thermal and Chemical Effluents: Heat dissipation effects of power generation lead to two important constraints; water availability and land availability. In most cases, a lack of one can be accommodated by increasing the requirements of the other. A once-through cooling system minimizes the land requirements and the cost, but maximizes the cooling water requirement. On 
the other hand, a dry cooling system minimizes the water requirement but increases the cost. Specific site conditions, however, will determine the choice of the heat dissipation system.

The following approach used to assess the impacts of heat dissipation resulting from the collocation of a large number of reactors is adopted from that in NUREG--0001.10 Further it is assumed that the reactors will be built in four-unit clusters of from 4000 to 4800 MWe, as are many LWRs. A spacing of 4 kilometers between four-unit clusters with natural draft evaporative cooling towers will produce a heat flux about three times that from the global average solar heating. The heat flux from a large city such as New York is about four times the global average, and, while the heat releases from several point sources such as cooling towers are not truly analogous to the very large area source from a city, an FCC siting constraints of three times solar heating would be likely to produce local climatic changes no worse than that of a large city.

Large water vapor additions to the atmosphere can cause increased fogging, icing, and atmospheric convective activity. Using natural draft cooling towers, the moisture release rate is about $5.6 \times 10^{5} \mathrm{gm} / \mathrm{sec}$ per 1000 Mwe plant. On the $16 \mathrm{~km}^{2}$ site defined by heat flux considerations, the above moisture addition rate would be about $15 \%$ of that from natural causes during periods of strong convection. Therefore, the cooling system of a $16 \mathrm{~km}^{2}$ site containing four 1000 MWe units would produce a sma11 moisture addition rate compared with natural atmospheric dynamics.

The blowdown required from the cooling system to control water chemistry contains not only the impurities of the makeup water in higher concentrations, but also chemicals for corrosion control, decontamination and cleaning, and biological growth control. The blowdown from a large FCC power center is not different from that of dispersed reactors except that it would be likely to be discharged to a single body of water rather than to a number of bodies. The fact that the clusters of 4 reactors would be 4 kilometers apart would imply that the discharge would be adequately dispersed; however, a dispersion enchancement device may be needed. Blowdown to smaller bodies of water may exceed water quality criteria; therefore, higher levels of treatment might be required. Thermal discharge standards might also be exceeded by the blowdown without careful engineering and/or auxiliary cooling, such as cooling/settling ponds. These considerations are highly site dependent, but if these additional measures are needed, they are well within current technology. The additional cost is not expected to be significant when compared to the alternative of dry cooling.

b. Radiological Effluents: Radiological aspects of power generation can affect siting feasibility considerations in any of three ways: routine releases, accident releases, and design basis evaluations. Of these, only the first effect, routine releases, is additive and is therefore an important consideration for reactor groupings in a power-production center. The latter two effect are based on severe accidents, the occurrence of which, in more than one reactor at any given time, would be extremely unlikely. The sixteen-square-kilometer site size defined by heat dissipation considerations is about twice that normally used in U.S. reactors for radiological dispersion purposes, and, as would be expected, radiological dose 
commitments are low for the four-1000 MWe unit cluster. Even as large a facility as 40,000 MWE FCC with four-kilometer spacing between clusters would have only a slightly more than 1.8 times the radiological impact from gaseous effluents and 1.1 times the impact from liquid effluents at the site boundary from routine operations as wculd a single 4000 MWe cluster. ${ }^{14}$ The cumulative dose commitments are below that of background plus other common sources of radiation.

c. Deployment Configuration Effects: The reference international FCC system permits collocation of reactors within the site provided for the fuel cycle service facilities. An FCC consisting of fuel fabrication, reprocessing, nitrate conversion, and waste solidification facilities having a 1500 tonnes per year capacity might logically be collocated with a cluster of four-1000 MWe FBRs. The land and water requirements and the dose commitments from such a FCC are given Table IV. For comparison, the zero onsite power production case is also shown. As indicated previously, once-through cooling would allow substantial reductions in land requirements with a substantial increase in cooling water requirements.

TABLE IV. Siting Requirements for Reference International FCC

\begin{tabular}{|c|c|c|}
\hline & \multicolumn{2}{|c|}{ Onsite Power Production } \\
\hline & 0 & $4000 \mathrm{MWe}$ \\
\hline Land, hectares ${ }^{a}$ & $2.4 \times 10^{3}$ & $4.1 \times 10^{3}$ \\
\hline Water, $\mathrm{gpm}^{\mathrm{a}}$ & $2.5 \times 10^{2}$ & $5.6 \times 10^{4}$ \\
\hline \multicolumn{3}{|c|}{$\begin{array}{l}\text { Maximum Individual Dose } \\
\text { Commitment for Several } \\
\text { Exposure Pathways, mremb }\end{array}$} \\
\hline Total Body & 17 & 20 \\
\hline Thyroid & 89 & 92 \\
\hline Bone & 40 & 40 \\
\hline Infant Thyroid & 200 & 230 \\
\hline \multicolumn{3}{|c|}{$\begin{array}{l}\text { a The use of once-through cooling could reduce land require- } \\
\text { ments to about } 3.2 \times 10^{3} \text { hectares (without optimizing facili } \\
\text { arrangements) and increase water requirements to about } \\
2.2 \times 10^{6} \text { gpm for the } 4000 \text { MWe source production case. } \\
\text { These figures are estimates of the maximum dose received b } \\
\text { an idividual residing continuously at the site boundary. }\end{array}$} \\
\hline
\end{tabular}

The secure area FCC system includes onsite FBRs and offsite reactors operating on denatured fuel. The ratio of offsite to onsite reactors will vary from about 1 to 3 depending on the reactor design and fuel cycle parameters selected. 2 The land and water requirements and the dose commitments are given in Table $\mathrm{V}$ for a 1500 tonnes/yr fuel cycle facility and two onsite reactor power levels, 10,000 MWe and 25,000 MWe. As discussed above (b) the reactor effluents do not increase proportionally with an increasing number of reactors, hence the exposure due to the reprocessing plant overrides the small increase due to a large number of reactors.

Integral cycle deployment of an FCC means that all reactors using the fuel cycle service facilities would be collocated. The FCC might be small in terms of reprocessing throughput ( 300 tonnes/yr and 10,000 MWe), and other studies $^{l}$ have considered collocation of facilities as large as 1500 tonnes/yr and 50,000 MWe. Table VI shows the land and water requirements and the dose commitments for these two sizes. Again, the exposure due to the reprocessing plant overrides the small increases due to the increased number of reactors. 
TABLE V. Siting Requirements for Secure Area FCC

\begin{tabular}{lcc}
\hline & \multicolumn{2}{c}{ Onsite Power Production } \\
\cline { 2 - 3 } & $10,000 \mathrm{MWe}$ & $25,000 \mathrm{MWe}$ \\
\hline Land, hectares & $6.6 \times 10^{3}$ & $1.3 \times 10^{4}$ \\
Water, gpm & $1.4 \times 10^{5}$ & $3.5 \times 10^{5}$ \\
Maximum Individual Dose \\
$\begin{array}{l}\text { Commitment for Several } \\
\text { Exposure Pathways, mrem }\end{array}$
\end{tabular}

aThese figures are estimates of the maximum dose received by an individual residing continuously at the site boundary.

TABLE VI. Siting Requirements for Integral FCC

\begin{tabular}{|c|c|c|}
\hline & $\begin{array}{c}300 \text { tonnes/yr } \\
\text { and } \\
10,000 \mathrm{MWe}\end{array}$ & $\begin{array}{c}1500 \text { tonnes/yr } \\
\text { and } \\
50,000 \mathrm{MWe}\end{array}$ \\
\hline Land, hectares & $4.5 \times 10^{3}$ & $2.3 \times 10^{4}$ \\
\hline Water, gpm & $1.4 \times 10^{5}$ & $7.0 \times 10^{5}$ \\
\hline \multicolumn{3}{|c|}{$\begin{array}{l}\text { Maximum Individual Dose } \\
\text { Commitment for Several } \\
\text { Exposure Pathways, mrem }\end{array}$} \\
\hline Total Body & 20 & 20 \\
\hline Thyroid & 92 & 92 \\
\hline Bone & 40 & 40 \\
\hline Infant Thyroid & 238 & 244 \\
\hline
\end{tabular}

aThese figures are estimates of the maximum dose received by an individual residing continuously at the site boundary. 
In all cases the radiation dose commitments are relatively low (generally comparable to that received from background and medical sources) and less than that permitted by current U.S. regulations. If the infant thyroid dose commitment at the site boundary is considered to be too high, quite a few means of reducing it are available including increasing stack 40 CFR 190 which become effective in January 1979 place upper limits of 75 Mrem/ yr to thyroid and $25 \mathrm{Mrem} / \mathrm{yr}$ to all other body organs. Additional effluent controls may be required to satisfy these new standards.

d. Transmission Cost Penalties and Power Reliability Considerations If large numbers of reactor are collocated in an energy center (whether or not with other fuel cycle facilities), then local use and/or transmission of the energy becomes an important consideration. Several studies have evaluated this with the Nuclear Energy Center Site Survey Study by the USNRC ${ }^{10}$ devoting considerable attention to transmission system cost and reliability. The summary discussion that follows is taken largely from that study.

Some of the key assumptions in the USNRC study were:

a. A principle voltage of $765 \mathrm{kV}$ a.c. was used in analysis although it was noted that other options, including $1200 \mathrm{kV}$ lines, underground transmission, d.c. transmission, and superconducting transmission, might offer advantages as the technologies develop.

TABLE VII. Summary of Transmission Costs

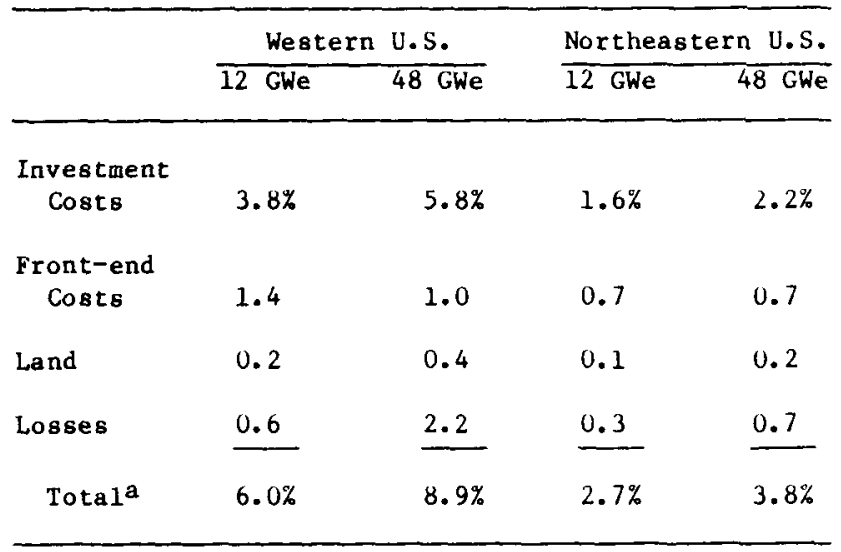

apercentage of total annual electrical costs.

tornado damage of the lines converging on an energy center.

Table VII shows a summary of some of the USNRC study results for a particular scenario which assumed that energy centers filled most of the incremental U.S. electrical need between 1985 and 2000. These summary numbers, presented as a percent of total annual electricity costs, are based on 1975 costs and on U.S. conditions. The basic comparison was between 12 GWe and 48 GWe energy centers. The obvious conclusions from this are that (1) transmissi costs are not a large fraction of the total electricity costs, (2) costs go up appreciably for the extreme 48 GWe center cases, (3) costs go up appreciably 
for less-populated regions (more dispersed large load centers), and (4) the largest costs are associated with construction of the system, rather than for land or to account for losses.

The deployment of large electrical generating capacities at a single site would require a comparable electrical demand in some region about the site. However, the USNRC study indicates that the region could be fairly large (the average differential transmission distance in the West for 48 GWe energy centers as compared to dispersed sites was 290 miles) without an overriding cost penalty ( $\$ 45 / \mathrm{kWe}$ in 1975 dollars in this extreme case). In higher usage areas, such as in the northeastern U.S., the cost penalty would be lower ( $\$ 17 / \mathrm{kWe}$ for a 48 GWe energy center).

\section{LEGAL, ADMINISTRATIVE, AND ACCEPTABILITY CONSIDERATIONS OF INTERNATIONAL FBR FCCS}

Legal and administrative considerations of potential importance to an FBR FCC under some form of international control are considered in this section. The discussion below of generic considerations follows closely that in the IAEA study and relates the points considered in that study to an FBR FCC.

A. Legal/Administrative Considerations

1. Legal Status and Structure: There are a number of possible legal arrangements for international FCC. The exact structure is not critical provided it is well designed to meet its objectives and sufficiently flexible to accommodate possible changes in the mix of governmental and commerical participation as required. There are no inherent technical reasons for an international FBR FCC to require organizational structures largely different from a thermal reactor FCC.

2. Governmental Role: Governmental involvement is likely, if not absolutely necessary, in effecting an FCC. A host country is likely to take a larger interest than other participating countries in the legal aspects of the FCC since it will have specific interest in the public health and safety. It must also be concerned about the long-term stability of the FCC operation; particularly, whether adequate decommissioning agreements are in place both for premature and normal cessation of FCC operations. Larger initial governmental involvement might be expected in the FBR case, partly on a historical basis, but also because of the potentially larger costs. Since all FBR development programs are largely government funded, such continued involvement in FBR deployment seems likely.

3. Internationa1 Administrative Structure: As stated in the IAEA study, 1 "the principal task ... (is) to develop an administrative structure which (can) be responsive to governmental interests and yet function effectively in constructing and operating a large-scale industrial complex ... ." This study indicated that such an objective can be achieved through the implementation of multitiered mixed organizations. A recent IAEA technical note ${ }^{15}$ indicates that there are no apparent unique differences for the administrative structure of an FBR FCC. 
4. Commerical/Service Arrangements: A necessary aspect of the legal arrangements for an international FCC is an agreement on customer service preference e.g., FCC participants only, participants and other preferred customers, any customer willing to pay a market price, etc. Breeder fuel cycles, at least initially, may put fuel supply assurance in a different context than for thermal cycles in that reprocessing is the only source of the plutonium fuel supply. Thus, the participants in an FBR FCC are likely to be more dependent on the FCC than in the LWR case in which more suppliers may be available. Further, the pressures for rapid service will be greater due to the effect of out-of-reactor time on system doubling time. This puts more burden on having clear-cut service arrangements.

Pricing of services is an important part of these arrangements, particulary with respect to preferred customer discounts, e.g. for participants, or to premiums for quick turnaround. Again, this is likely to be of greater importance in the FBR case because of the greater value of the product relative to the reprocessing cost.

5. Industrial Arrangements: Procurement of goods and services, possibly including FCC construction and operation, could be according to conventional business practice but might be allocated in some way among participants through negotiated arrangements. There should be no inherent differences here in FBR and LWR requirements.

6. Technology: For both proprietary and non-proliferation reasons, technology exchange and control agreements must be considered for technology both acquired for use in or developed by an FCC. One primary non-prolifertion concern of an international FCC has to do with transfer of sensitive technology.

The IAEA (Ref. 1) argues that proprietery protections against technology transfer will be a significant protective device and that general knowledge of the technologies is already easily available. However, this latter argument may be inapplicable for FBR technology. Independent of these arguments, there are no apparent differences between FBR FCCs and thermal reactor FCCs in the necessary approach to the management of technology transfer.

7. Financial Matters: A variety of financial matters must be resolved in effecting an FCC, particulary those involving initial financing, operating expenses, liabilities, flexibility for accomodating failure or withdraw1 of participants, and long-term investment returns. The IAEA notes that the initial investment for a reprocessing facility will be large, but still a relatively small fraction (probably less than 10\%) of the total capital requirements of the nuclear power program which the FCC would serve. An equally important point is that the required financial share of a participant would be lower, because of economies of scale, than if the state established national reprocessing facilities.

An FBR FCC is likely to involve a greater investment than a comparably sized thermal reactor FCC. Furthermore, in early stages of deployment the unproven state of the technology could limit funding sources. This may cause more difficulty in initial financing. Development cost payback should be faster, however, because of the greater value of FBR reprocessing. 
8. Special Privileges and Guarantees: Agreements on the degree to which the host country's existing treaties and laws would hold for an FCC should be explicit. Special exemptions, such as those regarding licensing, import and export of materials, access to the FCC, labor market restrictions, taxes (including import duties), etc., should be covered by these agreements. These considertions are discussed in detail in the IAEA study report. There appear to be no large differences between FBR and thermal reactor FCC requirements in these respects.

9. Staffing: The IAEA study suggests that 1100 personnel would be required for a fuel reprocessing plant of 1500 tonnes (HM)/year size. A necessary area for agreement involves the degree of staff allocation among the participant countries. Spread of sensitive technology would need to be considered in the allocation and assignment of personnel from the participating countries. For comparable reprocessing throughput, an FBR FCC might require a larger staff as compared to the IAEA estimate if full throughput fabrication facilities were collocated in the FBR case. The local impact should still not be largely different for an FBR FCC compared to an LWR FCC.

10. Physical Protection and Emergency Responsibilities: Security personnel within the FCC would likely be under the control of the plant managers, although other options are possible. Exterior security would probably be the responsibility of the host state. Agreements on the specific responsibilities and coordination in the event of emergencies would be necessary. There appear to be no large difference between FBR and thermal reactor FCCs on these issues.

\section{B. Acceptability Considerations in Implementing FBR FCCs}

There do not appear to be any unique differences in the organizational issues involved in implementing an FBR FCC from those for implementing a thermal reactor FCC. Furthermore, the greater value of the FBR reprocessing product in terms of reprocessing cost may provide greater incentives for establishment of FBR FCCs. However, a comparable FBR FCC (in terms of HM throughput) with full fabrication facilities might have a larger impact in terms of economic, manpower, and physical resource requirements, and the political and public sector acceptability are likely to be different.

Political acceptability depends upon many factors including a government's perception of the relation between the nation's energy needs and the potential of FBR fuel cycles to meet them. The technical decision factors involved in a nation's deployment decision are discussed elsewhere. 11 However, it should be recognized that in many cases public acceptability can also strongly influence a government's decision.

Obtaining public acceptance for the siting of any large development is of ten difficult, and it might be particularly difficult in many nations for an FBR FCC. Since opposition might tend to be based largely on siting, choosing sites such as unpopulated islands might mitigate opposition. Loca1 compensation through local taxes or other benefits could also bring support, particularly from local governments. However, the balance suggests that public acceptability would be a key problem involved in the implementation of an FBR FCC. 


\section{SUMMARY AND FINDINGS}

This report has examined in brief some of the non-proliferation, technical, and institutional aspects of internationalization and/or collocation of major facilities of the Fast Breeder Rector (FBR) fuel cycle. The incentives and disincentives for deployment of such FBR Fuel Cycle Centers (FCC) are considered as they relate to the INFCE objectives of minimizing nuclear weapons proliferation while pursuing the deployment of nuclear energy for peaceful purposes.

The major incentives for FBR Fuel Cycle Center deployment are the resulting economies of scale and the perceived reduction in proliferation risk. Reprocessing plants supporting only a very few FBR's are not economical. Since few nations will be able to deploy a large number of FBRs in the near future, an economic incentive exists for international cooperation in the development of FCCs. Availability of and access to such fuel services might encourage nations without commercial reprocessing capabilities to defer development and deployment of such facilities at a national level. This is the single most important non-proliferation advantage of international fuel cycle centers. Internationalization may also reduce national level diversion, permit greater cooperation with IAEA inspection, provide better material accountancy and lead to greater international stability as compared with national fuel cycle facilities. Collocation of fuel cycle facilities on either a national or international basis provides improved safeguards with respect to dispersed facilities because of reduced transportation links (primarly between reprocessing and fabrication), reduced site perimeter, and larger professional security forces. Internationalization and/or collocation of fuel cycle facilities have some proliferation related disadvantages of which the most important are the dangers inherent in a seizure of the facility by a national or subnational group and the access of many nations to sensitive fuel cycle technology. The concensus of many studies on international collocated FCCs suggest that there should be a net reduction in both national and subnational proliferation risks relative to dispersed siting of national facilities.

In addition to the proliferation related aspects of internationalization of the FBR fuel cycle, fuel supply assurance, economics and access to technology might provide national incentive for joining in the creation of such a FCC. The political feasibility of such a center is addressed by noting that precedents exist for international cooperation in the nuclear fuel cycle which range from LMFBR development and demonstration agreements to coopertion in the LWR fuel cycle through enrichment and technology exchange agreements. International concern with LWR waste disposal, nuclear fuel assurances and weapons proliferation concerns may provide the incentives required to eventually establish international FBR fuel cycle centers.

The technical feasibility of FBR Fuel Cycle Centers with collocation of reprocessing, fabrication, and reactor facilities is addressed, by considering how FBR and LWR centers would differ. Extensive studies of LWR FCCs performed by the IAEA and USNRC suggested that there were no major technical barriers to deployment of LWR centers. The greater fissile inventory and shorter cooling times characteristic of the FBR fuel cycle make it necessary to modify the LWR reprocessing facility and this may lead to changes in the optimum facility sizes. Siting criteria for LWR and FBR Fuel Cycle Centers are compared both 
with and without collocation of reactors. Based on a 1500 tonne HM/yr reprocessing facility for mixed oxide fuel, data are presented which suggest that radiological effluents from a FBR FCC are somewhat greater than those from an LWR FCC, but are sufficiently small to meet regulatory requirements. Since land requirements are controlled by exclusion distance considerations which are dominated by the reprocessing and solidification processes, collocation of fabrication with reprocessing facilities is found to require no additional land use. If collocation of fuel cycle facilities and reactors are considered, heat dissipation associated with power generation may be the primary consideration in siting because of the corresponding land and water requirements. Transmission cost penalites although a small fraction of total costs, must be considered when reactors are collocated at an FBR FCC. Similarly, grid reliability considerations would suggest that no more than $15 \%$ of the total grid be collocated at a single FCC. There are no major differences in these respects between LWR and FBR Fuel Cycle Centers.

Administrative and legal considerations for FBR FCCs are addressed relative to LWR facilities as the latter are studied in the IAEA FCC report. Although there are not unique legal or administrative problems for FBR facilities, special consideration must be given to the probability of a greater governmental role in FBR technology, the greater emphasis on fuel supply assurances, the need to consider sensitive technology transfer, and the greater difficulty in obtaining financing for a facility based on a new technology.

The report concludes that international FBR Fuel Cycle Centers do satisfy the INFCE objectives of minimizing nuclear weapons proliferation concerns while providing for development of nuclear energy for peaceful purposes. The feasibility of an FBR FCC is found to be likely from both technical and institutional considerations, and political acceptability is likely to be one of the most important problems in actual implementation. 


\section{REFERENCES}

1. International Atomic Energy Agency, Regional Nuclear Fuel Cycle Center, Vol I and II, IAEA (April 1977).

2 - C. E. Till, Y. I. Chang and R. R. Rudolph, Altemative Fuel-Cycles and Deployment Strategies: Their Influence on Long-Term Energy Supply and Resource Usage, INFCE/5-TM-2 (July 1978)

3 U.S. Department of Energy, Barmwell Nuclear Fuels Plant Applicability Study, Vol I and II, DOE/ET-0040/1 and 2 (April 1978).

4. L. Schienman, Safeguarding Reprocessing Facilities: The Impact of Multinationalization, pp. 65-68 International Arrangements for Nuclear Fuel Reprocessing, Ballinger Publishing Co. (1977)

5. Commission of the European Communities, Nuclear Science and Technology, A Reference Regional Nuclear Fuel Center - Summary Report, EUR 5955 EN, FR (1978).

6. International Nuclear Fuel Cycle Evaluation Program, Working Group 3 Supply Assurances, Uranium Enrichment Present Position (March 1978).

7. International Co-operation on Breeder Reactors - The Rockefeller Foundation, May 1978.

8. K. D. Dance et a1., Deployment Considerations, part 8 of this report.

9. W. R. Rhyne, Siting considerations for LMFBR Fuel Cycle and Power Generation Centers, Science Application Inc. (June 1978).

10. U. S. Nuclear Regulatory Commission, Nuclear Energy Center Site Survey 1975, NUREG-0001, Part III (January 1976).

11. M. J. Lineberry et. a1., Fuel Cycle Options, part 5 of this report.

12. LMFBR Fina1 Environmental Impact Statement, USERDA Report WASH-1535.

13. B. C. Finney, R. E. Blanco, R. C. Dahlman, G. S. Hill, F. G. Kitts, R. E. Morre, and J. P. Witherspoon, Correlation of Radioactive Waste Treatment Costs and the Environmental Impact of the Waste Effluents in the Nuclear Fuel Cycle - Reprocessing Light-Water Reactor Fuel, ORNL/NUREG/TM-6 (January 1977).

14. NECSS Reactor Plant Consideration, BNWL-B-457 (November 1975).

15. IAEA Note on Multi-National Fuel Cycle Centers as Related to FBR's (September 15,1978 ) submitted to INFCE WG5/A(C). 


\section{PART 7}

\section{SAFEGUARDS}

P.I. Amundson and G.K. Rusch

(Argonne National Laboratory)

\section{ABSTRACT}

This report describes fissile nuclear material safeguards technology, both current and developmental, and discusses the possible application of this technology to $F B P$ systems. The proliferation risks associated with both subnational and national-level diversion are addressed.

\section{I, INTRODUCTION}

The increasing acceptance of nuclear reactors as a source of energy throughout the world has magnified the concern that widespread access to weapons quality special nuclear material (SNM) could potentially result in diversion of these materials and additional proliferation of nuclear weapons. Accordingly, large national efforts, particularly in the United States, have been devoted to the development of safeguard systems and safeguards tools. International agreements and the IAEA have been formed to deal with the problem on an international scale. In part, the purpose of the International Fuel Cycle Evaluation (INFCE) report is to assess the safeguards problem and the solutions which have been developed or are being developed.

The development of the Fast Breeder Reactor (FBR), which is designed to increase greatly the available quantity of fissile fuel by converting fertile $238 \mathrm{U}$ to $239 \mathrm{Pu}$, has accentuated the importance of safeguards. Within the FBR fuel cycle, $\mathrm{Pu}$ exists in larger quantities and in higher concentration than in thermal reactor fuel cycles.

The diversion defenses of a reactor system include all the inherent technical features which make the fissile material unavilable or unattractive, the institutional factors which deter diversion, and the set of safeguards deployed to protect the fissile material and the facilities.

The inherent technical diversion defense features for the reference international cycle, and various alternative cycles are discussed throughout other parts of this report. Additional discussions of safeguards systems as applied to the specific elements of the fast breeder fuel cycle are included in Part 5. Various aspects of diversion defenses are also discussed 
in Part 6 on Internationalization and Collocation of FBR Fuel Cycle Facilities, Alternative Fuel Cycles (Part 1), and Deployment Strategies (Part 8).

This Part describes safeguards technology, both current and developmental, and discusses the possible application of this technology to FBR systems. Potential subnational and national-level diversions are addressed.

Safeguards for commercial nuclear fuel cycles are formulated to reduce the possibility of both national and subnational weapons proliferation by detecting or preventing diversion of SNM from the fuel cycle. National diversion could be either covert or overt and, depending on the political or military objective, could take particular forms that affect the required safeguards system, including one-time diversion of sufficient material to produce a limited capability and routine diversion of quantitites sufficient to support a continuing weapons program. The subnational threat could be from an individual or from an organization and, again, could be covert or overt. Safeguards responsibilities are organized to counter these threats. International safeguards are directed at both national and subnational threats, but depend on national programs which, while often directed primarily at subnational threats, must be formulated to support the international object of detecting national diversion.

A clear distinction should be made between the diversion risks associated with FBR facilities now and in the future. Only a few developmental FBR facilities are currently deployed, and these are generally in states for which there is little concern with national-level diversion. Currently there are no commercial facilities dedicated to FBR reprocessing. The stage where the full FBR fuel cycle exists independent of LWR fuel cycle is estimated to be many decades away. During the transition, plutonium for the FBR could come from the spent fuel of LWRs, and the associated reprocessing facilities would be designed to reprocess LWR spent fuel. A plant for largescale reprocessing of spent fuel from the FBR may not be needed until well after initial commercial FBR deployment. With safeguard planning initiated early in the development for the FBR fuel cycle, time is available to develop, evaluate and implement improved safeguards techniques and to incorporate them into the design phase of all FBR cycle facilities.

The safeguards technology described here has been developed primarily for the currently existing nuclear industry. Most of the systems, techniques and equipment can be applied to the FBR cycle either directly or with some modifications. The adaptation of this technology to possible future FBRs is discussed.

In the subsequent descriptions of current safeguards practices and safeguards development programs, emphasis has been placed on U.S. domestic activities. Because of U.S. recognition of the IAEA as the proper vehicle for future international safeguards and U.S. technical support toward IAEA goals, current domestic practices as well as future developments may find IAEA application by the time FBR deployment occurs.

Description of specific techniques in Section IV is not intended as endorsement of these techniques for application to international safeguards. They are primarily summaries of applications of several technical concepts, 
some engineered and tested, that have been found useful in the development of portions of a national safeguards program. The use of these, or other, advanced techniques by the IAEA would involve considerable development and testing. In addition, assessment by the IAEA of important areas of financial and manpower resources and contractual limitations on inspection will necessarily weigh heavily on related safeguards deployment considerations.

\section{BACKGROUND MATERIAL}

\section{A. Legal Background on IAEA Safeguards Implementation}

In 1978, the United States enacted Public Law 95-242, the Nuclear NonProliferation Act (NNPA) which strengthened the U.S. commitment to the principles of the Non-Proliferation of Nuclear Weapons Treaty of 1970 (NPT). Toward this end, the NNPA committed the U.S. to the establishment and operation of a safeguards training program and to renegotiation of U.S. export agreements to assure the implementation of full IAEA safeguards in the recipient nations.

There are two paths by which a nuclear facility legally may become subjected to the IAEA safeguards system. One results when the state in which the facility resides becomes a signator to the NPT. The other results when a non-signator state chooses to submit facilities to IAEA safeguards.

This latter route has traditionally been strongly encouraged by nuclear supplier states by means of conditions written into the material, service, and equipment exchange agreements they enter into with nuclear consumer states. Treaties between the supplier and consumer states stipulate that the consumer state will enter into a safeguards agreement with the IAEA. The London Suppliers Group requires that its member nuclear supplier states insist on ful1* IAEA safeguards in their exchange agreements. The U.S. Nuclear Non-Proliferation Act of 1978 also requires this for U.S. exports.

Nations party to the NPT agree that Non-Nuclear-Weapons-States (NNWS)+ undertake "to accept safeguards, as set forth in an agreement to be negotiated and concluded with the IAEA" with a view to preventing diversion of nuclear energy from peaceful uses to nuclear weapons or other nuclear explosive devices. The form of the safeguards agreements is specified in Ref. 1.

For those nations which are not party to the NPT but which choose to submit facilities to IAEA safeguards, the general agreement form and some specifications are delineated in Ref. 2. These states undertake that "special fissionable and other materials, services, equipment, facilities, and information" shall not be "used in such a way as to further any military purpose." For all agreements enacted since 1975 this undertaking has been modified to read "not to use nuclear material, facilities, and equipment for the manufacture of nuclear weapons or to further any other military purpose, or for the manufacture of any other nuclear explosive device." Reference 2

*"Fu11 IAEA safeguards" means that IAEA safeguards will be applied on all peaceful nuclear activities of a nation.

+Only the US, UK, France, USSR, and China are considered to be Weapons States. 
does not specifically require the IAEA to draw a conclusion with respect to diversion or to material unaccounted for. (The agreements signed by parties to the NPT require such a conclusion.) However, the IAEA by its own charter is required to draw a conclusion regarding compliance so that such a conclusion regarding diversion may result from the application of IAEA safeguards. Where non-compliance has been concluded, the IAEA is obliged to report to the board of governors. 3

Safeguards as defined by the IAEA are broken into the two general categories: (a) material accountancy; and (b) containment/surveillance. It is the IAEA view that material accountancy is the main principle of safeguards, while containment and surveillance (both of which may be thought of as physical protection) are viewed as "important complimentary measures" to accountancy (or accountability). Thus the emphasis of the IAEA safeguards system is on the implementation of a system of materials accountability backed up by physical protection and a sound system of independent verification of the accountancy data.

The IAEA safeguards system is essentially a three-tier structure with the facility operator providing the primary line, the state(s) providing a major check, and IAEA providing a third level of overview and verification. The emphasis of this system is upon "timely detection of the diversion of significant quantities of nuclear material."

The uppermost tier of safeguarding (by the IAEA) is generally directed at verification of compliance with the safeguards agreement. In establishing its verification criteria, the IAEA team is empowered to examine all accounting reports and records including special reports. They can take samples, make independent measurements and tests, verify that equipment is functioning properly, and receive clarification of data as requested. They are required to verify all nuclear material flows and inventories for any facility that uses, produces, or reprocesses nuclear material. (It should be noted that the specific agreement may exclude IAEA inspectors from portions of the facility which contain proprietary technical information.) The IAEA (for NPT signatory nations) is required to provide a technical conclusion regarding the amount of Material Unaccounted For (MUF) over a specific period of time and to estimate the limits of accuracy of the amounts stated for each material balance area.

To establish a second safeguards level, the IAEA suggests that the host state develop procedures and criteria with respect to timeliness, accuracy, and confidence levels to verify that the quantities in receipts, shipments, and discards are free from inadvertent mistakes and deliberate falsifications. Those states that are party to the NPT are required to establish a State System of Accounting and Contro1 (SSAC).

The purpose of the SSAC is to detect and prevent unauthorized use and loss of SNM and to provide information leading to recovery of lost material. The system includes requirements for regulation, licensing, information systems, control of compliance, sanctions, and recovery of missing material. The state SSAC thus specifies requirements to be followed at the base (operation) level of safeguards. 
B. Historical Background of Domestic Safeguards

Accountability requirements for SNM were first established in the U.S. by the Atomic Energy Commission (AEC) when all such material was government owned. Since then, the requirements have been periodically modified and strengthened to respond to changes in the operating environment and the growth in the nuclear industry. In 1954 the U.S. began to allow private ownership of special nuclear material. Following that, the regulations governing the safeguarding of the material underwent several major revisions, each strengthening various aspects of the program. In particular, Part 70 of Title 10, Code of Federal Regulations was amended substantially to strengthen material control and accounting practices. The most noteworthy of these amendments in recent years was (1) the addition in 1973 of material balance, inventory, and records requirements through issuance of $\$ 70.51$, (2) the codification in 1974 of the Fundamental Nuclear Material Controls, through $\$ 70.58$, and (3) the requirements, issued in 1975 , for measurement quality control in $\$ 70.57$.

Title II of the Energy Reorganization Act of 1974 created the Nuclear Regulatory Commission (NRC), and assigned certain safeguards responsibilities to an Office of Nuclear Material Safety and Safeguards (NMSS) within NRC. These responsibilities call for NMSS to perform specific regulatory functions "...involving all facilities and materials,...licensed under the Atomic Energy Act of 1954, as amended, associated with the processing, transport, and handling of nuclear materials, including the provision and maintenance of safeguards against threats, thefts, and sabotage of such licensed facilities, and materials." Section 204 of the Energy Reorganization Act of 1974 assigns NMSS the task of "...monitoring, testing, and recommending upgrading of internal accounting systems for special nuclear material and other nuclear materials licensed under the Atomic Energy Act of 1954, as amended."

In early 1976, NRC initiated a special review of safeguard practices at facilities of fuel cycle licensees who possessed significant amounts of strategic special nuclear material (SSNM), that is, plutonium, $233 \mathrm{U}$, or uranium enriched to $20 \%$ or more in the $235 \mathrm{U}$ isotope (HEU). In March 1976, the Energy Research and Development Administration (ERDA), now part of the Department of Energy (DOE), began participating in those reviews. As a result of early findings, NRC and ERDA created a joint task force to develop a proposed plan for improving material control and protection at these facilities. The task force decided to give first priority to physical security issues that constituted a first line of protection against malevolent acts. Improvements in material accountability were judged to be of longer term and needed to be addressed under other ERDA and NRC planning activities. In April 1976, NRC unilaterally formed a task force to develop a safeguards plan for material control and accounting.

The concept of a computerized, real-time material control and accountability system received little consideration prior to 1972 . Since then the field has expanded greatly, and recently, a comprehensive description of a real-time system which would exploit all available state-of-the-art technology was published.4,5 This system concept, identified by the acronym RETIMAC (Real Time Material Contro1), incorporates extensive on-line instrumentation, automated processing, access and transfer monitors, and computerized data 
acquisition and analysis. This concept study represents a point of reference toward which planned and existing systems might evolve. Related real-time concepts that are presently being used in various facilities are described in reports ${ }^{6}, 7$ on the DYMAC system (Dynamic Material Control) in a report ${ }^{6}$ on the DYMCAS system (Dynamic Material Control and Accounting System), and in a paper ${ }^{9}$ on the INMACS system (a computer assisted On-Line Fissile Material Inventory and Criticality Control System). A number of efforts are presently under way to determine effectiveness of these systems. Applications of real-time techniques to fuel refabrication facilities, to fuel reprocessing
plants, and to enrichment plants have been discussed. $10,11,12$

\section{POTENTIAL DIVERSION CONCERNS}

\section{A. Subnationa1 Leve1}

The potential subnational diversion threat is perceived to result primarily from terrorist activity. The threat could be from a single individual or it could involve large organizations.

The technical capabilities of subnational diverters can be presumed to be significantly less than those of nations. Therefore, diversion by these groups can be made more difficult and unattractive by maintaining the material in forms unsuitable for explosive devices, and/or mixed with highly radioactive materials, or by maintaining effective safeguards systems.

It is more likely that diversion attempts would involve relatively pure fissile material. The attempt could be by covert diversion and theft or by an assault on a facility perceived to be vulnerable to such an attack. Part 6 discusses the use of the collocation-of-facilities concept as a defense against diversion.

\section{B. Nationa1 Leve1}

At the national level, diversion could have several intents. Three arbitrarily selected levels of nuclear explosives capability are identified to demonstrate their impact on safeguards.

A single-device capability, although of major political concern, would have relatively limited military usefulness. However, presuming the technical capability to fabricate an explosive device exists within the country acquiring the SNM, this goal would be relatively easy to accomplish because of the small amount of fissile material needed.

A second level of capability might be a military capability based on a single diversion of fissile material, either in a single try or in multiple attempts over a short period of time. The goal might be to produce several devices for military use. This one-time capability would probably be attempted by diversion of plutonium from a Pu storage facility, reprocessing plant, or from material in transit.

An ongoing military program would be the upper bound on a national goal of becoming a nuclear weapons state. Here a production rate of up to 100 weapons per year might be considered. The state would have to establish 
a separate program to produce the required quantity of weapons-grade material or divert substantial quantities from a civilian power program. Advanced technology would be required not only to obtain the weapons-grade material, but also to produce compact weapons and be able to assure their military delivery (rockets, etc.).

The burden of detection of these postulated diversions would fall in part on the IAEA and its safeguards organizations.*

\section{SAFEGUARDS}

\section{A. Introduction}

IAEA safeguards responsibilities were delineated in Section II.A along with associated obligations of nations who have signed IAEA safeguards agreements. The U.S. is an IAEA member nation and an NPT signator.

U.S. national safeguards address the unauthorized possession or use of significant quantities of nuclear materials through theft or diversion, and sabotage of nuclear facilities. U.S. national safeguards measures have as their objective the deterrence, detection, quantification, and delay of unauthorized activities, as well as appropriate response to these activities should they occur.

Accomplishing this goal traditionally has been the function of security organizations and is effected by using physical-protection systems (PPS) consisting of security guards, barriers, and access controls. In addition, detection and quantification have also been the responsibility of special nuclear materials management and are effected by performing SNM assays, taking inventories, and through the use of appropriate accounting systems.

\section{B. The Generic Safeguards System}

A generic safeguards system, its instrumentation structure and associated measurement technology, is detailed in the following subsections to assist in developing an understanding of the automated approach to safeguards. The safeguards system described was intended to apply to an FBR fuel-reprocessing facility. The techniques and associated monitoring instrumentation will, however, be adaptable to most perceived reactor, fuel fabrication, and waste treatment facilities. As a consequence, it is presented as a generic model for all elements of the FBR fuel cycle. General applicability of these techniques to international safeguards is not implied. However, the IAEA presently uses or is investigating some of the described methods. ${ }^{13}$ Others may be considered for future application.

1. 14 Physical Protection System: Physical protection systems can include 14 (a) perimeter intrusion detection systems to detect and confirm unauthorized movement or activities in and around a protected area or facility;

*Part 6 discusses use of the internationalization-of-facilities concept as a defense primarily against diversion of SNM or facility misuse by a nation(s). 
( ) automated personnel identification systems to assure that only authorized people are in restricted areas; (c) SNM monitors, metal detectors, and explosives monitors to assure that sensitive materials do not move across barriers that are expected to restrict their passage; (d) closed-circuit television and other surveillance devices to monitor sensitive areas remotely; (e) delay systems to slow down an overt external attempt to enter a restricted area; (f) doorway monitors and alarms to detect movement of people into sensitive areas; and $(\mathrm{g})$ sufficient personnel to respond to an externally-generated overt act of a specified size.

Many of the equipment items referred to are available from commercial sources; 15 some have been available for many years. However, most have been engineered specifically for nuclear facilities within the past five years.

Commercial SNM monitors measure gamma rays emitted in the monitored space.16 Regardless of the true source of the gamma rays, it is assumed that they come from special nuclear material. Although this assumption may create certain operational problems, it results in highly sensitive monitors. U.S. regulatory specifications 17 for these monitors include the requirement to detect (a) $0.5 \mathrm{~g} 239 \mathrm{Pu}$ with a $95 \%$ confidence leve1; (b) $1.0 \mathrm{~g}$ of freshly refined $233 \mathrm{U}(7-10 \mathrm{ppm} 232 \mathrm{U}$ within $4 \mathrm{~h}$ of purification) with a $90 \%$ confidence level, and (c) $3 \mathrm{~g}$ of $235 \mathrm{U}$ (contained in uranium enriched to $20 \%$ or more) at a $50 \%$ confidence leve1. Al1 samples are assumed to be encased in, and thus shielded by, $3 \mathrm{~mm}$ of brass. The monitors must have false-alarm rates of less than $0.1 \%$.

Gamma rays naturally associated with SNM are primarily low energy emissions and are subject to absorption by moderate quantitites of shielding material. Therefore, metal detectors capable of detecting $200 \mathrm{~g}$ or more of nonferrous metals are utilized in conjunction with gamma radiation detectors to investigate the loss of radiation detection sensitivity caused by the shielding of SNM. The simultaneous use of sensitive gamma radiation detectors and sensitive metal detectors present an effective barrier to the unauthorized transport of SNM past monitored portals.18,19

Radiation monitoring equipment, piece counting equipment, etc., can be used at shipping or receiving points as part of a semiautomatic monitoring capability. Shipping drums, for example, can be placed on a test fixture, and appropriate instrumentation can identify the container, perform a non-destructive assay (NDA), and transmit the information to a central accounting system computer. The computer can check the information received against preprogrammed shipping information to provide a check on the manual inspection process. Discrepancy alarms can be incorporated into the system and can be activated by the computer if a discrepancy occurs.

Remotely operated radiation and metal-detection instruments can also be used to supplement the physical protection system. Door locks, television cameras, etc., can be controlled by remotely located computers receiving information from the detection instruments. These automatic control functions would normally be used only outside continuous flow processing lines to avoid unnecessary interruptions to critical process operations. 
2. Materials Control and Accountability System: The material measurement and accounting element provides an indication that nuclear materials are present and at their proper location within a facility. Material measurement equipment and procedures include bulk and sample analytic chemistry techniques, weights, volumes, dimension, position, and the non-destructive assay techniques. Material measurement equipment provides: (1) "single-theft" material detection based on material balance calculations when made on a near-real-time basis, and (2) "long-term" material diversion detection of amounts too small to be detected by a single material balance. The long-term material diversion detection is based on trends in successive material balances. Both single-theft and long-term material diversion detection are inputs to national safeguards systems design.

To achieve near-real-time (nearly continuous) materials control and accountability, a facility can be subdivided into physical areas within which SNM accounting is done. ${ }^{20}$ These physical areas can be chosen in such a way that all nuclear material crossing a process boundary must undergo a non-destructive assay, and a material balance can then be computed. The areas are chosen to localize the material within a given unit process, both in space and in time. On-line computers are used to cope with the large quantities of data collected over short periods of time. Material accounting statistics are calculated and monitored for each unit process. 21 If the value of such a statistic (or set of statistics) exceeds a specified alarm level, the materials control system alerts the appropriate authorities and investigative action is taken.

The development of this type of system has been made possible by recent availability of advanced non-destructive-assay instruments. These instruments monitor natural radiation, neutron-induced fission, or radiation absorption properties in order to determine the identity of materials in the process stream and to measure their abundance. Of nearly equal importance is the capability for direct, automated transfer of data from these non-destructive-assay instruments to a central computer, and the availability of sophisticated computer programs to do real-time accounting and make quick diversion assessments from vast quantities of non-destructive assay and other process data. 22,23

3. System Structure: The flow of information, authorizations, and control data through a safeguard structure and the plant process system is given in Fig. $1 .{ }^{24}$

Safeguards coordination, materials measurement, materials accounting, and process control coordination are to a large degree computer-controlled, automated functions. The ability of the safeguards system to maintain strict control of the in-plant SNM results from the automated coupling of these functions.

The basic data flow is from unit process NDA and associated monitoring sensors in the process line to the materials measurements and accounting system. Results of real-time statistical assessments of the data to determine potential diversion are transmitted to the safeguards coordination area, and 


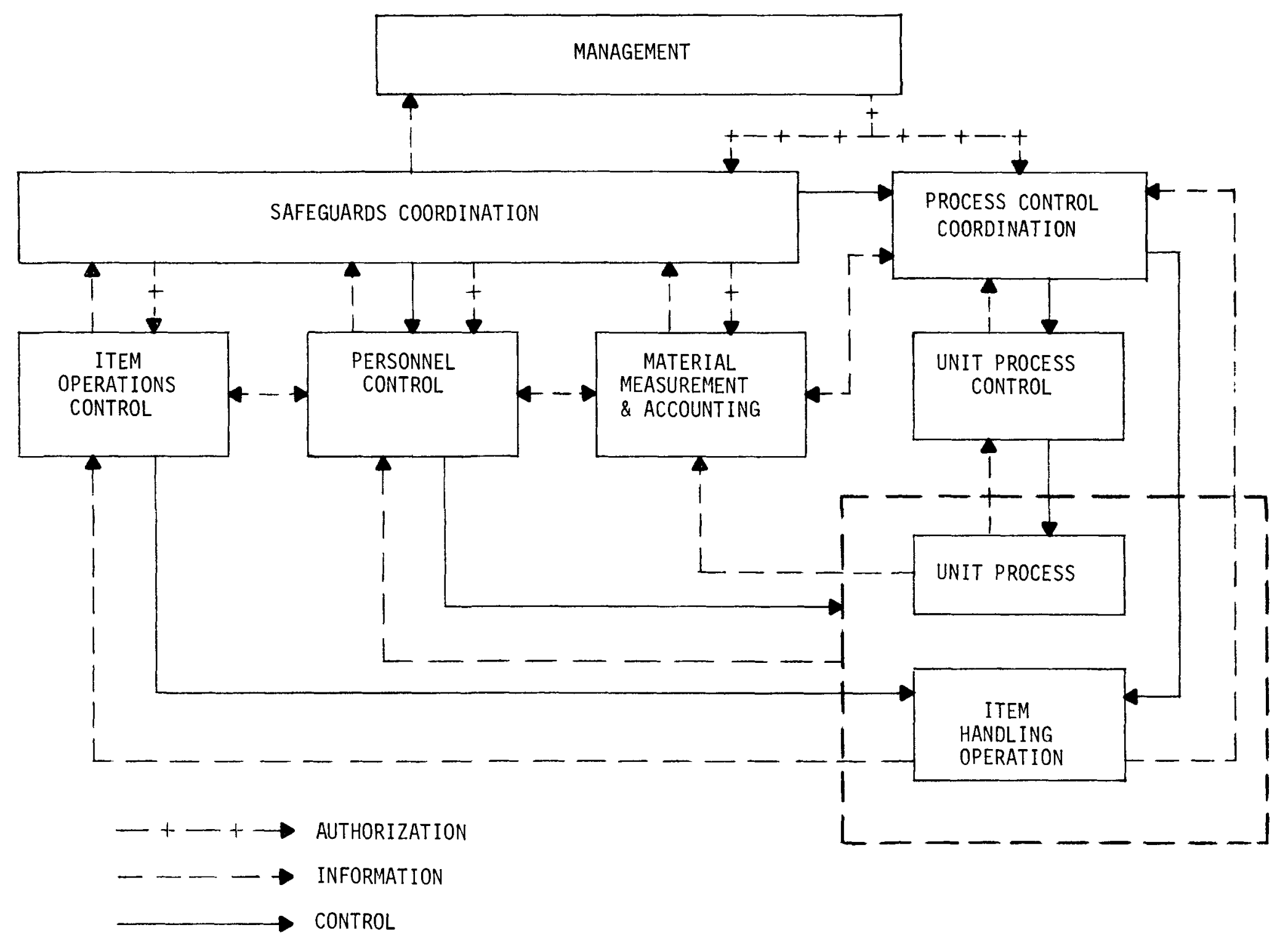

Fig. 1. General Structure of Safeguards System. ANL Neg. No. 116-79-147 
at times to the process-control coordination area. The latter depends on the presence of, and amount of, useful process information in the assessment.

Some head-end and tail-end operations are handled by the physical protection system due to the fact that items in these operations can be identified individually. NDA is not done, in this instance, but items are accounted for by automated data transmission to the safeguards coordination area. 14

To mathematically test the concept, two postulated DYMAC systems have been evaluated 24 for diversion sensitivity by computer modeling the process flow, the measurement system, and the safeguards analysis system.

A fuel reprocessing safeguards system designed around the Barnwe11 processing structure was evaluated using the process flow model FLOSIM 25 which simulates the fuel flow rates in the various parts of the reprocessing system. MEASIM 26 was used to model the measurement system, incorporating known instrument errors and measurement sensitivities. DECANAL ${ }^{24}$, the reference safeguard data analysis code, was used for diversion assessment. The results of these evaluations are given in Table I to show the range of capabilities for diversion detection. The results are evaluated at the $50 \%$ confidence level and a false alarm rate of 0.001 . In the optimum case, a single theft of $1.8 \mathrm{~kg}$ (or smaller thefts of $0.075 \mathrm{~kg}$ per balance period) would be detected in 24 hours, if a balance was done each hour and the assumed processing column (or tank) measurement accuracy was $5 \%$.

A fuel fabrication safeguards system developed around the Westinghouse Recycle Fuels Plant was evaluated by the use of a time-event Monte Carlo simulation of the fabrication line.27,28 The simulated process information was evaluated for diversion by the safeguards system methodology. 22 The results are given in Table II for five sensitive unit processes. The detectable levels are given for randomly timed, unrepeated thefts, at a $50 \%$ confidence level and a false alarm rate of 0.001 . The high level of sensitivity of the system can be attributed in part to the numerous NDA instruments and advanced automated accounting. The high sensitivity is also due to having easily assayed materials in a system readily accessed by NDA equipment.

The protection afforded SNM in reprocessing plants and fuel fabrication plants meets the NRC requirements for fuel fabrication plants of $1 / 2 \%$ of throughput at each 2-month inventory period after plant shutdown and cleanup, and $1 \%$ of throughout at each 6 -month inventory period after plant shutdown and cleanout for reprocessing plants. The detection sensitivity for material diverted clearly does not approach that of the PPM door monitoring equipment. This is a result of the fact that portal and pass-through monitors are not designed to evalute plutonium content and therefore have greater sensitivity. Any material that triggers the monitor is assumed to be plutonium. A comparison of process instrumentation sensitivity and PPS instrumentation sensitivity for SNM is given in Table III.

4. Non-destructive Assay Techniques: Plutonium compounds or mixtures which exist in the FBR fuel cycle can be assayed by various alpha particle, neutron, $x-r a y$, and gamma-ray NDA techniques. 
TABLE I. Reprocessing Safeguards Diversion Sensitivity ${ }^{24}$

\begin{tabular}{ccccc}
\hline $\begin{array}{c}\text { Max. } \\
\text { Detection } \\
\text { Time }\end{array}$ & $\begin{array}{c}\text { Material } \\
\text { Balances Per } \\
\text { 8-hr Shift }\end{array}$ & $\begin{array}{c}\text { Assumed Column } \\
\text { Measurement } \\
\text { Accuracy, } \%\end{array}$ & $\begin{array}{c}\text { Average Diversion } \\
\text { Sensitivity, } \\
\text { (kg Pu/Balance) }\end{array}$ & $\begin{array}{c}\text { Total at } \\
\text { Time of } \\
\text { Detection, kg }\end{array}$ \\
\hline $8 \mathrm{hr}$ & 1 & 10 & 4.2 & 4.2 \\
$1 \mathrm{wk}$ & 1 & 10 & 0.3 & 6.3 \\
$1 \mathrm{hr}$ & 8 & 5 & 2.6 & 2.6 \\
$24 \mathrm{hrs}$ & 8 & 5 & 0.075 & 1.8 \\
\hline
\end{tabular}

average detection time for single random diversion is 0.5 of that indicated.

TABLE II. Fuel Fabrication Safeguards Diversion Sensitivity

\begin{tabular}{lc}
\hline Unit Process & $\begin{array}{r}\text { Detectable Theft } \\
\text { Level, } \mathrm{g} \text { Pu }\end{array}$ \\
\hline PuO $_{2}$ Unloading & 110 \\
$\mathrm{MO}_{2}$ Blending & 130 \\
Pelleting & 150 \\
Grinding & 80 \\
Clean Scrap Recovery System & 200 \\
\hline
\end{tabular}

TABLE III. Diversion Detection Levels

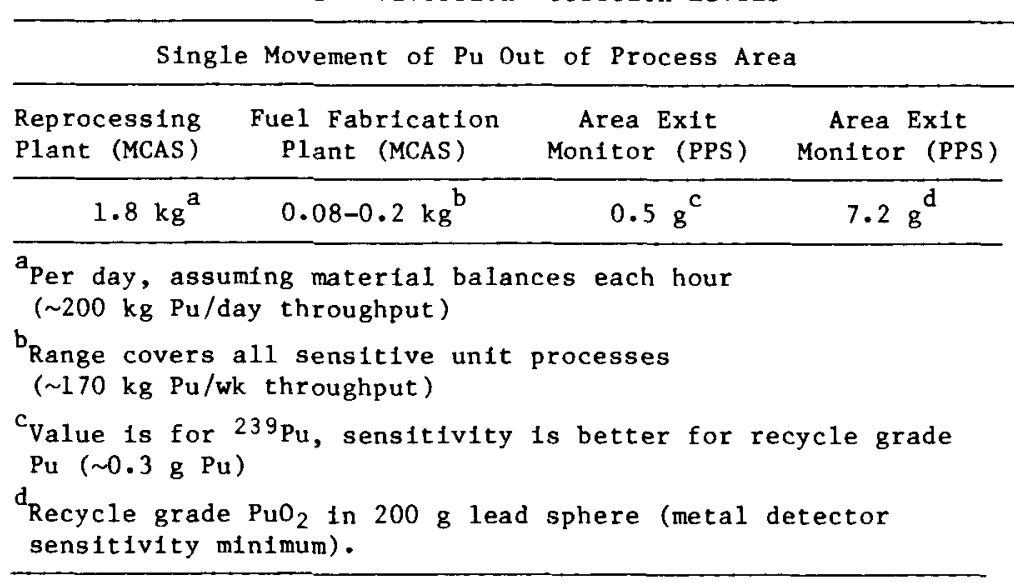

The measurement techniques employed, and the precision and accuracy obtainable for a given subclass of materials, will depend on the size, shape, mass, and to varying degrees on the SNM concentration in the sample. The presence of other radioisotopes, such as fission products and/or actinide contaminants, the intensity of fluorescent $x$-rays, the parent-daughter relationships, and the relative SNM abundances also affect the choice of measurement technique and the resulting precision and accuracy. No universal NDA technique exists. The proper choice can be made only after characterizing the material to be analyzed and understanding the inherent strengths and limitations of the available assay techniques.

This section presents some of the potential applications and problems of NDA analysis techniques as applied to a reprocessing plant. The fundamental principles of the various active and passive assay techniques are reviewed and the limiting assumptions are discussed. Techniques that have been applied for various applications are listed in Table IV. 
TABLE IV. NDA Methods for SNM Accountability

\begin{tabular}{lccc}
\hline & \multicolumn{3}{c}{ Applicability } \\
\cline { 2 - 4 } & Reprocessing & Converston & Fuel Fab \\
\cline { 2 - 4 }$\alpha$ Monftor & $\mathrm{X}$ & $\mathrm{X}$ & \\
Absorption Edge & $\mathrm{X}$ & $\mathrm{X}$ & \\
Y Ray & $\mathrm{X}$ & $\mathrm{X}$ & $\mathrm{X}$ \\
Neutron & $\mathrm{X}$ & $\mathrm{X}$ & $\mathrm{X}$ \\
Calorimetry & & $\mathrm{X}$ & $\mathrm{X}$ \\
\hline
\end{tabular}

a. Alpha Monitors: In-1ine alpha monitors were originally designed for process-control to determine whether excessive amounts of plutonium were being discharged into the waste streams. Discrimination between beta/gamma radiation and alpha particles is obtained by appropriate design of the detection system. An alpha/beta discrimination factor of $\sim 10^{4} \mathrm{can}$ be obtained. A commercial in-line alpha monitor has been designed to operate in the presence of fission-product activity up to $30 \mathrm{Ci} / \mathrm{l}$.

b. Gamma Absorption Techniques, Absorptometry: Gamma-ray absorption has been used on selected process lines. The technique utilizes a gamma source and detector on opposite sides of a process line to measure gamma absorption of materials within the line. Although the technique is simple and inexpensive, its deployment has been limited because the material mixes are usually unknown and because the technique is neither element nor isotope specific.

c. Absorption-Edge Densitometry: This technique measures $x$-ray absorption at specific $K$ or $L$ absorption-edge energies.

The $\mathrm{K}$-edge technique utilizes a radioactive source tailored to the element to be monitored and is applicable for concentrations between 20-500 $\mathrm{g} / \mathrm{l}$. For example, ${ }^{75} \mathrm{Se}$ and $57 \mathrm{Co}$ are used for assaying plutonium. In this measurement, a solid-state detector ( $\mathrm{Ge}(\mathrm{Li}$ ) or intrinsic germanium) is aligned directly with the source, and the sample cell is interposed between the source and detector. The x-ray transmission is determined.

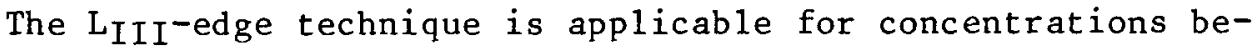
tween $\sim 1-40 \mathrm{~g} / \mathrm{\ell}$. It utilizes primary radiation from an $\mathrm{x}$-ray tube designed for the element to be determined. The technique has only recently been applied to safeguards measurements, and its limitations are not well understood. However, the technique is element specific and has high accuracy over wide ranges of solution/heavy-metal concentrations.

d. Gamma-ray Analysis: Gamma-ray NDA is based on measuring the intensity of specific gamma ray(s) emitted by the radioisotope of interest. Data obtained by this technique must be corrected for self shielding by the sample. This may be difficult for certain processes because the characteristic gamma-ray energies are low (typically $\sim 50 \mathrm{keV}$ to $<400 \mathrm{keV}$ ), the attenuation coefficients of the high-Z elements are large, the chemical composition of the sample may not be well known, and the sample volumes may be large. However, the technique works well on most Purex sample lines after fission product stripping, and during many of the MOX fuel fabrication processes. 
e. Neutron and Neutron Coincidence Counting: If the chemical composition and plutonium isotopic abundances are known and controlled, gross neutron counting may be suitable for NDA measurements and materials accounting. However, in many practical situations, notably scrap and waste measurements, these assumptions may not be valid because of the extraneous neutrons produced by $(\alpha, n)$ reactions.

Coincidence-counting of neutrons primarily from the spontaneous fission of ${ }^{24 \mathrm{U}} \mathrm{Pu}$ and other even-numbered plutonium isotopes has been used to assay a wide range of plutonium samples, fabricated fuels, and drums of plutonium-bearing scrap and waste. Application of this technique to the measurement of scrap and waste is slow, but is not affected by $(\alpha, n)$ reactions or sample self absorption.

f. Quantitative X-Ray Fluorescence Analysis of SNM in Solution: $X-r a y$ induced fluorescence of some actinides can be valuable for determining the amount of material present. The measurements are sensitive and accurate and are capable of measuring microgram quantities of material to relative accuracies of $1 \%$ or less. Typical analysis times are short (one-half hour or less). Currently, $x-r a y$ fluorescence is used primarily to measure the activity from spent fuel reprocessing solutions. However, the technique has been applied to solutions from all stages of the fuel cycle. These techniques have had only limited application, however, due to system complexity, sample conditioning requirements, and limited range. This is not an on-line technique, since samples must be drawn from the process stream for analysis.

g. Active Neutron Techniques: Active neutron techniques can be used to assay solid or liquid samples of fissionable material in various forms and over a wide range of enrichments. The samples are irradiated with short bursts of neutrons from either sources or accelerators. Induced neutron or gamma activity is then measured to determine fissile content. Either prompt or delayed neutrons can be used if the detection system is properly calibrated. Detection of passive gamma rays and post-irradiation neutron-induced gamma rays yield information on fissile/fertile material ratios. Reasonably accurate fissile mass determinations can be obtained using short counting times.

Active neutron methods are not useful for distinguishing between different types of fissile materials. Additionally, calibration can be complicated by the variation of system response with sample type.

5. Statistical Decision Analysis: The mathematical formulation of materials accounting is based upon the continuity equation which relates the inventory in a given material-balance region at the beginning and end of a material-balance period to the amount of material transferred into and out of the given region during the time interval. If all materials are accounted for and the statistics of the data collection are precise, the material balance for the given region and time period is zero. However, statistical and systematic errors in the measuring process and incomplete information about the process line, as well as the actual diversion of materials, lead to nonzero (positive) material balances. The lack of necessary information about the processing operation refers specifically to constraints in the data-collection function which prevent the measurement of material transferred into all regions for each material-balance period. As expected, these unmeasured 
material transfers (so-called sidestreams) tend to mask the presence of diversion. It is the function of decision analysis to distinguish actual material sidestreams, subject to the additional complexity of measurement uncertainties.

The primary goals of the analysis function are, qualitatively, to detect the diversion of nuclear material, to estimate the amount of diverted material, and to determine the significance of these estimates. The analyses must be designed to search for evidence of diversion that may have occurred in any of a number of possible patterns, from the theft of a relatively large amount of material during a single or several material balance periods to the theft of relatively small amounts during frequent, random material balance periods. The detection and estimation of diversion are well suited to statistical treatments using sequential, probabilistic techniques that have been developed for applications to communications systems and control systems 29-32 but the question of the significance of the estimate remains--that is, how the results should be interpreted. A currently evolving answer to this question of interpreting utilizes the theory of decision analysis. 33

In the decision-analysis process the observed source, that is, the nuclear material processing line, generates data which must lead to a yes or no answer. If the data from the observed source were true (complete and error free), the decision-making process would be trivial; however, these data are imprecise for two reasons. First, the measuring systems introduce random statistical fluctuations due to both electronic noise and the experimental counting statistics, and possible bias due to instrument miscalibration. Second, constraints on the processing operation may require that not all components of the material balance be measured during each time interval, producing incomplete and hence non-zero material balances.

Decision analysis, based on mathematically derived decision functions, can quantify material processing by condensing large collections of data to a set of "descriptors" and can provide a degree of consistency by eliminating personal biases in the subjective evaluation of the data. A variety of statistical tests is available for use in the decision process.

The decision-analysis techniques currently employed by the nuclear safeguards program are divided into two classes--smal1-sample-evaluation techniques and large-sample-evaluation techniques. The smal1-sample techniques, using only a few material balance periods, detect the diversion of all unmeasured nuclear materials if it appears "out-of-limit" (large) in relation to the measurement uncertainties (short-term diversions). The largesample techniques, using data collected over many material-balance periods, identifies the repeated diversion of nuclear material which, due to uncertainties in the measuring process, were too small to be detected individually (long-term diversion).

One method 20,34 (but not necessarily the most rigorous or up-todate) of identifying long-term trends occurring in industrial process control is the cumulative summation (CUSUM) method 35,36 evaluated using the V-mask test. 37 In applying the CUSUM/V-mask method, the sum of the material balances for a given region is accumulated over many material balance periods and tudied as a function of the period. The V-mask test is applied sequentially 
to the CUSUM result at each material-balance period to check for any "out-ofcontrol" conditions; these out-of-control conditions are related to the input miss and false alarm probabilities. This has been incorporated into the DYMAC System 22,23 as its basic decision-making tool.

A discussion of details of other statistical methods is beyond the scope of this review. References 38,39 and 40 can be consulted for these details.

C. Safeguarding the Reference FBR Cycle

1. Power Plant Safeguards: No standard FBR design exists at this stage in its development. However, for the purpose of discussing safeguards, all have certain common features.

The reactor core is generally contained within a sealed primary containment system. Access to the fuel is accomplished using remotely controlled equipment. Generally the primary containment system must be penetrated, shield plugs rotated, and perhaps other equipment manipulated to get at the fuel elements with remotely operated fuel transfer grippers. The fuel pins are contained within rods, which in turn are assembled into fuel element assemblies.

Figures 2 and 3 show certain features of the Super Phenix FBR design. Table $\mathrm{V}$ contains fuel-related information. The following discussion, although strictly applicable to the Super Phenix, gives a rough indication of the steps necessary to transfer fuel from any FBR.

Two diagonal transfer ramps are used to transport fuel assemblies between the reactor tank and the fuel storage tank. The ramp intersects above the reactor roof/shield deck in a transfer lock, where a turnstyle-type transfer machine simultaneously switches fuel assemblies between ramps. A carriage assembly and sodium pot, located on each ramp, are used to simultaneously transport fresh and spent fuel assemblies between the reactor and storage tanks. The transfer lock maintains the argon atmosphere above the reactor tank and fuel storage drum while fuel assemblies are being transported between these two regions.

Fuel assemblies which have been removed from the core are passed from the sodium transfer pot to a rotating storage drum. The decay heat of the assemblies is removed by two independent sodium systems connected to sodium-to-air heat exchangers. Transfer of the assemblies into the storage drum from the bottom of the loading ramp is accomplished by means of a rotating plug and a fuel transfer gripper.

The safeguards concerns involve the fuel and blanket assembly during the sequential period of: unloading the assemblies from the transport casks into the temporary storage pool; loading the assemblies into the reactor proper; unloading the spent fuel and blanket assemblies from the reactor into the temporary storage pool; and finally removal from the storage pool and transfer into the shipping cask. The total time interval from receiving fresh fuel assemblies to shipping of spent fuel and blanket assemblies 


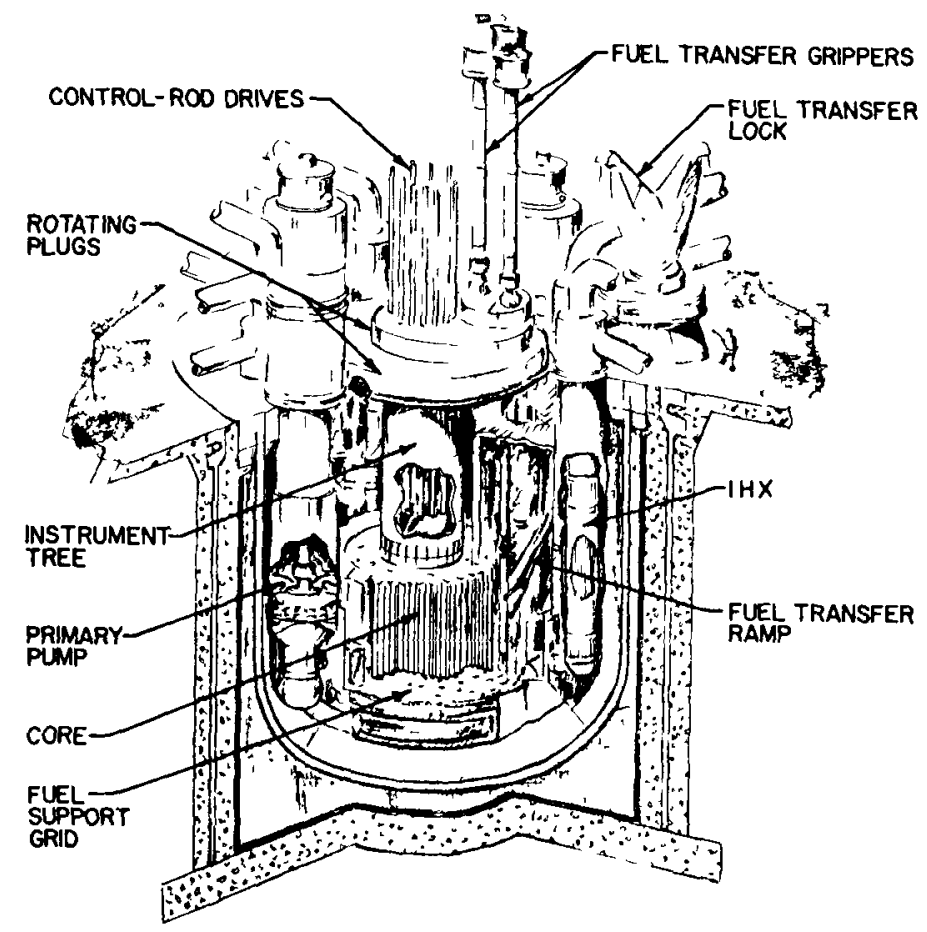

Fig. 2. Sketch of Reference FBR Primary System. ANL Neg. No. $116-79-148$.

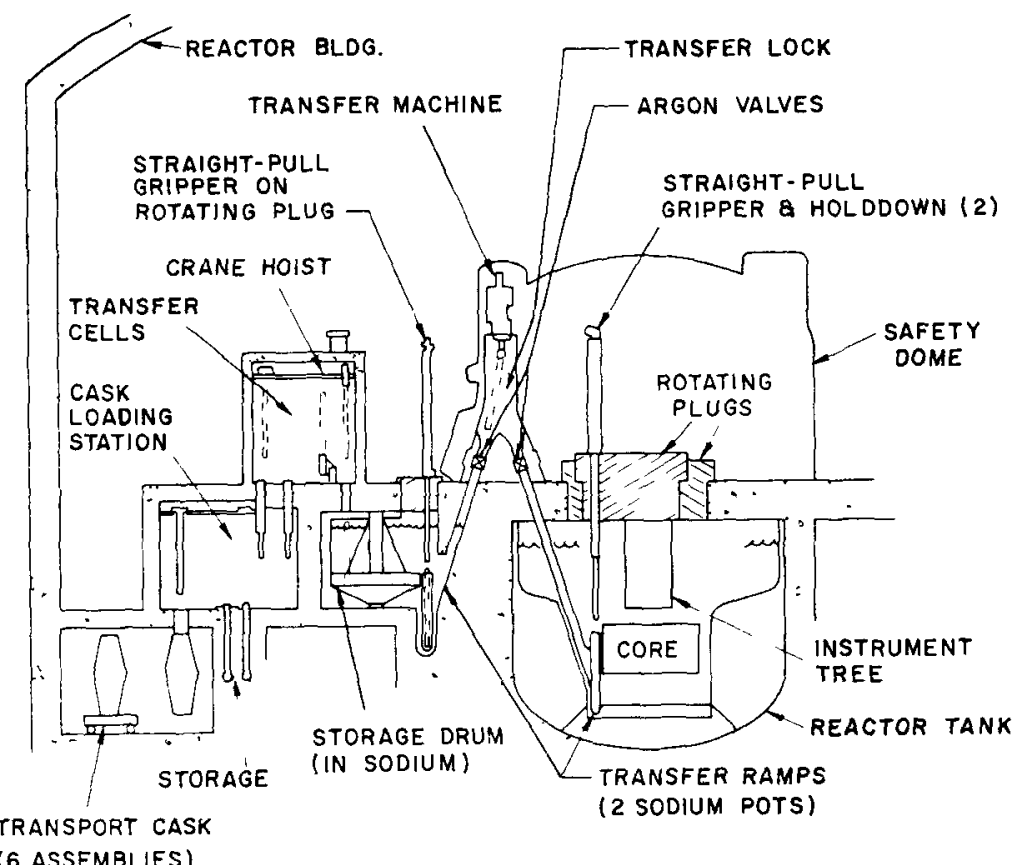

Fig. 3. Reference FBR Simplified Fuel Handling System Diagram.

ANL Neg. No. 116-79-149. 
TABLE V. Core and Fuel Specifications for Typical FBR Reactor (Super Phenix)

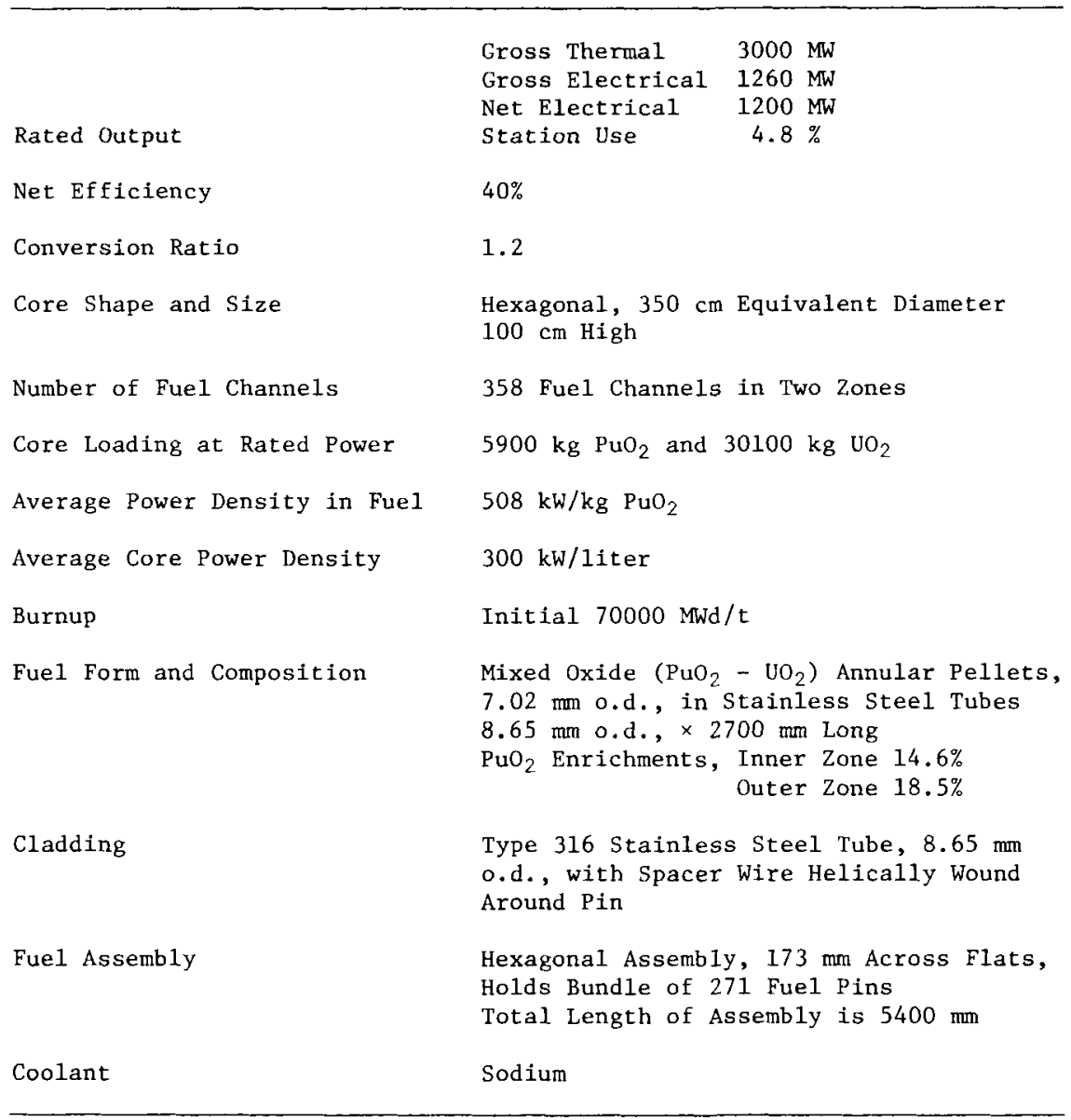

may be on the order of one year. The annual fuel mass flow in a typical FBR reactor is given in $\mathrm{Table} V I$.

One significant point which impacts the fuel safeguards is that the SNM is contained in discrete pieces. Therefore this material may be piece-counted, secured with appropriate seals, and at times visually observed. Unirradiated fuel may be assayed using techniques developed for fuel fabrication plants. Trradiated fuel is more difficult to assay. This topic is treated in Ref. 27.

The fuel is not readily observable when in the reactor. However, diversion from the reactor at times other than loading or reloading is not likely. Simultaneous monitoring of reactor power output, coolant flow profiles, and rod positions may be employed to ensure that covert diversion of fuel has not occurred. Inspectors and/or video cameras could be used to detect diversion attempts from the core. Inspectors could also observe loading and unloading procedures to ensure that diversion does not occur during that time. Physical protection systems and inspectors could be used to ensure that unauthorized removal from the plant does not occur. 
TABLE VI. Annual Fuel Mass Flow ${ }^{\mathrm{a}}$ in Typical FBR Reactor

\begin{tabular}{|c|c|c|c|c|c|}
\hline Fuel Cycle & \multicolumn{2}{|c|}{$\mathrm{Pu} / \mathrm{U}$} & ${ }^{2}{ }^{3}{ }^{3} \mathrm{U} / \mathrm{Th}$ & \multicolumn{2}{|c|}{$233 \mathrm{U} / \mathrm{U}$} \\
\hline Enrichment & $\begin{array}{l}16.3 \% \\
0.2 \%\end{array}$ & $\begin{array}{l}\mathrm{Pu} / \mathrm{HM} \\
35 \mathrm{U} / \mathrm{U}\end{array}$ & $14.7 \% 233 \mathrm{U} / \mathrm{HM}$ & $\begin{array}{l}11 \% \\
0.2 \%\end{array}$ & $\begin{array}{r}233 \mathrm{U} / \mathrm{HM} \\
235 \mathrm{U} / \mathrm{U}\end{array}$ \\
\hline Total HM, kg & $\begin{array}{l}\text { (core) } \\
15575\end{array}$ & $\begin{array}{c}\text { (b1anket) } \\
15100\end{array}$ & 15575 & $\begin{array}{l}\text { (core) } \\
21100\end{array}$ & $\begin{array}{c}\text { (b1anket) } \\
20500\end{array}$ \\
\hline \multicolumn{6}{|l|}{ Charge, kg } \\
\hline $\begin{array}{l}{ }^{235} \mathrm{U} \\
233 \mathrm{U} \\
\quad \mathrm{Pu}\end{array}$ & $\begin{array}{c}26.1 \\
- \\
2539\end{array}$ & $\begin{array}{c}30.2 \\
- \\
-\end{array}$ & $\begin{array}{l}- \\
2291\end{array}$ & $\begin{array}{r}42 \\
2324 \\
-\end{array}$ & - \\
\hline \multicolumn{6}{|l|}{ Discharge, kg } \\
\hline $\begin{array}{l}{ }^{235} \mathrm{U} \\
233 \mathrm{U} \\
\quad \mathrm{Pu}\end{array}$ & $\begin{array}{c}16.1 \\
- \\
2399\end{array}$ & $\begin{array}{c}29.3 \\
- \\
359\end{array}$ & $\begin{array}{l}- \\
2023 \\
-\end{array}$ & $\begin{array}{r}9 \\
1560 \\
510\end{array}$ & $\begin{array}{l}- \\
452 \\
-\end{array}$ \\
\hline
\end{tabular}

2. Transportation Safeguards: Before the early 1970s, SNM was transported within the U.S. using a variety of armed, courier-escorted transportation modes. Modes of transport included truck, rail, and water transport by barge and ship.

Strategically important shipments of SNM, i.e., $2 \mathrm{~kg}$ or more of Pu, or $5 \mathrm{~kg}$ of $235 \mathrm{U}$ contained in uranium enriched to $20 \%$ or greater, are now shipped domestically using transportation systems similar to those developed for the military weapons program. These transportation systems include escort vehicles, communications capabilities, specially designed transport vehicles, specially designed shipping casks, and armed escorts.

Potential accidents during transportation have been studied, 42 and shipping casks have been designed to withstand collisions and fire.43 The need for accident protection, radiation shielding, and decay heat removal results in casks as large as 90-100 tonnes 44 for shipping FBR spent fuel, and roughly half that for LWR spent fuel. The decay heat limits both the delay time between removal of fuel from the reactor and its shipment, and the amount of fuel that can be shipped in a single cask. 44

The size of the shipping cask (90-100 tonnes) in itself presents significant handling problems for potential diverters. Additionally, the cask design 44 itself provides some deterrent by requiring special equipment and/or a detailed knowledge of the system in order to gain access to the fissionable material.

Considerable experience in transportation of material protected by use denial systems has been gained in the last two years. One such system is the U.S. Department of Energy's Safe Secure Trailer (SST). 45 The SST is a $40 \times 8 \mathrm{ft}$ armoured trailer modified to function as a mobile vault, and includes digital communications with regional monitoring stations, electronically coded locks, and accident and fire protection. It is usually accompanied by one or two escort vehicles including several trained guards. ${ }^{46}$ 
Accountability for transported fuel involves a piece count of the sealed containers at the shipping and receiving points. Real-time monitors can probably be employed to detect tampering with the shipping containers. Appropriate assays can be performed to assure that the quantity of SNM received is the same as the quantity shipped. Assay equipment with data links to an automatic materials accountancy system could be used to expedite confirmatory determinations.

Estimated quantities of fissile material shipped each year are presented in Table VII.

TABLE VII. Estimated Quant1ties of Fissile Material Transported Within the U.S. In Metric Tonnes per GWe-year

\begin{tabular}{|c|c|c|c|c|c|c|}
\hline \multirow{3}{*}{$\begin{array}{l}\text { Transport } \\
\text { Step }\end{array}$} & \multicolumn{6}{|c|}{ Fissionable Material Transported, Te/GWe-Year } \\
\hline & \multicolumn{2}{|c|}{ PWR, $1000 \mathrm{MWe}^{\mathrm{a}}$} & \multicolumn{4}{|c|}{$\mathrm{FBR}^{\mathrm{b}}$} \\
\hline & Once Through & $\mathrm{Pu} / \mathrm{U}$ Recycle & Blanket & & & Core \\
\hline $\begin{array}{l}\text { Fuel Material } \\
\text { to Fab. Plant }\end{array}$ & $\begin{array}{l}0.85^{235} \mathrm{U} \\
(3 \% \text { enr. })\end{array}$ & $\begin{array}{l}0.67^{235} \mathrm{U} \\
(3 \% \text { en } \mathrm{r} \cdot)\end{array}$ & $\begin{array}{l}0.04 \\
235 \mathrm{U}\end{array}$ & & $\begin{array}{l}0.03 \\
1.59\end{array}$ & ${ }_{239}^{235} \mathrm{U}_{241} \mathrm{Pu}$ \\
\hline Fuel to Reactor & $\begin{array}{l}0.84^{235} \mathrm{U} \\
(3 \% \text { enr. })\end{array}$ & $\begin{array}{l}0.66^{235} \mathrm{U} \\
0.27 \mathrm{U} / \mathrm{Pu}\end{array}$ & $\begin{array}{l}0.05 \\
235 \mathrm{U}\end{array}$ & & $\begin{array}{l}0.03 \\
1.59\end{array}$ & $\begin{array}{l}235_{\mathrm{U}} \\
239^{+41} \mathrm{Pu}\end{array}$ \\
\hline $\begin{array}{l}\text { Fue } \frac{1}{235} \text { from Reacto } \\
239+241 \mathrm{Pu}\end{array}$ & $\begin{array}{l}0.22 \\
0.17\end{array}$ & $\begin{array}{l}0.17 \\
0.27\end{array}$ & & $\begin{array}{l}0.08 \\
1.60\end{array}$ & & \\
\hline Actinides ${ }^{c}$ & 0.005 & 0.32 & & 0.025 & & \\
\hline $\begin{array}{l}\text { Recycled Fuel } \\
235 \mathrm{U} \\
239^{+} 241 \mathrm{Pu}\end{array}$ & $\begin{array}{l}- \\
-\end{array}$ & $\begin{array}{l}0.15 \\
0.27\end{array}$ & & $\begin{array}{l}0.08 \mathrm{~d} \\
1.59\end{array}$ & & \\
\hline
\end{tabular}

assumes $30.4 \mathrm{GWd} / \mathrm{Te}, 3$-year dwe 11 time at $80 \%$ load factor.

${ }^{b}$ Assumes average burnup of $7 \%$ over 450 days in the core with a load factor of $80 \%$.

CActinide amounts include 1sotopes of $\mathrm{Am}$ and $\mathrm{Cm}$ oniy.

$\mathrm{d}_{\text {Does not include }} 0.1 \mathrm{Te}{ }^{239+241} \mathrm{Pu}$ product for use in other reactors.

3. Reprocessing Plant Safeguards: Plutonium is found in a variety of physical and chemical forms, in various degrees of chemical purity, and with various radiation levels in an FBR reprocessing facility. The diversion resistance is related directly to these chemical and physical characteristics. For purposes of this assessment of in-line flow and the radiation environment, it is assumed that the Purex process is used, that the plant has a capacity of $5 \mathrm{MTHM} / \mathrm{day}$, and that core and blanket assemblies are processed together. Process descriptions are meant to be representative rather than process specific.

Front-end steps of the fuel reprocessing cycle involve handling spent fuel assemblies. In this form, plutonium is highly contaminated with fission products; radiation levels are of the order of $15,000 \mathrm{R} / \mathrm{hr} *$ and a complete reprocessing facility is required to extract the fissile material.

*A11 radiation levels are unshielded dose rates at one meter away from the source and for each $\mathrm{kg}$ of plutonium. 
During the solvent extraction step, plutonium exists to various degrees of purity in a nitrate solution. The radiation levels from this feed solution (to the extraction cycle) would be about $10,000 \mathrm{R} / \mathrm{hr}$. The flow in the extraction cycle would be approximately $200 \mathrm{~kg} / \mathrm{hr}$ of heavy metal, of which about $8 \%$ is plutonium.

After the solvent extraction step, in which the heavy metals are separated from most of the fission products, the uranium and plutonium stream is passed into the plutonium partitioning cycle. The radiation level associated with the resulting aqueous plutonium stream is about $8 \mathrm{R} / \mathrm{hr}$, and the heavy metal flow rate is about $17 \mathrm{~kg} / \mathrm{hr}$, of which about $92 \%$ is plutonium. The radiation level associated with the uranium-bearing organic stream is about $600 \mathrm{R} / \mathrm{hr}$ with a material flow of $182 \mathrm{~kg} / \mathrm{hr}$ of heavy metal containing $<0.05 \%$ plutonium. The waste stream contains most of the fission products and a low fissile material content. The radiation level associated with the output from the plutonium purification cycle is only about $0.05 \mathrm{R} / \mathrm{hr}$. This stream contains about $10 \mathrm{~g} / \ell$ plutonium and flows at a rate of about $16 \mathrm{~kg} / \mathrm{hr}$. The radiation levels associated with the output of a subsequent plutonium purification and concentration cycle is only about $0.0005 \mathrm{R} / \mathrm{hr}$. The plutonium concentration in this stream is about $300 \mathrm{~g} / \ell$, and the flow rate is about $16 \mathrm{~kg} / \mathrm{hr}$.

Fuel materials may be found in processing columns, in piping, and in holdup tanks during various stages of the processing cycle. Except for head-end receiving and mechanical operations, and tail-end storage and shipping operations, the reference processing plant utilizes a continuous flow process. 47 Fuel is usually assayed in the flowing streams; however, in some stages the flow may be slow enough to use near-static measurement techniques. The reference safeguards system, engineered to meet these varying requirements, is described generically in Section IV.B.3.

NDA techniques are utilized primarily in the flowing process lines and depend on process instrument measurements of liquid levels and organicaqueous phase interface levels to determine plutonium quantities in the columns and tanks.47 The primary NDA techniques used are alpha monitoring, gamma ray analysis, and absorption edge densitometry. 22 These techniques measure plutonium quantities in the process line. By coupling standard flowmeter data and frequent non-destructive assay calibrations using analytical chemistry techniques, fuel mass flow is determined.

NDA measurements begin at the outlet of the first partitioning stage where separated $\mathrm{Pu}$ appears for the first time. The SNM upstream of this point is mixed with other materials, which are sufficiently radioactive to preclude use of presently available NDA techniques. These conditions also make the material unattractive for diversion.

NDA precision, and consequently the detectability of losses, improves as fission product contamination in the process stream decreases. The primary system limitation, as regards the ability to detect diversion of SNM, is a consequence of the detection difficulties caused by medium level gamma activity associated with the material in the holdup tanks and contactors near the front end of the process stream. 
The reference system has been studied for effectiveness by computer modeling of (1) the process stream; (2) the NDA instrument signals and the statistical accounting; and (3) the decisions logic. The results, i.e., the sensitivity for diversion detection, are given in Table $I$.

Physical protection is provided from elements of the previously described generic physical protection system. The interior plant areas where SNM is available, and material entrance and exit points, are monitored and controlled very carefully. Monitoring at exits and entrances is performed to assure personnel identification and for SNM control. SNM monitors are set to alarm at sub-gram to few-gram levels of $\mathrm{Pu}, 233 \mathrm{U}$ or $235 \mathrm{U}$. Monitor sensitivity is given in Table III.

4. Fuel Fabrication Plant Safeguards: Fuel fabrication involves the handling of large quantities of fissile material. This subject is treated further in Part 5 and Ref. 10. The material is accessible to varying degrees during the process, and therefore potentially vulnerable to diversion. For illustrative purposes the plant capacity is assumed to be 100 metric tons of heavy metal per year (i.e., about $400 \mathrm{~kg}$ per day). This represents a daily throughput of about $64 \mathrm{~kg}$ of plutonium metal equivalent. Unlike the reprocessing plant previously described, where the fissile material purity and chemical form is changing substantially during the process, the bulk of the fuel material in the referenced fabrication plant arrives and remains in the oxide form throughout processing. The separate stream of $\mathrm{PuO}_{2}$ feed material, both in storage and in the process line is, in a safeguard sense, of greatest concern.

Beginning with the powder blending step, separated $\mathrm{PuO}_{2}$ is not handled again in the fabrication process. Although the referenced fuel fabrication technique wherein $\mathrm{PuO}_{2}$ and $\mathrm{UO}_{2}$ is blended mechanically, compressed into pellets, and sintered to the required density, is not complex, it has a large number of process steps. As a consequence, the safeguards system must have a correspondingly large number of instruments monitoring the process. Each unit process contains weighing stations, gamma analysis NDA detectors, neutron counting NDA detectors, and visual identification accounting positions. There are also automatic pellet counters and points for extraction of samples for laboratory chemical analysis and isotope NDA. The single fabrication line in the reference plant contains 42 weighing stations, 33 gamma analysis NDA monitors, 20 neutron counting NDA monitors, 6 sample points for laboratory chemical and NDA isotopic analysis, 28 visual identification accounting steps, and 6 automatic pellet counters. 10 Information from these detectors and monitoring stations is transmitted to the materials and management accounting system for subsequent processing and diversion analysis.

The structure of a generic safeguards data analysis system is given in Section IV.B. A design study was performed for a mixed oxide fuel fabrication plant using $4 \% \mathrm{PuO}_{2}$ in total mixed oxide. 20 Although it is recognized that plant structure may change for fabricating $12 \% \mathrm{PuO}_{2}$ (average) mixed oxide, it is assumed that this change will not cause a significant change to fuel assay techniques and associated NDA instruments.

The physical protection subsystem would utilize stringent entrance and exit monitoring and control of people, material, and equipment to minimize 
covert diversion. It emphasizes hardened facility designs and delay systems to impede overt diversion.

A computer simulation study has been done for the in-place safeguard system. The results of this study are given in Table II. Results are generally in keeping with guidelines established by NRC for facilities of this type.

5. Fuel Storage Safeguards: Stored material is generally kept in identifiable containers. These containers can be assayed and item piece counts established. The items can then be placed in physically secure, monitored, limited access areas. Locks, seals, and closed circuit television $c$ an be used to ensure that tampering has not occurred. Other electronic detection systems may be employed if warranted in special cases.

Electronic self-monitoring seals have been developed 48,49 for use in SNM storage systems. A reusable, tamper-indicating, mechanical seal is also under development. bu These devices, utilized in conjunction with acceptable security areas and inspection programs, are useful tools for minimizing the probability of SNM diversion.

Application of a computerized control concept to the fuel storage areas would not be difficult. The adequacy of automated PPS monitoring with human control has been demonstrated (see Tables I and II).

6. Fuel Cycle Waste Safeguards: The only waste stream in the FBR fuel cycle which contains more than trace amounts of fissile material is the high level waste stream from the reprocessing plant. Estimates for recovery of fissionable isotopes from spent reactor fuel by current technology range from 93 to $99.5 \%$ of the $\mathrm{U}$ and $\mathrm{Pu}$, although anything below $99 \%$ would be unacceptable. Feasible improvements in process efficiency may raise the recovery to 99.95\%. The waste stream in the reprocessing plant presents no problems which are unique, and would be safeguarded by the same methods used for other streams.

Once in interim liquid-waste storage tanks, the reference process for ultimate disposal is that high level wastes would be solidified and prepared for disposal in deep geological deposits.

The production of actinides in an FBR would be substantially higher than for a once-through LWR cycle because of recycling and the presence of the higher $\mathrm{Pu}$ isotopes in the feed material. A proliferation concern raised by the presence of higher actinides in wastes is due to their decay scheme, which includes fissile isotopes. ${ }^{243} \mathrm{Cm}$ and ${ }^{243} \mathrm{Am}$ decay to ${ }^{239} \mathrm{Pu},{ }^{245} \mathrm{Cm}$ decays to ${ }^{24 \mathrm{l}} \mathrm{Pu}$, and ${ }^{24 \mathrm{l}} \mathrm{Am}$ decays to ${ }^{233} \mathrm{U}$. The important point is the very long half-lives associated with the production of fissile isotopes. In two of the cases, the half-life of the fissionable isotope is shorter than that of the actinide parent. As a result, the amounts of ${ }^{24}{ }^{1} \mathrm{Pu}$ and ${ }^{23}{ }^{3} \mathrm{U}$ present in secular equilibrium would be reduced substantially from the parent concentrations. At present the actinides are a second order concern. 
D. Safeguarding Alternative Fuel Systems

The diversion concerns which have given rise to the INFCE study and the emphasis on safeguards have also fostered proposals for a range of technical and institutional changes in the traditionally perceived $P u / U$ FBR fuel cycle. These proposals include the use of denatured fuel cycles based on $233 \mathrm{U}$ and thorium, the protection of fissile material by chemical mixing and/or spiking with radioactivity, and the design of tamperproof fuel cycle facilities. The impacts that these proposals (if they proved to be technically feasible) would have on resource utilization and fuel cycle operations are discussed in companion reports of this series.

Although little study has yet been made of the impacts such proposals would have on materials safeguards and accountability, some things are known. In this section we discuss what is known of the safeguards impact of alternative fuel systems.

1. Denatured Uranium/Thorium: The recent interest in $233 \mathrm{U} / 238 \mathrm{U} / \mathrm{Th}$ as an alternative fuel has been based on the difficulty of separating $233 \mathrm{U}$ from $238 \mathrm{U}$, and on the gamma-ray radiation associated with the $233 \mathrm{U}$ impurity.

In Thorex or three-way separation processes, thorium and $233 \mathrm{U} / 238 \mathrm{U}$ would be relatively clean following partitioning. Although $232 \mathrm{U}$ daughters would grow back, reaching one half of the equilibrium value in 1.9 years, their rate of growth is sufficiently slow to have only a minor impact on process line monitoring. The ${ }^{228} \mathrm{Th}$ daughter of $232 \mathrm{U}$ would be carried over with thorium in partitioning, and would reach virtual equilibrium with its daughters within three weeks; one half of its equilibrium value is attained in 3.66 days.

$232 \mathrm{U}$ concentrations on the order of 180-250 ppm exist in LWR fuel. To put this in perspective, the dose rate from a six-month-old sample of denatured uranium containing $500 \mathrm{~g}$ of $233 \mathrm{U}$ with $1250 \mathrm{ppm} 232 \mathrm{U}$ is $\sim 20 \mathrm{R} / \mathrm{hr}$ at a distance of one foot. 51

The spent fuel from a denatured $233 \mathrm{U} / \mathrm{Th}$ cycle contains $\sim 1 / 3$ to $1 / 4$ the $\mathrm{Pu}$ content of the fuel in reference $\mathrm{Pu} / \mathrm{U}$ cycle fuel. This $\mathrm{Pu}$, as is true of the $\mathrm{Pu}$ in the reference $\mathrm{Pu} / \mathrm{U}$ cycle, can be separated from the spent fuel by chemical means. The total fissile content in the spent fuel is not significantly different from that in a fresh assembly or from the fuel content in the $\mathrm{Pu} / \mathrm{U}$ assembly.

The fresh fuel for a denatured $U / T h$ cycle will contain $~ 11 \% 233 \mathrm{U} / \mathrm{U}$ and the spent fuel $\sim 8 \% 233 \mathrm{U} / \mathrm{U}$. To be useful as bomb material, the $233 \mathrm{U}$ must be isotopically separated from the $238 \mathrm{U}$. This separation would be relatively less difficult than separating $235 \mathrm{U}$ from $238 \mathrm{U}$ because of the larger spread in isotopic mass numbers and the relatively high initial concentration of $233 \mathrm{U}$.

The presence of $232 \mathrm{U}$ with its radioactive daughter products, particularly the $208 \mathrm{~T} 1$ which emits hard gamma rays, makes $233 \mathrm{U}$-based fuel materials relatively easy to detect by passive radiation monitors, even through substantial shielding. For example, ten days after purification, a one-gram sample of $233 \mathrm{U}$ containing $100 \mathrm{ppm} 232 \mathrm{U}$ should be detectable 
through $\sim 2$ in. of lead shielding by a standard type of doorway monitor equipped with $\mathrm{NaI}$ detectors. ${ }^{2}$ Likewise the surveillance and containment of denatured ${ }^{23} \mathrm{U}$ fuels would be enhanced during all process steps and during storage relative to ${ }^{235} \mathrm{U}$ or plutonium based fuel with the fission products removed.

One of the negative aspects associated with high gamma radiation
from ${ }^{232} \mathrm{U}$ and its daughter products is that the fuel probably must be fabricated by remote means. The relatively high background of high energy gamma rays interferes with the use of existing passive gamma-ray NDA measurement techniques. The extent of this problem has yet to be determined. The use of active neutron interrogation and calorimetry have been suggested, 33 but require additional work. In principle, advantage might be taken of the penetrating ${ }^{232} \mathrm{U}$ daughter radiation to assay the ${ }^{23} \mathrm{U}$, but the relationship between these gamma rays and the amount of ${ }^{23} \mathrm{U}$ depends both on the ratio of ${ }^{232} \mathrm{U}$ to ${ }^{23} \mathrm{U}$, and the processing history. The use of organic scintillators for fast-neutron detection would probably also be ruled out by the intense gamma-ray background.

The effect of the ${ }^{232} \mathrm{U}$ radioactivity on chemical assay measurements should be negligible, although taking the sample would be more complicated than for 235 .

2. High Radiation Level Fuel (HRLF): Alternate fuel technologies are being considered from the viewpoint of reducing the potential for theft by altering the SNM. Processing, fabricating or transporting fuel that emits lethal or disabling levels of gamma radiation may tend to inhibit its theft or fabrication into a nuclear explosive, or to enhance its detection during or after its theft. In the present context, the primary interest in HRLF is as a deterrent to theft or seizure of nuclear material because of its intense and dangerous radioactivity. This subject is treated further in Part 5 of this report.

Methods that have been proposed for increasing the activity of the fuel to accomplish these purposes are: (1) leaving certain fission products from spent reactor fuel with the recovered plutonium; (2) adding highly radioactive nuclides (e.g., ${ }^{60} \mathrm{Co}$ ) to the fuel at a step in its fabrication; and (3) pre-irradiating the fresh fuel before its shipment to a reactor. Each of these has certain advantages and disadvantages. The first method tends to protect the fissile species through all the fuel processing steps from spentfuel recovery to recycle into reactors, but, since it depends on the presence of certain relatively short-lived fission products, this technique may be less effective for back-logged fuel. In the second method the fissile material is vulnerable until the spikant is added. The third method, preirradiation, is probably the cheapest to use, since the fuel is not irradiated until after its fabrication. However, this technique protects only the transportation portions of the fuel cycle.

The first two methods have been the subject of several recent studies. The most comprehensive and detailed of these were the joint BNLIR\&T study, ${ }^{51}$ and the EPRI study. ${ }^{53}$ More recently the subject has been treated in a study of the Barnwell plant ${ }^{52}$ and in a reprocessing proposal by Levenson and Zebroski. ${ }^{4}$ Most of the work (Ref. 54 is an exception) has 
concentrated on an analysis of HRLF plutonium in water reactors (LWRs), but many of the results, conclusions, and issues apply to FBR fuel as well.

Spiking of plutonium to lethal levels (dose rate from $1 \mathrm{~kg}$ of spiked $\mathrm{Pu}$ at one meter $\widetilde{S} 1000 \mathrm{R} / \mathrm{hr}$ ) could be a considerable deterrent to theft or seizure. Also, removal of HRLF fuel would be easier to detect.

One of the adverse effects of spiking may be on the measurement of nuclear materials for accountability. At the levels required for deterrence, presently used NDA methods are not effective. The methods now relied on for the verification of flows and inventories of nuclear material would have to be replaced. Potentially applicable techniques include active neutron assay and selected chemistry procedures.

The effect of HRLF on analytical (chemical) measurements is less serious since such measurements are performed now on the hot dissolver solutions of reprocessing plants. However, the taking of samples in all other situations would be more difficult and time consuming. Faster techniques would have to be developed to be useful with a DYMAC-type system.

3. Co-processing: Co-processing is the treatment of uranium and plutonium at a spent-fuel reprocessing plant in such a way that the product consists of plutonium intimately mixed with uranium in some desired proportion. For FBR fuel the mixture could contain $8-18 \%$ plutonium, while for recycle LWR fuel the plutonium concentration would be in the neighborhood of $3-5 \%$ (see Ref. 55), depending on the requirements of the fuel fabricator.

The mixing of the two components could occur either by not completely partitioning them in the reprocessing steps, or by producing separated $U$ and $\mathrm{Pu}$ and then mechanically mixing them. The former is the preferred route for safeguards, since at no time does pure, concentrated plutonium appear in this scheme.

The impact on the safeguards structure of the plant lies in the increased amount of material that must be diverted out of the system to make a bomb. System defenses are enhanced if diversions on the order of $100-230 \mathrm{~kg}$ of $30 \%$ material or $300-700 \mathrm{~kg}$ of $1 \%$ material must be made for a critical mass.

Co-processing the uranium and plutonium would inconvenience a nation attempting to divert and refine the SNM for weapon purposes, and would present a technical obstacle in the path of acquiring weapon-grade material for a subnational group. It would require the theft of larger amounts of material to acquire a critical mass of plutonium, thus increasing the probability of detection.

Mixed oxide fuel of low fission product contamination levels will have little effect on safeguards system sensitivity. The fabrication plant system will remain virtually unchanged. Mixed oxide input material at $8-18 \%$ $\mathrm{Pu}$ could be assayed using the same passive gamma spectrometers that were used for $\mathrm{PuO}_{2}$.

The reprocessing plant system may require minor equipment modifications, but these will primarily involve process instruments in the previous 
$\mathrm{Pu}$ lines. Here alpha monitors may require increased sensitivity, or they may require replacement by passive gamma spectrometers.

4. Civex (Low Decontamination and Co-processing Fuel Cycle): The Civex (see Ref. 54) system is designed to provide barriers to diversion and theft of SNM and to maintain the fissile material in a relatively unattractive form, especially to subnational terrorist groups. The criteria deemed essential to the process are:

a. There shall be no pure Pu in storage.

b. There shall be no pure Pu anywhere in the process.

c. No relatively simple chemistry or plumbing changes should be able to accomplish production of pure plutonium.

d. Entry into very high radiation fields or decontamination would be necessary to achieve modifications which would enable production of pure Pu.

The Civex process has several major differences relative to Purex.

a. Once fuel is dissolved, the extraction is modified so that it contains no scrub system. Thus the material which passes from the extractor stage to the partitioning stage contains a few percent of the fission products,

b. In the partition stage, in which the fuel is partitioned into uranium to go to blanket fabricating and $\mathrm{Pu} / \mathrm{U} \operatorname{mix}$ to go to fuel fabricating, the excess $U$ is removed by fluoride volatility producing $\mathrm{UF}_{6}$. This process is not capable of separating $\mathrm{Pu}$ from fission products, and the plant must be modified to significantly vary the $\mathrm{Pu} / \mathrm{U}(\sim 20 \% \mathrm{Pu})$ ratio produced.

c. The fabrication stream is to be remote and the scrap is to be recycled into the dissolver.

d. The facility design precludes changes to the plumbing or process system without a major effort. Since the facility is designed to prevent diversion, the material is safeguarded automatically.

e. Finally, pumps, flow meters, and auxiliary equipment are designed to operate near the extremes of their range of operation so that the operator has very little flexibility in readjusting the operation.

This design results in two major effects on the diversion potential:

(1) Since pure $\mathrm{Pu}$ is not readily available, the short lead time potential for weapons is removed.

(2) The only potential for facility misuse requires extensive technical knowledge and facility modification, and hence is purported to require much longer times (months) to accomplish.

The safeguards system would require modification from that described previously. The carryover of a few percent of the fission products 
would rule out most on-line analysis techniques. Presently-used alpha monitors could probably be used, and $\mathrm{L}_{\mathrm{III}}$ absorption edge densitometry may operate on selected segments of the process.

\section{SUMMARY}

Concern over diversion and the subsequent potential misuse of SNM has increased in recent years. This, in part, is due to the development of the FBR and the potential for generating large quantities of pure Pu. In response to this concern, research and development efforts have increased significantly to design quality safeguards systems, SNM accountability systems, suitable NDA instrumentation, and security aids.

Among the recently devised safeguards systems are those designed to safeguard isotopic enrichment facilities, fuel fabrication facilities, and fuel reprocessing plants. DYMAC, DYMCAS and INMACS are examples of near real-time SNM-balance assessment systems that have been developed in recent years. Instrumentation development has ranged from improving passive gamma radiation spectrometry, e.g., utilizing Ge-Li crystals, to utilizing active, neutron coincidence measuring systems to detect and quantify SNM samples. Security aids such as microwave detection systems, electric-field presence monitors, and closed-circuit television monitors have been developed and are employed as perimeter fence monitors. Doorway radiation, metal and explosive monitors have been developed, and continued work is directed at improving these. Motion monitors and closed-circuit television systems are now employed widely to monitor access to SNM storage areas. Tamper-proof electronic seals have been developed, and reusable, tamper-proof mechanical seals are under development for sealing doors, fuel containers, etc. Special fuel shipping casks and transport vehicles have been developed to protect SNM shipments from the consequences of serious accidents and from armed theft.

The history of application of high-technology to safeguards of fissile material is short. The pace of development has increased rapidly in the last three to five years. With continued research and thoughtful application, secure FBR facilities could predate full FBR deployment.

\section{ACKNOWLEDGMENT}

The authors wish to express their appreciation to the following individuals for contributions and discussions relevant to this report.

P. Abramson, R.G. Bucher, L.G. LeSage, J.A. Morman, P.J. Persiani, D.C. Wade, and B.S. Yarlagadda. 


\section{REFERENCES}

1. Intemational Treaties Relating to Nuclear Control and Disarmament, Legal Series No. 9, International Atomic Energy Agency, Vienna, pp. 35-40 (1975).

2. The Agency's Safeguards System, International Atomic Energy Agency, INFCIRC/66/Rev. 2 (September 1968).

3. International Treaties, op.cit., pp. 41-67 (1975).

4. T.E. Shea, IEEE Transactions on Nuclear Science, 22(1), 752 (February 1975).

5. T.E. Shea, RETIMAC, A Real Time Material Control Concept for Strategic Special Nuclear Material, NRC Working Paper B (January 1975).

6. H.A. Dayem and D.D. Cobb, Coordinated Safeguards for Materials Management in a Uranium-Plutonium Nitrate-to-Oxide Coconversion Facility, Los Alamos Scientific Laboratory, LA-7521 (1979).

7. Nucleonics Week, 15(42), 8 (October 1974).

8. E.F. Gambi11, New Emphasis on Material Accountability's Role in Special Nuclear Materials Security, Inst. Nucl. Mt ls. Mgmt., New Orleans, CONF-750608 (June 1975)

9. R.N. Pau1, G. Yan, and A.M. Ross, INMACS: A Computer Assisted On-Line Fissile Material Inventory and Criticality Control System, Nucl. Mtl. Mgmt., 7, 453-463 (1978.)

10. G.R. Keepin, Technical Implementation of Safeguards in the Nuclear Fuel Cycle, Trans. Am. Nucl. Soc., 30, 136 (1978).

11. H.A. Dayem, D.D. Cobb, R.J. Dietz, E.A. Hakkila, J.P. Shipley, and D.B. Smith, Dynamic Materials Accounting in the Back End of the LWR Fuel Cycle, Los Alamos Scientific Laboratory, LA-UR-78-814 (1978).

12. N.H. Hurt, Enrichment Plant Management Safeguards, Inst. Nuc1. Mt1s. Mgmt., Cincinnati, Ohio, CONF-780606-15, (June 1978).

13. T. Shea and D. Tolchenkov, Role of Containment and Surveilzance in IAEA Safeguards, International Atomic Energy Agency, IAEA-SM-231/110 (1978). (Also see Report on Advisory Group Meeting on Development of Containment/Surveillance Measures and Surveillance Instrumentation and Techniques for IAEA Safeguards, AG-190, IAEA Vienna, June 26-30, 1978).

14. L.D. Chapman et al, Development of an Engineered Safeguards System Concept for a Mixed Oxide Fuel Fabrication Facility, Sandia Laboratories, SAND 76-0180 (August 1976). 
15. Entry-Control Systems Handbooks, Sandia Laboratories, SAND 77-1033, Chapter 1 (September 1977).

16. Ibid., Chapter 4 .

17. USAEC Regulatory Guide, 5.27 (June 1973).

18. T.E. Sampson and P.E. Fehlau, Sodium Iodide and Plastic Scintillator Doomay Monitor Response to Shielded Reactor Grade Plutonium, Los Alamos Scientific Laboratory, LA-6566-M5 (November 1976).

19. USAEC Regulatory Guide, 5.7 (June 1973).

20. J.P. Shipley, D.D. Cobb, R.J. Dietz, M.L. Evans, E.P. Schelonka, D.B. Smith, and R.B. Walton, Coordinated Safeguards for Materials Management in a Mixed-Oxide Fuel Facility, Los Alamos Scientific Laboratory, LA-6536 (February 1977).

21. J.E. Lovett, Concept of Real-Time and Semi-Real-Time Material Control, Nuc1. Mat1. Mgmt,, IV(III), pp. 24-33 (1975).

22. R.H. Augustson, Development of In-Plant Real Time Materials Control: The DYMAC Program, Nuc1. Mat1. Mgmt., V(III), pp. 302-316 (1976).

23. G.R. Keepin and W.J. Maraman, Nondestructive Assay Technology and InPlant Dynamic Materials Control-DYMAC, Safeguarding Nuclear Materials, Proc. Symp., Vienna, 1975, IAEA SN-201/32, pp. 305-320 (1976).

24. E.A. Hakkila et al, Coordinated Safeguards of Materials Management in a Fuel Reprocessing Plant, Los Alamos Scientific Laboratory, LA-6881, Vo1. I (September 1977).

25. E.A. Hakkila et al, Coordinated Safeguards for Materials Management in a Fuel Processing Plant, Los Alamos Scientific Laboratory, LA-6881, Vol. II (September 1977).

26. J.L. Jaech, Statistical Methods in Nuclear Material Control, Technical Information Center, Oak Ridge, Tennessee, TID-26298 (1973).

27. J. Kleijnen, Statistical Techniques in Simulation, Marcel Dekker, Inc., (1974).

28. T. Naylor, J.L. Balintfy, D.S. Burdick, and Kong Chu, Computer SimuZation Techniques, Wiley (1966).

29. W.L. Rott, An Introduction to the Theory of the Detection of Signals in Noise, Proc. IEEE (Special Issue on Detection Theory and Applications) 58(5), pp. 610-623 (May 1970).

30. A.P. Sage and J.L. Melsa, Estimation Theory with Applications to Communications and Control, McGraw-Hill (1971).

31. A. Wa1d, Sequential Analysis, John Wiley and Sons, Inc. (1947). 
32. R. Deutsch, Estimation Theory, Prentice-Hall (1965).

33. R.A. Howard, Decision Analysis: Perspectives on Inference, Decision, and Experimentation, Proc. IEEE (Special Issue on Detection Theory and Applications) 58(5), pp. 632-643 (May 1970).

34. D.D. Cobb and D.B. Smith, Modeling and Simulation in the Design and Evaluation of Conceptual Safeguards Systems, Los Alamos Scientific Laboratory, LA-UR-77-1366 (1977).

35. E.S. Page, Cumilative Sum Charts, Technometrics 3(1), 1-9 (February 1961).

36. W.D. Evans, When and How to Use Cu-Sum Charts, Technometrics, 5(1), 1-22 (February 1963).

37. J.M. Lucas, A Modified V-Mask Control System, Technometrics, 15(4), 833-847 (November 1973).

38. D.H. Pike, G.W. Morrison, and C.W. Holland, Linear Filtering Applied to Safeguards of Nuclear Material, Trans. Am. Nuc1. Soc., 22, 143-144 (1975).

39. D.H. Pike, G.W. Morrison, and C.W. Holland, A Comparison of Several Kalman Filter Models for Establishing MUF, Trans. Am. Nucl. Soc., 23, 267-268 (1976).

40. D.H. Pike and G.W. Morrison, A New Approach to Safeguards Accounting, Oak Ridge National Laboratory, ORNL/CSD/TM-25 (March 1977).

41. Hsue et al, Nondestructive Assay Methods for Irradiated Fuels, Los Alamos Scientific Laboratory, LASL 6923 (January 1978).

42. S.H. Sutherland et a1, Waste Transportation Systems, Trans Am. Nucl. Soc., 28, 347-348 (June 1978).

43. H.R. Yoshimura et al, High-Speed Impact and Fire Test of a Spent Fuel Rail Cask System, Trans. Am. Nucl. Soc., 28, 348-349 (June 1978).

44. R.B. Pope et al, Conceptual Designs for LMFBR Spent Fuel Shipping Casks, Sandia Laboratories, SAND 77-1483 (March 1978).

45. D.P. Dickson, The Department of Energy (DOE) System for the Transportation of Strategic Quantities of Special Nuclear Materials, Proc. 5th Int. Symp. on Pkg. and Trans. of Rad. Mtls., Las Vegas, NV, May 7, 1978, to be published.

46. J.R. Gallagher et al, The Evaluation of Road Transit Physical Protection Systems, Proc. 5th Int. Symp. on Pkg. and Trans. of Rad. Mt Is., Las Vegas, NV, May 7, 1978, to be published. 
47. Barmell Nuclear Fuels Plant Separations Facility--Final Safety Analysis Report, Docket 50-332, Allied-General Nuclear Services (October 10, 1973).

48. G. Stein, K. Kennepoh1, and H. Buker, Application of Electronic Sealing Systems for Nuclear Material Monitoring, Inst. of Nuc1. Mt ls. Mgmt., $7,400-409$ (1978).

49. J.W. Campbell, Electronic Self-Monitoring Seal, Inst. of Nuc1. Mt1s. Mgmt., CONF-780606-6 (also see SAND 78-1242), Cincinnati, Oh io (1978).

50. M.J. Ryan, Argonne National Laboratory, personal communication.

51. E.V. Weinstock, The Spiking of Special Nuclear Materials as a Safeguards Measure, Vols. I and II, Brookhaven National Laboratory Draft Report (1975).

52. Barmwell Nuclear Fuels Plant Applicabizity Study, U.S. Department of Energy, DOE/ET-0040/3 (March 1978).

53. Denatured Plutonium--A Study of Deterrent Action, Electric Power Research Institute, EPRI-310 (July 1975).

54. M. Levenson and E. Zebroski, A Fast Breeder System Concept, Proc. 5th Energy Tech. Conf., Washington, D.C., pp. 230-255 (1978).

55. Safeguarding a Domestic Mixed Oxide Industry Against a Hypothetical Subnational Threat, Office of Nuclear Material Safety and Safeguards, U.S. Nuclear Regulatory Commission, NUREG-0414 (May 1978). 


\title{
PART 8
}

DEPLOYMENT CONSIDERATIONS

K. D. Dance, * Y. I. Chang, and T. A. Daly

Technical Contributors:

\author{
C. H. Adams \\ R. J. Armani \\ S. K. Bhat tacharyya \\ H. Henryson II \\ J. R. Honekamp \\ R. A. Lewis \\ (Argonne National Laboratory) \\ Organizationa1 Contributors:
International Energy Associates Limited
General Electric Company
Atomics International
Stanford Research Institute
RAND Corporation

\begin{abstract}
Th1s report addresses considerations of fast breeder reactor dcvelopment and deployment from a national perspective. Nations vary greatly in their expertise and interest relative to nuclear power, and hence a single set of steps to be taken by a nation in decisionnaking on breeder development and deployment cannot be presented. The approach taken in this report is to present discussions on key factors influencing the breeder development and deployment decisions, especially in non-breeder nations, by drawing upon historical perspectives of the iight Water Reactor for comparison.
\end{abstract}

\section{INTRODUCTION}

The purpose of this report is to discuss breeder development and deployment considerations faced by present-day nuclear consumer nations and to outline possible strategies and issues which may bear on their decision-making. The perspective of the LWR is drawn upon for comparison with breeder program elements. The factor of timing is examined in assessing the relationship between current speculation regarding breeder deployment and conditions which might be in place at the actual point of deployment. 
With the successful development efforts of the 1950's and 1960's, nuclear energy from converter reactors has now emerged as a viable option in helping to meet the electrical energy needs of our society, and it is expected to remain a significant energy contributor in the future for the following reasons :

1. Nuclear power internationally is generally economically competitive with fossil-fueled power, and is apt to remain so in the future.

2. The reserves of fossil fuels (oil, coal and gas) are limited and there is concern about their present rate of depletion. A significant fraction of the world's electricity is generated in fossil fuel plants.

3. Nuclear power contributes to diversification of energy supply which can help provide energy supply assurance.

In the meantime, nuclear technology has been further pursued through development programs for the fast breeder reactor (FBR) aimed at extending the energy potential of uranium resources by orders of magnitude. Concern has arisen, however, that the amounts of plutonium associated with the present fast breeder reactor concepts have implications on weapons proliferation, and the INFCE effort has been instituted to consider many of the tradeoffs and considerations inherent in continued conventional breeder and alternative nuclear development.

National planning for future energy supplies, in terms of both supply alternative development and system deployment, will depend on many factors. National situations and perspectives for energy supply vary widely from one nation to another. The FBR is simply one of many alternative future energy supply options.

One important factor involved in a consideration of energy supply planning is the present national energy situation. In order to focus on the issues associated with nuclear energy options, some approximate categorizations are necessary. As a minimum the following characterizations of national situation are useful:

1. Nuclear supplier nations with present generation reactor types, with committed efforts in FBR development,

2. Nuclear supplier nations with present generation reactor types, with no FBR development programs,

3. Nuclear consumer nations (non-supplier nations with nuclear energy), and

4. Nations with no nuclear energy.

Planning considerations and objectives differ significantly depending on the time frame: long-term, intermediate-term, or near-term. In long-term energy planning, the main concern is to explore various alternative energy 
sources far into the future, and the focus on this time scale is on basic research activities. As an example, in the U.S., the long-term options currently being considered are fusion, solar, and a variety of other potential sources. At the other extreme are countries that may consider nuclear energy itself to be in this category.

Another important phase is the intermediate planning to make the longterm goal a reality. It is this phase that involves the development decisions and demonstration programs involving large commitments of national resources. (In some nations, the FBR is a development goal. In others, it may be an advanced converter reactor, a first reactor of the current type, or options not involving nuclear at a11.)

Over the near-term ( 10 years), planning will necessarily center around deployment choices between existing power generation systems. In many of the highly developed nations, deployment decisions are made largely on the basis of present market competitiveness and power growth projections by individual utilities or national utility systems. In these cases the government role is centered around regulation and policy rather than around central planning of power deployment. On the other hand, in many developing countries, deployment decisions, particularly those requiring major commitments (such as nuclear requires) are often largely determined by government policy as a part of a long-term energy planning program. For all countries, however, actual nearterm deployment decisions involve important commitments of resources which may strongly influence the total national economy.

In the technologically advanced supplier nations development and deployment are quite separate processes; the one necessarily precedes the other. Developing countries, however, tend to follow the lead of the supplier nations, and technology transfer may replace the role of technology development in the sequence of events. Technology transfer and deployment are tightly coupled in energy policy decisions.

In considering issues associated with deployment decisions, distinctions between development and deployment, and between differing national perspectives, are helpful. The history that led to the present status of nuclear technology (that is, of commercially available reactor types) contains parallels that are helpful to this discussion. Section II gives a brief historical perspective with the focus on pertinent factors that relate to the future development activities (FBR and/or technology transfer) and deployment considerations relevant to the $\mathrm{FBR}$.

Section III explores priorities and considerations in nuclear technology development. Two main issues are discussed in light of the experience with the present generation reactor technology. First, the nature of the nuclear power decision process is discussed, with distinctions drawn between development and deployment decisions. Technological elements of high priority are considered. Second, the common elements of current generation nuclear systems and breeders are identified, and significant differences related to breeder development are discussed.

Against the overall picture presented in Sections II and III, the breeder deployment considerations are presented in Section IV. Specific factors associated with deployment decisions for each broad category of national situation defined above are identified and discussed. 


\section{HISTORICAL PERSPECTIVE AND CURRENT NUCLEAR STATUS}

The discussion of historical perspective and current nuclear status is broken down into parts. The first two parts will be related to the major segments of the nuclear power system: the reactor, and the optional fuel supply service facilities (enrichment, fabrication, and reprocessing). The third area which has played a major role in nuclear power development is uranium supplies and resources. The last area which will be considered is breeder technology status. A background in these four areas will help to put in perspective the important considerations affecting development and deployment decisions.

\section{A. Reactor Technology}

Many nations have engaged in the development of reactor technology as an electric energy supply source, and many different reactor concepts and technologies have been pursued. Each different path in this development encountered technical and economic difficulties.

Most of the concepts pursued in the early days demonstrated technical feasibility, and power reactors were built utilizing a variety of concepts. LWR technology has emerged as dominant among present developed concepts, in terms of reliable and economic commercial applications. The CANDU heavy water reactor, developed in Canada, has also accumulated commercial reliability experience and is beginning to compete with LWR's in the world market.

The first LWR's were manufactured almost exclusively by two U.S. companies: General Electric and Westinghouse. This situation changed in the second part of the 1960s, and two other U.S. companies, Babcock \& Wilcox and Combustion Engineering, have acquired a significant portion of the U.S. market. Several European and Japanese firms, which have been manufacturing the major part of their domestic nuclear power plants, are now in competition with U.S. vendors in the export market.

Only a very few nations have opted for a lengthly internal development program for reactor systems. With the exception of Sweden, all of the reactor manufacturers outside of the U.S. have acquired their LWR technology from the U.S. through license agreements with U.S. manufacturers. As shown in Table I, there are over 20 reactor supplies spread over 11 nations. It is important to note that nearly all of the countries listed in Table I have reached their present status through a process of technology transfer rather than through an indigeneous development program. Other nations have found it much more advantageous to first deploy reactors using externally-supplied knowledge and experience and then to build their own capabilities through technology transfer combined with reduced development programs. This process was aided greatly by competitive pressures which resulted in favorable sales conditions; nations could buy into LWR experience without having to pay for the 20 years or so of research, development, operating experience, and design evolutions of the internal U.S. program.

While there are several nations which have now achieved sufficient technological expertise, largely from technology transfer, to become supplier nations, there are many more nuclear consumer nations which have varying 
TABLE I. LWR Suppliers ${ }^{\mathrm{a}}$

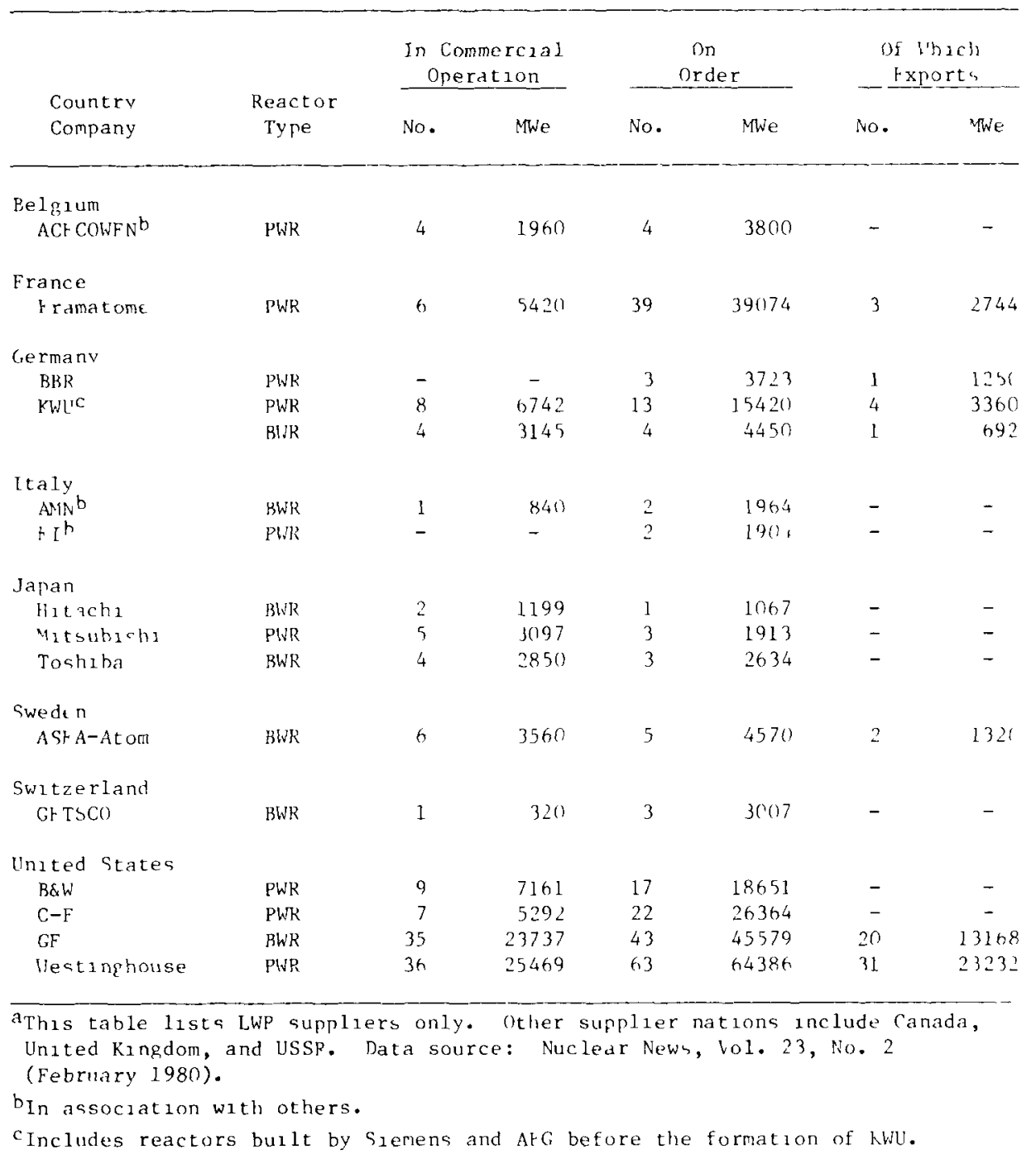

degrees of nuclear technological competence. These consumer nations have followed a pattern similar to that followed by supplier nations, in which the nation initially buys reactors and then works, through technology transfer and internal development, to achieve an ever increasing domestic nuclear technological base.

\section{B. Fuel Cycle Technology}

The three major elements of the fuel cycle (enrichment, fuel fabrication and reprocessing) require complex technologies. They do not require, however, as broad an industrial base or as extensive a technical competence as does reactor technology.

1. Enrichment: The U.S. has traditionally been the sole supplier of enrichment service for the world's commercial LWR industry. The USSR has begun to offer enrichment service in recent years. Other countries such as UK, France, Germany, Japan and South Africa have been involved with enrichment 
technology development or had production capability for small domestic requirements and other purposes. Mostly through joint ventures, several commercial scale plants are being constructed in these countries and a competitive enrichment service market should become available during the next several years.

The current U.S. production capacity is 17.2 million SWUs per year. Eurodif began commercial operation in 1979, and is scheduled to reach full capacity of 10.8 million SWUs in 1982. Other large scale plants, Coredif, Urenco, and UCOR are all planned for commercial operation in the 1980's. Japan is also aiming at the operation of an internationalized competitive enrichment plant by 1985 .

From a historical perspective, enrichment has been achieved using a very capital- and power-intensive process, gaseous diffusion, which has been limited to a very few nations. At present, however, new processes have been developed (centrifuge and aerodynamic) and others are being studied (such as laser) which would greatly reduce the entry cost associated with enrichment. As a result several new national or multi-national enrichment plants are being started, and even more are possible.

2. Fabrication: Fuel fabrication technology is intimately related to reactor technology because the fuel design is an essential part of the reactor design. The fabrication facilities are usually operated by the reactor suppliers or their subsidiaries. However, fuel fabrication represents a relatively small cost of the total nuclear system cost and does not require large technological developments. Consequently, the development of indigenous fabrication can be expected in the future. For instance, India used about 50\% locally fabricated fuel in the CIRUS reactor as early as 1960 .

3. Reprocessing: The basic reprocessing processes have been demonstrated by more than 20 years of exprience with plants for military plutonium production in the U.S. and Europe. For application to the civilian nuclear fuel cycle, plant designs have been and continue to be modified to reflect different fuel characteristics and increased emphasis on safety and reliability. Table II presents a summary of existing reprocessing plants and their operational status.

Commercial development of reprocessing has been slower than for other components of the fuel cycle. Even though reprocessing technology is not difficult in theory, commercial scale operational experience is limited. Several factors contributed to this:

a. The back end of the fuel cycle is not on a critical path of the reactor opertion.

b. The window for target cost is narrow, that is, the reprocessing cost versus throwaway cannot exceed the value of of the fuel remaining in the spent fuel.

c. Licensing regulations and national and international policies related to reprocessing have not been defined very well, in particular with respect to the waste disposal and plutonium safeguards. 
TABLE II. Major World Reprocessing Facilities ${ }^{a}$

\begin{tabular}{|c|c|c|c|c|}
\hline Country & Facility & Fuel Type & $\begin{array}{l}\text { Design Capa- } \\
\text { city (t e/yr) }\end{array}$ & Status \\
\hline Argentina & Ezeiza & $\begin{array}{l}\text { Metal (research } \\
\text { reactor fuel) }\end{array}$ & Lab-scale & $\begin{array}{l}\text { Shut down, but } \\
\text { belng reactivated } \\
\text { for operation in } \\
1977 \text {; may include } \\
\text { redesign for low- } \\
\text { enriched } \mathrm{UO}_{2} \text { fuel. }\end{array}$ \\
\hline Belglum & $\begin{array}{l}\text { Eurochemic- } \\
\text { Mol }\end{array}$ & $\begin{array}{l}\text { Multipurpose } \\
\text { plant }\end{array}$ & 60 & $\begin{array}{l}\text { Start-up } 1966 ; \\
\text { shutdown } 1974 . \\
\text { Has been used for } \\
\text { reprocessing } \\
\text { development; prob- } \\
\text { ably w111 not } \\
\text { reopen }\end{array}$ \\
\hline Brazıl & & $10_{2}$ & & \\
\hline \multirow[t]{3}{*}{ France } & $\begin{array}{l}\text { La Hague } \\
\text { (UP2) }\end{array}$ & $\begin{array}{l}\text { Natural U } \\
\text { metal }\end{array}$ & 800 & $\begin{array}{l}\text { Start-up } 1966 \text {. } \\
\text { Oxide head-end } \\
\text { being installed } \\
\text { whlch will permit } \\
\text { reprocessing of } \\
10_{2} \text { fue } 1.50 \\
\text { te/vr in } 1976, \\
800 \text { te/yr in } 1980 .\end{array}$ \\
\hline & $\begin{array}{l}\text { La Hague } \\
\text { (UP 3) }\end{array}$ & $\mathrm{IO}_{2}$ & 1600 & $\begin{array}{l}800 \text { te/yr } 1984 ; \\
1600 \text { te/yr } 1986 .\end{array}$ \\
\hline & Marcoule & Natural " & $900-1200$ & $\begin{array}{l}\text { Start-up } 1958 \\
\text { for military } \\
\text { purposes; w1 } 11 \\
\text { take over commer- } \\
\text { clal natural U } \\
\text { metal reprocessing } \\
\text { from La Hague. }\end{array}$ \\
\hline \multirow[t]{2}{*}{$\begin{array}{l}\text { Federal } \\
\text { Rep. of } \\
\text { Germany }\end{array}$} & $\begin{array}{l}\text { KEWA } \\
\text { (Inited } \\
\text { Reprocessors) }\end{array}$ & $\mathrm{UO}_{2}$ & 1500 & $\begin{array}{l}\text { Start-up in late } \\
\text { 1980s. }\end{array}$ \\
\hline & $\begin{array}{l}\text { WAK } \\
\text { Karlsruhe }\end{array}$ & $\begin{array}{l}\text { Breeder } \\
\text { and } \mathrm{uO}_{2}\end{array}$ & $\begin{array}{c}40 \\
(p+10 t \text { plant })\end{array}$ & $\begin{array}{l}\text { In operation since } \\
1970 .\end{array}$ \\
\hline \multirow[t]{2}{*}{ India } & Trombay & Metal and $\mathrm{UO}_{2}$ & 100 & $\begin{array}{l}\text { In operation } \\
\text { since } 1965 .\end{array}$ \\
\hline & Tarapur & Metal and $\mathrm{UO}_{2}$ & 150 & Being cold-tested. \\
\hline \multirow[t]{2}{*}{ Italy } & $\begin{array}{l}\text { Eurex-1- } \\
\text { Sallugia }\end{array}$ & $\mathrm{UO}_{2}$ and metal & 10 & $\begin{array}{l}\text { Currently shut down } \\
\text { for modification. }\end{array}$ \\
\hline & Unnamed & $\mathrm{UO}_{2}$ & 500 & $\begin{array}{l}\text { Start-up 1985; plans } \\
\text { temporar11y shelved. }\end{array}$ \\
\hline \multirow[t]{2}{*}{ Japan } & $\begin{array}{l}\text { PNC } \\
\text { Toka1-Mura }\end{array}$ & $\mathrm{UO}_{2}$ & 200 & $\begin{array}{l}\text { Start-up 1978; cold } \\
\text { testing. }\end{array}$ \\
\hline & Unnamed & $\mathrm{UO}_{2}$ & 1000 & $\begin{array}{l}\text { Start-up late } 1980 \text { s } \\
\text { If site can be found. }\end{array}$ \\
\hline \multirow[t]{2}{*}{ Spain } & $\begin{array}{l}\text { Juan Vigon } \\
\text { Ctr., Madrid }\end{array}$ & Metal & Pilot plant & In operation. \\
\hline & Unnamed & $\mathrm{UO}_{2}$ & 1000 & Possibly by mid-1980s. \\
\hline
\end{tabular}


C. Uranium Supply

The most widely accepted source of data on world uranium resources and production capacity is the NEA/IAEA publication "Uranium Resources, Production and Demand," usually called the Red Book. The 1977 edition of the Red Book lists a total of 4.29 million tonnes of uranium in the "Reasonably Assured" and "Estimated Additional" categories of resources recoverable at costs up to $\$ 50 / 1 \mathrm{~b} \mathrm{U}_{3} \mathrm{O}_{8}$. A recent update has raised this uranium resource figure to about 5 million tonnes.

Through 1978 the cumulative world production of uranium was 533,000 tonnes. World production capacity will be about 50,000 tonnes in 1980 and is expected to reach 116,000 tonnes by 1990 .

Table III breaks down uranium resources and electrical demand according to the current nuclear development of nations. The overall picture is one of modest resources. The situation for individual countries, of course, differs dramatically. Some nations have found uranium resources that are enormous relative to their electrical needs; others have no known uranium deposits.

TABLE III. Uranium Resources and Electrical Demand by National Group ${ }^{a}$

\begin{tabular}{|c|c|c|c|}
\hline National Group & $\begin{array}{c}\text { Uranium } \\
\text { Resources } \\
1000 \text { tonnes U }\end{array}$ & $\begin{array}{c}\text { Expected Nuclear } \\
\text { Capacity through } \\
1985 \text {, GWe }\end{array}$ & $\begin{array}{l}1975 \text { Electrical } \\
\text { Capacity } \\
\text { GWe }\end{array}$ \\
\hline $\begin{array}{l}\text { Supplier nations with } \\
\text { breeder development }\end{array}$ & 1875 & 207 & 839 \\
\hline $\begin{array}{l}\text { Supplier nations witn no } \\
\text { breeder development }\end{array}$ & 1144 & 29 & 150 \\
\hline $\begin{array}{l}\text { Consumer nations with } \\
\text { existing nuclear energy }\end{array}$ & 918 & 39 & 167 \\
\hline $\begin{array}{l}\text { Nations with no nuclear } \\
\text { energy }\end{array}$ & 414 & 0 & (b) \\
\hline \multicolumn{4}{|c|}{$\begin{array}{l}\text { The resource figures are recent estimates submitted to INFCE Working Group } 1 . \\
\text { Electricdl capacitv figures are Erom INFCE data, the } 1977 \text { Red Book and the } \\
\text { "World List of Nuclear Power Plants" published in Nuclear News (Feb. 1977). } \\
\text { b Almost all the nations in this categorv have electrical grids under } 5 \text { GWe. } \\
\text { Most have grids under } 1 \text { GWe. }\end{array}$} \\
\hline
\end{tabular}

\section{Fast Breeder Reactor}

As discussed in detail in a companion report dealing with the role of the FBRs in a long-term energy supply, the FBR is envisioned as a next generation nuclear power source replacing the current generation reactors as uranium resources are depleted. Most of the current nuclear supplier nations, including France, the Federal Republic of Germany, Japan, the United Kingdom, USA and USSR, have been carrying out major FBR development and demonstration programs for more than a decade. India has an experimental ( $50 \mathrm{MWt}, 20 \mathrm{MWe}$ ) LMFBR in final stages of construction at Kalphkkam. 
Even though the FBR is just another type of reactor, the technology development required for the FBR is far more advanced than for current reactor types. Because of the sodium coolant and fast neutron environment, fuels/materials and components development are required.

Because of the enormous cost and limited short-term benefits associated with FBR technology development, it is quite unlikely that any other nations would join in the FBR development effort in full scale. Rather, the opposite trend is apparent. With the obvious motivation of cost sharing, interdependent FBR research, development and demonstration programs have been established. Following the successful operation of the protototype reactor Phenix, a company (NERSA) was established by the main utilities in France, Italy and FRG to build a European demonstration plant, the 1200 MWe FBR Super Phenix. A detailed cooperative arrangement between France and FRG led to establishment of a joint company SERENA which also includes Belgium, the Netherlands and Italy. A commercial sized LMFBR, SNR-2, is planned by the FRG in cooperation with Italy, France, Belgium and the Netherlands. A company, ESK, was formed by the main utilities of these countries in support of this reactor project. Smaller cooperative programs have also been established among the European nations, Japan, UK and the USA.

In spite of this trend, however, it is expected that other nations with no major commitment for the full scale FBR technology development leading to a commercial breeder could get involved with partial component development or other smaller scale activities. For example:

Austria is one of the five nations in the world with demonstrated experience in the fabrication of large reactor vessels for LMFBR power reactors. Their having built and tested the Kalkar SNR-300 reactor vessel is a measure of progress in an area not yet demonstrated in several of the generally recognized breeder nations, such as Germany and Japan.

Czechoslovakia has had a comprehensive LMFBR development program underway for many years, including physics, safety, sodium technology, materials development and component design and fabrication, including sodium-heated steam generators fabricated for use in the Soviet BOR-60 and BN-350 LMFBR's.

Spain is steadily increasing its LMFBR-related technologies, including the installation of several sodium testing facilities and two fast neutron critical assemblies.

A number of European nations continue to support and actively participate in gas-cooled fast reactor development through the Gas-cooled Breeder Reactor Association, headquartered in Brussels. Among "non-breeder nations," Switzerland and Sweden are most heavily involved in the gas-cooled breeder studies. Minor experimental work is in progress. Switzerland is also involved in advanced fuel development for LMFBR's and Sweden is a major supplier of LMFBR hardware, principally tubing.

\section{BREEDER DEVELOPMENT CONSIDERATIONS IN NON-BREEDER NATIONS}

For the discussion in this section we define the non-breeder nations as those who have no major commitment to the development of FBR technology. This is not a clear-cut distinction, and there could be a wide spectrum of national 
situations. At one extreme there are nations with no nuclear program and/or plan at all. At the other extreme there are nations with nuclear technology and conventional reactor supply capability but only marginal or partial involvement in FBR development. To focus the discussion in this section, we exclude these extreme cases, and consider those nations that fall into the nuclear consumer category, that is, those who decided to go nuclear (conventional reactor types), but with very little supply capability.

This discussion is based on the assumption that a nation decides to devote at least minimal resources to breeder development. In making that decision the nation must consider the prospects for alternative sources of power. This report recognizes that it is possible that the decision will be to ignore the breeder.

Nuclear technology development encompasses a wide range of activities. The term "development" used in this report needs to be distinguished from either deployment or research. We make the following distinctions in this context.

1. Research: Any nation with a nuclear program is engaged in research activities covering various disciplines. Laboratory or pilot scale activities on reactor technology or fuel cycle technology will be also considered as research activities. In the context of this report, research is associated with long range energy options.

2. Development: Activities requiring a major financial and manpower commitment and aimed at commercial or non-commercial application, such as the development of indigenous reactor technology or manufacturing capability. In the industrialized nations "development" is most of ten applied to new technologies such as FBRs. In consumer nations, the term is of ten used in its broader sense, viz., technology transfer and/or development of capability to indigenously support a conventional technology. In this context, a consumer nation may consider itself to be "developing" LWR capability, even though many of the industrialized nations consider LWR technology "developed."

3. Deployment: Decision to utilize nuclear power plants as electricity generating stations. (By definition, we assume the nations in the nuclear consumer category have already made deployment decisions to install conventional reactor type(s). Deployment decisions for FBRs are discussed in the next section.)

This chapter focuses on factors which influence non-breeder nations in considering development of breeder technology. Since many of those nations have not yet completely developed LWR capabilities, the factors often are closely allied to the problems of nuclear development or industrialization in general. In recognition of this, this chapter is structured in three parts as follows :

a. Factors influencing breeder development decisions in non-breeder nations.

b. Considerations in setting general nuclear development priorities in consumer nations.

c. Areas for nuclear development. 
A. Factors Influencing Breeder Development Decisions in Non-Breeder Nations

Nations which are not currently developing breeders have a spectrum of possibilities for breeder deployment. At either extreme of the spectrum are:

1. Totally independent development and subsequent independent indigenous deployment.

2. Purchase of foreign designed, manufactured, and constructed reactor systems and fuel services.

Between the extremes are a range of mixed strategies involving transfer of technology, and the development of indigenous construction/manufacturing capabilities.

Generally, choice of the "independent development" extreme involves early commitment of large domestic and personnel resources. Pursuit of the "foreign purchase" route involves little current commitment, but is likely to require large commitments at the point of deployment -- possibly far in the future. Mixed strategies would involve varying combinations of investment of resources now and deferment of costs to the future. The choice is complicated by the numerous uncertainties surrounding breeder development costs, future deployment costs and fuel resource availability.

Faced with the spectrum of choices, national capital and personnel resource constraints, and breeder development/deployment uncertainties, a nation consideraing a start in the breeder development process will initially consider three major questions:

1. Potential for Deployment: Is the probability sufficiently high that a breeder deployment decision will be made in the affirmative to consider investing in preparation? (Issues to be considered in assessing deployment are addressed in more detail in Chapter IV.) A factor in this consideration will be progress in the development of alternative energy sources.

2. Anticipated Mode of Deployment: Given a possibility of future deployment, is the mode of such deployment more likely to be:

- Purchase of foreign supplied plants.

- Indigenous construction/manufacture under foreign license.

- Indigenous construction/manufacture of indigenous technology or through hybrid strategies?

3. Independent Development/Collaborative Development: Given a possiblility of future deployment, and an anticipated mode for deployment, is the strategy during the development stage to:

- Independently develop breeder technology.

- Join an existing breeder effort.

- Make other provisions which will aid in later technology transfer (for example, assignment of personnel to foreign programs).

or some combination of the above? 
Answering these questions involves consideration of a series of fundamental issues regarding the goals, resources and capabilities of the nation. These issues include:

Economics: What is the magnitude of the investment required to engage in development of the technology? Do the potential returns justify the investment? Will there be impacts on trade balance during the development stages? Are there preferable alternative uses of capital? Will the participation in development programs substantially reduce future deployment costs?

Assurance of Energy Supply: Is the technology vital to the nation's access to energy? Will the technology improve assurance of energy and/or fuel supply? Will it result in other forms of dependence? Does engaging in development improve assurance of access to the technology or technology supply system?

Energy Supply Requirements: Is demand growth projected to outrun supply? Are there alternative means of meeting demand? To what degree can breeder technology reduce a projected energy supply shortfall?

Industrial Infrastructure: Does the nation have sufficient industrial capability to manufacture and construct developmental facilities: Will engaging in breeder research, development and demonstration help develop such an infrastructure?

Lead Time/Planning Horizon: Can development proceed rapidly enough to meet potential deployment schedules? Will engaging in the development process speed the deployment process?

Status: Will a breeder development program improve national prestige or morale, and if so, will this tanslate into tangible national benefits?

Tieback to Balance of Nuclear Program: Will a breeder development program spin off tangible aids to the rest of a nation's nuclear program? Will symbiotic systems be made possible to allow fine tuning of energy supply to changing demands?

The net balance of these factors will depend on the specific goals, resources and capabilities of individual nations. However, it is possible to gain some insight into which direction the balance might be leaning by considering the development priorities which non-breeder nations might establish. This is considered in the next section.

B. Considerations in Setting General Nuclear Development Priorities In Consumer Nations

Nuclear consumer nations, having made the decision to go nuclear, are likely to carry out some level of development activities, often jointly ventured by government agencies, industries and utilities. There will be some nations, however, which are not involved with development activities at all. In this section we examine considerations associated with the development riorities. There are many factors, including those identified in the last section, that determine development priorities. However, it is possible to speculate on a general pattern of decision making: 
1. The incentive for the development of an indigenous nuclear technological and industrial base is much stronger when this base is being developed to support and expand an existing nuclear power system.

2. Considering the history of LWR technology transfer for the industrialized nations which are nuclear suppliers now, it is most likely that consumer nations would concentrate on technology transfer of their reactor systems rather than developing new reactor technologies of their own.

3. In a nation with few resources, technology transfer and the domestic supply capability are likely to proceed in an evolutionary and somewhat piece-meal manner, with different priorities depending on that nation's situation.

Hence, the development priorities in consumer nations are most likely to be in those areas associated with current-generation reactor types they have deployed, instead of the areas associated with FBR technology. This does not imply that there would be no incentives for FBR technology development, nor that these priorities would remain unchanged in the future. Even though there are no near-term benefits, many nations could get involved with FBR technology as a long-term R\&D program. Futhermore, the development priorities could change in the future, from the conventional reactor types to the $F B R$ or both, if a nation decides to deploy FBRs.

\section{Areas for Nuclear Development}

If a non-breeder nation decides it is useful for it to engage in breeder development, it may choose to do so in one or more technological areas. Several of these are identified below:

1. Low Cost, General Conventional Nuclear Support: Activities directed to support purchased conventional technologies. These may involve maintenance or improvement of performance, fuel and material problems, core management, etc., generally directed at reducing outages. This activity improves the consumer nation's ability to deal with vendors on conventional and advanced nuclear technologies.

2. Conventional Nuclear Component Manufacture: Activities directed at the development of a capability to supply general components (such as instruments, valves and piping) and design specific components (possibly manufactured under license) such as pumps and heat exchangers. Development of this capability supports personnel training and development of industrial infrastructure, both of which can later be applied toward advanced nuclear technologies.

3. Breeder Reactor NSSS RD\&D: Activities directed specifically at RD\&D on the nuclear portion of breeders. As noted previously, the approach could range from independent activity in specific areas, to an independent development program, to any of the many forms of collaboration with ongoing programs.

4. Sodium Technology RD\&D: Activities directed at developing technology specifically for LMFBRs. Again, the range of cooperative strategies apply. This may be a fruitful area for a non-breeder nation to support FBR development without being involved in the necessity of handling nuclear materials. 
5. Reprocessing: While reprocessing provides some increased assurance of fuel supply it does not represent a long term solution for most nations. Nations with substantial uranium resources would likely place less priority on acquisition of reprocessing technology, especially in view of the relative state of commercial technology in reprocessing. However, the nation with little uranium could view a domestic reprocessing capability as the step to a breeder system, assuming that they can acquire the breeder reactor technology when needed. This latter view of reprocessing is the historic basis for most national programs, with varying emphasis on the value of plutonium recycle in LWRs. Most nations which have significant nuclear experience are well aware of the problems that the major supplier nations have encountered in developing commercial-scale reprocessing. They are also awa re that commercial-scale plutonium fuel fabrication for the breeder is yet to be developed, although substantial quantities of breeder fuel have been fabricated from "clean" plutonium in large pilot facilities. Thus a modest-scale development program in plutonium recycle in LWRs is still considered by many to be a logical approach to the orderly development of a domestic breeder fuel cycle capability as well as the assurance of a plutonium supply to start breeder deployment. Some nations view reprocessing as a fundamental part of waste management.

The specific choice of development priorities is unique to each national situation. However, for nations which have elected to pursue the nuclear option and which have limited domestic investment resources, focusing on LWR development with potential spinoffs to breeder development may be the preferred approach.

\section{BREEDER DEPLOYMENT CONSIDERATIONS}

In this section, we examine the considerations involved in national decisions on breeder deployment, with a focus on the consumer nations. The discussion centers on two elements: (1) the possible strategies which a nation may utilize in planning breeder deployment, and (2) the issues or factors which are faced by the nations involved. Chapter $V$ presents the possible observations or conclusions which may be drawn from (1) and (2).

\section{A. Strategies}

Once a nation has decided to implement a breeder deployment program, there are many strategies which may be available to it. Options depend on the state of breeder development in the nation, the capabilities and offerings of the breeder supplier countries, and the deployment factors or issues (discussed in $B$ ) as they are viewed by the nation at the time of making a deployment decision. It is significant that each of these options would most likely change over time, and the timing of a consumer nation deployment decision may be twenty to thirty years in the future.

A reference set of strategies for breeder deployment includes at least six possible acquisition modes:

1. Buy Reactor/Buy Fuel Cycle Services: The reactor is designed and manufactured, and construction is managed by a supplier nation or consortium. There is little or no reactor technology transfer.

Fuel cycle services are provided by a supplier nation or consortium, ith no technology transfer. 
2. Build Reactor/Buy Fuel Cycle Services: The deploying nation may have a breeder development program, separately or with others. However, to build the reactor requires a license and technology transfer arrangement with a supplier nation/group.

Fuel cycle services are as in (1).

3. Buy Reactor/Build Fuel Cycle Facilities: Buy reactors as in (1).

The deploying nation may have a breeder fuel cycle development program, separately or with others. However, to build and operate the facilities, requires a license and technology transer arrangement with a supplier nation/group.

4 Build Reactor/Buy Fuel Cycle Facilities: Build reactor as in (2).

The fuel cycle facilities are designed, manufactured and construction is managed by a supplier nation/group. The facilities are located in and operated by the deploying nations with the intent of minimum technology transfer.

5. Build Reactor/Build Fuel Cycle Facilities: Build reactor as in (2). Build fuel cycle facilities as in (3).

6. Develop Reactor/Develop Fuel Cycle Facilities: The deploying nation has committed to a long-term development program through which commercial-scale reactors and fuel cycle facilities are built independent of other nations.

The options available are even more varied where symbiotic systems (FBRs plus converter reactors) are considered. The factors affecting decisions, however, are substantially the same.

Strategy (1) (Buy Reactor/Buy Fuel Cycle Servies) requires the least anticipation and preparation by the deploying nation. This nation could be in the same pure "consumer" status now as at the time of making a deployment decision. This strategy requires confidence by the nation that the international supply system will function adequately for its purposes well into the future, given the longer time scale of breeder development. The initial LWR deployment decsions made by non-nuclear supplier nations, at that time, were patterned after this strategy.

At the other end of the spectrum, strategy (6) (Develop Reactor and Fuel Cycle Facilities) would demand that a nation embark on development programs and deployment planning which shifts it out of the consumer category.

The progression of strategies ( 1 through 6 ) is in part suggested by the experience of the LWR reactor program. Initial LWR natinonal deployments were outright purchases. Then licensing and technology transfer followed, providing indigenous and foreign supply capability to the nation receiving the technology. Finally independent LWR programs were developed and supplied by nations which initially had to import the technology.

The risk of deployment can be assumed by the supplier nation/group (for instance in strategy (1) if it elects to do so in order to build a market 
position. In the example of stragety (1), the deploying nation could, with little preparation or anticipation, commit to a breeder reactor (versus a fully deployed program) and associated fuel cycle services without accepting more than conventional risks because of the suppliers' warrantees. The LWR program history argues that such supplier risk-taking on a small number of breeder rectors is not out of the question. The impact of supplier risktaking to build market position could not extend to an entire commercial scale program without a completely proven breeder. Therefore, nations may be induced to have a single or small number of "guaranteed" breeders. Two follow-on courses are seen for the "guaranteed" deployment. Either the deploying nation would evaluate the breeder commercial success before proceeding with a full scale progam, or it would be drawn into full scale deployment in advance of proven success because of internal factors such as competition, program momentum, and the desire to share program cost (training, support facilities, and regulation) among a broader reactor plant base.

\section{B. Factors to be Considered in Breeder Deployment Decisions}

There are a number of factors which must be considered in making basic "go" or "no-go" decisions in breeder deployment and in choosing between deployment strategies if a "go" decision is reached. These factors must be considered by each nation within the context of its own present and projected economic situation as well as within the perceived international context which will exist at the time considered for breeder deployment. Some of the key factors are discussed below. For a more complete discussion, see "International Cooperation on Breeder Reactors," by the Rockefeller Foundation (May 1978), from which much of the following material has been abstracted.

1. Resource Adequacy: The degree to which each nation feels certain regarding future aggregate resource adequacy* will strongly influence the perceived need for the development of an effective "insurance policy" breeder technology capable of deployment if optimistic resource scenarios do not materialize. At present many industrialized nations tend to feel strongly that immediate development of breeders is needed from the standpoint of resource adequacy considerations in order to provide for possible timely future deployment. At present, however, actual full-scale deployment of breeder reactors is not of ten argued for in terms of present global resource considerations, and certainly consumer nations are not considering short-term breeder deployment.

2. Assurance of Supply: A national government is likely to make a development/deployment decision on the breeder in light of its individual energy supply-demand situation, with consideration of global resources as secondary. (See a companion report, Part 1 of this series for a discussion of global situations.) On this basis an industrialized nation which lacks domestic energy resources is likely to view it as necessary to develop breeders as soon as possible and to be able to deploy them on a timely basis.

In general, within governments the potential dangers of interruptible and/or high cost foreign energy supply tend to be viewed as national

*The term "resource depletion" will refer to the aggregated world system, while the question of distribution of resources is considered within the context of "assurance of supply." 
security issues, and afforded high priority. The degree to which breeder reactors offer an assurance of supply to consumer nations will depend largely upon the deployment strategy being followed and the degree to which international fuel service arrangements and technology transfer arrangements can be viewed as assured in comparison to raw fuel supply uncertainties.

3. Economics: Two important characteristics of breeder economics are noted. First, energy economics will be a major driving force in determining when and if breeders can be successfully deployed; and second, the economics of both the capital plant and the fuel cycle over the next 20 to 30 years are so uncertain as to be considered speculative. A recurrent theme of national breeder policy in the supplier nations is that to decrease the economic uncertainties, one must build at least a few commercial-scale demonstration breeders. This may turn out to be an expensive proposition, especially if the economics do not prove out, and the breeder is therefore (or for some other reason) not deployed. However, many industrialized nations view the potential economic payoff over the years ahead, if the breeder becomes a commercial success, to be so large as to dwarf the cost of development. Within the consumer nations where actual full scale deployment is not apt to start for 20 to 30 years, present economic projections are not likely to be a major consideration in any near-term considerations of the prelude to actions to breeder deployment.

4. Health, Safety and Environment: Satisfactory resolution of health, safety and environmental issues is essential for breeders to achieve the acceptance required for widespread deployment. Because breeders are in an early stage of technological development, relative to conventional nuclear technology, so are the appropriate health, safety and environmental regulations and the related public acceptability. For breeders the public process of evaluating the health, safety and environmental aspects may be less tortuous than it has been for earlier nuclear technology because of lessons learned in LWR deployment.

Part of the process for resolving health, safety and environmental issues is the construction and operation of demonstration projects. It is likely that satisfactory resolution of these issues will not be achieved short of such demonstrations. In conjunction with demonstration projects, resolution of the issues requires an effective institutional process for defining technical and social objectives, and for evaluating proposed solutions. International cooperation on health, safety and environmental matters has a potential to improve the institutional approval process and the technical solutions as we11.

5. Non-proliferation: There is widespread concern over the potential proliferation problem associated with the increased usage of plutonium in breeder reactors. The degree to which breeder reactors are perceived to actually increase proliferation, the degree to which institutional or technical fixes can minimize or control proliferation, and the degree to which international acceptance of fuel cycle controls is considered likely will all influence national breeder decisions. Whether consumer nations are actually provided with the option of future breeder deployment, or in what context such deployment could take place, may be largely determined by international controls and institutions which may be formed in the near future as a result of nonproliferation concerns. 
6. FBR Performance Assurance: As discussed in Section III, the FBR is far from being available commercially in a competitive market. Any reactor type, FBR or other, which incorporates new technology, new design or new materials, or is offered by a supplier new to the market can only be acquired with risk: the risk of the reactor not performing to the standards of conventional reactor types, or the risk that the vendor might not be able to meet specifications and/or schedules. These risks can be substantial for individual electric power utilities or consumer nations, from the economic burden of capital and operating costs exceeding expectations to the risk of not having the plant available when needed.

Financing institutions have applied criteria of performance assurance in the past in order to minimize the risk to themselves. The World Bank has, for instance, applied a criterion to all equipment it finances, and specifically to nuclear, defined as follows:

"... when a complex mechanical plant is required (and this covers a broad range from thermal power plant to locomotives) a developing country should limit its consideration to makes and designs which have already been manufactured and operated successfully in some other country's system. The view is based on two principal foundations, namely:

a. A developing country requires even greater reliability of operation than a developed country and demands an even greater assurance of the successful outcome of any project investment; and

b. The Bank has been familiar with numerous instances where complex equipment, even though manufactured by we11established and generally reliable firms, gave serious and long-lasting difficulties in the case of prototype even when no new principles were involved.

As all of these considerations are valid a fortiori, in the case of nuclear plants, which involve radical new principles and technologies, the Bank would consider it risky for a developing country to install plant having basic design and components which differ materially from what has been in successful utility operation elsewhere ...."

Note that the risk associated with the unproven nature of the FBR may be largely removed from the consumer nation, for token deployments of one or two reactors, by supplier assurances, as was the case for many initial LWR deployments. However, any consumer nation considering a commitment to true full-scale breeder deployment in the near-term would almost assuredly have to be willing to take a very large risk associated with a technology with which there would be no real proven domestic operating experience.

7. Technological/Industrial Base: For technology transfer to be successful, the recipient consumer nation must have the technological/ industrial base to absorb the transfer and the indigenous technological ability to complete the transfer. Consumer nations may well be, at the deployment decision point in question, in the process of absorbing the conventional reactor technology from a supplier nation. Traditionally, consumer nations have elected to undertake some degree of domestic participation in the transfer 
of high technology principally from foreign exchange savings considerations. The experience of several nations in their attempts at domestic manufacture of conventional nuclear power plant components reveals that it required a heavy government participation and a large coordination effort to bring local industry on board the venture. The manufacture of nuclear components requires adherence to high quality control standards and local industries experience initial difficulties in meeting these standards. The costs of the units produced on a small scale were of ten higher than purchase prices in the international market. These considerations suggest that the first priority for each nation in the energy field would be to build up and consolidate the industry base to support the existing power plants. It has to be recognized that the level of technology required for breeder deployment is different from that for conventional reactors and implies a new associated industrial base to support the technology. Since the general problem of consumer nations is shortage of energy, it seems very likely that the technological effort would be concentrated on obtaining solutions to existing problems (to assure continuity of energy supply) rather than on absorbing the new breeder system. Most of the consumer nations in this class operated with limited national resources with energy production competing with many other goals for these resources. With these constraints the incentives to build up the technological/ industrial base to support an existing nuclear power system are much greater than to absorb the new breeder system.

8. Planning Horizon: The breeder deployment planning time frame is dependent upon the strategy type (Section IV.A) in force. Longer-term resource commitments are sensitive to changes in policy, available energy alternatives and other factors. Utility plaming focuses upon a single plant life, while the time frame for commercial breeder planning must span many plant lives.

9. Prestige/Status: Initial breeder deployment decisions may be strongly influenced in special cases by considerations of national prestige and status. However, given the costs and resource commitments likely to be associated with breeder deployment, it is unlikely that deployment would continue beyond an initial first plant or two unless tangible national benefits were accrued or were expected from further deployment.

\section{OVERALL DEPLOYMENT CONSIDERATIONS AND CONCLUSIONS}

Given the factors considered in the section above as well as the present developmental and demonstration status of the breeder reactor it would appear that there is no basis on which to expect serious breeder deployment decisionmaking by consumer nations to start in the near term. Because of this time frame, it would appear that much of the current effort to assess or quantify breeder economics would not be of significant interest to these nations at present. This is not to say that there will be no "showcase" or individual reactor deployment started within the near term. It is possible that pressures on supplier nations to gain competitive advantage could result in breeder reactor sales in the relatively near time frame. Such sales, however, would probably only be possible if the supplier were to effectively subsidize or guarantee breeder price and performance. Such guarantees, by analogy to LWR development, could occur but there would appear to be no impetus for supplier nations to continue to subsidize large scale breeder deployment in consumer nations. On the basis of the above it appears that normal breeder 
deployment decision in consumer nations would not occur before the longer term ( year 2000 or beyond). Given this time frame, it is important to note that present nationa1 categorizations as well as major issues are apt to have changed. For example, nations which are now classified as nuclear consumer nations in the context of this report may have progressed in nuclear technology equivalent to the current potential supplier nations. Similarly, institutional arrangements may have evolved in the longer term to accommodate current considerations such as proliferation concerns or fuel supply assurances. This suggests that the development of rigid deployment scenarios may be meaningless or even misleading. It is possible, however, to anticipate, on the basis of historical perspective, some of the broad outlines of probable deployment scenarios for classes of nations that may exist in the future.

The historical development of LWR's would suggest that initial breeder deployments in consumer nation would start with rather limited involvement in the consumer nation and would progress towards even greater domestic involvement of the consumer in the building of the reactor. Historical perspective would also suggest that at the time that a nation began to deploy breeders, the more advanced in nuclear technology the nation was, the greater would be the initial involvement in the actual deployment. There are, however, several differences between LWR's and breeders as well as possible differences between the past and the future which may render historical perspective invalid.

The ability of consumer nations to approach breeder deployment in a stepwise manner, as was done for LWR's, will largely depend upon the desire of supplier nations to push for breeder deployment in consumer nations. International arrangements among supplier nations, for instance, to limit breeder deployment could greatly reduce or lengthen the amount and time scale of breeder deployments. Likewise, international restrictions on fuel cycle activities could seriously impede the ability of some nations to deploy breeder reactors, particularly if the deployment program would not support commercial scale fuel cycle facilities.

From a national perspective, breeders also differ from LWR's in that one of the principal driving forces for breeder deployment is assurance of energy supply independence. To the extent that this is a dominant factor, it follows that breeder deployment would be attempted with a minimum of outside support dependence, which would lengthen the time before breeder deployment is started by demanding a higher level of domestic capability. In addition to the above, it is also true that many nations in the process of acquiring their present converter reactor capabilities have largely committed their reserves and will not be as free to embark on breeder deployment as might have been the case when initial converter deployment was considered.

All of the above suggests that breeder deployment by consumer nations is not likely in the near term, but may start gradually in the longer term. Thus, it is likely that there is time for an orderly development of arrangements to properly assure that breeder deployment is consistent with both energy supply and nonproliferation goals.

It is also possible to speculate that international involvement in nuclear matters, particularly those related to the breeder reactor and supporting fuel cycles, will increase in the future; for instance, as uranium resources become more constrained, international arrangements related to fuel 
supply assurances will become more necessary for any orderly nuclear expansion. Similarly, proliferation concerns related to any future breeder development will almost necessarily imply strengthened international safeguards and controls.

It is also important to note that breeder deployments have been largely discussed in the context that they will occur and progress in the near term. This will not be the case if the breeder reactor option proves to be uneconomical or is surpassed by new energy source developments. At this time, there is not sufficient demonstration and experience with breeder reactors in any nation to be assured of ultimate breeder economics, nor can the future avai1ability or prices of alternative sources be known with certainty. Breeder reactors, therefore, must be considered to be still in the development/ demonstration stage. 


\begin{abstract}
ANNEX
DECOMMISSIONING OF A LARGE CENTRAL-STATION LMFBR POWER PLANT: A COMPARISON WITH THE PWR

A. Amorosi, J. R. Honekamp, and H. O. Monson

(Argonne National Laboratory)
\end{abstract}

\begin{abstract}
I. ABSTRACT
The decommissioning of a liquid metal fast breeder reactor ( $L M F B R$ ) is qualitatively compared with that of a more conventional presurized water reactor (PWR). The PWR and LMFBR are examined for differences which might impact the total station decommissioning costs, and the primary systems of both reactor types are compared to determine if design differences in their radioactive portions would substantially alter the overall balance of costs evaluated in earlier comparative studies of decommissioning alternatives. Consideration of the ease of disassembly, relative quantities of structural material to be treated, and the special aspects related to the sodium coolant indicated that, for otherwise equivalent circumstances, dismantling operations are of corresponding difficulty, decommissioning costs are comparable, and, if the primary sodium is reused in another reactor and proper credit taken, the sodium coolant does not add to the cost of decommissioning. If the sodium must be converted for disposal, the LMFBR decommissioning costs would be somewhat higher than those of the PWR.
\end{abstract}

\title{
II. INTRODUCTION
}

It is of interest to know how the decommissioning of a liquid metal fast breeder reactor (LMFBR) compares to that of the more conventional water-cooled reactors. The chief pertinent differences between the sodium-cooled fast reactor and the water-cooled thermal reactor are: ( 1 ) the difference in the core design, and (2) the difference in the coolants used. The core (including blanket, reflector, and core shielding) design affects the neutron activation of the primary system. The use of sodium coolant compared to water affects the primary system layout, pipe and vessel wall thicknesses, transported radioactivity, and surface decontamination procedures. These have an effect on major decommissioning considerations and will be given primary emphasis.

A PWR will be used as a reference for the conventional-type water-cooled plant. Differences in decommissioning aspects between PWR's and BWR's are 
adequately treated elsewhere. For the sodium-cooled fast reactor, both looptype and pool-type are briefly described; the pool-type is then used as the model, since it represents a somewhat greater contrast with LWR practice.

\section{DESCRIPTION OF LMFBR COMPARED TO PWR REACTOR}

A. Basic Features of LMFBR Compared to PWR

The PWR ${ }^{1}$ is a thermal reactor and employs water-to-fuel ratio of the order of $4: 1$ to thermalize the neutrons. The fuel enrichment is about $3 \%$. The PWR core is larger than that of an LMFBR because of the larger coolant-to-fuel ratio and the larger amount of fuel (fissile and fertile material) required. An LMFBR uses a "pancake" type core for reactivity considerations and to prevent excessive coolant presure drop of a longer core. A 1200 MWe PWR core is $10 \mathrm{ft}$ diam $\times 12 \mathrm{ft}$ long and an LMFBR core is $12 \mathrm{ft}$ diam with an active length of 3-1/2 ft. Figure III-1 shows a PWR fuel assembly compared to an LMFBR fuel assembly. The PWR operates at a presssure of about 2200 psig, and to keep the vessel wall thickness down the vessel is made only slightly larger than the core diameter (basically, only large enough to accommodate the core barrel and the shielding needed to meet radiation embrittlement criteria and to provide an adequate inlet downcomer section). The LMFBR vessel on the other hand is designed for atmospheric pressure and is made large for a number of reasons. 2 The core is surrounded by a uranium blanket to capture leakage neutrons and make plutonium. Iron shielding is provided around the core to limit the flux level on various components as discussed in Section IV to provide lateral stability against bowing and seismic forces and to minimize shielding outside the vessel. Typical core and shielding arrangements for the two types of systems are illustrated in Fig. III-2. The neutron flux profiles for the two systems are also quite different, as discussed in section IV.

An LMFBR has a closed radioactive primary heat transport system, but transfers its heat to a non-radioactive intermediate system, which in turn transfers its heat to the water-steam system, Fig. III-3. In the PWR no intermediate system is used.

\section{B. Brief Description of LMFBR}

Two major concepts for LMFBR's are being considered, one being a loop concept in which the major components of the primary system are piped together (see Fig. III-4). The other is the pool concept, in which all the major components of the primary are contained in a single large vessel (Fig. III-5); the reactor outlet is connected to the heat exchanger by the upper pool and the heat exchangers are connected to the pumps by the lower pool. SRE, HALLAM, SEFORE, and Fermi are loop-type sodium-cooled plants. Fermi is also a fast reactor. Since the pool-type reactor represents a greater departure than the loop-type from the conventional water-cooled system practuce, it is used as the primary reference in this report (see Figs. III-5 and -6 ).

Figure III-5 shows the reactor and primary system of the pool type. Figure III-6 is a plan view of the pool showing the location of the pumps and IHX's. Figure III-7 shows a representative design of the reactor building. The building contains not only the primary system but almost all of the associated radioactive systems, such as cover gas purification system and the 


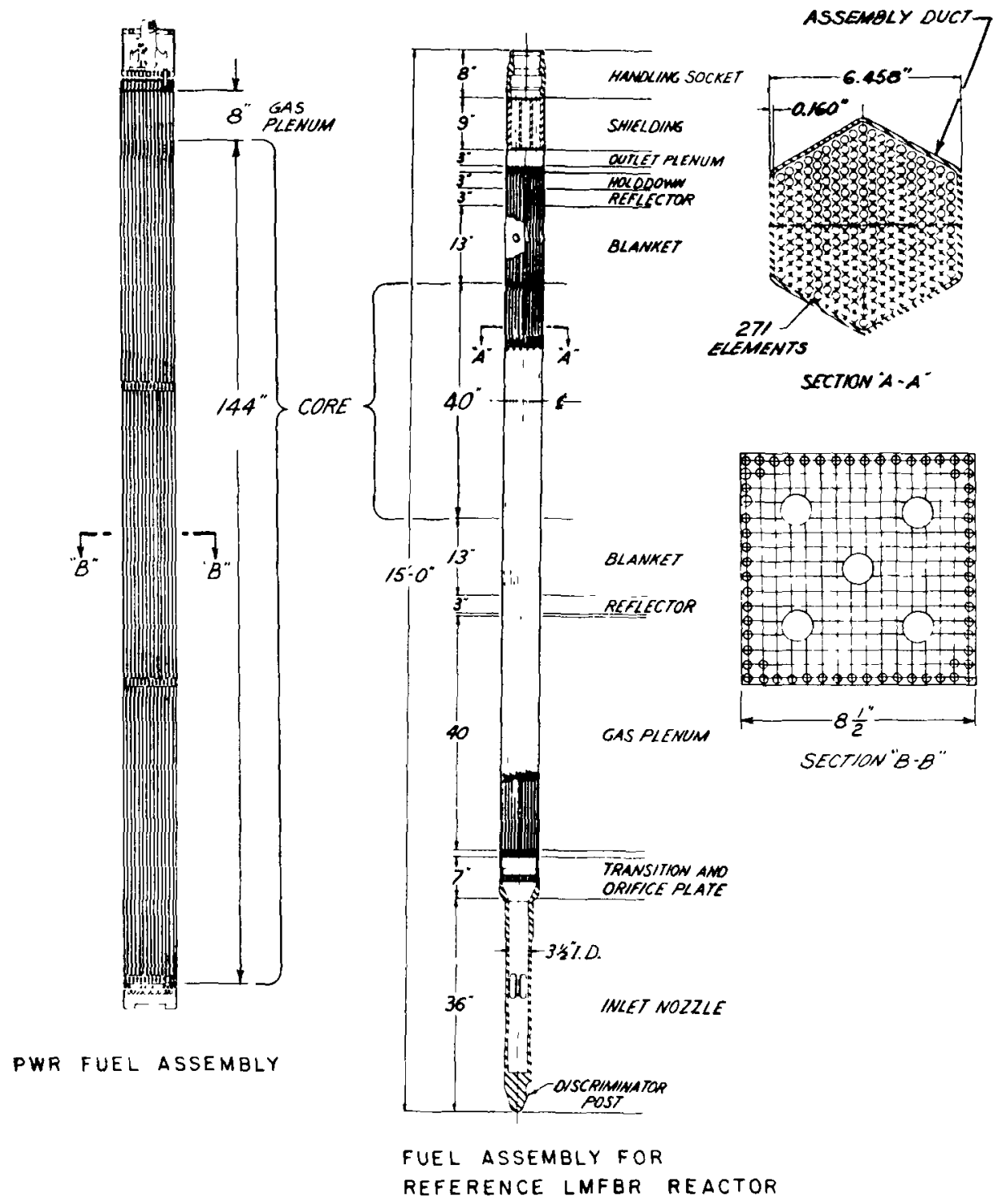

Fig. III-1. Comparison of LMFBR and PWR Fuel Assemblies 

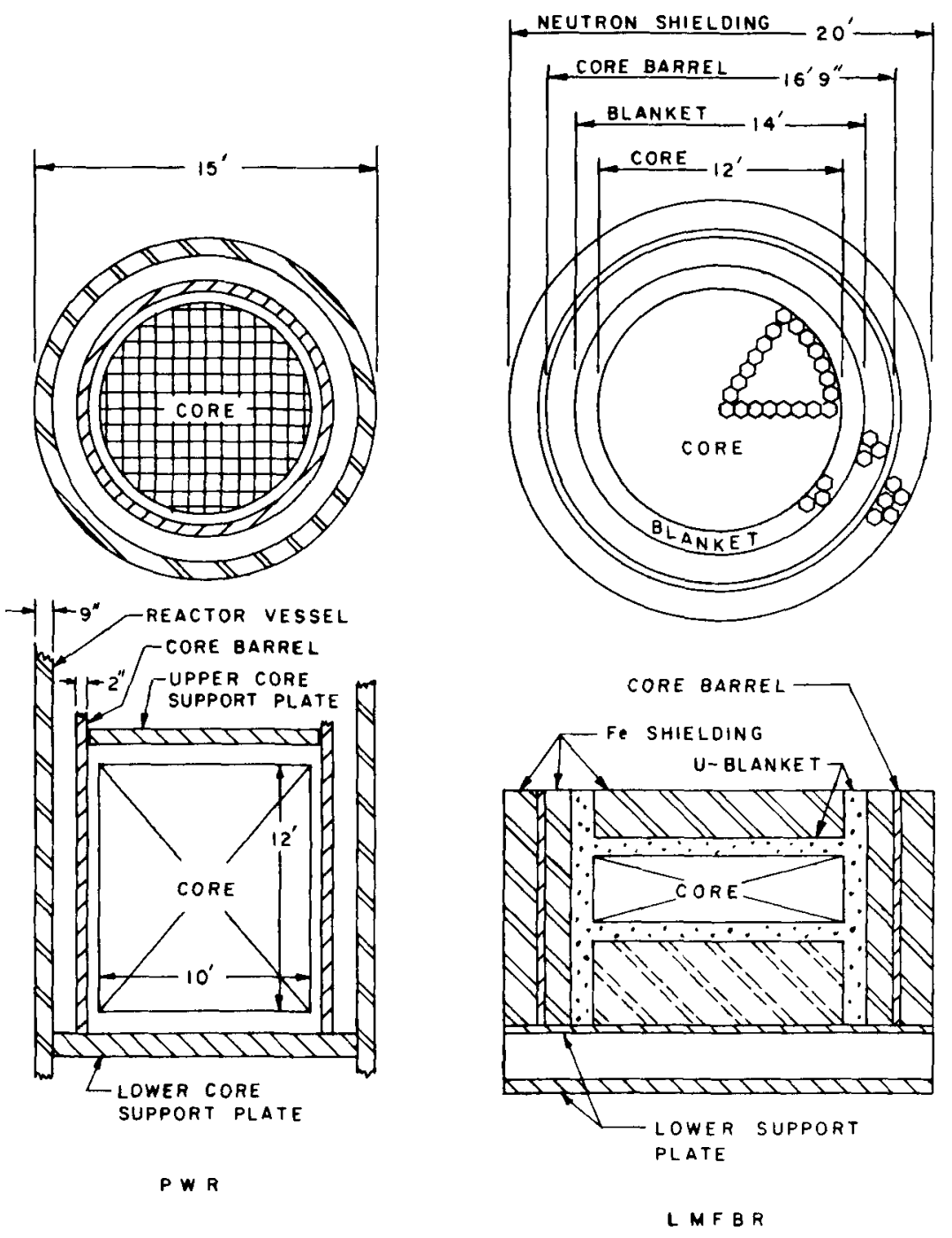

Fig. III-2. Comparison of PWR and LMFBR Core and Shielding Design 


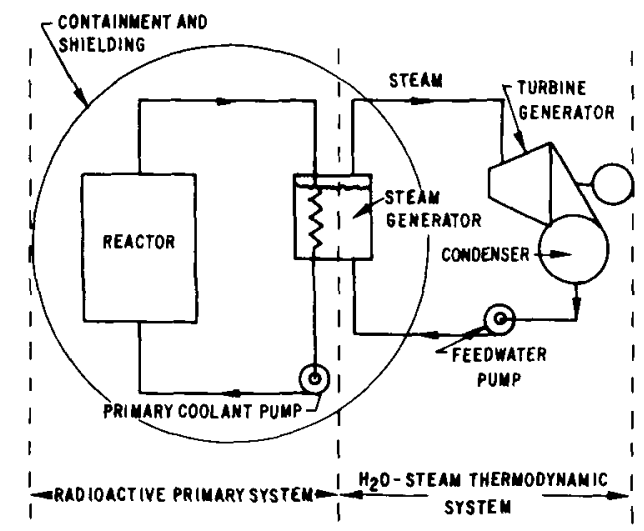

SCHEMATIC PWR NUCLEAR POWER PLANT

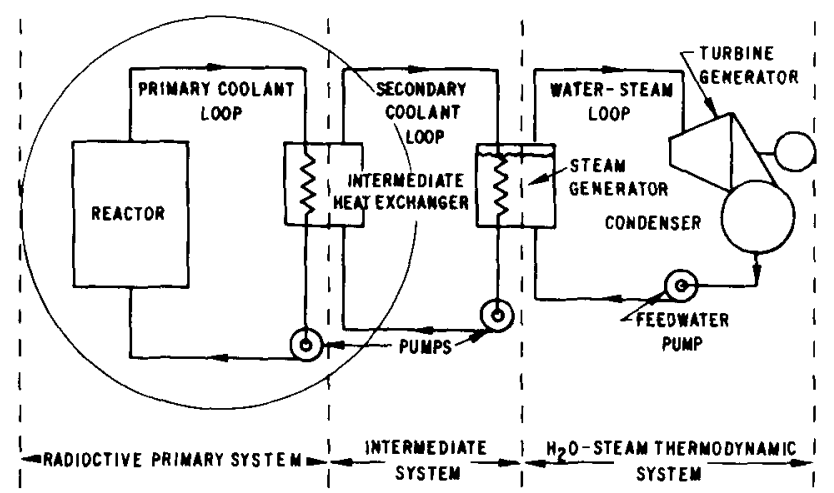

SCHEMATIC LMFBR MUCLEAR POWER PLANT (LOOP TYPE)

Fig. III-3. Comparison of LMFBR with PWR Power Plant

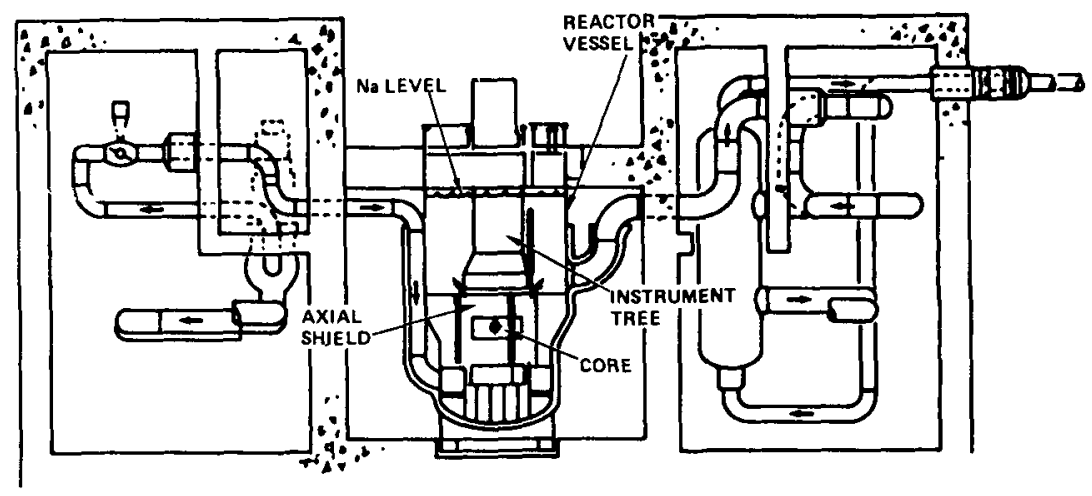

Fig. III-4. Loop Configuration 


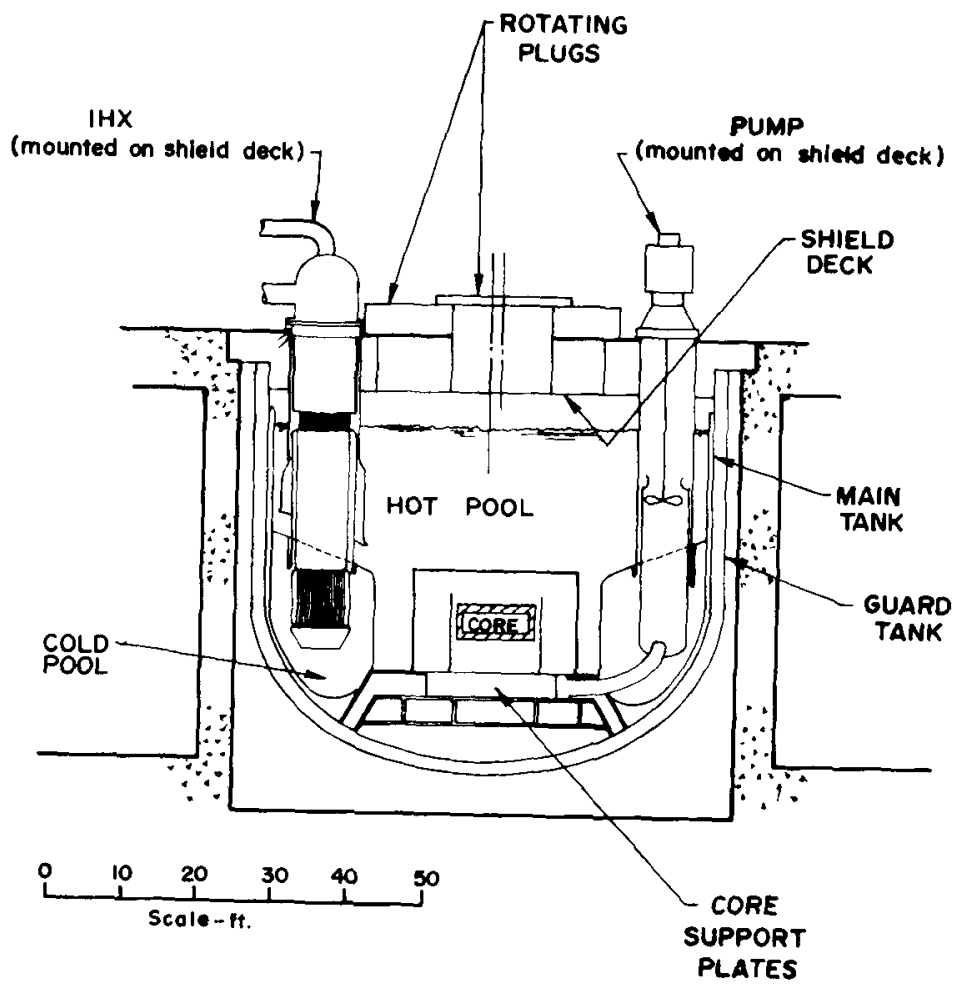

Fig. III-5. Schematic of LMFBR Pool Type Primary System
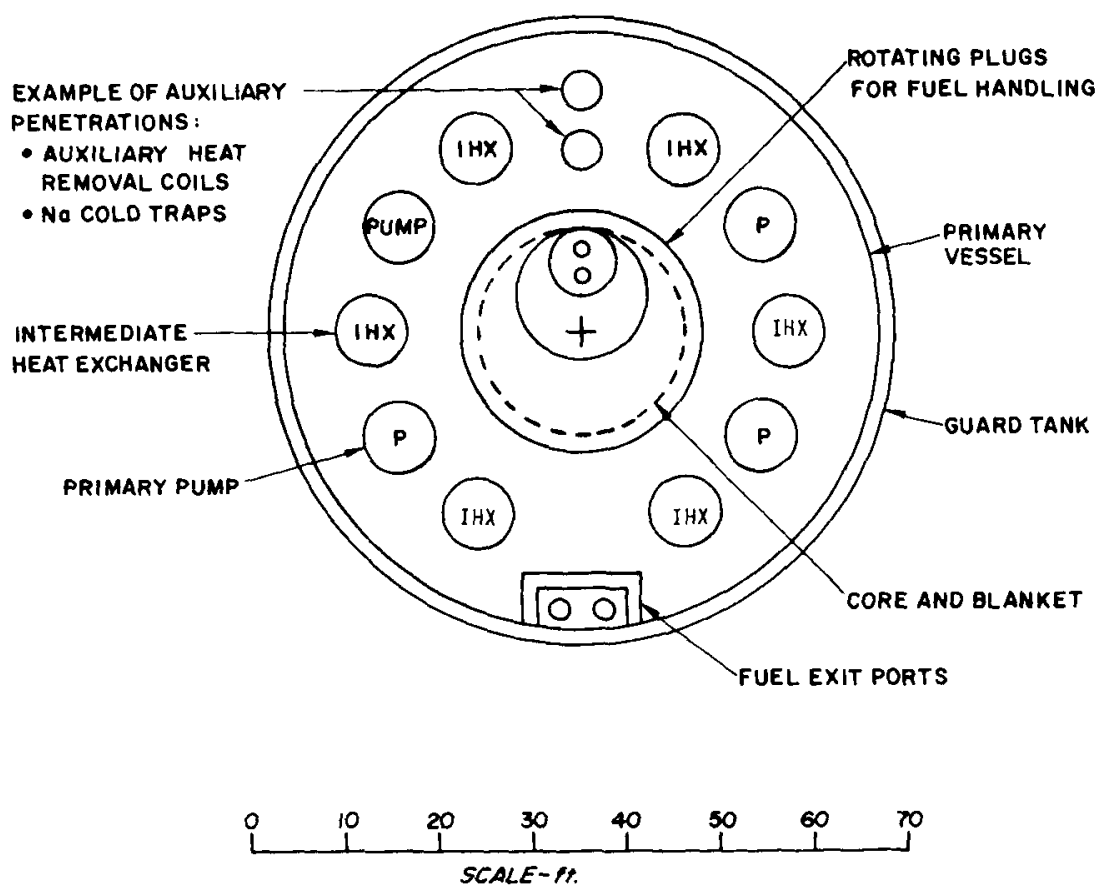

Fig. III-6. Schematic Plan View of Pool Tank Showing Location of IHX's and Pumps 


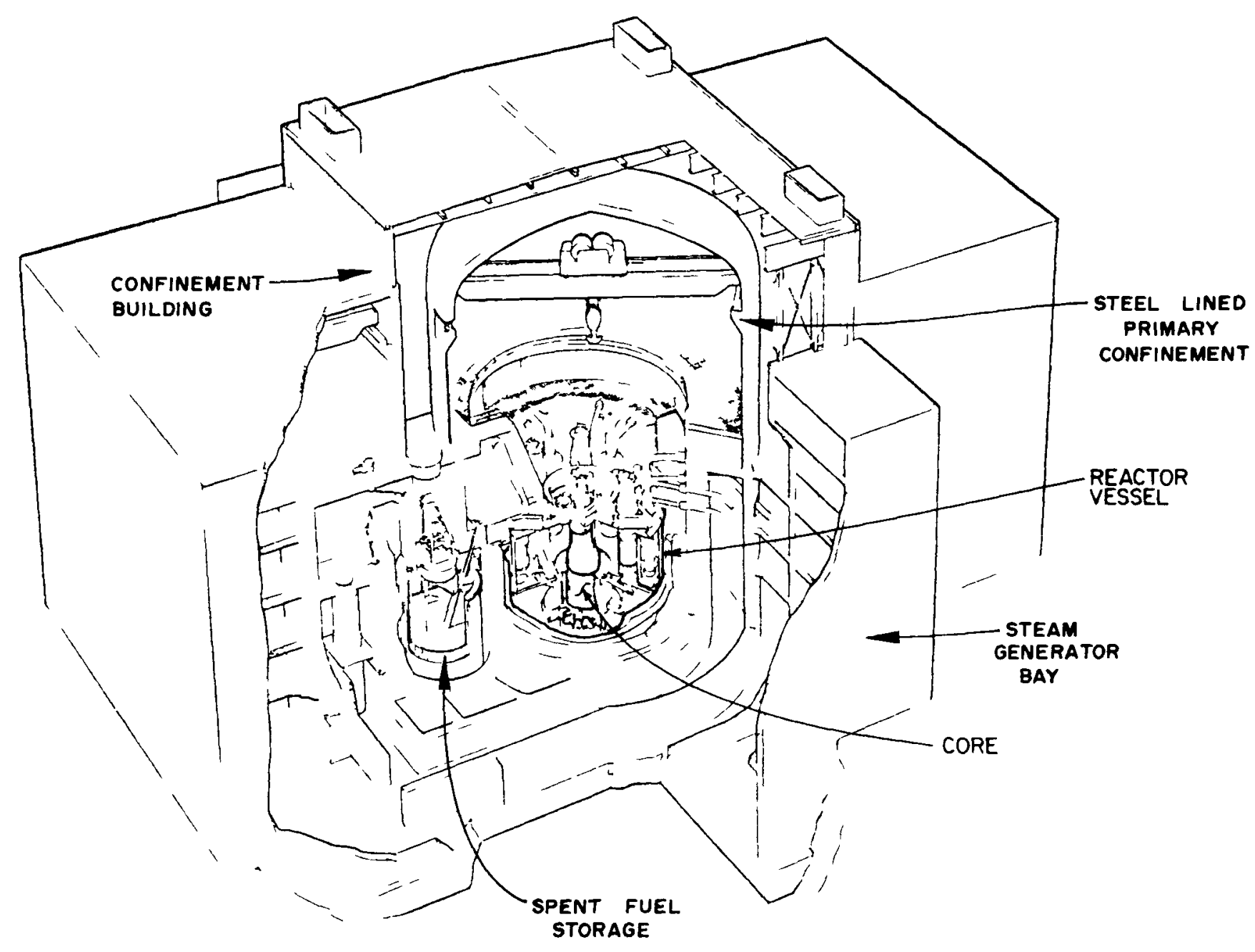

Fig. III-7. Cross-Section LMFBR Reactor Building. ${ }^{3}$ 
sodium purification system. Reactor building concepts usually include two independent containment envelopes. One of a number of different approaches to this redundant containment is shown in Fig. III-7. The primary containment can be located close to the building wall as in CRBR, or closer to the reactor as in Fermi and in Super Phenix.

Spent fuel is usually transferred in a sodium pot to a sodium-filled spent fuel storage pool where fuel is held up for several months to allow the fission product heat and radioactivity to decay prior to shipment (see Figs. III-7 and -8). The elements are prepared for shipment in an inert gas handling cell (Fig. III-8). The cell is exposed to some fission products from the reactor and to sodium vapor.

The intermediate system is cooled with sodium and operates at a pressure slightly higher than the primary system to preclude possible leakage of radioactive primary system sodium into it. The intermediate system sodium does become slightly radioactive by very low direct neutron activation. The activity is only ${ }^{24} \mathrm{Na}$ with a half-life of $15 \mathrm{hr}$ which completely dies away in less than a month. A representative intermediate system is shown in Fig. III-9.

The sodium-water reaction products system, the cold trap purification system, and the sodium drain tanks for the intermediate system are shown schematically in Fig. III-10.

\section{Comparison of LMFBR with PWR}

In order to put into perspective the similarities and differences of an LMFBR with a PWR, some particularly pertinent features of the plants are compared here.

A cross section of the reactor vessel for the LMFBR and the PWR are shown in Fig. III-11. The pool-type LMFBR vessel is much larger in diameter because it contains the primary system pumps, heat exchangers, inclined fuel unloading ramp, and shielding. It is longer because the sodium level above the core is set by the practice of fuel handling below the sodium level, sodium level being some 6 meters above the top of core assembly heads. Fuel transfer in a water reactor is accomplished by flooding the compartment above the reactor vessel.

Cross sections of the respective reactor buildings are shown in Fig. III-12. The PWR building is smaller in size and includes the steam generators. The PWR reactor vessel is positioned lower than the LMFBR reactor vessel to allow for the fuel handling pool located above the vessel. Considerable equipment is located in the PWR building to provide for emergency core cooling. In the cross section for the LMFBR, the steam generator bays are shown so that the systems included in each cross-sectional view contain systems of comparable nuclear supply system functions. However, only the domed portion of the building contains radioactivity.

Schematic overall plot plan views of the respective plants are shown in Fig. III-13. The plot plan for a PWR is slightly smaller than for an LMFBR. It is pointed out that plot plans vary greatly from one design to the next, regardless of reactor type. 


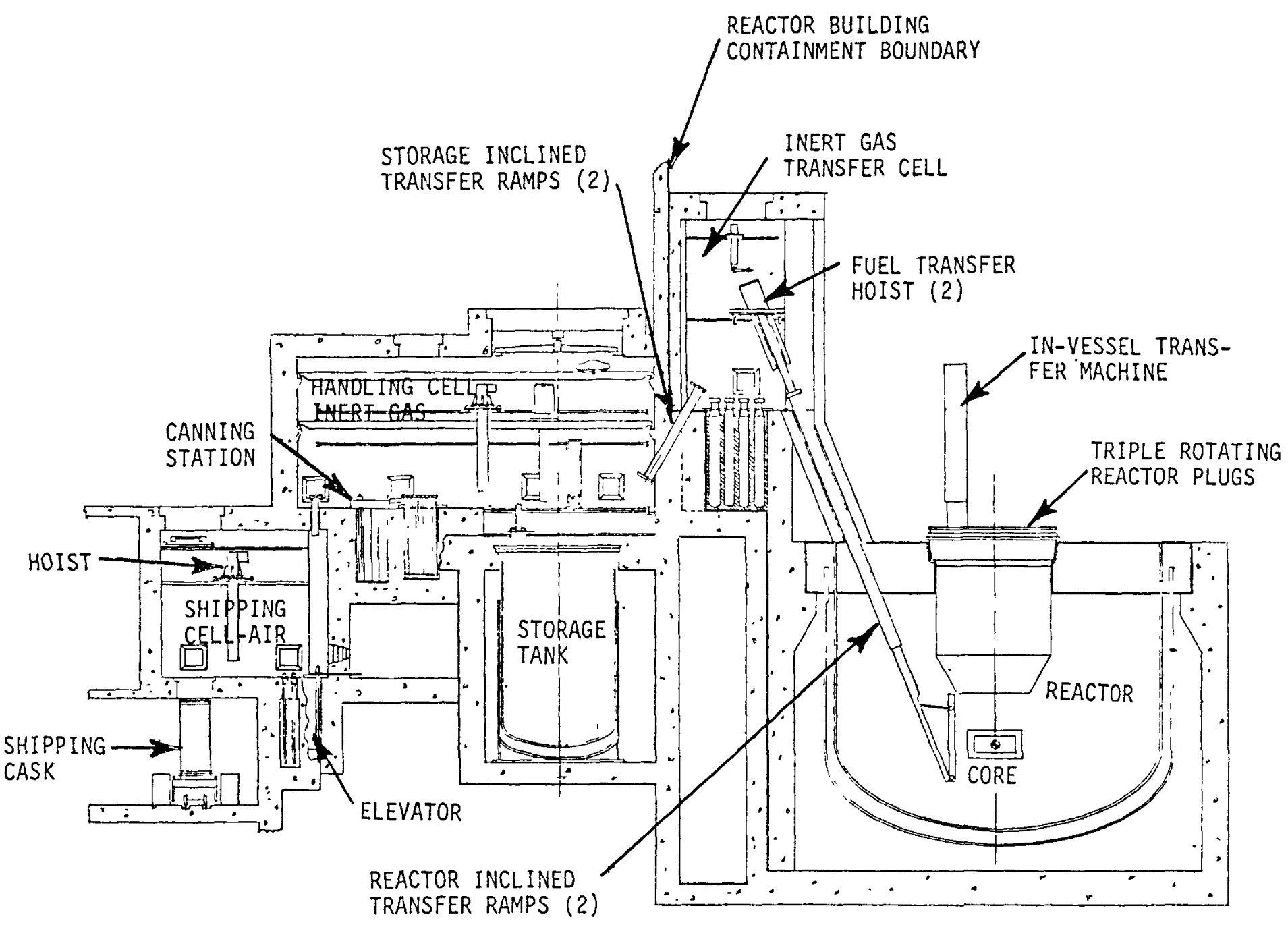

Fig. III-8. LMEBR Spent Fuel Handiing 


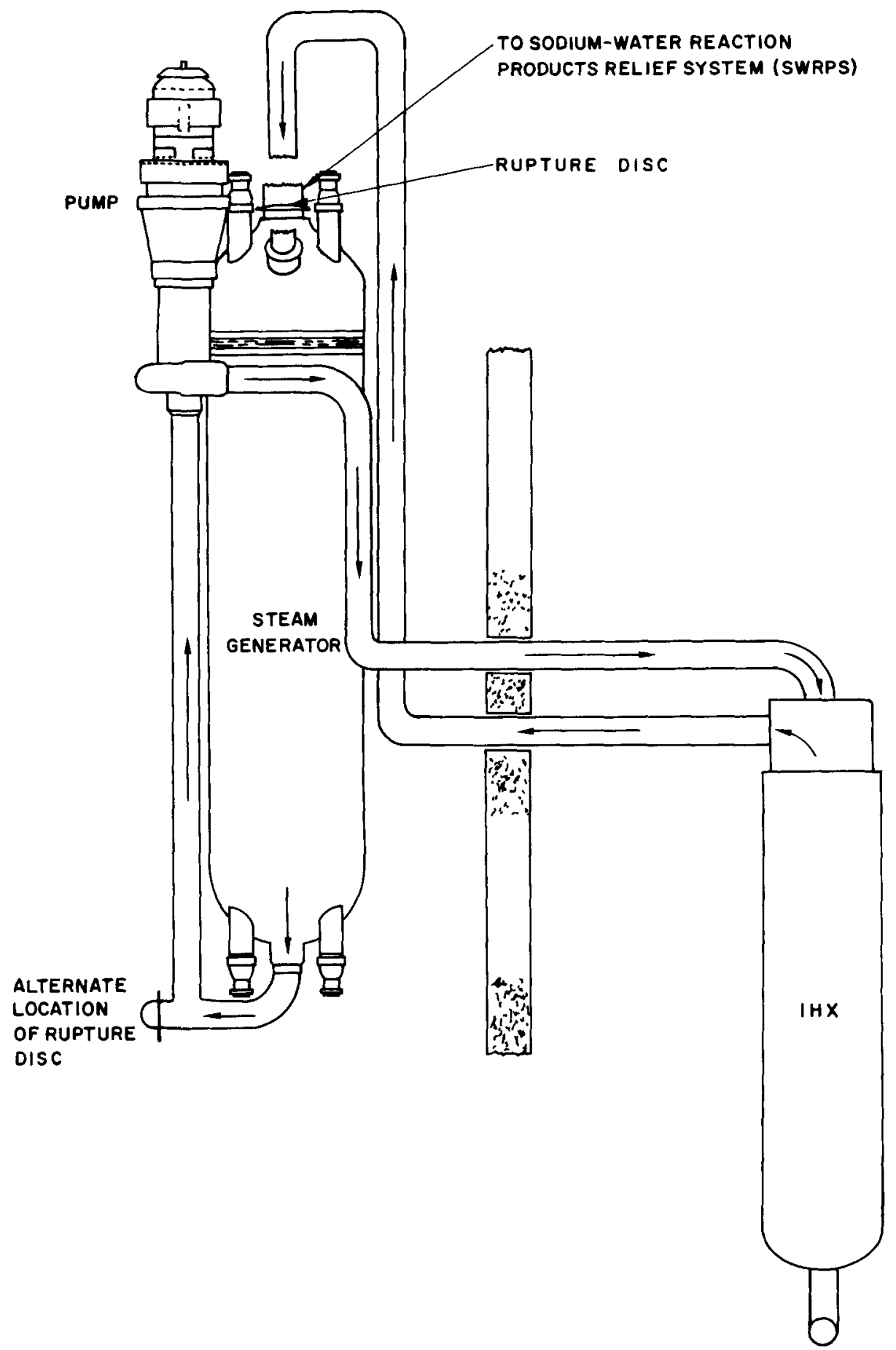

Fig. III-9. Schematic of LMFBR Intermediate Loop Piping Layout 


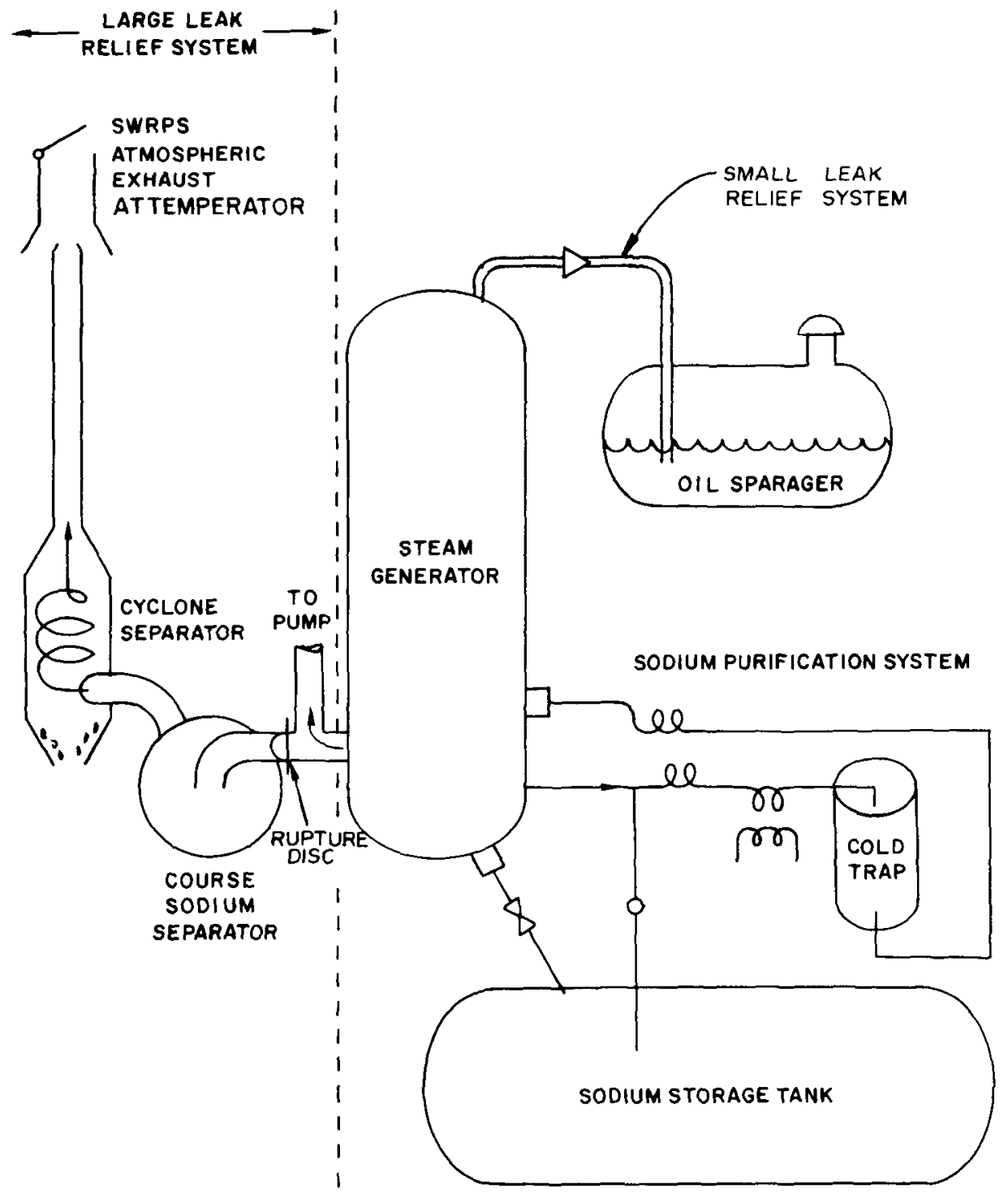

Fig. III-10. Other Components of the Steam Generator System Exposed to Sodium 

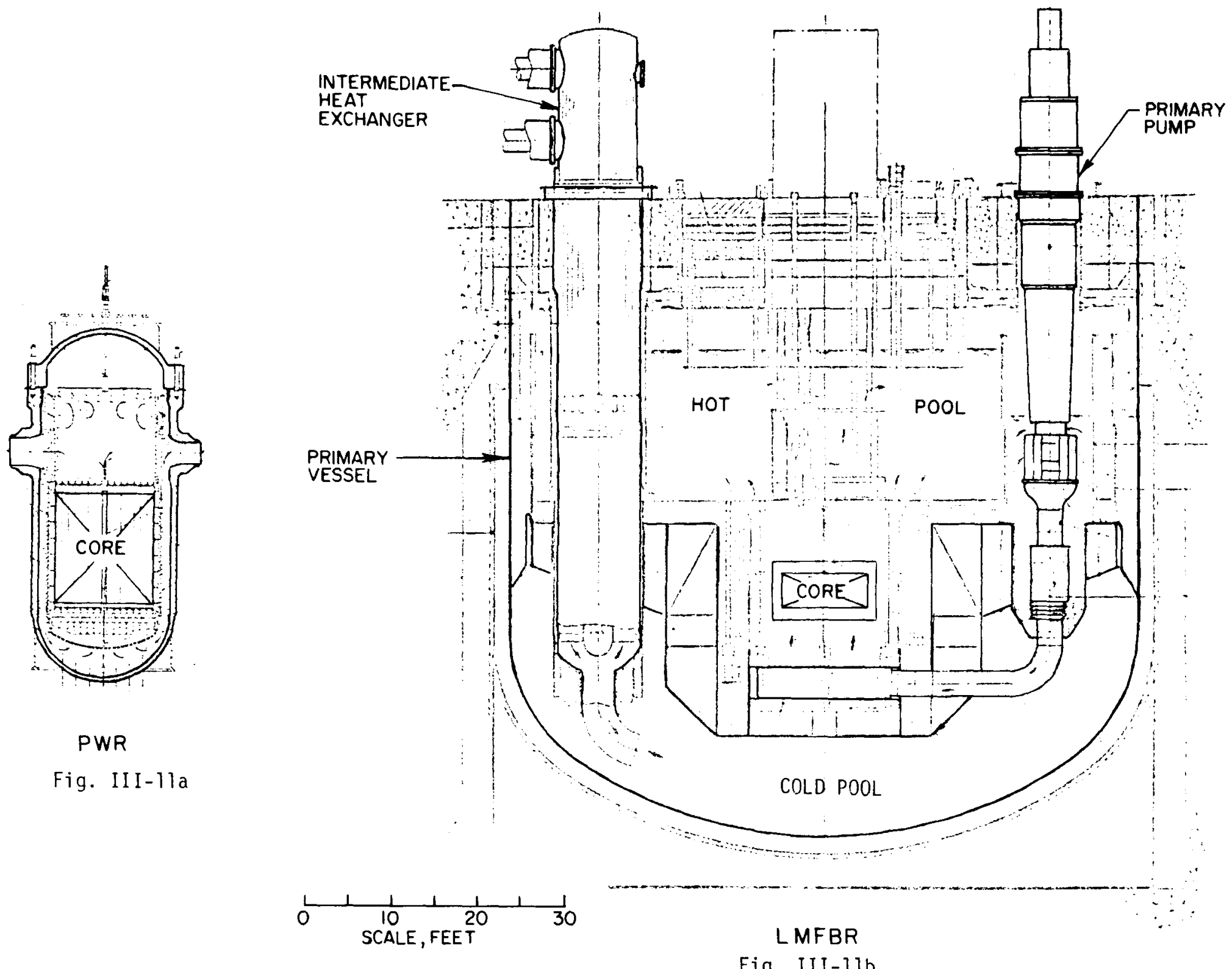

Fig. III-11. Comparison of Elevation View of LMFBR and PWR Reactor Vessels 
STEAM

GENERATOR

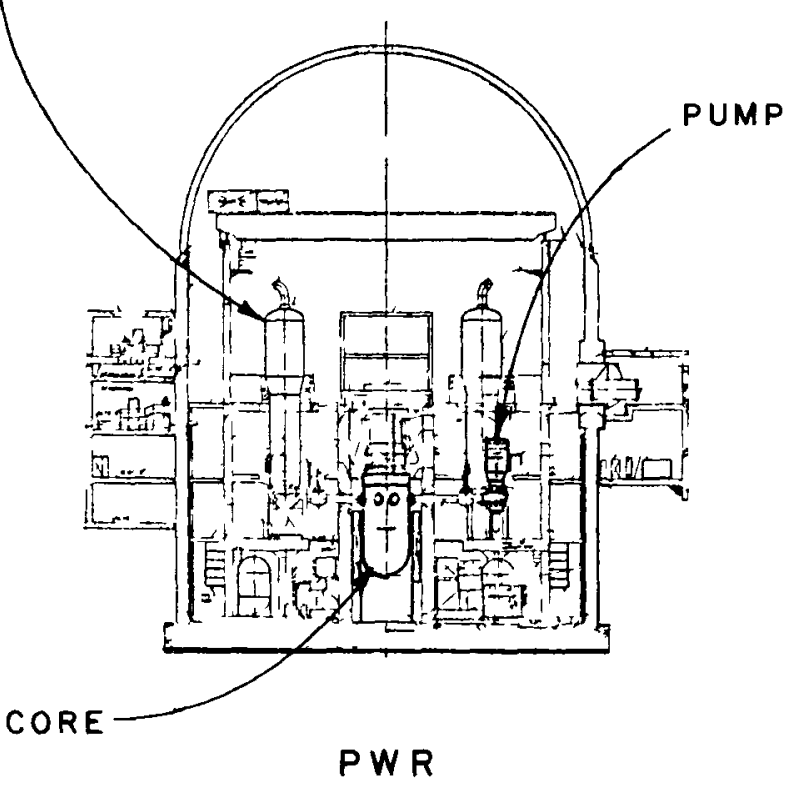

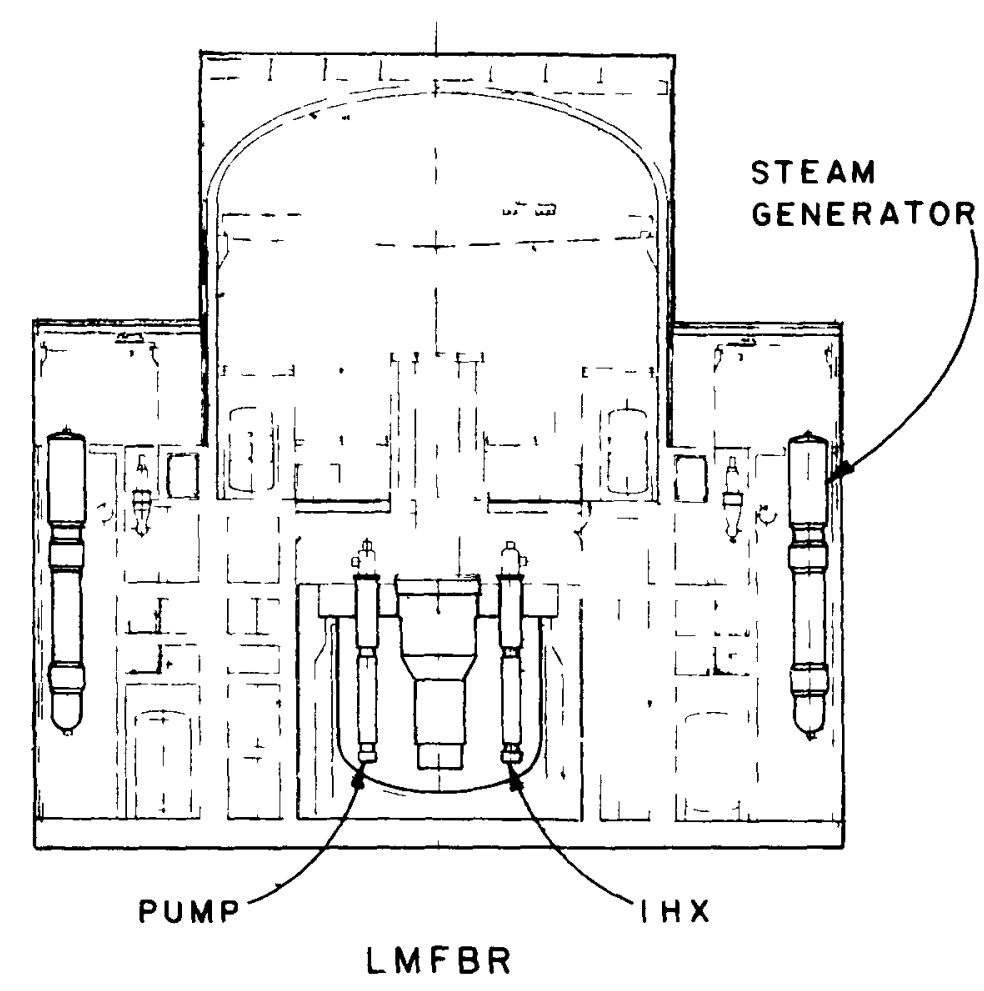

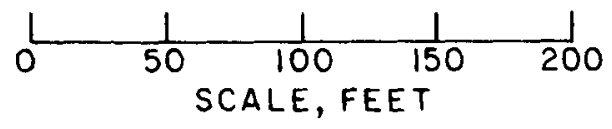

Fig. III-12. Comparison of LMFBR with PWR Reactor Building 


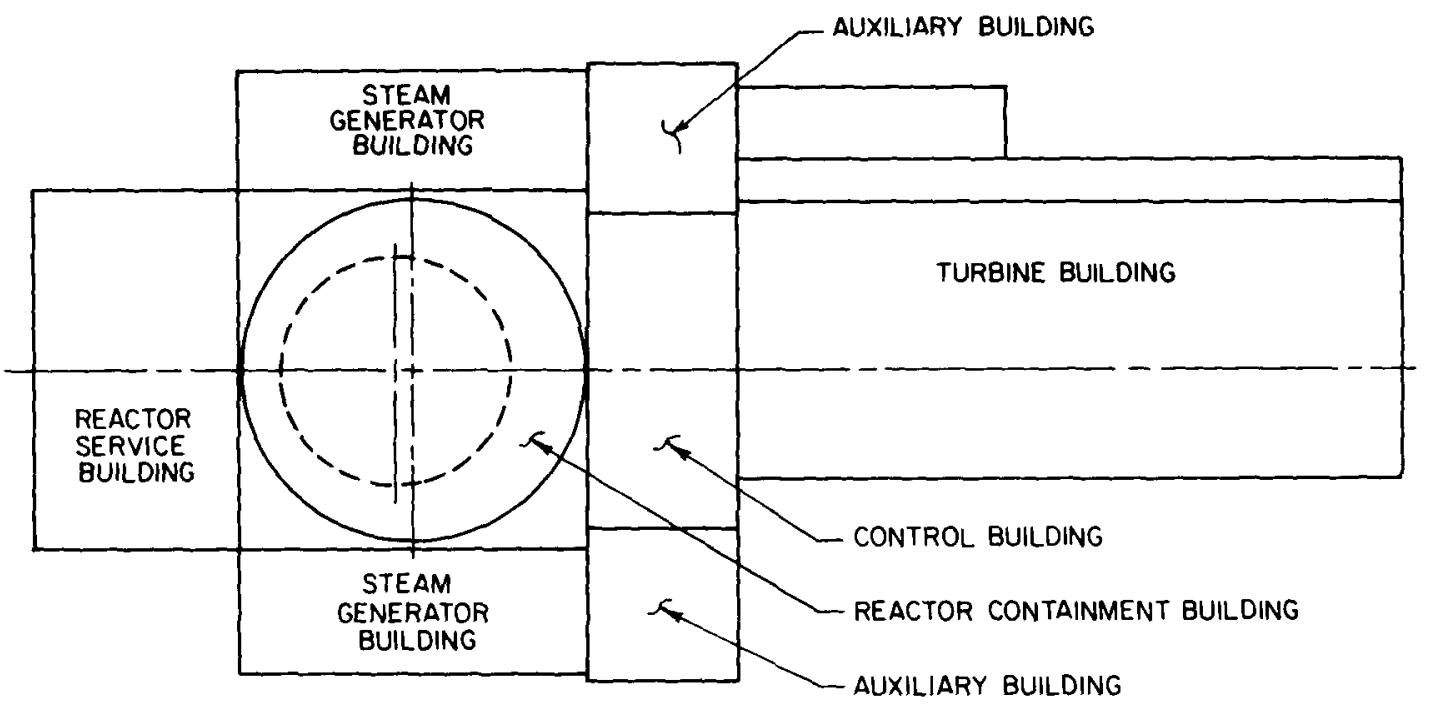

SCHEMATIC PLAN VIEW OF LMFBR PLANT

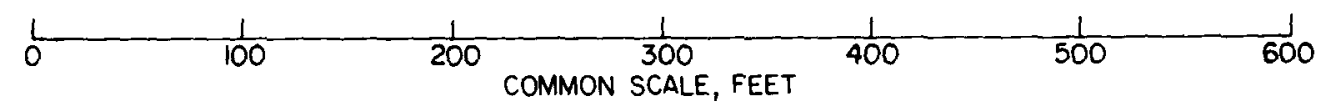

BORON -

RECOVERY

BUILOING
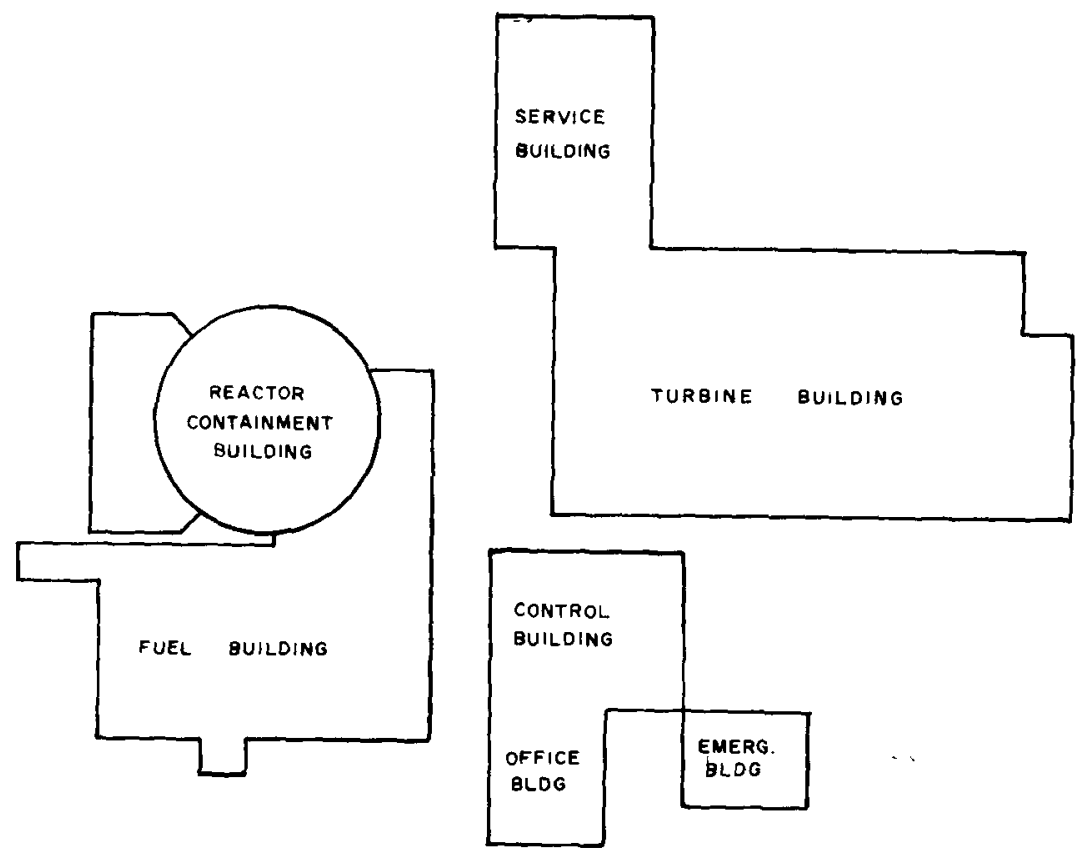

schematic Plan VIEW OF PWR PLANT

Fig. III-13. Comparison of Plot Plan for LMFBR vs.

PWR Reactor Plant 


\section{PRIMARY SYSTEM RADIOACTIVITY}

In the context of decommissioning any reactor, there are three general categories of primary system activation which need to be considered: (1) activity induced in fixed structures and removable components, (2) deposits of fission products and activated corrosion products fixed structures and removable components, and (3) residual activity in the coolant. The first two categories of primary system activation are covered in this section. The third category, residual coolant activity, is covered in Section V, Sodium Activation, Decontamination, and Disposal.

\section{A. Activation of Components and Structures}

The design requirements chosen by LMFBR reactor engineers greatly facilitate disassembly and decommissioning of these reactors. Neutron fluence limits to components are set based on maintenance of the major components of the plant. The core is surrounded by removable shielding so neutron fluxes on major structures and components are quite low.

Shielding is provided to reduce the neutron flux to acceptable levels primarily with respect to: (1) radiation damage in structural materials; (2) activation of repairable components; (3) activation of the secondary (intermediate) system sodium; and (4) biological dose to operating and maintenance personne1.

In the area of radiation damage in structural materials, the principal components requiring protection are the core barrel (if one is used), and core support structure, all other major components being subjected to a significantly lower fluence. Adequate protection can be achieved by providing approximately 13 in. of depleted uranium blanket and 12 in. of steel shielding (the reactor reflector) between the reactor core and these components.

In the pool-type system in which components requiring removal for maintenance, such as pumps and intermediate heat exchangers (IHX's), are located in the sodium pool at about, say $16 \mathrm{ft}$ from the core barrel, the activation of these components by neutron capture can be kept to levels that allow efficient maintenance by providing the equivalent of about 16 in. of steel shielding additional to the 12 in. required for protection of the core barrel. (Ease of maintenance is affected, however, by fission products and corrosion products that may be deposited on the component surfaces, and provision is made for decontaminating components prior to maintenance.)

Activation of the secondary-system sodium can be kept to acceptable levels by providing adequate shielding between the core and the IHX's. In a pool-type system, approximately $18 \mathrm{in.} \mathrm{(minimal)} \mathrm{of} \mathrm{steel} \mathrm{shielding} \mathrm{additional} \mathrm{to} \mathrm{the}$ 12 in. required for the protection of the core barrel are needed for this purpose. This again assumes the presence of about $14 \mathrm{ft}$ of sodium between the reactor and the IHX's. The neutrons contributing significantly to the activation of the secondary sodium have energies in the range of 2 to $300 \mathrm{keV}$. The sodium in the main tank is an effective shield for the secondary sodium in the IHX's.

Based on experience, it is reasonable to assume that dose rates at the pump and IHX component surfaces at the time of completion of component removal 
on a normal maintenance operation from the system and decontamination should not exceed about $20 \mathrm{mR} / \mathrm{hr}$.

A schematic vertical section of the primary system area of a conceptual 1200-MWe pool-type LMFBR based on the EBR-II design approach is shown in Fig. IV-1. Represented are the reactor, an IHX, the main tank, guard tank, main tank cover, rotating shield plug, top biological shield (shield deck), and radial biological shield. The reactor employed is the reference reactor (with minor deviations) described in Section III. Proceeding radially outward from the reactor core, the principal locations requiring consideration of shielding are noted in the figure: (1) the core barrel; (2) the IHX tube bundle; (3) the intermediate system sodium within the IHX; and (4) the area immediately external to the radial biological shield. In Fig. IV-2, proceeding vertically from the reactor core, similar locations are noted: (5) the reactor assembly support grid; (6) the instrument tree positioned in the reactor outlet plenum; (7) the area on top of the rotating plugs; (8) the general area above the shield deck; and (9) the peripheral area above the shield deck.

Reasonably typical shielding criteria for all of the critical areas discussed are summarized in Table IV-1.

The calculated neutron flux as a function of radius is shown in Fig. IV-3a. The highest energy flux is seen to fall off extremely rapidly from the edge of the core outward. The flux at energies greater than $0.11 \mathrm{MeV}$ is reduced by approximately five orders of magnitude as it traverses the radial blanket, the reflector, the core barrel, the in-vessel shielding, the reactor vessel, and the stainless steel shield outside the reactor vessel. It is reduced more than another twelve orders of magnitude as it traverses the approximate $24 \mathrm{ft}$ of sodium in the main tank. The 6-10 MeV flux drops even more steeply. The thermal flux decreases substantially more slowly, but nevertheless is reduced to the order of $10^{3} \mathrm{n} / \mathrm{cm}^{2}-\mathrm{sec}$ at the outer surface of the main tank. After traversing only a fraction of the radial biological shield, the total neutron flux is reduced to a negligible value.

The neutron flux distribution in the vertical direction is shown in Fig. IV-3b. The vertical flux distribution is qualitatively similar to the distribution in the radial direction.

For comparison the thermal flux information for a 1200 MWe PWR is shown in Fig. IV-4. Figure IV-4a gives the radial thermal flux distribution at the core axial midplane. Figure IV-4b gives the axial flux distribution in terms of a normalized activity distribution.

\section{B. Comparison of LMFBR with PWR Activation}

\section{Introduction}

In order to compare the relative degree of activation of primary system components, the PWR described in Appendices $B$ and $C$ of AIF/NESP-009l is used as a reference. Examination of the activation of the Fermi reactor, Table IV-2, and the material in AIF/NESP-009 indicates that the comparison can be made using only three radioactive isotopes, ${ }^{55} \mathrm{Fe},{ }^{60} \mathrm{Co}$, and ${ }^{63} \mathrm{Ni}$. Each of these is the dominant isotope at some time in either stainless steel or carbon steel, the materials of interest. ${ }^{55} \mathrm{Fe}$ is the dominant radioactive isotope at 


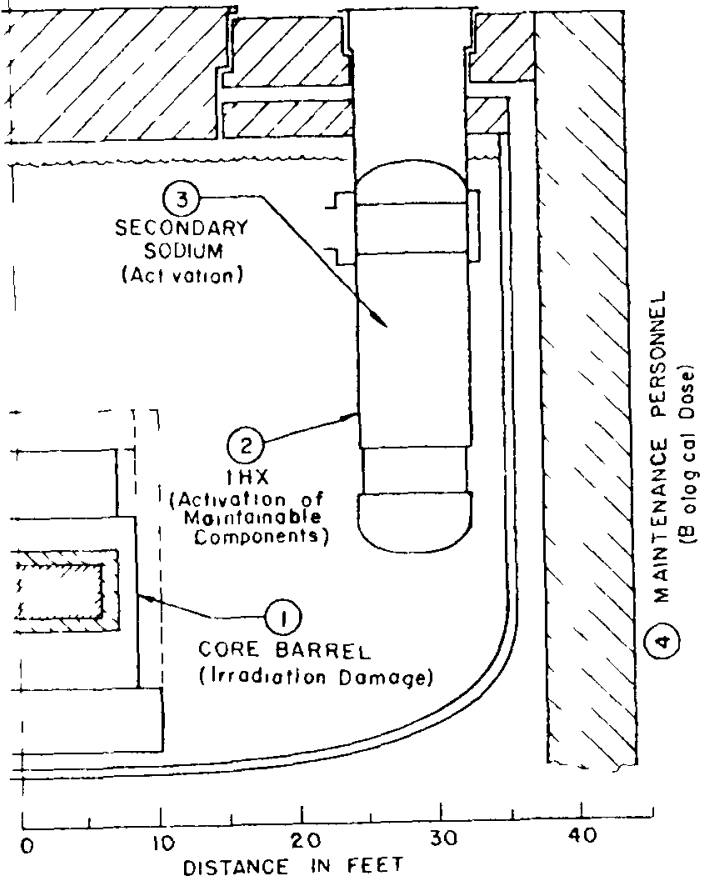

Fig. IV-1. Schematic Vertical Section of Conceptual Reference Reactor, Showing Shielding Areas: Proceeding Radially from Core.

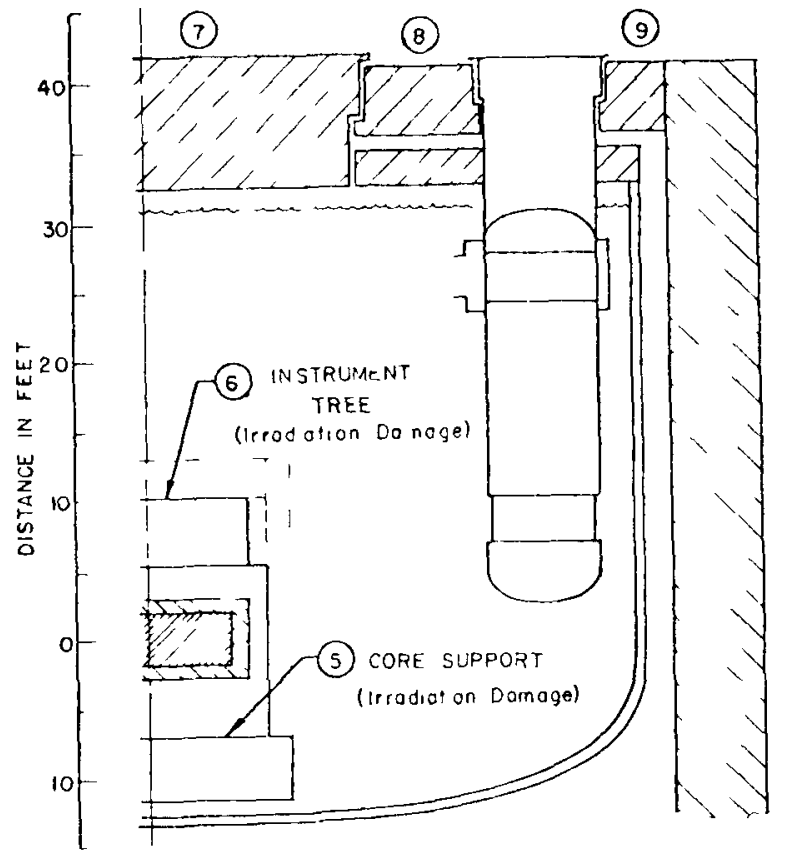

Fig. IV-2. Schematic Vertical Section of Conceptual Reference Reactor, Showing Shielding Areas: Proceeding Vertically from Core.

TABLF IV-1. Summary of Specific Shielding Criteria

\begin{tabular}{|c|c|}
\hline Location & Criterion \\
\hline 1 & 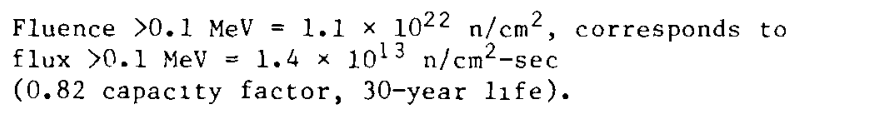 \\
\hline 2 & $\begin{array}{l}<20 \mathrm{mR} / \mathrm{hr} \text { (from lnduced activity) at component surface } \\
\text { after } 48 \mathrm{hr} \text {, corresponds to thermal flux } 10^{8} \mathrm{n} / \mathrm{cm}^{2}-\mathrm{sec} \text {. }\end{array}$ \\
\hline 3 & $\begin{array}{l}<2 \mathrm{mR} / \mathrm{hr} \text { at surface of secondary system piping and com- } \\
\text { ponents, corresponds to total flux } \sim 5 \times 10^{7} \mathrm{n} / \mathrm{cm}^{2}-\mathrm{sec} \text {. }\end{array}$ \\
\hline 4 & $\begin{array}{l}<0.2 \mathrm{mR} / \mathrm{hr} \text { dose rate, corresponds efther to (1) thermal } \\
\mathrm{flux}=200 \mathrm{n} / \mathrm{cm}^{2}-\mathrm{sec} \text { or fast flux }=3 \mathrm{n} / \mathrm{cm}^{2}-\mathrm{sec} \text {, } \\
\text { or (2) gamma dose rate }=<0.2 \mathrm{mR} / \mathrm{hr} \text {. }\end{array}$ \\
\hline 5 & Same as for Location 1 . \\
\hline 6 & 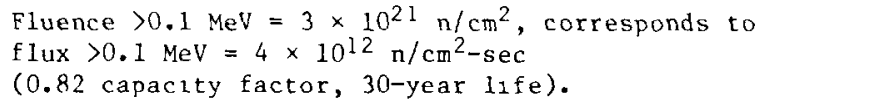 \\
\hline $7-9$ & Same as for Location 4. \\
\hline
\end{tabular}




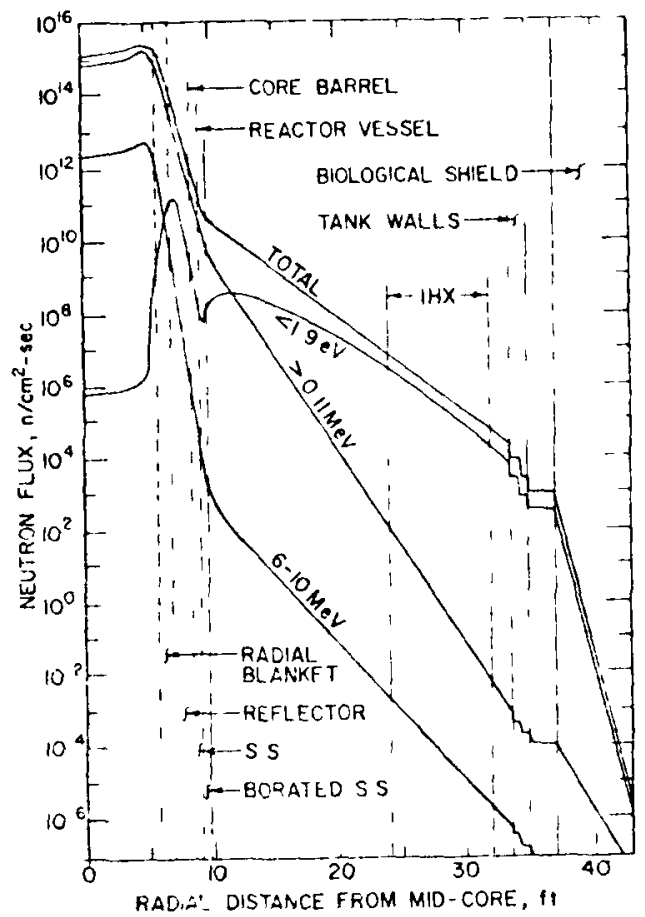

Fig. IV-3a. Radial Distribution of Neutron Flux in Reference LMFBR Reactor

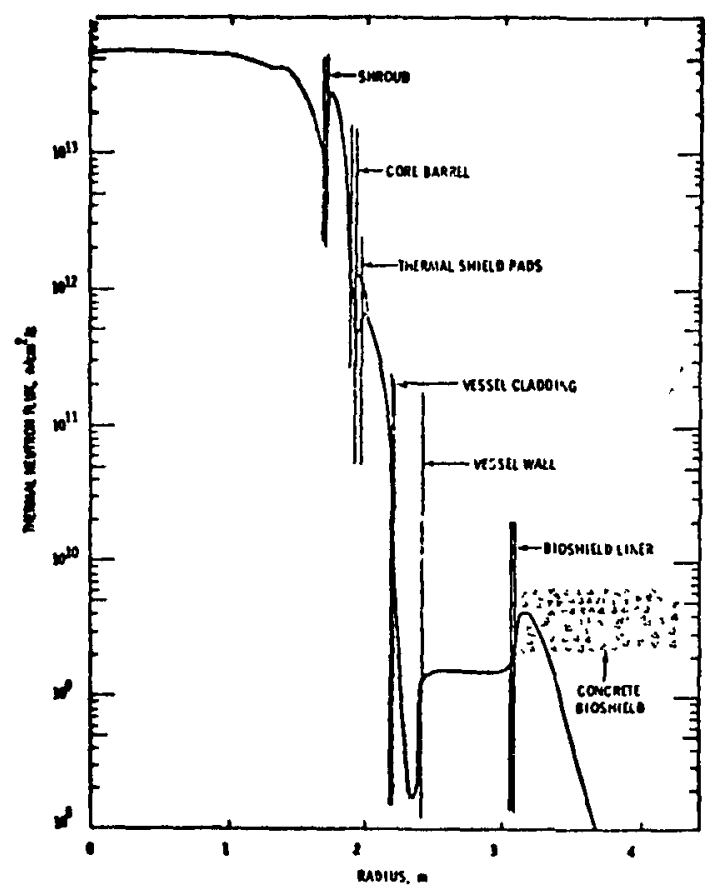

Fig. IV-4a. Radial Thermal Neutron Flux Distribution at Core Axial Midplane of a PWR

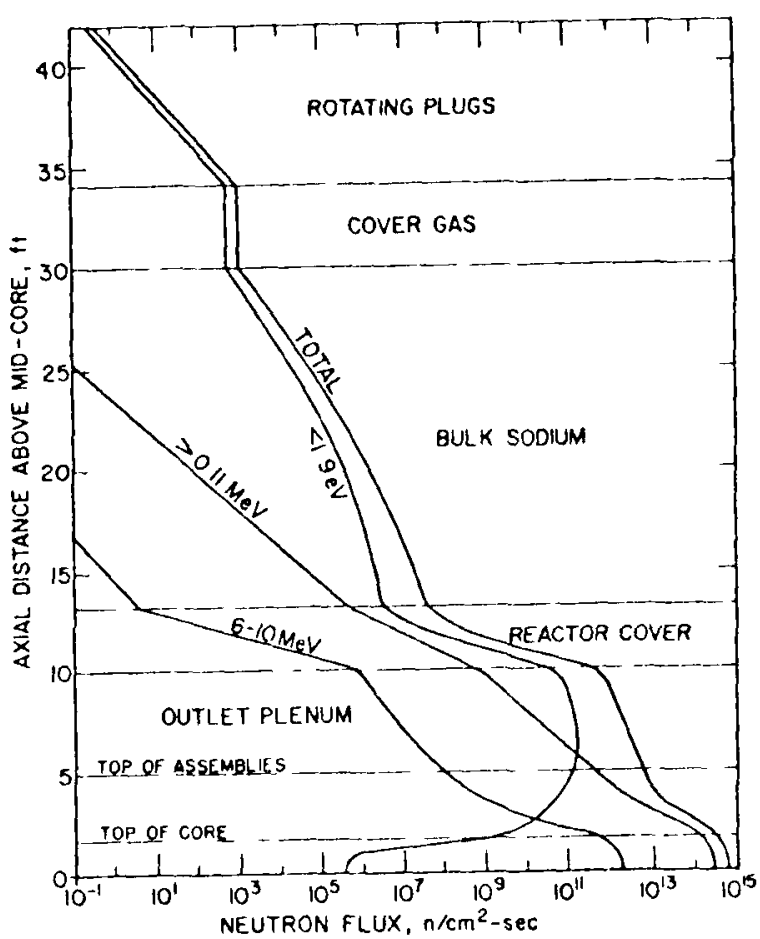

Fig. IV-3b. Axial Distribution of Neutron Flux in Reference LMFBR Reactor

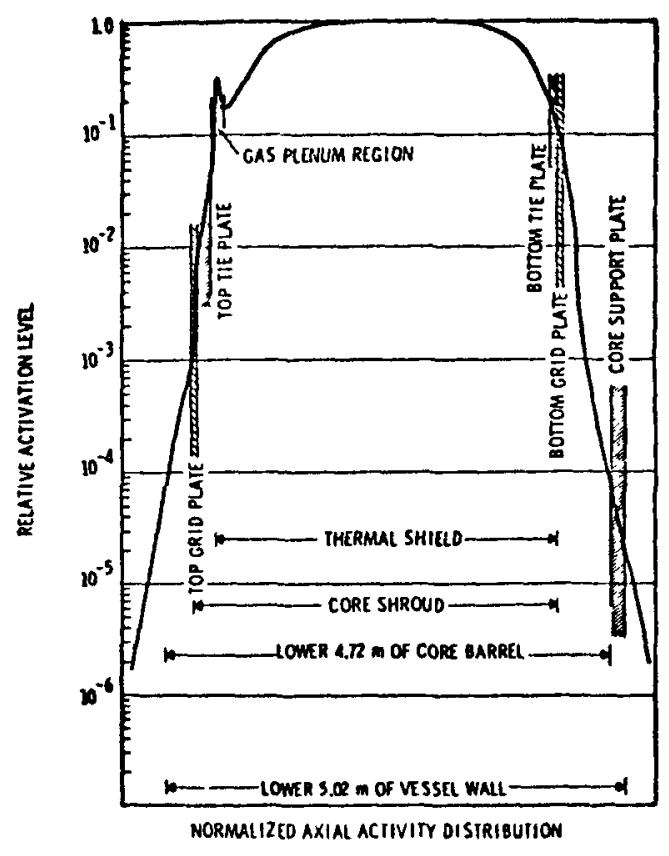

Fig. IV-4b. Normalized Axial Distribution of a PWR 
TABLE IV-2. Stainless Steel Activation in Fermi Reactor Vessel (Neglecting Blanket Subassemblies)

(as of June 1,1973$)^{a}$

\begin{tabular}{|c|c|c|c|c|c|}
\hline \multirow[b]{2}{*}{ Component } & \multicolumn{5}{|c|}{ Activation Source, curies } \\
\hline & $\begin{array}{c}{ }^{63} \mathrm{Ni} \\
(100 \mathrm{a})\end{array}$ & $\begin{array}{c}{ }^{55} \mathrm{Fe} \\
(2.7 \mathrm{a})\end{array}$ & $\begin{array}{l}{ }^{58} \mathrm{Co} \\
(71 \mathrm{~d})\end{array}$ & $\begin{array}{l}{ }^{60} \mathrm{Co} \\
(5 \cdot 3 \mathrm{a})\end{array}$ & Total \\
\hline \multicolumn{6}{|l|}{ Control and Safety Rod Channels } \\
\hline Portion in core & 2 & 76 & 21 & 9 & 108 \\
\hline Portion in blanket & $\mathrm{L}$ & 22 & 1 & 9 & 32 \\
\hline $\begin{array}{l}\text { Portion between blanket } \\
\text { and holddown }\end{array}$ & $\mathrm{L}$ & 1 & $\mathrm{~L}$ & 1 & 2 \\
\hline \multicolumn{6}{|l|}{ Holddown Mechanism } \\
\hline Inner region & 4 & 152 & $L$ & 158 & 314 \\
\hline Outer region $(\mathrm{R}>41 \mathrm{~cm})$ & 1 & 54 & $\mathrm{~L}$ & 70 & 125 \\
\hline Shield Bars & 22 & 796 & 12 & 105 & 935 \\
\hline \multicolumn{6}{|l|}{ Thermal Shield } \\
\hline Lower & 20 & 720 & 1 & 88 & 829 \\
\hline Upper & 2 & 76 & $\mathrm{~L}$ & 9 & 87 \\
\hline Holddown Column & $\mathrm{L}$ & 22 & $\mathrm{~L}$ & 3 & 25 \\
\hline \multicolumn{6}{|l|}{ Safety Rods - Poison Section } \\
\hline Lower & $\mathrm{L}$ & 1 & $\mathrm{~L}$ & 1 & 2 \\
\hline Middle & $\mathrm{L}$ & 1 & $\mathrm{~L}$ & 1 & 2 \\
\hline Upper & $\mathrm{L}$ & 1 & $\mathrm{~L}$ & 1 & 2 \\
\hline Rotating P1ug & $\mathrm{L}$ & 1 & $\mathrm{~L}$ & 1 & 2 \\
\hline Support Plates & 24 & 860 & $\mathrm{~L}$ & 965 & 1849 \\
\hline Support Structure & 7 & 258 & $\mathrm{~L}$ & 35 & 301 \\
\hline Support Structure Shielding & 8 & 269 & $\mathrm{~L}$ & 35 & 312 \\
\hline Flow Baffles & $\mathrm{L}$ & 10 & $\mathrm{~L}$ & 2 & 12 \\
\hline Conical Flow Guide & $\mathrm{L}$ & 1 & $\mathrm{~L}$ & 1 & 2 \\
\hline Lower Reactor Head Shielding & 4 & 152 & $\mathbf{L}$ & 18 & 174 \\
\hline Transfer Rotor & $\mathrm{L}$ & 1 & $\mathrm{~L}$ & 1 & 2 \\
\hline $\mathrm{OHM}$ & 1 & 44 & $\mathrm{~L}$ & 6 & 51 \\
\hline Reactor Vessel & - & - Negli & ible - & & - \\
\hline Total & 96 & 3515 & 35 & 1519 & 5168 \\
\hline
\end{tabular}

athe last operation of this reactor was in December 1971.

NOTE: $L=$ Less than 1 curie

This table has been updated since the January 19, 1973 submission. Activity due to ${ }^{55} \mathrm{Fe}$ and ${ }^{63} \mathrm{Ni}$ has been taken into account and that due to ${ }^{59} \mathrm{Fe}$ and ${ }^{51} \mathrm{Cr}$ deleted since these nuclides constitute less than 2 curies total 
short times, ${ }^{60}$ Co for intermediate, and ${ }^{63} \mathrm{Ni}$ for long times. The properties of these radioactive isotopes are given in Table IV-3a and $-3 \mathrm{~b}$.

Table IV-3a and $-3 \mathrm{~b}$ list various nuclear reactions which lead to the formation of radioactive nuclei. In general, there is a $(n, \gamma)$ reaction with thermal neutrons which leads to the formation of a radioactive nucleus, and there are high-energy-threshold reactions (Table IV-3b) of the $(n, p),(n, 2 n)$, $(n, 3 n)$ type which can lead to the same and nucleus but start from a different isotope. These are formed by high energy neutrons, In general, after one collision the neutron are removed from the high-energy region. In a fast reactor (as well as in a thermal reactor), the number of neutrons in this energy range decreases rapidly with increasing distance from the core and, therefore, component activation will be predominately caused by low-energy neutrons. Away from the core, the neutron energy distribution is characteristic of the environment for the neutron and not the location where they originated. Since there are no sources for high energy neutrons outside the core, the slowing down process will shift the mean neutron energy rapidly toward the thermal range. This slowing down process is so rapid that low-energy neutrons also dominate the activation of the core barrel. As shown in Fig. IV-3, the neutron flux in the range of $6-10 \mathrm{MeV}$ decreases by a factor $\sim 10^{7}$ from the core center to the core barrel while the total neutron flux decreases only by a factor $\sim 10^{3}$. The neutron flux below 1.9 eV increases from $\sim 10^{6} \mathrm{n} / \mathrm{cm}^{2}-\mathrm{sec}$ at the core center to $10^{9} \mathrm{n} / \mathrm{cm}^{2}-\mathrm{sec}$ at the core barrel. At this positon, the neutron flux between $6-10 \mathrm{MeV}$ is on $1 \mathrm{y} 10^{6} \mathrm{n} / \mathrm{cm}^{2}-\mathrm{sec}$. Therefore the higher fluxes at low energy combined with the higher low-energy capture cross section will clearly dominate the activation compared to the threshold reactions listed above.

The high energy neutrons exist only in the core region where they are born. High energy reactions play a role in PWR's in the activation of corrosion products which are contained in water and circulate through the core. In liquid-metal-cooled reactors the cladding can be activated by high-energy neutrons, and these corrosion products can then be transported by the sodium and deposited on structures. But even then, the low cross-sections for these reactions ( 0.1 b or less) do not contribute significantly to the formation of radioactive nuclei.

In the region beyond the blanket where the high-energy flux is low compared to the low-energy flux, a flux/mass weighting of activities rather than a reaction-rate/mass weighting can be used to estimate activities of components with different masses and subject to a different neutron flux.

The composition of the carbon steel and stainless steel used in this comparison are given in Table IV-4 and are those given in pages $B-3$ and $B-20$ of AIF/NESP-009. It is noted that NUREG/CR-0130 4 used a type 347 stainless steel which is stablized with niobium. This is not required in LMFBR's and, therefore, has been omitted from this study.

\section{Comparison of LMFBR and PWR Fluxes}

An indication of the specific activity which might be expected can be obtained by a comparison of the neutron flux levels in an LMFBR compared to a PWR. Figure IV-5 gives the fast-flux profile for PWR versus 
TABLE IV-3a. Properties of Radioactive Isotopes Formed by Neutron Reactions in Stainless Steel

\begin{tabular}{|c|c|c|c|c|c|c|}
\hline \multirow[b]{2}{*}{$\begin{array}{l}\text { Radioactive } \\
\text { Isotope } \\
\text { Formed }\end{array}$} & \multicolumn{3}{|c|}{ Initial Isotope in SS } & \multicolumn{3}{|c|}{ Radioactive Properties } \\
\hline & Isotope & $\begin{array}{l}\text { Isotope } \\
\text { Fraction } \\
\text { in Element }\end{array}$ & $\begin{array}{l}\text { Element } \\
\text { Fraction } \\
\text { in SS }\end{array}$ & $\begin{array}{l}\text { Half } \\
\text { Life }\end{array}$ & $\begin{array}{c}\text { Particles } \\
\text { Enitted }\end{array}$ & $\begin{array}{c}\text { Energy } \\
\text { of } Y \\
\text { Ray, } \\
\text { MeV }\end{array}$ \\
\hline \multicolumn{7}{|c|}{ FROM THERMAL NEUTRONS } \\
\hline${ }^{55} \mathrm{Fe}$ & $54 \mathrm{Fe}$ & 0.0582 & 0.68 & $2.7 \mathrm{a}$ & Y & $\begin{array}{l}0.236, \\
0.025\end{array}$ \\
\hline $51 \mathrm{Cr}$ & $50 \mathrm{Cr}$ & 0.043 & 0.19 & $2.3 \mathrm{~d}$ & $Y$ & 0.0324 \\
\hline $6{ }^{3} \mathrm{Ni}$ & ${ }^{62} \mathrm{Ni}$ & 0.032 & 0.0925 & $100 a$ & $B^{-}$ & \\
\hline $59 \mathrm{Ni}$ & $58 \mathrm{Ni}$ & 0.68 & 0.0925 & $8 \times 10^{4} a$ & $\gamma$ & $\begin{array}{l}0.289 \\
0.038\end{array}$ \\
\hline $60 \mathrm{Co}$ & ${ }^{59} \mathrm{Co}$ & 1.00 & $\begin{array}{l}0.002 \\
(\max )\end{array}$ & $5.3 a$ & $\gamma$ & $\begin{array}{l}1.17, \\
1.33\end{array}$ \\
\hline $182 \mathrm{Ta}$ & $181 \mathrm{Ta}$ & 0.99 & $\begin{array}{l}\text { Used in } \\
347 \mathrm{SS}\end{array}$ & $115 \mathrm{~d}$ & $\gamma$ & $\begin{array}{l}1.1, \\
1.29\end{array}$ \\
\hline $93 \mathrm{MO}$ & $92 \mathrm{MO}$ & 0.16 & $\begin{array}{l}\text { Used 1n } \\
316 \mathrm{SS}\end{array}$ & $3,000 a$ & $\gamma, B^{-}$ & 0.4 \\
\hline $94 \mathrm{Nb}$ & ${ }^{93} \mathrm{Nb}$ & 1.00 & $\begin{array}{l}\text { Used in } \\
347 \mathrm{SS}\end{array}$ & $20,300 a$ & $\gamma, B^{-}$ & 0.8 \\
\hline
\end{tabular}

TABLE IV-3b. Properties of Radioactive Isotopes Formed from Irradiation of Stalnless Steel

\begin{tabular}{|c|c|c|c|c|c|c|}
\hline \multirow{4}{*}{$\begin{array}{l}\text { Radioactive } \\
\text { Isotope } \\
\text { Formed }\end{array}$} & \multicolumn{3}{|c|}{ Initial Isotope in SS } & \multicolumn{3}{|c|}{ Radloactive Properties } \\
\hline & & Isotope & Element & & & $\begin{array}{c}\text { Energy } \\
\text { of } y\end{array}$ \\
\hline & & Fraction & Fraction & Half & Particles & Ray, \\
\hline & Isotope & in Element & in SS & Life & Emitted & $\mathrm{MeV}$ \\
\hline
\end{tabular}

FROM HIGH ENERGY NEUTRONS

\begin{tabular}{|c|c|c|c|c|c|c|}
\hline${ }^{54} \mathrm{Mn}$ & ${ }^{54} \mathrm{Fe}$ & 0.0582 & 0.68 & $312 d$ & $Y$ & 0.84 \\
\hline${ }^{60} \mathrm{Co}$ & ${ }^{60} \mathrm{Ni}$ & 0.262 & 0.0925 & $5.3 a$ & $B^{-}, \gamma$ & $\begin{array}{l}1.17, \\
1.33\end{array}$ \\
\hline${ }^{57} \mathrm{Co}$ & ${ }^{58} \mathrm{Ni}$ & 0.68 & 0.0925 & $271 a$ & $\beta^{+}, \gamma$ & 0.12 \\
\hline${ }^{58} \mathrm{Co}$ & ${ }^{58} \mathrm{Ni}$ & 0.68 & 0.0925 & $71 d$ & $Y$ & 0.81 \\
\hline${ }^{59} \mathrm{Fe}$ & ${ }^{62} \mathrm{Ni}$ & 0.0366 & 0.0925 & $45 d$ & $\beta^{-}, \gamma$ & $\begin{array}{l}1.1 \\
1.29\end{array}$ \\
\hline${ }^{63} \mathrm{Ni}$ & ${ }^{64} \mathrm{Ni}$ & 0.009 & 0.0925 & $100 \mathrm{a}$ & $B$ & 0.066 \\
\hline${ }^{59} \mathrm{Fe}$ & ${ }^{59} \mathrm{Co}$ & 1.00 & 0.002 & $45 d$ & $Y$ & $\begin{array}{l}1.1 \\
1.29\end{array}$ \\
\hline${ }^{57} \mathrm{Co}$ & ${ }^{59} \mathrm{Co}$ & 1.00 & 0.002 & $271 a$ & $B^{+}, \gamma$ & 0.12 \\
\hline $95_{\mathrm{Nb}}$ & ${ }^{95} \mathrm{Mo}$ & 0.16 & $\begin{array}{c}(\text { in } 316 \\
\text { SS) }\end{array}$ & $35 \mathrm{~d}$ & $Y$ & 0.76 \\
\hline $181 \mathrm{Hf}$ & $.81 \mathrm{Ta}$ & 0.99 & $\begin{array}{c}(i n 347 \\
\text { SS })\end{array}$ & $42 \mathrm{~d}$ & $Y$ & $\begin{array}{l}0.13 \\
0.48\end{array}$ \\
\hline
\end{tabular}


TABLE IV-4. Weight Fraction Composition of Carbon Steel and Stainless Steel

\begin{tabular}{|c|c|c|c|c|c|c|c|c|c|c|}
\hline \multirow[b]{2}{*}{ Material } & \multicolumn{10}{|c|}{ Element } \\
\hline & $\begin{array}{c}\text { C } \\
\text { Carbon }\end{array}$ & $\begin{array}{c}\mathrm{Cr} \\
\text { Chromium }\end{array}$ & $\begin{array}{c}\text { Mn } \\
\text { Manganese }\end{array}$ & $\begin{array}{c}\mathrm{Fe} \\
\text { Iron }\end{array}$ & $\begin{array}{c}\text { Co } \\
\text { Cobalt }\end{array}$ & $\begin{array}{c}\mathrm{Ni} \\
\text { Nickel }\end{array}$ & $\begin{array}{c}\mathrm{H} \\
\text { Hydrogen }\end{array}$ & $\begin{array}{c}0 \\
\text { Oxygen }\end{array}$ & $\begin{array}{c}\mathrm{Ca} \\
\text { Calcium }\end{array}$ & $\begin{array}{l}\mathrm{Al} \text { and } \mathrm{Si} \\
\text { Aluminum } \\
\text { Silicon }\end{array}$ \\
\hline Carbon Stee1 & 0.0025 & - & 0.01325 & 0.97 & 0.00016 & 0.0055 & & & & \\
\hline Stainless Steel & 0.0008 & 0.19 & 0.02 & 0.684 & $0.002^{\mathrm{a}}$ & 0.925 & & & & \\
\hline (Concrete) & & & & 0.03 & & & 0.006 & 0.50 & 0.077 & (rest) \\
\hline
\end{tabular}

${ }^{\mathrm{a}}$ Some nuclear grade stainless specify as low as 0.0005 . 


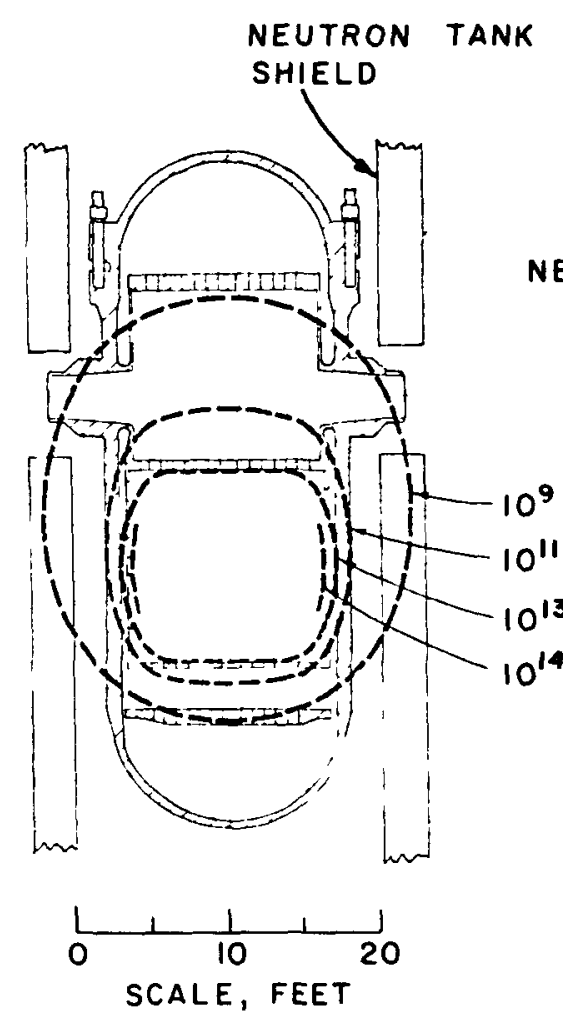

FAST FLUX PROFILE IN $1200 \mathrm{MWE} P W R$

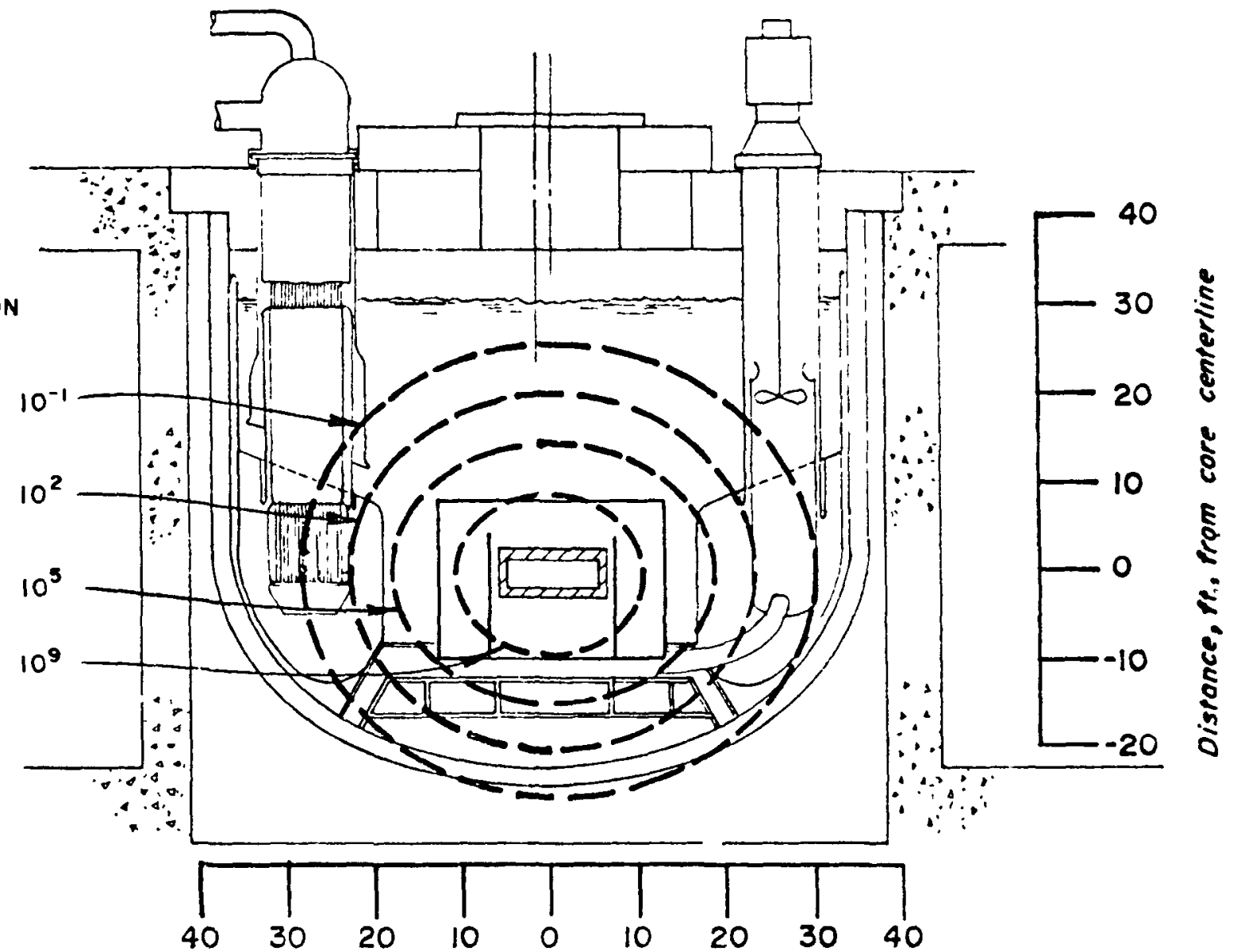

Oistonce, ft., from core centerline

FAST FLUX (>0.1 MEV) PROFILE IN 1200 MWe LMFBR

Fig. IV-5. Comparison of Fast Flux Profile in an LMFBR Compared to a PWR Reactor 
LMFBR. It should be noted that the fast flux for the PWR is chosen as flux above $1.9 \mathrm{eV}$ whereas the fast flux in the LMFBR is chosen as flux above $0.1 \mathrm{MeV}$. This fast flux information is for general interest. As mentioned in Section 1, it was not used in developing the LMFBR activation data.

LMFBR.

Figure IV-6 gives the thermal flux profile for a PWR versus an

The LMFBR flux data is essentially that given in Figs. IV-3 and -4 , and are taken from report ANL-76-61,5 with one exception. Report ANL-76-61 assumed a 24 in. thick steel cover (to form an outlet plenum) over the reactor. This is not now the prevalent method of design of pool-type reactors. A reactor cover is no longer used. On the other hand, more shielding is incorporated within the upper portion of the fuel assemblies and the reactor upper internals structure (instrument tree) extends through the upper pool; the total steel used involves close to the same mass of iron as the reactor cover but is much more diffuse. The neutron fluxes in the upper pool have been modified accordingly.

These figures show the effect of the difference in design approach used in PWR's compared to LMFBR's. The PWR has a large core with essentially no blanket and no reflector. The LMFBR has a small core with a large blanket, a large reflector, and a large section of removable shielding. As discussed in ANL-76-61, Appendix A, iron is very effective in stopping high energy neutrons, and sodium is an effective moderator when large volumes are available. The fast flux in an LMFBR is markedly reduced over a PWR in the areas beyond the removable fuel, blanket, and shield elements. The thermal flux is also greatly reduced but not as drastically.

Table IV-5 gives a tabulation of the fast and thermal fluxes for both LMFBR and PWR for representative components within the reactor compartment. The weights of these components are also tabulated.

\section{Comparison of Activation and Dose Rate}

The neutron-induced activation and dose rate are of interest in establishing the difficulty of removal of components, the shipping and burial charges, and the potential personnel exposure. Table IV-6 gives the induced radioactivity of the representative isotopes ${ }^{55} \mathrm{Fe},{ }^{60} \mathrm{Co}$, and ${ }^{63} \mathrm{Ni}$ for major components of the reactor compartment. The activity is given at shutdown and at two years, ten years, and fifty years after shutdown. These activities are for the total weight of the component as given in Table IV-5. The induced activity for LMFBR components is down by a factor of $10^{3}$ to $10^{5}$ compared to corresponding PWR components.

In actual practice the difficulty of removal of a radioactive component or section will be determined by the levels of both induced and deposited activity relative to exposure criteria as well as the nature of the component or section to be removed. However, since deposited activity is a fraction of the total system activity, and in many cases it can be removed by decontamination, the induced activity alone provides a useful guideline for assessing the difficulty of disassembly. Table IV-7 shows the specific activity levels and dose rates from ${ }^{60} \mathrm{Co}$ in several large components of an LMFBR and a PWR. Figure IV-7 shows the approximate dose rate profile from induced ${ }^{60}$ Co in LMFBR 


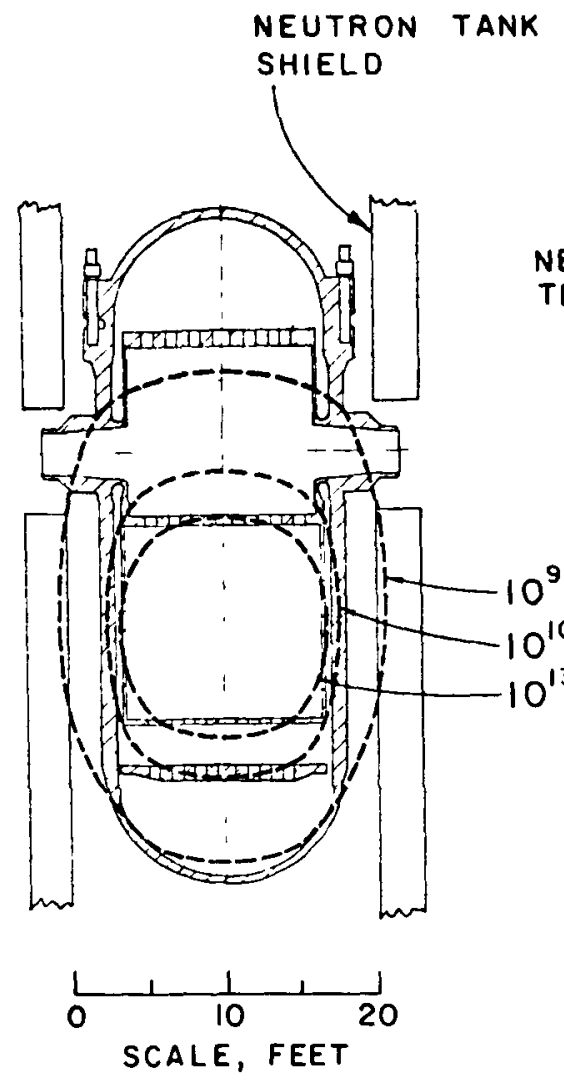

THERMAL FLUX PROFILE IN 1200 MWe PWR

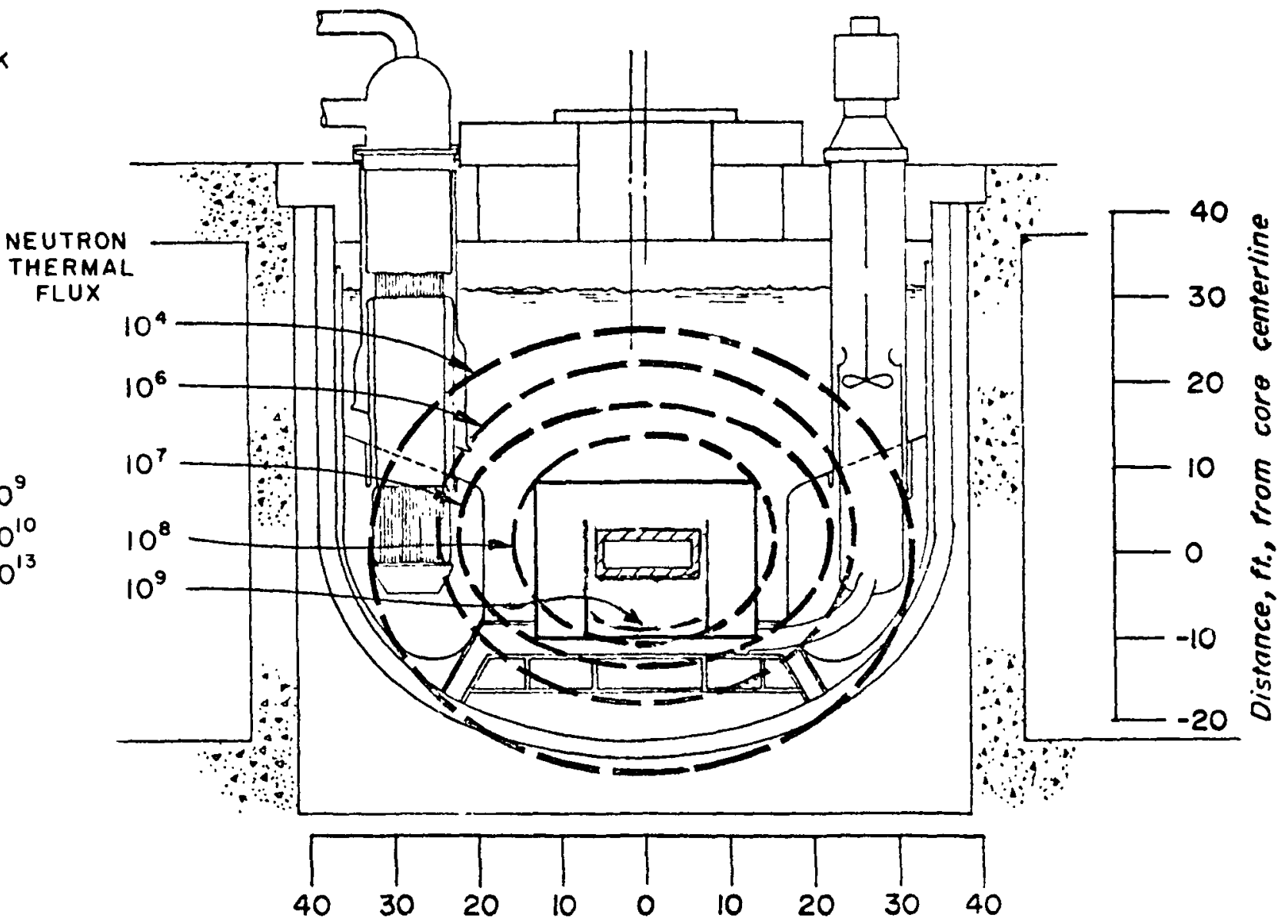

Distance, ft., from core econterline

THERMAL FLUX (<I.9 EV) PROFILE IN 1200 MWe LMFBR

Fig. IV-6. Comparison of Thermal Flux Profile in an LMFBR Compared to a PWR Reactor 
TABLE IV-5. Comparison of Weight and Neutron Flux Level of Pool Type to PWR Vessel Components

\begin{tabular}{|c|c|c|c|c|c|c|c|c|c|}
\hline & \multirow[b]{2}{*}{ Component } & \multicolumn{2}{|c|}{$\begin{array}{l}\text { Weight in } \\
10^{3} \mathrm{~kg}^{\mathrm{a}}\end{array}$} & \multicolumn{3}{|c|}{ Fast Flux } & \multicolumn{3}{|c|}{ Thermal Flux } \\
\hline & & $\overline{\mathrm{PWR}}$ & $\overline{\mathrm{LMFBR}}$ & & $\overline{P W R}$ & $\widehat{L M F B R}$ & & PWR & LMFBR \\
\hline 1. & Core barrel and shroud & 80 & 30 & 4 & $\times 10^{13}$ & $10^{11}$ & 5 & $\times 1012$ & $10^{9}$ \\
\hline 2. & Support Plates and columns & 50 & 100 & 2 & $\times 10^{11}$ & $10^{10}$ & & $10^{12}$ & $10^{9}$ \\
\hline 3. & $\begin{array}{l}\text { Removable Fe shielding } \\
\text { assemblies }\end{array}$ & - & 700 & & - & $10^{9}$ & & - & $5 \times 10^{8}$ \\
\hline 4. & Internal baffles and supports & - & 250 & & - & $10^{4}$ & & - & $10^{7}$ \\
\hline 5. & Reactor vessel clad or liner & 5 & 100 & 4 & $\times 10^{10}$ & $10^{-2}$ & 7 & $\times 10^{10}$ & $10^{3}$ \\
\hline 6 & $\begin{array}{c}\text { Reactor vessel } \\
(\text { PWW = stee } 1) \\
(\text { LMFBR = SS })\end{array}$ & 400 & 500 & 6 & $\times 10^{10}$ & $10^{-3}$ & 5 & $\times 10^{9}$ & $10^{3}$ \\
\hline 7. & Reactor cover & 50 & $\begin{array}{l}\text { Not } \\
\text { radio- } \\
\text { active }\end{array}$ & 2 & $\times 10^{8}$ & - & 2 & $\times 10^{8}$ & - \\
\hline 8. & $\begin{array}{l}\text { LMFBR IHX bundle and she } 11 \\
\text { or PWK steam generators }\end{array}$ & $10^{3}$ & 500 & & - & $10^{1}$ & & - & $10^{5}$ \\
\hline 9. & $\begin{array}{l}\text { Four primary pumps (without } \\
\text { motor and shielding) }\end{array}$ & 200 & 400 & & - & $10^{1}$ & & - & $10^{6}$ \\
\hline 10 & LMFBR guard tank ( $\mathrm{Fe}$ ) & $10^{3}$ & 300 & & - & $10^{1}$ & & - & $10^{3}$ \\
\hline 11. & Shield tank (inner wall, Fe) & 40 & - & 2 & $2 \times 10^{10}$ & - & 2 & $\times 10^{9}$ & - \\
\hline
\end{tabular}

a Does not include LMFBR deck, rotating plugs, shielding of pumps or IHX parts above tubesheet, which are not radioactive.

Fluxes are weighted average: segment (wt $\times 0=0 / \Sigma w t$ ), from Appendix $B-6$ of AIF-009. 
TABLE IV-6. Estimate of LMFBR Versus PWR Relative Induced Activity in Curies after Plant Shutdown for Representatıve Reactor Components

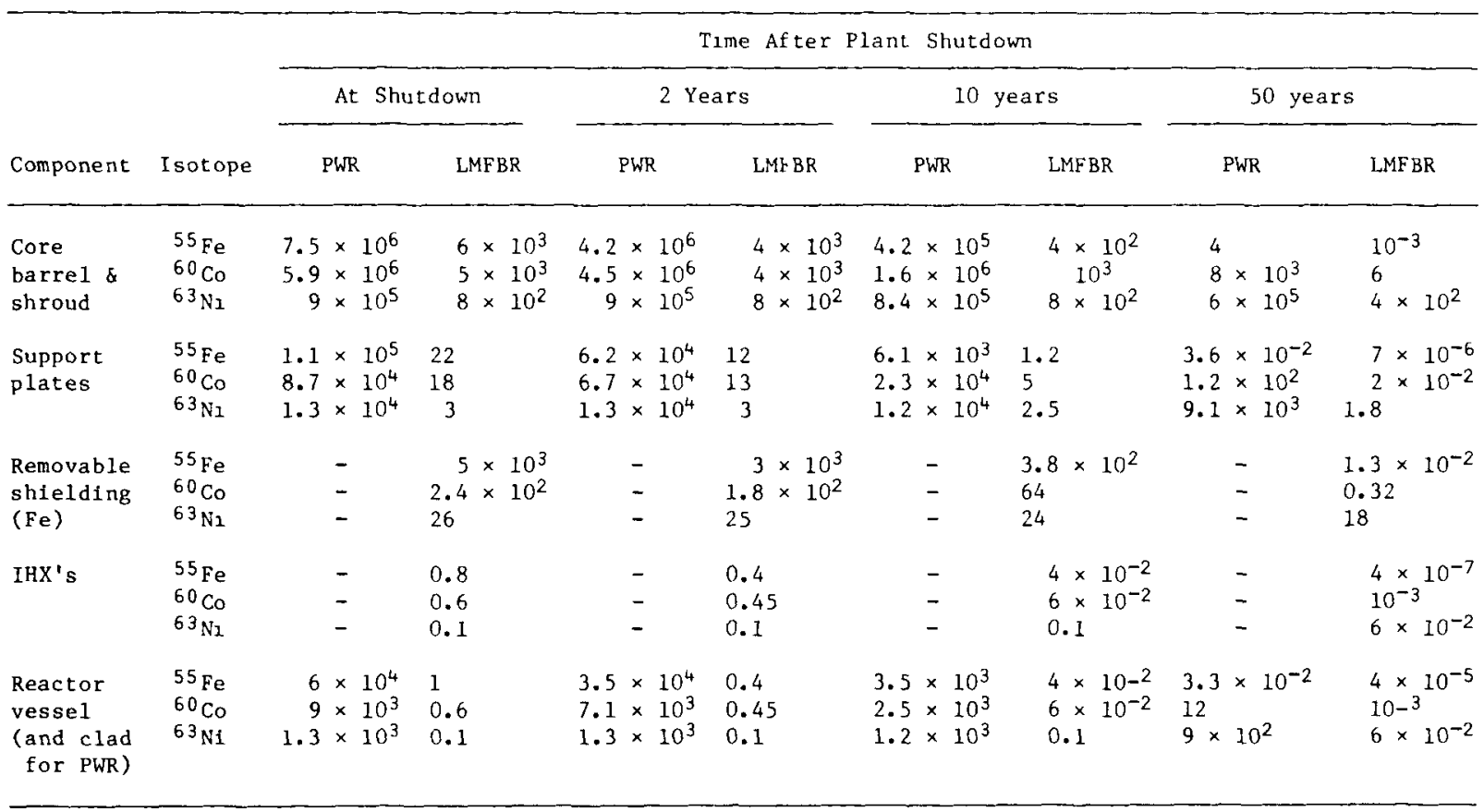

TABLE IV-7. Representative ${ }^{60}$ Co Specific Activity and Dose Rate Data for LMFBRs and PWRs

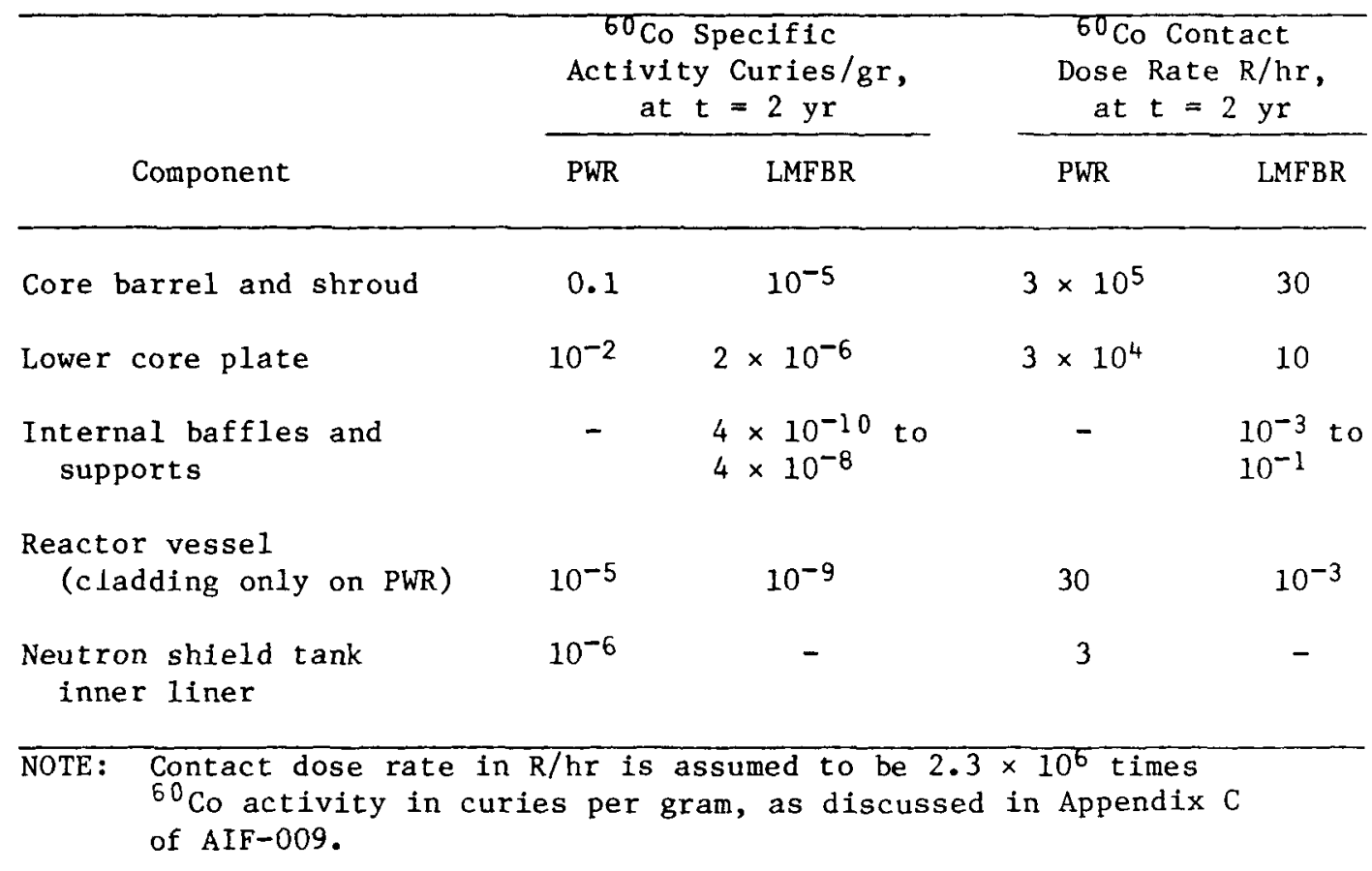




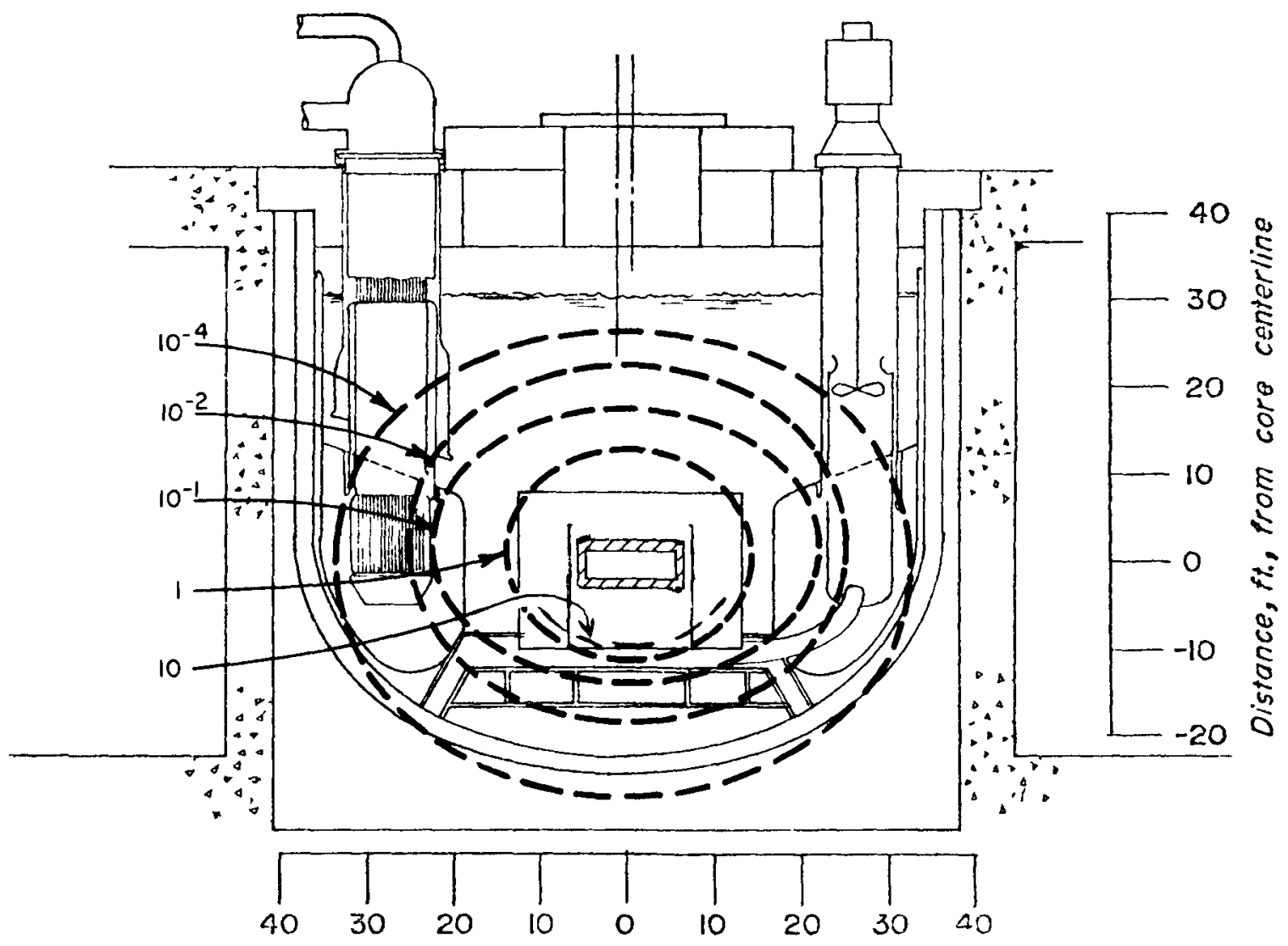

Distance, ft., from core centerline

Fig. IV-7. Profile of Contact Dose Rate in $R / h r$ at $t=2 \mathrm{yr}$ in 1200 MWe Pool-Type LMFBR 
two years after shutdown. For reference, a dose rate of $20 \mathrm{mr} / \mathrm{hr}$ is considered acceptable practice for infrequent maintenance. Above about $100 \mathrm{mr} / \mathrm{hr}$, remote methods are normally employed. The relatively low dose rates from induced activity in the LMFBR were considered to be an advantage relative to a PWR during decommissioning.

\section{Deposition of Fission Products and Activated Corrosion Products}

Radioactive fission products from defective fuel elements and corrosion products from the primary system structures, components, and fuel cladding are transported within the primary system of both LWR's and LMFBR's by the coolant. Both reactor types include primary coolant purification systems which remove substantial quantities of these contaminants. However, the fraction of these contaminants which deposit on surfaces within the primary system can be a significant consideration during decommissioning.

The mechanisms of corrosion and the transport and deposition of the corrosion products are quite different in water-cooled and sodium-cooled systems. In addition, the rates of corrosion, purification, and deposition in both types of plants are very sensitive to design and operating parameters. Finally, the radioactive isotopes in the corrosion products of the two plants will differ because the materials of construction, activation processes, and corrosion mechanisms are not the same. In a water-cooled reactor with zircaloy clad fuel elements, the major source of corrosion products is from oxidation of the primary system structure and components exposed to the coolant, not the fuel element cladding. In a PWR, a large fraction of the radioactive corrosion products originate in out-of-core regions and are activated during transport through the core by the coolant. In a sodium-cooled reactor, the major source of radioactive corrosion products is the slow dissolution or leaching of radioactive materials from the high temperature regions of the fuel cladding and core structure. In both plants, most of the deposition of the radioactive corrosion products occurs in the heat exchangers (steam generators in a PWR and intermediate heat exchangers in an LMFBR).

In the PWR and the reference LMFBR concept, the fuel elements are designed to minimize the release of fission products to the coolant. (Some LMFBR's have been designed and operated with vented fuel (DFR) and the present Gas Cooled Fast Reactor includes vented fuel.) Thus, for the two plant designs considered in this study, the only* source of fission products in the primary coolant is from defective fuel elements. The quantities of fission products deposited within the primary system of an LMFBR or an LWR are very dependent on detailed design and operating parameters. However, the experience with both water-cooled and sodium-cooled reactors indicates that by far the major contributor to fission product activity in primary system deposits has been $137 \mathrm{Cs}$. Cesium is highly soluble in both water and sodium and effective purification systems are available to remove cesium from either coolant. With normal design and operating practices, the levels of fission product activity in primary system deposits at shutdown should be much less than the activity due to corrosion products for both LWR's and LMFBR's.

*In the case of the LMFBR, tritium can diffuse through the clad of intact fuel elements. However, tritium is not deposited on surfaces within the primary system. 
As indicated in the introduction of Section $B$, only in the core are there high energy neutrons capable of producting other than $(n, \gamma)$ reactions. It is for this reason that some of the radioactive isotopes are different from those associated with induced activity in the structures. Table IV-3b lists the potential high energy neutron formed isotopes. Manganese is a major corrosion transport radioactive isotope in both the PWR and the LMFBR.

The total radioactivity of corrosion products deposited within the primary system of a large PWR has been estimated ${ }^{4}$ to be $\sim 4800$ curies of which $\sim 4400$ curies are expected to be in the steam generators. The relative contribution of the various radionuclides in the primary system deposits of a PWR are shown in Table IV-8 taken from Ref. 4. It can be seen that $78 \%$ of the activity at shutdown results from cobalt isotopes.

TABLE IV-8. Distribution of Isotopes in PWR Primary System Deposits (Fractional Activity Normalized at Reactor Shutdown)

\begin{tabular}{|c|c|c|c|c|c|c|c|c|c|}
\hline \multirow[b]{2}{*}{ Radionuclide } & \multirow[b]{2}{*}{ Shutdown } & \multirow[b]{2}{*}{10} & \multirow[b]{2}{*}{ Years } & \multicolumn{6}{|c|}{ Fractional Radioactivity at Decay Times of: } \\
\hline & & & & 30 & Years & 50 & Years & 100 & Years \\
\hline${ }^{5 \mathrm{l}} \mathrm{Cr}$ & $2.4 \times 10^{-2}$ & & (a) & & - & & - & & - \\
\hline${ }^{54} \mathrm{Mn}$ & $3.6 \times 10^{-2}$ & 1.1 & $\times 10^{-5}$ & & - & & - & & - \\
\hline${ }^{59} \mathrm{Fe}$ & $8.2 \times 10^{-3}$ & & - & & - & & - & & - \\
\hline${ }^{58} \mathrm{Co}$ & $4.6 \times 10^{-1}$ & & - & & - & & - & & - \\
\hline${ }^{60} \mathrm{Co}$ & $3.2 \times 10^{-1}$ & 8.6 & $\times 10^{-2}$ & 6.2 & $\times 10^{-3}$ & 4.4 & $\times 10^{-4}$ & 6.0 & $\times 10^{-7}$ \\
\hline${ }^{95} \mathrm{Zr}$ & $5.6 \times 10^{-2}$ & & - & & -. & & - & & - \\
\hline${ }^{95} \mathrm{Nb}$ & $5.6 \times 10^{-2}$ & & - & & - & & - & & - \\
\hline $103^{3 u}$ & $2.6 \times 10^{-2}$ & & - & & - & & - & & - \\
\hline $13^{7} \mathrm{Cs}$ & $1.2 \times 10^{-3}$ & 9.5 & $\times 10^{-4}$ & 6.0 & $\times 10^{-4}$ & 3.8 & $\times 10^{-4}$ & 1.2 & $\times 10^{-4}$ \\
\hline${ }^{141} \mathrm{Ce}$ & $6.6 \times 10^{-2}$ & & - & & - & & - & & - \\
\hline Total & 1.0 & 8.7 & $\times 10^{-2}$ & 6.3 & $\times 10^{-3}$ & 8.2 & $\times 10^{-4}$ & 1.2 & $\times 10^{-4}$ \\
\hline
\end{tabular}

${ }^{\mathrm{A}}$ dash indicates values less than $1 \times 10^{-10}$.

Comparable information is not available for a large LMFBR. However, based on operating experience with small LMFBR plants plus studies of corrosion and deposition in sodium systems, the dominant isotope at shutdown in an LMFBR will be ${ }^{54} \mathrm{Mn}$ with ${ }^{58} \mathrm{Co}$ and ${ }^{60} \mathrm{Co}$ being less by an order of magnitude. Since the source of activated corrosion products in an LMFBR is the high temperature region of the fuel cladding and core structures, the total quantity of activated corrosion products released to the coolant is very dependent on design. For an LMFBR with outlet temperatures in the range of 900 to $950^{\circ} \mathrm{F}$ and a bottom plenum fuel design, the total quantity of activated corrosion products depositea 
in the primary system at shutdown should be much less than the 4800 curies expected in a PWR. LMFBR designs with outlet temperatures greater than $1000^{\circ} \mathrm{F}$ or which have more radioactive materials in the high temperature region could reverse this picture. However, the dominant isotope in the LMFBR case ( ${ }^{54} \mathrm{Mn}$, 312 day half-life) decays much more quickly than the dominant isotope in the $\mathrm{PWR}$ case $\left({ }^{60} \mathrm{Co}, 5.3\right.$ year half-1ife). Hence, even for higher outlet temperature designs, the total radioactivity of activated corrosion products in an LMFBR during decommissioning operations can be considered comparable. It is pointed out that he corrosion rates in a PWR are higher than in an LMFBR, and therefore, the mass of corrosion products is greater.

\section{SODIUM RADIOACTIVITY, DECONTAMINATION, AND DISPOSAL}

This section deals with the disposal aspects of the sodium itself. It covers the radioactivity contained in the sodium, removal of sodium from components, and the methods of disposing of the sodium.

\section{A. Sodium Radioactivity}

The main source of radionuclei in the primary sodium are neutron activation of the sodium itself, radioactive corrosion products, primarily ${ }^{54} \mathrm{Mn}$ and $60 \mathrm{Co}$, and fission products.

There are two isotopes induced by neutron absorption in the sodium. Sodium-24 has a half-1ife of 15.1 hours and sodium-22 (formed by an $(n, 2 n$ ) reaction) has a half-life of 2.6 years. The ${ }^{24} \mathrm{Na}$ is of little concern in regard to decommissioning since it becomes negligible in radioactivity in less than a month. The sodium-22 activity, however, is of the order of $400 \mu \mathrm{Ci} / \mathrm{liter}$ at shutdown and decays slowly.

B. General Cleaning Methods

Since sodium can react with water and give of $f$ hydrogen with a potential fire or explosion hazard, and also form sodium hydroxide which can cause irritation to the skin and lungs, it is necessary to remove the sodium from components to be reclaimed or disposed of.

Sodium is normally handled in an inert atmosphere and, therefore, is handled in a confined system. Cleaning practices for radioactive sodium contaminated components is, therefore, little different from those for noncontaminated components, except that the sodium is allowed to decay some 15 days in the former case.

Cleaning usually involves a process of slowly reacting the sodium by dilution of an aggressive reactant or by use of a slow reactant. Tables V-1A \& B list methods which have been used and the ones preferred for a large nonradioactive component like a steam generator.

When there is little entrapped sodium, the preferred method of cleaning is to thoroughly drain sodium from the component and then to blow residual sodium from pockets with a nitrogen lance, then follow with a superheated steam, and then finally with wet steam. The temperature is kept low to prevent alkaline stress corrosion, particularly of stainless steel. Where there are pockets of sodium which cannot be drained, an alcohol flush is often used. 6 
TABLE VI-1A. Current Cleaning Methods for Steam Generators

\begin{tabular}{|c|c|c|c|c|}
\hline Method & $\begin{array}{l}\text { Brief Description } \\
\text { of Technique }\end{array}$ & $\begin{array}{l}\text { Effectiveness in } \\
\text { Removing Sodium and } \\
\text { Reaction Products }\end{array}$ & Experience & Problems of Method \\
\hline Ethanol & $\begin{array}{l}\text { 1. Object placed in } \\
\text { a closed container } \\
\text { 2. Container filled } \\
\text { with alcohol and } \\
\text { continuously } \\
\text { sparged with } \mathrm{N}_{2} \\
\text { to agitate and } \\
\text { purge the alcohol } \\
\text { bath } \\
\text { 3. Container drained } \\
\text { 4. Water rinse } \\
\text { applied to termi- } \\
\text { nate cleaning } \\
\text { Application of } \\
\text { technique to } \\
\text { steam generators } \\
\text { is contained in } \\
\text { Refs. 10 and } 13 \\
\text { (actually used) }\end{array}$ & $\begin{array}{l}\text { Excellent for both } \\
\text { Leaves residue } \\
\text { which is removed } \\
\text { by either forced } \\
\text { alcohol circula- } \\
\text { tion or water } \\
\text { rinse }\end{array}$ & $\begin{array}{l}\text { Has been used } \\
\text { often in cleaning } \\
\text { many small and } \\
\text { large components. } \\
\text { An example of a } \\
\text { large component } \\
\text { is the No. } 1 \\
\text { steam generator } \\
\text { at EFAPP, cleaned } \\
\text { after a } \mathrm{Na}_{2} \mathrm{H} \\
\text { reaction }\end{array}$ & $\begin{array}{l}\text { 1. Is a fire hazard } \\
\text { because of its } \\
\text { lighly flammable } \\
\text { fumes } \\
\text { 2. Coking of alcohol } \\
\text { may occur at } \\
\text { high temperature } \\
\text { 3. Overpressure may } \\
\text { result due to } \\
\text { rapid } \mathrm{H}_{2} \text { release } \\
\text { 4. } \mathrm{H}_{2} \text { may come into } \\
\text { contact with air } \\
\text { and ignite }\end{array}$ \\
\hline $\begin{array}{l}\text { Steam } \\
\\
\text { (Water } \\
\text { Vapor } \\
\text { Nitro- } \\
\text { gen, } \\
\text { WVN) }\end{array}$ & $\begin{array}{l}\text { 1. Object placed in } \\
\text { container } \\
\text { 2. Container purged } \\
\text { with inert gas } \\
\text { 3. Superheat steam } \\
\text { admitted, replacing } \\
\text { inert gas } \\
\text { 4. Wet Steam added } \\
\text { and condensation } \\
\text { permitted } \\
\text { W. Water rinse applied } \\
\text { to terminate } \\
\text { cleaning } \\
\text { Application of technique } \\
\text { to steam generator is } \\
\text { contained in Reference } \\
\text { 10 and } 13 \text { (proposed) } \\
\text { Hand lancing is also } \\
\text { possible, but not } \\
\text { recommended for large, } \\
\text { complex components like } \\
\text { steam generators }\end{array}$ & $\begin{array}{l}\text { Excellent for both } \\
\text { when accessible } \\
\text { Fair to poor in } \\
\text { crevices and in } \\
\text { accessible spots }\end{array}$ & $\begin{array}{l}\text { Has been used } \\
\text { often in cleaning } \\
\text { many small compo- } \\
\text { nents and several } \\
\text { large components. } \\
\text { These large con- } \\
\text { ponents include: } \\
\text { EBR-II Prototype } \\
\text { Pumps } \\
\text { AI Heat exchangers }\end{array}$ & $\begin{array}{l}\text { 1. Possible thermal } \\
\text { damage (local hot } \\
\text { spots) in } \\
\text { confined areas } \\
\text { where poor flow } \\
\text { exists } \\
\text { 2. If not thoroughly } \\
\text { cleaned, chemical } \\
\text { attack can result } \\
\text { from reaction } \\
\text { products } \\
\text { 3. } \text { H }_{2} \text { may come into } \\
\text { contact with air } \\
\text { and ignite. }\end{array}$ \\
\hline
\end{tabular}


TABLE VI-1B. Other Cleaning Technıques

\begin{tabular}{|c|c|c|c|c|c|}
\hline Ammonia & $\begin{array}{l}\text { 1. Object placed in a closed } \\
\text { contalner located in a } \\
\text { well vented area } \\
\text { 2. The container is filled } \\
\text { with ammonia which if } \\
\text { possible is circulated } \\
\text { 3. When the fluld color } \\
\text { turns a dark blue, the } \\
\text { reaction of Na and } \\
\text { ammonia is complete } \\
\text { 4. Container drained } \\
\text { 5. Repeated until fluld } \\
\text { becomes colorless }\end{array}$ & $\begin{array}{l}\text { Poor for sodium in } \\
\text { crevices } \\
\text { Poor for sodium com- } \\
\text { pounds - won't dis- } \\
\text { solve oxides }\end{array}$ & $\begin{array}{l}\text { Has been used little } \\
\text { ln cleaning small and } \\
\text { large components. A } \\
\text { large component } \\
\text { cleaned was the IHX's } \\
\text { at Hallam }\end{array}$ & $\begin{array}{l}1 . \\
2 .\end{array}$ & $\begin{array}{l}\text { Produces } \\
\text { polsonous } \\
\text { vapors } \\
\text { Need either } \\
\text { refrigeration } \\
\text { or pressurized } \\
\text { handling to } \\
\text { keep ammonia } \\
\text { in liquid state }\end{array}$ \\
\hline $\begin{array}{l}\text { Vacuum } \\
\text { Distillation }\end{array}$ & $\begin{array}{l}\text { 1. Object placed in a } \\
\text { closed container } \\
\text { 2. Vacuun pulled on } \\
\text { contalner } \\
\text { 3. Object heated in } \\
\text { container (an absolute } \\
\text { pressure 1s maintalned } \\
\text { less than the Na vapor } \\
\text { pressure) } \\
\text { 4. Vent opened following } \\
\text { sodium removal } \\
\text { 5. Vessel filled slowly with } \\
\text { water, then drained }\end{array}$ & $\begin{array}{l}\text { Excellent for sodium } \\
\text { except for confined } \\
\text { areas where tt is } \\
\text { poor }\end{array}$ & $\begin{array}{l}\text { Has been used little } \\
\text { for small components } \\
\text { and not at all for } \\
\text { large components }\end{array}$ & $\begin{array}{l}2 . \\
1 \\
2 .\end{array}$ & $\begin{array}{l}\text { Requires high } \\
\text { component } \\
\text { bake-out tempera- } \\
\text { ture to boil off } \\
\mathrm{Na} \text { as vapor } \\
\text { Th1s method much } \\
\text { slower than the } \\
\text { others } \\
\text { Leaves film } \\
\text { Requires additiond1 } \\
\text { cleansing procedure }\end{array}$ \\
\hline Hot 011 & $\begin{array}{l}\text { Essentially the same as } \\
\text { alcohol except that a heat } \\
\text { source is needed }\end{array}$ & $\begin{array}{l}\text { Poor for both } \\
\text { Does not rerove Na } \\
\text { compounds. Flushing } \\
\text { action at high tempera- } \\
\text { ture to remove Na has } \\
\text { proven inadequate for } \\
\text { complicated geometries }\end{array}$ & Same as hot oxl & & \\
\hline Ultrasonics & $\begin{array}{l}\text { 1. Object placed in a } \\
\text { container } \\
\text { 2. Container filled with } \\
\text { light oil } \\
\text { ultrasonic vibrations are } \\
\text { used to disperse the } \\
\text { sodium into the oil } \\
\text { 4. Container drained }\end{array}$ & $\begin{array}{l}\text { Poor for both } \\
\text { often fails to clean } \\
\text { out pockets of } \mathrm{Na}\end{array}$ & Same as hot oll & 2 . & $\begin{array}{l}\text { Additional } \\
\text { process needed } \\
\text { to remove oll } \\
\text { carrier } \\
\text { Steam generators } \\
\text { too large for } \\
\text { this method }\end{array}$ \\
\hline $\begin{array}{l}\text { Liquid } \\
\text { Metals }\end{array}$ & Similar to alcohol & Same as hot oll & $\begin{array}{l}\text { Has been used very } \\
\text { little for small } \\
\text { components and not at } \\
\text { all for large compo- } \\
\text { nents }\end{array}$ & Same & e as hot 011 \\
\hline Water & Similar to alcohol & Good for both & Same as liquid metals & 2. & $\begin{array}{l}\text { Uncontrollable } \\
\text { reaction rate } \\
\text { with associated } \\
\text { hazards } \\
\mathrm{H}_{2} \text { may come into } \\
\text { contact with air } \\
\text { and ignite }\end{array}$ \\
\hline
\end{tabular}


If the component is contaminated, the cleaning process is followed by a decontamination process. A mild organic acid treatment seems to be effective and is preferred. Alternately a buffered sulfuric acid cleaning is also used. 7

\section{Sodium Disposal}

It is expected that the sodium used in LMFBR's will remain relatively clean with respect to fission products, activated corrosion products, and fuel-particle contamination. Some exceptions could be reactors that experience severe fuel/sodium interaction followed by immediate decommissioning. In this rare case, the sodium would certainly require decontamination prior to reuse in a new LMFBR plant; however, fuel/sodium iteraction does not, necessarily, mean that subsequent sodium decontamination will be required. A case in point is the Fermi reactor which experienced subassembly meltdown and fuel/sodium contact. Some 3 years after decommissioning, the primary sodium contained $9 \mu \mathrm{Ci} / \ell{ }^{22} \mathrm{Na}, 0.37 \mu \mathrm{Ci} / \ell{ }^{137} \mathrm{Cs}$, and $9 \mu \mathrm{Ci} / \ell^{9} 0 \mathrm{Sr} .{ }^{8}$ Other activities were negligible. The radiation level at the surface of a 55-gal drum of this Fermi sodium was approximately $10 \mathrm{mr}$. hr -- due primarily to ${ }^{22} \mathrm{Na}$ activity.

The CRBR is planning to reuse this Fermi primary sodium with no processing other than filtration with a $20 \mu$ filter to remove possible particulate carbon. The radioactivity level of this sodium, and even considerably higher, should be acceptable for use in the CRBR even during initial system shakedown. Al1 maintenance equipment is designed to handle the equilibrium ${ }^{22} \mathrm{Na}$ activity.

The EBR-II primary sodium would also be suitable for reuse if the EBR-II were decommissioned at this time. The activity levels are, typically, $91 \mu \mathrm{Ci} / \ell{ }^{22} \mathrm{Na}, 24 \mu \mathrm{Ci} / \ell{ }^{137} \mathrm{Cs}, 0.28 \mu \mathrm{Ci} / \ell{ }^{54} \mathrm{Mn}, 0.86 \mu \mathrm{Ci} / \ell{ }^{125} \mathrm{Sb}$, and $0.1 \mu \mathrm{Ci} / \ell{ }^{131} \mathrm{I}$. These activity levels (after several years decay) should be acceptable for reuse in a new LMFBR. No decontamination should be required for either the Fermi or EBR-II sodium for reuse.

For cases where the sodium is highly contaminated, three strategies have been considered:

(1) Separate the fission products, activated corrosion products, and fuel particles from the sodium; reuse the purified sodium in a new reactor; and convert the concentrated waste from the separated process to inert form for permanent repository.

(2) Separate the fission products, activated corrosion products, and fuel particles from the sodium and convert the sodium to inert form for landfill burial. Convert the concentrated waste from the separation process to inert form for permanent repository.

(3) Convert all the sodium to inert form for permanent repository (presence of transuranics might prohibit disposal in a landfill).

The above strategies have been analyzed with respect to cost. The results of this analysis are shown in Table $\mathrm{V}-2$. For the purpose of this cost 
analysis, the reference separation method was fractionation by low-pressure distillation. The cost of that process was estimated at approximately $\$ 12 / \mathrm{ft}^{3} \mathrm{Na}$. The reference conversion method was oxidation of $\mathrm{Na}$ to $\mathrm{Na}_{2} \mathrm{O}$ in the presence of an $\mathrm{SiO}$ carrier, the contaminated product $\left(\mathrm{SiO}_{2}+\mathrm{Na}_{2} \mathrm{O}\right)$ being used to make glass for long term disposal. The conversion process, if done in a rotary calciner, should cost approximately $\$ 14 / \mathrm{ft}^{3} \mathrm{Na}$.

TABLE V-2. Relative Costs of Sodium Disposal Strategies

\begin{tabular}{|c|c|c|c|}
\hline Strategy & Itemized Cost Normalized to $1 \mathrm{ft}^{3}$ volume & $\left(\begin{array}{ll}56 & 1 b\end{array}\right)$ & Total \\
\hline \multirow[t]{4}{*}{1} & Sodium replacement ( $10 \%$ of original) & $\$ 2.10$ & \\
\hline & Decontamination Cost (Distillation) & 12.00 & \\
\hline & Conversion Cost ( $10 \%$ of origina1) & 1.40 & \\
\hline & Permanent Storage of Waste ( $10 \%$ of original & 18.00 & $\$ 33.50$ \\
\hline \multirow[t]{5}{*}{2} & Sodium replacement & 21.00 & \\
\hline & Decontamination Cost (Distillation) & 12.00 & \\
\hline & Conversion Cost (A1l sodium) & 14.00 & \\
\hline & Land-fill Disposal ( $90 \%$ of original) & 8.10 & \\
\hline & Permanent Storage ( $10 \%$ of original) & 18.00 & $\$ 73.10$ \\
\hline \multirow[t]{3}{*}{3} & Sodium replacement & 21.00 & \\
\hline & Conversion Cost (All sodium) & 14.00 & \\
\hline & Permanent Storage (All sodium) ${ }^{a}$ & 180.00 & $\$ 215.00$ \\
\hline
\end{tabular}

$a_{\text {If }}$ it were acceptable to place typical LMFBR sodium (with possible transuranic contaminants) in land-fill sites, strategy 3 would be competitive at $\sim \$ 42$.

Landfill burial costs are in the range of $\$ 3 / \mathrm{ft}^{3}$ and permanent repository costs were assumed to be $\$ 60 / \mathrm{ft}^{3}$. It is important to note that, accounting for the increase in density in going from elemental sodium to glass and for the additional volume of the silica, the increase in waste volume in converting sodium to glass is a factor of $\sim 3$. So, in terms of sodium wast disposal, the landfill cost is approximately $\$ 9 / \mathrm{ft}^{3} \mathrm{Na}$, and the permanent repository cost is approximately $\$ 180 / \mathrm{ft}^{3} \mathrm{Na}$.

The volume of sodium in the primary system of a 1000 MWe LMFBR will be on the order of $10^{5} \mathrm{ft}^{3}$. Thus, at a price of $\$ 21 / \mathrm{ft}^{3}$ for new reactor grade sodium, the primary coolant of an LMFBR about to be decommissioned represents a substantial asset (i.e., $\sim \$ 2 \times 10^{6}$ ) provided that there is a market for reactor grade sodium. As indicated previously, the activity levels present in this sodium several years after shutdown do not represent a significant problem in handling or reuse. The fact that this sodium is valuable and can be reused, coupled with the fact that the alternatives are substantially more 
expensive, leads to the conclusion that direct reuse of the primary sodium is by far the most likely choice. It is also clear that even if the sodium has been substantially contaminated, well beyond the levels encountered in the Fermi sodium, decontamination and reuse is more economical than disposal of all contaminated sodium and purchasing new sodium for the next plant.

If the LMFBR option were to be phased out, the cost of sodium disposal can be estimated from the information in Table $V-2$. It is assumed that conversion to an inert, insoluble form such as glass would be used, although other less expensive conversion processes might be acceptable. For landfill burial of all the sodium, the cost would be $\$ 33 / \mathrm{ft}^{3}$ or about $\$ 2.3 \times 10^{6}$ for a large plant. If the sodium were heavily contaminated, the second strategy at $\$ 73 / \mathrm{ft}^{3}$ is more attractive economically and in terms of the reduced requirements for permanent repository space than the third option. The most expensive option is conversion of all the contaminated sodium for disposal in a permanent repository and is estimated for Table $\mathrm{V}-2$ to cost $\$ 215 / \mathrm{ft}^{3}$.

Present experience indicates that if the sodium is not reused, no cleanup may be required prior to conversion for landfill burial. However, if the sodium contamination levels do not meet landfill burial criteria, cleanup prior to burial is considered to be the most likely option. On this basis, an upper limit of $\$ 15 \times 10^{6}$ was selected for sodium disposal from a large LMFBR power plant. This upper limit includes a factor of three to cover more expensive cleanup methods and/or larger sodium volumes. The more likely value would be in the range of 2 to 5 million dollars.

\section{STEPS IN DISMANTLING AND SHIPPING INTERMEDIATE SYSTEM COMPONENTS AND PIPING}

The intermediate system is not radioactive. The IHX, the link between the intermediate and the primary system, is treated as a primary system component. The only problem with dismantling of the intermediate system is removal of the sodium from the components.

Gross drainage of the system is easily accomplished since the system contains a sodium dump line used to drain the sodium from the system in case of a water leak. Other drain points are not normally employed. There may be sodium pockets which will require draining.

All components of the intermediate system will probably be sold for scrap. After the sodium is drained from these components, they will be nitrogen steamlance cleaned to remove residual sodium.

If inspection of the component for operating performance is desired, the components such as the intermediate system pump and steam generators can be removed and cleaned by the method developed for their maintenance. Ethanol cleaning at the steam generator maintenance facility is preferred. For the initial plants being decommissioned, it is assumed that one steam generator and pump of each LMFBR plant will be cleaned in this facility in order to evaluate their long-term performance.

Piping is cut and cleaned, perhaps in a makeshift pit. The pipe is placed in the pit and cleaned of sodium with a nitrogen-steam lance. 


\section{STEPS IN DISMANTLING REACTOR VESSEL AND ITS COMPONENTS}

There are three basically different operations involved in dismantling the reactor assembly and the primary system components located inside the main tank. These are shown in Fig. VII-1 and involve (1) removal of all components designed on a "plug-in principle" via nozzles in the main tank cover, (2) remote manipulations where the piece is too radioactive for direct contact disassembly or dissection, and (3) direct contact operations where the radioactivity level is low enough to permit direct contact activities.

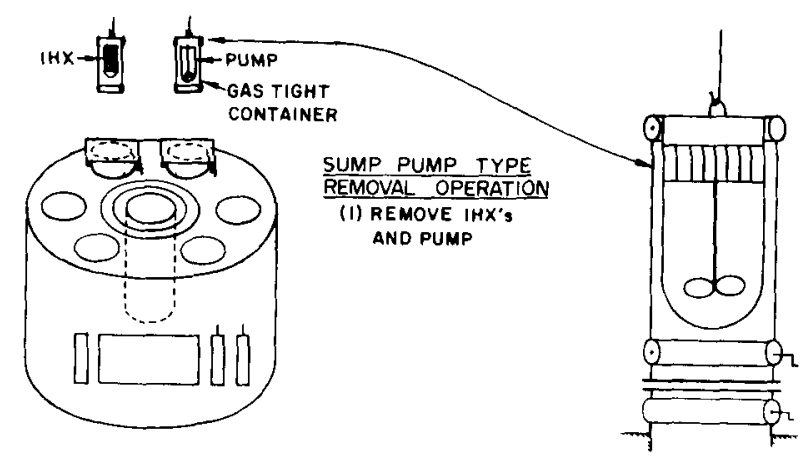

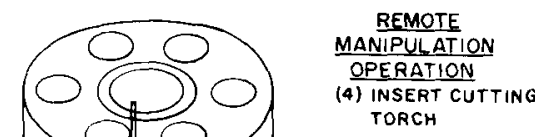
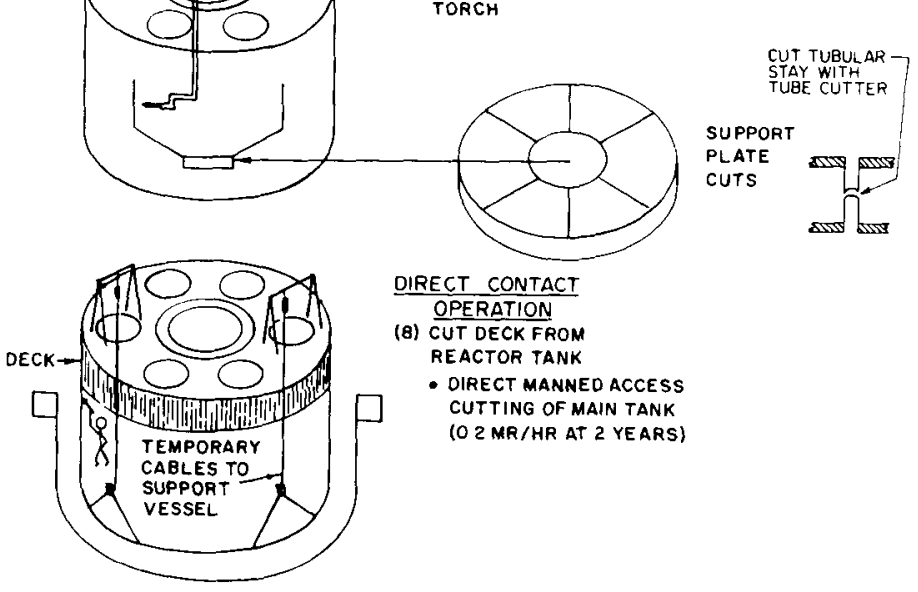

Fig. VII-I

Representative Operations in Removal of Vessel

As has been indicated in Section III, the basic design of the fast reactor reduces dismantling difficulties. The IHX's, pumps, instrument tree, rotating plugs, and fuel handling machines are all designed as "plug-in units" removable through vertical nozzles in the main tank cover. The primary system operating pressure is very low so uncoupling primarily involves removal of low pressure bolting and seals. Removable blanket, reflector, and shielding elements are used, so that the radioactivity of permanent structures, as indicated in Section IV, is lower by many orders of magnitude than for a PWR. Access and manipulation capability is excellent because of the large openings left by the removal of the rotating plugs, pumps, and IHX's. Prior to their removal, the rotating plugs provide horizontal "reach" so that remote manipulators for cutting equipment need only a limited offset reach and can perform many operations without offset reach. 
As indicated in Section IV, the major components which need to be removed remotely are the core barrel (if one exists), the core support plate, some core support structure, and some internal baffles located horizontally up to about $4 \mathrm{ft}$ from the rotating plug edge and $15 \mathrm{ft}$ distance in the vertical direction, from the center of the core. Options in the design and removal of these will be discussed later.

Removal of sodium has been briefly discussed in Section $V$. Syphon tubes are introduced into access nozzles provided in the deck for this purpose. Several are provided to assure specific locations are fully drained. The sodium is drained, to the level of the top of the fuel elements, into primary system sodium storage tanks. The remaining sodium is drained into the intermediate-system storage tanks, after the intermediate-system sodium is disposed of. The radioactivity of the sodium is low enough that no particular shielding needs to be provided other than the two-foot-thick fire wall. The reactor main tank is then exposed to $\mathrm{CO}_{2}$ which converts surface coatings of sodium to the inert $\mathrm{Na}_{2} \mathrm{CO}_{3}$ forms a protective layer so that sodium below a depth of greater than $1 \mathrm{~cm}$ is not likely to be converted. It remains solid sodium. The fact that the sodium is solid at room temperature and is protected by the $\mathrm{Na}_{2} \mathrm{CO}_{3}$ eliminates any real concern about sodium fires or spread of the low level radioactivity. Once the system is inerted with $\mathrm{CO}_{2}$, dismantling can proceed either in a dry air or inert atmosphere. If "heels" of sodium are found during dismantling, these should be removed. The transported corrosion products adhering to the hot pool walls are expected to be of the order of 1 millicurie per square foot and should not require decontamination. Loose $\mathrm{Na}_{2} \mathrm{CO}_{3}$ and manganese nodules are vacuum cleaned and rubbed of $\mathrm{fith}$ wet $\mathrm{cloth}$ as required.

The steps involved in dismantling are in many ways the reverse of the process of fabricating and assembling the reactor vessel and installing all the components.

Step 1. Remove IHX's and pumps, and clean these just as is done for maintenance (see Fig. VII-2).

Step 2. Remove control drives, and clean radioactive drive extension with standard maintenance methods.

Step 3. Remove steel shield bars with modified fuel handling machine, and remove fuel handling machine, clean, and ship to burial.

Step 4. Brush and vacuum clean all loose material from interior of main tank.

Step 5. Insert cutting devices and remote handling tools through openings in the rotating plugs into the main tank. Cut highly radioactive plates and move plates to nearest IHX or pump location for vertical removal.

Step 6. Use IHX and pump holes for access for cutting "redan" and radial thermal baffles. 


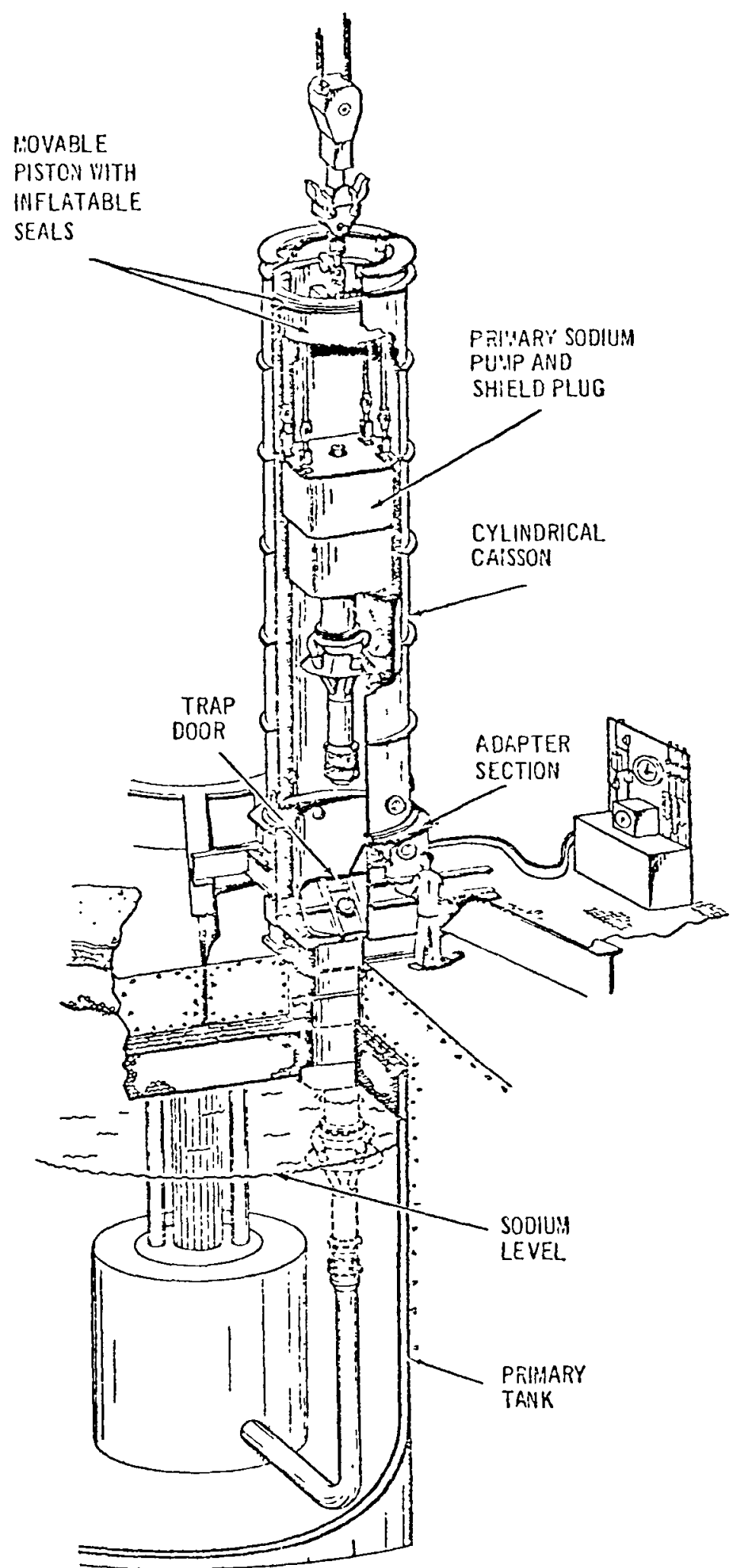

Fig. VII-2. EBR-II Removal of Pump into Caisson 
Step 7. After the radioactive portions of the vessel are removed, scrape all loose material and residual sodium carbonate, and vacuum clean.

Step 8. Still by remote means, lance-clean inside of main tank, including deck insulation.

Step 9. Allow air into the main tank and proceed with next steps by direct contact disassembly.

Step 10. Remove steel shot from deck.

Step 11. Cut deck from vessel.

Step 12. Remove deck and move to convenient place.

(a) Jack-hammer concrete, and

(b) Cut up deck.

Step 13. Remove the reactor tank.

Most of the steps above are reasonably straightforward; however, for the operations involving removal of components which are radioactive, the options involved are worthy of further discussion. These are steps 5 and 6 and involve the question of the best method for removal and disassembly for shipment of (1) the core barrel, (2) the core support plate, and (3) the core, blanket, and shielding support structure and the inner flow baffles.

It is to be noted that the U.S. is only now designing 1000 to $1200 \mathrm{MWe}$ size pool-type LMFR's, and that, therefore, only options in design can be presented as opposed to a firm reference. The U.S. has not yet established whether to use a core barrel or not. The French in Super Phenix do not use a core barrel. The U.S. 100 MWe Fermi reactor did not use a core barrel. One option is then to not use a core barrel. If one is used, it could be designed to be removable by being unbolted as shown for the 1200 MWe EBR-II type reference in ANL-76-61. In this case, the barrel could be removed from the reactor and cut into four sections in the maintenance pit. The barrel could also be cut apart in place and removed in pieces. The barrel is only 2 in. thick and should be relatively easy to cut in place. The core support plate can be made removable as indicated in Fig. VII-3. In any event, cutting this plate will require special procedures since the support is a double plate several feet apart, tied together with hollow stay bars. It probably will be desirable to cut the stay bars first with the equivalent of a tube cutter. This makes it possible to remove the top plate for access to the lower plate. Procedures will need to be developed to remove the support structure. Since these plates are thin, the procedures should be within present techniques. A certain amount of jigging will be required to remove the flow baffles. Again, these are thin and are within present cutting equipment practice. 
It is concluded that the actual operations are slightly easier for dismantling an LMFBR than a PWR because plate thicknesses are smaller and the

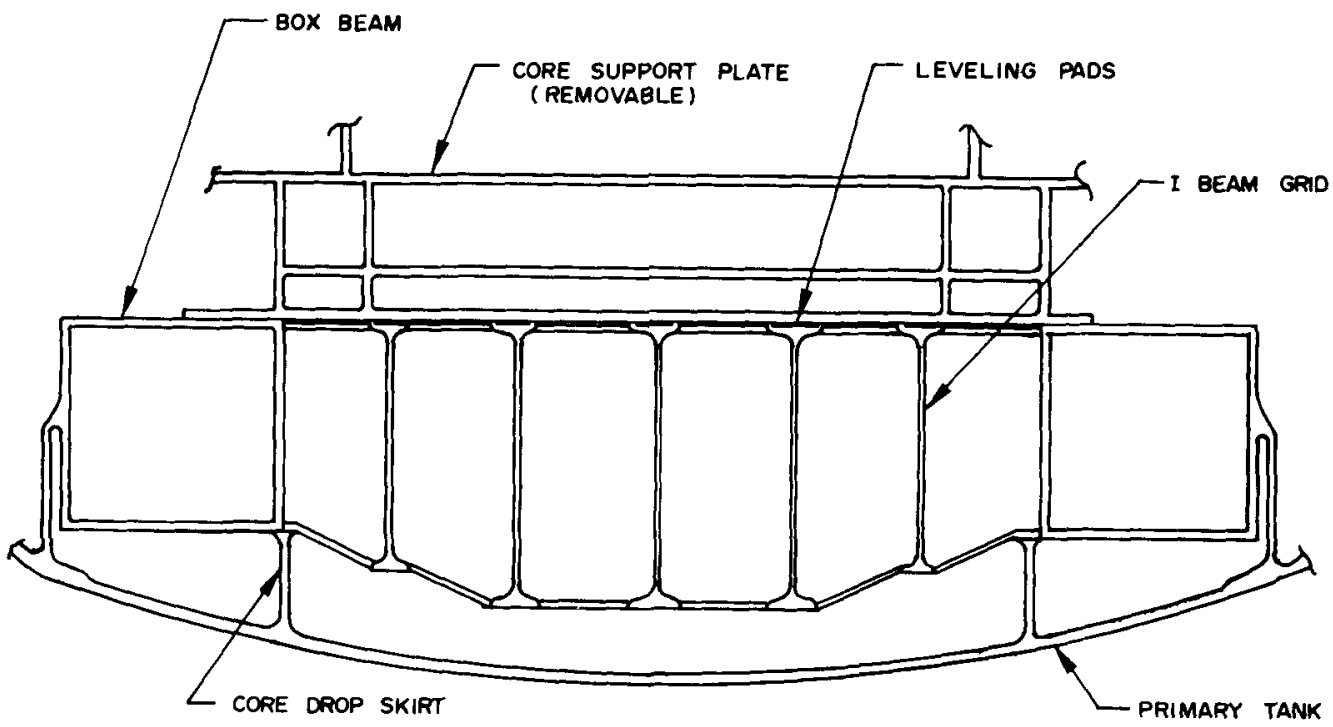

Fig. VII-3. LMFBR Core Support Structure

existing rotating plugs assist in the required manipulations. The cask available for removal of the instrument tree or for the IHX can be used to transport radioactive plate segments to the remote maintenance facility for packaging for shipment.

\section{TIMING AND COSTS}

\section{A. Timing}

Timing of final decommissioning is largely dependent on the reuse or other use of the land occupied by the radioactive part of the plant, or on liability attached to ownership of a radioactive facility. These consideration: are largely beyond the scope of this report.

The radioactive part of any reactor plant occupies only a few acres of ground. Since most sites will have more than one 1000 MWe reactor and will require perhaps 500 to 1000 acres, removing a few acres from active use may not be very important. Also for a multiple reactor site, monitoring of the mothballed area is considered to be a minor cost. In the context of an ongoing reactor employment for central station power generation, restoration of a few acres of ground, which can be used as part of the exclusion area, does not appear to have great economic significance. Timing of the final decommissioning, whether it be a few years after shutdown or 50 years, would not appear to have a large impact on cost.

Timing can be influenced by (1) the degree of difficulty and degree of xposure encountered in removing the reactor portion of the plant, (2) how components may be disposed of, i.e., temporary burial, permanent burial, or reuse, and ( 3 ) total personnel exposure. 


\section{Time Consideration in the Reactor Dismantling}

As has been brought out in Section VII, dismantling of the reactor vessel is reasonably straightforward for time two years after shutdown. A reduction in radiation levels will be gained by delaying the dismantling. 4 The reduction in the radiation levels could reduce the requirements for decontamination or permit contact disassembly of the reactor vessel and its internals if decommissioning is delayed until 50 years after shutdown. However, with the small amount of remote disassembly required at two years and the existing capability for remote disassembly, it appears that there may not be clear advantage to such delay.

\section{Disposal of Reactor Components}

The major components which need to be considered are listed in Table IV-4. The core barrel, support plates and columns, removable Fe shielding assemblies, and most of the internal baffling are radioactive enough to require permanent burial and will be shipped to such a site regardless of decommissioning time. The IHX's, pumps, reactor vessel, and guard vessel are of low enough activity to pose no direct contact disassembly problem after decontamination. They would, however, need to be shipped to permanent burial and parts of these could be used to encase more radioactive material. Dismantling time, therefore, would not appear to affect the component disposal method.

\section{Total Personnel Exposure}

No detailed estimate has been made of integrated exposure dose during decommissioning. The total radioactivity to be handled is less than for a PWR, and the plant is designed to facilitate remote disassembly. There is no practial limit to the shielding which can be employed to minimize personnel exposure. Exposure, of course, goes down with reduction in the radioactivity handled, but is not linear and can vary greatly with handling technique as witnessed by the fact that there is little exposure to personnel from an operating reactor. Techniques used in handling radioactivity an have a greater impact on total exposure than the radiation level of the material handled.

\section{B. Costs}

Costs are only dealt with in relative sense. The major components of cost of a PWR are given in AIF/NESP-009,1 pages 3-55 to 3-65, and can be generalized as given in Tables VIII-1, VIII-2, and VIII-3. In these tables, the costs for a PWR are listed and comments are made on the relative cost of an LMFBR. Table VIII-1 covers PWR cost items which would be expected to be more or less the same for a PWR and an LMFBR plant, and Table VIII-2 covers those which would be expected to be different. Table VIII-3 covers LMFBR items for which there are no PWR items. It is interesting to note that the cost for items which would be expected to be more or less the same is $\$ 22 \times 10^{6}$, whereas the PWR cost for the items which are expected to be different is $1 / 10$ of this (see Table VIII-2). For those items which are different, it is hard to see that the LMFBR items should be a factor of two different one way or the other. There are some operations required for an LMFBR for which there is no corresponding PWR operation. Aside from sodium disposal, these should not be large. Sodium disposal is discussed in Section V. It is concluded that the LMFBR dismantling cost would probably be of the same order as the PWR cost. These costs are not large compared to the capital cost of a plant. 
TABLE VIII-1. PWR Costs for Functions Which Would be Expected to be More or Less the Same for a PWR and an LMFBR Plant

Activity

1. Decommissioning staff, predecommissioning work activities

- Information required for license

$\$ 280,997$

2. Utility staff activities during predecomissioning

$2,100,000$

a. Unload fuel and core sources

b. Process liquid and solid waste

c. Provide plant technical information

3. Prepare functional specifications

740,160

4. Prepare plant for decommissioning and construct temporary facilities

5. Rigging and remote cutting equipment for reactor

$1,183,700$

6. Prepare detailed work procedures

533,520

7. Drain, flush, remove, ship and dispose of "non-essential systems" such as steam system (turbine generator, etc.)

$1,200,000$ auxiliary power, safety systems, fuel handling system

8. Drain, decontaminate, ship and dispose (the following portions) of "essential" system

9. Other miscellaneous facilities and functions

$1,736,000$

- remove buildings, cranes, missile shields, grade and final report

10. Undistributed Costs

$13,490,533$

- Decommissioning staff

$10,000,000$

- Security force

380,000

- Nuclear insurance

268,000

- Admission people and consultants

$1,708,000$

- Miscellaneous Total

$\frac{1,134,000}{\$ 22,167,000}$ 
TABLF VIII-2. PWR Cost ( $\$$ ) for Functions which vould be Fxpected to be Different tor a PWR than for an LMFBR

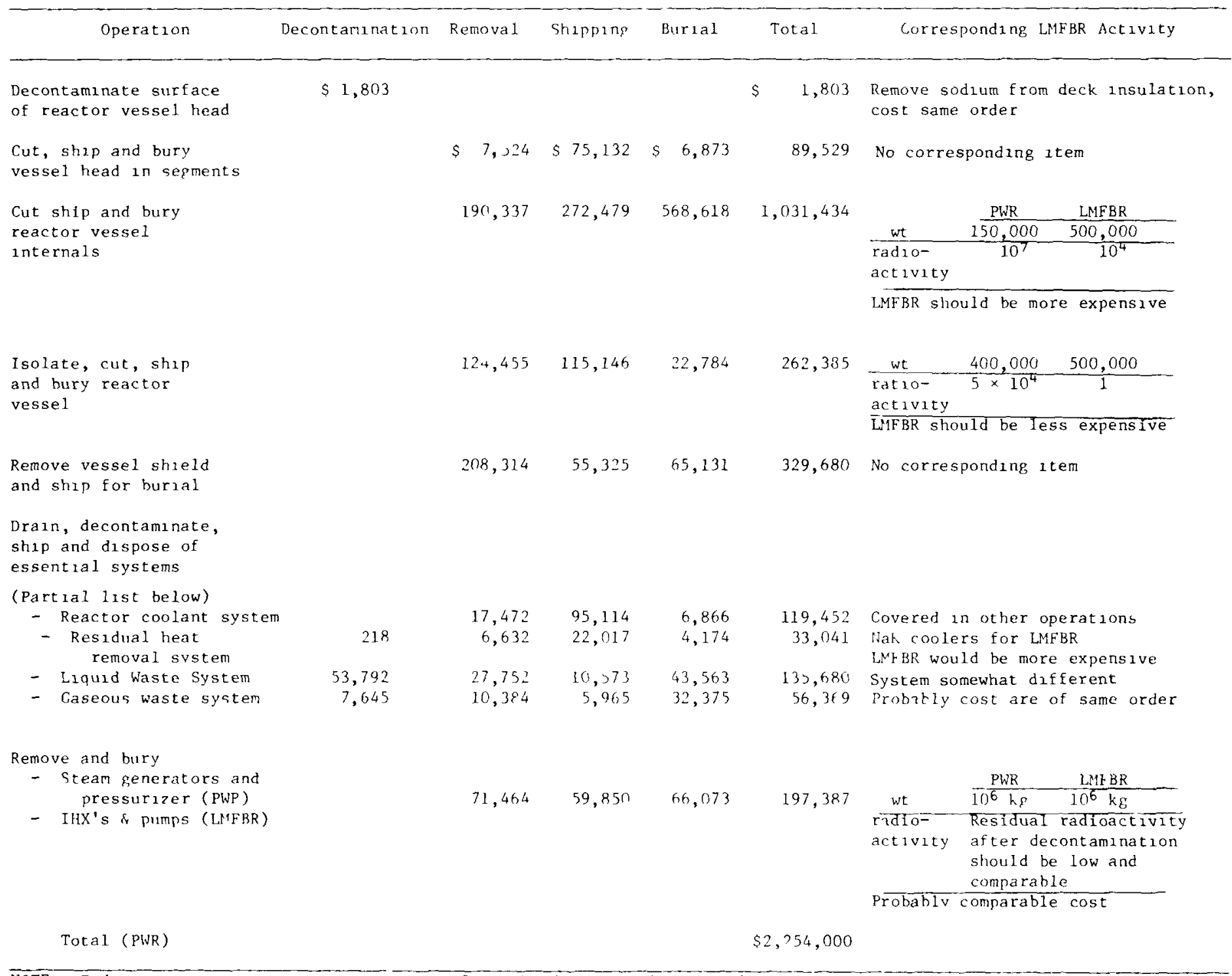

NOTS Radinactivity is in curies two vears ifter shutdown, veioht is in $\mathrm{k}$. 
TABLE VIII-3. LMFBR Items For Which There Is No PWR Item

\begin{tabular}{|c|c|c|}
\hline OPERATION & & Cost of LMFBR Functions \\
\hline $\begin{array}{l}\text { L-1 LMFBR intermediate plping } \\
\text { pumps, steam generators, etc., } \\
\text { sodium removal and prepare } \\
\text { for scrap }\end{array}$ & (not radioactive) & Estimate $\$ 300,000$ \\
\hline $\begin{array}{l}\text { L-2 Prepare sodium for resale and } \\
\text { NaK for disposal and dispose }\end{array}$ & & $\begin{array}{l}\text { See Chapter V for } \mathrm{Na} \\
\text { disposal cost; NaK } \\
\text { less than } \$ 200,000\end{array}$ \\
\hline L-3 Removable Fe shielding assemblies & & $\begin{array}{l}\left(700,000 \mathrm{~kg}, 10^{4} \text { curies }\right. \\
\text { less than } \$ 200,000)\end{array}$ \\
\hline
\end{tabular}

\section{STATE OF TECHNOLOGY}

It appears that all of the basic technology exists for the decommissioning of highly contaminated and highly radioactive portions of a reactor facility, whether the mode be protective storage, entombment, or dismantling. Basic difference in levels of activation and in materials of construction between FBR's and PWR's have previously been discussed. These differences call for adaptation of the basic technology for decommissioning. It should be noted that each reactor, even within a general class, is unique enough in construction, siting, nuclear design, retrofit requirements, management, and regulatory requirements that some degree of special development work is required to utilize basic technologies in the decommissioning. Included are:

(1) Advance planning, scoping, work package organization, and procedure writing.

(2) Analyzing and estimating for cost and radiation impacts.

(3) Time phasing of resources.

(4) Deconstruction engineering.

(5) Applying containment and personnel isolation features.

(6) Cutting materials remotely by plasma torch.

(7) Cutting materials and removing surfaces by controlled explosives.

(8) Applying remote handling, viewing, and tooling technology.

(9) Engineering for personne1 and environmental safety.

(10) Disposing of radioactive and contaminated waste products.

(11) Decladding fuel.

(12) Decontaminating surfaces.

(13) Performing radiological assessments and analyses.

(14) Preserving facilities for retrofitting or new uses. 
There are a number of firms who offer decontamination and decommissioning service. As an example, Atomics International has a Decommissioning Programs Organization with over fifty experienced technical personnel. Their experience includes technology applications ranging from contact work and straightforward tooling to complex and sophisticated remote handling tools and techniques. They have been involved in decommissioning a variety of facilities such as OMRE, Hallam, and Piquia reactors, SNAP Program reactors and test facilities, and the current project, the Sodium Reactor Experiment (SRE).

Nuclear Energy Services offers a similar service. They have recently completed the AIF/NESP study on decommissioning. 1 Their staff has experience with the Elk River and Bonus reactors and are preparing decommission plans for the Seabrook and Jamesport reactor.

Battelle Pacific Northwest Laboratory offers services in this area and has recently completed a report for NRC, "Technology, Safety and Costs of Decommissioning a Reference Pressurized Water Reactor Power Station," NUREG/CR-0130. ${ }^{4}$

As pointed out in AIF/NESP-009SR, 1 there have been some 65 reactors decommissioned. Five of these have been sodium-cooled reactors. There is, therefore, an experience base from which to establish methods which might apply to large commercial sodium-cooled reactors. Among these, the decommissioning of SRE, Hallam, SERFIR, and Fermi included the treatment of sodium, sodium contaminated parts, and irradiated structures.

\section{SUMMARY AND CONCLUSIONS}

The objective of this report is to examine the general considerations and efforts involved in the decommissioning of LMFBR's and to compare them qualitatively with those required by an LWR. The pressurized water reactor (PWR) is taken as adequately representative of the LWR's for the purposes of the comparison. A recent $1 y$ published study ${ }^{l}$ of decommissioning alternatives by the Atomic Industrial Forum is used as the principal point of departure for assessing the significance of the differences which would be encountered in decommissioning the two types of plants.

The AIF study considered differences of decommissioning modes for each of three reactors (BWR, PWR, HTGR). Their results indicate that the cost of decommissioning is much more dependent on the decommissioning mode than on the type of reactor. Further, for the removal/dismantling mode, the costs attributed to decontamination, removal, and disposal of the highly radioactive portions of the plants ranged 13 to $22 \%$ of the total station decommissioning costs. In view of the results of the AIF study, the approach used in this report is to first examine the two plants (PWR and LMFBR) in general for differences that might significantly impact the total station decommissioning costs. Next, the primary systems of a PWR and an LMFBR were compared to determine if the differences in design in the radioactive portions of the two plants were large enough to substantially alter the overall balance of decommissioning costs as indicated in the AIF study. It was felt that this approach provided a useful basis for the comparison since large scale experience is not available for either plant and actual decommissioning costs for nuclear power stations will depend on a number of factors not uniquely related to the design of the nuclear island. 
The comparison of the general sizes and design features of LWR and LMFBR power stations led to the conclusion that, exclusive of the radioactive portions of the plants and the presence of an intermediate sodium loop in the LMFBR, the two stations could be considered comparable in terms of the costs required for decommissioning. While there are many differences in detailed features such as containment structure, facility layout, etc., differences of comparable magnitude also occur among present generation nuclear power stations. It was concluded that the intermediate sodium loop in the LMFBR, being a low pressure essentially nonradioactive system, would not represent a large increment in the total station decommissioning costs. This conclusion was based on experience with decommissioning sodium systems and the assumption that most of the materials would be salvaged.

For the comparison of the radioactive portions of the power stations, it was assumed the normally replaceable reactor internals (fuel, control rods, blankets, etc.) and any spent fuel or blankets in storage at shutdown had been removed from the site. The pool design was selected as the reference LMFBR since it represents a somewhat greater contrast with PWR practice.

The differences in design of the PWR and LMFBR primary systems that might lead to a significant change in the balance of the overall station decommissioning costs relate to three areas:

1. The relative ease of disassembly operations.

2. The relative quantities of structural materials that must be treated as radioactive waste.

3. Special considerations that arise from the use of sodium as the coolant.

The primary system of an LMFBR is designed for operation at essentia11y atmospheric pressure, whereas the PWR operaties at a pressure of approximately 170 atmospheres and the BWR at approximately 85 atmospheres. The low operating pressure of the LMFBR makes feasible the use of a very large diameter, thinwalled reactor vessel. In a pool-type LMFBR, the vessel would be on the order of $70 \mathrm{ft}$ in diam and $2 \mathrm{in.} \mathrm{thick} \mathrm{compared} \mathrm{with} \mathrm{a} 15 \mathrm{ft}$ diam, $9 \mathrm{in}$. thick vessel for a PWR. In the LMFBR this large thin-walled vessel, the high level of radioactivity existing in the coolant during operation, and the need for an inert atmosphere over the coolant lead to a number of design features which are an aid during decommissioning. The large vessel, and the placement of the pumps and IHX within it, result in the use of removable shielding near the core. Major primary components such as pumps and heat exchangers are designed for plug-in replacement. The rotating plug structure used for refueling during operation can also provide manipulation and shielding for remote disassembly operations. The LMFBR vessel and fixed structures are generally 2 in. or less in thickness and fairly accessable for cutting and removal operation after the sodium has been removed.

The other factors which directly affect the ease of disassembly are the magnitude of the radiation levels in the primary system and their distribution. Although the core of an LMFBR operates at much higher neutron flux levels than 
an LWR, the presence of the blanket, reflector, and removable shielding near the core greatly reduce both the fast and thermal neutron flux to which surrounding structures are exposed. A comparison of the pool-type LMFBR and the PWR showed that the specific activities induced in the fixed structures are about a factor of $10^{3}$ lower in the LMFBR. A second source of high radiation levels within the primary system of both the LWSR and LMFBR plants is transport and depositon of radioactive corrosion products and fission products by the primary coolant. While the mechanisms of corrosion, transport, and deposition are very different in the LWR and LMFBR, and in both cases the activity levels are quite dependent on detailed design and operating parameters, the overall effect on decommissioning strategy is similar. Information on the buildup of deposited activity during the life of the plant plus surveys at shutdown provide the basis for establishing the decontamination plan. Effective methods for decontamination of both water-cooled and sodium-cooled systems exist, and improvements in the technology are being pursued. Both LWR and LMFBR power stations would have on-site decontamination facilities for component maintenance during normal operation. The extent to which these facilities would need to be augmented for decommissioning will depend on a number of factors such as where the activity is deposited, the effectiveness of in-situ decontaminaton prior to dismantling, criteria for reuse of materials, and waste management practices. Thus, while there are likely to be differences in decommissioning attributable to deposited activity in the primary systems, these differences are more strongly influenced by factors other than the reactor type.

The second area, relative quantities of structural material which must be treated as radioactive waste, was addressed in terms of weights and induced activity levels, or simply weight for those components in which the main source of activity is due to deposition. The lower flux levels in the fixed structure of the LMFBR lead to a significantly lower total induced activity for the LMFBR structural wastes. However, because of the larger size of the LMFBR primary system, the weight, and hence volume, of radioactive material that must be accommodated is about twice that in a PWR.

The third area, special considerations that arise from the use of sodium as the coolant, involves several different questions (i.e., the complexity of the sodium removal and dismantling operations, and the disposition of the primary sodium). Experience with decommissioning sodium-cooled reactors plus the fact that many of the special features required to accommodate the presence of sodium during decommissioning are built into the plant for normal operation and maintenance, led to the conclusion that the presence of sodium does not require dismantling procedures that are substantially more costly than for an LWR. As discussed previously, some of the design features that result from the use of a sodium coolant (large thin-wall vessel, rotating shield plugs, etc.) represent an aid during decommissioning. However, the use of sodium does lead to significantly different considerations relative to the disposition of the primary coolant upon station decommissioning. The radioactivity induced in the coolant of an LWR has a very short half-life so that it is of no concern during decommissioning. In addition, the equipment required to remove most of the fission products and activated corrosion products from the water is normally available at the plant and the decontaminated water itself is of little value. Sodium, however, forms two radioactive isotopes: ${ }^{24} \mathrm{Na}$ with $15.3 \mathrm{hr}$ half-life and ${ }^{22} \mathrm{Na}$ with a 2.6 year half-life. While the induced 
activity levels are not large after a short decay period, the sodium must still be handled as a radioactive material. In addition, reactor grade sodium is valuable ( $\$ 2-3 \times 10^{6}$ for a typical LMFBR) and would most likely be considered for reuse. Four alternatives were considered for the dispositon of the primary sodium: (1) direct use in another LMFBR, (2) decontamination and reuse in another LMFBR, (3) decontamination and conversion to an inert form for landfill burial, (4) conversion of the contaminated sodium to an inert form for waste disposal. The first option appears practical and is clearly the most economic as long as there is a market for reactor grade sodium.

It was concluded that as Iong as LMFBR's are in use there would be strong incentives to recover and reuse the primary sodium. If LMFBR's were to be phased out and there was no other market for the sodium, the cost of sodium disposal would represent a significant addition to the total station decommissioning costs. Depending on the level of contamination in the sodium, waste management criteria, etc., the cost of sodium conversion and disposal are estimated to range from $\$ 2 \times 10^{6}$ to $\$ 5 \times 10^{6}$ for a typical pool-type LMFBR.

Some consideration was given to the question of timing (i.e., decay period prior to dismantling) and personnel exposure. It was concluded that the decision on the timing of dismantling and the personnel exposures encountered during dismantling are primarily determined by factors other than the type of reactor.

While the scope of this study was limited in that detailed time studies, cost estimates, etc. were not made, the following general conclusions can be drawn from the information available:

- The rapidly accumulating experience with maintenance of LMFBR's, plus the experience attained to date with decommissioning sodium-cooled reactors (albeit limited) indicate that the operations required to dismantle and dispose of the radioactive portions of a large LMFBR are feasible and probably of comparable or lesser difficulty than those for a PWR.

- Total station decommissioning costs are primarily influenced by factors not related to the reactor type (i.e., PWR versus LMFBR). Thus for equivalent situations (e.g., decommissioning mode, waste management criteria, future site use, etc.) the costs of decommissioning LMFBR and PWR power stations should be comparable.

- The largest potential difference in the decommissioning costs of an LMFBR in comparison to an LWR is related to the disposition of the primary sodium. If the primary sodium is reused, this difference is not large and is probably an asset. However, if the sodium must be converted to an inert form for diposal as a radioactive waste, this additional expense would alter the distribution of decommissioning costs for an LMFBR in comparison to the reference PWR but would not significantly impact the total cost of power. 


\section{REFERENCES}

1. An Engineering Evaluation of Nuclear Power Reactor Decommissioning Alternatives, National Environmental Studies Project, Atomic Industrial Forum, Inc., AIF/NESP-009 (reference PWR described in Appendices B \& C).

2. A. Amorosi et al., A Study of Basic Approaches to the Design of the Primary System of Loop-Type LMFBRs, ANL-A78-3, p. 1-2 (March 1978).

3. Engineering Aspects of the Pool Type LMFBR, 1000 MWe, Rockwell International and Bechtel Corporation, NP-645-SY, Vol. 1 (April 1979)

4. Technology, Safety and Costs of Decommissioning a Reference Pressurized Water Reactor Power Station, (Study for NRC by Battelle Northwest), NUREG/CR-0130 (June 1978).

5. A. Amorosi et al., An Overview of Pool-Type LMFBR: General Characteristics, ANL-76-61 (May 1976).

6. J. A. Ford, An Evaluation of Proposed SNR Steam Generator Designs, Atomic Power Development Associates, Inc., APDA-272 (August 1971).

7. E. F. Hill et al., Development of Acidic Processes for Decontaminating LMFBR Components, IAEA Specialists' Meeting on Sodium Removal and Decontamination, Richland, Washington (February 14-16, 1978).

8. Power Reactor Development, Shipping Report No. 3502 (February 9, 1976). 
Distribution for ANL-80-40

Internal:
M. A. Abdou
P. B. Abramson
C. H. Adams
R. M. Adams
P. I. Amundson
P. J. Armani
R. Avery
C. C. Baker
C. L. Beck
E. S. Beckjord
J. C. Beitel
E. F. Bennett
S. K. Bhat tacharyya
M. M. Bretscher
R. G. Bucher
L. Burris
S. G. Carpenter
Y. I. Chang
D. W. Cissel
C. E. Cohn
T. A. Daly
L. W. Deitrich
G. J. Dilorio
G. A. Ducat
R. L. Ferguson
E. K. Fujita
B. R. Frost
P. L. Garner
J. M. Gasidlo
E. M. Gelbard
R. W. Goin
G. H. Golden
H. Henrys on

C. L. Herzenberg

W. P. Poenitz

J. R. Honekamp

R. P. Hosteny

P. R. Huebotter

H. H. Humme 1

R. Kaiser

Kal imu11ah

M. F. Kennedy

J. H. Kittel

H. Komoriya

J. A. Kyger

R. M. Lell

L. G. LeSage

R. A. Lewis

M. J. Lineberry

J. T. Made 11

D. J. Malloy

J. F. Marchaterre

F. H. Martens

W. E. Massey

J. E. Matos

H. F. McFarlane

R. D. McKnight

J. W. Meadows

D. Meneghetti

J. A. Morman

L. A. Neimark

M. V. Nevitt

N. L. O'Fallon

Y. Orechwa

E. M. Pennington

P. J. Persiani

P. A. Pizzica

R. B. Pond

K. G. Porges

W. R. Robinson

D. Rose

G. K. Rusch

J. I. Sackett

R. W. Schaefer

J. J. Sienicki

W. R. Simmons

D. E. Simpson

A. B. Smith

D. L. Smith

J. L. Snelgrove

W. J. Sturm (191)

R. J. Teunis

C. E. Till

B. J. Toppel

A. Trave11i

R. B. Turski

R. A. Valent in

D. C. Wade

D. G. Walters

D. S. Webster

R. W. Weeks

W. L. Woodruff

B. S. Yarlagadda

T. J. Yule

R. S. Zeno

A. B. Krisciunas ANL Contract File

ANL Libraries (3)

TIS Files (6)

\section{External:}

DOE-TIC, for distribution per UC-79d (173)

Manager, Chicago Operations and Regional Office, DOE Chief, Office of Patent Counsel, DOE-CORO

Director, Technology Management, DOE-CORO

President, Argonne Universities Association

Applied Physics Division Review Comnittee:

P. W. Dickson, Jr., Westinghouse Electric Corp.

R. L. Hellens, Combustion Engineering, Inc.

K. D. Lathrop, Los Alamos Scientific Lab. 
W. B. Lowenstein, Electric Power Research Inst.

R. F. Redmond, Ohio State U.

R. Sher, Stanford U.

D. B. Wehmeyer, Detroit Edison Co.

S. T. Brewer, Div. Program Planning and Analysis, USDOE

R. G. Staker, Div. Reactor Research and Technology, USDOE (2)

C. E. Weber, Div. Reactor Research and Technology, USDOE 